$\&$
$\&$

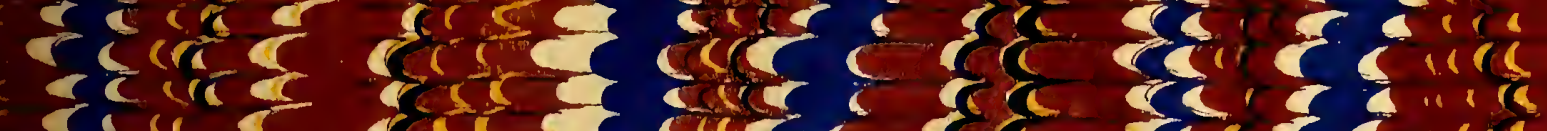

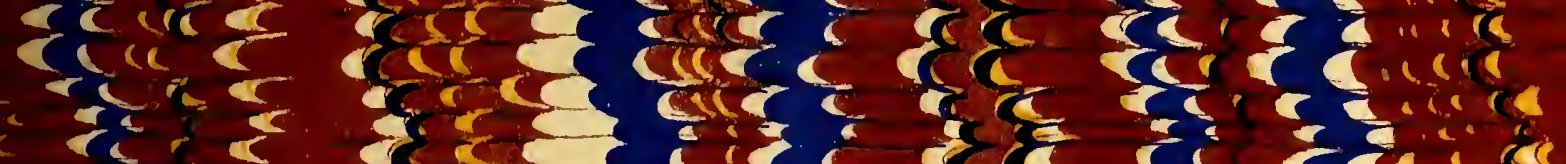

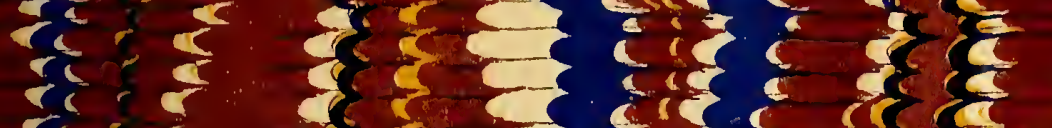

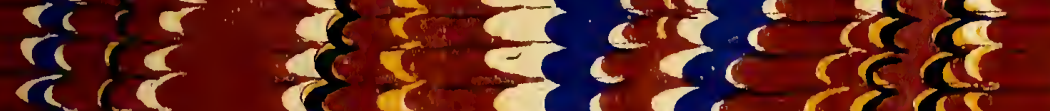

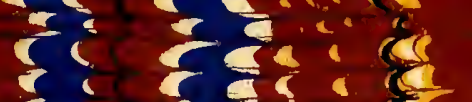

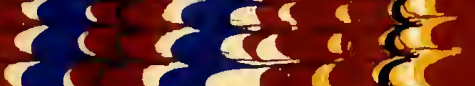
$r i c$
$r i c$
$r$
$r$

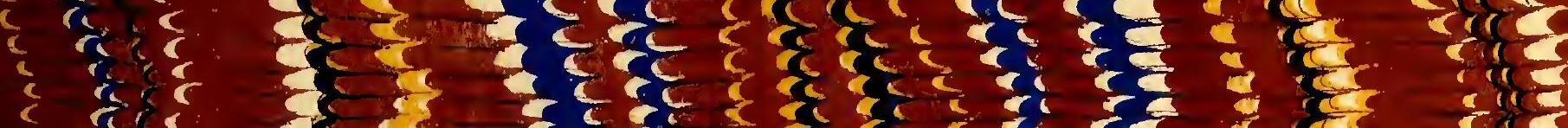

c.

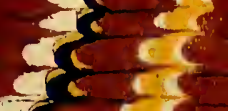

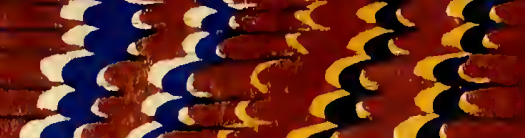

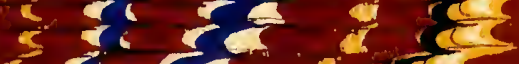
$\frac{1}{12}$

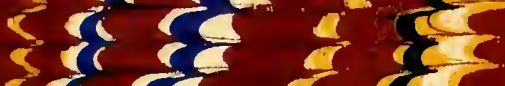

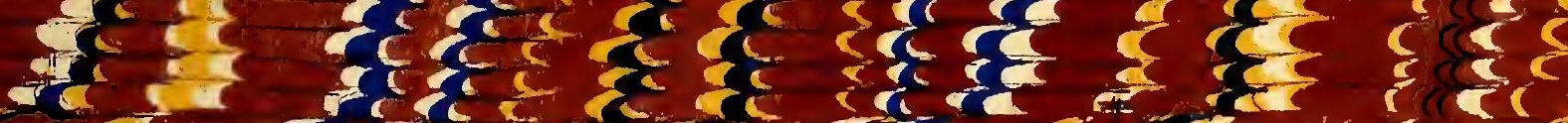

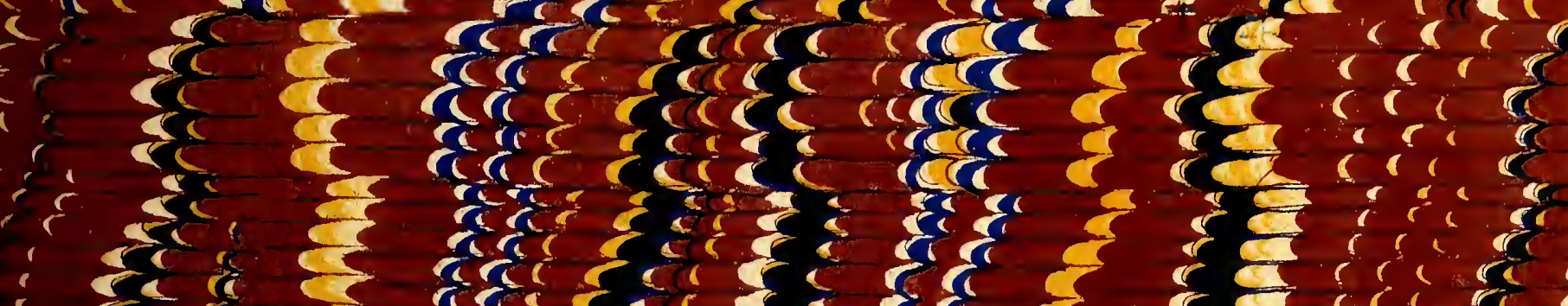

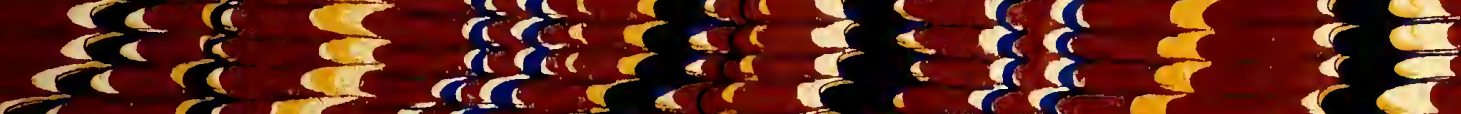

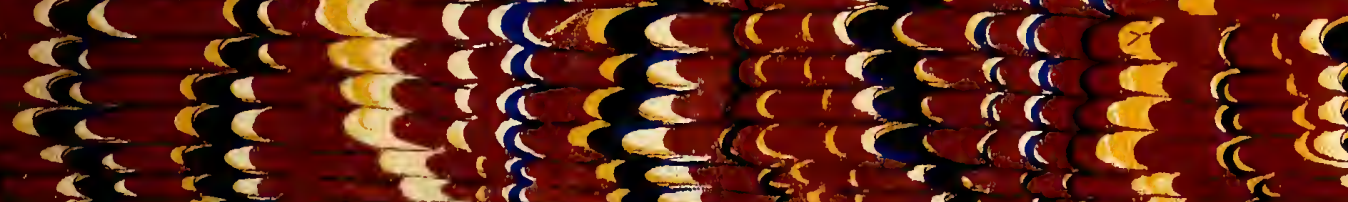
I $4<$

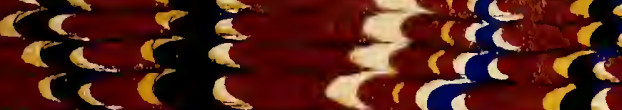

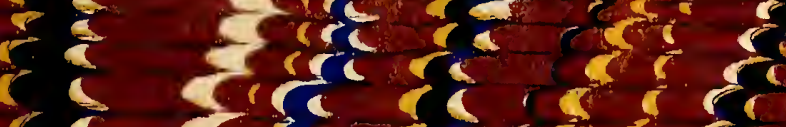

rerc

cre

<द $\operatorname{sic}$

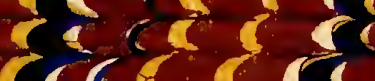

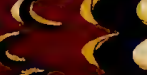

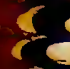

.

.

c

है है है तो तो है। है।

re

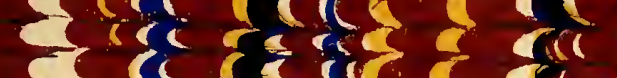

c

.

है। है तो दो है

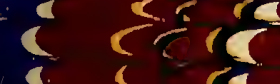

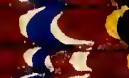

$<$

a.

48

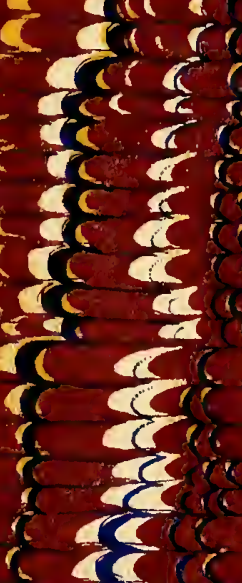

ra

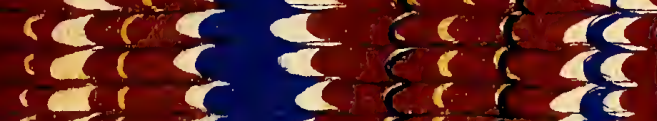

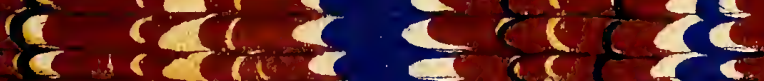

\& 120

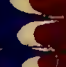

(1)

$\varepsilon$

s

$\& \frac{\pi}{2}<\frac{1}{2}$

द 28 $\rightarrow \cos 2$

हो ति है है दे

है तो दै है है

cese दे

$\cos 5$ a

c
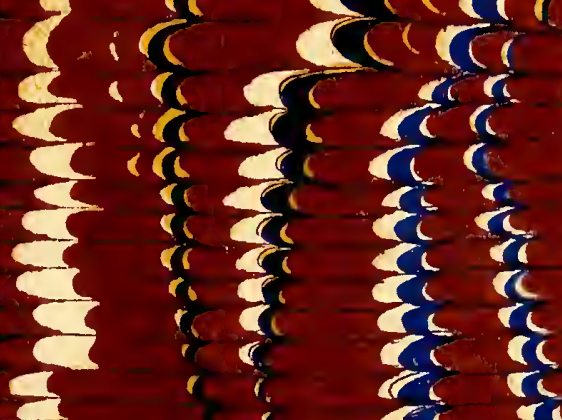

$\sum_{-2}^{2}$

$\therefore \frac{5}{4}$ 5

$C<C^{\circ}$

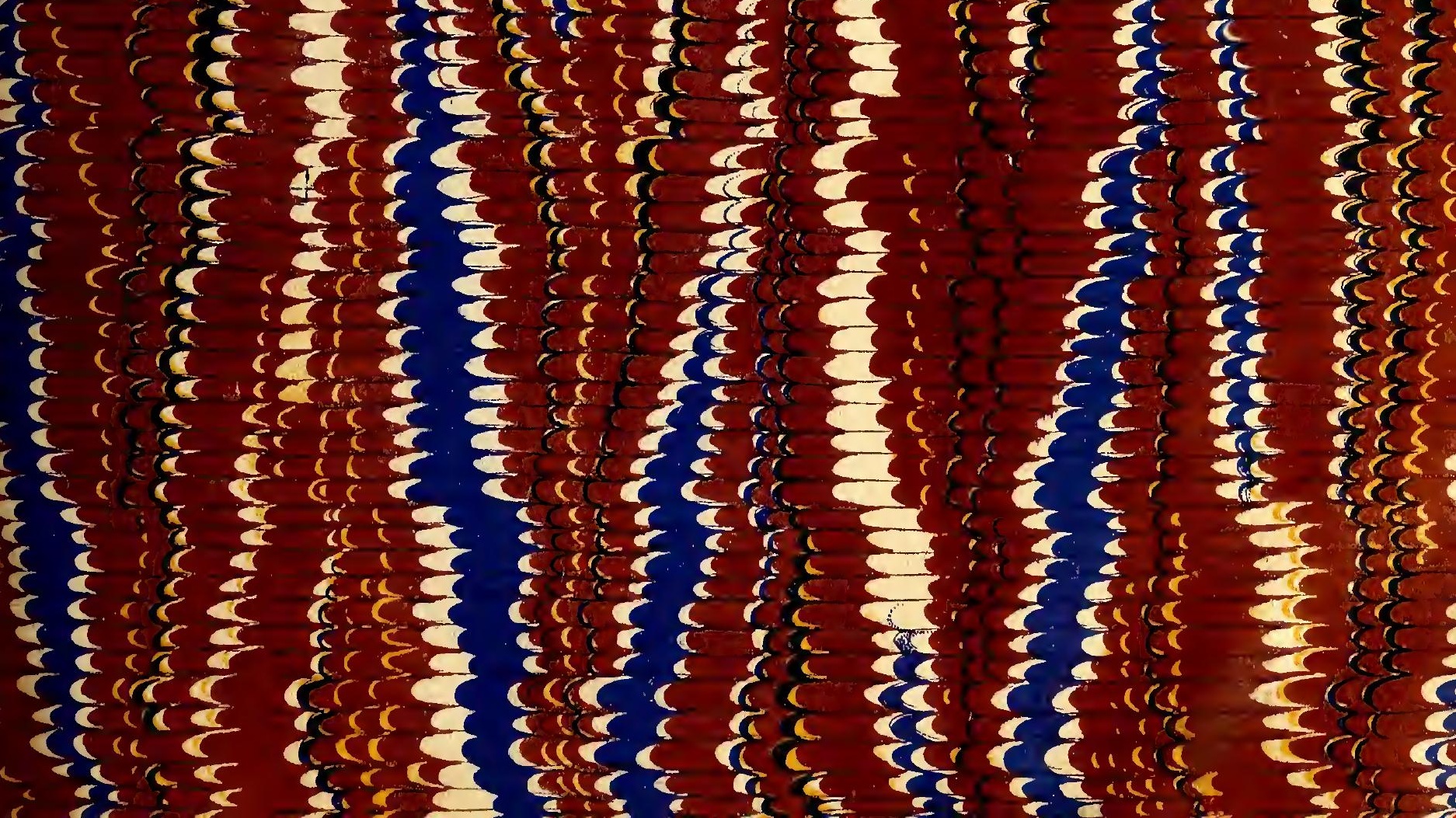









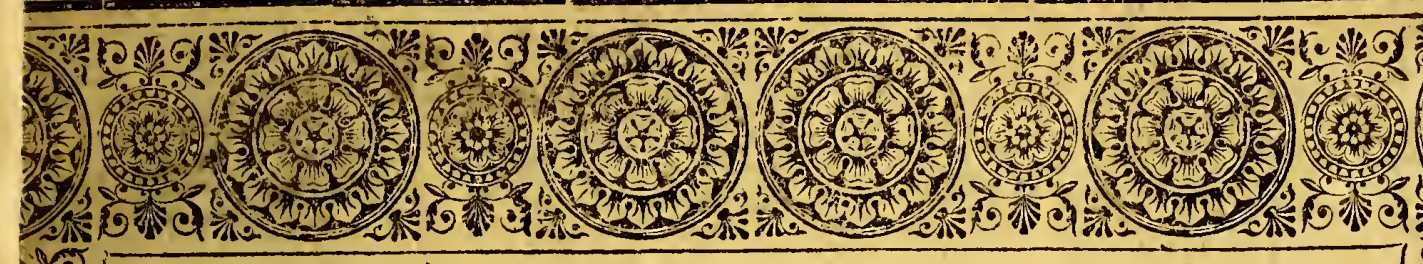

\section{NUEVOS ELEMENTOS}

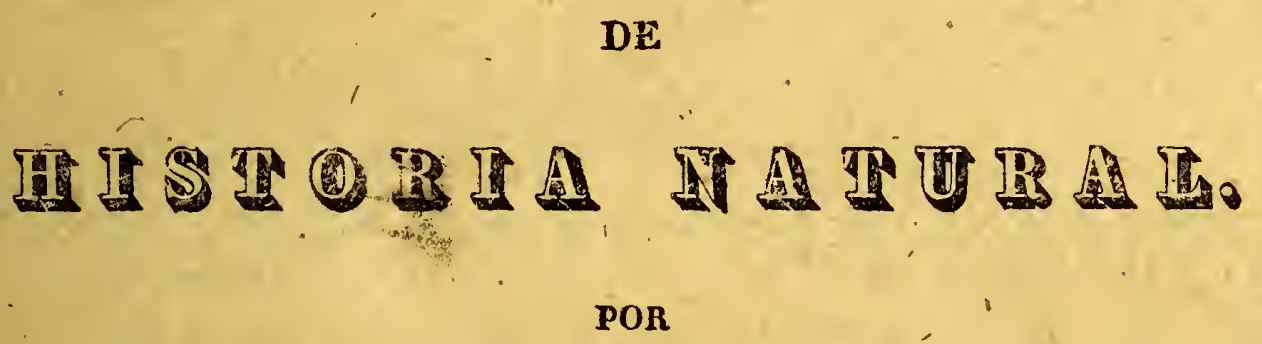

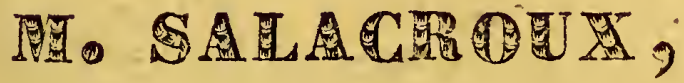

adoraba con. 50 laminas grabadas ath colie:

TRADUCIDA Y CONSIDEBABLEMENTE ALMENTADÁ

prox

DON JOS E ROD RT O

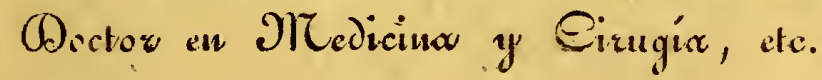

MADRID： IMPREYTA DF VERGES.

$$
\text { - i } 837 \text {. }
$$

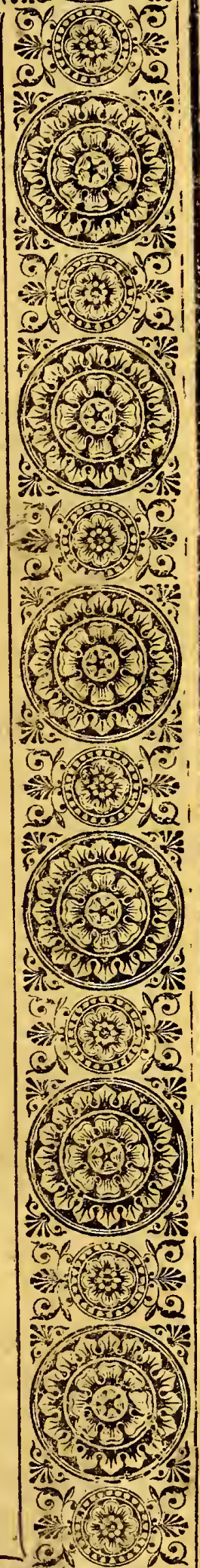

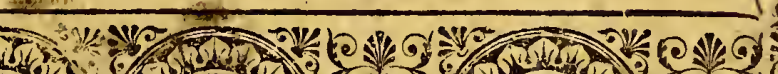

1. 5102 





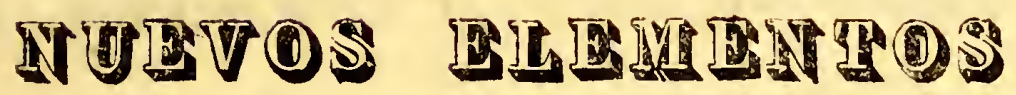

\author{
DE
}

\section{HISTORIA NATURAL.}





\title{
NUEVOS ELEMENTOS
}

DE

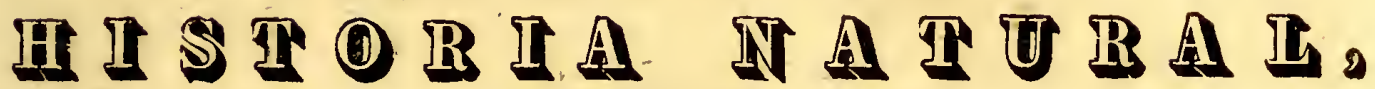

\author{
CONTENIENDO
}

\section{LA ZOOLOGIA, LA BOTANICA,}

LA MINERALOGIA Y LA GEOLOGIA,

APLICA DAS A LA MEDICINA, A LA FARMACIA

á las ciencias y aRtes comunes,

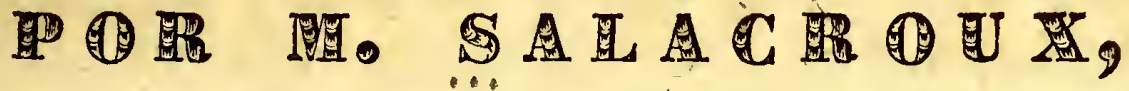
DOCTOR EN MEDICINA DE LA FACULTAD DE PARIS, PROFESOR DE HISTORIA NATURAL EN EL COLEgIO REAL DE SAN LUIS, MIEMBRO DE LA SOCIEDAD DE CIENCIAS NATURALES DE FRANCIA, ETC.

ADORNADA CON 50 LÁMINAS GRABADAS EN COBRE: Craducida y coissiderablenente aumentada POR

\section{O N J O S É, R O D R I G O,} Q Doctor en Mbedicina y Cinujia, etc.

TOMO III.

MADRID : IMPRENTA DE VERGES. 1838. 


\section{gomidistal eorgum}

\section{$\therefore$ is}

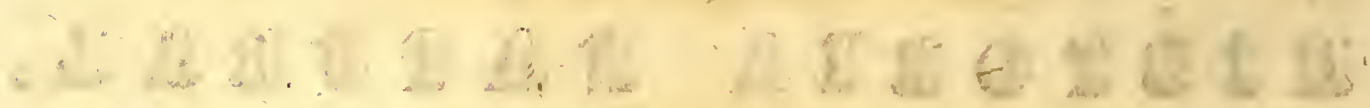

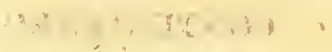

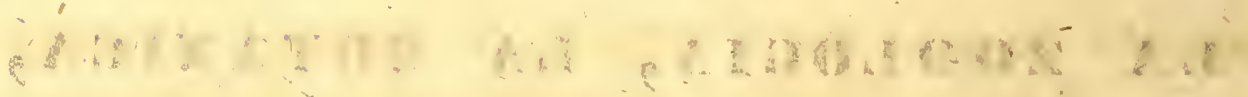

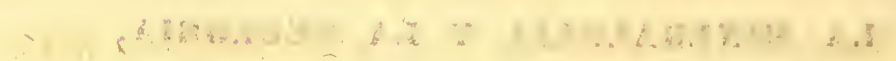

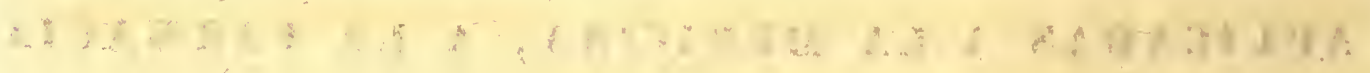

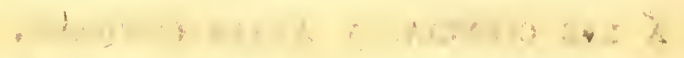

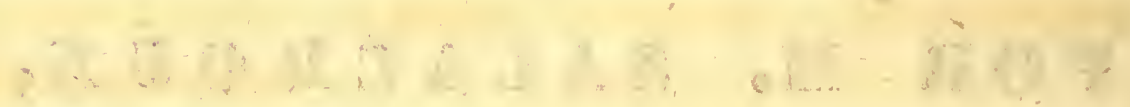

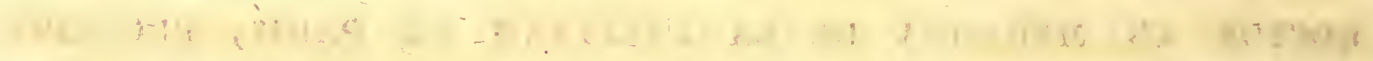

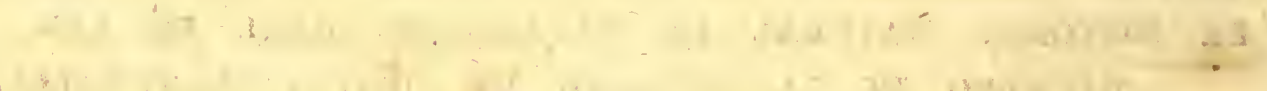

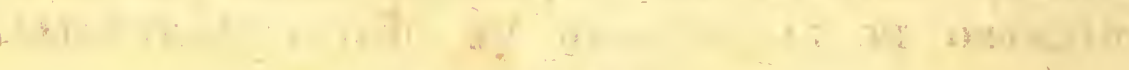

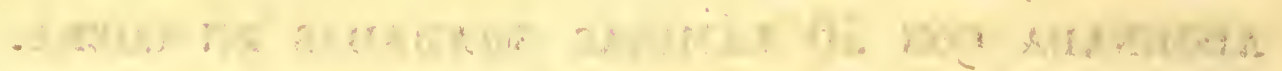

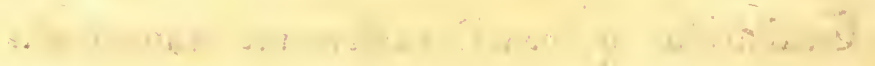

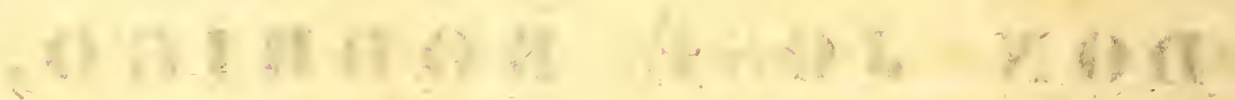
$+\frac{1}{2}+\cdots, \cdots$,

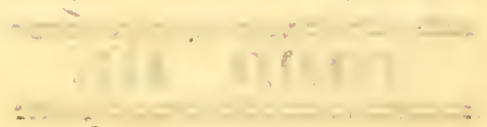

$-$

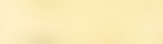

,

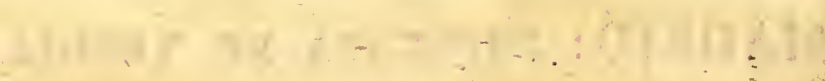




\section{ADVERTE NGIA.}

Aunque somos poco afectos á distraer la atencion del lector, nos vemos precisados á hacerlo ahora con motivo de algunas observaciones, que conviene se tengan presentes, acerca de la acentuacion y de la nomenclatura.

Ha sido bastante comun en las pocas obras que tenemos en nuestro idioma, y que versan sobre las ciencias naturales, el escribir los nombres de las cosas sin acentuacion, y bastante general que se acentúen y pronuncien de diverso modo, dejando al juicio de cada uno elegir aquel que mas le agradare. Muchos egemplos pudieran citarse en comprobacion de lo que acabamos de afirmar, pero los omitiremos en obsequio de la brevedad. Es verdad que al verter de un idioma á otro ó al formar los nombres derivándolos de una lengua estraña, es muy dificil dar á las sílabas su verdadero valor ó cuantidad, porque la que á unos suena bien larga á otros les parece mejor breve. Para salir de estas dudas únicamente podia apelarse á la analogía, pues no puede recurrirse al uso en el caso de ser nombres nuevos. Mas todos sabemos cuanta variedad hay respecto de la pronunciacion de las voces de orígen griego ó latino, que son las mas de las contenidas en esta obra. En efecto, á pesar de que siguiéndola exactamente deberia siempre decirse y escribirse Meteorología, Fisiolo- 
gia, Zoologia, Metalurgía, del mismo modo que se pronuncia Filosofía y Teologia, muchas y respetables personas escriben aun y dicen Zoologia, Patologia, Meteorologia y Metalurgia. Esta ha sido la causa por que hemos dado sin acentos los nombres de los seres que van descritos, y solo sé han acentuado cuando un uso general y la analogía nos lo dictaban asi; pero quedaron un corto número, que siendo dudosos, parécenos que estarian mejor de otra manera que no como se hallan actualmente. Los enumeraremos aqui para que si el lector se aviene á nuestro modo de ver, pueda acentuarlos fácilmente.

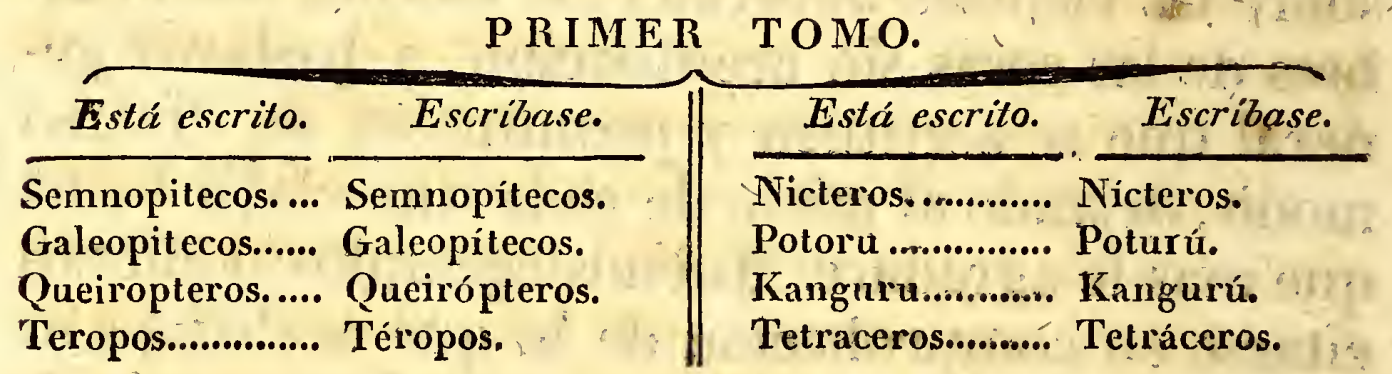

SEGUNDO TOMO.

\begin{tabular}{|c|c|c|c|}
\hline Está escrito. & Escríbase. & Está escrito. & Escribase. \\
\hline $\begin{array}{l}\text { Colibris............... } \\
\text { Jabirus............... } \\
\text { Espatulas............ } \\
\text { Tiflopes................. } \\
\text { Crotalo................ }\end{array}$ & $\begin{array}{l}\text { Colibrís. } \\
\text { Jabirús. } \\
\text { Espátulas. } \\
\text { Tíflopes. } \\
\text { Crótalo. }\end{array}$ & $\begin{array}{l}\text { Dactilopteros..... } \\
\text { Ciclopteros......... } \\
\text { Acantopterigios. } \\
\text { Malacopterigios. } \\
\text { Condropterigios. }\end{array}$ & $\begin{array}{l}\text { Dactilópteros: } \\
\text { Ciclópteros. } \\
\text { Acantoptérigios. } \\
\text { Malacoptérigios } \\
\text { Condroptérigios. }\end{array}$ \\
\hline
\end{tabular}

TERCER TOMO.

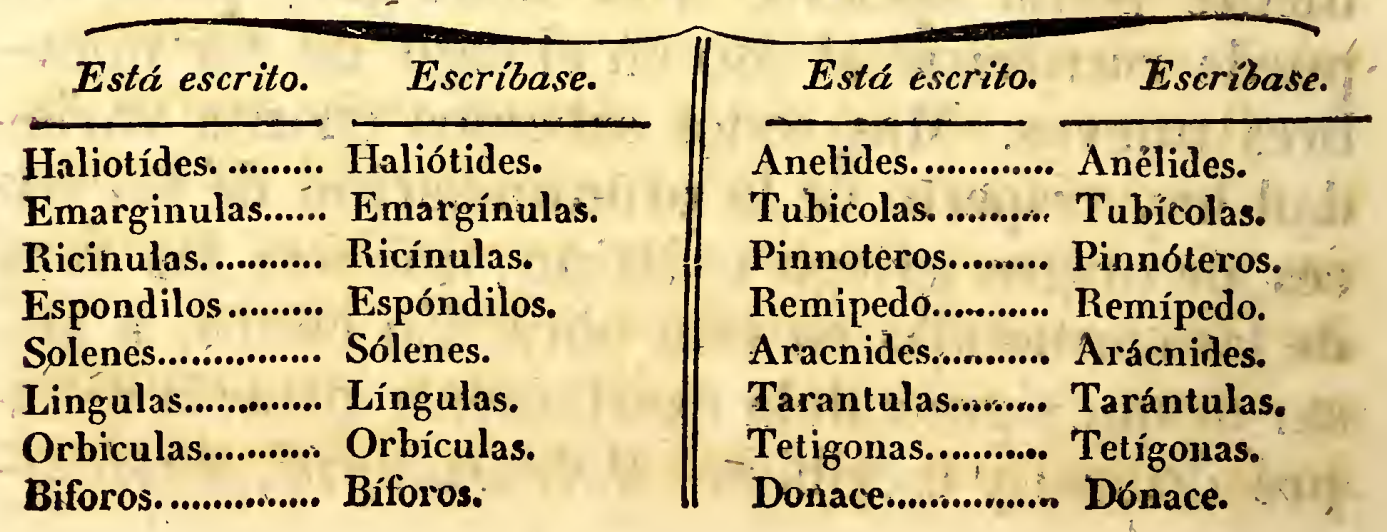




\section{VII}

Pero tanto estos nombres como aquellos que por omisiones involuntarias les faltase algunos acentos, se hallarán escritos con su verdadera ortografía, segun la concebimos, en la tabla alfábética que va al fin de este tomo, y á la que recomendamos que se acuda en cualquier otro cáso de duda. Para la pronunciacion de los nombres no acentuados se seguirán las siguientes reglas; en las voces disílabas se cargará el acento sobre la primera: en las trisílabas en la del medio, y finalmente de las tetrasílabas en adelante sobre la penúltima. Las combinaciones y uniones de vocales que forman diptóngos, como $e o$, $e a$, ou \&c. las consideramos como una sílaba; solo en el caso de estar acentuada alguna de las últimas se pronunciarán separadas.

Esta tabla de que acabamos de hacer mencion era de suma necesidad para encontrar con prontitud cualquiera nombre vulgar ó científico relativo á la materia de que tratamos; por eso no hemos titubeado en hacerla á pesar de lo molesta que ha sido su formacion.

No menos oportunos nos han parecido dos cuadros sinópticos de los sistemas zoológicos de Linneo y Blainville, que hemos hecho y colocado antes de aquella, con algunas reflexiones comparativas sobre los grupos y divisiones de estos sistemas respecto del que hemos seguido.

Réstanos en fin decir alguna cosa acerca de la nomenclatura. Es preciso palpar las dificultades que hemos tenido que vencer para acomodar los nombres científicos á los vulgares, y vice versa, y aun para salir entre los primeros de la confusion que reina en la diferente des- 
cripcion y equivocaciones de los autores para formarse una idea de ellas; porque volviendo á las denominaciones comunes, vése muchas veces que no hay mas de un solo nombre para infinitas especies, que otras se confunden géneros diversos; y otras en fin existen muchos nombres para las diferentes variedades de edades, sexos \&c. No nos lisongeamos que hayamos siempre acertado, pero hemos puesto todos los medios posibles para evitar errores. Hácese está advertencia porque tal vez se encuentren algunos cambios poco acordes con lo que se ha podido oir ó leer; pero antes de que se juzgue profundícese bien la materia. 


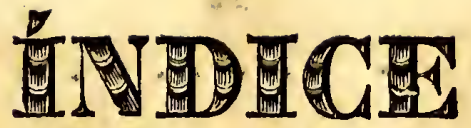

\section{DE T TOMO TERGERO.}

S

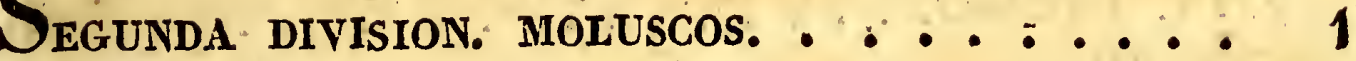

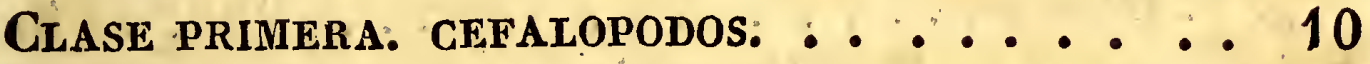

Familia primera. Sepiarios. ......... 12

§. I. Pulpos. ............... 13

§. II. Argonautas. ............. 14

§. III. Calamares: ............ 15

§. IV. Jibias. • . . . . ...... 16

Familia segunda. Nautilaceos. : . . ..... 17,

§. I. Nautilos............... 18

§. II. Belennitas. ............. 19

Ammonitás. ........... ib.

Nummulitas. . $\because \therefore \therefore \ldots . . .$. ib.

Clase segunda Y Tericha. Pteropodos y Gaste-

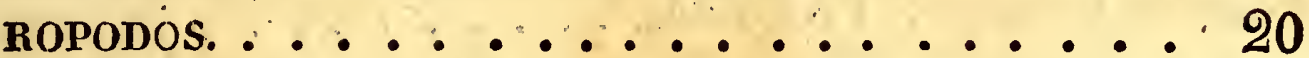

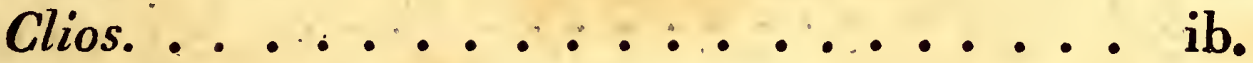

Cimbulios, neumodermos, limasinos, hialas,

cleodoros.............2 21 y 22

Orden I. pulmonádos. ........... 24

Familia primera. Limacíneos. . . . . . . 26

§. I. Limazas. .............. 27

§. II. Caracoles. ................. ib.

Subgénero primero. Caracoles propiamente di-

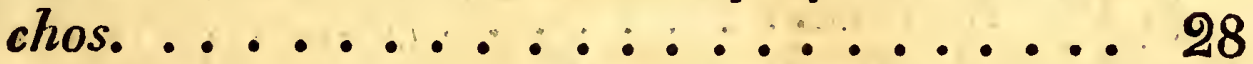

- segundo. Bulimos............ ib.

—. tercero. Clausilias. ........ 29

- cuarto. Agatinas. . ......... ib.

Familia segunda, Limneanos. .......... ib. 
§. I. Planorbes. ............ 30

§. II. Limneas. . . . . . . . . . . 31

Orden II. dermobrangutos. . . ....... ib.

Familia primera. Nudibranquios. ...... 32

§: I. Doris. . . . . . . . . . 33

§. II. Tritonias........ .34

§. III. Tetis. ............... ib.

§.IV. Escileas. . . . ....... ib,

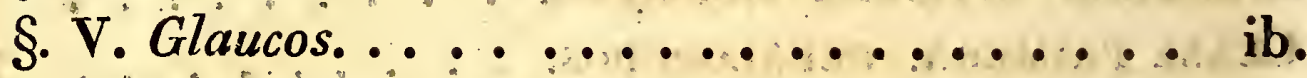

Familia segunda. Tectibranquios. ...... 35

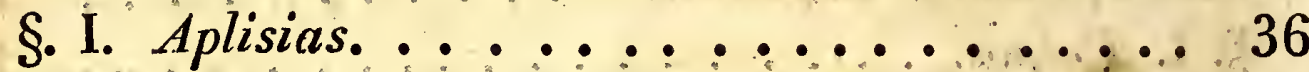

§. II. Bulas. . . . . . 38

Familia tercera. Escutibranquios. ....... ib.

§. I. Haliotides. . . . . . . . . . . . . . . 39

§. II. Patelas. . . .......... 40

Subgénero primero. Fisurelas. ......4 41

— segundo. Emargínulas. ........ ib.

- tercero. Patelas propiamente dichas. . . . ib.

§. III. Oscabriones. . . . . . . . ib.

Orden III. PECTINIBRANQuIOS. $\therefore . . . . . .42$

Familia primera. Trocoides. .......... 44

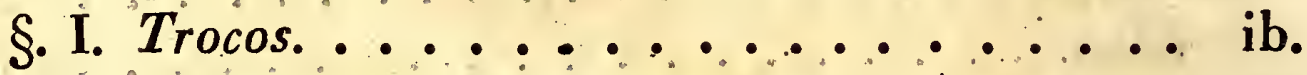

§. II. Trompos. . . . . . . 45

Subgénero primero. Trompos propiamente di-

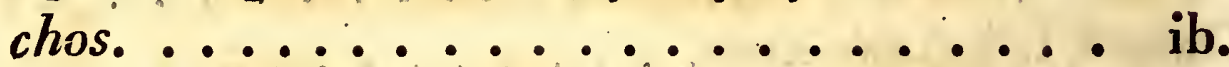

— segundo. Delfínulas. ......... ib.

— tercero. Turritelas. ............ ib.

_ cuarto. Escalatas. . . . . . . . ib.

§. III. Ampularias. ........... . . ib.

§. IV. Neritas. . : : : . . . . . . 46

Familia segunda. Buccinoides. . . ...... ib.

Tribu primera. Buccinoides arrollados. . . . . 47

§. I. Conos. . .............. 48

§. II. Porcelanas. . ................ 49 
Huevos. ................ 49

Tribu segunda. Buccinoides escotados. . . . . 50

§. I. Volutas. .................. ib.

Subgénero primero. Olivas. . . . . . . 51

— segundo. Volvarias. ......... ib.

- tercero. Kolutas propiamente dichas. . . ib.

—.cuarto Gondoleras. ......... ib.

—quinto. Marginelas. ......... ib.

— sesto. Colombelas. ......... ib.

- séptimo. Mitras............ ib.

_octavo. Cancelarias. . . . . . . ib.

§. II. Buccinos. ............... ib.

Subgénero primero, Tornillos. ........ ib.

— segundo. Buccinos propiamente dichos. . . ib.

- tercero. Nassas. ............ ib.

- cuarto. Harpas. .......... ib.

—quinto. Barricas. ......... ib.

- sesto. Perdices. ........... ib.

§. III. Púrpuras. . . . . . . . . . . ib.

Subgénero primero. Púrpuras propiamente di-

chas............... 52

— segundo. Licornes. ........... ib.

- tercero. Ricínulas. .......... ib.

Tribu tercera. Buccinoides canaliculados. . . . . ib.

§. I. Cascos ................ . 53

§. II. Ceritas.............. . 54

\$. III. Múrices. ................... ib.

Subgénero primero. Peñascos. . . . . . . 55

- segundo. Ranelas. .......... ib.

- tercero. Tritones . ......... ib.

§.IV. Husos. ................ ib.

Subgénero primero. Pleurotomos. . . . . . 56

- segundo. Pírulos............. ib.

tercero. Turbinelas............. ib. 
§. V. Estrombos. ............. ib. Subgénero primero. Rostelarios. . ....... ib. - segundo, Pteroceles. ........... ib. - tercero. Estrombos propiamente dichos. .. ib.

Clase cuartá. acéfalos. . . . . . ... 57. Orden I. monomiarios, ........... 59 Familia primera. Ostraceos. .........61, §. I. Ostras. . .............. ib. Subgénero primero. Ostras propiamente dichas. 62 — segundo. Espóndilos.......... 63

— tercero. Grifeas. .......... ib. - cuarto. Placunas............. ib. §. II. Peines. ............ 64 Subgénero primero. Peines propiamente dichos. ib. - segundo. Limas. ........... ib. — tercero. Huletas. .......... ib. Familia segunda. Maleaceos......... 65 §. I. Martillos. .............. ib. §. II. Pinnas. ............. 66 §. III. Golondrinas. .......... 67 Familia tercera. Tridacnos. ......... 68 §. único. Tridacnos. ............ ib: Orden II. dimiarios. . . . . . . . . 69 Familia primera. Camáceos. ......... 70 §. único. Camas. ............ ib. Familia segunda. Arcáceos. .......... 71

§. I. Arcas. . ............. ib.

§. II. Petúnculos............. ib.

Familia tercera. Mitilaceos..........72

§. I. Almejas. . . . . . . . . . 73

§. II. y III, Anodontes y unios. ........ 74 Familia cuarta. Cardiáceos. ......... 75 Tribu primera. Cardiáceos con dos especies de dientes. ............ 
$11 \ldots$ Bucarda.......... 77

Dónace ........... ib.

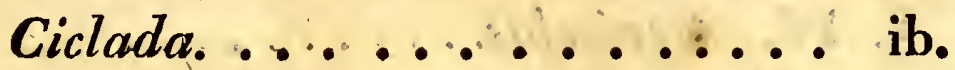

Canastilla.......... ib.

Lucina........... ib.

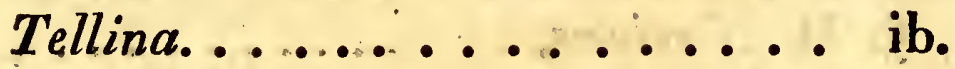

Tribu segunda. Cardiạceos que no tienen sino dientes cardinales. ........ ib. Venus............. ib.

Corbulas............ ib.

Mactras............. ib.

Familia quinta, Encerrados. ........... ib.

§. I. Mias................ 78

§. II. Sólenes. ............... 79

§. III. Foladas. .............. 80

§. IV. Bromas. .............. 82

§. V. Regaderas. ............. ib.

Orden III. Braquiopodos. ........ 83

Terebrátulas. ........ 84

Língulas'.......... ib.

Orbículas............ ib.

Orden IV. TUNICARIOS..............

§. I. Bíforos. ............... 85

§. II. Ascidias. . . . . . . . . . . . . 86

§. I. Botrilos. . . . . . . . . . . 87

§. II. Pirosomos. ............. . ib.

Policlino........... 88

Clase quinta. crrropodos.. . . . . . . . 89

§. I. Anatifas................ 90

§. II. Balanitas, ................. . . 91

Tercera diyision artigulados. ........ 93

Clase primera. Anélides. . . . . . . . . . . 97

Orden I. Tubícolas. . . . . . . . . . . . . . . . 99

§. I. Serpulas. ................ 100 


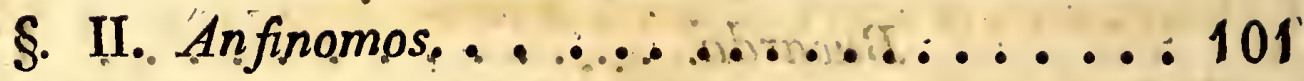

§. III. Anfitrites. . ................. ib.

§. IV. Arenícolas. . . .. . . . . . . . . . 102

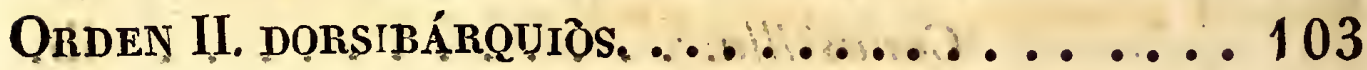

§. I. Afroditas................... 104

§. II. Nereidas. . ................. 105

ORDEN III. ABRÁNQUIOS. ........... id.

§. I. Lombrices................. 107

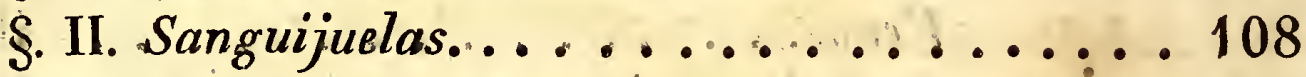

Clase Segunda grustáceos............ 110

ORdEN I. PEDIOCIOS. . . . . . . . . . . . 114

Familia primera. Braquiuros. ......... 115

§. I. Portunos ................ 116

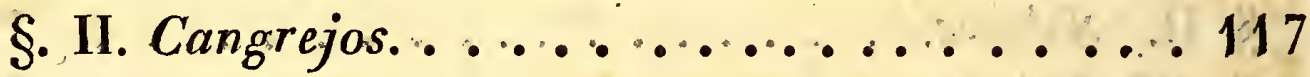

§. III. P.innóteros . . . ................. 118

§. IV. Gecarcinos. .............. 119

§. V. Dromias. .............. 120

Familia segunda. Macrouros. . . . ...... 121

§. I. Remípédos............... 122

§. II. Pagures. . . . . . . ......... ib.

§. III. Cangrejos comunes. ......... 124

§. IV. Langostas. . ............. . . 125

§. V. Langostinos. .............. 126

Subgénero primero. Cardos ó cardones. ..... ib.

— segundo. Palemones. .......... ib.

Familia tercera. Estomatopodos. ........ 127

§. único. Esquilas. ............ ib.

ORDEN II. HEDRIOFTALMOS. ... . . . . . . . 128

Familia primera. Anfipodos........... 129

§. I. Gamaros. .............. ib.

§. II. Corofios................ 130

§. III. Talitros. ............... ib.

Familia segunda. Isopodos. .......... 131

§. único. Cloportes.............. ib. 
Subgénero. primero. Cloportes verdaderos. . . . 132 4. segundo. Armadillos. . . . . . . . ib ORDEN III. .ENTOMOSTRÁCEOS. . . ..... ib. Familia primera. Branquiopodos. . . . . . 133 Cúclopes. .......... 134. Polifemas. . . . . . ib. Cipros. . ................. ib. Branquipas.............. ib. Apos.................. 135 Dafnias............... ib.

Familia segunda. Jifosuros. ............ ib.

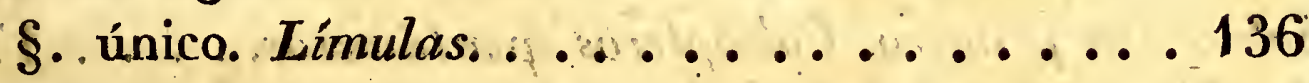

Chiase tergera. arácnides. . . . . . . . . 138

ORdEN I. PULMONARES. . . $\ldots \ldots \ldots \ldots$

Familia primera. Araneidas............ 141

§. I. Migalas................. 142

§. II. Araña. . . . . . . . . . . . 143

§. UII. Argironetas. ... , ......... 144

§. IV. Licosas. ............. . . . 145

Familia segunda. Pedipalpos. ........ 147,

§. I. Tarántulas. .............. ib.

§. II. Escorpiones. . . . . . . . . . 148

Orden II. Traquennós. . . . . . . . . . . 149

Familia primera. Falangianos. ....... 150

§. único. Segadores................. . ib.

Familia segunda. Acarides........... 151

Clase cuarta, miriapodos......... 154

Familia primera, Quiloñatos. ......... 156

§. único. Julos.. . . . . . . . . . . . . . 157

Subgénero primero. Glomeros. . . . . . . . . ib.

_ segundo. Julos propiamente dichos. . . . . ib.

Familia segunda. Quilopodos. .......... ib.

§. I. Escudiferos. ............. 158

§. II. Escolopendras. ................ . . 
Clase quinta. INsectos. : : : : : : : 159 Ordén I. Ápteros. . . . .......... 166 Familia primera. Tisanauros.......... 167 §. I. Forbicinas. . . . . . . . ib. §. II. Poduras.................. 168 Familia segunda. Parasitos. ......... 169 §. I. Piojos, .................. 170 §. II. Ricinos .............. 171 Familịa tercera. Sifonápteros. ......... 172 §. único. Pulgas. .............. ib. ORDEN II. COLEÓPTEROS............. 173 Sub órden primero. Coleópteros pentámeros....175 Familia primera. Carniceros. . . . . . . . ib. Tribu primera. Cicindeletos. ........176 Manticoros. ........177

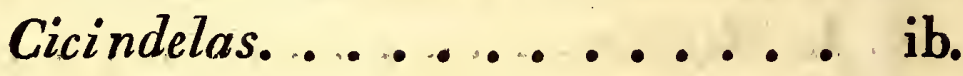
Tribu segunda. Carábicos. ............. ib. §. I. Braquinos.............. 178 §. II. Feronias. .............. 179 §. III. Elafros. . ............. . . ib. §. IV. Cárabos. .............. 180 Subgénero primero. Cárabos propiamente dichos. 181 - segundo. Calasomos. .......... ib. Tribu tercera. Hidrocántaros. . . . .... ib. §. I. Ditiscos................ 182

§. II. Jirinos. . . ........... 183 Familia segunda. Braquélitros......... 184 §. único. Estafilinos. . ......... jb. Familia tercera. Serricornes. ......... 185 Tribu primera. Esternoxos. ........ 186 §. I. Buprestes. ............... ib. §. II. Eláteres. . . . . . . . . 187 Tribu segunda. Molipennas. ......... 188 §. I. Lampiros................ ib. 
§. II. Barrenas á Carcomas. . . . . . . 189

Familia cuarta. Clavicornes. ........ 191

§. I. Necróforos. ................ . 192

§. II. Dermestes. . . ............... . . . . . .

Familia quinta. Lamelicornes. . . . . . . 193

Tribu primera. Escarabeides............ 194

§. I. Estercoleros............... 195

Subgénero primero Peloteros.......... 196

— segundo. Geotrupos. . . . . . . . . ib.

§. II. Abejorros. . . ............... id.

§. III. Cetonios. . ........... 197.

Subgénero primero. Goliats. . ......... 198

- segundo Cetonios propiamente dichos.. : . . ib.

§. IV. Escarabajos propiamente dichrs. . . .. ib. Tribu segunda. Lucanides. . . . . . . . 199

§. único. Lucanos. . ...... . . . . . . . ib. Sub-órden segundo. Coleópteros heterómeros. . . . 200 Familia primera. Melasomos.............201

§. I. Dañinos. ................ . 202

§. II. Tenebriones. . . . . . . . . 203

Familiá segunda. Traquélides. . . . .... . 204

§. único. Cantáridas. . . . . . . . 205

Sub-órden tercero. Coleópteros tetrámeros. . . . . 206 Familia primera. Rincóforos. . . . . . . ib.

§. I. Bruchos. . ........... 207.

§. II. Brentos............... 208

\$. III, Gorgojos, . . . . . ...... Ib.

Familia segunda, Longicornes.. . . . . . . 210

§. I. Prionos. . ............. ib

§.II. Capricornios............. 211

Familia tercera. Cíclicos. ........... 212

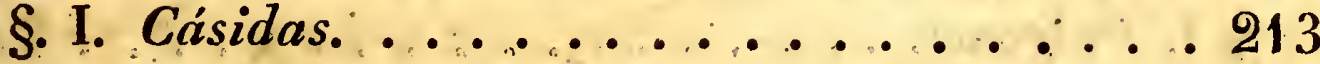

§. II. Crisomelas. ............ 214 Sub-órden cuarto. Caleópteros trímeros... . ...215 


\section{VIII}

§.único. Coccinelas. ............216

Orden III. oRtópteros. ........... 217

Familia primera. Corredores. . . . . . 218

§. I. Tijeretas. ............ 219

§. II. Blatas. ............... 220

§. III. Mantis. . .............. . 221

Subgénero primero. Mantis propiamente dichas.... 222

— segundo. Espectros. . . . . . . . . ib.

Familia segunda. Saltadores. . . . . . . . . ib.

§. I. Grillos. . . . . ............. . . 223

Subgénero primero. Grillo-talpas. ....... ib.

— segundo. Grillos propiamente dichos. . . . 224

§. II. Langostas. . . . . . . . . . . . 225

§. III. Acridios... . . . . . . . . . . . 226

ORdeN IV. HEMÍPTEROS. . . . . . . . . . . . . . . . 228

Sub-órden primero. Heterópteros. . . . . ...229

Familia primera. Geocorisos. . . . . . . 230

§. I. Chinches. ............. 231

§. II. Reduvios. . . . . . . . . . ... 232

Familia segunda. Hidrocorisos . . . . . . . . 233

§. único. Naucoris. . . . . . . . . . . 234

Nepas. .......... ib.

Sub-órden segundo. Homópteros. . . . . . . 235

Familia primera. Cicadarios. . . . . . . . . . 236

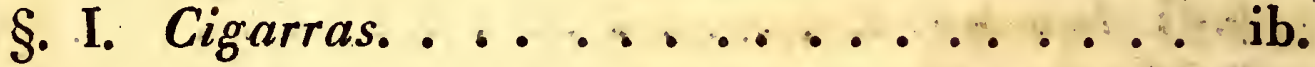

§. II. Cicadelas. . . . . . . . . . . 238

Subgénero primro. Tetígonas. . . . . . . . . 239

— segundo. Centrotos. . . . . . . . ib.

- tercero. Cercopos. . . . . . . . . . ib.

§. III. Fulgoras. .............. ib.

Familia segunda. Afidianos. . . . . . . . 240

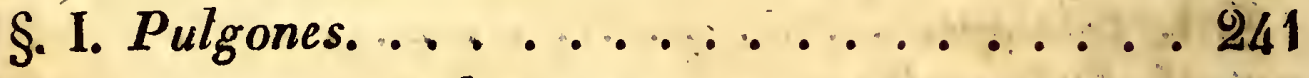

Psilos. .......... 243

§. II. Cochinillas. . ........ . ib. 


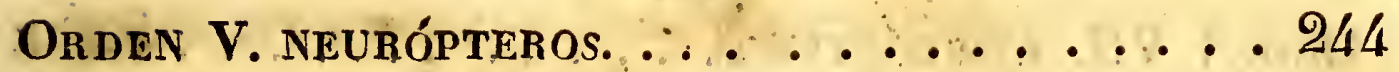
Familia primera. Subulicornes. . . . . . . . 245

§. I. Libélulas. . .............. 246

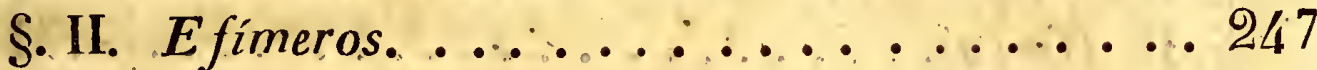

\$. 1II. Friganeos............. . . 248

Familia segunda. Planipennas. . . . . . 250

§. I. Hormigas leones. . . . . . ...... . ib.

§. II. Hemerobios. . . .......... 252

§. III. Termites. . . . . . . . . . 253

Ordẹn VI, Hịeñópteros. . . . . . . 256 Sub-órden primero. Terebrantes. ...... 257 Familia primera. Serriferos. . . . . . . 258

§. único. Tentredos. .......... 259 Subgénero primero. Cimbes. ..........260 segundo. Hilotomos ........... ib. tercero. Tentredos propiamente dichos. . . ib. Familia segunda. Pupívoros. . . . . . . . ib.

§. I. Icnéumones. . . . . . . . . . . 262

§. II. Cínifes............. 263

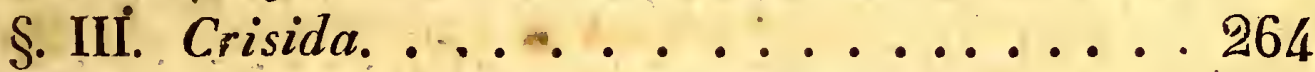
Sub-órden segündo. Aculeíferos. . . . . . 263 bis. Familia primera. Formicarios. . . ..... 265

§. I. Hormigas. ............. . ib.

§. II. Mutilas. . . . . . . . . . . . . 268

Familia segúnda. Cavadores. . . . . . . . 269

§. I. Esfeges. . . . .......... ib.

§. II. Crabros................ 271

Familia tercera. Diplópteros. . . . . . . $\therefore$ ib.

§. único. Avispas. . ........... ib.

Familia cuarta. Mélíferos: ...........273

§. I. Andrenas. . . . . . . . ..... ib.

§. II. Jilocopos. . . . . . ....... 274

§. III. Abejones. . . . .......... . 275

§. IV. Abejas. ................. 276 


\section{$\mathrm{XX}$}

ORdeN VII. LEPIdópteros. . . . . . . . 278

Familia primera. Diurnos.......... 279

§. I. Mariposas. . . . . . . . . . . . 280

§. II. Ninfas. . . . . . . . . . . . .... 282

Subgénero primero. Sátiros. ............ ib.

— segundo. Ninfas propiamente dichas. . . ib.

- tercero. Vanesas. ................. ib.

— cuarto. Arginias. ............ . 283

§. III. Argos. . ............... . ib.

§. IV. Hesperias. ................ 284

Familia segunda. Crepusculares......... ib.

§. único, Esfinges. . . . . . . . . . . . 285

Subgénero primero. Es finges propiamente dichas.... ib.

- segundo. Cigenas. . . . . . . . . . 286

Familia tercera. Nocturnos. . . . ........ ib.

§. I. Bómbices. . .............. ib.

§. II. Noctuas ................. 289

§. III. Falenas. ............... 290

§. IV. Polillas. ................. . 291

Orden VIII. dípteros. . . . . . ...... 292

Familia primera. Nemóceros. ........ 294

§. I Mosquitos. . . . . . . . . . . 295

§ II. Típulas. . . . . . . . . . . . 296

Subgénero primero. Típulas-mosquitos. . . . . 297

— segundo. Típulas comunes. . ..... ib.

Familia segunda. Tanístomos. ........ 298

§. I. Asilos. . . . . . . . . . . . ib:

§. II. Leptos. . . . . . . . . . . . . 299

§. III. Tábanos. . . . . . . . . 300

Familia tercera. Notacantos. . ......... 301

§. único Estratiomos. . : . . . . .... ib.

Familia cuarta. Ateríceros." ........ . 303

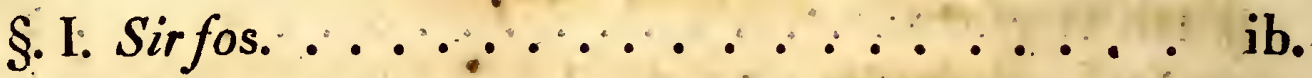

§. II. Estros. . . . . . . .... 304 
§. III. Moscas. . . . . . . . . . 306

Familia quinta. Pupíparos......... 308

§. único Hipoboscos. . . . . . . . . . ib.

Cuarta division. radiatios. . . . . . . . . 310

CLASE PRIMERA. EQUINODERMOS. . . . . . . 314

ORdeN I. ESTELIFEROS. . . . . . . . . . . 315

Familia primera. Estelérides. ........ 316

Asterias. .......... 317

Eurialas. ........ ib.

Familia segunda. Equínides. . . . . . . . . 318

§. I. Equinos. . . . . ......... . 319

§. II. Clipeastros. ............. ib.

Familia tercera Holotúrides. . . . . . . . ib.

§. único. Hcloturias. . ........... ib.

Orden II. helMintoldes. ' . . . . . . . . . 321

§. único. Siponclos. . . ......... ib.

Clase segunda. ENTOZOÁrIOS......... . 323

ORden I. cavitarios. . . . . . . . . . . 325

Familia primera. Filaréos. . . . . . . . . 326

§. I. Filarias. ............. ib.

§. II. Tricocefalos. . . . . . . . . . 327

Familia segunda. Ascaridéos. . . . . . . . ib,

§. I. Ascäides. . . . . .......... . . 328

§. II. Estrongilos. . . . . . . . . . ib.

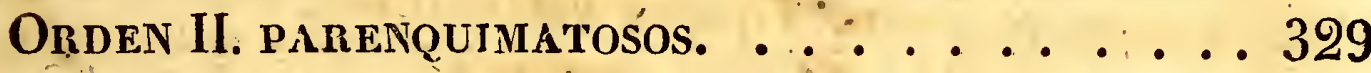
Familia primera. Trematodes. . . . . . . . ib.

§. único. Dístomas. . . . . . . . . . . 330 Familia segunda. Tenioides. . ....... . 331

§. I. Tenias. ............. ib.

§. II. Hidátidas. . . . . . . . . . . . . . 332

§. III. Ligulas. . . . . . . . . . . . 333

Clase tercera. acalefos. . . . . . . . 334

Familia primera. Acalefos simples. . . . . . 335

§. I. Medusas. ............... . 336 
§. II. Porpitas. . . . . . . . . . 337

Familia segunda. Acalefos hidrostáticos. .... . 338

§. único: Fisalias. . . . .......... ib.

Clase cun rta. pólipos............ 340

OrdeN I. GIMNOPólipos. . . ...... . . 341

Familia primera. Actinianos. .......... 342

§. único. Actinias. . ........... ib.

Familia segunda. Hidroides. . ....... 344

§. I. Hidras. . . . . ......... ib.

§. II. Cristatelas. . . . .......... 346

§. III. Vorticelas.............. . ib.

OrdeN II. sIMPólipos. . . . . . .... : 347

Familia primera. 'Tubiporéos. ...... . 349

§. I. Tubíporas. ........... ib.

§. II. Coralinas. . ........... ib.

Familia segunda. Corticiferos. . . . . . . 351

§. I. Antipatos. ............. 352

§. II. Gorgonias. . . . . . . .... ib.

§. III. Isis. . . . . . . . . . . 353

§. IV. Corales................ . ib.

§.V. Madréporas. ............ 354

Subgénero primero. Oculinas. . . .... 355

- segundo. Madrëporas propiamente dichas. ib.

- tercero. Astreas. ............ ib.

§. VI. Miléporas. …........ ib:

§. VII. Pennatulas. .......... 356

§. VIII. Alcionios. . . . . . . . . . 357

§. IX. Esponjas........... ib.

Clase quinta. microzoáños......... . . 360

Orden I. Rotíferos. ................... 361

Familia primera. Rotíferos propiamente dichos. . . 362

Furcularios. .......... 363

Tubicolarios. ........ ib.

Familia segunda. Crustodéos. ........... ib. 
Orden II. gimnodéos $\ldots \ldots \ldots \ldots$ Familia primera. Vibrionides. . . . . . . . 365 §. único. Vibriones. . . . . . . . . . ib. Familia segunda. Monadarios. . . . . . . 366 §. I. Vólvoces. . . . . . . . . . . . . . . ib. §. II. Protéos. . . . . . . . . . . . . . 367 §. III. Monades. . . . . . . . . . . ib. SISTEMAS zoóLOGICOS. . . . . . . . . . 369 


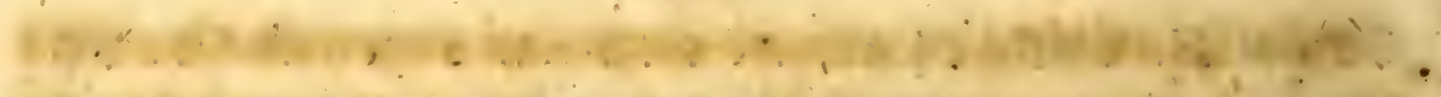

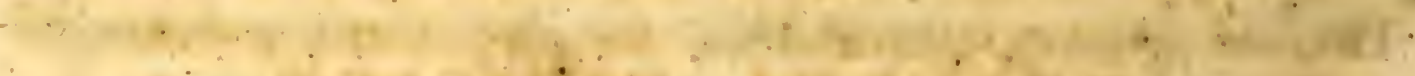

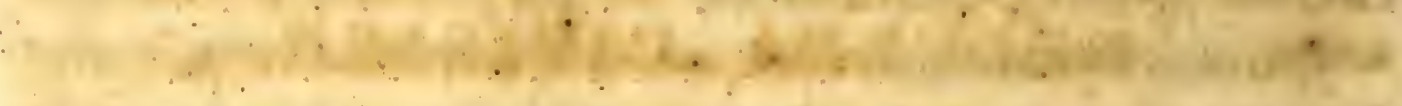

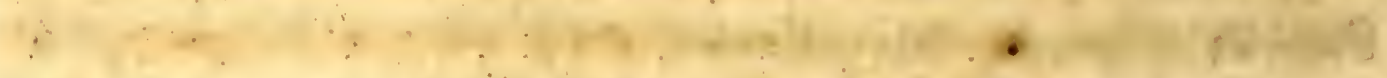

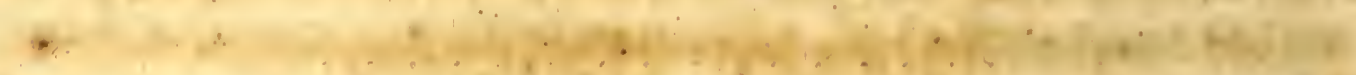

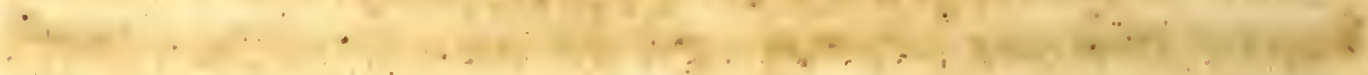

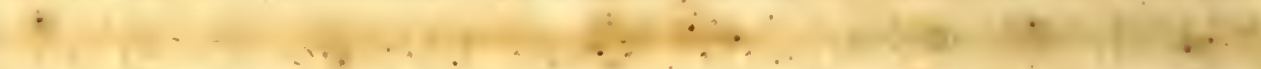

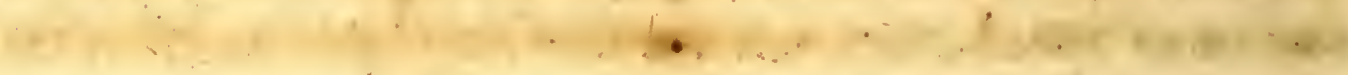

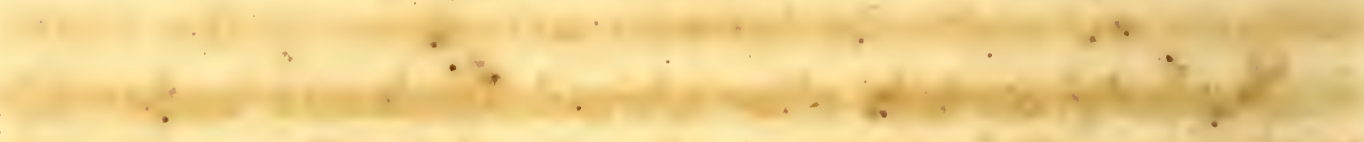

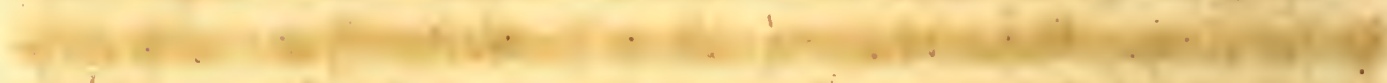

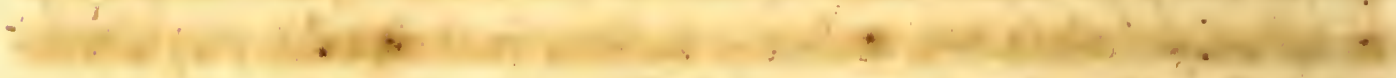

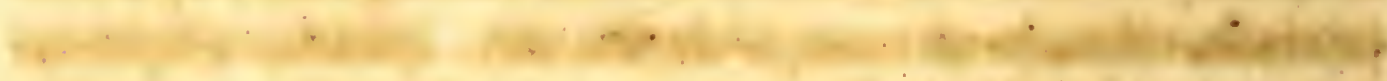

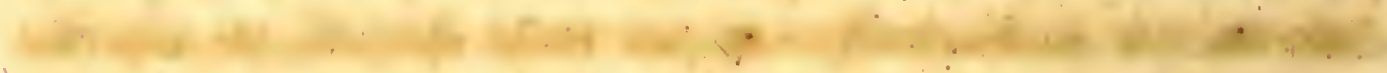

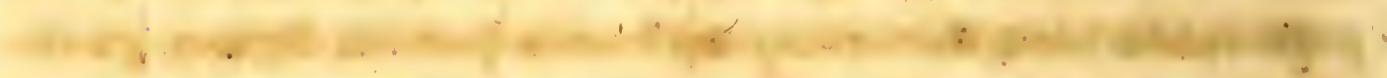

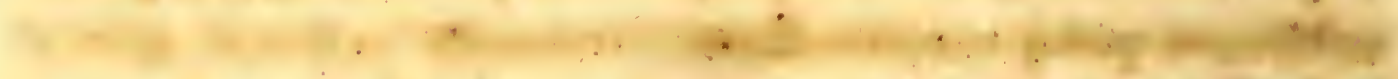

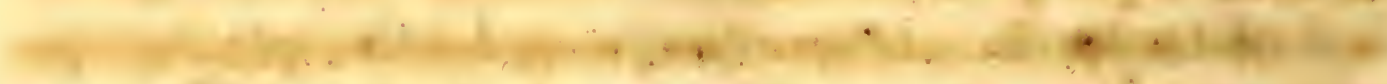

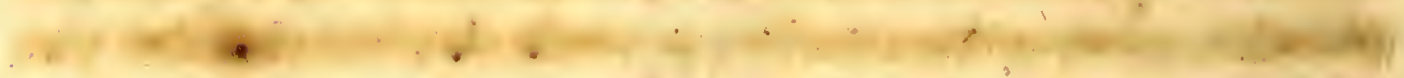

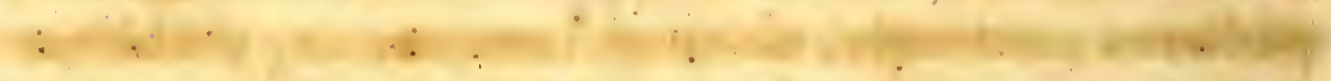

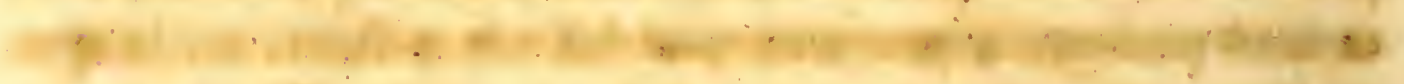

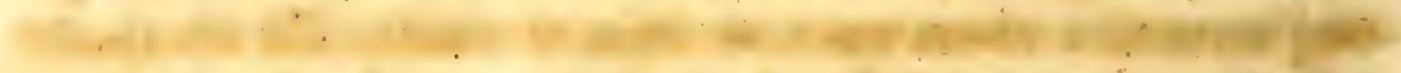

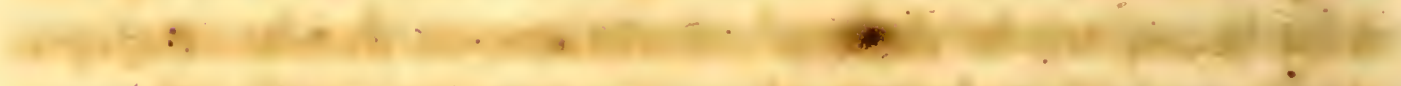

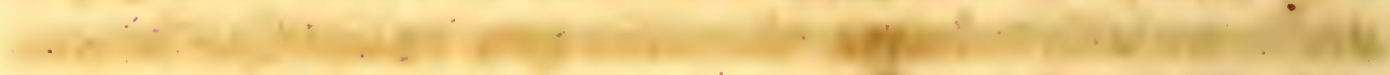

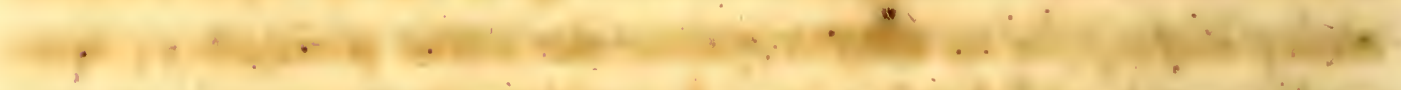

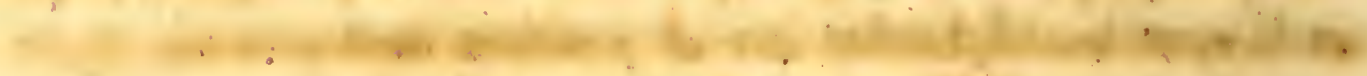

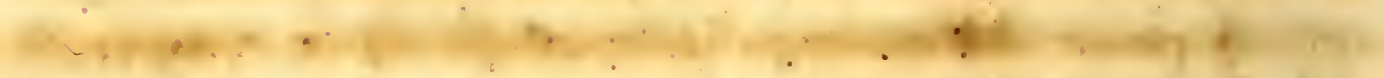

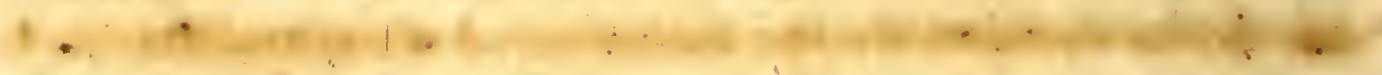

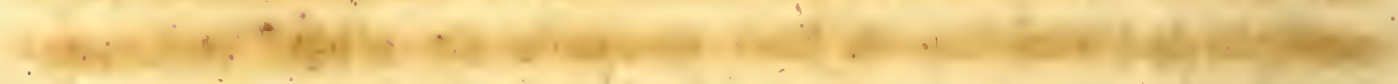

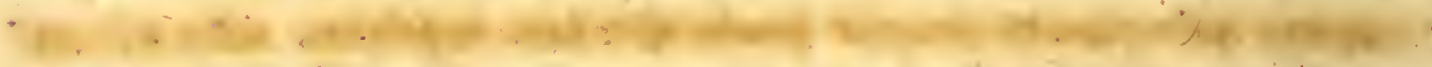

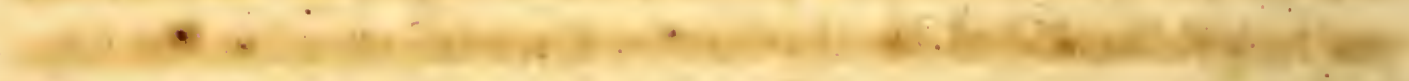

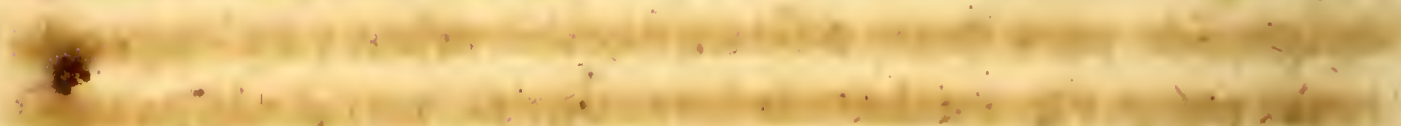

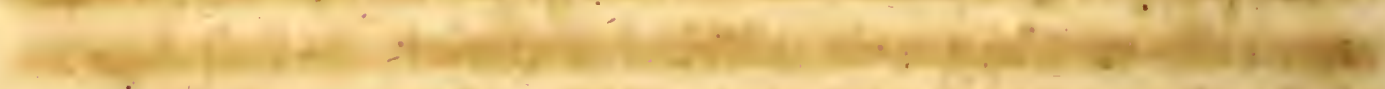

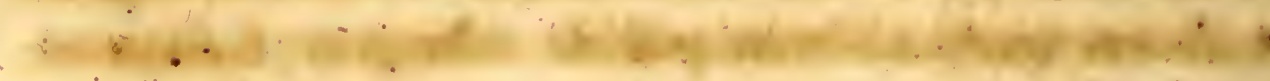




\section{SEGUNDA DIVISION.}

\section{Animales Alvltuscos.}

Se designan bajo el nombre de moluscos unos animales desprovistos del esqueleto interior que caracteriza á los vertebrados, y de los anillos esteriores, cuyo conjunto constituye el cuerpo de los articuládos, y que se diferencian de los radiarios por estar dotados de nervios y de vasos bien distintos, asi como por su figura generalınente par y simétrica:

Se les ha dádo el nombre de moluscos, que significa blandos, porque su cuerpo, privado de piezas sólidas que pudieran sostenerle, no tiene consistencia, y únicamente está protegido por una piel blanda y floja, en la que está envuelto como en una capa ó manto. En el espesor ó en la superficie de esta membrana, es donde se depo- sita la materia calcarea ó cornea que constituye la con- cha (testa) de la mayor parte de estos animales, que es la que les ha hecho dar el nombre de testáceos.

A pesar del número inmenso de seres comprendidos en la division de los moluscos, los naturalistas de la antigüedad casi no se han ocupado de ellos, primeramente porque la mayor parte de las especies solo viven en la profundidad de los mares, á una distancia demasiado grande para que pudiesen encontrarlas; $y$ en segundo - lugar porque generalmente los antiguos, no fijando su atencion sino en objetos de utilidad material, no hallaban en los moluscos que hubieran podido observar fácilmente,

Tono III. 
resultados bastante satisfactorios que les indujeran á estudiarlos de un modo especial. Pero despues que por los progresos de la navegacion se handescubierto tantas conchas tan variadas en sus formas y tan ricas en colores: desde que se ha podido 'ser testigo de las costumbres interesantes de algunos de los animales que las habitan, el celo de los aficionados ha sido escitado por el deseo de hacer nuevos descubrimientos, de suerte que cada viage marítimo de larga travesía ha ido aumentando las riquezas conquiliológicá con algunas conchas notables por su henmosúrá su singularidad. Una vez conocidas las especies bonitas, se han ocupado de las especies menos hálágüễas álà vista, pero no menos interesantes por la singularidad de la organizacion de los animales que en ellas viven. Por medio de este estudio sostenido, se ha aumentado de tal modo el número de los móluscos conocidos que en la actualidad pasa de cinco mil.

Se deja de ver que parallegar á distinguir un número tan considerable de seres cuya organizacion es poco complicada, ha sido preciso examinar atentamente todas las partes del animal. Desde luego la atencion se ha dirigido sobre la concha, cuyas formas variadas son tan favorables para la distincion de estos animales. Se ha estudiado esta parte con un cuidado minucioso en su estructura, su formacion \&c.; y es preciso convenir en que la concha es un órgano importante que debe ser - observado de un modo especial, y sobre el que vamos á entrar en algunosipormenores.

Toda concha es producida por un humor particular, que contiene en disolucion una gran cantidad de materia calcarea, $y$ que depositándose por capas sucesivas, forma á consecuencia de la evaporacion de la parte liquidà, una serie de láminas ú hojitas sólidas, cuyo 
conjunto constituye un todo de aspecto variable, pero las mas veces agradable á la vista. Las capas mas interñas y por consiguiente las mas nuevas, sobresalen siempre un poco de las mas esternas y antiguas; lo que hace que con el tiempo lá concha crece en longitud y anchura, asi como tambien en espesor.

La figura de la concha presenta, como hemos dicho, grandes diferencias; las mas principales é importantes se sacan del número de ventallas, valvas (valvas) ó piezas que la constituyen. Es univalva, cuando no está formada mas que de una sola pieza, como en el caracol, el buccino \&cc; ; bisalva, cuando se compone de dos, cono en la ostra, la almeja; tambien á estas se les denomina conchrs propiamente dichas (conchas); multivalva, cuaado ofrece mas, como la de algunos moluscos poco importantes, tales son la anati$\mathrm{fa}_{\text {; }}$ la balanita, En todos cásos; está cubierta de una epidermis fina, que se llama comunmente paño marino.

El estudio de los moluscos se ha limitado por mucho tiempo al conocimiento de esta concha, y la ciéncia de estos animales habia tomado de esta circunstancia el nombre de conquiliologia; pero habiende llamado la atencion la observaeion de esta cubierta sobre el ser que la ha formado, se ba cambiado esta denominar cion por la de malacologian, que quiere decir tratado de los moluscos.

Este segundo estudio, mucho mas importante que et primero, aunque este es de grande interes, ha rever lada una multitud de hechos curiosos, y ha hecho conocer la organizacion de estos animales singulares.

Aunque un gran número de moluscos tienen una cabeza distiata, con una boca y algunos de los órganos de los sentidas, nipguno tiene celebro en esta para 
te de su cuerpo el órgano á quien se da este nombre, está colocado en estos animalés á poca distancia de la entrada del conducto digestivo sobre el esófago, al rededor del cual forma una especie de collar (lám. 1. fig. 3. a); nunca tienen médula espinal ; esta es reemplazada por pequeñas masas de materia nerviosa, esparcidas en las'diferentes partes del cuerpo del animal (lám. 1. (fig. 4.) Sus sentidos jamas son en número de cinco; el oido no se encuentra sino en una pequeña clase de esta division; la vista existe en máyor número, péro la mayoria carece de ella. En cuanto á los del gusto y olfato se ignora su sitio. El tacto únicamente puede tener alguna delicadeza, por razon de la blandura estremada de la piel que envuelve al animal.

6) Esta disposicion del sistema nervioso, y la imperfeccion de los órganos de los sentidos no permiten á los moluscus tener una inteligencia muy estensa; pero esta facultad está abundantemente compensada en éllos con el desarrollo del instinto, que les sugiere á todos mil: medios de procurarse su alimento y para escapar de sus enemigos. Las jibias persiguen su presa á nado ; los pulpos la alcanzan con sus largós brazos; Ios que no pueden mudar de sitio forman, cón ciertos apéndices movibles, una especie de remolino de agua que termina en su boca, y les trae continuamente las particulas de materias nutritivas que nadan en este fluido.

Para sustraerse los moluscos á los alcances de sus enemigos no tienen menos recursos; la mayor parte se encierran en su concha que es excesivamente dura, y que solo un corto número de ánimales pueden quebrantar; otras hacen alejar á sus agresores derramando alrededor de sí un líquido de un olor fétido y/aun peligroso para cualquier otro que no sea de ellós mis-? mos ; è fin, algunos sebcaltan ála vista de sus ene- 


\section{5}

migos tiñendo, por medio de un líquido que producen, el agua en que están sumergidos, de modo que se hacen invisibles 'á los animales que los persiguen.

Sin estas pequeñas astucias y otras análogas, los moluscos no hubieran podido evitar su destruccion total. Privados de miembros articulados y de esas partes óseas ó córneas que constituyen la armazon del cuerpo de los demas animales, y que dan á sus movimientos fuerza, estension y precision, no mudan de sitio la mayor parte sino con muchisima lentitud, y por consigiente no podrian perseguir una presa que huye. Aun un gran número, reducidos á algunos movimientos parciales de ciertas partes de su cuerpo, permanecen fijos durante toda su vida en el sitio donde han nacido; sin poder cambiarle.

Sin embargo, por limitada que sea la locomocion de estos animales, los órganos que la ejecutan no son por eso menos notables. En todos casos, la cubierta exterior ó manto es el único agente de los movimientos del cuerpo entero. Para este efecto está guarnecido interiormente de un gran número de musculos, y toma formas muy variables, pero siempre apropiadas á la locomocion. Ya se estiende en largos tentáculos (lám. XXIX. fig. 1. y 2.), que le sirven para nadar ó fijarse á los cuerpos sub-marinos; ya forma unas especies de alas colocadas á cada lado del cuerpo, de las que el animal se vale para sostenerse en el agua; otras veces se ensancha debajo del vientre en una especie de pie carnoso, por cuyo medio el animal se arrastra, ya sobre la tierra, ya en el fondo del agua; esta es la disposicion que nos presenta la babosa y el caracol (fig. 6. y 8.). Algunas veces tambien se retuerce en forma de un largo tubo contractil, que estrechándose $y$ dilatandose alternativamente, se llena y se vacia continuamente de agua y pro- 
duce una pequeña corriente que hace adelantar al animal.

Hemos hablado de las diversas estratagemas que los. moluscos emplean para atraerse su alimento. En cuanto á los órganos que deben hacerle sufrir los cambios necesarios para su asimilacion, ofrecen unas relaciones bastante admirables con los de los animales vertebrados: y esta semejanza es la causa de que Cuvier haya colocado los moluscos inmediatamente despues de la pri- $<$ mera division y antes de la de los articulados, aunque estos últimos les aventajan en mucho por lo restante de: su organizacion.

Relativamente á la digestion, los moluscos tienen una boca que las mas veces no hace mas que el oficio de un simple chupador, pero que algunas está armada de cuerpos duros que les sirven, ya para cortar, ya para triturar sus alimentos. Viene en seguida un estómago, unas veces sencillo, otras multiple, despues del cual se hallan unos intestinos mas ó menos. largos y: arrollados sobre sí mismos.

Pór lo que toca á la circulacion, se observa que su sangre es acuosa, sin color ó ligeramente colorada de blanco ó de azul; por lo demas, tienen un sistema completo de venas $y$ arterias, y un corazon unas veces sencillo $y$ haciendo el oficio del corazon izquierdo de los mamíferos y de las aves, otras doble y análogo al de los vertebrados, á escepcion de que las dos partes que le componen estan separadas y no unidas una con otra.

En cuanto á la respiracion, el animal unas veces tiene un pulmon, otras branquias, segun que respira el fluido atmosférico ó que viviendo en el agua, saca de este líquido el aire que contiene en disolucion. La posicion de estos órganos ya es esterna, ya interna; en este último caso se halla en la su- 
superficie del cuerpo un orificio que conduce á ellos -el aire ó el agua necesaria para esta funcion.

Las mismas variedades que se observan relativamente á la digestion y respiracion de los moluscos se advierten respecto de su generacion. Efectivamente presentan todas las variedades de ella; unos se fecun-dan á sí mismos, otros aunque hermafroditas, tienen necesidad de una cópula recíproca : muchos tienen los sexos separados. Unos son vivíparos, otros -ovíparós, y los huevos de estos últimos tan pronto estan -cubiertos de una concha mas ó menos dura, como de -una simple viscosidad.

Terminaremos estas generalidades sobre los moluscos, con algunas consideraciones particulares sobre su habitacion y las relaciones que pueden tener con nosotros: La gran mayoría de las especies conocidas frecuentan las aguas del mar, y viven ya cerca de laroriHa, ya en los parages mas profundos. Se distinguen las especies riberiegas en que tienen un pie para andar, ó mas bien para arrastrarse, al paso que las pelagianas estan provistas de alas ó aletas para nadar; las primeras tienen la concha generalmente fuerte y gruesa, por que hallándose espuestas á ser lanzadas contra las rocas que forman las costas, serian infaliblemente estrelladas, mientras que las segundas, no teniendo que temer una cosa semejante en sus aguas profundas, pueden tener una concha ligera ó simplemente córnea.

Ademas de las especies marinas, se conocen tambien otras fluviales y terrestres; 'estas son ilas que mejor se han estudiado porque son mas fáciles de observar que las demas.

En cuanto á las relaciones que los moluscos pueden tener con el hombre son generalmente muy limitadas; hay pocos que nos presten algun servicio ó nos hagan daño. 
Sin embargo, hay algunos que nos sirven de alimento; por ejemplo; la ostra, el caracol \&cc.; y un mayor número, si se conocieran mejor, podrian sernos útiles bajo el mismo aspecto; otros nos suministran algunos productos, tales son la jibia, la madre perla, las pinnas y los murices.

Aunque estos servicios no son de grande importancia, al menos son muchos mas que las pérdidas que nos ocasionan. Entre las especies terrestres los caracoles y las babosas son casi los únicos que dañan á la jardinería; y entre las especies marinas las folades y las polillas son los únicas que pueden ser peligrosas, atacando las madéras que forman las estacas de los muelles y de los puertos, ó la quilla de los buques botados al mar.

Se conoce bien que para no confundirse en medio del gran número de estos moluscos, que á pesar de su variedad, tienen tantas relaciones entre sí, ha sido preciso clasificarlos con metodo, á fin de no reunir especies desemejantes, y de no alejar unas de otras á las que se parecen. Esta clasificacion ha sido difícil por mucho tiempo, porque no se tenian mas que nociones incompletas sobre estos animales; solamente de algunos años á esta parte es cuando se han podido didivir en cinco clases : los cefalópodos, los pterópodos, los gasterópodos, los acefalos y los cirropodos (1).

1. Los cefalopodos se conocen en que tienen una cabeza distinta, la boca rodeada de tentáculos ó brazos en número de ocho ó diez, y la concha simétrica, cuando existe, (el pulpo, la jibia).

2. Los pteropodos tienen tambien una cabeza distinta; pero en vez de tentáculos, tienen una especie de aletas culocadas, como unas alas, á cada lado de la boca

(x) Otros escriben cefalopodes, ptcropodes, \&c. 
su concha, cuando la tienen, es muy frágil y delicada (las hyalas ó cristalinas).

3. ${ }^{\circ} \quad$ Los gasteropodos tienen tambien la cabeza bien distinta, pero no tienen alas ni tentáculos como los precedentes, y se arrastran sobre un disco carnoso ó pie colocado en la parte inferior de su cuerpo; su concha es siempre univalva y mas ó menos arrollada en espiral (la babosa, el caracol, el buccino).

4. Los acéfalos carecen de cabeza, como lo indica su nombre; su boca está escondida en el fondo de su manto, en el cual se hallan tambien las principales visceras del animal (la ostra, la almeja).

5. En fin, los cirropodos se parecen á los acéfalos por la falta de cabeza y por la disposicion de su manto; pero se diferencian de ellos en que tienen una especie de miembros córneos "y articulados, y un sistema de nervios análogo al de los animales de la division siguiente (la anatifa). 


\section{PRIMERA CLASE.}

Cefalopologia

HISTORIA NATURAL DE LOS CEFALOPODOS.

Se llaman cefalopodos los moluscos que llevan en su cas beza una especie de brazos ótentáculos carnosos é inarticulados, colocados en forma de corona al rededor de su boca.

Estos animales son los que tienen la organizacion mas complicada de todos los de su division. Tienen una cabeza bien distinta, unos ojos redondos y muy grandes, un oido análogo al de los peces, dos mandíbulas córneas semejantes al pico de un papagayo, y un celebro encerrado en una caja ternillosa.

Por medio de sus tentáculos, cuya superficie está toda guarnecida de chupadores ó ventosas, y cuya estremidad es algunas veces ancha, los cefalopodos pueden fijarse á los cuerpos colocados en el agua, coger su presa, arrastrarse por el fondo de los mares, ó nadar con agilidad en su seno. En este último caso llevan siempre la cabeza hácia abajo y el cuerpo hácia arriba; lo que no les impide ir en todas direcciones con mucha rapidez.

Sus órganos digestivos, circulatorios y respiratorios estan contenidos en el manto que está cerrado por to- 


\section{1}

'das partes, escepto por delante, en donde se encueñtra una grande bolsa que deja pasar la cabeza con sus dependencias; y en la cual se abren el orificio del con'ducto que conduce á las branquias el agua necesariá para la respiracion, la abertura del que espele el residuo de la digestion, $y$ en fin, la estremidád dél tubó por donde sale al esterior una secrecion particular de un color muy intenso que el animal derrama alrededor 'de sí, para hacerse invisible cuando se ve perseguido por sus enemigos.

La boca de los cefalopodos presenta, ademas de las dos mandíbulas, una lengua erizada de puntas córneas que forman unos órganos masticatorios muy enérgicos? por esta razon estos moluscosison muy voraces y carniceros, y se alimentan de cangrejos, langostas, peces $y$ de todos los animales marinos que pueden coger y vencer. Uniendo la destreza á la fuerza y agilidad, unas veces estan escondidos entre las algas y los fucos, esperando que se acerque alguna víctima al alcance de sus largos tentáculos; otras vogan en el seno de las aguas dirigiendo á todos lados sus atentas miradas; luego que perciben una presa conveniente, se lanzan en su persecucion, y enlazándola en sus brazos, la conducen á su boca, en donde es quebrantada y engallida inmediatamente.

La piel de estos animales, sobre todo la de los incluidos en el primer género de esta clase, cambia de color por partes' con una rapidez superior á la del camaleon.

Casi todos los cefalopodos tienen una concha; los que no la tienen esterior, llevan un rudimento interno que adquiere algunas veces una dureza petrosa, " $y^{\prime}$ que es con bastante frecuencia completamente córnea. Pero en todos casos la sustancia córnea ó petrosa que 
la compone es de forma simétrica, y puede dividirse en dos partes iguales y semejantes. Segun la consideracion de la posicion interna ó esterna de esta concha, se ha dividido esta clase en órdenes, familias, géneros \&c. Pero como los animales que se encuentran en este grupo son la mayor parte microscópicos, ó no existen sino en el estado fósil, se pueden mirar las especies interesantes que se conocen como no formando sino un solo órden, que dividiremos en dos familias, de las cuales la una no tiene mas que un rudimento de concha interior ó una concha entera con una sola celda ó cavidad, y la otra tiene siempre una concha arrollada en espiral y dividida interiormente en muchas cavidades: la primera es la de los sepiarios, y la segunda la de los nautilaceos,

\section{P R I M E A F A M I L I A.}

SEPIARIOS. (Lám. XXIX.)

Sacan su nombre del latino sepia, gibia, que es la principal especie de la familia. Son unos moluscos de gran magnitud, cuyas principales vísceras ú órganos estan encerrados en el saco formado por el manto; y que presentan debajo de su cuello una especie de embudo en donde se abren los conductos respiratorios del animal, asi como el del líquido oscuro que derrama para enturbiar el agua y ocultarse á la vista de sus enemigos.

Todos los cefalopodos de esta familia son marinos; unos, lentos en sus movimientos, se arrastran en el fondo del agua, y no se alejan nunca de la orilla, porque en ella encuentran mas cómodamente su alimento; otros, mas ágiles, se adelantan hácia alta mar, en don- 



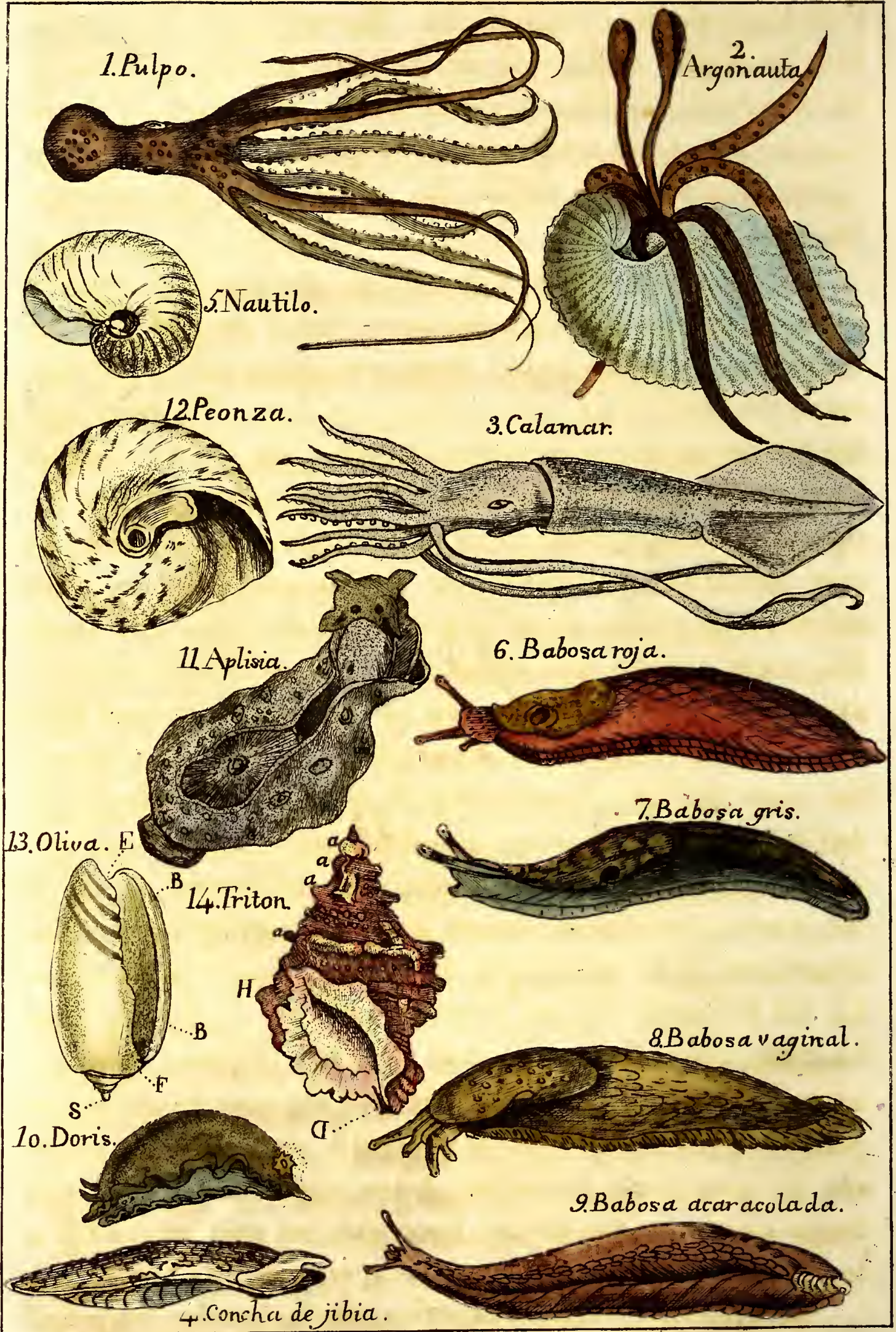

CEFALOPODES.

L.XXI :

GASTEROPODES. 


\section{3}

de nadan fácilmente con la ayuda de sus largos brazos y de los apéndices abdominales formados por su manto. Por lo demas todos son igualmente voraces y cruelés; todos tienen tambien la carne buena de comer, y suministran una tinta empleada en la pintura. Se dividen en cuatro géneros: los pulpos, los arganautas, los calamares y las jibias.

S. I. La voz pulpo (polypus), que significa muchos pies, se aplicaba antiguamente á todos los cefalopodos conocidos, y se les habia dado en razon del gran número de tentáculos que rodean su boca. Despues que los progresos de la historia natural han hecho descubrir muchas especies análogas á lass que conocian los antiguos, no se ha dado ya el nombre de pulpo, que no es mas que una corrupcion de la voz polipo, sino á los animales provistos de ocho grandes tentáculos casi iguales, cuya concha está reducida á dos granos cónicos de sustancia córnea, situados en el espesor de su piel dorsal; y cuyo vientre está desprovisto de esas alas laterales, que facilitan la natacion de las especies pelagianas. Asi es que los pulpos no pueden nadar, ó al menos nadan mal; por esta rażon viven con preferencia cerca de las costas, en donde hacen grandes estragos entre los crustáceos y los peces que frecuentạn los mismos sitios. Es tal la fuerza de sus brazos, que casi no hay animales que, enlazados en las asas de estos órganos, puedan escapárseles; y aun se pretende que algunas veces hacen perecer á los nadadores. El número inmenso de ventosas de que estan cubiértos estos péndices, que llega hasta ciento reinte pares, hace que sea casi imposible á los animales que han cogido escaparse de sus apretones.

Se conocen muchas especies, de las cuales las principales son: el pulpo comun (sepia octopodia, L.) (octopus vulgaris, Lamarck.) (fig. 1.), que tiene cerca de dos 
pies de diámétro, y cuyos brazos son seis veces mas lara gos que el cuerpo ; este es el mas grande y peligrosa de todos; es muy dificil á los animales marinos evitar sus emboscadas, en razon de que tiéne la costumbre de esconderse en las hendiduras de las rocas. Asi es como triunfa por sorpresa de cangrejos enormes, que si no hubieran sido cogidos de improviso, se hubieran defendido con ventaja tis prèciso añadir á esta especie el pulpo árrugado (sepia rugosa) (octopus rugosa, Lam.), al que se debe, segun algunos autores, la buena tinta de China.

A este género parecen pertenecer tambien los elodones de Aristóteles; pues en realidad únicamente se diferencian en que estos tienen una sola fila de ventosas en cada pie. Tal es la especie del Mediterráneo llamada pulpo almizclado, notable por su fuerte olor á almizclè.

S. II El ARGONAUTA (argonauta) (fig. 2.) tiene grandes relaciones con los pulpos por toda su organizate cion y por el número de sus tentáculos; pero se diferencia de ellos en que dos de estos apéndices son un poco mas largos que los otros, y se dilatan en su estremidad en forma de una ancha membrana ; por otra parte estan encerrados en una hermosa concha anacarada $\hat{y}$ trasparente, cuyo interior no presenta mas que una sola cavidad.

Este género, del que se cuentan muchas especies, que los antiguos confundian bajo el nombre de argonauta, y á las que el vulgo da todavía el nombre genérico de nautilo papiraceo en razon de la finura de su concha, ha sido célebre en todos tiempos por sus costumbres singulares; los poetas principalmente los han descrito con entusiasmo. Este animal vive siempre en alta mar. Iy jamas se acerca á la orilla. Cuando el tiempo' está tranquilo, se le ve elevarse á la súperficie del agua, 
en donde su concha, ligera sobrenadá como una barquił lla. Desplegando entonces sus tentáculos ensanchados; presenta una especie de vela á los vientos, á cuya merced se deja llevar mientras dura la calma; pero si el tiempo se oscurece ó llega á espantarle algun ruido, el animal plega sus velas, se mete én su concha, y llenándola de agua, wuelve á caér en el fondo del marl, en donde permanece hasta tanto que haya pasado el peligro.

S. III. El nombre de calamar (loligo) (fig. 3.), abreviacion de calamarium, ó mas bien de theca calamaria (tintero), se daba antiguamente á todos los cefalopodos que derramaban un líquido negro, de que se ha: cia uso para escribir. Ahora ya no se aplica sino á las especies cuya concha rudimentaria es cónea , y tiene la forma de una hoja de espada ó de lanceta, y que tienen la boca rodeada de diez tentáculos, de los cuales los dos mas lergos se terminan por una ventosa bastante ancha. Por otra parte su manto forma cen los lados y en la parte posterior de su cuerpo dós espet cies de aletas, ilo que hace que naden con mas facilidad que los pulpos. Por esta razon todos los calamares son pelagianos, y presentan una agilidad notable en unosanimales sin esqueleto interior ó esterior Noisolo persiguen su presa con velocidad, sino qué se les ve con frecuencia lanzarse fuera del agua á alturas bastante grandes para volver á caer algunas veces sobre el puente de las embarcaciones. Si estos moluseos hạbitáran siempre en las aguas profundas, se conocerian poco sus costumbres, pero se ha observado que, durante la tempestad; se acercan á las costás, sea para fijarse á las rocas por medio de sus ventosas.; sea para buscar alli víctimas que devorar.

Se pescan los calamares por muchos motivos; en primer lugar por su tiata que se emplea ventajosameni: 


\section{6}

te en las artes; $y$ despues por su carne, que sirve de alimento, pero de la que se hace principalmente un grande uso como cebo para la pesca del bacalao.

Se cuentan en este género mas de veinte especies, éntre las cuales lá mas célebre y la mas antiguamente conocida es el calamar vulgar (sepia loligo, Li); que llega hásta treinta pulgadas de largo, tiene sus aletas formando un rombo, y es muy comun en todos los mares de Europa. Se conocen tambien el calamar grande y pequéño (lóligo ságittata, Lam. y sepia media, L.) de lós cuales el uno es superior y el otro inferior al calamar vulgar. El primero tiene las aletas unidas y formando un triangulo en la parte inferior del saco, $y$ 'el segundo conformadas en elipse que se termina por una punta aguda.

§. IV. Las Jibias (sepia) tienen las mayores relaciones con los calamares, de los que no se diferencian sino por su concha y por sus aletá laterales. En las jibias, la concha es oval y de naturaleza calcarea, y las aletas se estienden por toda la longitud del cuerpo; al paso que en los calamares, la primera es larga y puntiaguda y las últimas no existen sino en la parte posterior del cuerpo.

8. Por lo demas estos dos géneros de moluscos tienen la misma organizacion y las mismas costumbres; tan ágiles y astutos unos como otros, destruyen una gran porcion de peces y crustáceos, ya en medio del mar, ya cerca de sus orillas. A su vez son tambien perseguidos por los peces grandes, y entre otros, por los congrios que hacen de ellos su principal alimento. Pero su fecundidad es inmensa; ponen sus huevos en forma de grandes racimos, á los que se da en los puertos el nombre de uvas de mar. Se buscan las jibias como los calamares, por su tinta y su carne; ila 
concha, que se llama vulgarmente hueso de jibia, se emplea para pulir diversas obras, y se cuelga en la jaula de los pájaros pequeños para que les sírva para aguzarse el pico. La príncipal especie es la comun (sepia officinalis, $L_{0}$ ), que llega hasta cerca de un pie de largo, y es lisa, blanquecina, moteada de rojo. El mar de las Indias produce otra especie cuya superficie está cubierta de tubérculos.

\section{SEGUNDA FAMILIA.}

\section{NaUtilaceos, (Lám. XXIX.)}

Esta segunda familia, aunque mucho mas numerosa que la precedente, no ofrece el mismo interes al naturalista, pero suministra á la geología ó á la ciencia que se ocupa de la estructura de la tierra datos preciosos para conocer la edad de las diversas capas que la componen; porque encierra un gran número de especies fósiles muy notables.

El carácter principal que distingue á los nautiláceos de los sepiarios se saca de la figura de la concha que aloja al animal; siempre es arrollada en espiral y simétrica, como la del argonauta, pero se diferencia de esta última por el número de tabiques que dividen interiormente su cavidad. En cuanto al animal que la habita, no se conoce al de todas las especies; pero en todas aquellas en que se ha observado, se ha encontrado casi semejante á los sepiarios; 'lo que hace presumir que el de las especies cuyas conchas se councen debia parecérsele tambien.

No se cuenta de esta familia mas que un solo género cuyas especies vivan; y son los náutilos (1); pe-

(i) No hablaremos aqui de las especies microscópicas que son tan abundantes en todos los mares, pero que son difíciles de observar; por otra parte no se está bien de acuerdo sobre el

'Tомо III. 
ro se encuentran en el seno de la tierra un gran número de conchas fósiles, que han pertenecido probablemente á esta familia. Se forman de ella tres géneros principales: las belemnitas, las ammonitas y las nummulitas.

§. I. Los NaUtiLos (nautilus) (fig. 4.) forman un género poco numeroso en especies vivientes, y cuya concha es la única parte bien conocida. Esteriormente esta concha se asemeja á la del argonauta, y en el comercio, se designa esta última con el nombre de nautilo. Una y otra parecen en efecto haber sido formadas por un cono arrollado muchas veces sobre sí mismo; pero en el argonauta el interior del cono está sin tabiques, y sus circunvoluciones están acanaladas transversalmente, al paso que en los náutilos, el interior del cono está dividido en muchos departamentos por unos septos transversales; y sus circunvoluciones tienen la superficie esterna enteramente lisa.

En cuanto al animal, es todavía poco conocido; pero se sabe que tiene muchas relaciones con el de las jibias; únicamente, como el nautilo vive metido en una concha, le es necesario un sifon ó conducto que le conduzca el agua que necesita para respirar.

No se cuentan mas que dos especies de naútilos; que son la espirula (nautilus spirula, y la taza de Venus ó náutilo de llamas (nautilus pompilius, L.) que se llama asi para distinguirle del naútilo papiráceo que pertenèce al argonauta. Esta última especie es muy grande, y tiene la concha de un hermoso nacarado interiormente, $y$ cubierta esteriormente de una costra blanca variegada de listas ó ráfagas amarillas.

lugar que deben ocupar estos animales en la serie animal, pues que ilgunos naturalistas los miran como moluscos, y otros como zoófitos. 
§. II. Se halla en lo interior del globo terrestre; en medio de las masas calcareas, una inmensa cantidad de conchas, cuya forma esterior é interior hace presumir que el animal que las habitaba debia parecerse al de los náutilos. Entre estas conchas, unas son rectas, cónicas y semejantes á un dardo; las llaman BELENNitas, (Véase la lám. L. fig. 1.) de una voz griega que significa dardo. Es una concha delgada y doble, esto es compuesta de dos conos unidos por su base, de los que el interior, mucho mas corto que el otro, está dividido por adentro en varias cavidades por unos tabiques paralelos cóncavos por el lado de la base. Desde el vértice del cono esterno al del interno se estiende un conducto, y desde aqui se continua, ya á lo lárgo del borde de los tabiques, ya á traves de su centro. Estas conchas son entre el gran número de fósiles, las mas abundantes en los terrenos gredosos y calcáreos.

Otras conchas fúsiles están vueltas sobre sí mismas como las de los náutilos, y llevan el nombre de ammonitas ó astas de Ammon, (Lám. L. fig. 2.) porque se parecen á los cuernos de carnero. Las capas de los terrenos secundarios, que se han llamado ammonenianos, abundan mucho en especies de este género de todas magnitudes, desde la de una lenteja hasta la de una rueda de coche.

Por último, algunas conchas tambien fósiles no tienen ninguna abertura aparente, $y$ se han llamado camerinas, nummulitas ó piedras numismales, (Lám. L. fig. 3.) en razon de su poco espesor y de su figura redondeada: Este es uno de los fósiles mas esparcidos y que forma câsi él solo cadenas enteras de colinas calcáreas y bancos inmensos de piedra para edificar. 


\title{
SEGUNDA Y TERGERA GLASE.
}

\section{f) $\mathfrak{c l i c o l o g i ́ a . ~}$}

\author{
ó
}

HISTORIA NATURAL DE LOS PTEROPODOS Y

GASTEROPODOS.

Los pteropodos forman una clase poco numerosa y poco importante, cuyo carácter distintivo consiste en tener en vez de apéndices locomotores unas nadaderas colocadas en forma de alas en cada lado de la boca. La disposicion de estos órganos anuncia que estos animales están destinados á vivir en médio de la inmensidad del Océano, en donde se mueven con agilidad y en que no tienen que temer el ser arrojados contra las rocas. Por esta razon huyen de las costas en donde hay muchas rocas por la esposicion que tendrian de ser estrellados contra ellas por las olas, á causa de la falta de concha, ó de la debilidad de este órgano. Estos moluscos son pequeños y carecen de concha, ó si la tienen es muy imperfecta. Tambien están muy abundantemente esparcidos en los mares del norte, donde sirven de alimento á las ballenas. No existe mas que un corto número de especies de moluscos pieropodos, todas ellas hermafroditas, y que podrian formar casi otros tantos pequeños géneros. Las clios tienen el cuerpo oblongo y membranoso, la cabeza formada por dos lóbulos redondeados, de donde salen unos pequeños 
tentáculos; y una red vascular en sus aletas que les sirve de branquias: entre estas especies la mas célebre es la clio boreal (clio borealis, L.) de la magnitud de una pulgada. Los cimbulios están caracterizados por tener una cabeza cartilaginosa ó gelatinosa en forma de chalupa, ó mas bien de almadreña erizada de pequeñas puntas dispuestas en series longitudinales. La boca con dos pequeños tentáculos, está entre las aletas hácia el lado cerrado de la concha. La transparencia de su superficie permite distinguir el corazon, el cerebro y las vísceras á través de sus cubiertas. Los neumodermos no tienen ni manto ni concha; las branquias están pegadas á la superficie y formadas de hojillas ordenadas en dos ó tres filas dispuestas en $\mathrm{H}$ en la parte opuesta á la cabeza; la boca es pequeña guarnecida de dos pequeños labios $y$ de dos haces de numerosos tentáculos terminados cada uno por un chupador. Los limasinos deben tener grande semejanza con los neumodermos, pero se diferencian de ellos porque su cuerpo se termina por una cola arrollada en espiral, y se aloja en una concha muy delgada de una vuelta y media, umbilicada por un lado y aplastada por el otro. Sus costumbres son parecidas á las del argonauta; esto es lo que junto á la forma de su concha ha hecho que á la especie que se conoce se la haya llamado árgonauta árlico, nombre que indica que vive en los mares del norte donde es tan abunte como la clio boreal. Las hialas tienen de particular que carecen de tentáculos; sus aletas son múy grandes, su manto abierto por los lados, aloja las branquias en el fondo de estas hendiduras, y se halla cubierto por una concha igualmente hendida por los lados, y cuya cara ventral es muy combada y la dorsal mas plana, que la otra. La principal especie que se encuentra en el Mediterráneo es la hiala córnea ó cris- 
talina, llamada ași por tener una pequeña concha amarillenta y transparente como el cristal. Finalmente, los cleodoros se asemejan á la hialas, pero su concha cóniça ó piramidal no está hendida por los lados. Á los pteropodos tambien parece pertenecer una pequeña concha fósil, globulosa muy delgada dividida por una hendidura transversal. Esta concha se llama pirgo.

Pero si la segunda clase es pequeña, la tercera es muy considerable; comprende un gran número de moluscos testáceos ó sin concha, provistos de una cabeza bien distinta y que se arrastran sobre un disco carnoso colocado en la parte inferior de su cuerpo, y que se designa con el nombre de pie: á esta disposicion deben su nombre de gasteropodos, voz griega que quiere decir vientre-pie.

Por la figura de la limaza y del caracol puede formarse una idea exacta de la de todos estos animales: en efecto, todos tienen el cuerpo terminado por delante por una cabeza prominente, pero susceptible de ser introducida al interior del manto y sobre la cual se distinguen las mas veces unos tentáculos en número par y variable, pero que nunca pasa de seis. Estos tentáculos se diferencian de los de los cefalopodos en que, en vez de rodear la boca, estan siempre situados en la parte superior de la cabeza. Estos órganos que estan encima de la boca, que no la rodean, y que son susceptibles de alargarse y acortarse á voluntad del animal, parecen ser el sitio de una sensibilidad esquisita y de un tacto muy delicado; porque se les ve retirarse no solo al menor contacto, sino tambien á la simple aproximacion de un cuerpo que puede herirles.

La mayor parte de los gasteropodos tienen ojos; pero la posicion de estos órganos varia segun las especies. 
Unas vẹces se hallan colocados en la estremidad dé los tentáculos, $\mathrm{y}$ otras sobre la cabeza á mayor ó menor distancia de estos apéndices. En cuanto á la boca, está siempre situada en la parte inferior de la cabeza; y unas veces consiste en una trompa enteramente carnosa ó guarnecida de dientecitos en su estremidad, otras en mandíbulas córneas de forma variable.

La concha de estos animales es siempre univalva, y se parece á la de los cefalopodos, esceptuando que el cono á aquien debe su nacimiento, en vez de ser recto y estararrollado sobre un mismo plano, es oblicuo y forma unas circunvoluciones ó espiras que se elevan unas sobre otras, como en el caracol: el buccino, \&cc.(lám. XXIX. fig. $12,13,14$.

Se distinguen en la concha univalva dos partes principales, la espira y la abertura. La primera, que forma el cuerpo de ella, es unas veces prominente y otras chata, pero en todos casos sirve para contener al animal. En cuanto á la abertura, está destinada á dejar pasar la cabeza y'el pie; ordinariamente es mas larga que ancha, y por consiguiente presenta dos estremidades $\mathrm{y}$ dos lados. De las dos estremidades la posterior (H. F.) se llama base de la abertura. En ella se observa con bastante frecuencia el orificio de un conducto mas ó menos largo, que se llama ombliğo (umbilicus.) La estremidad anterior es generalmente notable en que presenta ya una escotadura (fig. 13. E.), ya un conducto (fig. 14.D.) destinados á dar paso al tubo respiratorio del molusco. Por lo que toca á sús lados, aquel hácia el que se dirige la espira y sobre el que se arrolla el cono, se llama columnilla (columela); el opuesto lleva simplemente el nombre de borde. Cuando la espira es saliente se dirige siempre hacia la derecha (en la posicion atural del animal); si tira ha- 
cia el lado opuesto las conchas se llaman de espira al reves ó invertidas (perversae).

La abertura está ordinariamente guarnecida de una pieza córnea llamada opérculo, cuya figura está en relacion con su contorno, y que el animal puede mover á su voluntad, de modo que sale de su concha cuando quiere ó se encierra en ella hernéticamente.

Por lo demas esta concha, a unque esencialmente formada del mismo modo, presenta las mayores variedades de figura: algunas veces es simétrica como en los argonautas y los nautilos; pero las mas veces es irregular. En este último caso puede ser oval, cónica, fusiforme, en forma de cucurucho \&cc. Sobre estas diferencias y sobre las de la abertura de la concha se funda la clasificacion de los gasteropodos.

Esta clase de moluscos se divide en un gran número de órdenes, de los cuales los mas importantes son los pulmonados, los dermobránquios y los pectinibrán. quios.

\section{PR I M E Ó R DEN.}

PULMONADOS.

Ios pulmonados constituyen un órden perfectamente distinto, no solo entre los gasteropodos, sino tambien en toda la division de los moluscos, por su mödo de respirar y por la naturaleza del órgano que sirre para esta funcion.

Al paso que tódos los demas moluscos respiran el fluido atmosférico por el intermedio del agua, los pulmonados no pueden vivir sino al aire libre, y tienen para este efecto una cavidad cuyo interior está tapizado por las ramificaciones de la árteria pulmonar, y comunica con el esterior por un agugero abierto bajo su man- 


\section{5}

to, y que el animal estrecha ó dilata á su voluntad, de nodo que puede dejar entrar el aire ú oponerse á su introduccion.

Pero aunque la naturaleza de su respiracion exige que estos gasteropodos tomen dẻl seno de la atmósfera los materiales necesarios á esta importante funcion, por. lo que todas las especies comprendidas en este órden deben ser esclusivamente terrestres, sin embargo, hay un gran número de ellas que son enteramente acuáticas: únicamente en vez de frecuentar las aguas profundas, como pueden hacerlo los moluscos provistos de branquias, viven de preferencia en los arroyuelos, balsas y pantanos; ó si algunos habitan en el mar, jamas se apartan de las orillas, á fin de poder elevarse fácilmente á la superficie del agua para respirar libremente el aire atmosférico.

Por lo que toca á la figura y al género de vida de estos moluscos, son bastante diferentes segun las especies; unos tienen la piel desnuda y se arrastran sobre un pie, que se estiende por toda la parte inferior del cuerpo; otros viven en una concha, y no tienen su pie sino en la base del cuello. Su alimento es principalmente vegetal; pero son estremamente voraces, y las especies terrestres hacen muchos estragos en los campos y jardines: una mandibula en forma de hoz de que está armada su boca, les permite cortar las hojas y los frutos con una rapidez que, atendido el gran número de estos animales, arruina muchas veces al labrador, destruyéndole sus cosechas.

Este género de alimento exige un conducto alimenticio muy desarrollado: por esto los pulmonados tienen el estómago musculoso, y las mas veces multiplo; su hígado es principalmente de un grosor considerable. La respiracion de estos animales, aunque es del toTOMO IIr. 
do aérea, no es bastante enérgica para volver la sangre caliente; asi es que tienen como los reptiles los muvimientos lentos y las sensaciones obtusas; todos des:aparecen durante el invierno, y se ocultan en agugeros profundos, en los quể no sienten la influencia atmosfér rica, $y$ en donde caen en el entorpecimiento.

La diferencia del medio que habitan estos molușcos, asi como la organizácion que es su consecuencia, los han hecho dividir en dos familias: los limacíneos y los limneanos.

\section{PRIMERA FAMILIA.}

\section{LIMACÍNEOS.}

Toman su nombre de las relaciones que presentan con la limaza comun, este animal, tan esparcido por todas partes, en los bosques, praderas y jardines; tan notable por su forma prolongada, por su piel desnuda y glutinosa, y por su cabeza dotada de tentáculos movibles, que el rulgo llama cuernos.

Todos estos moluscos son terrestres, y tienen por carácter distintivo el número de sus tentáculos, que es siempre de cuatro, al paso que las especies acuáticas no tienen nunca mas de dos.

La boca de los limacíneos presenta en su conformacion una particularidad muy notable: sus bordes estan armados de un diente único, encorvado en forma de media luna y cortante por su concavidad. El animal se sirve de él para cortar las yerbas y encentar las frutas de que se alimenta. En razon de este género de alimento, estos moluscos viven con preferencia en los campos plantados de árboles frútales, en los que hacen los mayores estragos, no tanto porque coman mucho, como porque encentan las frutas de hueso que los in- 
sectos y los pájaros devoràn despues con mas facilidad.

Dos géneros principales componen la familia de los limacíneos, que son: las limazas que carecen de concha, y los caracoles que tienen una.

§. I. Se conucen fácilmente las Limazas (fimax) por su cuerpo prolongado, por su piel completamente desnuda ó protegida por una concha siempre demasiado pequeña para dar cabida á todo el animal, y escondida en el espesor de la cubierta cutánea.

Aunque estos moluscos son enteramente terrestres y no pueden vivir en el agua, solo durante los tiempos lluviosos es cuando se manifiestan en los campos; y cuando se ven obligados á salir, por un tiempo seco, de la guarida húmeda en donde permanecen habitualmente ocultos, tienen cuidado de no andar sino por la yerba verde que conserva siempre cierto grado de frescura.

Su progresion es escesivamente lenta, y se egecuta por medio de la contraccion y dilatacion alternativas de su cuerpo, el que todavia se arrastraria con mucha mas lentitud, á no ser por la mucosidad ó baba abundante que exsudan por toda la estension de su pie.

Se cuentan muchas especies de este género, de las cuales unas son estrangeras, y otras abundan en nuestros paises. Entre estas últimas citaremos como las rnas comunes la limaza roja (limax rufus, L.) (fig. 6.), la limaza gris (lim. maximus, L.) (fig: 7.), la pequeña limaza gris (lim. agrestis, $\mathrm{I}_{\text {L. }}$ ). Entre las especies exóticas, unas se llaman vaginales (fig. 8.), otras testacelas ó acaracoladás (fig. 9.), otras parmacelas.

§. II. Los caracoles (helix) forman un género escesivamente numeroso que comprende mas de doscientas especies esparcidas por todas las partes del mundo. Se conocen por su concha redondeada ó cónica, cu- 


\section{8}

ya abertura es generalmente muy, considerable, aunque la penúltima vuelta de la espira la corta de manera que la da la forma de una media luná.

Estos son unos moluscos muy conocidos en todos (los paises, por lo que no nos detendremos en su descripcion; nos limitaremos á hacer observar la semejanza que existe entre este animal y la limaza; su cabeza está tambien provista de cuatro tentáculos, de los cuales dos son anteriores, y estan mas cerca de la boca, y dos posteriores mas próximos al vértice. Estos últimos sostienen los ojos, y son retractiles de un modo particular: tienen la forma de unos tubos huecos que alojan al nervio óptico, con un músculo que, contrayéndosé, hace entrar al ojo en el interior de esta cavidad, y lo lleva hasta la cabeza. Esta disposicion hace que este órgano sea mas dificil de dañar que si, para ponerle al abrigo, hubiera sido preciso hacer entrar á todo el tentáculo, empezando por su base. Se divide el género $c a-$ racol en muchos subgéneros, de los cuales los principales son los que siguen.

1. Se llaman caracoles las especies cuya abertura es tan ancha o mas que larga; este es el subgénero mąs considerabie. Se conocen de estos mas de cien especies, entre otras el gran caracol de las viñas ó caracol comun (hel. pomaria, L.), la librea ó pequeño caracol de los árboles (hel. remoralis, L.). En muchos paises se come el primero, que es escelente cuando se tiene cuidado de hacerle arrojar su moco por medio de lavaduras frecuentes y ayunos prolongados. Parece que los romanos hacian de ellos un aprecio particular, y los criaban en parages dispuestos espresamente para este uso.

- 2.0 Los bulimos (bulimus) tienen la abertura más larga que ancha. De estos tenemos uno en el mediodia 
de España: el bulimo escotado (hel. decollata, L.), llamado asi por la costumbre que tiene de romper la última vuelta de su espira. Circunstancia que llama la atencion, y se cita como un ejémplo para probar que los músculos del animal puedèn desprenderse de la concha; porque llega un momento en que este bulimo no couserva ni una sola de las vueltas de la espira que tenia antes.

3. Las clausilias (clausilia), llamadas con mas frecuencia nomparelles, son todas pequeñas, de forma larga, delgada y puntiaguda, y tienen los bordes doblados'hácia afuera. Se encuentran muchás de ellas en los musgos, al pie de los árboles \&c.

4. Las agatinas (agathina) tienen la concha mucho mas larga que ancha y la abertura semejante á la de los bulimos'su borde es cortante y su columnilla está truncada en su base. Este subgénero es casi enteramente exótico.

\section{S E G U N D A F M I I A:}

\section{LIMNEANOS.}

Los limneanos se parecen á los limacíneos por la figura de su concha y por la del animal que la habita, con la diferencia de que los primeros no tienen mas que dos tentáculos en la cabeza, al paso que las especies de la fámilia precedente tienen siempre cuatro.

A pesar de esta semejanza las costumbrês de estas dos especies de gasteropodos son del todo diferentes, porque los limneanos no se encuentran sino en las aguas dulces, y principalmente en las lagunas y pequeños charcos que contienen poco de este líquido: Algunas reces se les ve nadar en el seno de laśaguas por medio 
de los lóbulos de su pie abdominal ; pero las mas andan arrastrándose por el cieno, en donde buscan su alimento; algunas especies salen de su elemento favorito para diseminarse por las plantas que rodean las aguas que habitan, y cuyas hojas y yemas devoran.

Los limneanos son unos moluscos muy comunes y esparcidos por todąs las partes del mundo. Unos carecen de concha, como las limazas; son en corto número, todos estrangeros, y los llaman onquidios (onchidium). Otros en mayor número tienen una: tales son los planorbes y las limneas

\$. I. Los PLANORBES (planorbis) tienen, como su nombre lo indica, unas conchas muy aplastadas que dejan ver las circunvoluciones de la espira por encima y por debajo, como en la de los cefalopodos, al paso que en dos moluscos de espira prominente no se ven las cir. cunvoluciones de esta última sino por un solo lado.

El animal que produce esta concha lląmá la atencion por dos largos tentáculos entre los que están colocados los ojos, y por un líquido abundante que exhala su manto; liquido que se toma rulgarmente por su sangre por que es de color rojo; pero esto carece de fundamento; pues los planorbes, como todos los moluscos, tienen su fluido nutricio enteramente trasparente ó apenas colorado. Esta pretendida sangre no es otra cosa que un liquidoanáloga al que las jibias, los calamares \&c.s derraman cuando son persegidos ó inquietados

Se encuentran muchos de estos animales en los rios lagunas, balsas \&cc, en donde se alimentan de materias vegetales como todos los pulmonados; sus conchas, son generalmente delgadas, frágiles y y casi completamęnte diáfanas. Las principales especies son el planorbe carneo. (He; lix curnea , Jám,)i, el B. de muchas vueltas (H. palsg girias Lám.) el P. blanco (H.albg, Lám.) \&c. 


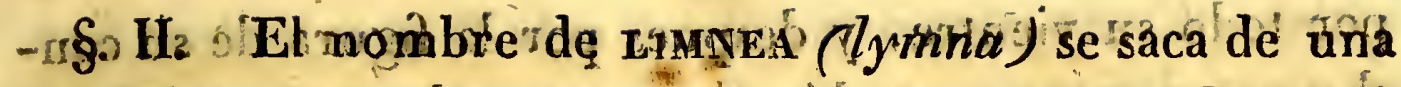

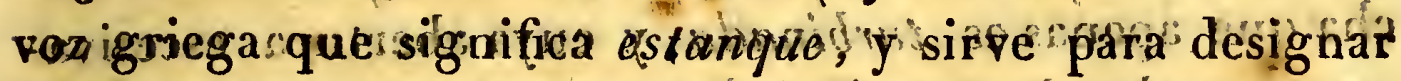
algunos mariscos murilcomunes la mayor párte en los charcos de agua dulce que se encuéntráñ pór todás partes. Vinen como tós precedentes, de yerbas $y^{3}$ semillas, $y$ tie-

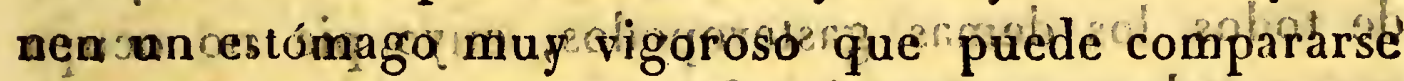

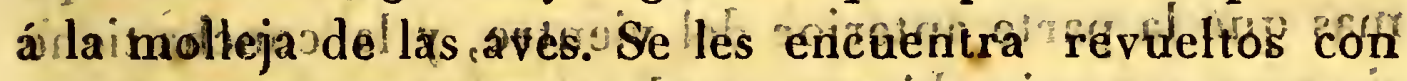
los planorbes, no solo en tida ế las balsas, sinó támbien

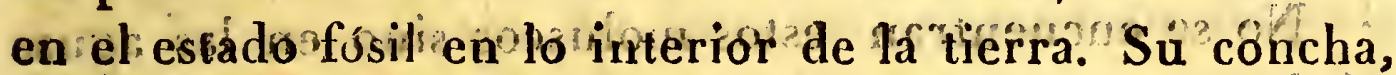
semejante a la de lós bulimós por su figura oblóng y su abertura mậs larga que anchá, se disting ue facilmente dé

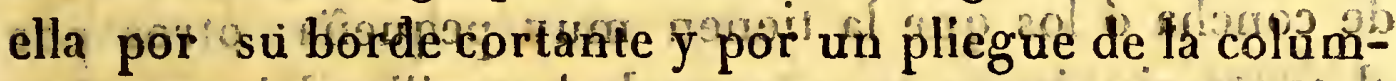
nilla que entrá oblicuánente efílo interiór de la concha. Las especies de este genero que se encuentran en Francia son la liminea de las lagunas, da limnéd meatana,

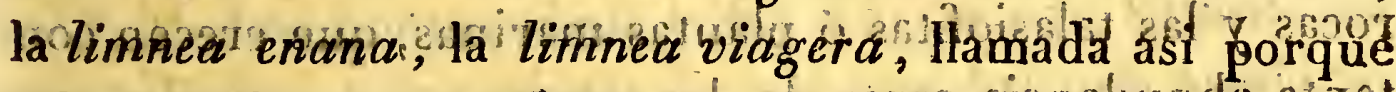
sale con frecuencia depa a da para trepar por dos ar-

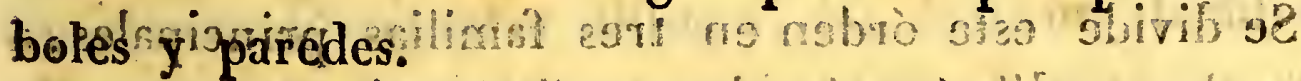

\section{SEGUNDO ÓRDEN.}

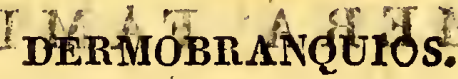

Entre los gasteropodos que respiran por branquias, y que por consiguiente no pueden vivir sino en el agua, hay un cierto númerb que tieñen estós organos visibles al esterior or simplemente cubiertos por un pliegue del manto del animal. Se ha dado a estos mónus cos el nombre de dermobranquios, que quiere decir branquias en la piel. Pero como la posicion de los oŕános respiratorios tho siempre es fácil de determinar se ha buscado un carácter esteribr por médio del cull pudieran conocerse estos anibales; $y$ se ha entrontrado, primeramente en la forma de su pie, que se estiende 
pór todo su vientre, y despues pór la figurá de sú côncha que apenas es turbinada, y cuya abertura escesivamente ancha, le permite hacer salir todo su pie, ya para nadar, ya para arrastrarse.

- Este doble carácter distingue á los dermobránquios de todos los demas gasteropodos cuyo pie no ocupa mas que la parte anterior del vientre, y la concha tiene siempre su espira bien marcada.

No se encuentran estos moluscos sino en las aguas saladas: unos, en corto número, habita n la profundidad de los mares; estos son generalmente los que carecen de concha ó los que la tienen muy pequeña; otros por el contrario, jamas se apartan de las orillas del agua. Los primeros tienen una especie de aletas para la natacion, al paso que los segundos andan arrastrándose por las rocas y las talasiofitas ó plantas marinas, que crecen con tanta abundancia cerca de las costas.

Se divide este órden en tres familias principales, á saber : los nudibránquios, los tectibránquios y. los escùtibránquios.

\section{PRI MERA FAMILIA:}

\section{NUDTBRÁNQUIOS. (Lám. $X X I X$.)}

Los gasteropodos de la familia de los nudibránquios son muy notables por la posicion de sus branquias ramosas, que llevan siempre sobre el dorso, en donde asemejan ya á pequeñas plantas y principalmente á musgos, ya á una especie de franjas (fig. 10.)

Estos son unos animales marinos de figura muy variable, sin concha aparente ú oculta, y cuya cabeza no se manifiesta sino por la presencia de dos ó cuatro tentáculos retractiles. Todos estos moluscos habi- 
tan en alta mar. Nadan ordinariamente con la cabeza hácia arriba y el lomo hácia abajo, sirviéndose de su ancho pie como de una barquilla para sustenerse én la superficie del agua, y de sus branquias ó de los bordes desu manto como de remos para acelerar sus movimientos. Tambien selles ve con frecuencia arrastrarse, por media de su pie, por las largas ovas que crecen en el már bajo todas las latitudes, y que parecen ser la base de su alimento. Su boca está situada en la parte inferior y anterior de su cuerpo, y su ano se abre unas veces hácia atras en el centro de las branquias, otrás en el lado derecho de su cuerpo.

Esta familia comprende varios géneros notables, que son los doris, las tritonias, las tetis, las escileas y los -glaucos.

§. I. Los noris (doris) (fig. 10.) se han llamado assi por alusion á las ninfas de éste nombre que presidian en el mar. Comoestas últimas, los doris no abandonan jamas las aguas saladas, ya arrastrándose sobre las rocas á poca distancia de las costas, ya sobre las plantas marinas tan comunes en alta mar, otras veces nadándo en la superficie de las olas por medio de su ancho pie:

Estos nudibránquios forman el género mas numeroso de toda la familia; se cuentan en él mas de treinta especies todas fáciles de conocer por su figura oval, por da posicion de sus branquias yor da diferencia que presenta sú cuerpo, según que está contraidó dilatado. Su manto está ordinariamente adornado de colores brillantes que hacen un contraste agradable con sus formas toscas y gruesas. Se cuentan muchas especies de ellos en el Mediterráneo y Océano, entre otras cl argos (doris argo, L.), que parecéque lleva en cada úno de los tentáculos superiores ungran número de ojos, el doris de Tolio III. 
ancho borde, el doris estrellado, el velloso, el tomentoso, el nudoso \&c.

§. II. Las TRITONIAS (tritonias) se asemejan á los doris por la forma de sus tentáculos superiores ; sus branquias estan colocadas á los lados del lomo, y tienen la figura de unos arbolitos; la boca está armada de dos mandíbulas laterales córneas y cortantes. Existen varias especies de este género; una de las mas grandes y que se encuentra en nuestras costas es la Tritonia Hombergii, Cuv.

§. III. Con el nombre de TETIS (thethys) se conoce un género de moluscos nudibránquios, cuyo carácter es llevar las branquias en forma de penacho sobre el lomo y una gran vela membranosa y frangeada en la cabeza. Las tetis tienen la boca dispuesta en forma de trompa membranosa En la base de la vela indicada hay dos tentáculos comprimidos, de cuyo borde sale una punta cónica. Este género es muy escaso en especies; pero con todo en el Mediterraneo tenemos una muy hermosa que es la thetys fimbria, $\mathbf{L}$.

§. IV. Las escrleas (scylloea) tienen el pie estrecho y con un surco para abrazar los tallos de los fucos; carecen de vela, y llevan en el lomo dos pares de crestas membranosas, cubiertas de pinceles dé filamentos por la parte interna. Estos pinceles son las branquias. El estómago de las escileas está revestido de un anillo carnoso, armado de láminas córneas y cortantes como cuchillos. La única especie de que se tiene noticia es la escilea comun (scyllea pelagica, L.) muy abundante en las ovás marinas.

§. V. No se conoce bien mas que una sola especie de Graucos (glaucus), finimal de forma prolongada términado em punta posteriormente, y muy notable por la hermosura de sus colores. Su cuerpo, de un gris de 


\section{5.}

perla, presenta en el dorso dos fajas longitudináles de un hermoso azul; color que se encuentra tambien en la cabeza y en la cola.

Lo que distingue al glauco de los doris es la figura de su pie y de sus branquias. Estas se asemejan á unos manojitos de franjas colocados por pares á cada lado del cuerpo, y sirven á la vez para la respiracion y la locomocion. En cuanto á su pie es estremamente pequeño, y á penas les sirve en la ejecucion de los movimientos; por esta razon el glauco no anda arrastrando, ó si lo hace, es con dentitud suma ; las mas veces cuando se mueve; lo hace nadando con la ayuda de sus branquias, y entonces sus movimientos son tan ágiles que es difícil cogerle. Cuando este molusco á pesar de susesfuerzos, se vé proximo á ser cógido ó cuando esperimenta algun dólor se contrae fuertemente y se arrolla en círculo como los cloportes, á fin de poner cubierto del peligro el mayor número posible de: sus órganos.

Se halla este animal en todos los mares de los climas cálidos en donde nada siempre en tropas numerosas.

\section{SEGUNDA FAMILIA.}

TECTIBRÁNQUIOS (Lám, XXIX).

En esta segunda familia el animal lleva las branquias sobre su dorso, como en la precedente; pero en tos nudibrámquios la posicion de estos órganós és del todo esterior, y permite distinguirlos sin que sea necesario quitar nada al molusco; en los tectibránquios por el contrario, las branquias estan alojadas en una cavidad especial del dorso, y cubierta por el manto, de suerte que para verlas es preciso levantar este último; por otra 
parte, los tectibránquios tienen casi todos una concha ó un rudimento de esta cubierța calcár ea (fig. 11.)

Con respecto á sus costumbres, estós gasteropodos son poco diferentes de los de los demas órdenes; únicamente viven generalmente mas cerca de las costas, y se alimentan de plantas marinas. Para este éfecto su conducto intestinal es muy aucho, y su estómago no solamente es multiplo, sino tambien guarnecido interior-? mente de piezas córneas ó ternillosas destinadas á facilitar la digestion.

Esta familia no es mas numerosa que la precedente, ni encierra mas que dos géneros importantes, que son: las aplisias y las bulas.

§. I. Las aplistas (aplysia) (fig. 11.) son unos moluscos desuudos, ó que no tienen en vez de concha mas que una lámina interna colocada encima de la cavidad branquial para proteger los órganos que contiene. Su manto forma encima de su dorso $y$ en cada lado un ancho pliegue que cubre casi enteramente la parte superió de su cuerpo, escepto por delante, en donde está situada la cabeza. Esta es estremamente notable por la presencia de cuatro tentáculos, de los cuales los dos posteriores son anchos y cóncavos anteriormente, como la concha de la oreja de un cuadrúpedo ; particularidad que ha hecho dar á estos animales el nombre de liebres marinas; tambien las llaman limazas de mar, en razon de la semejanźa que tienen con el mólusco terrestre de este nombre.

El cuerpo de las aplisias deja trasudar por todas sus partes un líquido fétido, y á veces colorado, que les sirve para hacer retroceder á su enemigo por su olor ó por su causticidad, ó cuando menos para hacerse invisibles á su vista, enturbiando alrededor de sí la tráspárécia de las aguas; y como este líquido glutinoso és escesi- 
vamerite tenaz, y no se quita sino muy dificilmente, les han dado el nombre griego que llevan, y que espresa esta particularidad (1).

Parece increible la diferencia que hay entre estos moluscos, según que se les examina en movimiento ó en quietud. En el primer caso son unos animales largos, cuya cabeza, aunque poco saliente, es siempre fácil de distinguir por la presencia de sus tentáculos; en una palabra, se parecen á nuestras limazas terrestres. Si se paran para descansar, todo cambia ; su cuerpo - se contrae en una masa gruesa é informe, en medio de la cual se pierde la cabeza con sus ojos y tentáculos; entonces se les tomaria por un pedazo de carne corrompida.

Se encuentran las aplisias en la mayor parte de los mares, y principalmente en el Mediterráneo; los antiguos las conocian, y les habian atribuido una multitud de propiedades quiméricas y opuestas; pues eran á la vez unos venenos violentos y unos remedios heroicos. En el dia únicamente los naturalistas son los que se ocupan de ellas. Se les puede observar fácilmente: unas veces se arrastran lentamente por las rocas próximas á las costas, otras nadan con agilidad golpeando el agua con los bordes de su manto; su alimento consiste en yerbas marinas, y aun en moluscos y gusanos marinos.

La especie mas célebre y mejor conocida de este género numeroso es la aplisia depilatoria (aplisia depilans, L.), llamada asi porque se creia que su líquido hacia caer el peló cuando tocaba una parte que estubiera cubierta de él. Es negra con grandes manchas

(1) Aplysia en griego significa inlavable, que no puede lavarse. 
anubarradas parduscas. Tambien se encuentran otras muchas en nuestros mares, como la aplisia ribeteada (apl. fasciata), que es negra con los bordes de las crestas laterales rojos, y la aplisia móteada (apl. punctata, (Cuv.), de color de lila, sembrado de puntos verdosos.

§.II. Las bulas (bulla) se distinguen á primera vista de las aplisias por la falta de tentáculos ó por la pequeñez de estos órganos, si se quiere mirar como tales la especie de broquel carnoso, debajo del cual estan colocados los ojos de estos animales. La mayor parte de las bulas tienen por otro lado una concha que, aunque-demasiado pequeña para proteger el cuerpo del animal, no por eso es menos entera y visible esteriormente. Esta concha se conoce por la poca prominencia de su. espira y por la magnitud de su abertura, que es en forma de media luna.

Se cuentan muchas especies de bulas, de las cuales unas tienen la concha escondida en el espesor del manto, tal es la almendra de mar (bulla aperta et lobaria quadriloba, Gm.), que se encuentra en casi todos los mares; otras tienen una concha esterior, pero muy delgada, tales son: el barquillo (bulla lignaria, L.), la ampolla ó almizclada.(B. ampulla), la gota de agua (B. hydatis.) \&c.

\section{TERGERA FAMIL IA}

\section{ESCUTIBRÁÑQUIOS.}

- Esta familia comprende un cierto número de moluscos, todos provistos de una concha que casi nunca está formada de circunvoluciones en espiral, como en las conchas ordinarias, y que por su aplastamiento parece mas bien una especie de escudo ó de copa que la 
habitacion de un animal. Su abertura es incomparablemente mas ancha que en ninguna otra especic, $y$ su forma es las mas veces simétrica, no porque sea como la concha de los cefalopodos, cuya espira es igualmente prominente por los dos lados, sino porque parece formada por la reunion de dos láminas cóncavas perfectamente semejantes, colocadas una al lado de otra.

Todos estos moluscos son marinos y litorales; se arrastran por el fondo del agua á poca distancia de las costas, y viven principalmente de talasiofitas. Como la concha de los escutibránquios es bastante grande para cubrir todo el cuerpo del animal, necesita este último de un sifon ó tubo para ir, cuando está asi retirado, á buscar el agua necesaria para la respiracion.

Esta familia comprende tres géneros principales: los haliotides, las patelas y los oscabriones.

f. I. Los HALIotimes (halyotis), conocidos mas comunmente con el nombre de orejas de mar por razon de la semejanza de su concha con la oreja de un cuadrúpedo, son los únicos de la familia que no tienen simétrica la cubierta testácea. Esta es de figura oval aplastada, de espira ligeramente saliente, y presenta en lo interior un hermoso color anacarado con reflejos metálicos, y en uno de los lados una fila de agugeros cuyo número se aumentá á medida que el animal envejece, y de los cuales el mas nuevo, que es también el mas anterior, sirve para dar paso al sifon ó conducto respiratorio.

La oreja de mar es uno de los moluscos mas adornados; todo alrededor de su ancho pie se estiende una doble membrana recortada en festones y guarnecida de filamentos que hacen un asombroso efecto á la vista. Se cuentan de élla muchas especies, de las que solo una vive en el Mediterráneo; siempre habita cerca de las costas, 


\section{0}

y se alimenta de plantas marinas. A pesar de la ánchura de la abertura de su concha, siempre su pie sobresale mas ó menos de los bordes de ella. Las principales especies son: la oreja de mar comun ó tuberculosa (hal. tuberculosa), ovalada por afuera con estrias cruzadas, y por dentro hermosamente anacarada, y la oreja de asno (hal. asinia), ovalada, estrecha, lisa, con manchas por afuera verdes sobre un fondo gris.

§. II. Las Patelas (patella) que llaman tambien lapas y lámparas, constituyen un géinero tan numeroso como notable por su figura y costumbres. Fijadas por decirlo asi sobre las orillas del mar que jamas abandonan, á fin de no alejarse de las plantas marinas que alli crecen $y$ de las que se alimentan, se fabrican; en las rocas próximas á la costa, unas escávaciones poco profundas en las que establecen, su morada, y que no dejan sino para ir á buscar su alimento; se ha creido por espacio de mucho tiempo que permanecian allí inmóviles toda su vida; pero se han asegurado positivamente de lo contrario, examinando en épocas diferentes estas escavaciones, las que unas veces se han encontrado vacías, $y$. otras ocupadas.

Por lo demas, los movimientos de estos moluscos son tan lentos, que la vista no los distingue sino en que los bordes de la concha, que tocan el suelo cuando el animal está inmóvil, se hallan mas ó menos apartados de él cuando anda. Se pretende que cuando están fjjadas en un sitio, se adhieren con tanta fuerza por medio de su pie, que es imposible arrancarlas de él. Por lo demas, son poco buscadas: su carne es tan coriácea que no puede servir de alimento. Pero si no se hace caso del animal, no sucede lo mismo con la concha; esta es de una figura bastante singular, y presenta muchas veces hermosos colores, que 


\section{1}

la hacen buscar por los aficionados á la conquiliologia. Es orbicular ú oval, en fórma de escudo ó de cono aplastado, de suerte que se asémeja mas ó menos á un pequeño plato; por razon de esta semejanza han recibido estos animales el nombre de patelas que en latin, tiene esta significacion.

Este género numeroso ha sido preciso dividirle en muchos subgéneros: $10^{\circ}$ Se llaman fisurelas (fissurella) las especies que presentan un agugero en el vértice del cono, como la patela griega, la fisurela de las tierras magallánicas ó agugero de cerradura. \&c. 2.0 Se llaman cmarginulas (emarginula) las que ofrecen una escotadura en la parte posterior, como la muesca. 3. En fin se da el nombre de patelas á aquellas cuyo borde y vértice son enteros: tales son el ojo de rubi, el ojo de buey, la cabeza de Medusa, la patela comun, y un número considerable de otras especies.

§. III. Los oscabriones (chiton) son unos moluscos muy notables por la especie de escudo que los cubre. El a nimal tiene la figura de una limaza sin tentáculos en la cabeza; pero su dorso, en vez de estar desuudo, presenta una serie de piezas córneas cuyo número varia de seis á diez, y que están sobrépuestas entre sí como las pizarras de un tejado, de modo que le forman una concha multivalva.

- Esta disposicion de la concha ticne una influencia muy marcada en los movimientos de los oscabriones; estos no permanecen constantemente fijos en el mismo sitio como las patelas. Como la multiplicidad de las piezas de su concha les permiten volverse á derecha é izquierda, se arrastran con la misma velocidad ó mejor cou la misma lentitud que las limazas, los caracoles y otros animales análogos.

Estos moluscos, que son bastante numerosos, se Tono III. 
arrastran sobre un pie ó disco carnoso y ventral, como todos los de su clase. Viven en el mar, á poca profundidad y cerca de sus orillas, y se fijan de tiempo en tiempo sobre las rocas y las piedras; sobre todo gustan mucho de adherirse á lo largo de las plantas marinas, de las que parece se alimentan.

Encontramos muchas especies de ellos en los mares de Europa, entre otras el oscabrion escamoso, y el oscabrion ribeteado.

\section{TERCER ÓRDEN.}

\section{PECTINIBRANQUIOS.}

Este tercer órden es sin comparacion el mas númeroso de la clase de los gasteropodos; comprende uria inmensa cantidad de moluscos fáciles de conocer por su concha generalmen te cónica, arrollada en espiral (lám. XXIX. fig. 13. y 14.) y por su pie carnoso, que en vez de estenderse por toda la parte inferior de su cuerpo, no ocupa mas que la porcion anterior de él, hácia el cuello, to que les ha hecho dar tambien el nombre de traquelipódos, que quiere decir pie en el cuello. La porcion posterior, que contiene los principales órganos de la digestion, permanece siempre oculta en la espira de la concha, y lleva el nombre de rodete.

Todos los moluscos de este órden son esencialmente acuáticos, y la mayor parte no viven sino en el mar; por consiguiente necesitan branquias para respirar. Estos órganos, que como lo espresa su nombre de pectinibranquios, estan en forma de peines ó compuestos de tirillas colocadas paralelamente, como los dientes de un peine, se hallan constantemente adheridos al techo de una cavidad situada en la última circunvolucion de 


\section{3}

la cancha, y comunicando con el esterior ya por un simple agugero, ya por un sifon mas ó menos largo que atraviesa una escotadura (fig. E.) ó un conducto (fig. D.) practicados en la circunferencia de la abertura. En todos casos, esta abertura está ordinariamente provista de una tapadera ú opérculo movible, que el animal puede abrir ó cerrar á su voluntad.

En este grupo de moluscos se hallan los mariseos mas notables por la diversidad de sus formas $y$ por la variedad y brillo de sus colores. Estos son por consiguiente los que desde mas remotos tiempos han llamado la atencion de los naturalistas y de los aficionados: Se ha tenido tanto mas gusto en reunirlos en coleccion, en razon de que no necesitan de preparacion alguna, y que son muy fáciles de conservar.

Para no confúndirse en medio de la multitud deespecies, á veces poco diferentes que componen este órden, ha sido preciso recurrir á las más minimas particularidades de estructura que ofrecen, para formar de ellas los caractéres distintivos. Se ha estudiado su concha con los mas estensos pormenores. La magnitud de la abertura, la existencia ó falta del conducto respiratorio, la estension de la escotadura, el estado de la columnilla que puede ser lisa ó arrugada, la figura del borde, la pulidè ó las asperezas de la superficie, la longitud de lá espira, todo ha ayudado y servido para caracterizar los géneros y las éspecies.

Se han dividido desde luego los pectinibranquios en dos grandes familias: los trocoides y los buccinoides. 


\section{PRIMERA TAMILIA.}

\section{TROCOIDES.}

Los moluscos de esta familia se distinguen fácilmente, en que su cavidad branquial no comunica con el ex-: terior sino por un simple agujero al paso: que en lá siguiente; esta comunicacion se verifica por medio de un sifon ó conducto prolongado. Esta particularidad de organización se manifiesta hasta en la cubierta calcárea. En efecto, en los trocoides la abertura de la concha es siempre entera es décir que no se observa en ella ni escotadura ni surco respiratorio (fig 12.), al paso que en los buccinoides esta abertura está constantemente escolada ó provista de un conducto en su estremidad posterior (fig. 13. E. y 14. D.)

La mayor parte de los trocoides son fitofagos ó viven de sustancias vegetales; lo que exige un conducto intestinal generalmente desarrollado, y órganos propios para cortardas hojas y los frutos de que el animal se alimenta Por esta razón, sú boca está formáda de doś mandibulas armadas de dientes.

Se hallan en esta familia cuatro géneros principahes: las pconzas, tos trompos, las ampularias, y las néritas.

5. I. Los trocos ó peonzas, (trochus) toman su nombre de la semejanza que tienen con él juguete de este nombre, tan conocido de lós niñós. Su carácter distintivo consiste en que la abertura de su concha jamas es redonda, y tiene sus bordes mas ó menos angulosos y separados por la eminencia que forma hácia dentro la penúltima circunvolucion de la espira. Esta disposicion hace la abertura de la concha deprimida y como 
aplastada, lo que les ha hecho dar el nombre vúlgar de caracoles de boca aplastada.

Todos estos mariscos son marinos y ofrecen al esterior con bastante frecuencia hermosos colores y una forma elegante, y en lo interior un bruñido considerable, y un brillo anacarado. El número de especies que se conocen los ha hecho dividir en muchos géneros, entre los que se distinguen las espuelas, las' poleas, las hormillas de boton, los embudos, los telescopios. que no tienea ombligo, las peonzas, los cuadrantes, que le tienen, y la prendera que junta pedacitos de concha y los iucorpora groseramente á la suya.

§. II. Los TRompos ( $t u r b o$ ) tienen como las peonzas los bordes de la abertura separados por la penúltima circunvolucion de la espira; pero esta circunvolucion no forma eminencia interior, y nada ó casi nada perjudica á la redondez de este orificio.

Estos moluscos son tambien todós marinos; y se hallan en número muy considerable en las colecciones: son abundantes en todos los mares, y los buscan con tanto mas cuidado, cuanto que ofrecen en lo interior un hermoso color anacarado $\mathrm{y}$ en el esterior unas formas y matices agradables.

Se distinguen en este género los trompos propiamente dichos, las delfinulas ó delfines (Lám. L. fig. 4.) ó trompos de tornillo, las turritelas y las escalatas que forman otros tantos subgéneros, la mayor parte muy numerosos.

$\S$. III. Al paso que en los trompos y en las peonzas la abertura de la concha tiene sus bordes separados por la eminencia que la penúltima vuelta de la espira forma entre ellos, en el punto en que deberian tocarse, las a MPULARIAS (ampularia) tienen estos bordes enteramente reunidos, de modo que forman un 


\section{6}

círculo casi regular. Sus conchas son por otra parte generalmente mas cortas y ensanchadas que en los géneros precedentes, $y$ aunque poco elegantes y ricas en colores, sin embargo son estimadas en los gabinetes por razon de su estrañeza. Todos estos moluscos son terrestres ó habitan las aguas dulces de -los lagos y de los rios.

Se cuentan en este grupo tres subgéneros principales, las valuadas ó porta plumages, las paludinas y las ampularias propiamente dichas.

§. IV. Las NeriTas (nerita) son unas conchas semi-globulosas, cuya espira apenas es prominente, y cuya columnilla quita algo de la abertura, de modo que la hace semicircular.

Estos moluscos notables por su forma aplastada, viven ya en el mar, ya en las aguas dulces. Unos tienen un grosor muy considerable, al paso que otros son estremamente delgados; en fin los hay que tienen un solo ombligo, al paso que los demas no tienen ninguno.

Las especies de ombligo se llaman natices, las que carecen de él y que tienen la concha delgada se denominan neritinas, y se reserva el nombre de neritas, para las que no teniendo ombligo, tienen la concha gruesa.

\section{SEGUNDA FAMILIA.}

\section{BUCGINOIDES. (Lám. XXIX.)}

Los moluscos de esta segunda familia se distinguen bien de los de la primera, ya por el animal que no tiene mandíbulas en la boca sino una trompa cilíndrica susceptible de alargarse mucho ó de ocultarse enteramente en lo interior del cuerpo, ya por la con- 
cha, cuya abertura está unas veces acanalada en su base, otras escotada para el paso del sifon respiratorio, que no es mas que un doblez prolongado del manto.

Todos los buccinoides que se conocen son esencialmente marinos y carniceros, y tienen, en vez de mandibulas para roer la yerba, un largo apéndice carnoso y armado de diez piezas sólidas, con las que estos moluscos atacan á los cuerpos mas duros, entre otros los mariscos de los que el animal hace la principal base de su alimento: su cabeza esta provista de tentáculos.

Se dividen los buccinoides en géneros segun la mayor ó menor longitud del conducto cuando existe, la mayor ó menor anchura de la abertura, y la forma de la columnilla y de la espira. Las diferencias que ofrecen estas diversas partes son tan numerosas que se han podido formar mas de sesenta géneros, que se han reducido á tres tribus: la de los buccinoides arrollados, la de los buccinoides escotados, y la de los buccinoides acanalados.

\section{PRIMERA TRIBU.}

BUCCINOIDES ARROLLADOS.

Esta tribu se compone de conchas ovales de abertura estrecha, que reina en toda su longitud. Casi no tienen espira, ó cuando esta parte de la parte calcárea es bien visible, es casi enteramente plana, lo que se debe á la magnitud de su última circunvolucion, que cubre casi enteramente á todas las demas. El animal que habita esta morada es, como todos los de la familia de los buccinoides, bastante análogo al caracol por su conformacion general; pero á mas de que tiene la boca y las branquias del todo diferentes, se encuen- 
tra tambien en la figura de su pie un carácter que basta para distinguirle de los gasteropodos pulmonados. Este órgano es escesivamente delgado, disposicion necesaria por la estrechez de la abertura por la que debe pasar para entrar y salir.

Esta tribu comprende dos géneros principales; los conos y las porcelanas.

§. I. Los covos (conus) que se llaman vulgarmente cucuruchos por razon de la figura de su concha, constituyen el género mas numeroso é interesante de toda la clase de los gasteropodos. La espira de estos moluscos, enteramente plana ó apenas prominente constituye la base del cono cuya última circunvolucion forma los lados; disposicion notable, por ser opuesta á la que se observa en las demas conchas univalvas, en las que los lados del cono estan formados por la espira y su base por la última circunvolucion ó por la abertura. Añádase á esto que la abertura de los conos es longitudinal, que sigue en casi toda su longitud y que es igualmente lisa en sus bordes, de los cuales el derecho es delgado y cortante, en vez de estar arrollado como en los huevos y las porcelanas.

Todas las especies de este género estan adornadas de hermosos colores, y pertenecen á los mares meridionales. No se encueutran sino muy pocas en los paises templados ó frios. Este grupo es tan natural, que á pesar del número de especies que encierra (cerca de doscientas), ha sido imposible subdividirlas en subgéneros bien caracterizados.

Las principales especies son: el cono grande almirante (conus ammiralis summus, L.), que és raro y precioso, de color blanco con manchas leonadás, el cono atigrado, el cono paño de oro (con. textilis), de fondo amarillo con rayas negras, el mil puntos ó cono escrito 
(rconus literatus), con las vueltas formando canal, blanco con infinidad de puntos pardos; el tablero de damas (con. marmoratus), liso con el foudo pardo lleno de manchas grandes triangulares blancas y muy juntas \&c. \& cc.

\$. II. Las porceranas ó conchas deVenus (cipreea) son unas conchas de figura oval, cuya espira es tan pequeña que es muy dificil percibirla. 'Sús $s_{3}$ bordes arrollados hácia deutro $\mathrm{y}$ marcados en toda su longitud de arrugas transversáles, hacen la abertura esılremamen. te estrecha; pero al -mismo tiempo esta es muy larga y se estiende á todo ló largo de la concha.

Esta disposicion de la abertura depende de la figura del pie del animal, que es estremamente delgado. A pesar de esto las porcelanas son ágiles en sus movimientos, porque la accion del pie es ayudada por la de dos apéndices lateŕales en forma de alas y bastante estensos para poder, desplegándose hácia fuera, cubrir casi enteraménte la superficie de la concha. En el estado de quietud estos móluscos viven metidos en lá arèna, á alguna distancia de las costas; son bastante comunes en todos los mares de los paises cálidos ó templados, y sin émbargo son buscados pó razon de sus hermosos colores y de su figura, que se presta bastante bien á la fabricacion de lindas cajas para el tabaco.

Se cuentan cerca de cincuenta especies de porcelanas, de las cuales unas son lisas y otras verrugosas ó estriadas. Las principáles son: el argos (cipraa argus), el mapa geográfico (cip. mappa), el coris ó moneda (cip. moneta).

Un género muy análogo al de las porcelanas es el de los huevos (ovula), buccinoides tambien sin espira aparente, pero que tienen las dos estremidadés un poco

ToMo III. 
terminadas en punta, y la abertura arrugada solamente por un lado.

\section{S E G U N D A T R I B U.}

\section{BUCCINOIDES ESCOTADOS.}

La tribu de los buccinoides escotados comprende un gran número de conchas de figura variable, pero cuya abertura constantemente mas ancha que en las especies arrolladas, ofrece en su base una escotadura mas ó menos profunda para el paso del sifon. Tienen toda la espira turbinada y mas ó menos prominente para alojar el rodete del animal. Este último por lo demas es del todo semejante al de la tribu precedente, y por consiguiente marino y carnicero.

Se cuentan tres géneros principales de este grupo, que son: las volutas, los buccinos y las púrpuras.

§. I. Las volutas (voluta) (fig. 13.) se distinguen de todos los demas géneros por su abertura, que es mas ensanchada, por su escotadura y por las arrugas oblicuas de que está guarnecida su columnilla.

La conformacion de esta abertura permite al animal tener el pie mucho mas grueso que ninguno de los géneros precedentes; lo que le facilita los movimientos de reptacion, y le obliga á habitar en los sitios măs profundos. Este molusco es eminentemente carnicero; su trompa, armada en su estremidád de pequeños dièntes ganchosos, es un instrumento poderoso, por medio del cual atraviesa la mayor parte de los demas mariscos de que se alimenta.

Estos animales no ise encuentran sino en los mares meridionalés no se hallan ni en el Océano Atlántico, 
ni en la parte septentrional del Mediterránco. Por estä razon casi todos son notables por la hermosura y variedad de sus colores; cualidades que los hacen buscar generalmente por los aficionados, y dar á algunas de sus conchas un precio muy elevado.

El número de las volutas seria todavía mas considerable que el de los conos si diferencias poco esenciales, aunque constantes, no hubieran permitido dividirlas en muchos subgéneros, como las olivas, las volvarias, las volutas propiamente dichas, las gondoleras, las marginelas, las colombelas, las mitras y las cancelarias.

§. II. Los Buccinos (buccinum) no tienen como las volutas mas que una simple escotadura en vez de un conducto ; pero su columela no presenta nunca atrugas trasversales ú oblicuas, y su abertura generalmente oval.

Toman su nombre de buccino de la figura, unas veces prolongada, otras corta de su concha, que se asemeja á un instrumento de música guerrera que los antiguos llamaban buccinum.

Estos moluscos son todos marinos, litorales, y generalmente de poca magnitud. Se encuentran en gran número sobre las rocás, adonde los pescadores van á buscarlos, porque la mayor parte de las especies sirven de alimento.

Este género estenso se ha subdividido en tornillos, buccinos, nassas, harpas, barricas y perdices.

§. III. Las púrpuras (purpura) se diferencian de los buccinos, con quienes se confundian antiguamente por su columnilla aplastada y por un conducto ligeramente encorvado y no prominente que se observa detras de la escotadura destinada al sifon respiratorio. $\mathrm{Su}$ concha, de figura muy variada, pero siempre mas ó menos oval, se hace muchas veces notar por el gran nú- 
mero de ángulos, espinas ó tubérculos que la crizan.

Estos moluscos se han llamado asi porque entre ellos es donde principalmente se encuentran las especies que suministran esta materia colorante de que los antiguos hacian sú hermoso color de púrpura. Ánálogo en algun rnodo á la tinta de las jibias, de los calamares, de las aplisias \&c., este liquido éstá contenido en un dépósito particular en forma de vegiga, colocado en las inmediaciones del estómago. Parece que esta materia no adquiere su hermoso color sino cuando está disuelta én el agua y espuesta al contacto del aire.

Los modernos, despues del descubrimiento de la cochinilla, que les suministra en abundancia los colores rojos que necesitan, han descuidado totalmente el beneficiar el líquido de las púrpuras, y hasta han perdido el secreto de fijarle en las telas. Se encuentran estos ani- males en gran número sobre las orillas de la mayor parte - de los mares, principalmente en las del Mediodia. Sè* gun la figura de la concha, se han dividido en tres subgéneros: las púrpuras, los licornes y las ricinúlas.

\section{TERCERA TRIBU.}

\section{BUCGINOIDES CANALICULADOS.}

Esta tercera tribu es de mucho la mas numerosa en géneros, y encierra todos los buccinoides, cuya abertura presenta en su base un conducto de longitud y direccion variablés, pero constantemente destinado á dar paso al sifon respiratorio. Por lo demas, la espira de estas conchas es siempre prominente como en la tribu precedente, y el animal que las habita presenta las mismas particularidades de organizacion y las mismas cos- tumbres. 


\section{3}

i) Se cuentan cincó génerơs principales en esta tribu: - los cascos, las ceritas, los murices, los husos, y los estrómbos.

§. I. - Los cascos (cassis) han sido confundidos dúrante mucho tiempo con tos buccinos de la tribu que precede, aunque se diferencian esencialmente de ellos por Ia estrechez y por la figura longitudinal de su abertura, que sé parece á la de las porcelanas, asi como por las arrugas de que está guarnecida en cada lado. Por otra parte ofrecen siempre en su base un conducto recto al principión ry despues vuélfo de pronto hácia el dorso del aninat.

Estas conchas son gencralmente notables por la poca emiriencia de su espira, por las arrugas de que estan guarnecidos sus bordes, y por su figura combada posteriormente $y$ mas estrecha por delarite.

El animal que construye estậs conchas es todavía poco conocido; sin embargo parece que debe tener relaciones con los buccinos, porque los cascos tienen las costumbrés de estos últimos moluscos; viven en el mar, á poca distancia de las costas, y buscan principalmente los fondos arehosos, por los que andan arrastrándose para buscar los maríscós de que hacen su presa. Tienen la costumbre de meterse en la arena, ya para ponerse alli al abrigo de sús enemigos, ya para poder engañar mas fácilionte á los animales de que se alimentan.

Se cuenta un gran número de especies de este género, entre otras el casco rojo (bucc. rufum, $\mathbf{L}$ ), el casco con malla (B. cornutum, L) y el casco triangütar (B. tuberosum), que tienen la espira plana, el casco rayado (B. testiculus, L.), cuya espira es redonda, y el casco dentado (B. vibex, $L$ ) que la tiene un poco puntiaguda. 
\$. II. Las GERITAS (cerithium) tienen poco mas ó menos el conducto de los cascos, pero tienen la abertura mas oval y la espira muy prominente y aun turriculada, casi como los tornillos, las mitras \&c.

Esta figura de la concha es determinada por la del animal, cuyo rodete es largo y el pie ancho y oval como el de los caracoles, de los buccinos \&ce., de los que sin embargo se diferencia bastante bajo los demas aspectos. Su cabeza es gruesa, terminada por un hocico en forma de trompa, en el que no se encuentra ni diente falciforme, como en los pulmonados, ni espinas córneas como en los demas buccinoides. Parece que este molusco se alimenta aspirando las particulas animales que tiene el agua en suspension, ó que halla en la tierra que forma el fondo del mar; porque se observa que al modo de los cascos, las ceritas tienen la costumbre de meterse en la arena y en el cieno; esta es la razon por qué no se apartan nunca de las costas, y por qué frecuentan principalmente la embocadura de los rios.

El género cerita es uno de los mas numerosos de la clase de que hablamos en especies vivientes y fósiles. la mas notable entre las primeras es la cerita gigante, que tiene diez y seis pulgadas de largo.

§. III. El nombre de MURiCEs (murex) (fig. 14.) se aplica á todas las conchas de conducto prominente, cuya espira tiene las circunvoluciones cubiertas de espacio en espacio de tubérculos romos ó de eminencias puntiagudas. Esta particularidad, unida al grosor generalmente considerable de la cubierta calcarea, hace ś esta dificil de quebrar, y forma al animal que envuelve un escudo capaz de resistir a presiones muy fuertes; lo que le ha hecho dar el nombre de peñascas. El animal que habita estas conchas présenta da misma órganizacion y las mismas costumbres que el de los bucciugs, 


\section{5}

del que no se diferencia sino por un sifon mas prolongado. Frecuenta, como estos últimos, las cercanías de las costas, y se esconde en las sinuosidades de las rocas, entre las ovas, y aun en la arena. Los murices prefieren estos sitios porque encuentran en ellos con abundancia los moluscos litorales de que hacen principalmente su alimento no teniendo para moverse mas que su pie abdominal, se arrastran con tanta lentitud, que no podrian procurarse en otra parte su subsistencia sino con mucha dificultad.

Estos moluscós cuyo número es muy considerable en todos los mares,y principalmente en los del Mediodia, han lla mado de mucho tiempo á esta parte la atencion de los aficionados por la singularidad, estravagancia y variedad de sus formas, y algunas veces por la hermosura de sus colores; sin embargo, es pret: ciso observár que estos últimos son ordinariamente empañados, y no adquieren jamas este brillo que admira en las conchas de superficie lisa.

Se divide este género en tres subgéneros principales, á saber: los peñáscos, los ranelas y los tritones.

§. IV. Bajo el nombre de Husos, (fusus) seder signa un gran número de conchas fusiformes (es decir engrosadas en el medio y terminadas en punta en sus estremidades), cuyo borde es liso en toda su circunferencia, la columnilla las mas veces arrugada, y que tienen un conducto recto y prominente, poco mas ó menos como los murices. Asi es que poco ha no se distinguian estos dos géneros de moluscos, que tienen las mayores relaciones entre sí, no solo por la estructura del animal que es absolutamente la misma, sino tambien por la figura de la concha que no se diferencia mucho. En efecto, la principal diferencia que separa unos de otros, se saca de los tubérculos que se obser: 
van en la espira y en el borde dé la abertura de los murices y que faltaná lós husos : Lodaría estecarácter no es absoluto, y se hallan diferencias intermedias que forman el paso de un grupo al otro.

un Sea como quiera, se ha encontrado en la figura de los husos el medio de subdividirlos en siete ú ocho subgémeros, d’e los que los mas notables son los pleurotomos, los pirulos y los turbinelas.

§. V. Los estromios (strombus) son muy notables, entre los buccinoides de conducto respiratorio, por la dilatácion del borde derecho que se aparta de la conchá con la edad, y por un seno fabricado en este borde muy cerca del condúcto: seno destinado á alojar la cabeza del animal.

c. Estos son unos moluscos singulares que se asemejan á los murices por los tubérculos de que está erizada su superficie en la mayor parte de las especies. Se encuentran en todós los mares meridionales, y principal mente en el de las Indias.

Se dividen en tres subgéneros; que son los rostelarios, los pteroceles, y los estrombos propiamente dichos. 


\section{CUA R T GLASE.}

\section{Conchología.}

б

HISTORIA NATURAL DE LOS ACÉFALOS.

Esta cuarta clase comprende una inmensa cantidad de conchas vivientes, y tal vez mayor número de fósiles, que "se hallan eśpárcidas con profusion, $y$ algunas veces en bancos enormes èn las capas que forman la corteza sólida del globo terrestre. Pero á pesar de su estension, esta clase no es menos fácil de caracterizár que las precedentes. Compuesta únicamente de a nimales sin cabeza aparente, no puede confundirse con las clases anteriores, que no comprenden sino especies cuya cabeza, mas ó menos prominente, está ademas marcada por la presencia de ojos ó de tentáculos movibles.

Su cuerpo está encerrado en un manto que estando doblado en dos, le envuelse del mismo modo que un libro lo está por su cubierta únicamente sucede con bastante frecuencia que las dos hajas de esta cubierta se reunen por delante, de modo gue forman una especie de tubo, ó un saco en el que el animal se halla enteramente oculto Entre la pared interna de este saco y el cuerpo que olla cubre estau colocadas. las branquias que reciben el agua por rogdio de un sfon formado por un doblez del manto:

Tono III. 
La boca de estos moluscós está siempre situada en el fondo del saco, y no presenta ni trompa, ni mandibulas, ni dierites, en una palabra, ningun órgano particular para la masticacion. Es una simple abertura que no sirve mas que para admitir las moléculas nutritivas que el agua las lleva contantemente: por consiguiente todos los acéfalos deben ser acuáticos; porque si no vivieran en este elemento, cuyo movimiento les conduce los alimentos sin participar de él el animal, seria preciso que pudièsen ir buscarlos á lo lejos, lo que es imposible á las numerosas especies que permanecen toda su vida fijas en el mismo sitio, y dificil á todas atendiendo á que sus movimientos les son siempre penosos cuando no les son imposibles.

Se concibe que unos animales tan poco favorecidos por la naturaleza en el ejercicio de la locomocion, y tan desprovistos de armas ofensivas, se verian espuesios á ser la presa de sus mas débiles enemigos, si aquella no les hubiera dotado de una cubierta sólida, capaz de protegerlos: esta es una concha bivalva, formada de dos piezas articuladas entre sí cerca de su base, por medio de un ligamento elástico que tiende continuamente á abrirlas. La union de las dos valvas está asegurada por los dientes ó eminencias de $\mathrm{l}_{\mathrm{a}}$ una, á las que corresponden unas depresiones ó cavidades análogas de la otra de modo que su articulacion forma una verdadera charnela.

Es evidente, atendida esta disposicion, que el animal no necesita hacer ningun esfuerzo para abrir su concha, pues teniendo el ligamento bastante elasticidad para mantener sus valvas apartadas; únicamente pues necesita para cerrarla contraer sus músculos. Pero este último caso es mucho menos frecuente que el primero; porque estos animales, debiendo estar constantemente preparados para recibir el alimento que el agua les conduce: 
'deben tener su concha casi siempre abierta; asi es que nó la cierran sino cuando temen algun peligro.

La existencia de los musculos destinadós á cerrar la concha puede conocerse, a un en esta última, por la sola inspeccion de la cara interna de las valvas : en ellas. se observa siempre en los alrededores de la charnela una ó dos partes mas ó menos rugosas que se llaman impresiones musculares, porque este es el sitio adonde estaban atados los múscúlos durante la vida del animal.

Con todo eso observamos que todos los acéfalos no son testáceos; pues hay algunos, aunque es verdad que en corto número, que estan completamente desriudos: Segun la: presencia ó la falta de concha, asi como segun el número de los músculos que cierran las valvas; se ha dividido esta clase en cuatro órdenes; los monomiarios, los dimiarios, los braquiopodos y los tunicarios.

De estos cuatro órdenes, los tres primeros son test táceos y únicamente los tunicarios estan privados de concha. Entre los testaceos, unos tienen dos tentáculos ó brazos cerca de la boca, y una especie de pie para fijarse; estos son los braquiopodos. Los otros dos carecen de estos apéndices; pero losímonomiarios no estan adheridos á sù concha mas que por ún solo músculo, que se dirige de una á otra valva, atravesando el cuérpo del lanimal; $\mathrm{y}$ los otros, los dimiariós, tienen dos que pasan por las estremidades de su cuerpo.

\section{PRIMER ÓR DEN}

\section{MONOMTARTOS.}

El nombre de monomiarios tiene una etimología griega (monos, uno solo, mys, musculo), y espresa el caracter esencial de los moluscos de este órden, cuyo 
cuerpo está atado á su concha por un músculo único, que atravesando al animal, se dirige hacia la base de las val vas que está destinado á mover. Este carácter está marcado en las conchas por una impresion ó desigualdad mas ó menos profunda, pero siempre única, al paso que en las del órden siguiente se encuentran siempre dos, de las cuales la una está hacia delante, y la otra hácia atras.

Pero no es esté el 'único carácter distintivo de este órden ; la concha de estos moluscos es ordinariamente irregular, de valvas desiguales, y formada, por decirlo asi, de hojitas pegadas una á otra, y cuyo punto de union está márcado esteriormente por unas lineas convexas dirigidas en la direccion del borde de la concha; al paso que en los dimiarios, la concha es casi siempre regular , de valvas iguales, y marcada de líneas que cáen perpendicularmente sobre su borde. Está particularidad sufre muy pocas escepciones, que son fáciles de retener: Asi es que las camas tienen las valvas desiguales, aunque pertenecen al órden de los dimiarios; y entre las espécies del órden de que háblamos, los peines en vez de tener la concha foliacea la tienen surcada de líneas transversales, como se observa en el órden siguiente.

Los moluscos monomiarios, privados de la facultad de moverse, se fijan regularmente á las rocas, por medio de un apéndice compuesto de filamentos sueltos que sale de la base del pie, y al que se da el nombre de biso (bysus).

Se dividen los monomiarios en tres familias : los ostraceos, los maleaceos, y los tridacnos. 
ostrACEOS.

Estos moluscos toman su nombre de la semejanza que tienen con las ostras comunes, llamadas en latin ostrea. Todos tienen la concha de dos valvas desigualés, de las cuales la una es inferior, mas grande $y$. combada, y la otra superior, mas pequeña y chata. Jamas se observa en su base ni dientes ni eminencia alguna para facilitar su reunion; esta no se verifica sino: por medio de ligamentos fijados en ló interior, y que de ningun modo son visibles al esterior, cuando la concha está cerrrada. Rara vez el animal goza de la facultad de mudar de sitio; casi siempre se adhieren a los cuerpos submarinos por la valva inferior; sin embargo; algunas especies permanecen libres y se mueven abriendo y cerrando alternativamente su concha por medio de sacudimientos frecuentemente repetidos, y no se fijan sino momentaneamente á las rocas y demas cuerpos situados debajo del agua.

Esta familia encierra dos géneros principales: las ostras y los peines.

§. I. Las ostras (ostrea) son muy numerosas, pero siempre faciles de distinguir por su concha irregular, foliacea, unas veces delgada y lisa como un papel, otras gruesa y aspera como una piedra.

De las dos caras de sus valvas, la interna és siempre lisa de color mas ó menos blanco y á veces anacarado, al paso que la esterna es desigual y guarnecida de asperezas y aun de espinas. El animal que ha-r bita esta morada es dé los mas sencillos de la familia; no tiene pie, ni tentáculos, ni sifon; por consiguiente no 


\section{2}

puede mudar de sitio; permanece siempre echado sobre su valva convexa, en el fondo del agua, en donde sus movimientos se limitan á abrir y cerrar su concha, y su instinto se reduce á esperar pacientemente que el agua le lleve su alimento.

Se ha dividido este géneró en cuatro subgéneros: las ostras, los espondilos, las grifeas, y las placunas.

1. Al primer subgénero perlenece lá ostra comun, tan conocida de todo el mundo y principalmante de los golosos. Se sabe el prodigioso consumo que se hace de ellas en todas las partes del mundo. Hay aficionados á os-3 tras que se comen hasta treinta docenas de ellas y aun mas, y la carne de estos moluscos es tan fácíl de digerir, que es raro que per esto se hallen incomodados. Los sujetos cuyo estómago es delicado pueden por consiguiente hacer uso de ellas con preferencia á otros manjares. $\mathbf{P e}-{ }^{-1}$ ro la ostra no siempre es igualmente buena dé comer; en el verano tiene menos gusto, y ademas se echá á perder mas pronto; asi es que apenas no se consume sino en invierno. Las que se acaban de sacar del agua conservan un gusto deságradable á cieno pero se les hace perder haciéndolas permanecer durante algun tiempo en unas pilas ó estanques cuya agua puede renovarse á voluntad. Por este medio su carne se hace mas tierna y fácil de digerir.

Las ostras se pescan en casi todos los mares de Europa, y principalmente en el Océano. Forman poca distancia de las costas unos bancos ínmensos, de donde las sacan con una especie de rastrillo atádo á un palo que se arrastra en todas direcciones en medió de estos moluscos, los desprende y los hace caer en' una ancha red: De este modo se cojen de diez aldoce mil á la vez la pesca de costras mas considerablé que hay en Francia es la de Cancal Cérca de San Mălo. 
Se conoce bien que una pesca tan activa no podria menos de agotar tarde ó temprano el banco, por abundante que fuese, si no se interrumpiera de tiempoen tiempo, y si el animal no fuera de una gran fecundidad; pero la precaucion que se tiene de no pescar durante el verano, época en que las ostras se reproducen, basta para permitirles reparar las perdidas ocasionadas por la pesca de las demas estaciones. Ademas de la ostra comun se conocen la ostra pequeña del Mediterráneo (ostrea cristata, L.), la ostra parasita (os. parasitica, L.), que es redonda y aplastada, y se fija á las raices de los árboles que se crian á la arilla de los mares de la zona tórrida, y la ostra hoja (ostrea folium, L.) que es oval con los bordes plegados en zig-zag, y que se adhiere por los dentellones del dorso de su valva convexa á las ramas de las gorgonias $y$. otros litofitos.

2. Los espondilos ú ostras espinosas (spondilus) tienen la concha gruesa, irregular y espinosa. La valva mas convexa es muy maciza. La cobertera es plana y tiene dos dientes fuertes, corvos que encajan en dos pequeñas cavidades de la valva opuesta; ien el medio hay á ambos lados un hoyito para iel ligamento. La especie mas notable es el espondilo gederopo ó pie de asno (spondylus gaderopus) cuya conchaes las mas veces blanca; otra variedad de colores rojos está erizada de gruesas espinas.

3. ${ }^{\circ}$ Las grifeas, que se llaman mas comunmente grifitas porque no se encuentran mas que en el estado fósil, ino se diferencian de las iostras, sino porque la base de sus valvas es prominente y encorvada en forma de gancho, (Lam. L. fig. 5), lo queles ha dado su nombréque en griego quiere decir, ganchoso ó encorbado. Se encuentran muchas en todos los paises, y principalmente en Francia.

4. ${ }^{\circ}$ Las placunas ó anomias se distinguen de los precedentes subgéneros por su concha delgada y transpa- 
rente, lo que les ha hecho dar el nombre vulgar de vidrio ó tela de cebolla.

§. II. Los PEINes ó conchas de peregrino (pecten.) se parecen á las ostras por la falta de dientes en la articulacion de las valvas, pero se diferencian de ellas por la figura semicircular de su concha marcada de costillas ó lineas prominentes que, partiendo de su base, se dirigen en forma de radios hacia su circunferencia; cada valva está ademas guarnecida en su vértice de dos alas ó auriculas mas ó menos largas que ensanchan los lados de la charnela.

Estos moluscos tienen los movimientos mas estensos y ágiles que las ostras; su pie es bastante'grande que les sirve para arrastrarse, y los músculos que se atan á su concha pueden agitarle con bastante rapidez para sostenerlossobre el agua y ayudarles á trasladarse de un punto á otro.

La carne de los peines sin ser absolutamente mala está lejos de ser tan estimada como la de las ostras; 'únicamente los pobres son los que la usan como alimento. Pero tambien su concha, mas regular y agradablemente colorada, es mucho mas buscada por los aficionadós á la conquiliologia. Aun algunas especies cuyas dimensiones són mas considerables, se emplean á modo de platos por razon de la resistencia que oponen al fuego.

Tres sub-géneros están comprendidos en este género numeroso: que son los peines propiamente dichos; las limas y las huletas, entre los primeros se distingue el peine mayor, peregrina grande ó concha de Santiago

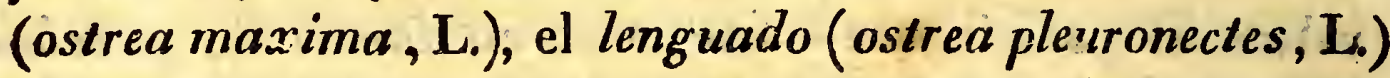
de valvas delgadas y muy planas, y el coraí (ostreanodosa, L.) con valvas gruesísimas de un rojo hermoso y nueve costillas guarnecidas de grandes nudos redondos. 


\section{S E GUN D A F A I I I A.}

\section{MALEACEOS (Lám. XXX.)}

Esta segunda familia saca su nombre de una concha singular, á la que se ha dado por raźon de su figura el nombre vulgar de martillo llamado en latin malleus. No porque todas las especies que se hallan comprendidas en ella presenten esta figura estraña, sinọ porque se ha observado en todas alguna relacion de semejanza con esta concha; relacion que ha permitido reunirlas en una sola familia.

Los caractéres comunes que sirven para distinguirlos de los demas monomiários consisten en su concha irregular, siempre foliácea y las mas veces negruzca ó córnea, y en la forma de la charnèla, que no ofrece dientes y no está unida maś que por un ligamento situado enteramente en el borde de las valvas y visible al esterior, aun cuando la concha esté cerrada.

Casi todos estos moluscos se fijan á los cuérpos marinos por un biso mas ó menos largo, y no gozan sino de movimientos muy limitados, $y$ aun algunos jamas mudan de sitio.

En esta familia se hallan los géneros martillo, pinna y golondrina.

29. \$I. Se llaman MartiLios (malleus) únas conchas singulares ó mas bien disformes, que por su disposicion se asemejan á la del instrumentó de este nombre. La charnela que reune las dos valvas está casi en línea recta y forma la cabéza del martillo, al paso que lo restante de la concha imita su mango por su longitud y estrechez. El esterior de esta concha, que es foliáceo ú hojoso y áspero como el de la ostra, no tiene nada Tomo III. 


\section{6}

que halaguae á la vista; pero su cara interna, de un hermóso colot analcarado /ó violéta, ofreke un Brillo y un tinte que la hacen estimar. Por otra parte su escasez asi como la estravágáncia de sus formas, /serian un motivo suficiente para hacerla buscar por los aficionados. Sé conocen muchas especies óvariedades de martillos, que pertenecen casi todas alo mar de las Indiás.

T. II. Sará formatse una idea de la figura de las: PINNÁs ó jamoncillos (pinna), és preciso representarse una grande almeja cuya base estuviera considerablemente estrechada y alárgada enpuntay esta concha tendria. una semejanza girosera con urijamon y esto es: lo que ha valido á los moluscos de que hablamos el nombre que se les da vulgarmente:

4. La dureza de estas conchas no está de ningun mo. do en relacion con sue magnitud, son por el contrario muỳ delgadas y filfoliáceas, y fá noóserl por la solidez de su tejido, se quebrarian fácil ménte al menor choqué; són tan ligeras que el viento puede levantarlas:

El animal del jamoncillo es muy notable por da lon* gitud y frnora de su biso que eśtá formado de un gran númerorde hilọs tustrosos y ysedosos, que se templean para hacer diferentes tẹjidos, estimados pori rázon de su suavidad y flexibilidad. Pero es precisallevárlós con los colores que la naturaleza les ha dado, porque hasta ahora ha sido imposible teñirlos. Ademas, los que hacen uso de (ellos no deberi echar menós stos colores artificiales, atendido que sus tintes nátapales trenén un brillo, yespincipalmente una permanericial, que jamas altera el tiempo hì las leoladas: fo unico que puede sentirse en lbs objetrosnfábricados del este chódo, es qué su precio demąsixdo ulevado no permite su uso sino á las gentes ricas, ylopulentas. Gasinúnicamente en Turz

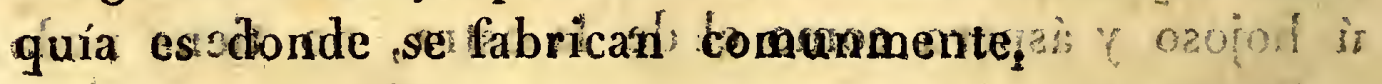




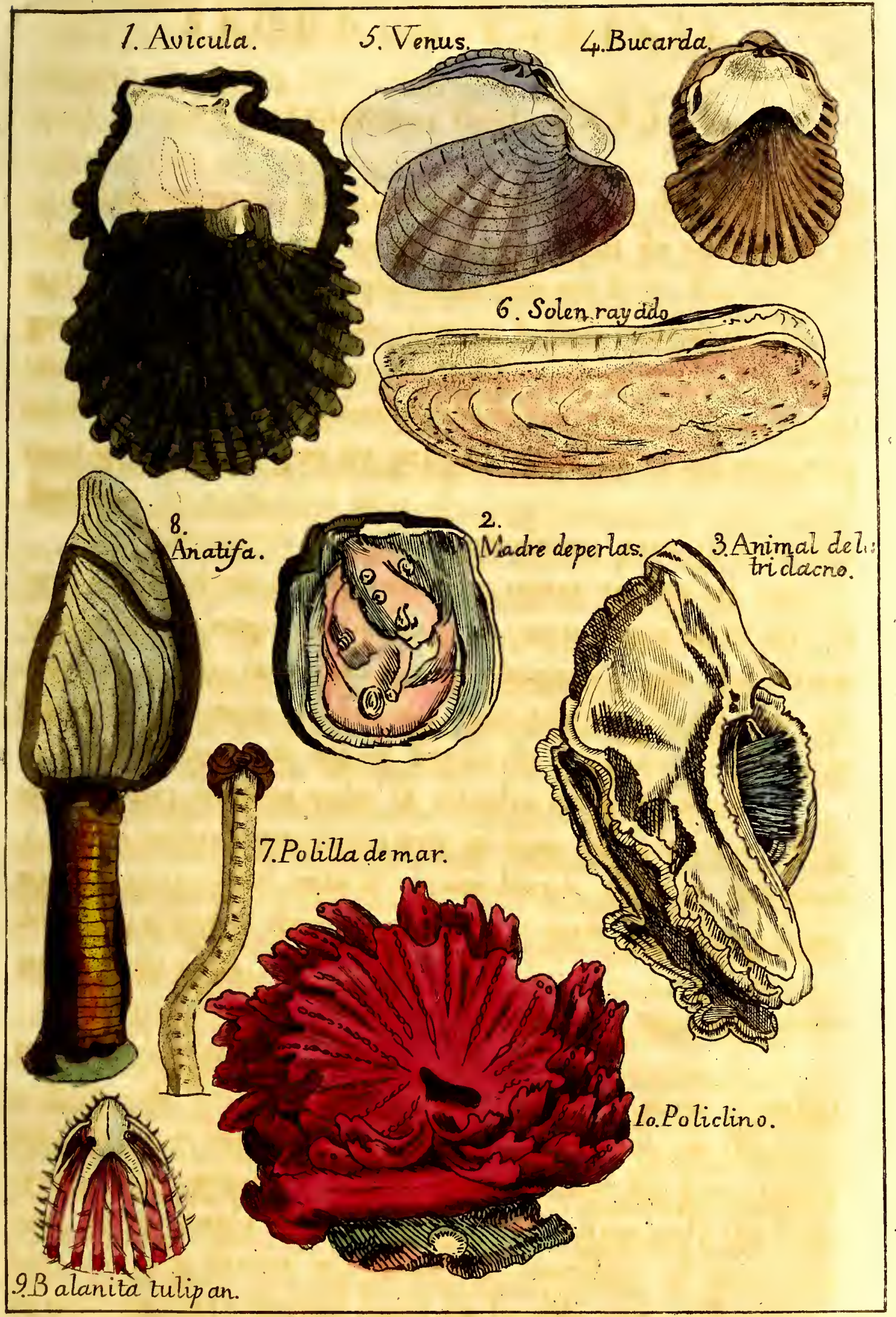

ACEIFALOS.

$$
\text { L. XXX . }
$$




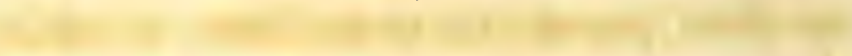

-

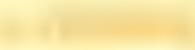

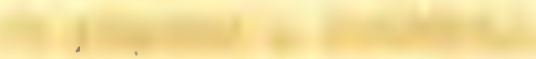

\section{4.}

\section{th}

-

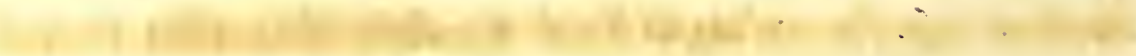
(20)

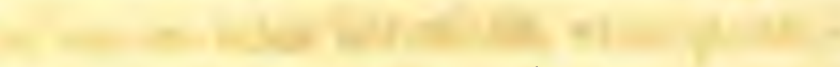
-

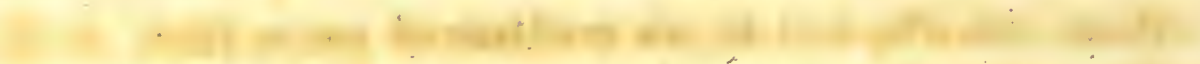

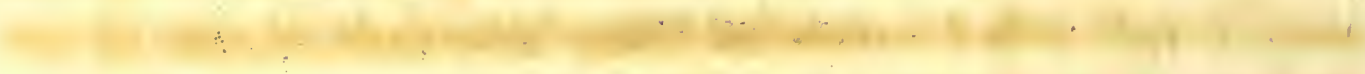

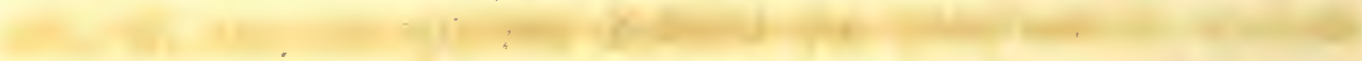
.

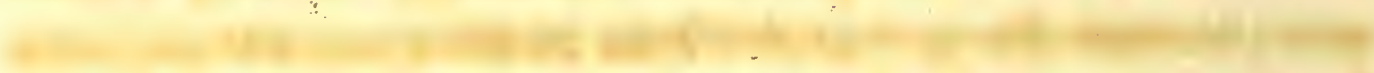

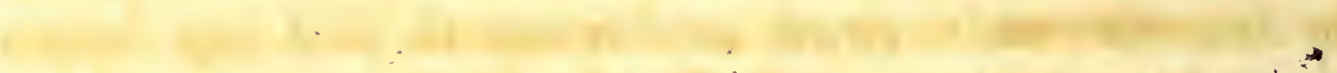

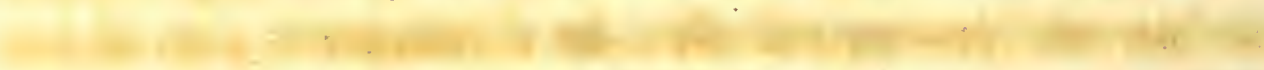
- 2. . . .

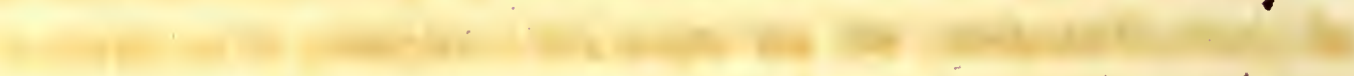
C.

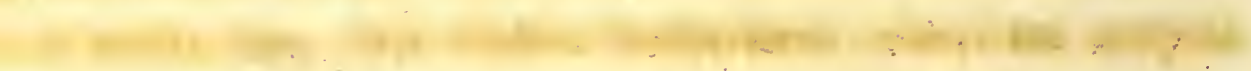

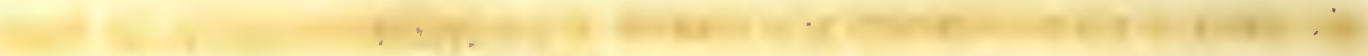

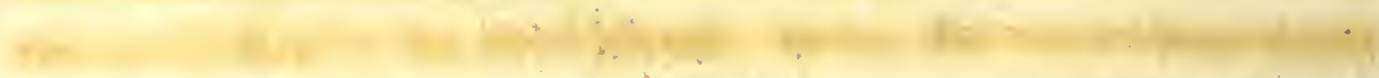

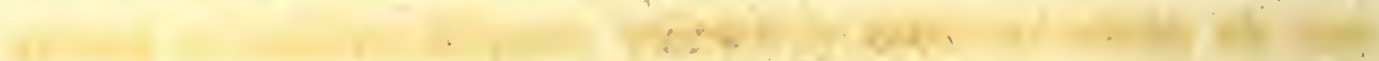
W

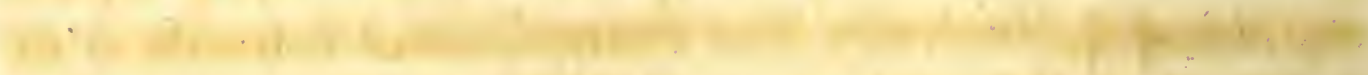

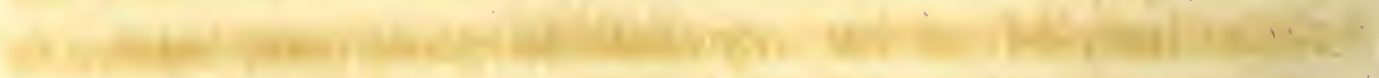

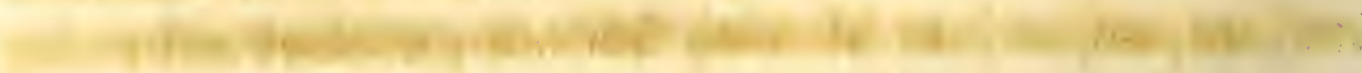


Estos moluscos tienen las mismas costumbres que las ostrás: se reunen en tropas innumerablés en los fondos areniscos ó cenagosos; á poca distancia de las costas, y se fijan á los cuerpos marinos por medio de sú biso ; de aqui los desprenden como á las ostras, con un gran rastrillo. Esta pesca es tanto yenáajoșa, cuanto que, á mas de la seda que suministran, ofrecen en su carne/un aliméntó bastánte agradable.

§. III. Las Golondrinas (avicula) (fig. 1.) que tambien se llaman aviculas se parecen bastante á unas almejas, cuya concha fuera casi redonda y la charnela prolongada en formande ala, lo que les da alguña relacion con una aye' que tuiviera las alas estendidas; por razon de esta consideracion, se les han dado estos dos nombres, que quiere decir, i uno avecilla, y el otro

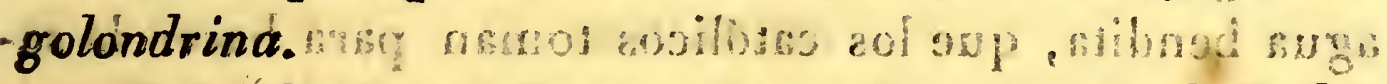

Estas conchas son generalmenté pequeñas, delga das, -muy frágiles /y anacaradas interiormente; ; peco a pesar de esta última particularidad se haria poca caso de ellas, si no fuera porque pertènece á este género da espécie que produce las perlas; de Oriente. Esta especiero que ofe - ha Ila mado madve de perlas: ó margaritifferdi (figi Ar) por razon de esba, circunstancia , se encuentrar cono abundáncia en los mares méridionales y principalmente en el golfo Pérsico; en las costas de Ceylan, \& e. Pero no todos los individuos de esta especie suministran perląs, es preciso pana esto que la materia que sirve ordina- niamen tes para traceg el nacar que barnizo toda la cara interna de las valvas, se denrame en su cavidad en forma de globulos mas ó menos conșiderables, parece que esta estravàsacion siempre es causada por alguna enfermedad.

Se encuentran las avículas /margaritiferas reunidas en tropas ó mas bien en báncos enormes, que tię- 
nẹn hasta tres leguas de largo. Unos buzos habituados á estè egencició van á pescarlas con grandes cestos; despues se sacán las perlas. Parece que en la mayor parte de los puntos donde se verifica esta pesca, se hace su apertura con solemnidad, y da lugar á fiestas y: regocijos públicos.

\section{TERCERA FAMILIA.}

\section{TRIDACNOS.}

\section{of $4017 \sin ^{3}$}

Estal familia no comprende mas que un solo género, el de los Tridacrós (tridacne) ó pilas de agua bendita, al cuál se da este último nombre, porque en muchas iglesias su concha sirve de vaso para contener el agua bendita, que los católicos toman para hacer la señal déla crúz cuando entran en el templo del Señor. Tseg Estas conchas son notables entre todos los monomiariós, no solo por los dientés que guarnecen su charnela y por su ligamento visible al esterior, sino tambien parsu magnitud, su fuerza, y por la entera ócasi enterầ igualdad de sus valvas. Aunque su superficie esterna está marcada , como en los peines, de eminencias rtrasversales, no" por eso deján de ser compuestas de hojas fomo lo prueban las cespecies de escamas levantadas que erizan sús lados.

- Hos tridacnos son todos hermosos, de una magnitud mas que mediana, y á veces gigantésca ; su cara interna es lisa y de un blanco mate, bastante semejante al del alabastro, ál paso que en lo esterior están cubiertos de grandes asperezas. Las mas veces existe delante de la charnela una abertura oval (la lunula) por la que el animal hace pasar el biso, por médio del cual se cuelgá de las rocas á pesar del peso de su concha. Su car- 


\section{9}

ne, aunque dura, se come, y es tan abundante en algunos de estos moluscos, que basta para saciar á muchas personas.

Se cuentan unas diez especies de este género; la principal es la que se ha llamado gigantesca, porque llega hasta tres pies de largo, y pesa mas de trescientas libras. Su biso es tan sólido y tenaz, que se necesita una hacha para cortarle y separarle de las rocas á que está adherido. Una concha de esta especie es la que se ve én S. Sulpicio, en Paris; fue regalada á ésta iglesia por Francisco I, que la habia recibido de los venecianos. Esta especie se pesca en el Océano Indio. .

\section{SEGUNDO ORDEN.}

DIMIARIOS.

Este órden es mucho mas considerable que el anterior, y encierra un número mucho mayor de conchas bonitas; por lo que los aficionados reunen muchas mas de estas en sus gabineles, y son mas comunes que las precedentes.

Estos acéfalos son fáciles de distinguir por el número de músculos, cuya doble insercion se observá en su concha, por la ligualdad de las valvas de esta última, por la regularidad de su forma, y por su estructura, que no es hojosa como en los monomiarios; pero presenta lás mas veces, como en los peines, una serie de costillas, que saliendo de la base, se dirigen en forma de radios hácia el borde.

Sin embargo, es préciso advertir que estos caractéres no son absolutos. Asi como entre los monomiarios hemos hallado conchas con costillas casi regulares; del mismo modo observaremos entre los acéfalos delosegun- 
do órden espećies con concha foliácea, y algunas veces irregular. Pero á mas de que estas escepciones son en corto número, las especies que las presentan tienen en ellas caractéres toug isuficientes para distinguirlas, ja en su conformacion general, ya en los dientes que guarnecen su charnela para darla mas solidez.

Segan el modo como se unen las idos valvas entre síl; èl número de dientes que sirven para su union y la figura de la concha ó del manto del animal, se han dividido los dimiarios en cinco familias: los camaceos, -los arcaceos, los mitilaceos, los cardiaceos y los encerrados.

\section{PRIMERA FAMILIA.}

\section{CAMACEOS.}

Esta familia se asemeja á la de los tridacnos por la -forma dẹ la charnela que reune las valvás de la con-cha. En ella se observa, como en las precedentés, un fuerte diente qué se aloja en un surco análogo de la pieza opuesta, lo que da una gran solidez á la articulacion.

-isu Pero sin hablà de la doble impresión muscular grabada en cada valva, hay un carácter esterior muy mani- fiesto que distingue las camas de los tridacnos, y, es la - desigualdad de las piezas que componen la concha; caoracter que los asemeja á los acéfalós del órden precedente. Asi es muy evidente que estos molúscos estan - déstinados á formar él paso entré las especies de los dos órdenes.

- No se conoce sino un solo género de esta familia; las camas (chama), conchas irregulares, gruesas, de superficie áspera, escámosa ó guarnecida de espinas, quéseléncuentran en los mares australes i una sola, ó. 


\section{1}

tal vez dos, pertenecen al Mediterráneo. La carne de esttos moluscos parece ser tan agradable al gusto como la de las ostrás y mejor que la de las almejas; pera como todos pertenecen a mares lejanos, no se hace ningun caso de ellos para este uso. Unicamente los conquiliologistas se ocupan de ellos porrazon de la hermosut rá ó de la singularidad de su concha.

\section{SEGUNDA FAMILIA.}

\section{ARCACEOS.}

Estas conchas toman su nombre del género princi pal de la familia ; todas son regularés, de valvas iguales, guarnecidas de numerosos dientes; su figura es oblonga, y la charnela esta situada en direccion rde su lont gitud.

Esta familia no comprende sino moluscos marinos, de los cuales unos estan libres $y$ otros fijos, $y$ que sé pueden reducir á dos géneros: las arcas y los petúnculos. - §. I. Las ARCas (arca) son unas conchas ditorales que se conócen por su figura oblonga y por tos snứnerosos dientes de su charnela, ló que estan coloçados' en línea recta. El animal que làs habita cárece de verdadero pie para arrastrárse, y èste órgano es reèn zado en él por un ligamento tendinoso, por medio del cual se fija, pero sin poder nadar. Esta es la razon por qué no se encuentran las especies de este género sino en las cercanías de las costâs, uifas veces hundidas en el cieno, otras suspendidas de las rocas. A este grupo se refieren como especies principales: el arca torcida, una de las mas preciosas; el drca de Noé, wúy común

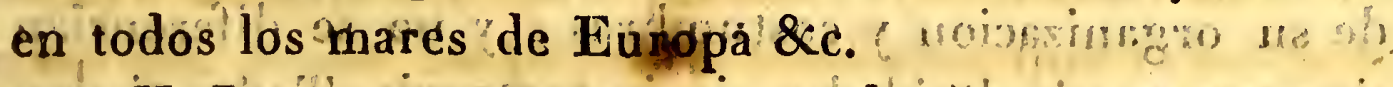

\$. II. Los Petunculos (pectunculus) son otbículares, 
de charnela combada, pero guarnecida de dientes numerosos, como en las arcas. El animal que vive en estas conchas tiene un gran pie de dos bordes, que le permite arrastrarse por el fondo de las aguas y nadar en su superficie. Pero como tiene los movimientos muy lentos, le sucede muchas veces, despues de haber seguidó la marea, que se encuentra en seco en la orilla, en donde no tardaria en perecer si no poseyera el medio de volver á alcanzar el agua. Para llegar á ella abre ámpliamente su concha, despues la cierra de repente; da un pequeño salto que le aproxima a su objeto; y esta maniobra repetida con constancia concluye por conducirle á su tẹ́rmino.

Cuando el mar está sosegado, los petunculos en vez de permanecer en el fondo del agua, se elevan á su superficie, en donde se les ve nadar en tropas numerosas sobre una de sus valvas, mientras que la otra, estando abierta y espuesta al viento, hace el oficio de una vela que sirve para mover esta barquilla viviente. De este modo se pasean mientras dura la calma y no tienen enemigos que temer. Mas luego que una de estas causas viene á turbar su paseo, cierran de repente su concha ye precipitan al fondo. Nuestros mares crián un gran número de estos animales singulares, entre otros el petúnculo comun, el petúnculo jaspeado \&c:

\section{TERCERA FAMILIA.}

\section{MitiLACEOS.}

Los mitilaceos forman una familia muy natural, cuyas especies se parecen todas por los principales rasgos de su organizacion y costumbres, y no se diferencian sino por particularidades sin importancia. Todos tienen 
la concha oblonga, regular, de valvas iguales, negruzcas y córneas, de estructura lás mas veces foliácéa, y! de charnela unas veces bidentada, otras privada de dientes.

Estos moluscos se encuentran en el mar y en las aguas dulces, corrientes ó muertas, en donde son muy comunes; se reunen en tropas muy numerosas, fijándose en las piedras y troncos sumergidos, principalmente en los sitios en donde el agua está quieta y tranquila. Asi es que se encuentran frecuentemente montones considerables de ellos debajo de los puentes y en los recodos que hacen los rios cuando encuentran algunobstáculo.

Se cuentan en esta familia tres géneros principales: las almejas, los anodontes y los unios.

§. I. Las AlmeJas (mytilus) se conocen por dos caractéres: por la carencia de dientes en la charnela, y por la presencia de un biso; son unas conchâs marinas de valvas iguales, combadas y triangulares, cuyo animal tiene un pie puntiagudo y largo, que no puede servirle para arrastrarse, pero que le emplea muy diestramente para fijar su biso á los cuerpos marinos.

Se encuentran las almejas con abundancia en todos los mares á poca distancia de las costas. Como su carne es bastante agradable al gusto, se pescan grandes cantidades de ellas. Pero como al mismo tiempo se venden á un precio bajo, únicamente las mugeres y los niños son los que se ocupan en esta pesca. Provistos de una cesta y de un rastrillo, van mientras baja la marea á desprenderlas de los cuerpos á que estan adheridas por su biso. Solamente durante el invierno, al fin del otoño y al principio de ta primavera es cuando se verifica esta pesca; en lo restante del año, que es la época de su desove, su carne es dura, coriácea y sin sabor.

Tono III. 
Durante este intervalo principalmente parece que su uso ocasiona accidentes á las personas que se alimentan de ellas, accidentes que se atribuyen ordinariamente á la presencia de un pequeño crustaceo venenosó; pero que mas bien son debidos á la mala calidad del molusco.

La principal especie de este subgénero es la almeja. comun ó comestible, muy esparcida en todas nuestras. costas, en donde se cuelga en largos racimos de las rocas, de las estacas, de las embarcaciones \&c. La almeja litofaga es nolable por la costumbre que tiene, cuando se adhiere á las piedras, de escavarlas para fabricarse en ellas una habitacion, en la que se fija por el resto de su vida. Parece que con el movimiento de sus valvas atraviesa de este modo los cuerpos mas duros.

§. II. y III. Los ANodóntes (anodon) ó almejas de estanque y los unios (unio) ó conchas de los pintores tienen muchas relaciones con las especies del género precedente: pero su concha es ordinariamente mas bonita ý presenta interiormente un color anacarado ó purpurino. Los unios principalmente son notables bajo este punto de vista. No se encuentran los moluscos de estos dos géneros sino en las aguas dulces; todos tienen un pie para arrastrarse, y no se fijan jamas como las almeas de mar. Pero hay una diferencia entre los anodontes y los unios, y es que estos tienen la charnela armada de dientes en una de sus valvas y escavada de fositas análogas en la otra, lo que da mas solidez á la articulacion de las dos piezas de la concha; al paso que los anodontes carecen completamente de dientes, y. no tienen las valvas unidas sino por un ligamento. Por lo demas, el animal de estos dos géneros está igualmeñte desprovisto de biso, en vez del cual tiene un ancho pie carnoso, del que se sirve para andar arrastrando por la arena ó por el cieno. 
Los principales anodontes son el anodonte de los es. zanques y el anodonte cisne.

Entre los unios citaremos el unio ó almeja del Rhin y el unio ó almeja de los pintores; esta última se ha llamado asi porque los artistas se sirven muchas véces de sús valvas para desieir sús colores.

\section{CUARTA FAMILIA.}

\section{CARDIACEOS.}

Interesante por el gran número de èspecies que comprende y por la hermosura de las conchas que en ella ce encuentran, esta familia es una de las que mas se han estudiado entre los acéfałos, y que súministran á los aficionados a colecciones la mas abundante cosecha para thermosear sus gabinetes. Adornados Ias mas vecés de brillantes colores, siempre elegantes y regulares en sus formas, estos moluscos marinos han recibido de los sabios los nombres de la diosa de las Grácias, que segun la Mitologia, ha tomàdo orígen como ellos en el seno de las ondas saladas.

El vulgo los designa ordinariamente con el nombre de corazones, á cuya figura se asemejan en èfecto sus valvas; y los naturalistas, queriendo cambiar esta denominacion, la han sancionado, por decirlo asi, sustifuyéndola otra que, sacada del griego, tiene absolutamente la misma significacion (1). Se pueden pues mirar todas las conchas cordiformes como pertenecientes á la familia de las cardiaceas. En cuanto al animal que las habita, tiene siempre el manto hendido por delante en el sitio en que se halla la boca, y horadado por dos aberturas,

(1) Cardia en griego quiere decir corazon. 
de las cuales la uná es para el ano y la otra parä el órgano respiratorio. Siempre está provisto en su parte inferior de un pie carnoso, como el de los gasteropodos, y que les sirve para los mismos usos. Los cardiaceos son pues unós moluscos rastreros, y que no se fijan como la mayor parte de los acéfalos precedentes; no obstante, hay un cierto número que apenas se mueven, y permanecen casi siempre ocultos en el cieno. Se conocen en que su abertura respiratoria y su ano estan provistos de un tubo que emplean, ya para arrojar á lo lejos el residuo de su digestion, ya para ir á buscar el fluido acuoso indispensable para el acto respiratorio.

Se puede dividir esta numerosa familia en dos tribus. En la una la concha tiene, ademas de los dientes cardinales que hacen parte de la charnela, dos láminas prominentes apartadas del centro de la articulacion y colocadas la una delante y la otra detras (fig. 4.) En la segunda, la concha no presenta mas que dientes cardinales (fig. 5.)

A la primera se refieren los géneros bucarda, donace, ciclada, canastilla, lucina y tellina.

La' sègunda comprende las Venus, las corbulas, las mactras ó artesas.

Como todos estos moluscos presentan absolutamente las mismas costumbres y por consiguiente la misma organizacion, no haremos la historia de cada uno de estos géneros; nos contentaremos con dar el cuadro comparativo para que puedan distinguirse los unos de los otros. 


\section{P R I M E R A T R I B U.}

CARDIACEOS CON DOS ESPECIES DE, DIENTES.

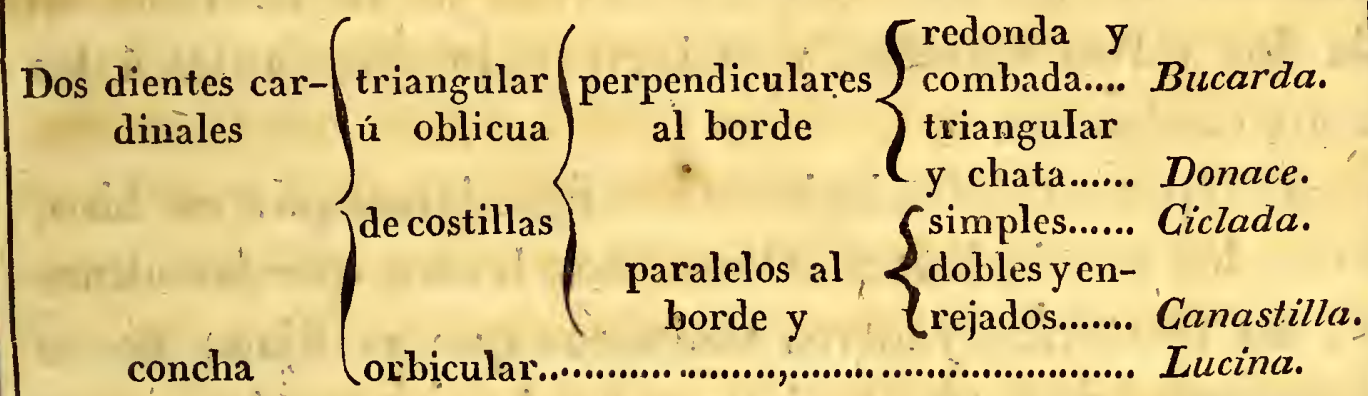

Tres dientes cardinales

Tellina.

\section{SEGUNDA TRIBU.}

CARDIACEOS QUE NO TIENEN SINO DIENTES CARIINALES.

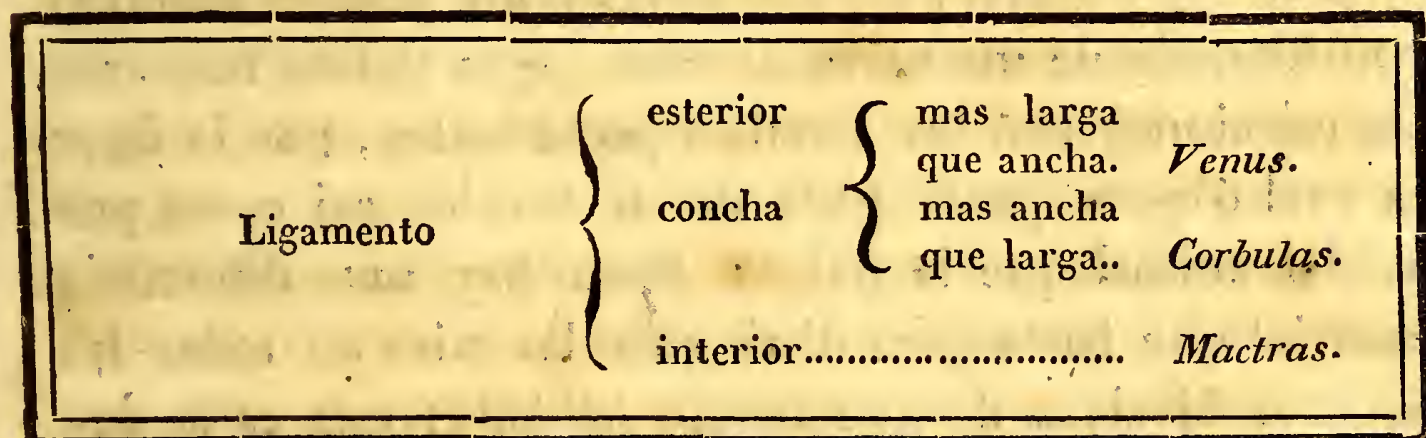

\section{QUINTA FAMILIA.}

\section{ENGERRADOS. (Lám. $X X X$.)}

Este grupo comprende un gran número de géneros singulares, $y$ tan diférentes, que muchos naturalistas los han trasladado á familias y aun clases diferentes. Su carácter comun consiste en tener el manto arrollado so- 
bre sí mismo, en forma de tubo saliente fuera de la concha, casi enteramente cerrado, escepto en el punto en que se halla una abertura para el paso del pie. La concha de estos moluscos está por consiguiente siempre abierta; por lo demas, á pesar de la diversidad de figura que presenta en los diferentes géneros, se encuentran en ella dos valvas iguales, y casi en todo semejantes á las de los cardiaceos.

Aunque estos dimiarios no se fijan jamas por un biso, tienen los movimientos tal 'vez mas lentos que las almejas, los tridacnos y otros moluscos que se fijan; no se encuentran sino en el cieno y en la arena; algunos se introducen en lo interior de las rocas ó en las maderas colocadas en el agua, y allí se cavan una guarida que les sirve de habitacion $\mathrm{y}$ de sepulcro.

Esta familia comprende cinco géneros principales: las mias, los solenes, las foladas, las bromas y las regaderas.

§. I. Las MIAS (mya) forman un género bastante considerable de moluscos acéfalos, que tienen numerosas relaciones con las familias precedentes, por la figura oval ó poco prolongada de su concha, asi como por la del animal que la habita. Pero hay una diferencia esencial que basta para distinguir las mias de todas las conchas bivalvas de que hemos hablado: esta es la doble abertura que presentan por delante y por detras. Por otro lado, la articúlación de sus valvas, que se hace pór medio de un diente cardinal, al cual corresponde una fosita análoga, y la figura oblonga de su concha, las alejan de todos los demas géneros de la misma familia.

Las mias viven hundidas en la arena, cerca de làs costass, y estan constantemente en una posicion vertical, téniendo la abertura de la bocá hácia abajo, y el si- 
fon respiratorio hácia arriba. En esta posicion tienen la libertad de respirar sin mudar de sitio: condicion muy necesaria para unos animales cuyos movimientos son penosos y lentos. En cuanto á su alimento se ignora si lo encuentran en medio de las arenas ódel cieno que habitan; pero es mas probable que les sea conducido por la llegada del agua hácia su abertura bucal. En todos casos es muy cierto que no dejan su sitio para ir á buscarlo: ésta mutacion de lugar seria demasiado dificil y les costaria mucho tiempo.

Tenemos en nuestras costas dos especies de este género: la mia truncada, que es muy comun en el Océano y el Mediterráneo, y la mia de las arenas, que se halla tambien en estos dos mares.

§. II. Las conchas que hemos estudiado hasta de aqui, nos han ofrecido sin duda una gran diversidad de formas; pero ninguna nos la ha presentado tan estraña como la de los SOLENES (solen) ó mangos de cuchillos (fig. 6.) Viendo a estos últimos, se les tomaria mas bien por un producto del arte que por un marisco. Figúrense dos láminas delgadas, semicilíndricas, unidas entre sí de modo que forman un cilindro entero, con una abertura en cada estremidad, y se tendrá una idea del molusco de que hablamos. A esta figura singular, que se asemeja á la de un mango de cuchillo, debe el solen el nombre que le dan ordinariamente los comerciantes de curiosidades.

Por lo que toca al animal que habita esta concha, está completamente envuelto en su manto, escepto por sus dos estremidades, de las que la una da paso á su pie, y la otra tiene dos tubos destinados á la respiracion y á la digestion.

Las costumbres de estos acéfalos son muy singulares: no se mueven sino con mucha dificultad cuando 
estan en el agua ó en la superficie de la tierra ; pero cuando se ven espuestos á algun peligro, se fabrican en la arena un agugéro de uno á dos pies de profundidad para sustraerse al peligro, y esto lo hacen con una rapidez que sorprenderia en animales mucho mas ágiles. Llegan á este resultado por medio de su pie, del cual se sirven "como de una pala para horadar el suelo. En agugeros preparados de este modo es donde pasan la mayor parte de su vida; y es tanto mas dificil descubrirlos en ellos, cuanto que no salen sino muy ràra vez, y no hacen movimiento alguno que pueda descubrirlos: su alimento les viene por sí mismo sin que se tomen ningun trabajo para buscarle.

Se cuenta un número bastante grande de especies de este género, de las que cinco ó seis pertenecen á nuestros mares, entre otros el mango de cuchillo (solen maximus), la vaina (solen vagina), el solen rayado (sol, strigilatus), la espada (sol. ensis).

§. III. Las FoLAdAS, dátiles ó mangones (pholas) son todavía mas notables que los solenes por la facilidad con que agujerean los cuerpos mas duros: no solo ahondan el suelo sobre el que corre el agua, sino que atacan á las rocas mas duras, y á fuerza de paciencia llegan á practicarse en ellas una morada cómoda y tanto mas bien abrigada, cuanto que es inaccesible á todos los animales marinos que les son algun tanto temibles. Para engañar todavía mejor á sus enemigos, dan al principio de su galería una direccion horizontal, y la terminan repentinamente por un recodo, en cu2 ya estremidad establecen su habitacion: de este modo su vivienda tiene la forma de una pipa de fumar. Nó es raro encontrar en las cercánías del mar grandes rocas horadadas de este modo en todas direcciones por animales de este género. En esta especie de celdilla, de 13 
que ya no debe salir el animal, recibe del agua que en ella penetra, sin tomarse ningun trabajo, todo el alimento que necesita para su subsistencia, y alli se desarrolla como si lo hiciera en el seno mismo de las aguas en donde goza de toda su libertad.

Podria imaginarse que el molusco capaz de escavar de este modo la peña mas dura, debe tener un instrumento muy sólido para llegar á un resultado semejante. Pues nada de eso, la folada es un animalito que no tiene mas de una pulgada de longitud, y que no cuenta á su disposicion sino un pie carnoso, de la misma naturaleza que el de la limaza, y su concha que de ningun modo es notable por su dureza. Asi es que algunos sabios han pretendido que no era el animal el que habia agugereado la piedra, sino que al contrario, la piedra se habia formado al rededor de él. Pero unas columnas de un templo situado en la orilla del agua, que se han encontrado acribilladas de agugeros hechos por estos moluscos, han probado patentemente que era la misma folada la que horadaba la roca. Otro hecho que lo demuestra con la misma evidencia, es que se han encontrado en algunas rocas unas foladas atravesadas de parte á parte por otras.

Se hallan estos moluscos con mucha abundancia en todos los mares: su carne, aunque poco delicada, es sin embargo buscada por los pobres: aun la hacen escabechar para conservarla por mas tiempo; pero el principal uso de estos animales es servir de cebo para la pesca.

Se conocen facilmente las foladas por su concha prolongada, ampliamente abierta por cada lado, y guarnecida de piezas accesorias, cuyo número varia mucho segun las especies.

La mas comun en nuestras costas es el dátil ó foToN10 III. 
lada vulgar, que es muy abundante en todo el litoral de Francia y España.

§. IV. Las BRovias ó polillas de mar (terédo) (fig. 7.) son para la madera lo que las foladas para las piedras; agugerean todas las piezas de carpintería que encuentran en el agua, y á veces causan de este modo estragos espantosos, no solamente en los diques, sino tambien á las embarcaciones que en poco tiempo las ponen fuera de servicio. En 1731 destruyeron uná parte de las estacas de los diques de Holanda. Se necesita una activa vigilancia para librarse de sus ataques; el embreado frecuente de las maderas que es preciso - dejar permanecer mucho tiempo en el mar és el medio mas á proposito para impedir que las perjudiquen.

El animal peligroso que causa tan grandes perjuicios al hombre es de forma prolongada y cubierto de una pequeña concha que no defiende mas que la par te posterior de su cuerpo. La parte anterior está protegida por un tubo cilíndrico, y por una especie de costra calcarea que deposita, á medida que progresá en las paredes del agugero que se practica en lá madera.

Se conocen muchas especies de polillas de mar, de las que la principal, que es la naval, tiene seis pulgadas de largo ; y se ha hecho célebre en todos los puertos de mar por el daño que hace á los navios.

S. V. Las REGAderas (aspergillum) son unas conchas singulares, cuyo animal es todavía desconocido, por lo qual no se puede determinar el sitio que debe ocupar en la escalá de lós seres animados; esta es la razon porque algunos naturalistas las colocan en la familia de los moluscos de que hablámos, al paso que otros las ponen entre los anelides tubícolas, que perteñecen á la division de los animales articulados. 
Las régaderás toman su nombre de su figura, que es la de un tubo largo, con dos aberturas, de las que la una mas estrecha está siempre abierta, al paso que la opuesta, mas ancha, está tapada por una chapa ó casquete calcareo, sembrado de un gran número de pequeños tubos capilares muy frágiles.

Todas estas conchas son marinas y pertenecen á los mares meridionales. Las mas notables son : la inegadera de Java y la regadera de manguitas que son de un precio muy alto, principalmente cuando están bien conservadas y guarnecidas de sus tubos.

\section{TERGERÓRDEN.}

\section{BRAQUTOPODOS.}

Estos moluscos tienen las mayores relaciones con los precedentes, por tener como ellos una concha bivalva con un uranto de dos lóbulos, comparables á las hojas de un libro. Pero se distinguen de ellos en que en vez del pie carnoso que se observa en la mayor parte de los monomiarios y dimiarios, se les ve dos tentáculos ó brazós guarnecidos de filamentos los que pueden estender fuera de la concha ó esconderlos enteramente en ella; y por razon de esta particularidad de organizacion, ham recibido estos moluscos el nombre de bnaquiopodos. En la base de estos dos apéndices es donde se halla situada la boca, la cual consiste en una simple hendidura, sin ningun órgano sólido para la prehension ó la masticacion de los alimentos.

A mas de los brazos de que acabamos de hablar, slos braquiopodos tienen un tercer apéndice, lanálogo al biso, que está compuesto de fibras sólidas y que les sirve para adherirse á las rocas submarinas Pero nó 


\section{4}

parece 4

to á otro la

durante tóda, su

que el alimento les.

medio de sus brazos un

termina en su bocá, y les hic

mátèria nutritiva que contiene.

La historia natural de estos animales es poco impor tante para el hombre; ninguno de ellos nos hace bién ni mal; y como todos viven en la profundidad de los mares en donde es casi imposible observarlos; apenas se conocen sus costumbres, que por lo demas deben ser poco interesantes, aun mènos de lo que puede presumirse segun lo que se sabe de su organizacion.

Este órden no se compone mas que de tres géneros: las terebrátulas, las lingulas y las orbiculas. El de las TEREBRatulas (terebratula) que es el principál; está cáracterizado por unas conchas de dos valvas desiguales, de las que la una tiene el vértice prominente y horadado por una abertura para dejar pasar el pedículo bisoideo qué sujeta al animal á las rocas ó á otras conchas.

Esta abertura suministra un caracter muy a parente para distinguir estos moluscos delos de los dósórdénes que preceden. Se conocen muchás éspeciés vivientes de este género; pero el número de estas no pủede compararse con el de las fósiles que se encuentrán en cantidad innumerable en las capas profundas. de los terrenos antiguos.

\section{CUARTO ORDEN.}

TUNICARIOS Ó MOLUSCOS ACEFALOS DESNUDOS.

Estos moluscos, que se han llamado asi porque tienen el cuerpo cubierto de una doble membrana; de las cuales la una es interua y mas fina, y la otra ester- 
na, más sólida y de naturaleźa cási ternillosa, se distinguen de los tres órderies precedentes por la fal-z? ta de concha; por lo demas, pertetiecen a la clase de los acéfalos por las principales particularidades de su organizacion; asi es "que todos tienen un celebro situado sobre el esófago, nervios, arterias, venas, \&c. y cuantdo se para la atencion en ellos, se que la segunda túnicaz ternillosa puede mirarse como reemplaźando la concha de los moluscos téstácéos.

Este órden poco númeroso, no comprende mas de dos familias, la primera incluye los génerós cuyos individuos estan aislados, y sin conexion orgánica unós con los otros; aunque viven muchas veces en sociedad y contienen los biforos y las ascidias. La segunda es la de los agregados.

§. I. Las bíroros ó salpas (salpa) son unos animales muy blandos, lárgos, cuya piel es tan trásparente que se pueden estudiar, sin disecarlos, todos los pormenores de su organizacion interior.

Estos moluscos son todos pelagianos y no acercan jamas á las costas: precaucion necesaria para unos sẹres tan delicados y tan poco ágilęs, que:los moviỉientos de las aguas los estrellarian infaliblemente contuar las orillas, si no vivierán apartados de ellas. Gưando el tiempo está tranquilo, se les encuentra flotando en la superficie de los mares vécinos á la zona tórrida , unas veces libres y separados, otras reunidos en tropas de diversos modos. Por la noche; esparcen en las aguas una luz fosfórica muy brillante El "modo como lestos, animales se mueven es bastante singular; su cuerpo está provisto de un tubo que le atraviesa en toda su longitud y que goza de una gran contractilidads Haciendo entrar água por la abertura posterior de este tubo, y arrojándola con fuerza por la del nado iopuesto, el 
chorro que forma iel líquido tos impele hácia atras, de modo que se mueven a reculass. Este hechol, que por lo demas no es raro entre los moluscos ha inducido en error muchos maturalistas y les ha hecho confundir, en estos acéfalos, la parte anterior del cuerpo con la posterior.

- \$. II Las AsGIDIAS (ascidia), que tambien se llaman odres de mar se distinguen facilmente de los biforos por su manto cartilaginoso y por su completa inmovilidad viven constantemente adheridas á los cuerpos marinos, como son las ovas y los mariscos, y no esperimentan otra mutacion de lugar que la de los objetos á que estan fijadais La priacipal señal de vida que șe observa en ellas se deduce de la absorcion y evacuacion alternativas del agua por sus orificios tubulosos.

- Se sencuentran un gran número de ellas en todos los mares y la major parte de las especies podrian suministraral houbre un alimento de mediana catidad; perosu pequeñez las hace despneciar delos peșeadores. No sucede to mismo con los peces y atres habitantes de los mares; estas les bacen continuamente la guerra o $y$ con mucha ventaja o por razon de que las ascidias privadas de conchà ly de movimiento, no tienen para defenderse de éllos, imas que el inutil recurso de lanzar con tra su enemigo algunos chorros de agua que tienen de reserva en una cavidad interior, particularidad que les. há heoho dar el nombre vulgar delodres de mar. an La ségunda familia de los acéfalos desnudos ó sin concha, los agregádos, tómprende unos animalès mas ó meros análogos: á las ascidias; pero reumidos en una mása comun, de ssuerte que parecen comunicar órganica-

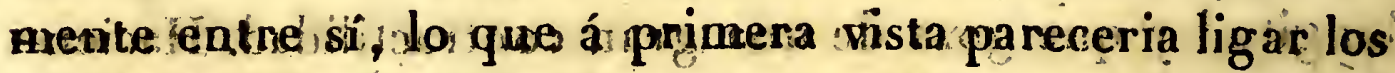
moluscos á los zœófitos; pero lo que independientemente do su ongąnizacion ṕpopia se opone á esta idea, es que. 
segun las observaciones de Andoưin y Milne Edwárş los individuos viven y radan al principio separados, y no se reunen sino á cierta épóca de su vida.

Sus branquias', forman como en las ascidias un gran saco que los alimentos deben atravesar antes de llegar á sư bòca.

Entre ellos unos tienen, como los biforos, una abertura en cáda estremidad, tales son los botrilos y los pirosomos.

§. I. Los Botrizos (botryllus) son de forma ovalada , y están fijos söbre diversos euerpos, como los fucos y las ascidias, en número de diez ó doce como los radios de una estrellay; los orificios branquiales estan en las estremidades de los radios, y los anos terminan è una cavidád comun que hay en el centro de la estrella cuando se irrita un orificio, thanimal solo se contrae, pero sies el centro se contraén todos! En algưnas éspecies'se se bo servan tres ó cuatro estrellas colocadas anàs isobre otras. Tal és el botrilo amontonädo (botryllus conglomeratus).

§. II. La roz pirosomo (pyrosomá), ?que quiere decir cuerpo de fuego, se ha dado á estos moluseos por razon del resplandor con que brillan ; pero únicamen-

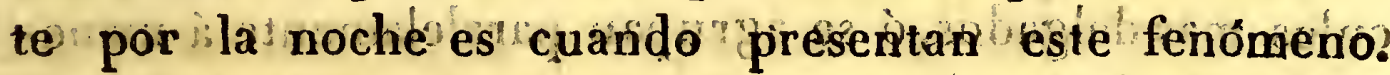
Reunidos en tropas innumerables, espareen en la superficie de los mares una luz brillante, que los haria tener por una grande hoguera encendida; por todas partes se ven ráfagas de luz ofreciendo los mas hermosos colores del arco iris, entre los cuales se distinguen principalmente el rojo, el naranjado y el azul. Este efecto depende del fósforo que los pirosomos desprenden, durante la noche, de la superficie de su cuerpo; y como estos moluscos, colocados en hileras unos tras de otros, se mueven continuamente, próducen ráfagas de luz que simulan un incendio, cuyos progresos se estienden mas 
á medida que adquiere mas fuerza. Pero lá ilusion desaparece con el dia; no se éncuentra mas, en vez de un cuerpo en ignicion, que un animalito de forma prolongada, cilíndrico y erizado de pinchios elásticos, que por nada llama la atencion del observador.

Otros tienen como las ascidias comunes, el año y el orificio branquial dirigido hácia la misma estremidad. Todos los que se conocen eštan fijos y se les habia confundido hasta aqui con los alciones. La masa de las visceras de cáda individuo es mas ó menos prolongada en là masa cartilaginosa ó gelatinosa comuri, y mas ó menos estrechada ó dilatada en ciertos puntos t pero cada orificio répresenta siempre en la superficie una pequeña estrella de seis radios. Tal es el género policuino (policlynum) (fig.. 1.9.) cayas especies pueden reducirse á grupos de los que Sayigni ha formado ot ros tantos'géneros. Unas vèces se estienden sus cuerpos como unas cor lezas carnosas; otrás se elevan en una masa cónica ó globulosa ; estos se abren formando un disco comparable á una flor ó una actiniă, adornado de hermosos colores, como el policlïno diazôna (fig. 10.), que es de un precioso color de púrpura; aquellos se alargan en ramas cilindricas, sostenidas por pediculos mas delgados, ó se agrupan paralelámente á manera de cilindros.

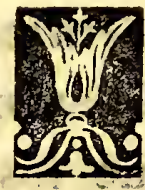

39356. 


\section{Q UINTA G LA S E. \\ Cirropologia.}

ó

HISTORIA NATURAL DE LOS CIRROPODOS

Esta clase, aunque poco numerosa, no deja de ser interesante bajo muchos aspectos. En primer lugar los moluscos que abraza présentan en su estructura alguna analogía con los animales de la tercera division. Asi es que tienen en cada lado del cuerpo unos rudimentos de miembros articulados, que se llaman zarcillos y que se pueden comparar á los pequeños apéndices que se encuentran debajo de la cola de los cangrejos y de las langostas; su boca está armada de mandíbulas laterales; su concha ni es univalva ni bivalva ; se compone de muchas piezas desiguales y dispuestas con cierta simetría á cada lado del animal : en fin, sus ganglios no estan ya esparcidos sin órden por todas las partes del cuerpo sino que forman una especie de cadena debajo del vientre, casi como en los animales articulados. Pero ofrecen con los acéfalos relaciones todavía mas numerosas; su cuerpo está siempre envuelto en un manto ya en totalidad, ya en parte; no tienen cabeza distinta ni órganos especiales para los sentidos, su boca no está jamas rodeada de tentáculos; y lo que les distingue esencialmente de los animales articulados, es que están privados de la facultad de moverse en totalidad, y por consi-

Tомо III. 
guiente condenados á vivir siempre fijos en el mismo sitio. La única diferencia que se observa en los cirropodos con respecto á su movimiento es que los unos están adheridos á los cuerpos marinos inmediatamente por su concha, al paso que los otros estan sostenidos por un pie movible del que solo la estremidad toca en el suelo.

Esta imposibilidad de trasladarse de un punto á otro hace necesariamente acuáticos á los cirropodos; asi es que no se encuentran sino en el mar, en donde viven de los restos de los cuerpos organizados que sus aguas tienen en suspension, y que acarrean sin cesar hácia la orilla.

- Esta clase no nos ofrece mas que dos géneros notables, que son las anatifas, y las balanitas.

§. I. Las aNATIFAS (anatipha) (lám. XXX. fig. 8.) se han llamado asi por corrupcion de la roz anatifera, lleva patos, porque se creia antiguamente que estos moluscos daban orígen á estas aves en las orillas del mar. La causa de este error absurdo se halla en la costumbre que tienen las palmipedas, y principalmente los bernachos, de buscar en las orillas del mar los insectos, gusanos y pequeños moluscos, y en particular los del género de que hablamos. $\mathbf{Y}$ como se les ve mas vecés levantarse del suelo que descender á él, por razon de que la presencia del hombre basta para impedirles bajar á tierra, los marineros, que los veian salir volando de entre estos mariscos sin verlos jamas descansar entré ellos, se imaginaron que tomaban origen de ellos, y miraron á las anatifas como huevos de ánade producidos por el mar.

Este error las ha hecho muy célebres, aunque por sí mismas no tienen nada de notable por su hermosura ni por sus costumbres. Son unos moluscos de muchas valvas dispuestas con regularidad, y cuyos lados 
del cúerpo están guarnecidós de doce pares de zarciHos, y sostenidos por una especie de tuho ó de pie que se asemeja a un dedo, lo que les ha hecho dar el nombre de policipidas. Söbre este pedículo giran todos los movimientos del animal ; por su medio, este molusco imprime á su cuerpo un movimiento circular que produce, como lós tentáculos de los braquiopodos, ún remolino de agua cuyo efécto es atraer á su boca las partículas de las materias animales que flotan en mar.

Las ànatifas son muy comuries en todás las icostas de Francia, y principalmente en los parages azotados por las olas. Fijadas á las rocás márinas mas espuestas á los movimientos de las aguas, se diria que desafian al furor de las tempestades. Auaque la carne de estos moluscos no es delicada, se comen muchas es: pecies en algunos. parages; se observa que la' coccion les comunica un color rojo como á los cangrejos. Las principales especies son la anatifa lisa (anat. lavis). que tiene cinco valvas comprimidas, lisas y el tubo arrugado, y la anatifa de pie de cabra (An. pollicipes) que tiene ademas de las cinco valvas ordinarias un sin número de pequeñitas en la base.

§. II. Las batanitas (balanus) (fig. 9.) llamadas mas comunmente bellotas marinas se asemejan á las anatifas por la pluralidad de sus valvas, por el número considerable de sus zarcillos, por la privacion de toda locomocion y por la costumbre que tienen de vivir en las orillas del mar, pero las valvas de las balanitas estan soldadas entre sí de una manera inmóvil, y constituyen por su reunion una cơncha câsi univalva de figura cónica ú oval, y casi semejante á una bellota de encina, lo que las ha hecho dar su nombre vulgar. Ademas, esta concha, en vez de estar sostenida por un pedículo como la de los policipidas es completamente 
sentada y descansa inmediatamente sobre una de sus valvas. El animal no puede pues emplear la estratagema de las anatifas para atraer el alimento á su boca; pero consigue el mismo objeto por medio de sus sentáculos, cuyos movimientos circulares producen el mismo remolino que el cuerpo entero de los cirropodos precedentes. Por medio de estos tentáculos se adhieren tambien á las rocas, á los corales, \&cc. Algunas especies de este género sirven tambien de alimento al hombre; las principales son la bellota de mar (lepas balanus, L.) que es pequeña, blanquizca y tan abundante que cubre las peñas, los pedernales y muchas veces á las :demas conchas, cangrejos y otros animales; y la balanita tulipan (lepas tintinnabulum, L.) la cual es mucho mayor y con la concha mas alta que la del animal precedente, y hermoseada con rayas blancas y de color de púrpura. 
00000000000000000000000000000000000

\section{TERCERA DIVISION.}

\section{Animales articulados.}

Dos caractéres bien marcados distinguen á los animales de esta division: la conformacion esterna de su cuerpo y la disposicion de su sistema nervioso. Su piel se compone de una serie de anillos ó articulaciones mas ó menos marcadas y reunidas entre sí por una membrana intermedia fiexible, que les permite ordinariamente cierta movilidad, y su sistema nervioso consiste en un pequeño celebro situado sobre el esófago, y en una doble serie de masas nerviosas ó ganglios, colocados én uno $\mathrm{y}$ otro lado del tronco debajo de su conducto alimenticio. (Lám. I. fig. 5 y 6.)

Eśtos animales nunca tienen esqueleto interior; pero la naturaleza sólida y ordinariamente córnea de los anillos que constituyen su cubierta esterior, reemplaza hasta cierto punto al sistema huesoso de los animales vertebrados, no solo para proteger á los órganos esenciales á la vida, sino para facilitar la egecucion de la locomoción. Asi es que los articulados no ceden á estos últimos en la precision y variedad de sus movimientos; pueden andar, saltar, trepar, nadar, volar. arrastrarse, y presentan por consiguiente en la estructura de sus órganos locomotores la misma diversidad que hemos observado en los animales de la primera division.

Sin embargo, se observa una diferencia muy esencial en la disposicion de los miembros de los articulados 
comparados con los de los vertebrados. En estos últimos las partes sólidas que entran en la composicion de un miembro son interiores, y se hallan cubiertas por los músculos que deben moverlas; en los animales articulados sucede lo contrario; las partes duras ó córneas son las esteriores y las que envuelven y protegen á sus músculos. Por lo demas, encontraremos á sus miembros terminados en puntas agudas para trepar, ensanchados en forma de remos para nadar, estendidos en forma de alas para volar \&c.; las especies que se arrastran son las únicas que estan totalmente desprovistas de ellos. Pero generalmente su existencia es constante, y su número es tambien mucho mas considerable que en los vertebrádos; pues cuando menos tienen seis pares, y á veces mas.

Ia forma de los animales articulados es regularmente prolongada; pero lo mismo que en la division de los vertebrados, la longitud del cuerpo está siempre en razon inversa del desarrollo de los miembros. Asi es que los anelides ó gusanos que carecen de ellos', ó no los tienen sino imperfectos ó rudimentarios, tienen la forma prolongada de las serpientes, al páso que los insectos que tienen patas para la marcha ó el salto, y alas para el vuelo, nos ofrecen un cuerpo corto ú oval, yá vecés completamente redondeado.

Pero, en todos casos, el cuerpo de los articulados presenta una cabeza muy fácil de conocer por la existencia de una boca, de dos ó muchos ojos, y de diversós apéndices que los naturalistas llaman antenas ó palpos, y que se designan vulgarmente con el nombre de cuernos; estos órganos parecen tener por uso palpar, oler, gustar, en una palabra, reemplazar los órganos de los sentidos especiales.

Segun esto, se ve que con respecto á lasi sensacionés 


\section{5}

y movimientos, los articulados de ningun modo son inferiores á.los vertebrados. Lo mismo sucedecon los ór ganos de la digestion; pero su circulacion no es tan perfecta; rara vez tienen un corazon para lanzar el fluido nutricio á los diferentes órganos; pero esta particularidad es consecuencia de la misma naturaleza de su respiracion. Como esta funcion se efectúa en ellos por medio de traqueas ó vasós que conducen él aire á todas las partes del cuerpo, es inútil la existencia del corazon, cuya funcion es enviar á los órganos la sangre que ha respirado, ya en las branquias, ya en los pulmones.

El estudio de los animales articulados es por lo menos tan interesante al hombre como el de los vertebrados, y si el resultado de este estudio no es tan fértil en aplicaciones inmediatas á nuestras necesidades, àl menos nos proporciona recreos mas dulces, y no ofrece las mismas dificultades que el de los animales precedentes.

Esta division, la mas numerosa sin disputa de la Zoologia, se divide en cinco clases: los anclides, los crustáceos, los aracnides, los miriapodos y los inseitos.

Estas cinco clases no pueden ser mas fáciles de caracterizar :

1. Los anelides nunca tienen miembros articulados, y estan cubiertos de una piel blanda ó calcárea; todos tienen la sangre roja, uno ó muchos corazones, y órganos particulares para la respiracion y la circulacion (la lombriz de tierra, la sanguijuela).

2. Los crustáceos tienen siempre miembros articulados, las mas veces en número de siete pares; cada uno de los cuales corresponde á uno de los anillos del tronco; tienen tambien un corazon, vasos arteriales y venosús, como tambien branquias para respirar; su sangre es sin color ó blanca, su piel mas ó menos incrustada de materias duras, y su cabeza provista de antenas 
ó de cuernos (el cangrejo propiamente dicho, el de rio y el cloporte).

3. ${ }^{\circ} \quad$ Los aracnides tienen siempre cuatro pares de miembros, ojos numerosos, y las mas veces en el mismo número que las patas; ofrecen en cada lado de su cuerpo unas aberturas llamadas estigmas, que son los orificios de las traqueas, de esos vasos elásticos destinados á conducir el aire á las diversas partes del cuerpo; su cabeza no lleva jamas antenas (la araña, el escorpion).

4. ${ }^{2}$ Los miriapodos se distinguen por el gran número de sus patas, que es lo menos de diez pares, y llega algunas veces á mas de ciento; por lo demas respirán como los precedentes por medio de traqueas (la escolopendra, los julos).

5. En fin, los insectos nunca tienen mas que tres pares de patas; su cuerpo se divide en cuatro partes bien distintas: la cabeza, en la cual se observan los ojos, la boca y las antenas; el coselete, al cual se fijan las patas, asi como las alas cuando existen; el abdómen, que encierra los órganos de la digestion, y á cuyos lados es. tan colocados los estigmas; por fin los miembros, que se dividen ordinariamente en patas y alas (la pulga, el abejorro, la mariposa, la mosca).

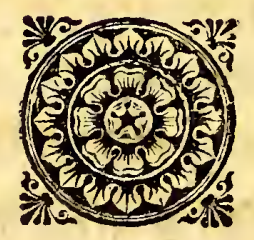




\title{
PRIM ERA CLAS E.
}

\section{fjclmintologia}

\author{
ó
}

HISTORIA NATURAL DE LOS ANELIDES.

Los anelides serán siempre fáciles de distinguir entre los animales articulados por la blandura de su cubierta esterior, y principalmente por la falta de verdaderas patas, y por el color rojo de su sangre.

Estos son en efecto los únicos animales de está division que nos ofrecen dichos caractéres. Sin embargo, no es decir que todos tengan una piel absólutamente blanda y que carezcan completamente de apéndices locomotores; algunas especies trasudan en su superficie una materia calcárea análoga á la concha de los moluscos; otras se forman una especie de vaina, conglutipando alrededor de su cuerpo granos de arená y restos de mariscos; casi todos, ó al menos la mayor parte. tienen en cada anillo de su tronco unas cerdas tiesas $y_{1}$ brillantes; que les sirven de miembros para mudar de sitio,

-13 Pero ademas de que la existencia de estos miembros nol es cónstanté, estos órganos nunca estan dotados de esas articulaciones que por su flexibilidad dan $\tan _{-}$ ta váriedad y facilidad á los movimientos de los demas animales de su divișion. Por lo que respecta á la sustancia calcárea. yé á los restos pedregasos de que se incrusTomo III. 
ta su piel, es evidente que no son parte integrante de ellos, menos todavía que en los moluscos, pues que en estos últimos se atan los músculos á ella, al paso que en los anelides el tubo es enteramente libre; asi es que puedeu dejarle algunas veces sin comprometer su existencia, al paso que no hay un solo molusco que pueda abandonar su concha sin perecer.

La figura de los anelides es generalmente oblonga; únicamente las especies, cuyas cerdas locomotrices son muy desarrolladas, son mas ovales que las demas. Su cabeza nunca está separada del tronco por una estrechez particular; por consiguiente carecen de cuello: pero lo que hará conocer siempre esta parte, es la presencia constante de la boca, y las màs veces la de dos ó cuatro ojos y de dos tentáculos ó ántenas. La boca se compone unas veces de una trompa para chupar, otras de man-! díbulas pára cortar ó triturar; en algúnós casos consiste en un simple orificio sin trompa ni mándibulas.

El régimen de los anelides depénde siempire de la conformacion de la boca': con la trompa ćhupan la sangre de los demas animales; con las mandíbulas muclen toda especie de materias, como gusanos, pecesi? crustáceos \&c.; desprovistos de una y otras; se ren obligados á sacar del agua y de la arena los restos de las sustancias orgánicas que en ellas' se hallan en suspension. En todos casos son esclusivamente carniceros.

Todos los animales de esta clase, á escepcion de las lombrices ó gusanos de tierra, viven en el agua y respiran por medio de branquias; sin embargo hay algunos en los que no se han podido descubrir todavia los órganos respiratorios; pero en la mayor parte de ellos son muy aparentes al esterior, is forwan ranos, bor las y penachos, cuya superficie está tapizada de vasos sañ guineos que conducen alli el fluido venoso. 



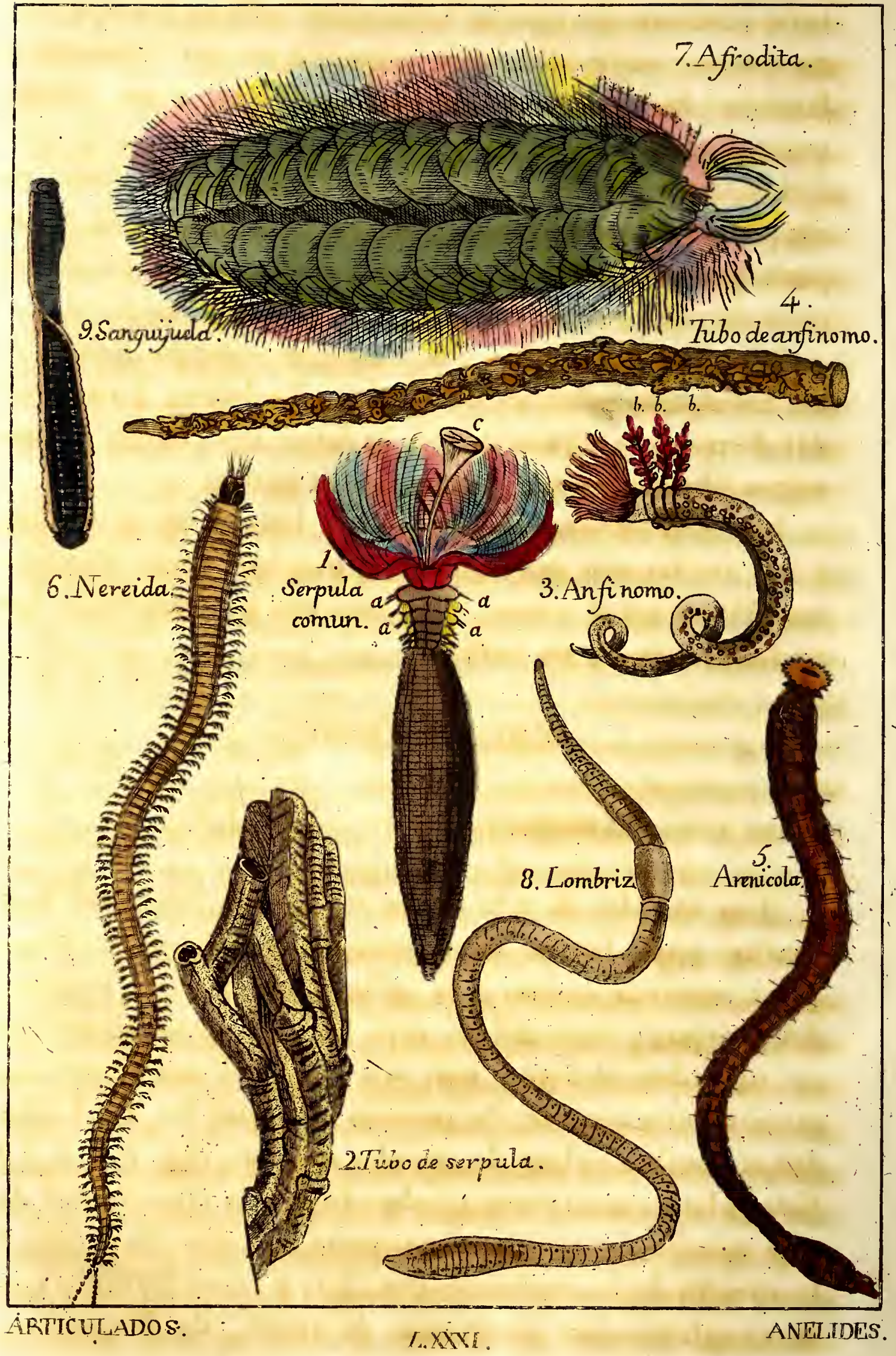


La clasificacion de los anelides está fundada en la existencia ó falıa de las branquias, de las cerdas y del tubo calcáreo en que se halla encerrado su cuerpo. Segun esto, se dividen estos animales en tres órdenes ó familias : los tubicolas, los dorsibránquios y los abránquios.

1.. Los tubicolas habitan un tubo, ya calcáreo, ya simplemente membranoso; tienen sus branquias en la parte anterior del cuerpo, y sus cerdas locomotrices un poco detras de estos órganos. Todos son sedentarios.

2. Los dorsibránquios tienen el cuerpo desnudo, las branquias sobre el dorso ó en los lados, y sus cerdas dispuestas alguna vez á lo lärgo del cuerpo. Estos vagan libremente en el seno de las aguas.

3. Los abránquios no tienen branquias aparentes, y sus cerdas son muy cortas, y muchas veces no existen. Viven en el cieno, y se mueven por medio de las ondulaciones de su cuerpo.

\section{PRIMER ÓRDEN.}

\section{TÜiCoLAs. (Lám. $X X X I$.)}

Los anelides de este órden no forman mas que una familia, y son fáciles de conocer en que tienen las branguias esternas unidas á la caheza ó á la parte anterior del cuerpo, y este último está las mas veces encerrado en un tubo calcáreo, mas allá del cual sus branquias forman una especie de manojo, lo que les ha hecho dar el nombre vulgar le pinceles marinos (fig. 1, 2,3,4.) Este pubo es unas veces producido por la trasudacion de una maleria inorgánica, semejante á la que da origen á da concha de los moluscos (fig. 2.), y otras formado por la couglutinacion de granos de arena, de fragmentos 
de concha y de partículas de piedras unidás entre sí por una especie de viscosidad que el animal segrega (fig. 4:)

Estos gusanos son esencialmente sedentarios, porque estan sus tubos casi siempre adheridos á los cuerpos marinos é enterrados en la arená y en las hendiduras de las rocas; $y$ aunque pudieran dejar su habitacion calcárea, pues que no han contraido ninguna adherencia con ella, no siendo favorable su orgánizacion á lá ejecucion de los movimientos, se ven obligados á permanecer encerrados alli durante toda su vida.

No obstante seria un error el creer que estos seres estan condenados á una inmovilidad completa. Por medio de las cerdas tiesas y ganchosas de que se hallan guarnecidos los anillos anteriores de su cuerpo (fig. 1 $a, a, a, a)$, pueden salir de su estuche ó entrar én él, segun lo exijan su gusto ó sús neçeśidades. Este órden contiene los géneros siguientes: las serpulas, los an finomos, los anfitrites $\mathrm{y}$ las arenicolas.

§. I. Las serpulas ó cañutos de mar (serpula) (fig. 1. y 2.) constituyen ún género numeroso y notable por la solidez de su tubo calcáreo y principalmente por la hermosura de sus branquias. Estas forman en la entrada del tubo un lindo penacho adornado de los colores inás vivos $y$ agradablés, el rojo, el azul $\mathrm{y}$ el morado. Asi es que nada hay mas digno de verse que las ser pulas, cuando hallándose muchas reunidas abren bien sus penachos varicgados; pero es preciso, para gozar de este espectáculo, que el mar esté en calma y que estos animales nada tengán que temer. Entonces salen de su habitacion para procurarse alimentos, y permanecen en este estado mientras nada les inquieta. Pero luego que los movimientos del agua vienen a anunciarles algun peligro real ó imaginario, sé meten de rèpenté en su túbó, cufa entrada tienen cuidado de cerrar bien con ún opérculo 
(c), y permanécen escondidas en él hasta tánto que sẻ ha restablecido la calma y ha pasado el peligro.

Se encuentran muchas especies de serpulas en nues tros mares, en donde viven a grandès profundidades, tales son : la serpula lcomun ó tripa de mar (sérpulá. contorluplicata), y la serpula vermicular (serp. vermicit laris, Gm.)

§. I. Los ANFinomos ó terebelas (terebella) (fig. 3 y. 4.) tienen como las serpulas las branquias situadas en la cabeza ; pero estos órganos, en vez de formar á cada lado una especie de abanico, parecen unos pequeños ramos frondosos $\left(\mathbf{b}, \mathbf{b}, \mathbf{b}_{;}\right)$, situados en $\mathbf{l}^{\prime}$ parte superior del cuerpo; ademas, su estremidad anterior está provista de tentáculos numerosos dispuestos en cír culo, y análogos á los que rodeán la boca de los cefalopodos. Por otra parte su tubo (fig. 4.) no es liso y homogéneo como el de las precedentes, sino áspero y compuesto de materiales diversos, unidos por una especie de argamasa aglutinante.

Los anfinomos habitan en gran número las costas de todos los mares; el Océano y él Mediterráneó crian muchas especies de ellos, que se confundian antiguamente bajo el nombre de terebela conchilega o recoge conchas.

§: HH. Los anfTRITES (amphitrité) viven en tubos como los precedentes, pero estos tubos en vez dé ser duros y calcáreós, sỏn simplemente membráńósos, cono de pergamino. Unicamerte algúnas veces, pára darles más solidez; el animal incrüsta én ellos esteriomente you dist tancia en distancia, algunois granos dé arena, réstos de conchas yoiras materias análogas. Sus branquiás forman al're-

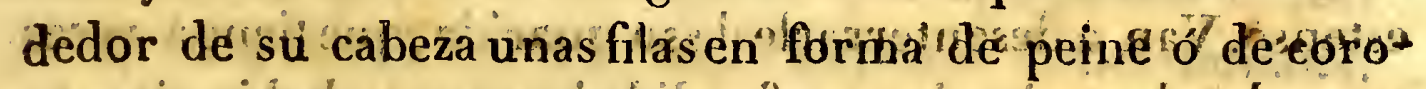
na y les sirven no solamente cóno órganós respitatorioz sino tambien como instrumentos de defeńsa liaéreptación 


\section{2}

y de prehension, porque las emplean igualmente para rechazar á sus enemigos, coger su presa, moverse en su tubo y recoger los materiales con que guarnecen á cste último. Por lo demas estas branquias, son tac hermosas y ofrecen unos colores tan ricos y tan variados como las de las serpulás.

Tenemos muchas especies de anfitrites en nuestros mares, entre otras el anfitrite de las ostras, que se, ha llamado asi porque se fija principalmente sobre la concha de estos moluscos, y perjudica mucho, segun dicen, á su propagacion, y el anfitrile de panal (sabella alveolata, $\mathbf{L}$ ) cuyos tubos estan formando una masa compacta que imita al panal de las abejas,

§. IV, Los arevícolas forman un género curioso, porque á pesar de que habitan como los anfitrites un tubo membranoso, tienen sin embargo sus branquias hacia el medio del dorso.

La úuica especie conocida de este género es el arenícola de lus pescadores ó lombriz de mar (fig. 5). Este es un gusano de seis á diez pulgadas de largo que, como lo indica su, nounbre, vive entre la arena, en unos agut geros profundos que en ella se practica Es muy notable por la hermosura y disposicion de sus branquias, que cambian continuamente de color y pasan sin cesar del rojo al amarillo, del amarillo al pardo \&ce; fenómeno que depende de la llegada de la sangre á estos órganos, en donde el contacto del aire la modifica y la bace cambiar de color. Este anelide es muy comun ex todas las ori Ilas arenosas de nuestros mares, y es muy buscado para hacercebos para la pesca de las pescadillas $\mathrm{X}$ de las sardas lo que es causa de que sea el objeto de un comercio bastante estanso. Van á desenterrarle de su guarida, que tjenéá veces csrcasde dos piesde profundidad, pero su habitacion es siempre fácil de conocer por el montoncito de tierra 
que se encuentra en su aberfura, poco mas 6 menos cotho enila de la loubriz o gusano de tierra.

\section{SEGUNDO ÓR DEN.}

\section{DORSIBRánquios (Lám. XXXI.)}

Este órdeń, el mas numeroso de esta clasé, comprende las especies cuyas branquias ocupan toda la longitud del cuerpo y principalmente su parte posterior. Por consiguiente, estos anituales no debeñ vivir en tubos sólidos, ó al menos no pueden estar en ellos habitualmente.

En efecto son libres, y nadan en el seno de las aguas con una agilidad, que les ha hecho dar el nombre de anelides errantes. Para este efecto están provistos de cerdas grandes y nuy desarrolladàs (fig. 6.) que les sirven de aletas, y les permifen moversé á su volúntad para buscar su alimento. Pero como su carácter vagabundo y la carencia de tubo sólido los espone a fré cuentes peligroś, la naturaleza les ha dado, a mas de la velóeidad de los móvinieútos, unas armas defensivas, de las que se sirven con mucha destreza contra sus ene

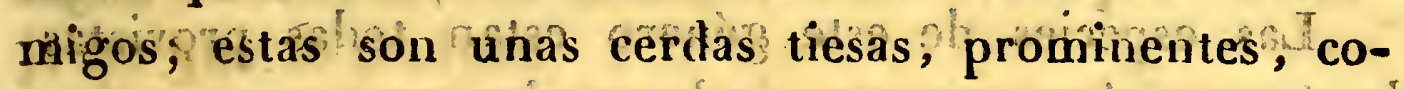
locadas à uno y otro ládo de su cuerpo, y euteramente diferentes de las de la locomocion; llevan el nombre? de aguijones (acicula): Y para que no pierdan su ágat dezá đurante la marcha del animal èste puede hacérlos entrán' á sú voluntad én lo interior de su cuerpo, por medio de los músculos de que están guarnecidos en su báse, asi es que son tan agudos que agugerean la piel de los mayores animales, sin esceptuar la del hombre.

Los dorsibránquios son los ánelides mèjor organizados; todos tienen una cabeza bien distrata con ojos, 


\section{4}

antenas, y una cavidad que se tomaria á primera vista por su boca, pero que en realidad no es mas que el estuche destinado á alojar la trompa del animal.

Este órden comprende dos géneros principales, que se pueden mirar como el tipo de otras tantas familias: estos son las a froditas y las nereidas.

§. I. Las AFRoDrTAS (aphrodita) (Gig. 7.) tienen generalmentefuna figura diferente de la de los demas anelides. Su cuerpo, en vez de ser prolongado como el de los gusanos de tierra, y el de la mayor parte de los animales de la misma clase, es corto a plastado y mas ó menos oval. - Is Pero su, carácter distintivo mas a parente, y al mismo tiempo el mas seguro, se saca de la existencia de un cierto número de chapas membranosas, que forman sobre su dorso dos series longitudinales, y reemplazan: en ellas el tubo en que estan encerrados los anelides del órden precedente Estas láminas, que se designan, con el nombre impropio de iélitrqs porque, se les comiz para á las alas córneas de algunos insectos cono los abejorros, estan destinadas á projeger las branquias, y sirven para formar en la época de la reproduccion

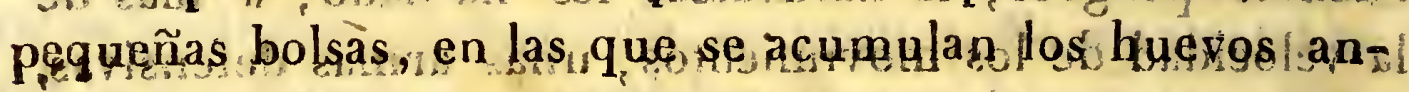
tes de ser puestos. - Las especies de este género estan todas provistas de órganos locomotores, de los cuales unos son agudos $y_{s}$ les sirven para arrastrarse, al paso que otros siende aplastados en forma de aletas yles facilitan la natacion

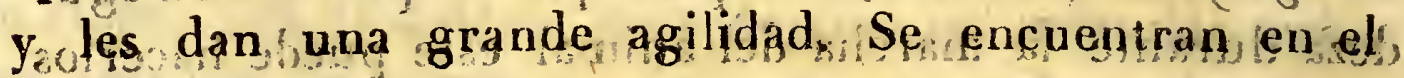
mar, debajo de las piedras en donde la mayor parte de ellas se arrollan en forma de bola Nosotros tenemos una de estas en nuestras costas, la afrodita erizada, (aphrodita aculeata, L.) que se llama vulgarmente raton ó topo marino. Este es uno de los animales marinos mas bonitos de nuestros climas; los colores de sus, 
cerdas brillan con el resplandor del oro, y toman todos los tintes del arco iris,

§. II. Las NeretDas (nèreis) (fig. 6) tienen muchás relaciones con las lombrices por su conformácion esterna; el cuerpo es largo, delgado y cilíndrico ó ligeramente aplastado; pero sus anillos y cerdas locomotrices son mas aparentes; lo que les ha hecho dar el nombre de escolopendras de mar. Ademas tienen la cabeza más distinta y provista de cuatro ó cinco antenas.

Estos anelides son todos marinos y viven ya debajo de las piedras, ya en las escavaciones de las rocas. Algunas especies se ocultan en el cieno ó se fijan en las piedras, y se forman unas pequeñas cavidades que rapizan de un baño glutinoso. Pero diferentès en esto de los tubícolas, pueden salir de aqui, cuando les parece, sin ningun inconveniente. Unicamente se retiran a ellas cuando les amenaza átgun peligró ó estan én acecho para aguardar su presa. En este último cáso se contraen fueriemente en lo interior de su guarida, $y_{i}$ si algun animul se presenta á su alcance, se dilatan repentinamente y le cogen con sus teoráculos.

Todas las neicidas son buscalas para la pesca; se cogen cuando buja la marea rolviendo las piedras bajo las que se ocultan.

\section{TERGER ORDEN.}

\section{ABRánQuios.}

Tomando el nombre de abránquios en una acepcion rigorosa, no podria aplicarse sino á los animales desprovistos de branquias, y no convendria á los anelides de este órden, los cuales tienen ciertamente branquias interiores aunque no se hayan visto hastal ahora;

ToMo III. 


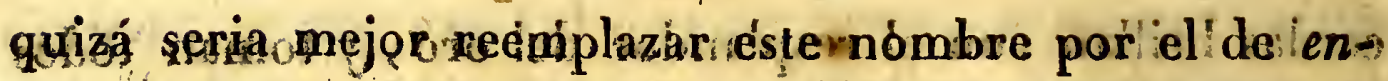
dobránquios, que Dumeril ha dado á estos animales,

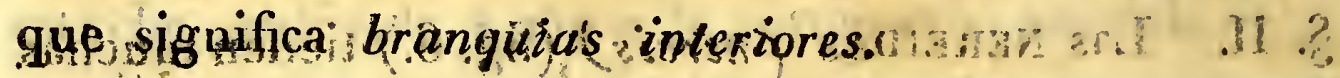

Seá como qujera, se conocerán siempre estos anelides por la falta la posicion interna de sus lórganos respiratorios, como tambien por la dificultad de distinguir su cabeza de lo restante de su cuerpo; porque no se encuentrap en esta parto ojos w in antenas y aun se la confundiria con la cola, si la presencia de la boca no suministrase un medio segúro de conócerla; todavía este carácter no debe examinarse á la ligeraty sino sé quiere engañarse Algunos anelides de esta familia pres sentan en la parte posterior de su cuerpo una espeoie de ventosa, que se podria tomar á primera tista por la boca.

Otra particularidad de estructura que separá á los abránquios de los dos órdenes precedentes, es la lalfaltà de pies En los dorsibránquios y tubícolas, ademas de las varias cerdas que sirven para lalacomocion, secencuen tran unos pedículos carnosos que forman su base y's lés dan una gran movilidad; aqui por el contrario jamas en. eontramos éstos pedículos.Por otra parte sus cerdas son tanbien menos númerosas y mas cortás, y aun algunas veces faltan totalmente.

Podria creerse segun esta disposicion que los abránquios, deben estar desprovistos de la fácultad locomotriz, pero lejos de ser asi, sus movimientos son por el contrario bastante ágiles, álò menos enlas especies acuáticas. Por medio de las ondulaciones de su cuerpo flexible. surcan el agua con rápidez, cúandó tratán de alcanzár una presă ó de escapar de algun peligro. Apesar de todo esto todos los abránquios estan sujetos, düante el tiempo frió, si no á una verdádera inverna cion bal menos á un sestado de inaccion que se aseme: 


\section{1}

ja mucho a entorpecimiento; ponqué pasan todo el invierno ocultoss ęn la tierra ó èn el cieno, á una pro fundidad considerable.

Este ârden no nos ofrece sino dos géneros impor-

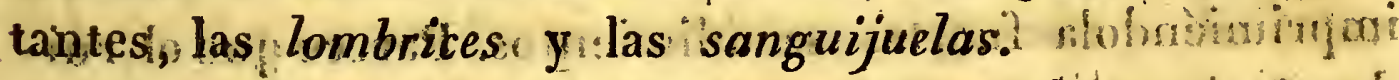

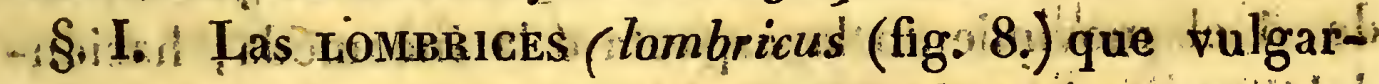
mente se Illaman gusanos ó lombrices de tictra por que en ella viven habitualmenté : al pasb que todos los demaś, anelides són mas ó menos acuáticos, tienen dos caractệ́res que lihpediran siempré confundivlas con nin -í

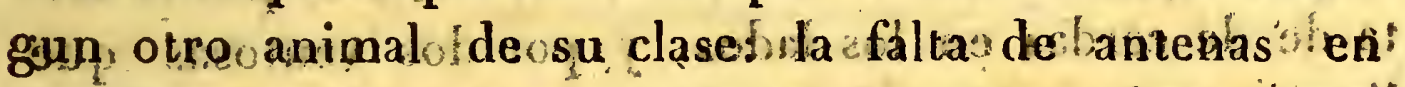
la cabeza y la desnudez dé) la pieles A estol se püede añadir la cortedado des las cerdas que guarnecen los anillosi de su cuerpolsy la falta de branquiasi si es ciento, womo lo pretendenralgunosiz naturalistas, que

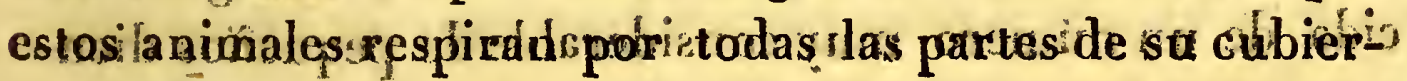

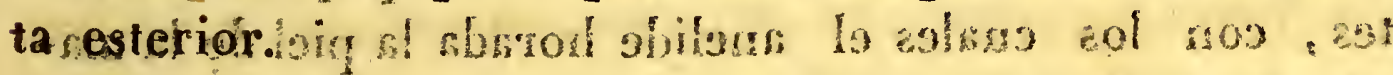

$\mathrm{El}$ modo de vivir de jla espécie icomán de éste! gél? nero es roneralmente conocido y se ehcuentra habitualmente en el aseno de das tierrás humedas y y tgrasas it iye prinçipalmente ęn sel iestiercolsomuy apodrido, en donis de pululai con muchá ábundancia. No s se manifiestá én la: superficie del suelossino despues de la dlavia cuando está segura de en'cońtrar da tierra mojada. Elige "con: preferencia estos sitios, en primer lugar porque de es mas fácil pràcticar alli sul shabitacion, y despuessporque halla en abundancian los nestós de máterías animales: de qne hace su principal alimènto Párá procurárse con mas facilidad / su subsistencia, este animal escava con-? tinuamente la tiérra por medio de su màndibula su-s perior, y arroja sus escombros fuera bajo La forma de cordones retortidos que anuncian siempre su presencia á los que la buscan. for otra parte no es dificil encon-1 


\section{$108 i$}

trarla; pues ade pras de queise presenta frecuentemente per sírmismą en la superficie del suelo, cuando el tiempo es favorable, se tiene siempre la seguridad de hacerla. salir de su guarida, metiendo una estaca en la tierrá imprimiéndola fuctes sacudimientos. Parece que el ruido ó el movimiento la espanta ó la incomoda, haciéndola temer la aproximacion de algun topo, su mortal enemigo, ó apretando demasiado el terreno.

§. II. Las sanguijuelas (hirudo) (fig. 9.) se distinguen gerieralmente de los demas anelides por la fal-') ta de de cerdas en los lados, y por dos ventosas que llevan en las estremidades de su cuerpo largo y estrecho. Por medio de estas ventosas es cómo principalmente se mueven arrastrándose en cieno; pero la de la parte anterior sirve ademas de boca ; está guarnecida de un número muy considerable de pequeños dientes, con los cuales el anelide horada la piel de la mayor parte de los animales para estraer su sangre.

-10 Las sanguijuelas, aunque muy voraces y carniceras, sufren muy facilmente el ayuno. Sin hablar de la abstinerícia que aguantan en el invierno, mientras permanecen inetidas en el cieno, se las ha visto vivir años enteros sin tomar otro alimento que las partículas de materias orgánicas contenidas en disolucion en el agua que se les daba; y todo el mundo sabe que las que se emplean para sangrar á los enfermos, no quieren volver á morder sino despues de un ayuno muy largo.

9 - Estos anélides se hallan en abundancia en casi todas las aguas estáncadas, $y$ aun á veces se hacen incómodas agarrándose á los ganados, que van á beber á las balsas que habitan.

Se cuenta un gran número de especies de este género, entre otras la sanguijuela medicinal (Hirudo 


\section{9}

medicinalis, $\mathrm{L}$ ) y la sanguijuela del caballo ó borriquera (hir. sanguisuga, L.). La primera es regularmente de color de aceituna mas ó meños claro, rayada de amarillento por encima, amarillenta manchada de negro por debajo. La segunda es mucho mas grande y de color negro verdoso. Algunas veces puede causar picaduras peligrosas. 


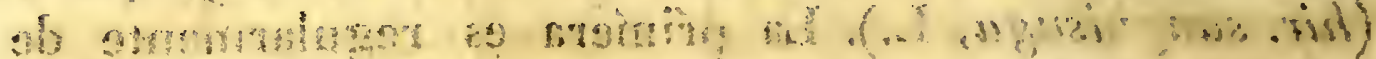

-

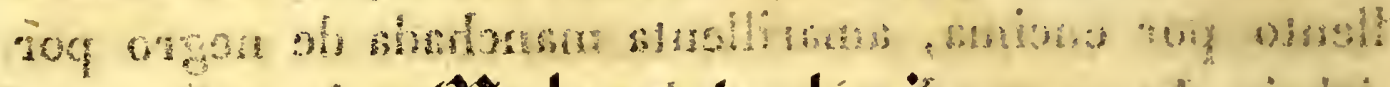

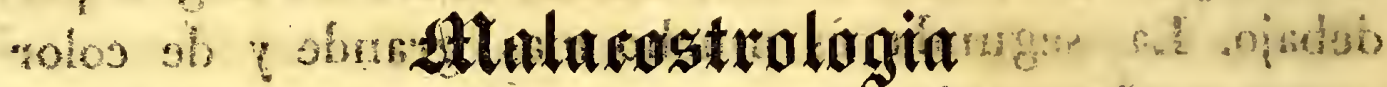

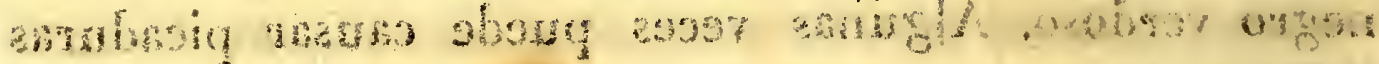
ó .2500130134

\section{HISTORIA NATURAL DE LOS CRUSTÁGEOS.}

I

dos crustáceos se comprendian antiguamente en la clase de los insectos, á los que se asemejan por los anillos y por la naturaleza córnea de su cubierta esterior, asi como por sus miembros articulados; pero se diferencian esencialmente de estos animales por su respiracion branquial y por su circulacion, á la cual concurren un corazon, arterias y venas. Ademas, el número de patas es siempre mas considerable en los crustáceos que en los verdaderos insectos, al paso que estos no tienen mas que tres pares, los primeros tienen cuando menos cinco en cada lado del cuerpo, y muchas veces mayor número. La piel de los articulados de que hablamos es por otra parte mucho mas sólida que la de los insectos; tiène el medio, por la dureza, entre la concha calcárea de los moluscos y la cubierta membranosa de los gusanos, orugas \&c.; y esta es la razon por qué los griegos habian dado á los crustáceos el nombre de malacostráceos, que significa concha blanda.

La naturaleza de esta cubierta inflexible se opondria al desarrollo del animal que está cubierto de 'ella, si este no tuviera la facultad de cambiarla; asi es que todos los crustáceos estan sujetos á una muda periódica, 


\section{1}

camò los ofidianos. Se dèsembarazan de su piel cuando esidemasiado pequeña para contener sucuerpo, $\mathrm{y}^{\prime} \mathrm{a}^{\prime}$ reemplazan por otra de una dimension apropiada á su magnitud: Y como en el momento en que estan despojados de ella se hallan espuestos á ser la presa de los' animàles mas peçueños que encontrasen, se ven desdel luego abligados buscar un abrigo inaccesible a sus enemigos, época crítica, ha preparado en lo interior de su estó-? mágo una provision de materia calcárea pronta á ser elaborada y á infiltrarse en los poros de la nueva piel.? De este modo esta adquiere en poco tiempo una dureza conveniente, y permite al animal salir mas pronto de su guarida,

Pon lo demas el cuerpo de los crustácéos se divide, como el de los insectos en cuatro partes distintas: la cabeza; el torax, el abdómen y los miembros.

La primera, que está algunas veces soldadä cón el torax, es sin embargo siempre fácil de distinguir por la presencia de cuatro antenas articuladas y muy movibles, por sus ojos, que unas veces son prominentes $y$ otras engastados en la cabèza; en fin por su boéa, que está las mas vecés formada de un gran númeró de mandíbulas.

El torax se confunde con bastante frécuencia , ya con la cabeza, ya con el abdómen. En el prímêr cásó no está formado superiormente sino de tina sola pieza llamąda coselete, como en los cangrejos de rio y ca la almohaza ; los anillos no son entonces marcadós sino en la parte inferior del cuẹrpo, $y$ cada uno dè ellós lleva un par de miembros; en el segundo caso, el Lor $\dot{a} x$ se compone de tántós anillos como pares de patas tiene, y la cabeza es siempre distinta de lo restatis te del cuerpo.". 


\section{2}

El abdómen ó vientre es la parte que se designa vulgarmente con el nombre de cola. En algunos crustáceos adquiere un volúmen considerable, y se halla guarnecido en cada lado de unos pequeños apéndices, que se llaman patas falsas (las langosias de mar, los langostinos); en otros es tan reducido, que es imposible distinguirle del torax, por egemplo, los cangrejos propiamente dichos. En todos casos contiene los principales órganos de la digestion.

Las patas hemos dicho que son siempre articuladas y en gran número. Este número es casi constantemente de catorce; únicamente sucede algunas veces, como en los cangrejos, que los primeros pares estan tan recogidos hácia la cabeza, que forman parte de la boca, y toman el nombre de pies-mandibulas; entonces no hay mas que diez, que sirven para la locomoción.

La figura de las patas es muy variable, é influye considerablemente en la especie de movimientos propios de cada especie. Las mas veces las primeras son en forma de pinza, y hacen las funciones de una verdadera mano, al paso qué las últimas estan trasformadas en aletas. Pero, por un lado, se hallan algunas veces un número mucho mayor organizadas, ya para lá prehension, ya para la natacion; y por otro, algunas especies tienen todos los miembros únicamente apropiados para andar.

Las costumbres de los crustáceos son generalmente acuáticas; no hay mas que un corto número que sean terrestres; pero unos viven en las aguas saladas, y otros en las aguas dulces, ya corrientes, ya estancadas, y parece que son muy raros sobre ta eleccion de su habitácion; porque es casi imposible habituar á los que viven en un punto á que permanezcan en otro que no se diferencia sensiblemente del que habitaban precedentemente. 


\section{3}

El régimen de estos articulados es muy carnicero, $y$ su alimento se compone principalmenie de materias animales corrompidas que ellos huelen desde muy lejos; por consiguiente su conducto intestinal es poco desarrollado, yesin embargo su hígado es generalmente considerable, y su estómago está guarnecido de unas piezas duras, destinadas evidentemente á triturar los alimentos.

Los crustáceos se multiplican por medio de huevos; la hembra los deposita á veces en el agua; en donde empollan con la influencia de la humedad; pero en algunas especies se halla debajo de su cola una bolsa particular, en la que permanecen hasta su nacimiento. Todo el mundo sabe que en ciertas épocas se encuentran huevos debajo de la cola de los cangrejos que se comen; $y_{0}$ aun parece que entonces su carne no es tan sana como en las demas estaciones.

Se conoce un número bastante grande dè crustáceos, que se dividen en tres órdenes.

1. Unos tienen una cubierta dúra y calcárea, de diez á catorce pies articulados y locomotores, dos ojos bien distintos y sostenidos por un pedículo movible; estos son los pedioclos (los cangrejos de riv y los nadadores).

2. Otros tienen la cubierta y los pies de los precedentes; pero sus ojos, que son tan perfectamente distintos como en estos, estan sentados (sbssiles), es decir, colocados al nivel de la cabeza; se llaman hedriuftalmos, nombre griego que quiere decir ojos sentados ( los talitros, los cloportes).

3. Por fin, otrós tiencn la cubierta generalmente delgada y córnea, las pates nátatorias y aplastadás en su estremidad, y las mas veces un solo ojo, ó cuando tienen dos, sus patâs son mas de veińte, estos son los entomosirríceos, animales estravagantes ó microscópicos.

Tono IIr. 


\section{PRIMER ÓRDEN.}

\section{PEDIOCLOS.}

Los crustáceos de este primer órden se distinguen de los siguientes; no solo por el pedículo movible que -sostiene los ojos, sino tambien por otros muchos caractéres importantes. Son los únicos de todos los animales de su clase que tienen la parle superior del cuerpo cubierla de un verdadero escudo que no deja libre mas que la cola; son los únicos tambien que tienen uno ó muchos pares de patas terminadas en pinzas, ó con un dedo morible, del cual se sirven para agarrar su presa. Los músculos que ponen en movimiento á este dedo son tan vigorosos, que se han visto langostas y otros cangrejos de mar de gran magnilud agarrai con su pinza á una cabra por la pata, y llevársela consigo á pesar de su resistencia.

Es muy dificil arrancarles lo que cogen, en razon de que su dedo movible está armado por su borde interno de dientés prominenies que encajan en unas ranuras análogas del dedo fjo.

Todos los pedioclos son voraces y crueles, dotados la mayor parte de una fuerza muscular considerable, provistos de una pinza robusta, de mandibulas fuertemente armadas y de un estómago guarnecido de partes duras y cortantes, tienen apetitos carniceros y los medios de satisfacerlos. Unie ndo la astucia á la violencia, unas veces aguardan á su presa en guaridas que encuentran entre das peî́as , o tras la persiguen á nado ó corriendo y la vencen á viva fuerza. La disposicion de sus ojos, que pueden hacer salir ó retirar en su estuche, por razon de la movilidad de su pedículo, les permite idistinguêr sus victionas desde lejos al mismo 


\section{5}

tiempo que los hace menos vulnerables en los combates que pueden tener contra los animales de que se alimentan.

Se divide este órden, el mas numeroso de la clase, en tres familias: los braquiuros, los macrouros y los estomapodos.

\section{PRIMERA FAMILIA.}

\section{BRAQUIURos. (Lám. $X X X I I$.}

Se conocen fácilmente los crustaceos de esta familia por la cortedad de su cola, siempre desprovista de aletas en su estremidad y constantemente recojida, en el estado de quietud, en una fosita situada debajo del torax. Su escudo es generalmente aplastado, yan largo cotho ancho; sù cabeza está enteramente confundida con el, escepto en la parte inferior en donde és facil distinguir la separacion. Estos son, en una palabra, todos los crustaceos que se designan vulga rmente con el nombre de cangrejos propiamente dichos (fig. 1), pu

Todos estos animales viven en el mar y permanecen generalmente á poca distancia de las costas probablemente porque alti encuentran en abundancia los moluscos y los cadáveres de que se alimentan poincipalmente. Pero aunque son esencialmęnte acuáticos por la naturaleza de sus órganos respiratorios, pueden permanecer en tierra por un tiempo considerable. Sus branquiàs que están siempre colocadas en una cavidadformada por el borde laterál del escudo, conserván con tanta mas facilidad la húmedad, cuanto que estan casi enteramente preservadas del contacto del aire atmos. férico.

Tan valientes como voraces, estos animales se entregan con frecuencia entre sí combates sangrientos por la 


\section{6}

posesion de algún troźo de carne corrompida. En estas batallas, siempré reñidas, pero rara vez mortales, se arrancan muchas veces las patas y aun las piuzas. Pero estas mutilaciones se reparan prontamente; despues de algunos dias de retiro, se presentan con nuevos órganos, que reemplazan á los que habian perdido. Tambien se esconden, cuando sufren su muda, lo que sucede todos los años en.la primavera.

La carne de los braquiuros, aunque indigesta, es bastante buena de comer. Se observa que su coselete toma por la coccion un hermoso color rojo, fenómeno que es debido á la infiltracion de un fluido sutil, que penetra ei los poros de sus tegumentos á medida que son dilatados por el calórico.

Esta familia no comprendia antiguamente mas que un solo género; pero de algun tiempo á ésta parte se ha aumentado de tal modo el número de éspecies, que para no confundirse entre tantos seres diferentes, ha sido preciso subdividirla en muchos géneros. Se cuentan mas de cincuenta; de estos los mas principales son los portunos, los cangrejos propiamente dichos, los pinnoleros y los dromias.

S.I. Los porín ós ó almohazas (portunus) bacen parte de una tribu de esta familia que se han llamado cangrejos nadadores, (fig. 1.) porque como tienen un cierto súmero de sus patas terminadas en áletas, nadan con mas facilidad que los demas, yo temen alejarse de la orilla y arrostrar á la alta mar; se han encontrado muchas veces algúnos de ellos en medio del Océano que separa á la Europa de la América. Sin embargo observamos que no todos son tan atrevidos; hay bajo esta consideracion grandes diferencias que dependen del mayor ó menor número de pies transformados en aletas. Unos tienen todos estos apéndices organizados de 
T.LIT. PFDIOCLOS, HEDRLOE'TALMOS, ATFIPODOS. ' : P. PE

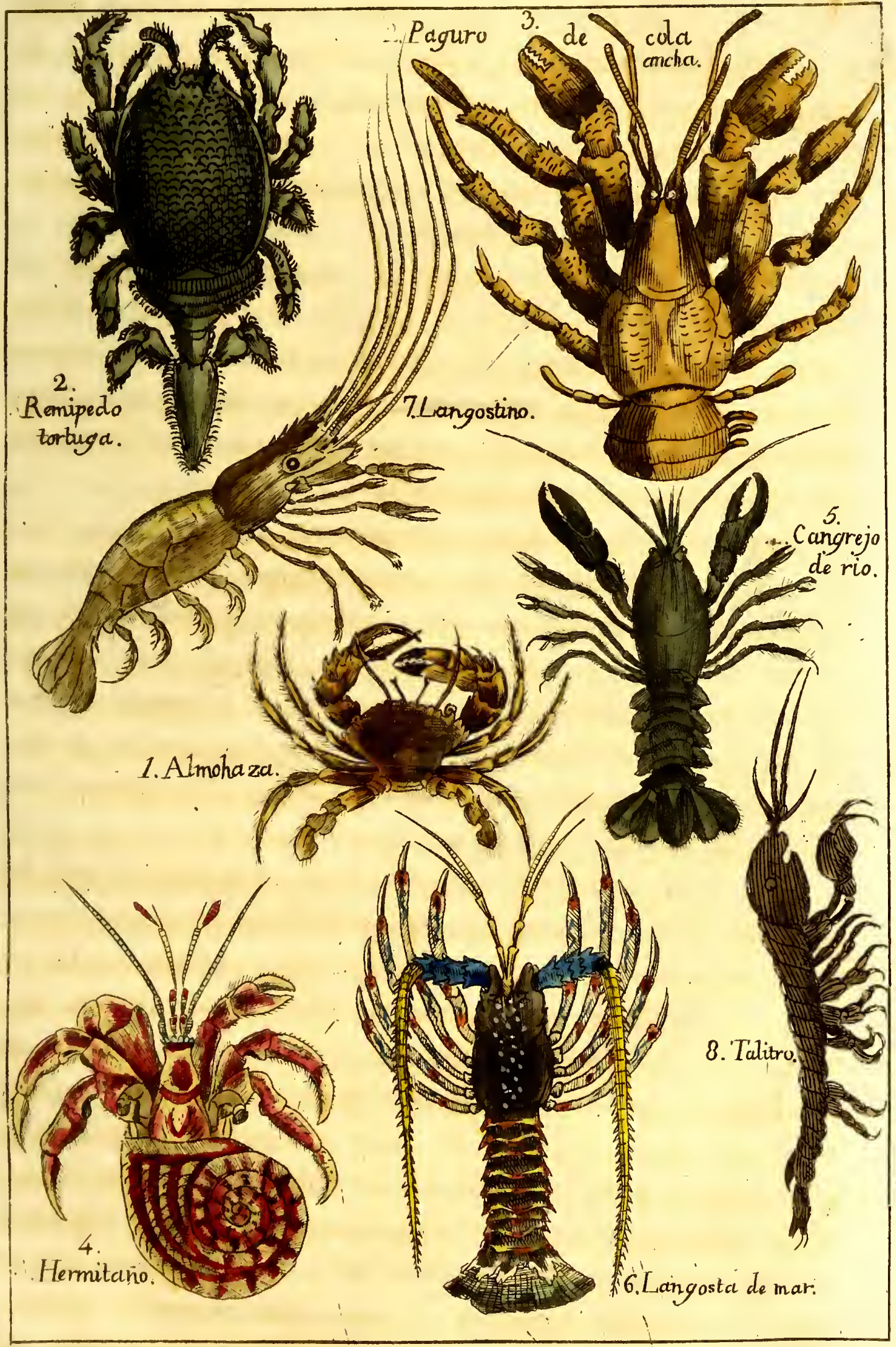

ARTICUIAADOS.

L.XIYII.

CRUSTACROS 

este modo, á escepcion de las pinzas; y se conoce bien que deben nadar mejor que los otros, que no tienen mas que los dos posteriores propios para la natacion. Los portunos ó almohazas se hallan en este último caso; asi es que aunque algunas veces se arriesguen á introducirse en alta mar, permanecen mas comunmente cerca de las costas, en donde los pescadores los cogen en gran número. Se encuentran en casi todos los mares; los de Francia pasan por muy delicados, principalmente la almohaza comun (cancer puber, L.) (fig. 1). La pequeña almohaza (cancer corrugatus, L.) es menos abundante. Tambien hay otros portunos exóticos que se distinguen por tener de seis á nueve dientes á cada lado tal es el portuno de Tranquebar (P.tranquebaricus.)

§. II. Los CANGREJOS propiamente dichos (cancer) pertenecen á una segunda tribu, que se difereacia de la precedente por la figura de los pies que se terminan en punta y jamas en aleta. Asi es que no solamente nadan menos que los portunos sino que tambien son, por decirlo-asi, menos acuáticos; porque salen frecuentemente del agua, para ir á la orilla á buscar los cadáveres que el mar arroja de su seno, y alrededor de los cuales se reunen como los cuervos, los buitres, las gaviotas, \&c. lo que es causa muchas veces de contiendas sangrientas. Pero si los verdaderos cangrejos nadan mal, andan con agilidad, ya en el fondo del mar ya en sus orillas; es un gusto verles menearse para correr, cuando ven una presa que puede disputarsela algun rival.

Esta segunda tribu de braquiuros presenta, ademas del carácter de sus pies, el de su coselete cuyo horde anterior es redondeado en forma de arco de círculo y el posterior truncado, lo que ha hecho dar á las. especies que comprende el nombre decangrejos arqueados: 
Aunque todos los mares crian cangrejos de este género, son mucho mas abundantes en los mares intertropicales que en los templados: tambien alli están pintados de colores mas vivos y llegan á una magnitud mucho mayor. Sin embargo nuestras costas los crian tambien muy grandes, y cuya carne es muy estimada; tales son el menas ó cangrejo comun de nuestras costas (can. manas, L.) llamado tambien cangrejo rabioso y que se listingue por tener cinco dientes á cada lado, y otros tantos en la frente, comprendidos los oculares internos; y el escudado, que otros llaman la torta (can. paragus, L.) que tiene nueve fesiones en cada borde lateral $y$ tres dientes en la frente. Es animal que llega hasta cerca de un pie de ancho, yentonces pesa hasta cinco libras; sú carne es muy estimada.

§. III. Los PINNoteros (pinnothera) corresponden á la tribu de los cangrejos orbiculares; son unos pequeños crustáceos, cuyo coselete es redondeado y cuyas patas son todas apropiadas para andar.

Todos son de poca magnitud y llaman la atencion por sus costumbres. Pasan la mayor parte del año en el mar; pero durante el otoño se recogen en diversas conchas bivalvas, principalmente en las almejas y los jamóncillos. En virtud de la observacion de este hecho, los antiguos creian que vivian en sociedad con estos moluscos, los avisaban del peligro é iban á cazar para ellos. En el dia se atribuyen á su presencia en las almejas 10 s accidentes que se manifiestan algunas zeces en las personas que han hecho uso de estos moluscos. Es probable que esta última suposicion tenga tan poco fundamento como la primera, y que los pinnotenos no tengan tnas cualidades dañosas para los jamoncillos y las almejas que la adherencia que contraen con ellas. Por 10 demas , se ignora absolutamente cual pueda ser el obje- 
to de estos crustáceos al meterse de este modo en lo interior de las conchas.

§. IV. La palabra GeCAncino (gecarcinus) es de origen griege y significa cangrejo terrestre. Este género está comprendido en la numerosa tribu de los braquiuros, que se han llamado cuadrilateros, por razon de la figura de su coselete; lo que unido á la organizacion de sus pies terminados en punta, basta para distinguirlos de todos los demas géneros de la misma familia.

Eslos crustáceos son muchio mas terrestres que ninguno de los demas animales de su clase; no temen el salir á muchas leguas de distancia del mar, y viven mucho tiempo en parages en donde ni aun se ve el agua. Pero, á pesar de estas costumbres es muy dificil que puedan pasar sin ella; evilan siempre los lugares secos y áridos para buscar los pantanosos; y para ponerse mejor al abrigo de la sequedad que tanto temen, tienen cuidado de fabricarse unas madrigueras, en las que siempre tienen mas frescura, y en donde muchas veces se sumergen casi enteramente en el agua. No salen de esta guarida sino durante la noche ó en tiempos lluviosos, y únicamente cuando les obliga á ello la necesidad de alimentarse: como son voraces y carniceros, se establecen con preferencia en los cementerios, en donde tienen abundantemente con que satisfacer su apetito.

Uno de los bechos mas curiosos de la historia de estos animales es el viage anual que hacen hácia las orillas del mar. Reunidos en tropas innumerables, dejan su habitacion terrestre, y se dirigen en línea recta hácia el punto de su viage. Su instinto es tan seguro, que nada puede hacerles desviar de su camino: atraviesan los rios, escalan. las casas y las peñas, $\mathbf{y}$ allanan todos loś obstáculos que tienden á hacerlos desviar de la línea recta. Una vez llegados al término de su carrera, depo- 
sitan allí sus huevos, vuelven pasos atras sin pararse, y llegan á sus madrigueras tan flacos y estenuados, que necesitan mucho tiempo para reparar sus fuerzas. La especie mas comun es el gecarcino de los campos (cancer ruricola, L.), de color rojo de sangre mas ó ménos vivo, algunas veces manchado de amarillo, y con una impresion muy marcada en forma de $\mathbf{H}$.

§. V. Los Dhomias ó cangrejos tortugas (dromia). hacen parte de una pequeña tribu de los braquiuros, que se han llamado notopodes (pies sobre el dorso), porque tienen los cuatro ó los dos últimos pies insertos encima de los otros, y casi sobre el dorso, de modo que parece que miran al cielo.

Esta disposicion singular, unida á un doble gancho en que terminan ordinariamente estos pies, les da costumbres diferentes de las de los demas cangrejos. Dotar dos de una agilidad rara entre los crustáceos, agilidad que les ha valido el nombre de dromias, que significa corredores, persiguen á los zoófitos ó á los mariscos para acomodarse sus despojos sobre el dorso, en donde los sujetan por medio de sus patas dorsales. El alcion; especie de zoófito que se parece á la esponja, es una de sus victimas favoritas; estan casi siempre cubiertos de ellos, $\mathrm{y}$, cosa singular; á pesar del estado de mortificacion en que debe hallarse el animal, no cesa de vivir $y$ desarrollarse, de suerte que al cabo de cierto tiempo forma alrededor de estos crustáceos una coraza, tanto mas súlida, cuanto que es organizada y viviente.

Los dromias se hallan esparcidos én las costas orientales del Océano Atlántico y en las septentrionales de Africa; en el invierno se ocultan en la arena, y en el verano se pasean por el cieno y las rocas del fondo del mar. Se cuentan murbas especies de ellos, de las que las mas conocidas son: el dromia comun (cancer dro- 


\section{1}

mia, L.), que se tiene por venenoso, y el dromia calavera (cancer caput mortuum, $\mathrm{L}_{0}$ ) b mas pequeño y convexo que el anterior, y con la frente corta, escotadá en el medio iy sinuosa lateralmente.:

\section{W SEGUNDA FAMILIA. \\ MACRỏynos. (Lám. XXXIF.)}

Se ha dado el nombre de macrouros á los crustáceos de esta familia por razorg de la longitud de isu cola, ó mas bien de su abdómen, que forma siempré á la otra parte del torax una emineureia considérable ; tales son la langosta de mạcy el cangrejo de rio.?

Quizáa admirárá el ver reunidos anos animales tan diferentes parsous formasicomo dos çangrejos propia mente dichos, y los de rio ; pero por poco que se idom, pare su estructura interną n aun únicamente sus órganos esteriones, se verá que estas dos especies de crustáceós tienen tos mismosyearacténes, las mismas costumhres y el mismó género de vidai

Unos y otrós tienen la cabeza cónfúndida con el torax, los ojos pediculadós y retractileŝ en su órbita, cuatro antenas articuladas, movibles y dotadas de una sensibilidad esquisita, diez patas ambulatoriás ú locomotrices, de las que las dos anteriores se terminan en pinzas, y das demas unas véces son apropiadas para andar, otras aplastadas en forma de alétas. En torles la boca es muy complicada, porque en ella se encuentran dos mandí bulas con dos palpos, especies de antenas destinadas probablemente á la gastacion de los alimentos ". cuátro mandíbilas y seis pies mandibúlas, en! fnetodos los ón"ganos de la circulacion, la respiracionr, la sensibilidad y Ja digestion son absolutamente iuénticos. 
Las principales diferencias de los macrouros se limitan puesifí tener el cuérpo mas largo, el coseleté mas ancho, el vientre mas grueso, y la estremidad de esta última parte terminada por unas laminitas cónrneas que la trasforman en una aleta poderosa. Sus antenas son tambien generalmeñte mas largas y movibles. (fig. 3 y 4.)

Pero estas diferencias son muy poco importantes para modifican sus costumbres ycrégimen. Asi es que los macrouros son, como los precedentes, la mayor parte marinos, y todos acuáticos, aunque pueden vivir bastanté tiempo fuera del agua, son igualmènte voraces $y$ carniceros.

Se divide esta familia, como la de los braquiuros, en un gran número de géneros, que corresponden á diferentes tribus. Los mas notables son los remipedos, los paguros, los cangrejos comunes las langostas y los langostinos:

- \$. I. Los REMIPEDos (remipes) (fig. 2.) tienen los pies anteriores prolongados con la úlıma articulacion comprimida vellosa las anterias muycortas o proximadas y casi de la misma longitud; los pedículos oculares son muy cortos y cilíndricos; los pies mándíbulas esteriores en forma de pequeñas garras, adelgazadas, arqueadas en là punta y tér minadas en uiv ganchó; su coselete es casi ovoideo, truncado en las dos estrémidades y convexo. $\mathrm{El}$ primer segmento de la cola suele ofrecer dos líneas trasversales. Se conocen dos especies de este género; uná de los mares de la Nueva Holanda, el remipedo tortuga, (remipes destudinarius), cuya cola es blanda y en forma dé saco; y la otra de las Antillas y de la costa del Brásil. §. I. Aunque los Paguros (pagurus) pertenecen evideritemente á la familia de los macrouros, tienen la cola más corta que la mayor parte de los demas animales que esta encierra jeste órgano no es mas largoique 
su coselete; carácter qué, unido á sus patas anteriores terminadas en pinza y á la blandura de sus tegumentos, basta para distinguirlos de todos los demas géneros de la miśnà fámilia.

Nada hay mas singular que las costumbres de estos crustáceos. Como su cubierta es demasiado débil para preservarlos de los choques esteriores, necesitan apropiärse la concha de algunos moluscos, en la que se meten casi enteramente, á escepcion de sus pinzas. Por razon de la costumbre que tienen de vivir asi en una habitacion prestada, les han dado el nombre de ermitaños, Diógenes, soldados, porque los han comparado á un religioso en su relda, al filósofo cínico en su tonel, á un centinela en su garita:?

Es casi imposible imaginarse los trabajos que pasan los paguros para procurarse esta habitacion prótectora, los esfuerzos que tienen que hacer para establecerse en ella, los péligros que corren por parte de sus enemigos, que aprovechan este momento de debilidad para atacarles, $\mathrm{y}$ los combates que tienen que sostener para disputarla con los semejantes suyos que quieren apoderarse de ella en su perjuicio. Aun sí les sirviera para siempre podrian consolarse de la dificultad de adquirirla con disfrutarla por mucho tiempo; pero como su cuerpo crece sin cesar, se ven obligados á cambiar todos los años de habitacion, volver á empezar sus maniobras y correr los mismos peligros.

Estos crustáceos son comunes en nuestros mares; en el invierno viven en las aguas profundas ó en las concavidades de las rocas; pero durante el buen tiempo permanecen á lo largo de las costás, y aun sé pasean por la orilla, Este momento se aprorecha para pro curarse aquellos que se necesitan paralla pesca ó para el consumo; porque son buenos de comer y húcen aiz 
escelénte cho: Tambiènósuministran ui aceite que pasa por calmantecenslas a fécciónes lreumáticas. Pero muchas veces en el moménto mismo en que se crec tenerlos cogidos, se dejan rodar al mar, y escapan asi de la mano que iba á cogerlos: Las principales especies son el págurd de cola ancha (pag. làticauda) (fig.3.) , y el ermitaño Bernardo (can. Bernhardus, L.) (fig. 4.)

§.III. Los Cangriejos comunes (astacus) (fig. 5.) forman el principal género dè una tribu numerosa, á la que se ha dado el nombre de astacianos. Se distinguen de los paguros por su cola dos veces mas largá que su coseleté, y de los demas crustảceos de cola larga por las pinzas en que terminan sus tres primeros pares de patas, asi como por la disposicion de sus antenas, que estan colocadás en urä línea recta horizontal.

Estos cangrejos són los crustáceos mejor conoçidos y mas comunes de la familia; se encuentran igualmente en las aguas dulces $y$ en los mares, $y$ todas las especies son buscadas como alimento, aunque su carne es un poco indigesta. Tienen el carácter tan tímido, que á pesar de suvoracidad, abandonan su presa luego que yiene á asustarles el menor ruido; asi es que los pescadores que les tiendén lazos se ven obligados á observar un profundo silencio si quieren hacer una presa abundante. Se cogen en grandes cantidades colocando un trozo de carne corrompida en medio de un haz de ramas atadas flojamente. Los cangrejos se enredan queriendo ir morder el cebo, de suerte que cuando se saca el haz está casi enteramente cubierto de ellos.

Se distinguen dos especies de cangrejos; los de agua dulce, que son tan comunes por todas partes, y los de mar ó cabrajos, que son mucho más gruesos', y de los que algunos individuos tienen algunas veces veinte pulgadas de longitud. 
§. IV: Las Langostas (locusta) (f. 6.) tienen las mayores relaciones con los cangrejos còmunes, de los que no se diferencian sino por la falta de pinzas en todas! sus patas, escepto alguna vez en el últiono par. No tienen ninguno de sus pies terminado en aleta, $y$ sin embargo nadan con bastante facilidad para permanecer en alta mar durante la mayor parte del año, Su cola vigorośa y ensanchada en su estremidad reemplaza á las patas nectoides de los cangrejos nadadores, y aun produce mucho ruido en los movimientos que hace el animal para nadar.

En la primavera las langostas se aproximan á las costas para hacer en ellas su postura; sus huevos, que son de un hermoso rojo, forman por su reunion una especie de tronco, al que se da el nombre de coral. La hembra los lleva por algun tiempo debajo de sú cola, y los deposita despues sobre alguna roca, en donde no tardan en empollarse y romperse. En esta época es cuando se pescan estos crustáceos, cuya carne es es celente. Las hembras son entonces mas buscadas que los machos, al paso que en las demas estaciones son estos últimos los que mas se estiman; esta preferencia es debida al gusto que los huevos comunican á su carne. Terminada la postura, las langostas vuelven á ocupar la profundidad de las aguas jara hacer su muda. Para este objeto se retiran á los agugeros de las rocas, para éstar menos espuestás á la vista de sus enemigos. Del mismo modo se esconden durante el ińvierno, á fin de preservarse del frio.

Estos macrouitos son comunes en todos los mares templádós ó intertropicales; generalmente son muy grandes, y tienen frecuentemente un pie de largo; en lo's paises cálidos se han encontrado á veces individuos de 
mas de dos pies de largo, y que pesaban hasta quiṇce libras.

5. V. Los IANGostinos ó salicotes (caris) (fig. 7.) son fáciles de distinguir de los macrouros precedentes por la disposicion de sus antenas, de las cuales las dos medias estan situadas mas arriba que las laterales. Su cuerpo es combado, como giboso, y de una consistencia menor que en la mayor parte de los demas crustáceos.

Todos estos animales son marinos y muy buenos nadadores. No es raro encontrarlos en los rios, á gran distancia del mar; pero su permanencia en esta agua dulce no es sino momentánea, y no tardan en volver á su habitacion favorita.

Se hace un' gran consumo de langostinos en todas las partes del mundo, aun se salan algunas especies á fin de conservarlas. Los de nuestras costas, que son generalmente pequeños en comparacion de los de los mares meridionales, se pescan en todos nuestros puertos de mar, y los llevan muchas veces á nuestros mercados. Este género numeroso se divide en muchos subgéneros, de los que los mas importantes son los cardos ó cardones y los palemones, que se comen igualmente; pero los segundos son mas buscados como alimento. Entre los primeros se distingue el cardon comun, $\mathrm{y}$ apenas tiene mas de dos pulgadas de largo. Es de un color verde de agua marina moteado de pardo y liso. Se pesca todo el año con redes. Su carne es muy delicada. Entre los segundos citaremos el palemon esquila ó camaron (cancer squilla) (fig.7.), que tiene una especie de cuerno frontal que apenas escede el pedúnculo dé las antenas superiores; es casi recto ó poco encorvado, cón siete ú ocho dientes encima y tres debajo. Los dedos de 


\section{7}

las garrás ison un poco mas largos que la mano. Es comun. en nuestras costas.

\section{TERCERA FAMILIA.}

\section{ESTOMATOPODOS.}

Esta familia no se compone mas que de un corto número de crustáceos, fáciles de distinguir de los precedentes por la conformacion de su cabeza, que está separada del torax, y por el número de sus patas, que es constantemente de catorce; únicamente los dos primeros pares, muy próximos á la boca, pueden servir igualmente para comer y moverse; y por razon de la posicion de estos pies, se hau llamado estos animales estomatopodos (pies en la boca). Otra diferencia que distingue á estos últimos de los demas pedioclos es que sus branquias se hallan á descubierto y pegadas á las patás falsas que llevan debajo de la cola ó abdómen. Su cosèlete está dividido en dos partes, de las que da anterior cubre la cabeza, $\mathrm{y}$ la posterior el torax. Sus tegumentos son por otra parte delgados y casi membranosos; y aun trasparentes, lo que los espone á mas peligros que los demas crustáceos, y los obligá á permanecer en la profundidad de las aguas mejor que en las cercanías de lás costas.

El principal género de esta familia es el de las esquilas (squilla), cuyo coselete se adelanta hasta la cabeza de modo que la cubre casi enteramente, á escepcion de las antenás y de los ojós. Su cuerpo es geuéralmente delgado, fuo, y se asemeja por su forma abovedada, al aspecio de los mantos, cuyo nombre llevan en algunos paises. Tambien los llaman suplicantes (ruega á Dios), porque tienen el ademar de juritar sus pa- 


\section{8}

tas como un suplicante que implora a la Divinidad.

Estos estomatopodos son muy comunes en el Mediterráneo y en los demas mares vecinos al ecuador; pero son raros en el Océano Atlántico, y principalmente en el mar del Norte Por todas partes se les busca como alimento, y los antiguos hacian de ellos un caso particular. Todos saben la historia de aquel Rómano, qué habiendo oido hablar de las esquilas magníficas que se pescaban en las costas de Sicilia, hizo aprestar un navio para asegurarse del hecho; pero no habiéndolas hallado superiores en grosor á las que se encontraban en Italia, se volvió atras sin desembarcar.

\section{SEGUNDO ÓRDEN.}

$25 \%$ eot HEDRIOFTALMOS.

5. A

Na solo se distinguen los hedrioftalmós de los crustáceos precedentes porque careoen de aquel pedículo movible y articulado que sostiene los ojos de los pedioclos, sino que su estructura presenta ademas otras muchas particularidades notables, que no permiten confundirlos con ellos Su cabeza es siempre bien distinta del tronco; su torax presenta superiormété, en vez de una pieza única, de cinco á siete anillos articulados en̉tre si, de suẹrte que seria imposible encóntrar la linea de separacion entre esta parte ý el abdómen sin la presencia de las patas que caracterizan á los segmentos torácicos y faltan á los del abdómen. Sus pies son siempre lo menos en número de catorce, y no presentan nunca en su estremidad aquellas pinzas vigorosas, que hemos hallado en casi todos los pedioclos. Sus costumbres son tambien menos acuáticas, y muchos no van 
jamas al agua; la humedad de los sitios en que se establecen les basta para la respiracion.

Todos los hedrioftalmos son muy fecundos; las hembras llevan sus huevos en una bolsa que tienen debajo del pecho y los conservan en ella no solamente hasta su nacimiento, sino tambien hasta que los hijuelos han adquirido bastante fuerza para poder mirar por sí.

Este órden se puede dividir en dos familias: los anfipodos y los isopodos.

\section{PRIMERA FAMILIA.}

\section{A N I PODOS.}

Los anfipodos tienen todavía algunas relaciones con los crustáceos, que hemos estudiado hasta de aqui, por la figura general de su cuerpo, escepto que no tienen coselete sobre el dorso y que sus primeras patas no tienen, en vez de pinzas, mas que un simple gancho; llevan tambien antenas en la cabeza y palpos en las mandibulas. Sus costumbres son enteramente acuáticas, y la mayor parte de ellos nadan y saltan con mucha facilidad, pero siempre de lado. Algunos se encuentran en los arroyuelos y fuentes; pero la mayor parte habitan las aguas saladas.

A esta familia corresponden los géneros siguientes: las pulgas de mar, los corofios y los talitros.

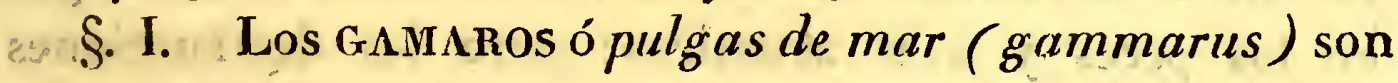
unos pequeños crustáceos cuya magnitud no pasa de algunas líncas, y cuya figura se asemeja á la de una pulga, lo que ha hecho que se conozcan con este nombre en la mayor parte de nuestras costas. Por consiguiente viven en el agua, y las mas veces en el mar, en donde son muy abundantes. Su cuerpo es tan comprimido Tomo III. 
lateralmente, que no pueden andar derechos y se ven obligados para moverse por tierra, á echarse de lado; pero cuando nadan entre dos aguas, toman la posicion natural á todos los demas crustáceos.

Tenemos una especie muy comun en los arroyuelos, el gamaro propiamente dicho, ó cangrejo pulga, (cancer pulex, $\mathrm{L}$ ).

§. II. Los corofros (corophium) forman un género tan notable por su organizacion como por sus costumbres. Su cuerpo casi filiforme, está sostenido por unos pies esclusivamente ambulatorios, y se termina anteriormente por dos enormes antenas muy fuertes, que parecen servirles como órganos de prehension.

Estos crustáceos, á pesar de su poca magnitud; son de una audacia sorprendente; reunidos en tropas numerosas, atacan á animales diez y veinte veces mayores que ellos; hacen principalmente una guerra continua á las nereidas, á los arenícolas y á otros anelides que viven como ellos en el mar; y cosa sorprendente, su obstinacion y su valor concluyen casi siempre por triunfar de estos enemigos.

Es muy curioso el ver á estos pequeños crustáceos como, cuando sube la marea, revuelven el cieno con sus largas patas, y lo vuelven todo de arriba á abajo, procurando descubrir su presa oculta. Muchas veces se introducen en las ostreras y devoran cantidades innumerables de ostras. A su vez tienen muchos enemigos en los peces y aves acuáticas; pero las destrucciones que de ellos bacen no disminuyen sensiblemente su número; su fecundidad reemplaza prontamente á los que han sido devorados.

§. III. Los talitros (talitrus) (fig. 8.) no tienen ningun pie en forma de garra y la tercera articulacion de las antenas inferiores es mas larga que las dos an- 



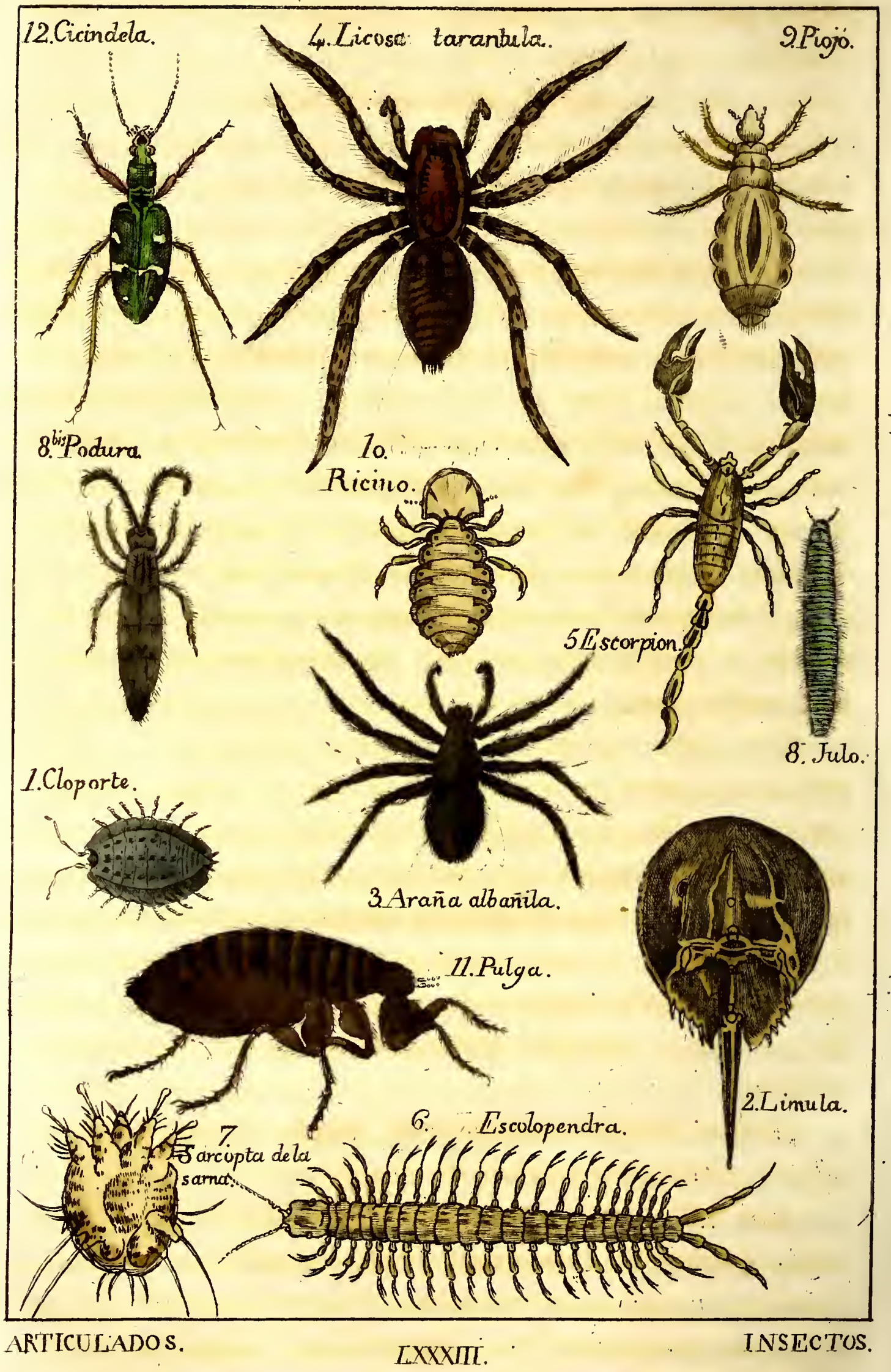


teriores; estas antenas son grandes y espinosas. Las primeras piezas de los últimos pares de patas son muy grandes.

\section{SEGUNDA FAMILIA.}

\section{ISOPODOS.}

La palabra isopodos, que en griego significa pies semejantes, conviene perfectamente á los crustáceos de que hablawos que tienen todas sus patas de la misma fi-, gura, al paso que en las familias precedentes, uno ó muchos pares se distinguen de los demas, por la existencia de una pinza ó de un gancho en su estremidad. A este carácter se reune la falta de palpos en las mandíbulas, la posicion de las hojas branquiales debajo de la. cola, y la figura de su cuerpo que es aplastado horizontalmente y compuesto en toda su longitud de unos anillos uniformes.

De estos animales, unos son terrestres y otros acuáticos; pero los primeros buscan los lugares obscuros y húmedos, en donde la atmosfera les suministra el agua suficiente para: que sus branquias puedan llenar sus funciones. Hay una diferencia entre los isopodos de tierra y los de agua, y es que los primeros parece que se alimentan indistintamente de materias regetales ó animales, al paso que los últimos son esclusivamente carniceros.

Todos los animales de esta famila se pueden reunir bajo el nombre genérico de cloportes.

Los cloportes (oniscus) (lám. XXXIHI. fig. 1.) son unos pequeños crustáceos muy conocidos de todo el mundo, $y$ que se encuentran en gran número en las bodegas, almacenes: $y$ en general en todos los lugares húmedos y abscuros. Rara vez se presentan á la luz dél 


\section{2}

dia. Fijados constantemente en las paredes y en los largueros de las puertas, se asemejan, por su forma redondeada y por su color gris de hierro, á unas cabezas de clavos metidos en la madera, lo que les ha hecho dar el nombre de Cloportes, ó clavo en las puertas.

Es tal su apatía que permanecen inmóviles en esta posicion por muchas horas consecutivas, y cuando se mueven no lo hacen sino con lentitud, á menos de que no se vean perseguidos por algún enemigo; en este caso se menean mucho $y$ corren con bastante velocidad.

Estos animales son estremamente voraces; todo alimento es bueno para ellos; los frutos que se caen, las hojas de algunas plantas, la corteza de los arboles, los insectos, la carne fresca ó corrompida todo parece serles indiferente. Roen, y despedazar todas las sustancias orgánicas que están á su alcance; y aun en los casos de escasez se atacan entre si, y los mas fuertes devoran á los mas débiles.

Este género comprende dos subgéneros; de los: cuales unos, los verdaderos cloportes, jamas se arrollan en forma de bola, al paso que los otros llamados armadillos. tiencn estafacultad, y usan de ella muchas veces cuando se ven cogidos.

\section{TERGER ÓRDEN.}

\section{ENTOMOSTRÁCEOS.}

- Este órden comprende un gran número de crustáceos acuáticos, de los que la mayor parte estan esparcidos á millones en nuestras balsas y estanques, en donde su pequeñez nos impide que los veamos. En efecto, son tan pequeños que se necesita del auxi-? 


\section{3}

lio del microscopio para distinguirlos. Algunas especies estrangeras son las únicas que presentan una magnitud mas considerable.

Por lo demas, sean grandes ó pequeños, s e conocen por su cabeza indistinta, por sus ojos inmóviles, aproximados y aun á veces confundidos entre sí, lo que les habia hecho dar antiguamente el nombre comun de monoculos (ojo único). Sus patäs posteriores, aplastadas en forma de ligeros remos, sirven igualmente para la natacion, $y$ su boca está unas veces formada de mandíbulas sin palpos, otras de una trompa propia para chu par; en este último caso, el animal vive como parasito sobre el cuerpo de otrós animales acuáticos.

Los entomostráceos nacen generalmente con una forma diferente de la de sus padres; y no llegan á la que les es propia, sino despues de muchos cambios $\ddot{o}_{3}$ metamorfósis sucesivas que se han comparado á las de, los insectos. No citaremos de este órden mas que dos familias: los branquiopodos y los xifosuros.

\section{PRIMERA FAMILIA.}

\section{BRANQUIOPODOS.}

Esta familia comprende una multitud innumerable de crustaceos, la mayor parte miscroscópicós, que Linneo reunia en un solo género, cuyo cárácter distintivo consistia en la conformacion de sus pies, siempre aplastados en forma de nadaderas, y sirviendo al mismo tiémpo para la locomocion y la respiracion.

Todos estos animales son esencialmente acuáticos y muy comunes en las balsas, los arroyuelos y aun en los mares. Aun las aguas mas puras contiènen milláres de ellos, que nosotros tragamos muchas veces sin co- 
nocerlo. Se ve cual debe ser la fragilidad y sutileza de los órganos de unos seres tan pequeños: pero lo que es mas difícil de concebir, es como pueden conservarse en medio de las causas destructoras que los rodean por todos lados. Por una parte los animales de toda especie los engullen ámillares en su estómago, por otra los calores del verano los privan del elemento necesario para su existencia; en fin, los frios del invierno llegan á helar el agua en que pululan.

- Pero en primer lugar las cantidades considerables que son destruidas por los animales son nada si se comparan con la totalidad de los individuos de una especie; en segundo lugar, cuando los calores del verano hacen evaporar el agua de las balsas, las zanjas \&\&c., que habitan los brarquiopodos, estos han hecho ya su postura, y sus huevos quedan para el año siguiente. Ademas de que algunos: dias de sequedad no bastan para hacerlos perecer. Sucede cón frecueneia que habiendo desaparecido estos animales por efecto de lá desecacion de su habitacion, las lluvias posteriores los hacen volver á. aparecer en tan gran úmero como antes. En fin, en cuanto á los frios del invierno, es verdad que hacen perecerá todos los branquiopodos existentes, pero no ejercen ningun poder destructor sobre los huevos que han dejado en el cieno; asi es que los vemos todos los años cubrir los menores chareos de; agua en cantidades incalculables.

Todos las crustáceos de esta familia estan sujetos mudàs periódicas y frecuentes, en las que el número de sus patas, que: es al principio poco considerable; se aumienta gradualmentedesde cuat ro hasta cerca de cincuenta: ?

Lös principales géneros de esta familia son los cichopes, los palifemos, los cipros, las dafnias, los bran- 


\section{5}

quipos y los apos. Como su historia es poco más ó menos sémejante, no refériremós mas que la de las dafnias ó pulgas de agua dulce.

Las DafNias (daphnia) pueden mirarse como los crustáceos mas pequeños, y sin embargo han sido estudiados con tanto cuidado, que hay pocos cuya historia y organizacion sean mejor conocidas. Estos animalés abundan en todas las bälsas, en las zanjas que se hallan en las orillas de los cáminos , en una palabra, en todas las aguas estancadas. Se multiplican con tal rapidez, que á pesar de su pequeñez, forman algunas veces en la superficie de las aguas que habitan, una capa de muchas líneas de espesơ'; y como tienen generalmente an hermoso color rojo, se diria que el agua esta teñida de sangre; lo que ha podido hacer crecr alos" que no conocian la causa de este feuómeno, en la existencia de lluvias de sangre; pues en los tiempos Ilu viósos es cuando las dafnias se multiplican de este modo. Las largas, sequedades del verano, que agotan ordinariamente toda el agua de las balsas, dejando á su habitacion en seco, las hacen perecer á millones, $y$ pronto las hubieran aniquilado; si sus huevos no çonservasen hasta la estacion siguiente la facultad de desarrollarse. w ot an bies on

La 'principal éspecie de este género es la dafnia pulga ó papagayo de agua quése encuentra por todas partes durante el buen tiempo.!

\section{SEGUNDA FAMILIA.}

\section{xifostros (Lám. XXX11I.)}

En la familia precedentedas patas son todas nectoides, y únicamente apropiadas para la natacion ; endos ‘xifosuros estos órganós 'so'n de dos especiesld Los anteriores son 
locomotores ó propios para la prehension, al paso que los posteriores, semejantes á los de los branquiopodos, son branquiales y natatorios. Por otra parte, la magnitud de los xifosu ros es mucho mas considerable que la de las especies precedentes; no solo no son microscópicos, sino que aun puedea pasar por los gigantes de su clase, porque hay especies que tienen hasta dos pies de largo con una anehura proporcionada. Por consiguiente su magnitud es suficiente para caracterizarlos.

Esta familia no comprende mas que un solo género, el de las limulas.

Las timulas (limulus) (fig. 2.), que se llaman mas: comunmente en el comercio cangrejos de las Molúcaś, porque de estas islas es de donde pri ncipalmente las recibimos, contrastan con las dafnias por su gran magnitud, y quizá mas por la singularidad de su estructura. Su figura es tan singular, que les dan en Arnérica el nombre de cacerolas, y se dice que los salvages se sirven de su escudo á modo de vaso para sacar agua; lo que se cree sin dificultad cuando se conoce la figura de estos crustáceos, cuyo coselete convexo superiormente y cóncávo en su parte inferior tiene, cuando está vuelto, la forma de una sarten; y esta semejanza es tanto mas sorprendente, cuanto que se termina posteriormente por una larga cola que representa un mango de no pequeña longitud.

Estos animales son muy comunes en todos los mares de los paises cálidos, $y$ por todas partes son buscados como alimento; su carne se compara á la de los me-

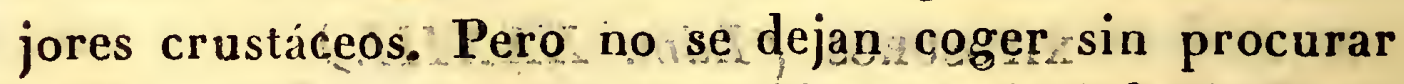
vengarse. Su cola está guarnecida en cada lado de dientes agudos y penetrantes, que hacen unas heridas dolorosas ; y como ellos la pueden dirigir casi á su voluntad, es casi imposible cogerles sin ser herido Sus pi- 
caduras son bastante difíciles de curar, porque se las mira como envenenadas, y esta persuasion es causa de que los salvages adapten la cola de estos crustáceos á la punta de sus flechas con êl objêto de hacẹr mas daño á sus enemigos.

Aunque llaman as limulas cangrejos de las Molucas, no pertenecen esclusivamente al mar de las Indias; se hallan igualmentecien las costas de la América meridional. Esta especie está comprendida en las obras de Linneo con el nombre de monoclus polyphemus.

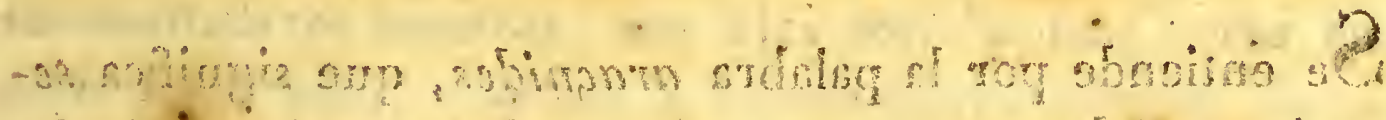

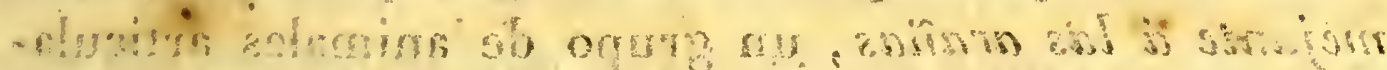

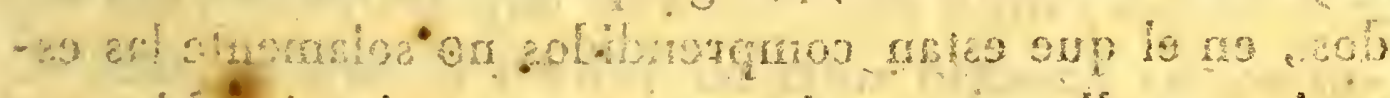

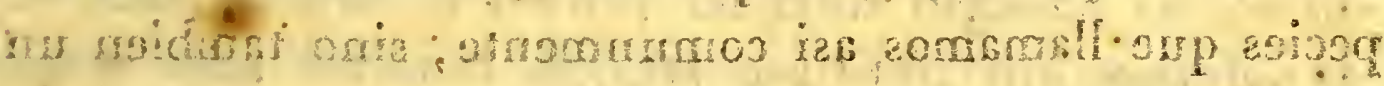

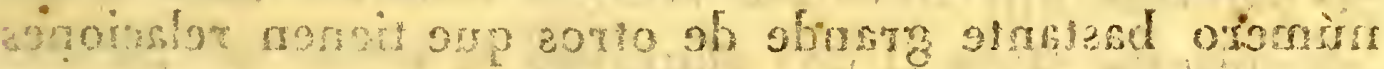

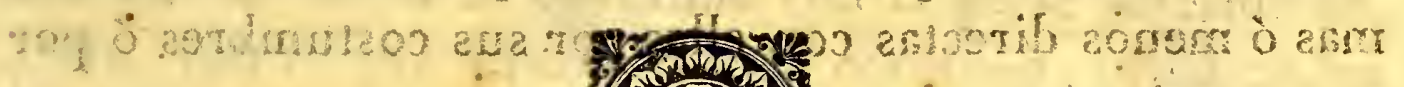

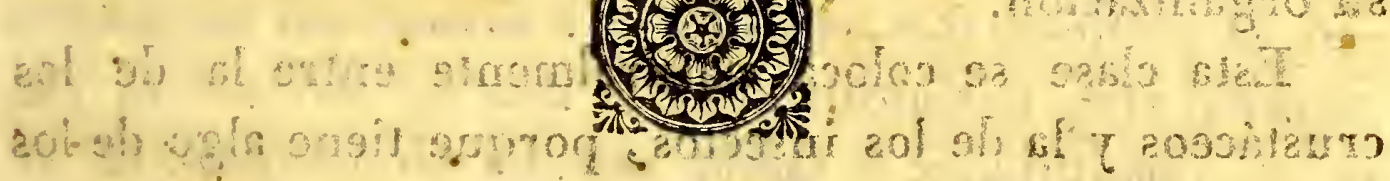

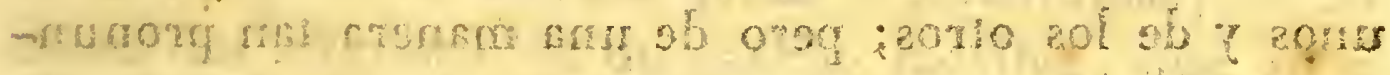

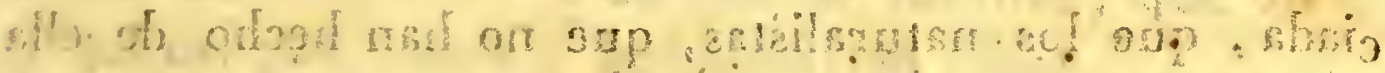

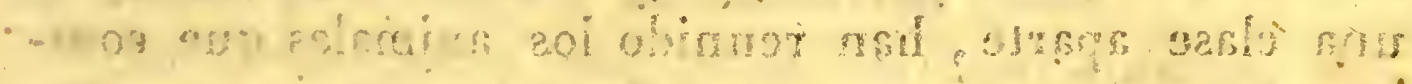
-

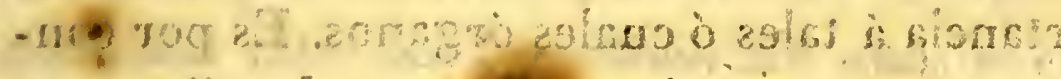

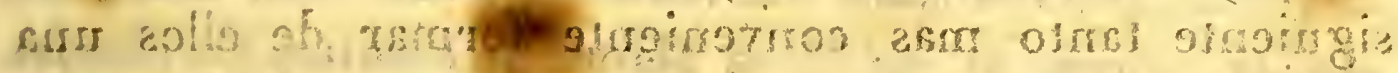

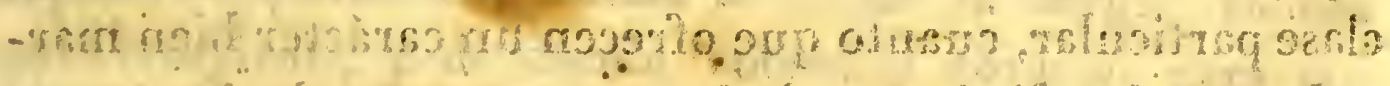

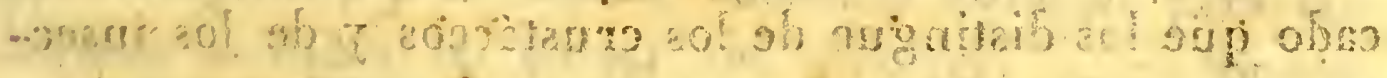

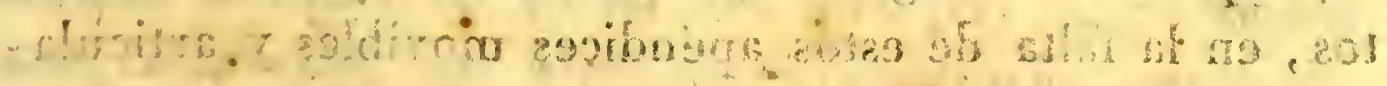

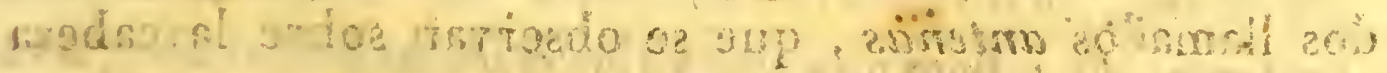

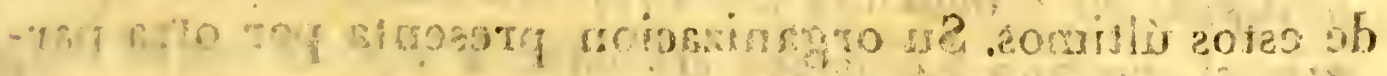

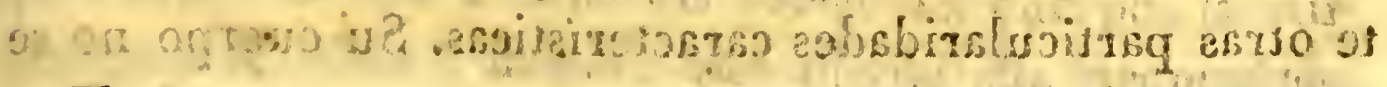




\section{TECERA CLASE.}

\section{$\mathcal{A r a c h o l o g i a}$}

HISTORIA YATURAL DE LOS ARAGNIDES.

Se entiende por la palabra aracnides, que significa semejante $\ddot{a}$ las arañas, un grupo de animales articulados, en el que estan comprendidos no solamente las especies que llamamos asi comunmente, sino tambien un número bastante grande de otros que tienen relaciones mas ó menos directas con ellas por sus costumbres ó por su organizacion.

Esta clase se coloca naturalmente entre la de los crustáceos y la de los insectos, porque tiene algo de los unos y de los otros; pero de una manera tan pronunciada, que los naturalistas, que no han hecho de ella una clase aparte, han reunido los animales que comprende, ya á los unos, ya á los otros, segun que daban mas importancia á tales ó cuales órganos. Es por consiguiente tanto mas conveniente formar de ellos una clase particular, cuanto que ofrecen un carácter bien marcado que los distingue de los crustáceos y de los insectos, en la falta de estos apéndices movibles y articulados llamados anteñas, que se observan sobre la cabeza de estos últimos. Su organizacion presenta por otra parte otras particularidades caracteristicas. Su cuerpo no se 
compone sino de dos partes, la una anterior formada por la cabeza y el tôrax reunidos, y que sirve de sosten á los miembros, y la otra posterior, el abdómen, que es generalmente mayor que la precedente, encierra los organos de la digestión y presenta hácia los lados los estigmas ú orificios de los conductos respiratorios. La piel que cubre estas diversas partes, aunque rara rez córnea, es sin embargo bastante consistente para servir de sosten á los apéndices locomótores, y de punto de apoyó á los múscúlos del animál. Tienen casi siempre ocho patas, número inferior al que se observia en los crustáceos y los miriapodos, y superior al que nos presentan los verdaderos insectos; sus ojos son las mas veces en númerode ocho, y tienen la córnea ócara anterior siempre lisa, mientras que los crustáceos nunca tienen mas de dos, y que la córnea de estos órganos en los in seços está formada de una mulitud iñnumerable de facetas. Su cabeza se confunde con la parte anterior del torax, con la que forma un todo continuo, como en los crustáceos macrouros y braquiuróros. En cuanto á su boca, ya consiste en una trompa apropiada para chupar, yá se compone de maxchas píezas ó mandíbulas, de las cuales dos terminan en un gancho movible, que sirve al animal para coger y despedazar sú presa.

La circulacion y respiracion de estos ianimales son notables por la diversidad de los órganos á que estan confiadas iestas dos funciónesi En unqs se encuentraiuna especie dè pulmon, iá donde se dirige la sangre venosa para respirar, y de donde vuelve al corazon para ser lanzada á todas las partes del cuerpo estos tienen una circulacion; los otros por el contrario, no la tienen; efect uándose su respiracion por medio de traqueas, que llevan el aire á todas las partes del cuerpo, la sán gre se arterializa á medida que pierde stus propiedades 
nutritivas, y la circulacion les es inútil, àsi como los órganos que estan encargados de esta funcion.

Las costumbres de los aracnides son muy variables; unos son libres $y$ andan vagando á su voluntad; todos son carnívoros, y pasan su vida en buscar su presa, que consiste en insectós ; otros viven como parasitos sobre otros seres organizádos, ya sóbre animales cuya sangre chupan, ya sobre plantás, cuya corteza y Jos ińsectos que encubre forman la báse de su àlimento. cthose dividen los articulados de esta clase en dos ópdenes; segun el modo con que respiran oel de las pulmonares y el de lós traqueenos, cobogsinim as t 110 1. Los pulmonares tienen pulmones, ún corazon - - vasos; ; sus ojos son lisos y len número de seis ú ocho. 2. Los Lraqueenos carecen de órganos para lá circulacion, y dienen traqueas que se abren hácia los ladós del abdómen pór medio de estigáas no tiénén mas que Icuatro ojos disos.

\section{PR I MER OR DEN.}

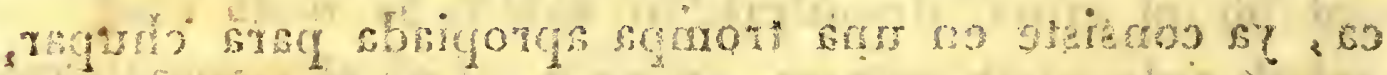

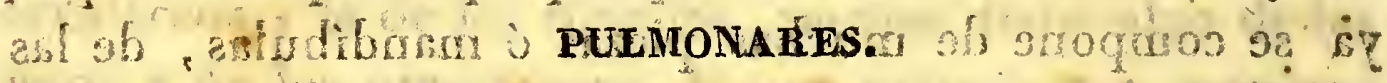

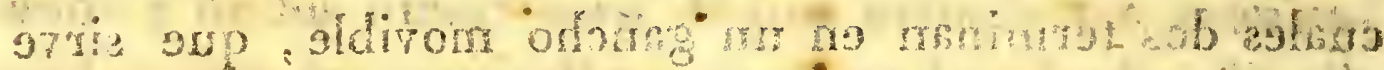

El órden de los aracnides pulmonares no solo se distingue del siguiehte por la naturaleza de su organo respiratorio quejès ú verdadero púlmon sino tambien pordiversos pormeñores dessu estructurn interior y de sus órganos esterióres. Nurca itienen estos animales menos de ocho patas: sus ojos son, cuando inenos, en número de seis ýlo más de ocho, y presentan una disposicion diferente en cada especie. Su's 'mandíbulàs, que se terminan, ya en gancho, ya en forma de pinza movible, son el principal instrumento de que se sirve el animal para matar á los insectós de que se alimenta, lo 


\subsection{1}

que hace con tantá mas seguridad, cuanto que existe siempre en la base de estos órganos una glándưla que segrega un líquido venenoso, y le vierte, por medio de ún conducto, en el que atraviesa elinterior de sus mandíbulas, y por consiguiente en la herida que hace la pinza ó è gancho.

Todos estos animales son carnívoros é insectivoros; deben pues tener la boca acomodada para triturar su alimento, y por consiguiente compuesta de piezas movibles. Por lo demas su género de vida ofrece diferencias bien marcadas, diferencias que provienen de las de su organizacion, y que se hạ podido, á causa de esto, tomar por base de su division en dos familias: los araneidas y lòs pedipalpos.

\section{PRIMERA FAMILIA.}

\section{ARANEIDAS.}

Esta familia se compone de especies muy semejantes por su forma esterior, por su organizacion, y aun pór sús costumbres: Un cuerpo grueso, velludo, compuesto de ú pequeño coselete y de un enorme abdómen separados por una depiresion, y colocado sobre ocho patas largas y cubiertas dé pelos, les da á todos un aspecto desagradable, y en algun modo feo, que les atrae el odió de múchas pérsonas, para dás que son al mismo tiempailun objeto de asco y horror. ¿Cuál puede ser la causa del espanto que inspiran y del odio con que se les persigue? Estos dos sentimientos nacen de una preocupacion inconsiderada que atribuye á su veneno bastante-fuerza para ocasionar graves accidentés, y aun la muerte. Péro ápenas tenemos en nuestros paises animal alguno deresta familia iguel pueda producir seme- 
jantes efectos; su mordedura puede matar las moscas; las abejas $\mathrm{y}$ otros pequeños insectos; pero no puede hacer un gran daño al hombre; cuando mas puede causarle un dolor análogo al que le causa la picadura de un mosquito ó algo mas Pero no sucede asi en-los paises mas meridionales; estos animales adquieren algunas veces un grandor considerable, y su mordedura ocasiona casi siempre una hinchazon enorme, y aun puede determinar la muerte en los individuos débiles y mal sanos por temperamento.

Una de las particularidades mas interesantes de la historia de:los araneidas es la propiedad que tienen de hilar esas telás que tienden por todas partes, $y$ hasta en nuestras habitaciones; lo que les ha hecho llamar aracnides hiladores. Deben esta facultad á un aparato glanduloso colocado en el abdómen, y que produce un líquido glutinoso; susceptible de formar largos hilos, y de secarse luego que se pone contacto con el aire. Este aparato comunica con lo esterior por un cierto número de aberturas en forma de pezoncillos colocadas en la parte posterior del abdómen.

La naturaleza les ha dado este aparato con el doble obgeto de suministrarles el medio de apoderarse de sü presa y de formar para sus huevos unacubierta protectora en que puedan desarrollarse.

El modo con que estos animales tienden sus telas y forman sus capullos (cubiertas de sus huevos) Iraría mucho de una especie á otra, y permite dividirlos sén muchos géneros, de los que los mas principales sơn: las migalas, las arañas, las argironétas y las licosas.

\$. I. Las Migalas (mygále) se conocen en que tienen cuatro estigmas respiratorios, mientras que los géneros siguientes nunea ofrecen mas de dós. Su grande estatura; unida á la longitud y fuerza lde sus pátas, 


\section{3}

les ha hecho dar el nombre de arañas cangrejos, que tienen en las Antillas.

Son unas arañas gruesas, que no tienden jamas sus telas en el aire, sino que las emplean principalmente en tapizar su nido y fabricar su capullo. Se establecen, ya en los troncos de los árboles huecos, ya sobre hojas convenientemente dispuestas; otras veces en cavidadès subterráneas que ellas mismas se escavan; algunas especies se ocultan simplemente bajo las piedras.

Una de las especies mas notables del género, por su grandor, es la araña de las aves (aranea avicularia), que se encuentra en :América, y que ha sido llamada asi porque tiene bastante fuerza para matar los pájaros pequeños, como son los colibris y los pájaros moscas. En Francia y España se encuentra la migala ó araña albañila (fig. 3.) que se ha llamado asi porque tiene la costumbre de fabricarse una galería subterránea; que tapiża interiormente de una espesa capa de seda, y cuya entrada tapa con una puerta, que fabrica con tierra é hilos: Esta puerta está dispuesta de manera que se cierra por sí misma, ya que la migala se encuentre dentro, ya que esté ausente. $Y$ para que ningun indicio pueda descubrir la presencia de la obrera, la superficie esterior de la puerta está cubierta de tierra semejante á la que la rodea, de suerte que se necešita mucho hábito para conocerla, á no ser que se vea al animal entrar ó salir de ella.

Las especies de este género son las que hacen estas numerosas telas que se encuentran tan frecuentemente en los campos y jardines, entre los surcos, cerca de las piedras \& 8 .

§. II. Las ARAÑS (aranea) hacen parte de una numerosa tribu de araneidas que se han llamado sedentorios, porque se construyen telas y permanecen quietos 
aguardándo que algun insecto vaya á enredarse en eś ta red. Para que su caza sea mas abundante, tienen cuidado de tenderlas en los parages mas solitarios, en donde los animales de que se alimentan abundan mucho mas, en donde sus telas estan mas libres de ser destruidas. En el sitia mas oscuro de su habitacion,, y casi siempre en el rincon de las paredes, se fabrican una especie de bolsa en la que se mantienen ocultas, teniendo la vista en acecho y fija sobre toda la estension de. su tela. Asi que los movimientos de estáltima les anuncian que un insecto se ha enredado en ella, se lanzan. inmediatamente sobre él, si es pequeño, y le atraviesan con sú aguijon venenoso. Si la presa les parece bastante fuerte para poder romper su tela y escaparse, se apresuran "á hilar al rededor de ella nuevas sedas, y á envolvęrla mas solidamente, á fin; de que no pueda romper sus lazos, y cuando su víctima se ha rendido por esfuerzos inútiles, se acercan con precaucion pára acabar con ella. En todos casos, se apresuran á devorarla, y á arrojar los restos lejos de allí, para que no anuncien su presencia á los demas insectos.

Pero, á pesar de esta precaucion y del cuidado que ponen en ocultar su artificio, no son siempre tan dichosas las arañas, pues están sujetas á largas abstinencias y y sị la naturaleza no les hubiera dado un conducto intestinal condescendiente, un gran número de ellas perecerian de hambre: Pero como pueden soportar ayunos de muchos dias, es raro que durante este intervalo no les llegue alguna buena presa.

Las principales especies de este género numeroso son la araña pérfida, la araña atroz, la araña domés. tica, \&ci, que forman el tipo de otros tantos pequeños subgéneros.

¿. SII. Las ARGIRONETAS 6 arañas de agua (argyrone- 


\section{5}

ta) se diferencian mucho de los demas grupos de la misma familia por su género de vida, $y$ ofrecen costumbres muy curiosas y una industria admirable. $\mathrm{Co}$ mo viven en medio de las agúás y sin embargo no pueden respirar sino al aire tibre, se vẹn obligadas' á formarse en el seno de este elemento, unallatmósfera artificial, en donde encuentráni el fluido necesário para su respiracion. Parà este efecto hilan en el aguazun ca: pullo oval y bastante apretádo para que pueda conte: ner aire. En séguida le sujetan á algun cuerpo sumergido en al agua, y le colocan de manera que la abertura de que está atravesado se hálle en la parte inferiór. Despues de haberle fijado asi en el fóndo, estos animalos suben à la superficie dél agủa, en donde cogen bajo su vientre una burbuja de aire, $y$ la llevan al capullo, del que arroja una cierta cantidad de agua. Repiten sus viages hasta que haya sido enteramente reemplazáda el agua/ por el äire atmosférico. Entonceses es cuando se ponen en emboscada, preparadas á cóger los insectos imprudentes que pasen á su alcance. $\mathbf{P e}$ ró no pueden estar sino un cierto tiempo en esta habitacion sin renovar el aire de ella. Luego que este fluido se écucutra alterado, vuelven el capullo que se vacia inmediatamente, y le llenan de nuevo de un aire puro y respirable.

No se conoce mas que una especie de este género; esta es la argironeta comun, (aranea acualica, $\mathrm{L}_{\text {. }}$ ) que se encuentra frecuentemente en las aguas estancadas. - §. IV. Las LICOSAS (lycosá) ó arañas-lobas han sido llamadas asi á causa de su voracidad; son generalmente de gran magaitud, y tienen por consiguiente el medio de satisfacer sus apetitos carnívoros. Algunas tienen mas de una pulgada de largo, y apenas ceden en grosor á las migalas.

Tomo III. 
Estos animales hacen parte de la tribu de los araneidas que se hąn llamádo vagabundos, porque en lugar de establecerse de asiento en algun punto, van errantes al acaso buscando su alimento. Se mantienen habitualmente en tierra en donde corren con una celeridad estraordinaria, principalmente cuando persiguen su preșa Cuando estan repletas se retiran á unos agujeros que sé encuentran formados ó que hacen ellas mismas. Aqui es donde sufren su muda y las hembras hacen su postura. Pero estas no ponen los huevos en tierra; les hacen un capullo de seda, sobre el cual velan con una viva solicitud, y que llevan consigo siempre que se ven obligadas á salir No los abandonan hasta que isu prole ha salido á luz; todavia la suministran por larga tiempo insectos ó la ayudan á cogerlos, $\mathrm{y}$ la défienden contra todos los animales que procuran hacerla dañ́o.

El grandor de estas arañas las hace generalmente temibles; el temor que inspiran no está destituido de fundamento, porque parece que en el Mediodia su mordedura produce accidentes bastante graves, $y$ aun la muerte, si no se tiene cuidado de aplicar un remedio pronto para precaver sus efectos. Se encuentran muchas: especies de este género, entre otrạs la tarcinlula de Italia, que parece ser aquella cuya picadura tiene mas peligro.

En Italia y en España se cree que lá música es solo capaz de curar la herida causada por esta licosa asi luego que se sienten mórdidos sus habitantes, buscan un músico para hacerle tocar un baile ánimado, que se ponen a ejecutar hassta que caen rendidos por el sudor y fatiga; por este medio "quedan libres de todo accidente peligroso. Pero no es la música quien los cura los movimientos á que se entrégà ; y los 


\section{7}

sudores àbundantes que los acompañan, son los que producen lá espulsion del venenó introducido en la herida.

\section{SEGUNDA FA M LIA:}

\section{PEDIPALPOS. (Lám. XXXIII.)}

Esta segunda familia es incomparablemente menos numerosa que la precedente, pero mas difícil de conocer. Estos aracnides tienen en efecto el torax y el abdomen confúndidos entre sí, ó al menos poco separados, $y$ formados uno y otro de anillos articulados ; sus mandíbulas terminan en pinza y parecen unas especies de brazos, lo que les ha hecho llamar pedipalpos; sus tegumentos son mas sólidos que los de los araneidas, sin tener la dureza de los crustaceos. Su vientre, que es mas largo y menos grueso no contiene nunca esás glándulas que sirven á las arânás pára hilar : su tela; se termina por una cola bastante larga, y. presenta cuatro ú ocho estigmas en los lados, en vez de dos ó cuatro á lo mas que se encuentran en lás especies de la primera familia.

Los pedipalpos habitan los paises meridionales y viven en tierra; en donde corren con muchá agilidad en persecucion de los insectos; porque no son menos temibles ni menos carnivorós que las arañas. Su picadura pasa por venenosa, como la de las licosas y de las migalas, y produce ordinariamente accidentes incomodos

Esta familiq nócomprende mas que dos géneros, las tarántulas ý los escorpiones.

§. I. Las tarantulas (tarantula), que no se deben confundir con las licosas que se llaman asisi en el Mediodia, se distinguen de los escorpiones por una ligera de- 
presion que se nota entre su pecho y abdómen, por la falta de cola en la estremidad de este último, y por la figủra de sus mandíbulas que se terminan en una simple garra y nó en pinza de dos dedos.

Uniçamente en los paises múy cảlidós del Asia y de la Américá es donde se encuentran las especies poco numerosas de éste género.

§. II. Los ESCORPIONES ó allacranes (scorpio) (fig. 5.) tienen el cuerpo largo y terminádo dé pronto por una cola nudosa y provista en su estremidad de un dardo agudo, que viérte en las heridas que hace un líquido venenoso. Su torax y su abdómen son dificiles de distinguir bien, y estan formados el primero de una sola pieza larga, y el segundo de siete ú ocho anillos.

Estos aracnides habitan los paises cálidos de los dos continentes; viven en la tierra, se esconden bajo las piedras, en los troncos de los árboles, y buscan regularmente los sitios frescos y sombríos; y aun se establecen en lo interior de las casas. Cọrren con velocidad, enderezando su cola en forma de arco sobre * su lomo; pero cuando se hallan en peligro ó quieren picar á algun insecto, la dirigen sa voluntad contra su enemigo ó su presa, y se sirven de ella como de una arma ofensiva ó defensiva. Asi es que destruyen una gran cantidad de arañas, de cloportes, \&c; tambien gustan de huevos de insectos. La picadura de estos animales es siempre peligrosa; pero los accidentes que determina son proporcionados á la edad y grandor del que la hace. Los individuos mas viejos y fuertés son los mas temibles aunque su mordedura no producessiemprèla muerte á menos de que circunstancias particulares favorezcan los funestos efectos del véneno.

Los escorpiones son voraces y crueles en estremo; no solo destrujen unagran cantidad de insectós de to- 
da especie, sino que se devoran mutuanente, y no perdonan ni aun á sus propios hijos.

Se conocen ocho ó diez especies de.este género; una sola pertenece á Europa y se encuentra en el mediodia de Francia y España. Tiene cerca de una ó dos pulgadas de largo; que es el escorpion comun, su picadura no es tan peligrosa como la del escorpion de Africa, que, tambien es mucho mayor.

\section{SEGUNDO ORDEN.}

\section{TRAQUEENOS.}

Estos aracnides se diferencian de los precedentes bajo muchos aspectos importantes, porque no tienen esas bolsas àereas que sirven para la respiracion; estas especies de pulmones son remplazados por unos conductọs elásticos llamados traqueas que se abren hácia fuera en los lados del abdómen por dos agujeros ó estigmas y que conducen el aire á las diversas partes del cuerpo. En razon de esta disposicion, siendo vivificada la sangre á medida que sirve para la nutricion de los órganos; y aun en los órganós mismos, no tienen necesidad de vasos para hacerla circular, ni por consiguiente de corazon para darla el impulso necesario á su movimiento.

Este örden menos numeroso que el de los aracnides pulmonares se compone tambien de especies mas pequeñas y menos carnívoras; unas viven en las substancias animales corrompidas, como el queso, la grasa \&c.; otras se adhieren á las plantas y se alimentan ya de larvas de insectos, ya de las mismas partículas que - desprenden de la planta; algunas son parasitas y sếfijan 
sobre el cuerpo de animales cuyos humores chupan; solo un corto número son vagabundas y viven del producto de su càza.

Todos.los animales de este grupo son pequeños', y la mayor parte de ellos no pueden verse sino con el auxilio del microscopio, lo que hace su estudio tanto mas dificil, cuanto que la distincion de tos géneros y. de las especies está fundada sobre la conformacion de partes muy pequeñas, como son las mandíbulas.

Se divide este órden en cuatro familias, de las cuales las principales son las de los falangianos y de los acarides.

\section{PRIMERA FAMILIA.}

\section{FALANGIANOS.}

Esta familia no comprende sino un corto número de géneros, de los que el mas notable es el de los segadores, que forma el tipo de ellos. Las especies que encierra tienen el torax y el abdómen reunidos en una masa globulosa, cubierta por un epidermis comun. Su boca está siempre armada de una pinza con dos dedos, de los cuales el uno es movible y el otro fijo.

Todos estos animales viven en la tierra, corren con mucha velocidad, se esconden debajo de las piedras y en los agugeros, hacen la guerra á los insectos, y se alimentan de rapiña.

Tales son los SEGADORES (phalangius), aracnides notables por la longitud desmedida de sus ocho patás, que forman un contraste sorprendente con la pequeñez y cortedad de su cuetpo. Este es casi redondo como un guisante, y se termina por una cabezá tan poco distin- 


\section{1}

ta, que es preciso poner mucha atencion para percibirla. Todos conocen estos seres singulares que se encuentran por todas partes en el campo, principalmente en las páredes recientemente enyesadas y bien espuestas al sol. No hay persona que no los haya visto, ya fijos é inmóviles sobre sus patas aguardando pacientemente su presa, ya recorriendo la pared á grandes pasos buscándola por todas partes.

Los segadores son muy carnívoros; y tan feroces, que se baten casi continuamente, y que los mas fuertes devoran á los mas débiles; asi es que se mantienen siempre alerta, y tienen cuidado, mientras descansan al sol, de estender sus patas alrededor de sí como otros tantos centinelas vigilantes encargados de advertirles de la aproximacion de todos los animales. Si estos son pequeños y no de temer para ellos, los dejan adelantar hasta que estan á su alcance, y los devoran. En el caso contrario huyen prontamente, dejando muchas veces una de sus patas, porque estan tan poco adheridas al cuerpo, que basta el-menor tiron para arrancarlas. La prin. cipal especie es el segádor comun (phalangium opilio), gris por encima y por debajo blanquizco con las patas larguísimas.

\section{SEGUNDA FAMILIA.}

ACARIDES. (Lám. XXXIII.)

Bajo el nombre de acarides, y mas comun mente de aradores, se señalan un gran número de animalitos, de los que la mayor parte no son visibles sino por medio del microscopio, y que viven ordinariamente parasitos sobre las plantas ó sobre animales, cuya salud y aun 
la vida comprometen á pesar de su pequeñez, á causa de su escesiva pultiplicacion.

Aqui no podemos menos de hacer una reflexion so-i bre el poder y la inteligencia infimita del Criador. Estos seres, tan pequeños que nuestra vista no puede perci-: bir, estan sin embargo compuestos de una multitud de órganos, cuyo conjunto concurre al sosten de su frágil existencia. Todos estos animales, tan imperceptibles como son, tienen una cabeza; su cabeza tiene una boca y dós ojos; esta boca está formada de muchas mandíbulas; estas mandíbulas son movidas por músculos, $\mathrm{y}$ estos músculos deben recibir la influencia de los nervios. ¿Y sus ojos no deben tener una córnea para dejar pasar la luz y un nervio para recibir su impresion? ¡Cuál pues debe ser la tenuidad incomprensible de tantos órganos que por su reunion forman un todo imperceptible á nuestra vista.

Y sin embargo, el hombre ha llegado á estudiar todas estas partes, á determinar su figura, á servirse de ella para distinguir entre sí las especies de que, hace peco tiempo, no se tenia ninguna idea positiva. Armado de un cristal aumentativo, ha visto en la boca de estos aracnides, ya mandíbulas terminadas en pinza ó gancho, ya un chupador que contiene una especie de lanceta para penetrar la piel de los animales sobre que viven. Su cuerpo, que aun cuando es visible á simple vista, no parece sino un punto movible, sin órganos locomotores, le ha ofrecido, no solamente miembros articulados, sinó tambien. una piel velluda y cubierta de pelos, como la de las arañas.

A pesar de la dificultad que presenta el estudio de los acarides, ha habido naturalistas infatigables que han llegado á dividir esta familia en veinte géneros, segun 


\section{3}

las diferencias que presentan en la conformacion de su boca, el número de patas \& c.

Unos tienen ocho, como son el sarcopta ó arador que produce la pústula de la sarna (fig. 7.), el arador comun, de un rojo escarlaia, que se encuentra frecuentemente en los alrededores de Paris; la garrapata, que atormenta tanto á los perròs \&c. Otros no tienen mas que seis pies; tal es el encarnadillo ó lepto de otoño, que es tan comun en eśa estacion, y que insinuándose bajo la piel, causa en ella comezones insoportables \&.c. 


\title{
154
}

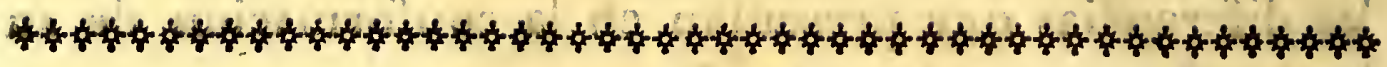

\section{GUA RTA GLASE.}

\section{Atiriapologia}

\author{
ó
}

HISTORIA NATURAL DE LOS MIRIAPODOS.

El hombre, cuando ve alguna cosa estraordinaria, es incitado á exagerarla todavía para dar á los demas una idea mas grande de ella. Asi es que al ver á unos animales articulados provistos de mayor número de patas que la mayor parte de las demas especies análogas, les ha dado el nombre de miriapodos, quilopodos, mil pies, cien pies \&c.; espresiones que, tomadas literalmente, harian caer en error al que no estuviera prevenido de la hipérbole; pero que á pesar de ser exageradas, tienen la ventajá de dar á conocer el principal carácter de estos seres singulares, que consiste en tener los lados del cuerpo guarnecidos de una serie de miembros articulados, cuyo número es lo menos de veinticuatro, y puede llegar hastit mas de ciento.

Si la velocidad de la locomocion fuera proporcionada al número de los órganos que están encargados de ella, los miriapodos serian sin duda alguna los mas ágiles de todos los animales; pero. dista mucho de ser asi; y los articulados de que hablamos, lejos de ser todos notables por su agilidad, tienen ordinariamente los movimientos lentos y embarazados, y mas bien parece que se arrastran que andan. Unicamente las especies cuyo 


\section{5}

número de pies es menos considerable, son las que tienen fácil la locomocion.

Los miriapodos son entre todos los animales articulados los que tienen los anillos circulares mas marcados y mas fáciles de distinguir; todos estos anillos son casi semejantes, y se ven igualmente bien por el dorso y por el vientre; cada uno de ellos sostiene uno, y muchas veces dos pares de patas, á escepcion de los dos primeros y de los dos ó tres últimos que estan desprovistos de ellas. Esta conformacion da á estos animales alguna semejanza con ciertos anelides, y aun con unas pequeñas serpientes, sin que por eso el número de sus patas y la naturáleza de sus tegumentos permitan confundirlos con unos seres tan diferentes por su organizacion interior. Algunos de ellos tienen tambien relaciones con los crustáceos de la familia de los isopodos, como los cloportes; pero ademas de que los miriapodos tienen mayor número de patas que estos últimos, se encuentran en cada lado del cuerpo las aberturas de las traqueas que se oponen que se confundan con ellos.

Los animales articulados de las tres clases precedentes nos han presentado un fenómeno curioso, el de la muda ó cambio anual de la piel; en los miriapodos este cambio no se limita á los tegumentos, sino que se estiende hasta las partes internas, de suerte que cada vez que mudan toman una forma diferente de la que tenian antes. Estos cambios se manifiestan principalmente por el aumento del número de los anillos y patas; no son ya pues simples mudas, sino verdaderas metamor fósis, análogas á las que sufren los insectos.

Pero es preciso observar que estas trasformaciones no duran toda la vida del animal; parece que el espacio de dos ó tres años á lo mas le es suficiente 
para llegar á su estado perfecto, es decir, á aquel en que no esperimentará mas cambios de forma; al paso que en las especies en que la muda se limita á la piel, estos cambios se renuevan anualmente durante toda su vida.

La clase de los miriapodos es muy poco numerosa, y no se componia para los antiguos naturalistas sino de dos géneros, de los que los modernos han hecho dos familias: la de los quiloñatos y la de los quilopodos.

\section{PRIMERA FAMILIA.}

\section{QUILOÑatos. (Lám. XXXIII.)}

Bajo el nombre de quiloñatos ó de iulides se comprende un cierto número de articulados muy notables por su forma prolongada y cilíndrica, por su cubierta córnea y sólida, y por el gran número de anillos que componen su cuerpo, y de los cuales la mayor parte sirven de sosten á dos pares de patas; de suerı que á igual longitud tienen mas miembros que ningun otro animal. Pero estos miembros, delgados y débiles, lejos de favorecer sus movimientos, los hacen por el contrario difíciles, porque como el animal mas bien se resbala que anda, se halla detenido por la eminencia que forman debajo de su vientre.

La multitud de piezas que forman su cubierta esterior permite á los quiloñatos arrollarse en espiral ó en bola como los armadillos; esta es la posicion en que se encuentran delajo de las piedras y en los, agugeros que frecuentan habitualmente. Tambien la toman cuando se ren atacados por algun animal mas fuerte, con la esperanza de poder proteger su cabeza; pero este es un recurso bien débil para ellos: lentos en sus mo- 
vimientos, privados de armas ofensivas $\mathrm{y}$ defénsivas, $\mathbf{z}$ escepcion de un líquido fétido que derraman en los momentos del peligro, no pueden oponer resistencia alguna á sus enemigos, ni aun podrian triunfar de los animales mas pequeños. Asi es que no se alimentan sino de sustancias vegetales ó animales ea descomposicion, y permanecen continuamente ocultos en sus guaridas y si las dejan alguna vez, no es sino para pasearse en parages oscuros y húmedos.

Esta familia no comprende mas que un solo género; los julos (iulus), que se divide en muchos subgéneros, tales son los glomeros, cuyo cuerpo es oval, ligeramente comprimido y semejante al de los cloportes y los jubos propiamente dichos (fig. 8.), que tienen el cuerpo mucho mas largo y del todo redondo, como el julo de las arenas, el julo terrestre \&c., que son comunes en Europa, y aun en Francia.

\section{SEGUNDA FAMILIA}

\section{QUILOPodos. (Lám. $X X X I I I$.}

Los quilopodos ó escolopendras se asemejan mucho á los iulides por su forma prolongada $y$ sus patas numerosas; pero se distinguen de ellos por sus anillos; que no sostienen mas que un par de piess cada uno, y por dos ganchos córneos y agudos que guarnecen su boca. Estos dos caractéres les dan unas costumbres enteramen-; te diferentes; tan lentos son en la carrera los quiloñatos, como ágiles las escolopendras; es tal su velocidad que aun el hombre halla dificultad en alcanzarlas, y principalmente en cogerlas sin que le muerdan; asi es que no hay insecto que pueda escapárselas. Por otro lado, la fuerza de sus ganchos y principalmente el veneno 


\section{8}

que destilan, las permiten defenderse con ventaja de animales mucho mas gruesos que ellos, y de hacer. su presa de todbs los de poca magnitud; los agarran con sus ganchos, y es tan pronto el efecto de su mordedura, que su víctima perece inmediatamente, lo que es debido á un veneno sutilque estos órganos vierten en la herida que han hecho; aun' se pretendé que su picadura no deja de ser peligrosa para el hómbre, a lo menos la de las espe. cies grandes; lo cierto es que en las Indias y en América son muy temidos estos quilopodos. Los que tenemos en España, como son mas pequeños, son tambien menos venenosos, y las mas veces su mordedurano ofrece pe ligro alguno; con todo se les teme á pesar de esto, a causa de la agilidad y petulancia de sus movimientos.

Esta familia comprende dos pequeños géneros los escudiferos y las escolopendras.

§. I. Los escudiferos (scutigera) tienen el dorso cubierto de ocho chapas córneas, al paso que inferiormenté tienen quince anillos , á cada uno de los cuales está adherente un par de patas. En España existe una especie de ellos que vive en las habitaciones, debajo de las vigas y en la madera podrida y se llama comunmente escolopendra de ocho patas.

§. II. Las ESCOLOPENDRAS (scolopendra) (fig. 6.) tienen lo menos veinte pares de patas, y los anillos semejantes en el dorso y en el vientre. Una especie de estas hay en España que tiene de seis á siete pulgadas de largo, que es la escolopendra comun; la escolopendra de América ó mordedora es casi de la misma magnitud, pero como habita un clima tmas caliente, es mas peligrosa. 


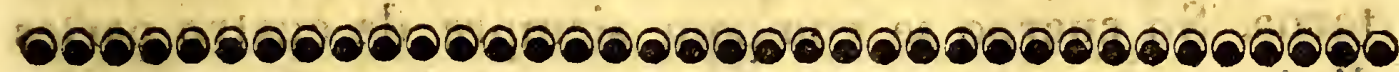

\section{QUINTA CLAS E.}

\section{Eutomalogir.}

\section{HISTORIA NATURAL DE LOS INSECTOS.}

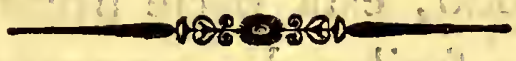

1

a palabra insecto (formada del latin intersectus, dividido en varias partes) tomada en su mayor estension, deberia aplicarse á todos los animales articulados guyo cuerpo presenta en efecto esas intersecciones y esos anillos alternativos, que les habian hecho dar este nombre; pero prescindiendo del inconveniente que habia de reunir en una misma clase á unos animales tan numerosos, su organizacion interior presenta difere pcias bastante marcadas para autorizar su separacion, asi es que los naturalistas mas distinguidos convienen generalmente hoy dia en no mirar como insectos sino lá los animales articulados, 5 de respiracion traqueal provistos de antenas y de tres pares de miempros articulados y sujetos á metamorfósis.

A pesar de la reduccion que esta defniçion hace del número de insectos, de los que separa á dos a anelides, crustáceos, aracnides y mirjapodos n,9 por esso deja de ser esta clase la mas considerable de la Zoologia. Forma

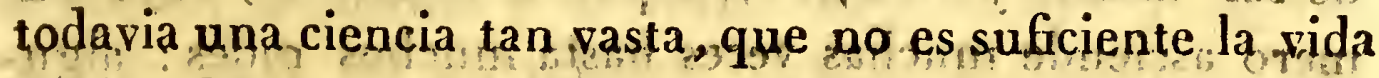
del hombre para abrazarla en toda su, estension; pero álp menos no encierra sino animales opteramente semejantes por sus formas esteriares $\mathrm{Z}$ or su organizacion in- 


\section{0}

terna. Su cuerpo se compone siempre de cuatro partes distintas: la cabeza, en la que se hallan la boca, los ojos y las aptenins el torax que sirve de sosten á los miembros; el abdómen que contiene los órganos de la nutricion, y los miembros, que se dividen en patas en número de seis, y en àlas, que no siempre existen.

Aunque los anatómicos han llegado, descomponiendo los órganos que forman la boca de todos los insectos, descubrir en ella siempre los mismos elementos esenciales, con todo, esta parte presenta dos modificaciones principales fáciles de comprender. En efecto, en unos la boca está destinada á masticar, y se compone de seis piezás, dos medias llamadas labios, y distinguidas en labio superior ó sombrerillo (cylpeus), y labio inferior, ó simplemente labio (labium); y cuatro lateráles, de las que las supériores se llaman mandíbulas, "y las inferiores, maxilas Esias últiuas sostienen á dós palpos mas ó menos desarrollados. En otros estas partes estan tan modificadas, que su boca se halla transformada en una verdadera trompa (proboscis), propria únicamente para chupar los humores de las plantas óde los animales en que se fijan, ó en un tubo metido dentro de una vaina que hace las veces de labio superior y es articulada, sólida, de figura cilindrica ó cónica, lo que se llama pico (rostrum), cuyos usos son los mismos.

Los ojos de los insectos son ordinariamente en número de dos como en la mayor parte de los demas animales; pero ofrecen una diferencia importante: en vez de ser llanos y lisos, se componen de facetas, cuyo número asciende muchas veces hasta muchos miles; algunas mariposas, por ejemplo, tienen hasta diez y siete mil. Pero ademas de estos ojos que estan situados uno en cada lado de la cabeza, muchos insectos tienen or- 
dinariaménte otros tres de superficie lisa, dispuestos en triángulo y que se llaman estemmas.

Por lo que respecta á las antenas, ocupan el mismo lugar que en los crustáceos y los miriapodos; pero varian mucho mas que en estos últimos por su magnitud, figura y usos.

El torax ó coselete (thorax) que se halla inmediatamente despues de la cabeza, y delante del abdómen, está formado por la reunión de tres segmentos ó anillos cuya magnitud relativa varía considerablemente según las especies, pero que son siempre fáciles de distinguir, en que sostienen cada uno un par de patas. Los dos posteriores isirven tambien de apoyo á las alas.

El abdómén que forma la tercera y última parte del tronco, encierra los órganos de la digestion y se compone de nueve á diez segmentos, en cada uno de los cuales se halla un estigma. La parte superior del abdomen se llama dorso (tergum) y la inferior vièntre (venter). Por lo demas, esta parte presenta las modificaciones mas notables en su figura, grosor, \&c.; muchas veces ofrece en su parte posterior una especie de estuche, en el que está alojado un dardo ó aguijon, ya macizo, ya escavado por un conducto, del cual se sirve el insecto para picar á sus enemigos ó para depositar sus huevos.

Los miembros de los insectos son ordinariamente de dos especies, las patas y las alas. Las patas son siempre en número de seis, como dijimos, y están constantemente adheridas al coselete; cada una se compone de cuatro partes: la anca, que se articula con el tronco, el muslo, la pierna y el tarso. Este último á su vez está formado de un número variable de articulaciones (de una á cinco) terminadas en pinza garra, gancho, aleta, \&c., segun su destino.

ToMo III. 


\section{2}

Las alas (alae) faltan en un corto número de insectós llamados por esta razon ápteros; pero la mayor parte tienen dos ó cuatro. En este último caso los dos pares son todos membranosos como una gasa y de igual consistencia, ó bien el uno es membrąnoso y el otro duro y coriáceo ; cuando es asi, estas alas duras; que algunos lla man elitros, pero cuyo verdadero nombire es elictras (elictra) son como unos estuches destinados a proteger las alas verdaderas y de ningun mọdo sirven para ci vuelo.

Segun esta eorta esposicion de la organizacion de los insectos, se ve que tstos animales la tienen bastante complicada; asi es que su conocimiento forma una de las partes mas interesantes de la historia natural. Son tán variadás y tán singulares sus cóstumbres, tảa desaro: llado su instinto, tan maravillosas sus obras, que se han querido conocer todas las particularidades de su existencias pero á pesar del celo que los naturalistas han empleado en el 'estudio de esta clase de animales, á pesar de los progresos inmensos de la entomología, todos los dias se hacen, aun en nuestros paises, nuevas observaciones sobre sus costumbres, desculbrimientos sobre su organización, $y$ se encuentran de tiempo en tiempo especies. desconocidas.

En los insectos la funcion de relacion está tan des arrollada como en los animales de la primera division; su vista sobre todo es escelente; tambien tienen el olfato muy fino; pero no se está de acuerdo sobre el sitio de este sentido, aunque generalmente se cree hoy: dia que reside en las traqueas, como lo ha sentado el primero, el profesor Dumeril. El oido existe igualménte, como lo prueban los diversos ruidos por medio de los cuales los insęctós se avisan múcuamente de su) presencia; pero su sitio es todavia mas incierto que el dél 
olfato. El gista reside en la boca y el tacto en las antenas.

La movilidad de estos avimales es por lo menos tan desarrollada como su sensibilidad tienen toda especie de movimientos: la reptacion, la marcha, el vuelo y la natacion.

Hemos visto que la boca de los insectos ofrece dos modificaciones principales, segun que sean masticadores ó chiupadores. Los primeros se alimentan geveralmente de materias sólidas, vegetales ó animales, cuya descomposicion abrevian de este modo. Los otros chupan los diferentes jugos de las plantas y algunas veces los líquidos animales, y viven la mayor parte parasitos. En ambos casos la longitud del conducto intestinal es proporcionada al género de alimento del insecto: corto, si es animal; largo, si es vegetal. Sin embargo es preciso observar que en general las especies fitofagas tienen dos estómagos; un buche membranoso, y una molleja musculosa y muchas veces guarnecida de piezas duras en lo interior.

El hecho mas curioso de la historia de los insectos es su reproduccion. Todos son vivíparos y ponen una enorme cantidad de huevos, cuya incubacion se rerifica por la influencia de los elementos; pero el hijuelo que resulta de ella no tiene casi nunca cuando nace la figura de sus padres; no llega á esta última sino gradualmente $\mathrm{y}$ por medio de cámbios sucesivos, que se llaman metamorfósis. Estas metamorfósis son en número de tres: primeramente el insecto es lärva ú oruga, (larva vel eruca) tiene una forma prolongada, bastante semejante á la de un gusano, unas veces sin patas, otras provisto de pies; en este estado que dura bastante tiempo, el animal es siempre movible y consume mucho alimento. Despues se convierte en ninfa ó crisálida 
(nympha, chrysalida vel pupa); entonces tiene la forma del animal perfecto, pero las diversas partes de su cuerpo estan contraidas y cubiertas por una membrana mas ó menos sólida, que le da el aspecto de una momia fajada ; por consiguiente está generalmente desprovisto de toda movilidad. Este estado, durante el cual el insecto jamas toma alimento, dura menos que el precedente, y se termina por un último cámbio, á consecuencia del cual el animal ha tomado la figura que debe conservar hasta su muerte. Entonces es insecto perfecto (imago), pero no vive sino poco tiempo bajo esta forma; su existencia se limita muchas veces á algunas horas y no pasa de algunos dias; se aprovecha de ellos para hacer su postura y para preparar á su posteridad un sitio comveniente.

Algunas especies no esperimentan unos cambios tan completos. La larva y la ninfa no se diferencia del insecto perfecto sino por rázon de sus alas; los demas órganos esternos son idénticos; estos son los insectos de semi-metamor fósis; que otros llaman metamorfósis media; aun hay algunos en los que las metamorfósis se limitan á simples mudas semejantes á las de los crustaceos y. aracnides.

La estension de la clase de los insectos, cuyo núme_ ro escede al de todos los animales reunidos, ha exigido que los naturalistas hiciesen un estudio profundo de todas las partes de su cuerpo, para dividirlos con método en órdenes, familias, tribus, géneros, \&cc. Su division se ha fundado principalmente en la carencia ó existencia de las alas, en la natura!eza y número de estos órganos, en la conformacion de las partes de la boca, en la figura de los palpos y de las antenas; en el número y disposicion de las articulaciones del tarso \&cc. 


\section{5}

Segun estas consideraciones se ha dividido toda la clase en ocho órdenes.

Unós carecen de alas y se llaman apteros; forman el primer órden, al cual pertenece el piojo, la pulga \&c.

Todos los demas tienen alas; pero unos tienen cuatro, al paso que otros no tienen mas que dos; estos constituyen el último órden, el de los dipteros, tales son la mosca, el mosquito \&c.

Las especies de cuatro alas tienen unas veces las cuatro membranosas, $y$ otras dos elictras y dos alas ordinarias. Los insectos que tienen elictras $y$ alas forman tres órdenes: el de los coleópteros que tienen la bo. ca organizada para la masticacion, y las álas plegadas solamente al traves (el abejorro, el ciervo volante \&c.); el de los ortópteros que son tambien masticadores, pero cuyas alas estan plegadas á lo largo ó en los dos sentidos (el grillo, la langosta \&c.) ; y el de los hemípteros, que tienen la boca conformada á modo de chupador (la chinche, el pulgon.) Es preciso observar por lo que respecta á estos últimos, que su clasificacion la decide mas bien la figura de su boca que la naturaleza de sus alas; porque hay algunos de ellos que no las tienen, por ejemplo, la chinche comun.

Los insectos que tienen cuatro alas de la misma consistencia, constituyen tambien tres órdenes : el de los neurópteros que tienen mandibulas y maxilàs, ordináriannente muy imperfectas y las alas de igual longitud y reticuladas (las doncellitas); el de los himenópteros que fienen poco mas ó menos la boca de los precedentes, pero cuyas alas inferiores son mas lpequeñas que las superiores $y$ simplemente venosas, y cuyo abdómen se termina, en las hembras, por un aguijon (las abejas, las avispas); y el de los lepidópteros, cuya boca es una trompa, y cuyas alas estan cubiertas de 


\section{6}

escamitas y coina llenas de polvo (las mariposas, las polillas.)

in La clase de losinsecilos,se compone pues de los bcho órdenes siguientes $10^{\circ}$ los ápteros, 2, los coleópterós; 3. los ortópteros, 4 io tos hemípteros, 5. Ios nevrópteros, 6.i. los himenópteros, $70^{\circ}$ los lepidópteros, 8. los dipteros. ni tree

\section{PRIMER ÓRDEN.}

ast and and and

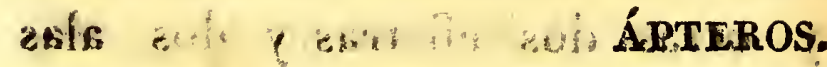

- El Lórden de los ápterios se compone de todos los insectos sin álas, y comprende especies bastante diferen tes por su organizacion y costumbres; pára que algunos naturalistas hayan hecho de ellas tres órdenes distintos. Pero como este grupo es poco considerable, se les puede reunir con mucha facilidad en razon de que ademas de la falta de alas, tienen tambien pòr carácter comun no esperimentạ s sino metamorfósis incompletas, y muchas veces ninguna.

Ademas la mayor parte de estosinsectos viven parasitos sobre los cuerpos de otros animales, cuyos humores sirven para alimentarlos y cuyos tegumentos los preservan de la intemperie del aire. No obstante un corto número de especies viven en la tierra,'se eseénden debajo de las piedras 6 de la madera podridà, y yllegan hasta el interior de nuestras habitaciones á buscar un asilo en nuestros armarios.

-5 Este órden comprende tres pequeñą familias : los tisanouros los parasitosigi los sifonápteros ó chupadores. 


\section{7}

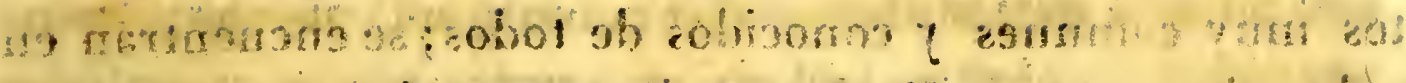

\section{PRIMERA PAMULEA:}

\section{TISANOUROS.}

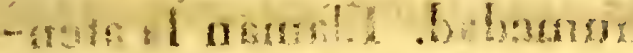

Escá familia esta ruicardel órdén de los ápteros que no encierra sino, ínsectos que viven ep la tiorra, los de las otras dos son todos parasitos. Son fáciles de distin guir por su boca armada de maxilas, por su abdómen separado del torax por un angóstamiento, y principal-s mente por las cerdas ó filamentos que terminan su: tronco por detrás y icarácter que les han hecho dar el nombre de tisanouros ó de 'seticaudos, que quière decir, cola con filamentos ó cerdas.

Estos sou unos insectos de cuerpo blando, prolongado, cubierto de escamitas finas y dellgadas, que dan áo swe cuerpo un brillo plateado, pero que se caen fącilmente cuando se toca al animal. Sus movimientosnian la tierra son siempréágiles, bien que anden pormedio de sus patas, bien que salten con la ajuda de sus filamentos abdominales.

Los tisanouros presentan una partácula ridad notable, y es que no mueren en ol invierab; siho que conservan: su actividad lurante toda esta estacion que parece ser la de la reproduccion. Na es rarovencontrarles, cúañdo el tiempo es bueno; saltạndo ý corriendo al pie de los árboles y a ún sobre la inieve: lo quel pruebá que duo sé alimentan solamente de insectos, isino que viven tambien

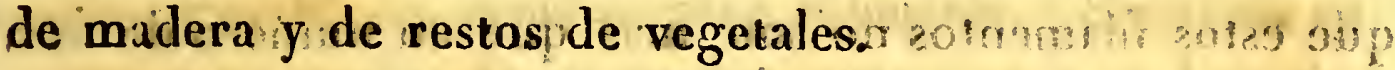

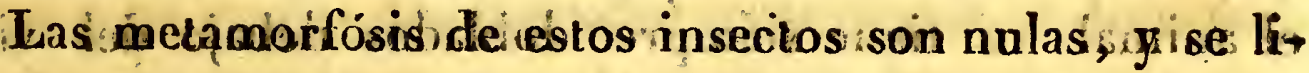
mitan á simples cambios de la piel. En España tenemos algunas espicies de los dos géneros do esta familia: las forbicinas y los poduros.

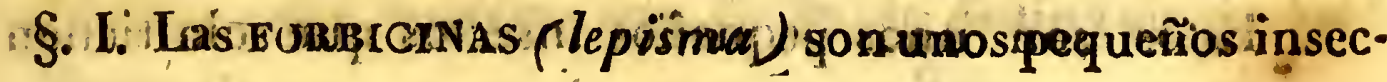




\section{8}

los muy comunes y conocidos de todos; se encuentran en todos tiempos, cornecido por losicercos de las ventanas, y escondiéndose, cuando se acercan á ellos, en las rendijas de los armarios, de los suelos entablados y en todos los sitios en que encuentran un poco de humedad. Llaman la atencion por la vivezá de sus movimientos por los tres filámentos rectos que terminan solà, oy por suihermoso color plateado que es debido á sus escamitas: seria muy fácil tomarlos pör unos pécecitos muy pequeños en razon de que á este brillo metáli correunen una forma prolongada unos moviduientas tan uniformes, que sé asemejan tảnto al nádo de un animal acuático, como á là marcha de un insecto terréstre.

De estas tenemos una especie muy comun en nuestras habitaciones, que es la lencera ó forbicina del azucar ó plateada (lepisma sacharina) que se ha llamado asi porque se la encuentra comunmente e $n$ los armarios de ropablanca $y$ en aquellos enque se guarda el azucar, No tiëne mas de tres á cuatro líneas de larga y ha sido importada de América, en donde es muy abundańte en las plantaciones de cañas de azucar. Otra especie menos comun es la forbicina jaspeada (lepisma polipoda) aspeada de oro y dé color pardo, y que se encuentra en las paredes viejas.

§. II. Los poduras (podura) (fig. 8.) se parecen á lis precedentes por su forma prolongada, por su piel blanda y cubierta de escamas, asi como tambien por los filamentos questerminan su abdómen. Pero ademas de que estos filamentos no son mas que en número de dos; ell animąl los tienersiempre doblados debajo del wientre cuando está én quietud, y sé sirve de ellos como de un resorte para elevarse á una altura considerable respecto á su magnitud.

- aser Estos son cunos péqueños insectos que solo tiènen 
una línea de longitud, y se encuentran ya én los árbóles' ya en las aguas, ya en las márgenes de los caminos, en donde forman por su reunion pequeños montones semèjanteś á la pólvora de cañon ligro que les ạmenaza, al menor temor que les ágita se separan prontamente, y desdoblando repentinamente su cola, se abalañzan á saltitos hácia alguna guarida próximá.

En España existen siete ú ocho especies de este género, entre otras la podura negra y la podura acuática.

\section{SEGUNDA FAMILIA.}

\section{PARASITOS. (Lám. XXXIII.)}

El nombre de parasitos indica la principal costumbre de estos insectos', que viven sobre el cuerpo de otros animales cuya sangre chupan, á pesar de haber pretendido algunos naturalistas, que no atacaban sino á sus plumas ó pelos. Todo se reune por el contrario para probar que se alimentan de su sustancia: las comezones que causan, las llagas que hacen en su cuerpo, la prontitud con que se alejan de los cadáveres, y por fin la sangre que se ha encontrado en el estómago de los que se han abierto. Por otra parte la organizacion de su boca no puede ser mas propia para este uso; unos tienen maxilas armadas de ganchos para adherirse á la piel de su victima y en medio ún chapador para sacar el líquido; otros no tienen mas que éśte último órganol que no podria servirles para cortar y roet materias duras como los pelos.

Todos estós insectos son fáciles de distinguir de las Tomo III. 
precedentes por la falta de esas petos abdóminales que estos nos han ofrecido asi camo tambien por la diferencia de sus costumbres.

- Esta familia no encierra mas que dos géneros, como la de los tisanouros, que son los piojos y los ricinos. 9. S. Pocas personas habrá que no hayan tenido ocasion de ver fejosos (pedicillus) (fig. 9.); itanmuliplicados y comunes son estos huéspedes incómodos! $\bar{Y}$ sin embargo se conoce poco là organizacion de estos insectos y los instrumentos de que se sirven para atormentarnos. Su cuerpo es aplastado, casi trasparente, y provisto de seis patas, terminadas cada una por una uña muy, fuerte ó por dós ganchos dirigidos el uno hácia el otro de modo que se agarran á los pelos y cabellos con uná fuerza estraordinaria para un animal tăn pequeño. Su cabeza, á pesar de ser tan pequeña, sostiene dos antenas movibles y compuestas de cinco articulaciones, y presenta en sa parte inferior el chupador, por medio del cual thúpan la sangre despues de haber horadado la piel del animal con un aguijon córneo que llevan debajo del vientre.

fir Se conocen generalmente las costumbres de estos se: res desagradables, y que se miran como asquerosos, no tanto por razun de su conformacion, como por el desaseo que anuncian en los que los tięnen. Pero lo que no todós saben es el gusto que algunos pueblos de Africa tienen por los piójos, los que comén con delêite; y lo que tal vez sersabe ménos es la rapidez con que estos insectos se pueden multiptiecar; se ha calculado que un solo individao dé éste género podia producir en dos meses diez y ocho mil hijuelos; fecundidad prodigiosa que esplica como en ralgunos casos han podido determinar en el hombre una enfermedad á reces mortal (la tiriasis ó enfert medud pedicular) ? I Sus huevos, que (se llaman liendres, 
se pegan ả los Icabellos, álos palos de los vestidos, la la ropa blanca \&c. por medio de un liquido viscoso que los cubre, y no tardan en producir un pequeño animal que se hâlla ęn estado de éngendrar ló diez ocho dias despues le su mácimienuo.

Sivb hanbre cria sobral su cueppo dos especies principales de este género: el piojo de la ropa for humanuís corporis), que es blanco, y el piojo de la cabeza (P. humanus capitis), que es negruzco. La mayor parte de los mamíferos crian cada uno una ó muchas especies particulares. Alganos de la que otros forman un género separado; esta es la

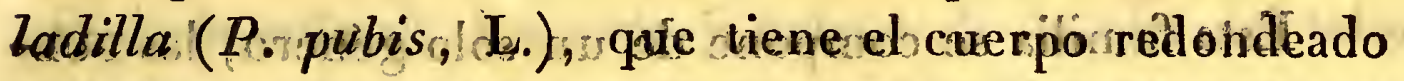
y ancho, el torax muy corto, y confundiéndose con $\mathrm{el}$ abdómen.

- §. II. Jos RICINos (ricihusi) ?(fig. 10i) ison' pana las aves lo que los piojos para tos cuadrúpedos, ounds pará sitos incómodos y roedores que viven á sus espensas. ISu forma estęrior y sus cóstumbres se parecen tanto á las de estos últimos; que los antiguós natutalistas los reunian en un solo género, y el pueblo los designazbódás vía con un solo y mišma nombré.

Con todo estás dos especies de insectos sor fáciles de distinguir por la figura de su boca, que én/lósi piojos coúsiste en un simple chupador, al paso que en los ricinos presenta ademas dos mandibulas y dos maxilas. Por otra parte, la cabeza de los ricinos es proporcional mente mayor, y sobre todo mas ancha que la de los piojos. Por lo demas se agarran á las plumas, como los precedentes á los pelos, por medio de los ganchos de sus patas, y chupan la sangre de sus víctimas del mismo modo. Pero se observa que los ricinos son muy ágiles y que andan con vélocidad, pripcipalmente cuando se 
procurá cogerlos , ó huyen del cadăver del ánimal sobre que vivian.

- Se cuentan casi tantas especies de ricinos como aves; los más comunes'son el ricinó de la pavióa, el ricino del verderon, el ricino de la gallina \&c. El perro es úno de los mamiferos en que se ha observado una éspecie de este género.

\section{TERGERA FAMILIA.}

\section{SIFONÁPTEROS. (Lám. XXXIII.)}

Esta familia se compone de un solo género, las puLGAS (pulex) (fig. 11.) que tienen por boca un chupador cubierto de dos escamas en su base; carácter que básta para disținguirlàs de los tisanouros y de los parasitos. Porcotra parte se diferencian de estos por lá longitud de sus patas posteriores, que sirven á estos animàles para e̊gecutar sus estraordinarios saltos, y por las verdaderas metamorfósis que sufren como los insectos aládos.

Si las pulgas no fueran tan incómodás, no se podria menos de admirar la elegancia de sus formas, la flexibilidad de sus miembros, y sobre todo la estension de sus saltos. Saltan, en atencion á sú magnitud, cien veces mas alto que el hombre mas diestro y ágil ; pero sus costumbres son demasiado desagradables para que se haga caso de su hermosura. Viviendo sobre el cuerpo de un gran número de cuadrúpedos, les causan picazonès dolorosas, muchas veces dolores vivísimos, principalmente cuando se introducen entre cuero y carne, 6 penetran en alguna abertura natural, como la del oido. Hacen tanto mas daño, cuanto que depositan alli algunas 
wecesisus huevos, y como las larvas que se desarrollan -son muy vivas y ágiles, producen dolores insoportables, que tendrian una terminacion funesta si no se llegase á estraerlas. Estas larvas, despues de haber vivido en este -estado por unos doce dias, se forman una especie de capullo, en donde pasan el mismo espacio de tiempo antes de llegar á serinsectos perfectos.

Se cuentan muchas especies de este género, la principal és la pulga comun (pulex irritans, L.), tan conocida de todos. La pulga penetrante, nigua ó chica ( pulex peñetrans), es otra especie análoga, muy esparcida en la América méridional, y que introduciéndose debajo de la uña de los pies y debajo de la piel del talon adquiere alli prontamente el volúmen de un guisante gordo, por el desarrollo de sus huevos que ella lleva debajo dél vientre. Entonçes determina los mas graves accidentes, $y$ aun á véces la muerte, si no se tiene cuidado y destreza en estraerla como lo hacen los negros, ó en destruirla cauterizando con aceite hirviendo el punto que ocupa, antes de que haya hecho su postura.

\section{SEGUNDO ÓRDEN.}

COIEÓPTEROS.

El órden de los coleópteros comprende todos los insectos de cuatro alas, de las que las anteriores (las elictras) son de naturaleza córnea, y sirven de estuche ó vaina á las posteriores, que son ligeras, trasparentés y plegadàs al traves en el estado de quietud.

Segun esta definicion; beria siempre fácil distinguir estos insectos si todos tuvieran alas; pero hay un cierto número de ellos que estan desprovistos de esta especie de órganos, y: que es preciso póder distinguir. 


\section{4}

por otro carácter. Este carácter pues se eńcuentra eñ la conformacion de su boca, cuyas maxilas estan siempre libres y no encerradas en una vaina ó dispuestas en forma de trompa: Por consiguiente su boca está completamente organizada para la trituracion de sustancias sólidas, y formada de dos tabios, dos mandíbulas y dos maxilas con palpos distintos y articulados.

A estos dos caractéres esenciales se debe añadir qứe los coleópteros tienen generalmente el labio inferior dividido en dos partes, una superior, quelleva dos palpós y conserva sola el nombre de labio, y otra inferior que sirve de apojo á la precedente, y que se designa con el nombre de barba. Su coselete, formado siempre de tres segmentos, tiene el de en medio mas desarrollado que los otros dos, y solo visible al esterior; este es el que sirve de apojo a tás elictras; y lleva el nombre de escudo. Su abdómen no presentalnada de particular, si no es que en las hembras se termina regularmente en forma de taladro destinado para colocar los huevos en el sitio mas favorable para su desarrollo. Sus patas ofrecen en el número de las articulaciones de sus tarsos un carácter del que se ha sacado mucho partido para la division y subdivision de los coleópteros; este número es invariable no solo en las mismàs especies y géneros, sino támbien én los génénes análogos por sus costumbires.

Las melamorfósis de los insectos del ónden de que hablamos son completas. Su larva, que dos jánidineros llaman comunmente orug blanca, es vermiformé, y casi siempre provista de seis patas ; es muy ágil y voraz, y vive generalmente muchbotiempo, poriconsiguien? te tiene costumbreś interesantes: despues se formá un capullo; en el cual perimanecę completagnente inimọivil 
durante un tiempo variable para pasar por fin al estada de insecto perfecto.

Se dividen los coleópteros, segun la consideracion de sus tarsos, en cuatro subórdenes unos tienen cinco articulaciones en todos sus tarsos, y son los coleópténos pentrimeros otros tienen cinco ó cuatro tarsos delante, y cuatro solamente ó dos detras, y son los coleópterios heterómeros ; los del tercer subórden son llamados coleópteros tetrámeros, porque no tienen mas que cuatro articulaciones en cada tarso; por fin el cuarto es el de los coleópteros trimeros, que no tiener en los tarsos mas que tres articulaciones ólmenos.

\section{PRIMER SUB-ÓR DEN.}

\section{COLEOPTEROS PENTÁMEROS.}

Este sub-órden es el mas numeroso, y comprende cuatro familias principales, que se distinguen por el número de sus palpos, por la figura de sus antenas y de sus elictras \&c. Estas familias son los carniceros, los clavicornes, los serricornes y los tamelicornes.

\section{PRIMERA FAMLLIA.}

\section{GARNIGEROS, (LÓT. XXXIII.)}

Estos coleópteros tienen dos caractéres distintivos bien marcados en el número de sus palpos, que es de seis, dos en el Jabio inferior $y$ dos en cada maxila; y en la longitud de su cadera, que iguala, en las patas de atras, al tercio de la de los muslos.

Todos estos insectos, como lo indica su nombre, se alimentan de, presa viva, y, tienen una destreza y una 
agilidad notables para apoderarse de ella. La fuerza de sus tarsos y los dientes córneos de que estan armadas sus maxilas les forman unas armas poderosas, por medio de las cuales vencen y devoran á la mayor parte de los insectos, y aun muchas véces á animales mas considerables. Sus larvas no son menos ágiles ni menos carniceras que el insecto perfecto; su boca presenta cași los mismos órgános que la de este último, y no está menos poderosamente armada.

Hay entre los carniceros especies terrestres y especies acuáticas. Las primeras se conocen por sus tarsos redondeados y apropiados para la progresion y el salto; se reducen á dos tribus, la de los cicindeletos y la de los carábicos. Los demas tienen esta parte aplastada en forma de aletas, y se llaman hidrocántaros.

\section{PR I M E A TR IB U.}

CICINDELETOS. (fig. 12.)

Esta tribu se distingue de los carábicos en que tiene en la estremidad de sus maxilas un gancho movible y articulado y los palpos del labio inferior mas gruesos ó mas largos que los de las maxilas. Estos insectos forman un grupo numeroso de carniceros terrestres, muy ágiles en la carrera, graciosos en sus formas y generalmente buscados por razon de su hermosura y el brillo de sús colores. Se encuentran en los paises secos y areniscos, y principalmente á la parte del Mediodia, en donde tienen los colores mas vivos, y relucen muchas veces con un brillo metálico. 'La longitud de sus patás da á sus movimientos una gran velocidad; pero generalmente vuelan mal, y únicamente á sacudidas. A un un gran número de ellos estan completamente desprovistos 
de alas membranosas y no pueden levantarse de la tierra. Sus larvas son muy curiosas por los medios industriosos que emplean para engañar su presa. Se practican con sus mandíbulas y sus patas un agugero, al cual dan hasta diez $y$ ocho pulgadas de profundidad, y en el que introducen toda la parte posterior de su cuerpo hasta la cabeza, la que les sirve para cerrar la entrada. Agazapadás en esta madriguera, esperan la llegada de algun insecto. Luego que han podido coger alguno, se dejan caer al fondo de su habitacion, en donde devoran'su víctima á su despacio; de la misma estratagema usan cuando se ven amenazadas de algun peligro.

Esta tribu encierra muchos géneros, de los que los principales son los manticoros, especies estrangeras y meridionales, notables por el grosor de su cabeza, y las cicindelas, que tienen la misma parte de mediana magnitud, y de las cuales tenemos muchas especies en España; tal es la cicindela campestre (fig. 12.), y la cicindela de los bosques \&c.

\section{SEGUNDA TRIBU.}

\section{CARÁbicos. (Lám. XXXIV.)}

Esta tribu es escesivamente numerosá, y comprende todos los carniceros terrestres cuyas maxilas estan terminadas en punta 6 en gancho inmóvil, y cuyos palpos labiales son tan cortos y delgados como los maxilares.

Eistos coleópteros pasan debajo de las piedras casi todo el tiempo de su vida en el estado perfecto, y salen de su madriguera mas bien por la noche que de dia; asi es que jamas ofrecen aquellos colores brillantes que se admiran en la mayor parte de los cicindeletos; sus tintas son generalmente negras y siempre obscuras: $\mathrm{Mu}$ cho menos ágiles que estos últimos, y las mas veces pri-

Tono III. 
vados de la facultad de volar, habitan todos en tierra, á escepcion de un corto número de especies, á quienes la agudeza de sus garras permite trepar por los árboles para devorar las orugas que no pueden moverse.

Al paso que los cicindeletos no frecuentan sino los parages secos y espuestos al sol, los carábicos por el contrario, buscan con preferencia los sitios húmedos, las praderas inundadas, y se esconden debajo de las piedras, en los troucos de los árboles \&cc., en donde se encuentran reunidos en tropel. La mayor parte de ellos esparcen, cuando se ven cogidos, un líquido acre, cuyo olor es bastante penetrante para alejar á sus enemigos.

Esta tribu podria por razon de su estension, formar una inmensa familia, encerrando muchos miles de espécies, que se reducen á diferentes géneros, de los: cuales los mas principales son los braquinos., las feronias, los elafros y los cárabos.

§. I. Nada tienen los Braquinos (brachynus) (fig. 1.) de notable en la forma de su cuerpo; pero son curiosos, por là facultad que tienen de producir, cuando son inquietados, una detonacion bastante fuerte, y de lanzar á sus enemigos un vapor cáustico, que enrojece primero y despues ennegrece la piel espuesta á su accion; pero no emplean este recurso sino en el último estremo, y cuando se ven á punto de ser cogidos. Mientras conservan la esperanza de escapar huyendo del enemigo que les persigue, corren con toda la velocidad que les permiten sus miembros hácia una guarida apropiada para protegerlos únicamente cuando este medio no pues de preservarles, es cuando hacen la primera descarga de su líquido vaporoso; si esta no basta para alejar á su perseguidor, recurren á una segunda, á otra tercera , y asi sucesivamente hasta diez ó doce. Pero á medida que sus descargas se multiplican, el liquido pierde 


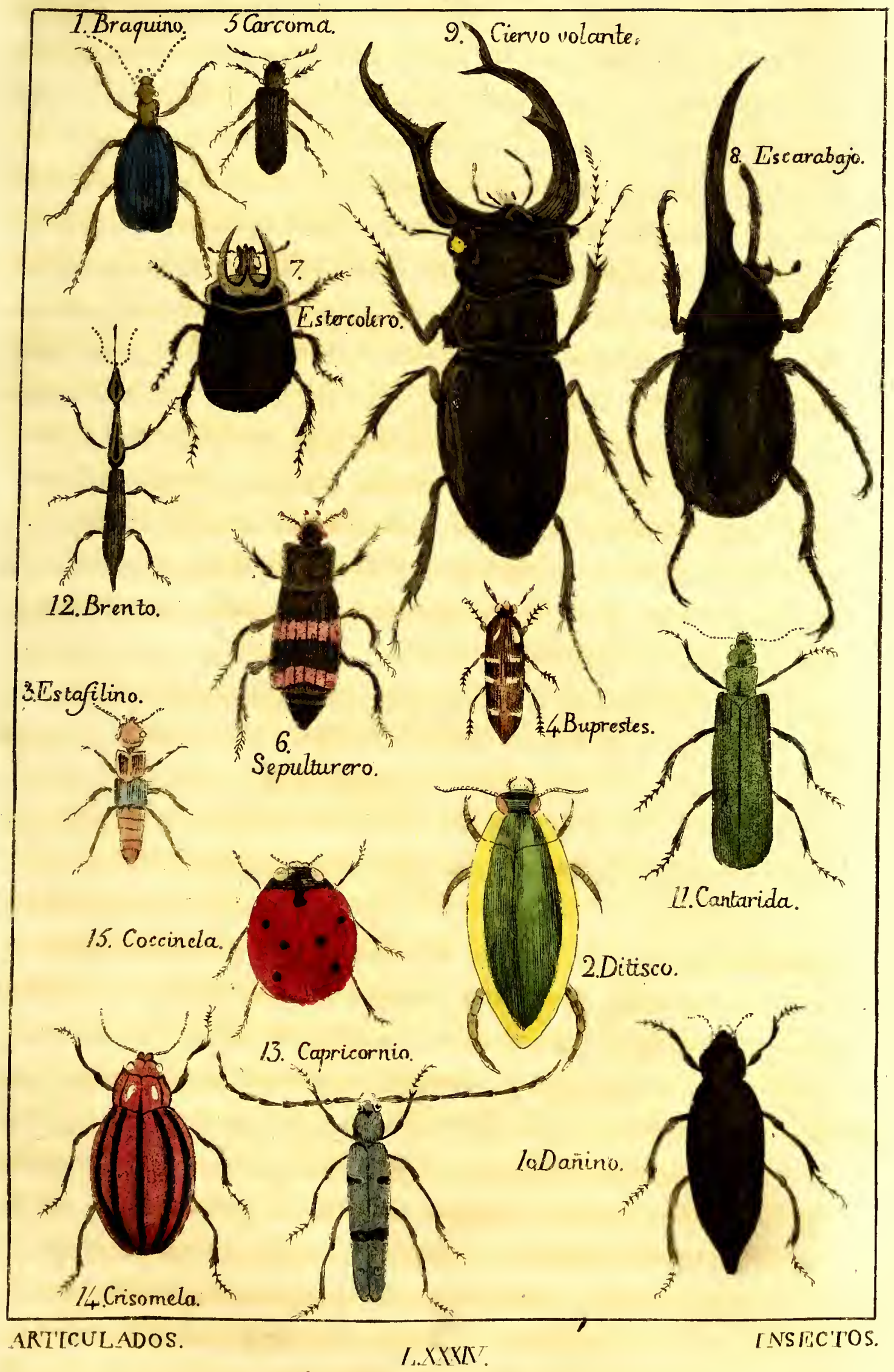



de su fuerza y disminuye en cantidad, de suerte que en las últimas el animal no produce ya sino una sustancia líquida, que no tiene propiedades dañosas, ni causa efecto alguno sobre sus enemigos.

En Francia existen muchas especies de este género, las principales son el braquino petardero (brachynus crepitans, Fabricius) (fig. 1.); el braquino pistola (brach. sclopeta, Fab.), que se diferencia de la especie anterior en tener la sutura de las elictras rojo-leonada desde la base hasta el medio; y el braquino bombardero (brach. bombarda), que tiene en las elictras una mancha amarilla al rededor del escudillo, pero que no se prolonga á lo largo de la sutura.

§. II. Con el nombre de feronias (feronia), que entre los antiguos era el de la diosa de la muerte, los naturalistas designan un género numeroso de insectos de colores obscuros y poco agradables á la vista. Asi es que estos coleópteros son generalmente poco conocidos porque, no llamando la atencion por la hermosura de sus formas ni por el brillo de sus matices, han estado largos años sin vérseles y confundidos en el género cárabo, que encerraba tambien en otro tiempo toda la tribu de los carábicos.

Todo la que se sabe de su historia es que viven en la tierra, debajo de las piedras y de los escombros, y que se encuentran en los campos y en los senderos que atraviesan nuestros bosques. Sus larvas, menos ágiles que las de los demas géneros de la misma tribu, tienen la forma de una oruga blanca, corta y gruesa; viven en la tierra á poca profundidad, y se construyen allí un capullo, en el que el insecto sufre su última trasformacion. En Francịa existen muchas especies de este género, tales son la feronia de ojos blancos, la feronia metálica \&c.

§. III. Los ELAFRos (elaphrus) son unos insectos de 
poca magnitud, y adornados la mayor parte de colores bastante vivos. Se parecen á las cicindelas por su agilidad y costumbres. Pero mientras que estas gustan de los parages secos y bien espuestos al sol, los elafros no apetecen sino los sitios húmedos y sombríos, las mas veces en las cercanías del agua. Por lo demas son igualmente carniceros, y se muestran muy encarnizados contra los insectos acuáticos, á los que persiguen vivamente por la arena que se halla en la orilla del agua.

Todas las especies conocidas de este género son europeas, y la mayor parte se encuentran en Francia, en los alrededores de Paris; el elafro riberiego (cicindela riparia, L.), de color negro bronceado con las elictras: llenas de hoyitos redondeados, es la mas comun.

§. IV. Lós cárabos (carabus) quehan dado su nombre á la tribu de que hacen parte, forman un género muy estenso, cuyas especies son todas grandes y adornadas de colores metálicos brillantes. Siempre se encuentran en tierra ó debajo de las piedras, de donde no salen sino durante la noche para ir en busca de larvas o de otros insectos. Estos son los mas temibles de todos los carniceros; no se contentan con devorar una inmensa cantidad de insectos; sino que se diria que encuenttran placer en quitarles la vida, sin que les obligue la necesidad del hambre. Se han visto algunos, de ello's hartos ya de orugas de toda especie, arrojarse con furor sobre otros individuos de la suya misma, á quienes el estado de replecion en que se hallaban reducia á la impotencia de defenderse, despedazarles y arrancarles uno por uno sus órganos interiores.

En el estado de larvas es cuando principalmente se muestran tan voraces; puede decirse que todo el tiempo de su vida se pasa en correrías ó en combátes para procurarse sú presa y en precauciones para ponerse, cuan- 


\section{1}

do estan repletos, al abrigo de los peligros que lés amenazan de parte de sus énemigos:

El género cárabo sé ha dividido en muchos subgeneros, de los cuales los mas principales son los cárabos propiamente dichos y los calasomos. Al primer subgénero se refiere el cárabo jardinéro ó dorado (qarabus auratus, L.) verde dorado por encima, negro por debajo, con los pies leonados y en cada elictra tres rayas de relieve; se encuentra en los campos y jardines durante todo el verano. Al segundo subgénero pertenecen el sicofanta (carabus sicophanta) de color brillante de violeta, con las elictras de bellísime verde dorado, y veinte estrias longitudinales en cada ; una y el inquisidor (car. indagator, Fab.) dos especies muy comunes en los alrededores de París.

\section{TERCERA TRIBU.}

hIDROCÁNTARos (Lám. XXXIV.)

Esta tribu se distingue fácilmente de las dos precedentes por la conformacion de sus tarsos, de los cuales los cuatro posteriores son comprimidos en forma de láminas y propios para la matacion, lo que hace quésús costumbres sean esclusivamente acuáticas. Pasan el primero y el último estado de su vida en las aguas dulces y estancadas de lós lagos, lagunási y estanques No obstante no pueden permanecer por mucho tiempo debajo del agua sin subir á su superficie parar respirar; la mayor parte del tiempo están vueltos sobre su dorso, y levantan la parte porterior de su cuerpo en la átmósfera, á fin de que el aire pueda introducirse ce tas traqueas para vivificar su sangre. Si mientras nadan asi tranquilamente viene á inquietarles algun peligtro, se 


\section{2}

precipitan rápidamente ál fondo del lagua, llevando debajo de sus elictras una burbuja de aire, para respirar mientras permanecen én él. La's larvas de estos insectos son estremadamente ágiles y carniceras; devoran una gran cantidad de animales terrestres y acuáticos y bajo este punto de vista hacen un verdadero servicio á la agricultura la que desembarazan de una multitud de oragas y gusanos incomodos.

Las costumbres enteramente acuáticas de los hidrocántaros no les impiden venir de cuando en cuando á tierra; $y$ aun parece que salen del agua todas las tardes para ir a pasar la noche en las oriltas; tambien habitañ en tierra firme durante su estado de crisalida ó ninfa.

Esta pequeña tribu encierra dos géneros principales, el de los ditiscos y el de los girinos.

§. I. Los Dirrscos (dytiscus) (fig. 2), cuyo nombre significa buzo, merecen bien esta denominacion por la rapidez con que descienden al fondo del agua, ya persiguiendo una presa fugitiva, ya procurando escapar de un enemigo; apenas pucde la vistä seguir sus movimieritos.

Pero no solamente en el agua dan prue bas de agilidad; sino que en la tierra andán y saltan casi tambien como las especies terrestres, $\mathrm{y}$ hasta pueden elevarse en el aire; de suerte que estos insectos andan, saltan, nadan y vuelan con la misma facilidad. Pero únicamente por -lá noche ó á su aproximacion es cuando se atreven á dejar su elemento favorito, para ir á dar una vuelia por tierra, ó para trasladarse á alguna balsa vecina; en donde esperan encontrar unalimento mas abundante; to- do el resto del dia te pasan en el agua ocupados en buscar sú presai.

92. Enicasi todas las aguas muertas se encuentran el 


\section{3}

ditisco marginal ó ribeteado (diliscus marginalis, $\mathrm{L}$.) negro, con el contorno del coseleté y de las elictras amarillo, el ditisco anchisimo (D. latisimus, L.), muy distinto por la dilatacion comprimida y cortante de ila margen esterior de las elictras, y el ditisco de Røesel (D. Raselii, F.) (fig. 2.)

§. II La palabra Jirino (gyrinus) es la traduc cion literal de la de torniquete que se da ordinariamente á unos insectos muy semejantes á los precedentes en sus costumbres y en los principales caracteres de su organizacion, pero que se diferencian de ellos por la cortedad de sus antenas, que son siempre mas cortas que su cabeza, al paso que en los ditiscos estos apéndices son mucho mas largos que esta parte del cuerpo.

Los jirinos son generalmente mas pequeños que los ditiscos; pero de ningun modo lés ceden en agilidad; se les ve dar vueltas sin cesar en la superficie del agua, describiendo círcúlos mas ó meinos éstensos; lo que les ha hecho dar su nombre; y como sus movimientos son muy rápidos y sús elictras de un negro de azabache brillante, se les: tomaria por unas perlas movibles, qué producen los reflejos masbvariados por eb juego de los rayos luminosos. : zolor

Aunque estos insectos hábitan con' smas frecuencia en la superficie que en el seno de las aguas, son muy difíciles de coger porque son muy pequeños y principalmente porque, luega que se ven perseguidos, se sumergen á una gran profundidad y no xuelven á parecer at aire libre hasta mucho tiempo déspues, y lá una gran distancia del parage en que se hà sumergido.

En casi toda Europa se encuentra el jirino nadador, que no tiene mas de tres líneas de largo; la $A_{-}$ mérica cria tambien muchas especies, unas mayores, y otras mas péqueñas que la nuestra. 


\section{SEGUNDA FAMILIA.}

\section{BRAQUÉlitros. (Lám. XXXIV.)}

Esta familia comparada con la precedente es poco numerosa; á ella correspondeu los coleópteros, que tienen el cuérpo prolongado, los palpos en número de cuatro solamente, y cuyas elictras son demasiado cortas para cubrir enteramente su abdómen. Este último forma siempre mas allá de estos est uches sólidos una eminencia considerable, to que permite al animal levantarle, moverle en todas direcciones y servirse de él para hacer entrar sus alas debajo de las elictras. Esta cortedad de las elictras es la que distingue principalmente á los insectos de esta familia; pero para mayor seguridad es preciso añadir que sus antenas son moniliformes, es decir, compuestas de articulaciones redondeadas en forma de granos y reunidas como las perlas de un collar.

Por lo que toca á las costumbres de los braquélitros son las mismas que las de los carniceros: se aliméntan principalmente de presa viva ó/descarnęs muertas, y pasan su vida en los parages húmedos; sus metámorfósis sexuefectúan débajo de tierrą de dondé no salen hasta que han llegado al estado perfecto.

- In Esta familia no encierra mas que un género importante, el de los ESTAFILINOS (staphylinus) (fig. 3.) insectos bastante comunes én todos los paises y y notables por la costumbre que tienen, cuando se les toca, de enderezar su abdómen y hacer salir de él, pará alcjar de sí á sus enemigos, un líquido que, volatilizándose, produce un olor penetrante y muy nauseabundo.

Estos coleópteros son muy ágiles; andan de prisa y vuelan con rapidez; por consiguiente hacen un gran 
consumo de insectos, que cogen con sus mandibulas; y que despedazan en seguida con los dientes de que están armados estos órganos. Los estafilinos se encuentran por todas partes, debajo de las cortezas de los árboles, en los estercoleros y en los cadáveres; en todos estos sitios se cavan con sus patas anteriores, cuyos tarsos son anchos y robustos, unos agugeros en donde depositan sus huevos que son muchísimos: Las larvas que provienen de estos huevos pasan debajo de tierra ó en el estiercol el tiempo de sus metarmorfósis. Se encuentran con frecuencia en nuestros paises el estafilino peludo (St. hirtus, L.) (fig. 3.), y el estafilino odorifero (St. olens, Fab.) de color negro, con la cabeza mas ancha que el coselete $y$ las alas rojizas.

\section{TERCERA FAMILIA.}

\section{SER I C OR N ES.}

Las antenas de los serricornes son de igual grosor en toda su estension ó se terminan en punta; pero en todos casos, son mas ó menos dentadas en figura de sierra ó de peine, y aup forman un abanico. Por otra parte sus palpos son en número de cuatro, y sus elictras siempre de la longitud del cuerpo entero, lo que impide confundirlos con los carniceros y los braquélitros.

Esta familia muy numerosa se divide en dos tribus, la de los esternoxos y la de los molipennas. 


\section{PRIMERA TRIBU.}

\section{ESTERNOXOS. ( $X X X I I I$.}

Estos coleópteros tienen las elictras grandes y sólidas y el cuerpo de consistencia firme, lo que los distingue de la tribu siguiente, cuyo cuerpo es blandujo y los estuches débiles y flexibles; pero su principal carácter, el que les ha hecho dar el nombre de esternoxo (esternon agudo) se saca de la figura de su esternon ó porcion inferior de su primer segmento torácico que se adelanta hasta debajo de la boca, y este carácter no permite confundirlos con los de la última tribu.

Este grupo comprende dos géneros principales, los buprestes y los eláteres.

§. I. Los BUPREstes (buprestis) (fig. 4.) no tienen las formas elegantes de muchos insectos; pero ninguno hay que pueda rivalizar con ellos por el brilló y vivèza de los colores; sus elictras presentan la fusion más ádmirable del oro, cobré y otros metales con el azul y la escheralda. Admirado de la hermosura de estos natices, un naturalista frances les ha dado el nombre de ricachos, que conviene perfectamente con el lujo y magnificencia de su adorno.

Estos insectos son muy estimados en las coleccionés ehtomológicas : pero aúnque son bastatte comunes en nuestros paises y poco ágiles en su marcha, cuesta mucho el procurárselos, porque estando continuamente sobre las ramas, de donde huyen volando cuando algúno se les quiere aproximar, escapan de la mano y de la red en el momento en que se cree tenerlos cogidos; y cuando se hallan sorprendidos, se dejan caer á 
tiẹra y se esconden tan bien entre las hojas, que es muchas veces imposible descubrirlos.

En los alrededores de Paris se crian muchas especies, entre otras el bupreste verde (B. viridis), large, estrecho y de un verde bronceado obscuro; el B. esternicornio (B. esternicornis), cuya parte inferior del pecho forma un cuerno romo. El cuerpo es dorado brillante. El coselete y la cabeza estan llenos de hoyitos. El B. pequeño ó enano (B. minuta, L.) (fig. 4.), es tambien de nuestro pais y muy comun en los avellanos.

§. II. Se ha dado á los insectos que componen el género exaTER (elater) el nombre vulgar de escarabajos de resorte, porque cuando estan echados sobre el dorso, tienen la facultad de ponerse en pie, doblándose en arco y soltándose repentinamente; lo que imprime á su cuerpo un impulso que le hace saltar en el aire á una altura bastante considerable, de donde cae ordinariamente sobre su vientre y patas. Si no salen bien al primer golpe con su tentativa, la vuelven á empezar segunda y tercera vez, hasta que han conseguido su objeto.

El aparato que produce este fenóneno curioso y fácil de observar, forma el principal carácter que distingue á los eláteres de los buprestes; consiste en dos puntitas que terminan su coselete por sùs ángulos posteriores y en una eminencia que forma su esternon hácia atras.

Se encuentran los eláteres en todas las partes del mundo; pero los mas hermosos parecen propios de la Anérica meridional. Viven sobre las flores, las plantas pequeñas, $y$ andan alguna vez por tierra. La mayor parte de gllos esparcen por la noche una viva luz, como nuestras luciérnagas; todavia sobrepujan á estas por el resplandor cop que brillan, pues que pueden servir 
para alumbrar mientras se trabaja. Los salvages, en sus viages nocturnos por medio de los bosques, se atan algunos á sus pies para dirigirse en sus correrias, y las mugeres se adornan con ellos la cabeza en sus paseos por la noche.

En Francia existe el elater bronceado (elater aeneus), el E. castaño (E. castaneus) negro, con las elictras de color de naranja en la punta, el E. de collar rojo (E. ruficollis) negro, con la mitad posterior del coselete rojo. Eatre las especies estrangeras, la mas notable por su resplandor es el cucuyo ó mosca de luz, (E. noctilucus) que es bastante comun en la América del Sur.

\section{SEGUNDA TRIBU.}

\section{MOL I PENNAS.}

Estos coleópteros tienen, como los de la tribu precedente, el esternon prominente hácia delante y la cabeza mas ó menos cubierta por el borde anterior del coselete; pero se diferencian de ellos por la blandura de sus elictras y de toda su cubierta esterior.

Como estos insectos no pueden oponer á sus contrarios armas ofensivas ni defensivas, los engañan muchas veces por medio de la astucia, y se les escapan por su destreza y constancia. Cuando se ven cogidos por sus enemigos, hacen el muerto, y se dejan dar tirones en todas direcciones sin manifestàr la menor señal de vida; lo que, unido á un líquido colorado que derraman, fastidia á sus agresores y les obliga á retirarse.

Este grupo mas numeroso que el precedente comprende dos géneros principales: los lampiros y las barrenas ó carcomas.

§. I. Los Lampiros (lampyris) son conocidos de 
todo el mundo bajo el nombre de luciérnagas, lucernas ó gusános de luz. Quien es el que no ha encontrado paseáudose por la noche en el campo, estos insectos brillantes, tan comunes a lo largo de los caminos, bajo los setos y en las praderas? Algunas reces los lampiros hembras, casi se tomarian por unas orugas, en razon de la blandura de su cuerpo, si no se supiera que sus machos son enteraménte diferentes, y presentan todos los caractéres de la tribu de que hablamos. Lo que les distingue de los demas géneros del misino grupo, es que tienen los palpos maxilares erigrosados en su estremidad, el coselete grande y formando eninencia sobre la cabeza, y las mandibulas pequeñas y terminadas en punta muy aguda y lisa.

Los lampiros se encuentran, en verano, despues de ponerse el sol, en todos los parages un poco húmedos, en donde esparcen una luz ligeramente verdosa. Esta luz se hace mas viva cuando sê les incomoda; pero si se cogen con la mano, no despiden mas que una débil claridad, y a veces no brillan mas. La causa de este fenómeno es poco conocida ; únicamente se sabe que el aparato que le produce reside en los últimos anillos del abdómen, y no obra sino por la voluntad del animal.

No tenemos en España mas que dos ó tres especies de este gériero, de las cuales la más conocida es la luciernaga comun (lampir. noctiluca, L.) de color gris ceniciento y el cuerpo rojizo ; la de Italiat (lium. it alica. L.) es negruzca, con el coseléte rojo y él estrecho del

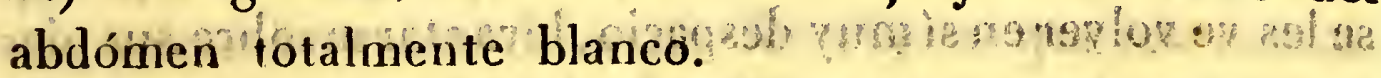

§. II. Se da el nombre de BARRENA ó carcormas (anobium) (fig. 5.) a unos pequerios itisectos que hacen en la madera unos agujeros redondós como los haria una barrena. Se distinguen por sus mandíbulas cortas, gruesas y, dentadas. 
Estos molipennas son muy comunes, en la primavera, en todos los sitios en donde hay madera, y hasta en nuestras habitaciones, Se les ve paseando á lo largo de los maderages, ú ocupados en agugerear los muebles viejos; estos son los que producen aquel polvo que se halla tantas veces cerca de las maderas carcomidas.

Sus larvas no son menos dañinas. Semejantes á un pequeño gusano blanco, roen continuamente la madera seca en que viren, y en donde verifican sus metamorfósjs de orugas en crisalidas, y de crisalidas en insectos perfectos. Unicamente entonces es cuando dejan su madriguera para cuidar de su reproduccion.

Uno de los hechos mas curiosos de la historia de las carcomas es el ruido que producen muchas veces desde el fondo de su escondrijo, ruido análogo al del volante de un reloj, cuya regularidad, y sobre todo cuya interfupcion y continuacion periódicas escitan casi siempre la sorpresa de las personas que, estando solas y tranquilas en un aposento, no saben á que atribuir la causa de esto, y le dan algunas reces un origen sobrenatural y ridículo. Parece que estos insectos de producen con el objeto de llamarse y atraerse recipros camente.

Otra particularidad no menos notable en astos animalitos, es esa obstinacion que muestran en hacer el muerto cuando se ven cogidos. Por mas que seles menee y atormente por medio del agua del, fuege no idan señal alguna de vida; pero apenas se cesa de tocarlos, se les ve volver en sí muy despacio, levantarse sobre sus pias y alejarse, pero con una lentitud sumamente estraordinaria La especie comun es negruzca con tas elictras es triadas longitudinalmente. 


\section{CUARTA FAMILIA.}

CLAVIConNes. (Lám. XXXIV́)

Estos coleópteros tienen, como los de la familia precederite, los palpos én número de cuatro, y las elictras bástante largas para cubrir casi énteramente el ábdóthen; pero se distingueh de ellos, en que sus antenas se terminan por ún engrosamiento que les da la forma de una máza, ordinariamente sólida : y cuando es tá fómada de hojas, las láminás que la componen no son hovibles a volúntad dél animal. De esta circunstancia sácan su nombre formado del lutin cornu antena, y clava maza.

La mayor parte de estos insectos viven, á lo menos en el primer tiempo de su existencia, de materiasanimales en putrefaccion, y pasan su vida én búscar los cadáveres de los animalés que perecen por casualidad. Bajo este punto de vista, los clavicofnes hacen un do ble servicio, destruyendo los malos olores que produciria su putrefaccion, y apresurando sudescomposicion.

Este género de vida, unido á la cóstumbre que tienen de no cazar sino de voche y de frecuentar mas que los sitios teuebrosos, haria inútiles para ellos esos hernósos cólores, que no encontramos mas que en las especies que viven en medio del dia; esta es la razon por que la mayor parte de los clavicornes son de colores puercos y oscuros como los objetos que los rodean y entre los cuales viven invisibles á los ojos de sus enemigờs:

Entre los géneros bastante numerosos que encierra esta familia, no citaremos nias que los necróforos y los dermestes. 
§. I. Los Necróronos (necrophorus) (fig. 6.) llevan' los nombres vulgares de sepultureros ó enterradores, que no son mas que la traduccion de la voz científica. Se les ha llamado asi, porque tienen la costumbre de enterrar los cadáveres de los péqueños cuadrupedos que encuentran en lós campos, como dos de dos topos, turones, musarañas, \&c. Para este fin, se reunen en tropas y empiezan á cavar la tierra por un lado, hasta que el cadáver rueda al pegueño agugero que han hecho; en seguida pasan al lado opuesto y hacen lo mismo. De este modo cavando alternativamente á derecha é izquierda, concluyen por cubrirle enteramente de tierra; concluida la operacion, hacen su postura en lo interior del misno cadáver, á fin de que sus hijuelos encuentren al salir del huevo un alimento conveniente á suorganizácion y necesidades.

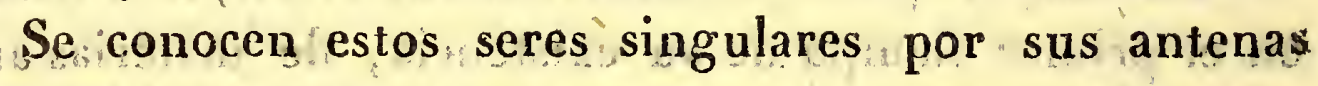
terminadas en botones, y por sus elictras un poco mas cortas que el abdómen. Se encuentran en el estiercol, sobre las materias animales en putrefaccion, \&c; asi es que todos tienen un olor muy fuerte á carne corrompidá, que conservan largo tiempo despues de su muerte, y que comunican á las cajas en que se les encierra. Cuando se coge en la mano alguno de estos insectós, derrama un líquido negrò y fétido que emplea segun dicen, para acelerar la descomposicion de los cadáveres de que quiere alimentarse.

- Se conocen muchas especies de este género, entre otras el enterrador ö punto de Hungria (silpha vespillio, Fab.) (fig. 6.) el zampa muertos, \&c.

§. II. La palabra DerMestes (dermestes) está formada de dos voces griegas que significan come-piel, y conviene perfectamente á estos insectos que vivèn todos á espensas de los despojos de los animales que se conser. 
van en los almacenes, gabinetes, \&c. Son principal. mente célebres por los estragos que hacen sus larvas en las colecciones de historia natural y en los almacenes de manguiteria; roen de tal modo el pelo ó las plumas de todas las pieles de los cuadrúpedos $\mathrm{y}$ aves, que pronto no queda mas que el cuero enteramente desnudo. Se introducen igualmente en las despensas, reposterías, \&c. y devoran todas las materias animales que alli se conservan. Se necesita la vigilancia mas activa para ponerlas al abrigo de su voracidad. Su poca magnitud, unida á la rapidez con que se reproducen, hace que hayăn destruido la mayor parte de las sustancias, antes de haber notado los primeros estragos que, han hecho en ellas.

Pero únicamente en el estado de larvas es cuando sou tan dañosos; luego que son insectos perfectos, viven muy poco para causar destrucciones; pasan todo el tiempo que dura su último estado, en buscar un parage conveniente para depositar sus huevos.

Se conocen los dermestes por su poca magnitud y por la maza que termina sus antenas, y que no está compuesta mas que de tres articulaciones. Las especies de estos son bastante numerosas: el dermeste raton, el dermeste de la peletería (D. pellio, L.), y el dermeste del tocino (D. lardarius, L.) son las principales.

\section{QUINTA FAMILIA.}

\section{IAMELICORNES.}

En los lamelicornes lo mismo que en los clavicornes las antenas se terminan en forma de maza; pero, en los primeros, la maza está formada de láminas foliaceas y susceptibles de abrirse y cerrarse casi como las hojas de 
un libro; por otra parte estas antenas estan implantadas hácia los bordes de la cabeza en una fosita profunda, que no se encuentra en los clavicornes.

El cuerpo de estos coleópterós es generalmente oval y grueso, y no tiene mas que movimientos pesados; pero ofrece una variedad de formas y de colores, que á pesar de su poca elegancia, los hacen buscar en las colecciones. No hay escepcion bajo este respecto sino para las especies que viven en el estiercol, la casca y la basura; estas tienen casi siempre los colores sombrios y uniformes.

Las larvas de estos insectos son largas, blandas, blancas, lo que les ha hecho dar mas especialmente el nombre de orugas ó gusanos blancos por los jardineros; viven generalmente en la tierra y permanecen en ella por mucho tiempo; sus metamorfósis no se concluyen completamente hasta el cuarto año de su edad. Durante este intervalo, las especies fitófagas, que son la mayor parte, causan muchos estragos en los jardines, $y$ hacen perecer una inmensa cantidad de vegetales destruyendo sus raices. Afortunadamente el invierno pone término á sus destrucciones, porque pasan esta estacion en el entorpecimiento ; á no ser por esto; es tal su voracidad, que aniquilarian toda vegetacion. Esta familia numerosa ha sido dividida en dos tribus: los escarabeides $\mathrm{y}$ los lucanides.

\section{PRIMERA TRIBU.}

escarabéides. (Lám. $X X X I V$.$) .$

Esta primera tribu, comprende las especies cuyas hojas antenarias son membranosas y susceptibles de abrirse y cerrarse alternativamente, ó estár arrólladas 


\section{5}

sobre si mismas en forma de cucurucho. Este grupo numeroso contiene coleópleros de gran magnitud y adornados la mayor parte de colores muy vivos.

Entre los géneros que encierra citaremos los estercoleros, los abejorros y los cetonios.

§. I. El nombre vulgar de ESTERCOLERo ó escarabajo pelotero (copris), asi como el nombre científico que se aplica á los insectos de que hablamos, se saca del elemento que parece prefieren á todos los demas; su habitacion la establecen casi esclusivamente en el estiércol y en la basura. Apenas ha depuesto un cuadrúpedo sus escrementos, cuando se ven acudir de todas partes estos escarabeides, que atraidos por el olor, vienen á hartarse de este alimento impuro. Con estas inmundicias forman una pequeña masa redonda y depositan en ella sus huevos; despues cubriéndola de tierra húmeda, la hacen rodar en el polvo para darla mas consistencia. Luego que está preparada, hacen un agugero proporcionado á su grosor, y la llevan rodando hácia él por medio de sus patas posteriores. Es un espectáculo singular durante el buen tiempo el ver á los estercoleros trabajar en comunidad, y ayudarse mútuameute á dirigir sus bolas hácia el agugero que las han preparado. Si durante el trabajo llegan á perder el equilibrio, la bola rueda por un lado y los estercoleros por otro, echados sobre el dorso y con las patas en el aire. Entonces agrada ver los esfuerzos que hace el propietario de la bola para volverse de pies antes que algun otro se apodere de ella en beneficio suyo, lo que nunca deja de suceder si no es bastante feliz en conseguir prontamente su objeto. En este caso, el pobre estercolero se ve obligado á volver á empezar de nuevo sus trabajos, á no ser que llegue á robar á su vez la bola de alguno de sus semejantes. 
Aunque estos insectos, que viven en las inmundicias, no ofrecen ordinariamente sino colores deslucidos, muchos de ellos, por una escepcion rara, brillan por el contrario con los tintes metálicos mas resplandecientes; estos son principalmente las especies estrangeras. Las de nuestro pais son negras.

Se divide este género numeroso en muchos subgéneros, de los que los principales son los peloteros propiamente dichos y los geotrupos.

Los peloteros no tienen escudo entre las dos elictras anteriormente, tales son el pelotero lunar (scarabeus lunaris , L.), y el pelotero sagrado (scar. sacer, L.), al paso que los geotrupos (fig. 7.) tienen uno pequeño, como el geotrupo de primavera (scar. vernalis, $\mathrm{L}$.), negro morado ó azul con los elictras lisas, el geotrupo estercolero (scar. stercorarius, L.), negro brillante, ó verde obscuro por encima, con rayas de puntos en las elictras, el E. tifeo ó falangisto (scar. tipheus, L.) (fig. 7.), y el $E$. momo (scar. momus.)

§. II. Los ABEJoirios (melolontha) son bastante conocidos de todos, aun de los niños, para que tengamos que hacer una descripcion detallada de ellos. Nos bastará decir que el carácter distintivo de estos coleópteros consiste en la figura de su caperuza, parte superior $\mathrm{y}$ anterior de la cabeza, que es ancha y guarnecida en su circunferencia.

Al principio del verano es cuando estos insectos hacen su postura. La hembra deposita sus huevos en el seno de la tierra en unos agugeros que tienen de seis á siete pulgadas de profundidad. De cada uno de estos huevos sale, en lo restante del buen tiempo, una larva muy voraz y temida de los hortelanos, que la llaman gusano ú oruga blanca. Mientras el tiempo está templado, vive cerca de la superficie de la tierra, en donde 


\section{7}

encuentra un alimento mas abundante en las raices de los vegetales; pero luego que empieza á sentirse el frio; se hunde tanto mas profundamente cuanto mas baja es la temperatura, y concluye por caer en el entorpecimiento. Pero á la vuelta del buen tiempo recobra su actividad, se aproxima á la superficie del suelo, y se pone á roer las raices nuevas. De este modo vive por espacio de tres años, estando entorpecida durante el invierno, y devorándolo todo durante el buen tiempo. Hácia el fin del tercer año se cambia en crisalida, para tomar alas hácia el mes de junio; entonces no le quedan al animal mas que algunos dias de vida. Todo este tiempo lo pasa en roer las hojas de los árboles y en preparar un nido á su posteridad: luego que ha provisto á esta necesidad convenientemente, cae desfallecido y muere.

Las principales especies de este género son el abejorro comun (scar. melolontha, L.), negro con las elictras rojas; los segmentos del abdómen tienen á ambos lados una mancha blanca triangular; y el batanero (scar. fullo, L.), pardo con manchas blancas, y el de estío (scar. solsticialis), mas chico que el comun y todo él amarillento.

§. III. Los CETonios (cetonia) son unos grandes y hermosos coleópteros, cuyas costumbres y organizacion se asemejan mucho á las de los abejorros; sin embargo, se diferencian de estos por su figura mas cuadrada, por su coselete mas puntiagudo anteriormente, y principalmente por una pieza triangular que tienen en la base de sus elictras.

Estos insectos se hallan durante el verano sobre las flores umbeliferas ó compuestas. Pero causan incomparablemente menos estragos que los abejorros, porque se alimentan esclusivamente del jugo de las flores, y ja- 
mas atacan al ramage. Volando de una planta á otra, producen igualmente que los abejorros un zumbido análogo al de las abejas grandes.

- Las larvas de los, cetonios, semejantes á las de los precedentes por sus formas y costumbres, emplean tres años en hacer sus metamorfósis. Unicamente al cuartó año es cuando se fabrican un capullo sólido, compuesto de las sustancias de que se alimentan, y cubierto de materias estrañas, como piedrecitas, pedazos de madera \&c., las que dándole un áspecto áspero y estraördinario, las enmascaran de tal modo que las hacen desconocidas.

Se cuenta un gran número de estos coleópteros, los que ha sido preciso separar en dos subgéneros: los goliats y los cetonios. Entre estos últimos citaremos el cetonio dorado (sc. auratus, Fab.), verde dorado por encima y rojo de cobre por debajo con manchas blancas; el cetonio magnífico (sc. fastuosus, Fab.), mayor que el anterior, verde dorado uniforme; ambos existen sobre las flores, asi como el cetonia pequeño (sc. sticticus, Fab.), negro bronceado con manchas blancas.

§. IV. Los escarabajos propiamente dichos tienen el cuerpo grueso, convexo, y el lado esterno de sus mandíbulas sinuoso y dentado. San propios de las regiones ecuatoriales de los dos mundos, en donde se encuentran tres especies notables, que son las siguientes: El escarabajo hercúleo (scar: hercules, L) (fig. 8.), de unas cinco pulgadas de largo, negro, de estuches de color de aceituna manchados de negro; el macho tiene en la cabeza un cuerno encorvado y dentado, y otro bastante largo, prolongado hácia delante, velludo por debajo, con un diente á cada lado en el coselete. Es propio de la América meridional, y ha recibido de algunos viageros el nombre de mosca cornuda. 
La segunda especie ó el escarabajo de cuérno ahorquillado (scar. dicholomus), es de un color pardo castaño, y tiene en la cabeza un gran cuerno ahorquillado, cuyas ramas se hallan subdivididas en dos, y otro mas pequeño encorvado y bifido en su estremidad sobre el coselete. Pertenece á las Indias orientales. Del mismo parage es el escarabajo de patas largas (scar. longimanus, L.), que es de un pardo leonado, sin cuernos ni tubérculos sobre la cabeza y el coselete. Las dos patas anteriores son una mitad mas largas que el cuerpo y arqueadas.

\section{SEGUNDA TRIBU.}

\section{LUCANIDES. (Läm. XXXIV.)}

En los insectos de este grupo, las hojas ó dientes de la maza antenaria estan dispuestos perpendicularmente al eje de la antena y en forma de peine (fig. 9.)

No citaremos de esta tribu mas que el género lucano, que es el principal y el que la ha dado su nombre.

Los LUCANos (lucanus) (fig. 9.) se conocen por sus antenas grandes y encorvadas hácia dentro; su cabeza es tambien muy voluminosa y sus mandibulas son fuertes, prominentes y dentadas en su estremidad interna. Se sirven de estos últimos órganos para cortar la madera y depositar en ella sus huevos. Las larvas que provienen de estos son estremamente voraces, y hacen mucho daño á los troncos viejos, los que reducen á polvo. Emplean, segun dicen, seis años en sus metamorfósis, y en el último es cuando se forman un capulló á espensas de las aserraduras que han hecho para construirse su habitacion, y que conglutinan al rededor de su cuerpo por medio de un líquido viscoso que segregan. Poco despues sale de él ùn insecto perfecto, que vive poco 
tiempo, chupando el líquido meloso que destilan las hojas de encina.

Este género comprende cerca de cuarenta especies. Una de las mas notables es el ciervo volante, el mayor de los insectos de Europa. Se le ha llamado asi porque se hán comparado sus mandíbulas á la encornadura del ciervo; estos órganos son bastante fuertes para causar un dolor vivo cuando llegan á coger el dedo. Este coleóptero se encuentra en todos los paises cálidos durante el buen tiempo; no vuela sino par la tarde, y produce un zumbido monotono bastante fuerte. Se cree que sea la larva de este insecto la que los antiguos llamaban cossus, y que miraban como un manjar delicado.

\section{S E G U N D O S UB - O R D E N.}

\section{COLEÓPTEROS HETERÓMEROS.}

Este sub-órden comprende todos los coleópteros que presentan cinco articulaciones en los cuatro tarsos anteriores, y cuatro solamente en los dos últimos. Para saber si un coleóptero pertenece á este sub-órden, se empieza por contar las articulaciones de una de las patas posteriores; si no ofrece mas que cuatro, se examina el tarso de una de las anteriores, y segun que en esta se hallen cuatro ó cinco, se la coloca entre los tetrámeros ó los heterómeros (lám. XXXIV, fig. 10).

Todos los insectos de este sub-órden tienen el régimen vegetal; por consiguiente su conducto intestinal es muy desarrollado, de una longitud considerable $y$. mas ó menos inflado, los jugos digestivos son tambien muy abundantes y enérgicos.

Esta tribu encierra dos familias principales: los melasomos y los traquelides. 


\section{PRIMERA FAMILIA.}

\section{MELASOMOS. (Lám: $X X X I V$.}

MELASOMOS es una voz griega, que significa cuerpo negro; se ha dado á los insectos de ésta fánilia porque todos tienen el cuerpo de color sombrío, ó á lo menos oscuro, y siempre uniforme.

Por este solo carácter se puede presumir que estos coleópteros estan destinados á vivir en las tinieblas y lejos de los rayos del sol, cuya influencia es siempre indispensable para producir los colores vivos y los reflejos metálicos que admiramos en algunas aves, peces, mariscos é insectos. Por esta razon todos los melasomos huyen de la luz, y se esconden, ya en las bodegas y piezas oscuras de nuestras habitaciones, ya en agugeros subterráneos; pero en este último caso, no encontrando en su aposento con que satisfacer sús necesidades, salen de su guarida todas las tardes al anochecer, y empiezan á andar de una parte á otra para procurarse su alimento; por lo demas este no es dificil de encontrar, pues los melasomos se contentan con todas las sustancias ve getales que la casualidad les presenta; pero como son muy voraces, necesitan una cantidad bastante grande, lo que hace muy incómodas y aun dañosas á las especies que viven en las habitaciones del hombre.

Se ve que las costumbres nocturnas de estos coleóp. teros les hacen inútiles las alas, porque para volar es preciso que el animal pueda distinguir á distancia los objetos contra los que podria tropezári por consiguiente los melasomos carecen de alas, á lo menos la mayor parte, y sus elictras están soldadas entre si en la línea media del cuerpo y completamente inmóbiles. I sischu ut Tono III. 


\section{2}

A estos caractéres generales es preciso añadir que estos insectós tienen las mandíbulas hendidas ó escotadas en su estremidad y las maxilas guarnecidas de un diente ó gancho en su borde interno; conformacion que da á su boca una fuerza estraordinaria, y que no deja de ser una de las causas mas poderosas de su voracidad y de su inclinacion á la destruccion. La descripcion dè dos géneros de esta familia bastará para darnos una idea de la forma y costumbres de estos coleópteros: citaremos á los dañinos y á los tenebriones.

§. I. Los DAÑINos, Tlamados tambienblaptos (blaps) sacan su nombre del griego blapto dañar, porque, viviendo en nuestras habitaciones, causan en ellas estragos bastante grandes atacando nuestros muebles, vestidos y provisiones; y es tanto mas difícil preservarse de sús ataques cuanto que confundidos por su color sombrío con los objetos que les rodean, y no mostrándose jámas durante el dia, no se les puede ver, ni hallar el medio de destruirlos, ni aun se ha podido hasta el dia llegar á encontrar sus larvas que nos son enteramente descono. cidas respecto á su figura y costumbres.

Sin embargo no es porque los dañinos sean pequeños ó escasos; pues por el contrario son muy abundantes. Algunas especies tienen mas de una pulgada de largo; y sus movimientos, sin ser lentos, con todo no son bas tante ágiles para que no se pueda estudiarlos; pero parece que ocultan sus larvas con mucho cuidado, y que estas no se presentan á la luz hasta déspues de haber-sufrido sus metamorfósis.

Todos estos insectos despiden un olor fuerte $y$ desagradable, lo que no impide, segun dicen que las damas turcas los coman en cantidades bastante grandes, á pesar del asco que deben inspirar, con la esperanza bien ó mal fundada de que el uso de estos animales como alimento 
hace engordar. Yo dudo que nuestras damas quieran ensayar si el medio es eficaz.

Estos coleopteros se conocen por la falta de alas, por su cuerpo grueso, por sus antenas que se ferhinan por un ensanchamiento en forma de triángulo ó de hacha; tal es el blaptocomun que se ha llamado por otro nombre mal agüero ó présagia muertos, y tambien vulgarmente (-cucaracha á corredena) (blaps mortisaga) (fig. 10.) - \$: II LUOS TENEBRONES (tenebrio) se diferencian de los blaptos porque tienen algs, el cuerpo casi línear $y$ las antepas mopiliformes yc sin ensancha miento notable en su estremidad; sus costumbres son tambien diferentes, andan con velocidad yc vuelán bien, y en vez de habitar esclusivamentę en nưestras casas, se encuentrán tambien en los bosques, bajo la corteza de los árboles \&c.

Un instinto muy cuniosa de estos animales es la costumbre que tienen de cubrirse el ouerpo de las par tículas mas menudas del suelo que habitan, á fin de disfrazar su color natural, y de tomar el de los objetos de que estan rodea dos; esta astucia les pone al abrigo de las miradas de sus enemigos; y les protege tanto mas eficazmente, cuanta que gozan tambien de la facultad de pararsé repentinamente en medio de uva carréra rálpida.

La larva de los tẹnebriones no está tan encubierta como la de los dañinos, pues es demasiado conocida de los panaderos y molineros por lós estragos que hace en el trigo Y la harina, lo que ha hecho dar el nombre vulgar de giusano ó lombriz de la harina á la del tenebrion de tahona (tenebrio molitori), que es la especie mas conocida del género. 


\section{SEGUNDA FAMHLIA.}

ru "ô TRAQUÉLIDES. (Lám.XXXIV.)

En los heterómeros precedentes la cabeza es oval y sostenida por un cuello muy corto, de suerte que susceptible de esconderse enteramente debajo del cose-) lete. En los traquélides esta parte es triangular ó en fórma de corazon, sostenida por un cuello mas ó menos largo, y no puede, á causa de su anchurà, que igua-: la á la del coselete, ser retirada debajo de él: á ésta par-s ticularidad de organizacion deben su nombre de tra quélides, que puede traducirse por animal provistoidé cuello.

4! Estos insectos se diferencian tambien de los precedentes por la blandura de su cuerpo y por la flexibili-? dạd de sus elictras, por consiguiente que no pueden protegerle sino de un modo muy ineficaz.

aㄴ Péro suplen por sú destreza ó su ágilidad á lo que: les falta bajo este punto de vista. Guando sé ven amena-I

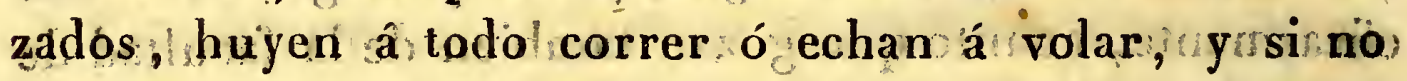
se sienten bastante listós para escapar de su enemigo por estos medios, imitan á los molipennas y hacen el muer to; débil astucia que no les salva siémpre, péro"que con todo des impide algunas veces el ser devorados.

Todos los traquélides son filófagos, es decir, que sé alimentan de hojas. Por consiguiente viven en los cam-z pos, en los bosqués, en una palábrá , en todas las partes en que da vegetacion les ofrece una subsistencia fácil cry apropiada á sus necesidades. Sus larvas, que viven debajo de tierra, se alimentan de raices, y aun, á lo que parece, de materias animales.

Como todos los insectos de esta familia tíenen las ma- 


\section{5}

yores relaciones entre sí, y puede formarse una idea de todos por un solo género, no citaremos mas que el de las CANTÁRIDAS (cantharis), que es el mas importante.

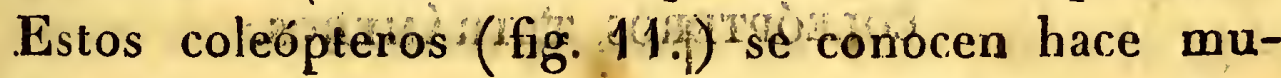
cho tiempo por la propiedad que tienen de producir una viva irritacion en la piel de la parte en que se les aplica propiedad que los hace emplear tódos los dias comó vegigatorios. Para esto, déspues de haber hecho secar el insecto, se le reduce á polvo, con el cual se cubré un emplasto, y se fija eśte último en él puninto en qué se quiere establecer ứ exútorio.

s) rSe conócen fácilmente estos animales, que forman ừ género mưy cónsiderable, pớr sưs tarsos, cuyos ganchos èstan divídidos profundamente, por su cabeza gruesa y redondeada, y tambien por su cuerpo de forma pro-

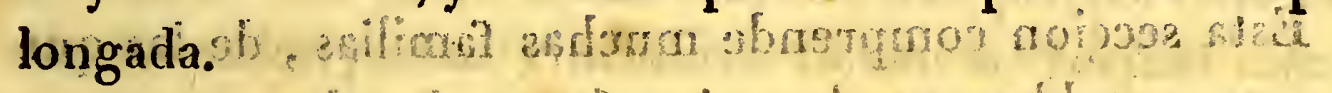

La especie más célebre és la cantárida comun (metoe vesicatorius, $\mathbf{L}_{\text {. }}$, que se encuentra en todas partes, pero principalmente en los paises cálidos, como España. Habita con preferencia sobó los fresnos y lilas. Es un coleóptero de seis á siete líneas de largo, notable por el grosor de su cabeza y la peçueñén de su coselete. Todo su cuerpo es de un verde dorado con antenas negras. Como ésteganimal vive en tropas cón siderábles y despide un olor fuerle á raton, es fácil de descutirir. Para a poderarse de él, sasta sacu dir fuertemén te el atbol en que habita como tiene la costúnbre de hacep ef muterto, permanece encierra sio hacer el menor novimiehto, $y$ se deja coger como se quiere. Ademas de estácantaridá hay otras dos, que son : Ta cantarida livida (cantharis livida, Fab.) , que es rojiza con las eličtrâs amariHas, $y$ se encuentra sobre las flores, y la cantárida negruzca (C. fusca, $\mathrm{Fab}$.) que tiene el color que ińdica su nombre, y el contorno del cóseléte rojó. 


\section{TERCER SUB-ORDEN}

\section{COLEÓPTEROS TETRÁMgROS}

Este sub-órden comprende los coleópteras cuyos tarsos estan todos coppuestos solamente de cuatro artiçulaciones. Estos sop generalmente unos pequeños insectos que se alimentan principalmente de materias ves getales, $X$ que hacen muchos estragos en los graneros y en la madera de construccion verde ó śeca, Sus lara yas, que roen tambien las mismas isustancias, son la mayor parte paco ágiles y carecen de pies, ó los tienen tap cortos que no pueden servirse de ellos ventajosamente para andar.

Esta seccion comprende muchas familias, de las que las mas notables sgn $_{\text {in }}$ los rinceforos, los longiconnes $y$ los cíclicos.

\section{PRIMERA FAMILIA.}

\section{BLAGÓFOROS.}

El nombre de rincóforos, que en griega significa porta-picos, padria inducir en error á los que se imat ginasen que estos coleópteros i en vez de tener la boca compuesta ${ }_{9} \mathrm{de}$ dos mandibulas o dos maxilas y, dos ilart bios como tedos los insectos del óriden á que pertenecena tienen por el contrario para tomar su alimęnto, una especie de trompajó pico. Este nombré sé les ba dádos porque su cabeza presenta en su parte antęrion una empinencia ósprolongacion en /forma de cuerno, que sei ha comparado á u picoi de avé. Pero este órgano no parece de nịg̣un módo deśtioado iácla mąsțicacionió ía 


\section{7}

da prekensión de los alimentos su uso se limifa há - radar la corteza de las sústanciàs vegetales, y principalmente la de las semillas o frutos de que se alimentan, y en cuyo thterior muchos de ellos pasan la mayor parte de su vida.

-1 Por esta razon todos estos insectos son temidos én Los aldaráties én que se conservan provisiones de trigo, avena, maiz \&c.; sus larvas pritcipalmente causan en ellos pérưưiciós incalculables.

Entre los géneros que componen esta numerosá familia citaremos , como los que mas interesa conocer, los bruchos, los brentos y los gorgojos.

§. I. Lós Bruchos (bruchius) tienen el pico mus eorto, ancho, y de tal modo deprimido, que permite dístinguir debajo de él sús lábios y sus palpos. Bajo éstá consideracion, estos rincóforos tienen las formas menos estraordinarias que los siguientes, qu quiénes su largo pico les da una enteramente diferente de la de los demas insectos del mismo órden.

En el estado perfecto, los bruchos són muy pequeños, y viven sobre las flores. Son comunes durante todo el verano révolbteando sobre lás plantas de la familia de las leguminosas, y luego que sus vamas estan formadas, las horadan y depositan un huevo o dos en cada uno de los granós que contienen.

La presencia de estos cuerpos estraños no impide que las vainas se desarrollen y è grano llegue á su madurež. Luego que la legumbre ésta en sazon, la larra sále del huevo y sé pone á roer la sustancia del grano, que la suministra su subsistencia durante todo el in vierno; pero tiene cuidado de no tocar a la corteza, por temor de descubrir sú moráda ó de hácerla menos segura. Solamente cuando se hálla próxima á cambiarse en ninfa es cuando adelgàza la piel por un lado, a fin 
de que el insecto perfecto tenga; qué trabajar poco parà romperla. A pesar de esta precaucion, sucede con frecuencia que los bruchos perecen en su prision, ya porque la corteza de la semilla no haya sido suficientemente adelgazada, ya porque el animal se encuentra en mala posicion para trabajar en la parte por donde debe salir.

En España tenemos el brucho de los guisantes, el del cacao, el de las semillas \&c.

§. II. Los BRENTos (brentus) (fig. 12.) son unos insectos casi todos exóticos, cuya figura es de las mas singulares. Su cuerpo es largo, delgado y casi linear; sè le tomaria por una paja, á la que estuvieran pegadoś cuatro pares de apéndices que representasen las patas y las antęnas del animal. Su cabeza y su abdómen no forman esos ensanchamientos que caracterizan al cuerpo de la mayor parte de los insectos que conocemos Todas las partes son de grosor casi igual, $y_{\text {peria dificil dis- }}$ tinguirlas, á no ser por las antenas que guarnecen la cabeza y las patas que sostienen al coselete, detras del cual se halla el abdómen.

No se conpcen ni las costumbres ni las metamorfó sis de estos coleóptęros la especie que se encuentra mas comunmente en las colecciones entomológicas es el brento ancoriformé de Cayena, que tiene cerca de quince líneas de largo. En Italia se cria tambien una, pero mas pequeña:

\$ III. Los Gorgojos (curculio) tienen muchas relaciones con los brentos, pero se distinguen de estos por su cuerpo mas macizo, y por sus antenas terminadas en forma de maza, al paso que las de los brentos son de un grosor uniforme en toda su longitud.

Estos insectos han sido conocidos de toda la antigüedad en razon de su voracidad y de los perjuicios que ocasionan en los graneros, en donde se conservan 
almacenadas las cereales necesarias para el consumo de las ciudades populosas. No solamente se alimentan de ellas en el estado de insecto perfecto, sino que sus larvas nacen, crecen y sufren sus metamorfósis en lo interior y á espensas de estos granos, y principalmente del trigo. Unicamente algunas especies se fijan sobre las hojas por medio de un jugo viscoso que trasuda de su cuerpo; pero estas no son las mas dañinas; Jas verdaderamente peligrosas son las que se ocultan en los graneros. Alli se multiplican con rapidez hasta el punto de destruir lá totalidad de los grảnos que encierran, y es tanto mas dificil preservarse de su voracidad, cuanto que jamas atacan á la corteza, y no roen mas que la harina; de suerte que montones enteramente devorados parecen tan sanos como los que no han tocado, y únicamenle por el peso se conoce el estrago.

El mejor medio de préservarse de estos insectos çonsiste en apalear frecuentemente el trigo que se tíene depositado; esto tes impide introducirse en él. Si ya dos hay es preciso formar un monton pequeño al lado del grande, y agitar continuamente á este último. Los gor: gojos, que no gustan de ser inquietados abandonan á este y se arrojantsobre él otro en donde encuentran tranquilidad. Cuando ya estan todos estáblecidós en él; se echa este pequeño monton en agua hirviendo, y de este modo se hacen perecer todos los insectos que contiene.

El género gorgojo es escesivamente numeroso, y encierra especies de todas magnitudes, desde una línea hasta pulgada y media. En España existe él gòrgojo comun, el gorgojo tenebroso, el gorgojo anubarrado \&<. Las especies mas bonitasusun el gorgojo imperial y el gorgojo brillanté.

'TOMO III. 


\section{SEGUNDA FAMILIA.}

\section{LONGICORNES.}

2. A Aunque por lo comun es dificil sacar el carácter dis tintivo de un género ó familia de la lóngitud mas cố ménos considerable de una parte cualquiera del cuerpo. "del animal, no obstanterise puede, tocante ála familia de los longicornes, emplear sin inconveniente la longitud de las antenăs pará caracierizarlá. Estos órgános son ordinariamente tan largos como todo el cuerpo, y muchas yeces mas ; de suerte que eșios insectos se pueden conocer casi siempre á primera vista. Un segundo carácter, que no es menos distintivo, es que la parte inferior de las tres primeras articulaciones de su tarso está cubierta de pelos, y que el cuarto ofrece un pequeño ensanchamiento que simula una quinta articulacion; Io que ha hècho colocar algunas veces á los tongicornes entre tos coleópteros pentámeros. 0109 : of cliecery

Los insectos de esta familia son generalinente grandes, y muchas veces adornados de brillantés colores; casi todos producen ni ruido agudo causado por la frotacion ide su abdómén contra él coselete, ó de su cabeza contra el éscudo. Sus larvas, provistas de fuertes maxilas, atacan á la corteza de los árboles, y aun á su tropco, los que acribillan de agugeros, ie tal manera que los inutilizan para las construcciones. Bajo este punto de vista hacen mucho perjuicio á la economía doméśtica.

Esta familia encierra dos généros principales, los prionos y los capnicornios.

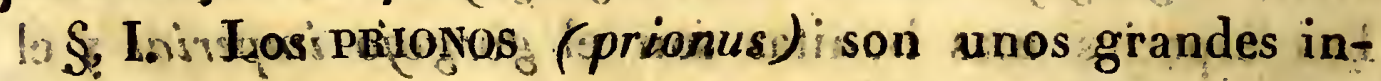
sectos cuya figura se asemeja á la del ciervo volante, en 


\section{1}

rạion de la estension de sus mandíbúlas quecsobresalén mas allá de la cabeza, y se parecen tanto mas á las mandibulas de este último, cuanto quie son dentadas por su borde interno. Pero lsin trablar de la sififenencias sacadas del número de articulaciones de los tarsos que alejan á estas dos especies de insectos ysy de la disposicion tán diferente de sus maxilas, se encuentia i la la longitud y tenuidad de las antenas de los prionos y en su coselete dentado ó espinoso por sus lados ; un cácácter que no permite confundir á estos coleópteros con los lucanos:

Por lo demás, los prionos están privados de esọs lcolores brillantes que se ven en los insectos que viven bajo la influencia de los ráyos del sol ecuátorial. Asices que estos coleópteros permânecen ocultos durânte todo el dia en los agugeros que han hecho eñl tostroncoside los árboles, mientras estaban en el estado de larvas. No salen sino por la tarde duranté el crepúsçulo; tambien tienen cuidado de no alejárse de su guarida sino lo menos posible, porque, como su vuelo es pesado, se verian demasiado espuestos á los ataques de sus enemigos, si no tuviesen siempre á asu álcance un asiło seg $u x o ̛$ para

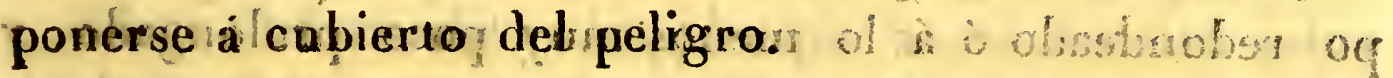
- if Selcuentan cerda de sesenta especies de este géénero, dé las que solamente cuat to operteneden ás Europai las mas comunes son el priono mohosa y el prionacurtidor ózurrador de los alrededores de Paris Eintre las especies estrangeras citaremos el priẹno cerivicornio de Amó-rica, que tienelcercadelseis pulgadas de largo. esfirmi -ilis. IIr Jjos capruconnos ól cerambices (cerambix) (frg. 13:) ise diferencian de los prionos par ynas antenas cmas lárgas $Y$ unas mandíbulas masc perqueìzas y conformadas como en los demas coleópteros; pero cou - carácier verdaderabente distintivo conisisteven el gran- 


\section{2}

dor del sombrerillo ó labio superior; que es muy visible y tan ancho como la cabeza.

Estos insectos tienen el cuerpo largo y adornado de colores brillantes ó variados, sus formas ligeras y elegantes anuncian en sus movimientos una agilidad que no tiénen lás especies del género precedente; su vuelo principalmente, es muy rápido y sostenido por mucho espacio; pero al mismo tiempo es ruidoso, lo que proviene de la frotacion de su coselete y de su escudo.

Se encuentran los capricornios en los bosques, sobre los troncos de los árboles, en donde se alimentan del jugo que destila de ellos; por medio de un làrgo tubo que llevan en lá estremidad de su abdómen depositan sus huevos en las hendiduras y debajo de la corteza de la madera, en donde al animal sufre todas sus metamoŕfósis.

\section{T E R E E A F A M LIA.}

\section{cícLicos. (Lám. XXXIV.)}

(1) Todos los coleópteros de esta familia tienen el cuerpo redondeado ó á lo menós múy poco prolongado, y sin distincion bien marcada entre el coselete y el ábdómen'; lo que les ha hecho cor su nombre que sighifca orbicular ó redondo.

- Estos insectos són generalmente de poca magnitud y sin pelos en el cuerpos, el que por el contrario está muchas reçes adornadónde colores brillantes y metálicos Lentos en sumarcha en su vuelo, se ven óbli-gádos á permanecerir ocultos ó tóman las precaucionés mas iminuciosas para evitar los peligros. El medio mas scornum qué emplean para escapar de sus enemigos , es - dejarsé caergátienra désde ló alto de lós árboles; y co- 


\section{3}

mo la mayor parte son muy pequeños, "ó á lo mas de mediana magnitud, encuentran entre las hojas que cubren la tierra, ó en las grietas que surcan el suelo, un escondrijo tanto mas seguro, cuanto que los cuerpos menos voluminosos pueden ocultarlos á la vista de sus perseguidores.

Las larvas de estos insectos tienen to das seis patas y pueden andar bastante bien; para sufrir sus metamorfósis se fijan á las hojas de los árboles, cuyo color, asemejándose al de su piel, las impide ser vistas por sus enemigos. Algunas especies tienen unos medios particulares y muy notables para engañarles ó desanimarles. Algunas otras se sustraen al peligro introduciéndose en la tierra durante el tiempo crítico que pasan en el estado de larva.

La familia de los cíclicos comprende dos géneros importantes; las cásidas y las crisomelas.

15. I. Las Cásídas (cassida) son vulgarmente llamadas escarabajos-tortugas, porque su forma redondeada ú oval se asemeja á la del espaldar de estos reptiles. Essta conformacion, unida á la disposicion de sú cabeza que está enteramente ó en gran parte oculta debajo del coselete, impide qüe se confundan estos pequệios coleópteros con los demas insectos de la misma familia; su coselete y sus elictras reunidas forman en la parte superior de su cuerpo una especie de broquel que protege su cuerpo con tanta mas eficacia, cuanto que sobrésale en todas direcciones de las patas, del abdómen y la cabeza, absolutamente como un casco (cassis) se estiende mas alla de la cabeza que está.desdestinado á défender.

Estos caractérés hubieran bastado para fjar en las cásidas la latencion de los naturalistas, cuando no se la atrageran por sus colores dorados ó plateados Pe- 


\section{4}

ro lo que mas interesa en estos coleópteros son sus costumbres en el estado de larvas; su forma no tiene de notable mas que una cola ahorquillada que termina su abdómen, y entre cuyas ramas se halla la abertura de su ano. Esta disposicion no es estraordinaria, pero el uso á que está destinada es de los mas curiosos; á medida que la larva arroja sus escrementos, las ramas de la horquilla, que "están guarnecidas de espinas, los detienen al liempo de pasar, de suerte que estas materias no tardan en formar una masa casi tan considerable como la de todo el animal.

Cuando este se ve perseguido por alguna àve ó por algun otro insecto, se para de repente, endereza su cola, y hace caer sobre su dorso el fardo asqueroso que su cuerpo trae consigo, de morlo que no parece mas que un monton de inmundicias, cuyo aspecto aleja á todos sus enemigos.

El géuero cásida es escesivamente numeroso; en Francia se crian muchas especies; las mas comunes son: la cásida verde, la cásida moteada, la cásida nebulosa.

§. II. Las CRISOMELAs (chrysomela) (fig 14.) tienen el cuerpo oval, liso y adornadó de lindos colores, como las cásidas. Sus costumbres son enteramente semejántes, y su cuerpo es igualmente pequeño; pero se conocen fácilmente por su cabeza prominente mas allá del coselete.

Estos insectos no son menos admirables que los precedentes, por el instinto de conservacion de que les ha dotado la naturaleza. Démasiado débiles para resisti $r$ á sus menores enemigos, serian presa dél primero que les atacára, si no estuvieran protegidos por un escudo sólido; y sobre todo si su pequeñez nó los hiciera muy - difíciles de percibivi Pero como sus larvas no tienen 


\section{5}

el priméro de estos recursos, suplen á él con un artificio al que recurren cada vez que se ven en peligro. De casi todas las partes de su cuerpo se trasula un humor viscoso, muchas veces colorado y siempre asqueroso, que puedén liacer salir ó entrar á su voluntad. Luego que ven aproximarse una ave ó un insecto grande, se cubren iumediagameute de su líquido protector, y su enemigo, que se dirigia á un bocado delicado, no encuentrá mas que una sustancia cuyo olor y aspecto le repugnan igualmente. Luego que ha pasado el peligro, la larva tranquilizada ya reabsorve la materia inutil en aquel momento, y la reserva para igual circunstancia.

- Este género no menos numeroso que el precedente comprende entre otras especies, la crisomela sanguinolenta (chrisomela sanguinolenta, I.), la crisomela del álamo (chri. populi, L.) que son comunes en Francia, y la crisomela de las cereales (chri. cerealis, L.), \&c. distinguillas, la primera, por ser negra ó de color negro azulado, con las costillas del coselete igualmente que las elictras moteadas y ribeteadas de rojo; la segunda por ser un poco mayor que la anterior, (unas 6 líneas) y tenér, el color azul, con las elictras leonadas ó rojas y marcadas con un punto negro; finalmente la última es de ur rojo de cobre por encima, con rayas azules longitudinales, tres en el coselete, y siete en los estuches. Es comun en las retamas.

\section{CUARTO SUB-ÓRDEN.}

COLEÚṔterís TRÍMERos. "( Lám. XXXIV.)

Este grupo, el menos numeroso del órden, encierra los coleópteros que no tienen mas que tres artí- 
culaciones en los tarsos y no se compone sino de cinco géneros, de los que solo uno comprende especies europeas, y es el de las coccinelas (coccinella) (fig. 15.) insectos conocidos de todos bajo el nombre de vacas de san Anton, de mariquitas; \&c. Son muy notables por su forma casi globulosa, por la cortedad de sus patas y de sus antenas, y por la variedad de sus colores. Sobre un fondo liso, amarillo ó rojo, presentan unas manchas regulares de color obscuro, que se asemejan á una pieza de embutido; sus elictras combadas y perfectamente arrimadas una á otra, parecen formarles una pequeña concha, bajo la que se oculian como las tortugas. La elegancia de su cuerpo y la hermosura de su color las hacen querer de todos y principalmente de los niños. Se debia casi sentir que estos lindos animales se vean obligados, para vivir, á destruir otros insectos; porque las coccinelas son esencialmente carniceras; devoran una gran cantidad de pulgones, ya en el estado de larvas, ya bajo la forma de insecto perfecto. Pero no debe impedir esta inclinacion el buscar á estos hermosos coleópteros; por el contrario nos los debe hacer estimar mas. Los pulgones son tan dañosos á la jardinería y agricultura, que no se puede menos de bendecir al Criador por haberles dado muchos enemigos.

Las coccinelas son muy comunes en todos los paises las aves "pequeñạs devoran una inmensa cantidad de ellas á pesar de la solidez de sus elictras y del humor fétido que derraman cuando se ven cogidas. Las principales especies de este género son: la coccinela de siete puntos, (fig. 15.) la coccinela de dos puntos, la de dos pústulas \&c. 


\section{TERGERORDEN.}

\section{ORTópteros.}

No considerando sino la naturaleza de las alas anteriores, se podrian confundir los ortópteros con los insectos del órden precedente; porque estos órgános son duros y coriacéos en unos y otros, aunque generalmente tienen más solidez en los coleópteros que en los ortópteros; pero la disposicion de lâs alás membranosas es enteramenté diferentè en estos dos órdenes. En los ortópleros, sobresalen las alas de las elictras en anchura y decesitan estar plegadas en forma de ábanico, cuando el animal está en quietud, al paso que las de los coleópteros no están jamas plegadás sino al traves en igualés circunstancias; por ótra parte las elictras de estos últimos tienen sus bordes interiores tan bien adaptadós úno otro, que parecen soldados entre sí, en vez de que en los ortópteros los bordes de estos estuches están siempre mas ônenos desunidos. Pör lo demas, tanto en unios como en otrós pueden faltar algunas veces las alas, lo que obliga a recurrir á otro carácter para hacer la distincion de los dos órdenes. Este carácter, que es constante é invariable, se saca de la conformacion de la boca, cuyas maxilas estan siempre libres en los coleópteros, y encerradas en una especie de vaina llamada por Fabricio capacete ó caseo (galea) en los ortópterós.

Estos últimos insectos se diferencian tambien de los precedentes pór sús metanor fósis que jamas son completas. Su larva, al salir del huevo, casi no se diferencia de la crisalida, y esta última núnća está envuelta en un capullo de seda; de suerte que el insecto conserva su agilidad bajo sus tres estados. Con todo siempre se po-

Tomo IIr. 
drá distinguir la larva de la ninfa en que esta presenta en su coselete los muñones de las alas, que deben desarrollarse en lo sucesivo.

El género de vida dẹ los ortóptenos ofrece poca variedad; todos estos insectos son terrestres bajo sus tres estados, y prefieren generalmente las sustancias vegetales á las materias animales Por consiguiente tienen el cunducto intestinal muy desarrollado; siempre se les encuentra un primer estómago ó buche , seguido de una molleja musculosa, guarnecida interiormente de piezas sólidas y córneas, propias para triturar las sustancias vegetales. Pero esle género de vida no sirte sino para hacer al órden de los ortópteros mas dañosos, en razon de que ata-t can á nuestras provisiones, cereales, legumbres, \&c. Hacen tantos mas esıragos cuanto mayor es su número; y se multiplican algunas veces hasta tal punto que son una rerdadera plaga; en los paises cálidos principalmente ocasionan perjuicios incalculables.

El órden de los ortópteros es incomparablemente menos cstenso que el que precede; no comprende mas que dos familias; los ortópteros corredores y los ortópte ros salladores.

\section{PRIMERA FA ILIA.}

\section{CORREDORES. ( Lám $X X X Y$.)}

Los insectos de esta primera familia se distinguen delos de la siguierte, en que tienen todos sus pies iguales $y$ acompdados para andar; carácter bien fácil de comprender pero que reune animales muy diferentes En efecto los tres géneros comprendidos en este grupo, los tijeretas, las blatas y las mantis podrian formarcada uno una familia distinta g los únicos rasgos que les: 



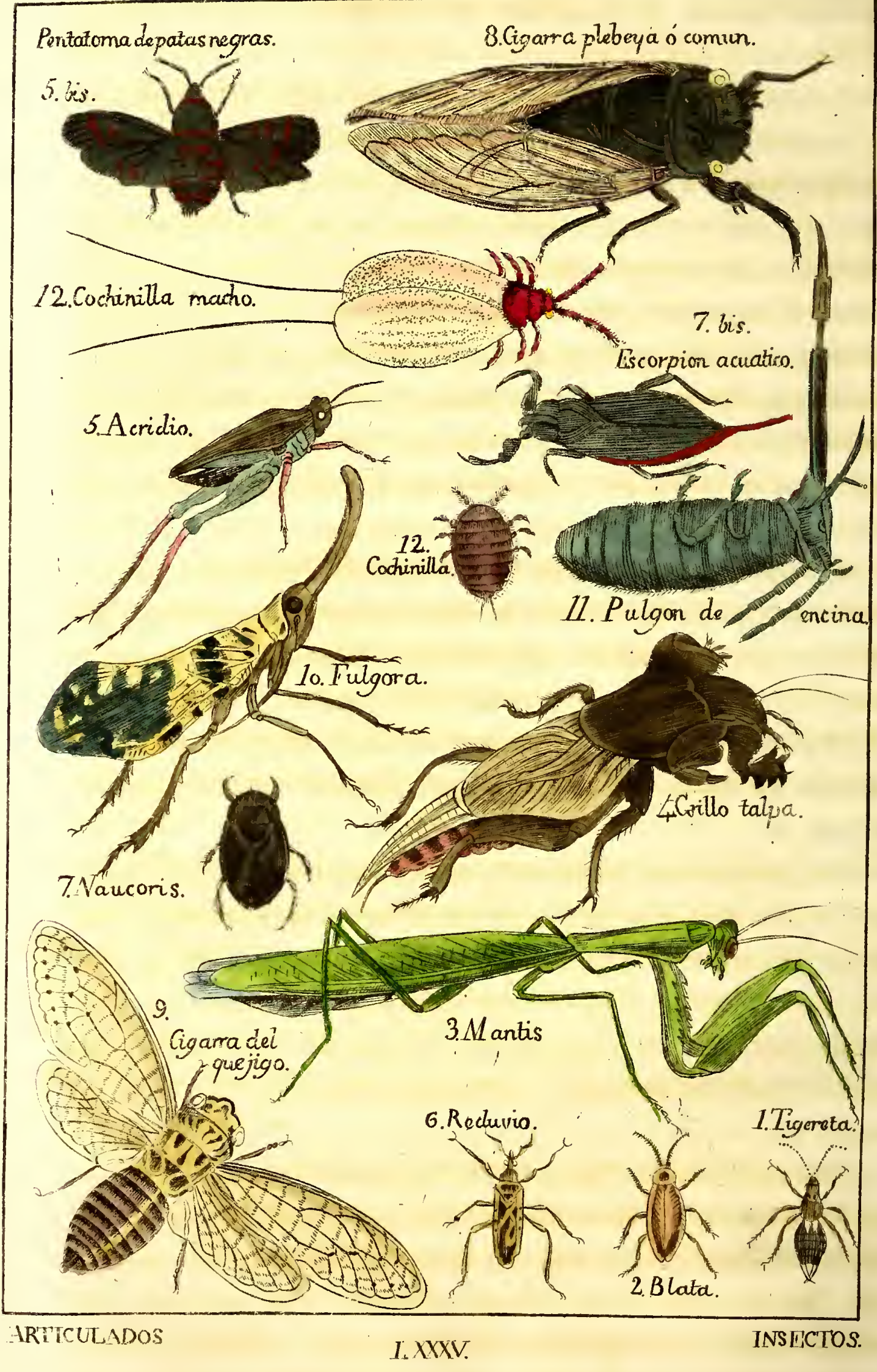


son comunes, son la igualdad y la semejazza de todas sus patas y la imposibilidad de producir ningun ruidb.

§. I. Los tiJenetas (for ficula) (fig. 1.) 6 gusanos del oido, sacan su nombre latino, que significa tenazas de dos prolongaciones escamosas que terminan su abdómen, y que siendo movibles como las ramas de este instrumento; tes sirven de armas ofensivas. Ea cuanto a la denominacion de gusanoś dél oido que se les da vulgarmente, está fundada en una prencupacion muy esparcida, que arribuye ra estos insectos la costumbre de introducirse en lo huteriop del eráneo, horadando la oreja ó mas bien el timpano, precocupacion tan ridicula $y$ absurda que ni aun merece ser refutada.

Siempre se cốnocerán fácilmentélos tijeretas por su forma prolongada y principalmente por la tenaza que termina posteriornente su cuerpo. Son tan ágiles y se mueven tanto, cuando se procura cogerlos, que és muy, dificil conseg airlo; y pör poé que uno se descuide en ténerlos bien asidos se escapan de las manos cuarndo nuenos se piensa.

Estos iasectos son muy comunes en todos tos parages frescos y húmedos, en donde se les halla reunido en tropas debajo de las piedras, de la madera podrida, \& c. Son muy voraces y destruyen muchos frutos en los jardines; $y$ aun parece que atacan algunas veces á los çadáveres que encueatran, ni aun perdonan a los de su propia especie.

Una particularidad notable de su vida es el cuidado que las hembras tienen de su prole. Es cierto que no es raro ver a los insectos proveer con afan a las necesidades de su posteridad; pero una vez tomada esta precácion, hay muy pocos que sé ocupen del resultado de sus cuidatos. Los tijeretas por el contrario famas abali? 
donan sus huevos il á los que parece empollan pues si se los dispersan los reunen de nuevo para hacerlos llegạ á su termino. A su salida del huevo, las larvas acompañan por todas partes á su madre la que las protege y defiende como una gallina á sus polluelos.

En España tenemos dos especies de este género: el tigeretas grande y pequeño.

§. II. Con relacion á las formas, las BLATAs (blatta) (fig. 2.) son enteramente lo opuesto á los tijeretas; al paso que estos últimos tienen el cuerpo delgado y la cabeza saliente, las blatas son ovales ó rredondas, chatas, rechonchas, y tienen la cabeza oculta por el coseleté, mas alla del cual no se distingue mas que sus largas antenas.

İ 2 Pero á pesar de la torpeza aparente de su cuerpo, estos insectos no son menos ágiles; corren con tanta rapidez que es difícil cogerlos; á mas de que se esconden en los menores agugeros ó rendijas del piso; y no salen de su guarida sino por la noche; lo que les habia hecho dar por los antiguos el nombre de lucifugce.

Antiguamente se creia que estos ortópteros no ponian mas que dos huevos: lo que hacia inesplicable su multiplicacion escesiva. Pero se ha visto, observándolos de cerca, que estos pretendidos huevos no eran sino unas pelotas llenas de gérmenes muy numerosos que la hembra llevaba á todas partes consigo, como lo hacen algunas arañas.

Las blatas viven generalmente en nuestras casas, y principalmente en las cocinas, panaderías, molinos \&c.; su voracidad no perdona nada: las provisiones de boca, los cueros, las lanas, \&c., todo es bueno para su yoracidad. Pero sobre todo las que se conocen en las colonias con el nombre de cakerlacs se hacen inso- 


\section{1}

portables, porque atacan hasta á lá botas y zapatos.

Las especies mas célebres de este género son la blata oriental ó de las cocinas ó cucaracha verdadera, de color rojo pardusco, y el cakerlas ó blata de América, (fig. 2:) bermeja, con el coselete amarillento, dos manchas y una bordadura en el de color negro

§. III. Las MANTis (mantis) (Gg.3.) se distinguen de los"dos géneros precedentes, porque tienen cinco articulaciones en los tarsos, el cuerpo estrecho y prolongado y la cabeza muy prominenté á la ótra parte del cosele: te. Independientemente de estos caractéres, la singalaridad de formas que es propia de las mantis impedira siempre confundir á estos inséctos con los tijeretas y las blataso Al ver su cuerpo largo y delgado, sus patas delgalas, y descarnadas, su abdómen saliente sus alas anchas y estendidas, se les tomaria por unas fantasmas. En algunos paises se ha creido encöntràrles alguna semejanza con unas religiosas, asi es que les dan unas veces el nombre de espectros, otras el de religiosas ó de rezadoras.

Estos ortópteros son raros en Europa; no se encuentra mas que una especie de ellos en las provincias meridionales de Francia, donde los del pais los llaman rezadorass (prie-dieu); viven sobre los árboles, en medio de las hojas, entre las que son difíciles de percibir ; á causa del color verde y de la forma ancha de sus alas, que se-confunden con el verdor de estas hojas la que les ha valido tambien ot ro nombre vulgar cual es el de hoja.

La diferencia que presenta el género de vida de estos insectos hạ permitido dividirlos en dos sub-géneros: los unos teniendo los miembros anteriores mas fucrtes que los demas y armados de espinas por debajo, son estremamente carniceros, devoran los insectos, las oru-r gas \&c. , y se atacan mútuamente coñ furomg aun áve- 


\section{2}

ces sin necesidad estos son las mantis propiamente dichas, tal es la mantis comun ó rezadora (mantis religio$s a$, L. ) que se encuentrà en España : los otros qque tienen todos los miembros semejantes, son herviboros, y tienen las formàs tan singulares, que se les tomaria desde lejòs por unas hojas ó por una pequeña rama de ạ́rbol; iestás espéciés s̀ cónocen con el nombre de espectros; tales son el espectro gigante, la hoja seca \&c. que todos son exóticos. La última sobre todo es muy notable por su estraña conformacion que se parece mas bien á una ramita cubierta de hojas que á otra cosa; su abdómen eśá guaraécido por atras de una hoja membranosa Y lo mismo sucede á los muslos y al coselete quees largo

\section{SEGUNDA FAMULA.}

\section{SALTADORES. (Låm. $X X X Y$.)}

Estos ortopteros son fáciles de conocer por la longitud y da fuerza de sus patas posteriores, que les permiten saltar con una agilidad poco inferior á la de las pulgas; lo que les ha hecho dar por todas partes a los mas de ellos cuando se les ve aislados, el nombre vulgar de saltamontes, y este caracter es tán marcado que es muy dificil habituar á las personas que ro se ocupan de historia natural designâr con otro nombre los diferentes géneros que componen esta familia bastante numerosa.

Todos los machò de estos insectọs producen un sonido ruidoso y monótona unas veces frotáte to no contra otro los bordies internos de su's elicras, otras re fregańdo el tborde postecrior de eśtos órganos ceontral stis mustos, que hacen asi el ofeio de ain arconde siolsn.?

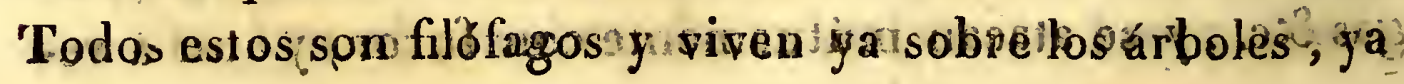




\section{3.}

en tierra en dịnde buscan sa alimento. Eú la tierra es donde las hembras depositan sus huevos.

Esta familia es tan natural que podria no hacerse dè ella mas que un solo género; sin embargo, para mayor facilidad se la divide én tres: los grillos, las ilangrostas, y los acridios.

§. L. No hay nadie que no haya visto Gritlos (gri. llus. (fig. 4.) insectos fáciles de conoce por la posicion de sus elictras que están colocadas horizontalmentè sobre su dørso, al paso que en los dós géneros siguientes son oblicuas y forman comó un tejadó sobre el cuerpo del animal.

Estos insectos se encuentran por todas partes en los campos, en los jardines y hasta en lo interior de nuestras casas, en donde producen un grito agudo y' penetrante (gri-gri), que les ha hecho dar el nomibre de grillo. Este género se divide en dos subgéneros : los grillotalpas y los grillos propiamente dichos.

1. Los primeros son una verdadera plaga para la vegetacion. Armados de dos patas anteriores propias al mismo tiempo para carar y cortar, se practican unas galerías subterraneas para hacerse una guarida y depositar alli sus huevos, $y$ de este modo destruyen las raitces de todas las plantas que encuentráná su paso. Se ve, en todos los sitios en donde han establecido su mo= rada, que las plantás jóvenes se ponen amarillentas y caen en un estado de languidez muy próximo á la muerte. Probablemente deben estos insertos á sús costumbres subierraneás, y sin duda tambien á la figura de sús patas anteriores, el nombre de grillo-talpa (grillos-topos) que les dan los hortelanos y labradores (fig. 4.)

Los grillo-talpas son muy comunes en Europa, principalmente en las tierras cultivadas con cuidado, 
porque en ellas se entregan á sus trabajós con menos pena. Por esta razon son temidos de todos los cultivadores de flores y hortelanos, que les hacen una guerra á muerte con tanto mas gusto, cuanto que son de por si horribles á la vista. Pero son dificiles de coger porque no salen jamas sino por la noche, y porque para matarlos es preciso sorprenderlos en su agugero. La especie mas comun de este sub-género es el grillo-talpa comun.

2. ¿Quién no ha oido alguna vez el canto monotono de los grillos? Apenas habrá persona que en la ciudad ó en el campo no haya sido importunada con su gri-gri, repetido durante horas enteras. Pero aunque muy comun en el campo y en las casas, principalmente en los sitios en donde se conserva continuamente fuego, el grillo no es fácil de percibir; prudente hasta' la timidez, oculta su guarida con todo el cuidado de que es capaz, y no sale de ella sino por la noche cuando sus enemigos descansan; y como es poco. ágil en sus movimientos, tiene cuidado de no apartarse nunca mucho de su habitacion, á fin de estar en disposicion de refugiarse á ella al menor peligro que le amenace. Pero á pesar de su prudencia, el grillo se deja coger fácilmente cuando se ha descubierto su madriguera. Como siempre está en acecho en su agugero a poca distancia de su abertura, á fin de atrapar los insectos que pasen por cerca de él, basta, para atraerle hácia fuera, enseñarle uno, sobre el cual se arroja con ardor luego que le ve, lo que facilita su captura al que le ha tendido el lazo. Esta astucia es muy conocida de los niños, que la emplean siempre que quieren procurarse estos insectos.

Tenemos dos especies de grillos muy comunes en España, que son el grillo de los campos (gr. campes. 
tris, L.) tan conocido de todo el mundo y el grillo doméstico (gr. domesticus, L.), de color amarillo claro mezclado de pardo. Otra especie, que es menos comun, pero muy particular, es el grillus umbraculatus de L., pues el macho tiene sobre la frente una prolongacion membranosa que cae en forma de velo. Entre las especies estrangeras la mas principal es la que Lefebre llama megacefalo, este es un grillo grande cuyo estridor se prolonga un medio minuto y puede oirse á casi una milla de distancia.

§. II. Unas elictras dispuestas en forma de tejado, unas antenas' setáceas y tan largas como el cuerpo; y cuatro articulaciones en los tarsos, forman unos caractérés que no permiten confundir á las LANGośtas rlo. custa) ni con los grillos ni con los acridios.

Mucho mas ágiles que los precedentes, las langostas, en vez de huir la luz como ellos, parece que la buscan con placer; y gustan de estar sobre las plantas pequeñas, ya silenciosas, ya cantando. Cuando el sol está en toda su fuerza es cuando principalmente tienen sus disonantes conciertos. Pero si viene á espantarlas algun ruido, toman inmediatamente la huida, ya saltando de planta en planta, ya echando á volar. Pero en todos casos no se van muy lejos; sino que despues de haber pasado una distancia de algunos pies, se paran un momento, á menos de que, perseguidas con demasiada viveza, no se vean obligadas á volver á tomar inmediatamente su vuelo.

Estos insectos son muy comunes en los campos y en las praderas, á pesar de la destrucción que las aves in. sectivoras hacen de ellos duránte todo el verano. Son tan fecundos que nada puede destruirlos. Las hembras pónen sús huevos en un capullo que esconden profundamente en la tierra, y de donde salen unos hijuelos que Tomo III. 


\section{6}

gozan de toda su agilidad inmediatamente despues de su nacimiento, lo que les espone á muchos menos peligros que las larvas que nacen prixadas de patas.

En España tenemos muchas especies de este gén ero: la langosta grande ó verdé (loc. viridisima, Fab.), que tiene dos pulgadas de largo, verde, con manchas negras en las elictras, y es la mas comun; la hoja de lirio lo es mucho menos; y la roe-verrugas (loc. verrucivora, Fab.), parecida á la anterior, pero mas pequeña y con manchas pardas ó negruzcas en las elictras; es especie, que se encuentra en el norte, y se ha llamado así, porque se dice que mordiendo los dedos de los que tienen verrugas, vierte en ellas un líquido negro que hace caer estàs escrescencias.

§. III. Ios ACRIDIOS ó criquetes (acridium) (fig. 5.) se diferencian de los dos géneros precedentes por sús elictras en forma de tejado, por el número de sus articulaciones, que es de cuatro, y por la cortedad de sus antenas, que nunca son tan largas como todo el cuerpo del animal.

Estos insectos, que el vulgo confunde con los precedentes bajo el nombre comun de langostas, cuando se hallain reunidos en gran número, son los mas temibles que se conocen por razon de su voracidad y de su fecundidad prodigiosa. La especie viagera, que se llama ordinariamente langosta de paso (gryllus migratorius), es principalmente nombrada por los estragos que ocasiona en las emigraciones que se ve obligada á hacer de tiempo en tiempo. Vuela en bandadas tan numerosas que interceptan la luz dél sol como una nube que pasa. ¡Desgraciado el pais sobre el que sorprende la noche á estas insectos! Descienden á él con la rapidez: del granizo, le cubren en muchas leguas cuadradas de estension como una inmensa red, y destruyen sallí en 
un momento hasta los menores vestigios de vegetacion; no solamente devoran todis las hojas, sino que ni aun perdonan la corteza ni las ramas tiernas de suerte que cuando se marchan de allí se diria que el pais ha sido devorado por un vasto incendio. Para formarse una idea de su número, bastará decir que en algunos parages se han llenádo, despues de su partida, de los huevos que habian puesto, hasta tres mil vasos, de los que cada uno contenia cerca de dos millones de ellos. Asi es que la piedra, la peste y el hambre no son unas plagas tan temibles como su aparicion. Afortunadamente se necesita poco pàra destruirlos; unä ráfaga de viento fuerte, una lluvia violenta los hacen perecer á millares; pero en este caso no es raro que el amonionamiento de sus cadáveres en putrefaccion produzca enfermedades epidémicás mortiferas, y aun algunas veces peste.

Estas emigraciones de los acridios no se verifican sino en épocas remotas, cuando habiéndóse multiplicado desmedidamente por alguna causa que ha favorecido su desarrollo, no encuentran ya en su pais con que satisfacer sus necesidades. En los años ordinarios, lejos de ser un azote, son útiles, porque se comen despues de quitarles las patas y las alas y poniéndolos en salmuera, y aun se hacen de ellos, segun dicen, un gran comercio en Oriente, de dande parece que proceden. En España tenemos el gryllus lineola, $L$., que se cree ser la especie que se come en Berbería ; prepáranla de la manera indicada. Los indígenas del Senegal parece que hacen secar otra que no es verde, con manchas oscuras, mandíbulas negras y estuches de color pardo claro como la $\mathrm{L}$. de paso, sino amarilla y manchada de ñegro. Cuando está seca la reducen á polvo y la usan como harina. Tambien se ven en nuestro pais el acridio ó langosta de alas rojas y el de alas azules; ambos son 
pardo negruzcos, pero el primero (gryllus stridulus, L.) tiene las alas rojas con la estremidad negra; y el segundo (gr. carulescens) las lleva de un azul un poco verdoso con una lista negra. Estas últimas especies núnca llegan ni con mucho á la magnitud de las dos primeras, que son á veces de mas de dos pulgadas y media de largo.

\section{U A RTO OR DEN:}

\section{HEMÍPTEROS.}

El carácter distintivo de los hemípteros no debe buscarse en la estructura de las elictras, como podria hacerlo presumir su nombre, que en griego quiere decir medias alas. Si algunos de ellos pueden conocerse por la disposicion de estos órganos, que son en efecto medio coriáceos y medio membranosos, la mayor parte, sin contradiccion, tienen estos apéndices diferentes, ya que carezcan de ellos absolutamente, ya que los tengan de consistencia uniforme en toda su estension. Los hemipteros pueden pues estar privados de alas ó tener cuatro, unas veces todas membranosas, otras parte membranosas y parte coriáceas; en este último cáso las elictras son las mas veces consistentes y opacas en su base, y trasparentes y ligeras en su estremidad; por consiguiente las alas son demasiado variables en su forma, número y estructura para que puedan servir para caracterizarlos. En la conformacion de los órganos de la boca es donde encontraremos los medios de distinguir á estos insectos de todos los demas animales de su clase. Nunca tienen mandíbulas ni maxilas : estas piezas estan modificadas de manera que forman por su reunion una especie de pico ó tubo, que contiene tres ó cuatro cerdas tiesas y agudas; por consiguiente su boca es im- 
propia para triturar un ialimento sólido, y no puede servir sino para agujerear la corteza de las plantas y da piel de los animales, cuyos humores les sirven de sustento. Como esta especie de alimentos estan más elaborados y son mas nutritivos que lás sustancias vegetaleŝ duras, no exige un conducto alimenticio tan deśr arrollado como el de los ortópteros; por esta razon los hemípleros no tienen mas que un soló estómago de paredes medianamente sólidas, y sus intestinos son de mediana longitud.:

Los hemípteros nunca sufren verdaderas metamorfósis ; sus cambios, muy análogos á los de los ortọ́pteros, se limitan al desarrollo de las alas, de las que carecen en sus dos primeros estados. Por lo demas el animal presenta eń los tres periodos de su existencia la misma organizacion interna y esterna, de suerte que sus costumbres no ofrecen casi ninguna diferencia en sus divèrsos estados:

El órden de los hemipteros puede dividirse en dos sub-órdenes; l los heterópterosisy los homópteros.

\section{PRIMER SUB-ÓRDEN.}

\section{HETERÓPTEROS.}

En estos insectos el pico nace de la frente ó de la parte superior de la cabeza; tienen las elictras duras por su base y membranosas en su estremidad, de suerte que estos son hemípteros en todo el valor de la espresion. A este carácter puede añadirse que son los únicos insectos del órden que tienen el primer segmento del coselete un poca mayor que los dos siguientes, y cuyas alas estan; cuando el animal no hace uso de ellas, colocadas hori- 
zon talmente sobre el dorso, ó apenas inclinadas en forma dertejado.

- Cási todós estos insectos son carniceros y y se alimentan de la sangre ó de los humoręs de otros animales. Generalmente se les designá con el nombre colectivo de chinches, aunque su organizacion presenta diferenciás bastante notables para que se hayan podido dividir en dos familias; lade los geocorisos y la de los hidravorisos.

\section{PRIMERA FAMILIA.}

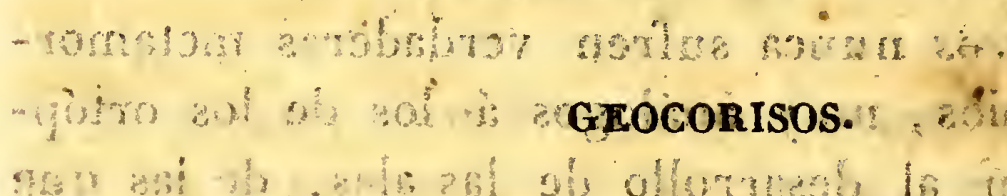

La palabra geocoriso es de orígen griego, y significa chinches terrestrés; se les ha dado este nombre por oposicion á las especies de la familia siguiente, que viven todas en el agua. it

Se conocen los geocorisos por surs antenas bieh visibles y mas largas que lacabeza, yór pla figura de sus tarsos, que jamas estan dilatidas en forma de hremos, ni guarnecidos de pelos dispuestos de modo que puedan golpear el agua, como las aletas de los peces.

Entre estos hemípteros unos viren parasitos sobre el cuerpo de los mamíferos, de las aves \&c.; otros tienen una vida errante, $y$ hácen continuamente la caza atros insectosi; algunos en fín son vagabundos como

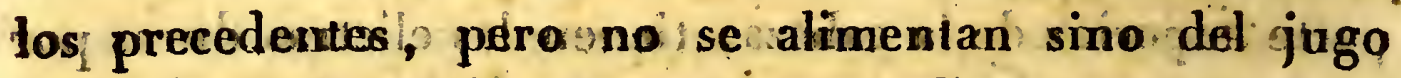
do los vegetales isobre los que ise establecen muchar veces ien gran cantidad.

Esta familia romprende un número considerable de especies, que todas se designan icon el imismo nombre nulgar, pero que se ideben dividir en dos géneros : las chinches ylos redudios. 


\section{1}

- \$. I. Las crinches (cimex) son unos insectos generalmente conocidos, por la incomodidad que nos causan, ya viniéndonos á chupar la sangre mientras dormimos, ya por el enorme hedor que comunican á los frutos sobre que han permanecido durante algun tiempo. Hày pocas personas que no hayan tenido basion de observar el aplastamiento estremado de su cuerpo, su forma oval, ó álo menos poco prolongada, su cuello corto $\mathrm{y}$ apenas perceptible. Pero lo que no saben todos es que exister especies de este gépero que brillan con colores agradables, y que, en vez de estar fijas sobre los cuerpos, á los que parecen estar pégadas, se remontan en los aires sobre sus alas, y escapan con agilidad de la mano que pretende cogerlas. Sin embargó á pesar de su hermosura, no debe procurarse el cogerlas, si se temen los malos olores, porque comunican á todo lo que tocan un olor muy fuer te $y$ hauseabundo.

El número de chinclies es muy considerable, se multiplican por todas partes con gran facilidad, porque las hembras ocultan sus huevos con tanto cuidado, $y$ los colocan en unos sitios tan farorables á su desarrollo; que es raro que dejen de llegar á salvo esto es lo que hace tan dificil la espulsion de estós insectos de un cuarto en donde se han establecido hace mucho tiempo. - En España tenemos muchos de estos odiosos hemípteros, de que se han formado dos subgéneros uno en el que las especies comprendidas tienen el cuerpo ancho y áptero, la cabeza escesivamente deprimidaly con antenas de cuatro articuláciones, y otro cuyas especies tienen elictras cruzadas parcialmente coriáceas, yanterras de cinco articulaciones. Al primero pertenecen la chincheidella col. (G. oleraceus, L.), la cruz de los caballeros (C. equestris, L.), la chinche de las cruciferas (C. ornatus, L.), la pentatoma de patas negras (fig. 5 bis.) \&c. pero la 
principal del segundo y la que mas nos incomoda es la de las camas (C. lectularius, $\mathbf{L}$.), que no necesita descripcion por ser demasiado conocida. Se han recomendado bastantes medios para ahuyentarla, lo que se consigue con algunas yerbas de olor fuerte, como el yezgo, la yerba buena \&ci, ó destruirla con el aceite de trementina o de tabaco: los huevos se destruyen tambien con los ungüentos mercúriales.

§. II. Los Reduvios (redivius) (fig. 6.) tienen bastante relacion con los precedentes para que se les dé vulgarmente el nambre de chinches-moscas, denominacion que anuncia que estos insectos tienen rasgos de semejanza con estos dos últimos géneros de animales. En efecto, se parecen á las chinches por todos los pormenores de su organizacion, al paso que su cuerpo prolongado, su cabeza bien separada del tronco por una depresion, $y$ la disposicion de sus alas, se asemejan á las formas esteriores de las moscas comunes.

Los reduvios son mucho menos conocidos que las chinches, aunque habitan nuestros aposentos como estas últimas. Se los observa menos porque no son tan incómodos, y porque permánecen escondidos ó se disfrazan de tal modo, que son dificiles de percibir. Pero. no por eso son menos interesantes sus costúmbres. $\mathrm{Co}^{\circ}$ mo son carniceros $y$ viven de insectos y principalmente de arañas, que son mas ágiles que ellos, se ven obligados á usar de estratagemas. Se revuclcan en el polvo y, las inmundicias, las que se pegan á su piel con. tanta mas facilidad, cuarto que estan erizadas de pelos. La àdhereneia de estas materias á su cuerpo forma al animal una verdadera máscara que le desfigura completamente. Disfrazado de este modo, se pasea por todos lados procurando descubrir su presa; lo que le es tanto mas fácil, cuanto que siendo del todo invisible $y^{2}$ 
andando con lentitud, parece mas bien una basura impelida por el viento que una criatura viviente y animada. Pero únicamente en el estado de larva es cuando los reduvios echan mano de este artificio; despues que han tomado alas persiguen su presa, la atacan á viva fuerza, y la devoran despues de haberla vencido.

En nuestro pais existen muchas especies de este género, de las que las mas notable es el reduvio enmascarado (cimex personatus, L.), que se encuentra con bastante frecuencia entre las barreduras y en todos los parages en donde se esconde ó deposita lả basura.

\section{SEGUNDA FAMILIA.}

\section{HIDROCORISOS.}

Los hidrocorisos ó chinches de agua no se diferencian solamente de las chinches terrestres por sus tarsos aplastados ó guarnecidos de pelos, lo que hace á estos insectos enteramente acuáticos, sino que ademas sus antenas son tan cortas, que su cabeza parece completamente desprovista de ellas, al paso que sus ojos por el contrario son enormes y muy salientes; sus patas se terminan por una pieza articulada ganchosa y movible, que hace el oficio de una pinza, por medio de la cual el animal coge su presa.

Todos estos insectos son acuáticos, y habitan los lagos, los estanques y en general todas las aguas muertas. Unos se arrastran lentamente en el fondo por el cieno; otros nadan con velocidad en la superficie, poniéndose algunas veces sobre el dorso. Se zambullen con mucha rapidez cuando se les quiere coger, y pican con mucha fuerza cuando se ven cogidos. Son muy carniceros bajo sús tres estados, y se alimentan de pequeños insectos

ToMo III. 
que atrapan con mucha destreza, ó se fijan sobre el cuerpo de animales acuáticos cuya sangre chupan.

No citaremos de esta familia mas que ún género, el NAuconis (naucoris) (fig. 7.) ó chinches navecillas. Estos insectos se parecen mucho á las chinches por su conformacion general, principalmente por su forma oblonga ú oval, y por su cuerpo aplastado; pero es fácil distinguirlos por los caractéres de la familia, y por sus patas anteriores que se terminan en un fuerte gancho, como las de las arañas. El animal se sirve de este instrumento para agarrar su presa, y detenerla mientras la traspasa con su aguijon, y chupa su sangre $y$ humores.

Los naucoris son muy ágiles, nadan con velocidad y vuelan con rapidez: pero no salen del agua sino por la tarde, para dar la caza á los insectos nocturnos ó crepusculares. Son tan voraces que no encuentran en el agua bastantes víctimas para satisfacer sus apetitos glotones, á pesar de que destruyen mas que ningun otro insecto acuático : esto es lo que les obliga á dejar su elemento favorito, para abalanzarse á otro que:les conviene mucho menos.

Se conocen tres ó cuatro especies de este género de las que la principal es el naucoris chinche (nepa cimicoides, $\mathrm{I}_{\text {.) }}$ )

Otro género que tiene mucha relacion con los que acaban de mencionarse es el de los NEPAS ó escorpiones de agua (fig. 7. bis.) que se hallan caracterizados por no tener mas que una sola articulacion en los tarsos anteriores, dos en los cuatro posteriores las antenas, como ahorquilladas, y su pico está encórvado hácia abajo. Su cuerpo es estrecho y mas prolongado que en los géneros precedentes, casi eliptico. Su abdómen se termina por dos cerdas, que unidas forman un tubo que sirve al ani- 


\section{5}

mal para respirar en los parages acuáticos y cenagosos que frecuenta. Los huevos que pone son ovalados con dos cerditas parecidas al vilano de ciertas semillas; existen varias especies de este género; pero entre ellas las principales son la nepa linearis (nepa linearis, L.) muy comun en todos los mares durante la primavera y la nepa cenicienta (nepa cinerea, L. ) (fig. 7. bis.)

\section{SEGUNDO SUB-ÓRDEN.}

\section{HOMÓPTEROS.}

No considerando mas que las álas ó las elictras, el nombre de hemípteros no convendria á las especies de esta segunda seccion, que nos ofrecen constantemente unos estuches de consistencia uniforme en toda su estension, y muchas veces apenas diferentes de las alas ordinarias. Pero su organizacion, género de vida, costumbres \&c., tienen tanta relacion con las de los hemípteros del primer sub-órden, que es imposible separarlos unos de otros, como lo han hecho algunos naturalistas que no fundaban su clasificacion mas que en la disposicion de los órganos del vuelo.

Aunque la estructura de las elictras pudiese, en rigor, bastar para caracterizar á los homópteros pro. vistos de alas, no podria emplearse con relacion á aquellos insectós que permanecen toda su vida apteros, ni para sus larvas y crisalidas. Es preciso considerar, para distinguir á estos últimos, el orígen del pico y la forma del primer segmento del coselete. El pico toma siempre origen en la parte inferior de la cabeza, y algunas veces entre las dos patas anteriores; y el primer segmento del tronco-, lejos de ser mayor que los dos siguientes, es casi siempre mas pequeño, ó á to mas de. 
la misma magnitud. Ademas, las hembras de todos éstos insectos se diferencian de las precedentes por un taladro dentado en forma de sierra que llevan en la estremidad de su abdómen en una vaina particular y el que les sirve para agujerear la madera-en que depositan sus huevos.

Todos los homópteros son hervíboros, y habitan sobre las plantas cuyos jugos sirven para alimentarless. Muchas veces las caúsan grandes perjuicios, ó las dan un aspecto desagradable, produciendo sobre sus hojas ó en su corteza unas escrescencias que no tardan en consumir al vegetal.

Se pueden dividir los homópteros en dos familias; los cicadarios y los afidianos.

\section{PRIMERA FAMILIA.}

\section{CICADARIOS. (Lám. XXXV.)}

Esta numerosa familia comprende todos los hemipteros de la segunda seccion que tienen tres articulaciones en los tarsos, las antenas pequeñas y terminadäs en una punta muy fina y las elictras siémpre un poco mas consistentes que las alas; los cicadarios se reducen á tres géneros: las cigarras, las cicadelas y las fulgoras.

§. I. Hay pocos insectos cuyo nombre sea tan conocido como el de las cigarras (cicada) (fi. 8.) á quienes los fabulistas han hecho tan célebres; tambien se conoce su canto que nos incomoda tan frecuentemente en èl campo, por su aspereza y monotonia. Pero no sucede lo mismo con su figura y costumbres; muchas veces se confunden estos insectos con los grillos, los que sin embargo son de una familia $y$ de órden diferentes. 
Pero examinando los órganos de su boca, es fácil ver que son hemípteros y no ortópteros; sus elictras, de consistencia uniforme en toda su estension indican que pertenecen al sub-órden de los homópteros, y sus patas, todas iguales y por consiguiente impropias para saltar impiden confundirlas con las cicadelas y las fulgoras. Eștos insectos tienen por otra parte, ademas de los dos ojos ordinarios, tres estemmas situados debajo de estos últimos; y sus antenas tienen siempre cinco artículaciones.

Se pueden mirar las cigarras como propias de los paises cálidos; no las hay en el Norte, y no se encuentra mas que una especie de ellas en los alrededores de Paris. Úuicamente durante los fuertes calores del verano gozan de toda su aclividad; solamente entonces es cuando producen sus ruidosos conciertos, y se las ve revolotear de árbol en árbol cantando. Pero por poco que se obscurezca el tiempo ó que llueva, cesa su canto, pierden su viveza, y quedan como entorpecidas é inmóbiles sobre su rama.

Estos insectos viven de la savia de los árboles y plantas, las que agujerean por medio de las cerdas de que éstá guarnecido interiormente su pico; y parece que su picadura no se limita á procurar la evacuacion de la cantidad de jugo necesario para su manutencion; sino que sale por mucho tiempo despues que han dejado su sitio, si es cierto, como se cree generalmente, que la conformacion del maná purgante tan usado en medicina, sea producida por la herida que hacen á una es. pecie de fresno, muy comun en Italia.

La reproduccion de las cigarras es muy curiosa. Luego que ha llegado el tiempo de la postura, la hembra busca una rama seca, en la que hace con su taladro muchos agugeros profundos, en cada uno de los cuales 


\section{8}

'deposita cierta cantidad de huevos. No es sin designio el elegir asi la madera muerta de mucho tiempo, para confiarla su descendencia. Como las larvas que deben salir no pueden desarrollarse sino en la tierra; su instinto lés hace prever que estas ramas no pueden tardar mucho en cáer, y que de este modo sus hijuelos podrán fácilmente meterse en el suelo para sufrir alli sus metamorfósis.

Digamos ahora algo sobre los órganos del canto de las cigarras; es propio esclusivamente de los machos, y no es producido, como en la mayor parte de los demas insectos, por el rozamiento de una parte dura contra otra de la misma consistencia; sino que hay un aparato particular situado en lo interior del abdómen. y que consiste en unas membranas que el animal estiende y encoge alternativamente con mucha rapidez. Asi es que se les puede hacer cantar artificialmente y á pesar suyo, dándole tirones en el abdómen.

Las cigarras no son hoy en dia de ninguna utilidad para el hombre; pero los antiguos hacian un gran caso de sus larvas, á las que llamaban tetigometras y- parece que se servian en las mejores mesas.

Entre las numerosas especies de este géncro, citaremos la cigarra hematodes, la única que se encuentra en los alrededores de Paris, la cigarra plebeya ó comun (C. plebeia, L.) (fig. 8.), la cigarra dèl quejigo \&c. (C. orni, L.) (fig. 9:), todas del mediodia de España y Francia.

§. II. Las cicadelas (cicadella) ó tetigonas se diferencian de las precedentes porque no cantan, también porque no tienen mas que dos estemmas, porque sus antenas no son sino de tres articulaciones, sus patas posteriores tienen mas longitud que los dos páres anteriores, lo que caracteriza á los animales saltadores. 
Las especies de este género no son tan propias esclusivamente del Mediodia como las cigarras; se encuentran un gran número de ellas en los alrededores de Paris. Pero son generalmente mas difíciles de coger que las precedentes, porque saltan con agilidad, $y$, se escapan, con mucha destreza, de la mano que procura apoderarse de ellas. Por lo demas, sus costumbres y organizacion no se diferencian cási de las de las cigarras, escepto con relacion al canto $y^{*}$ al aparato que le produce.

Se ha dividido este género numeroso en muchos subgéneros, de los que los principales son: las tetigonas ó cicadelas propiamente dichas que nada ofrecen de notable; los centrotos á quienes la singularidad de sus formas ha hecho llamar diablos, y los cercopos cuyas costumbres en el estado de larvas son estremamente curiosas. Como entonces son poco ágiles, y pasan este periodo de su vida pegados, por decirlo asi, á la planta, cuyo jugo sirve para alimentarlos; se verian muy espuestos á ser presa de las aves y de diferentes insectos que los apetecen mucho. Para ocultarse á sus miradas, exhalan por toda la superficie de su cuerpo un líquido, que, esponiéndose al aire, se cambia en espuma y se condensa alrededor de ellos, de modo que les forma una cubierta que los hace cási invisibles. Si se les quita esta capa protectora; no tardan en hacerse una nueva para reemplazarla. Sin embargo, á pesar de su disfraz, una especie de avispa sabe distinguirlos muy bien, y se los lleva muchas veces á su nido con su cubierta inútil.

§. III. Las FULGORAS (fulgara) (fig. 10.) tienen muchas relaciones con las cigarras y las cicadelas por su conformacion general; pero son fáciles de conocer por una prolongacion de su frente; que forma una 
eminenciá considerable, y por sus estemmas que sôn solo en número de dos y están situados debajo de los ojos. Sus costumbres son las de las cigarras, escepto que sus machos carecen de ese aparato abdominal, que produce el canto de estas últimas. Una de las especies mas notables de este género es la fulgora porta-linternas, que se encuentra en la América meridional. Es un insecto de cerca de tres pulgadas de longitud, cuya frente, hinchada como una vegiga, brilla durante la noche con una luz fosfórica tan resplandeciente, que aseguran que se puede leer al resplandor que despide; lo que le ha hecho dar su nombre específico de porta-linterna.

Se encuentra tambien en el mismo pais la fulgora porta-candela, cuya eminencia frontal es menos voluminosa, pero que esparce tambien luz. En el mediodia de España tenemos una pequeña especie de este género; pero es poco notada, porque la fulgora europea, no brilla como las precedentes.

\section{SEGUNDA FAMILIA.}

\section{AFidianos. (Lám. $X X X V$.)}

Se podrian, por decirlo asi, conocer los insectos 'de esta familia por su poca magnitud, que á veces no tiene una línea, y que rara vez llega á dos; pero su verdadero carácter se sáca del número de las articulaciones de sus tarsos, que no es mas que una ó dos (fig. 11 y 12.) al paso que en los cicadarios es lo menos de tres. Sus antenas son muy desarrolladas, y esceden constantemente en longitud á la caheza y muchas veces al cuerpo entero; sus elictras cuando las tienen, lo que no siempre sucede, son casi absolutamente se- 


\section{1}

mejantes á la alas membranosas, cuya trasparencia tienen. Por consiguiente su cuerpo es blandujo y ofrece un alimento delicado á la mayor parte de los animales insectívoros, que efectivamente devoran muchos de estos; pero, ademas de que sù pequeñez les preśerva en algun modo, tienen cuidado de cubrirse de diferentes. materias que los disfrazan completamente; y como por otra parte permanecen casi absolutamente inmóviles sobre la planta que les sirve de asilo y les suministra su subsistencia, quedan las mas veces sin ser vistos $y$ hallan de este modo su seguridad en su misma debilidad.

La fecundidad de los afidianos es prodigiosa, porque hacen muchas posturas al año, y en cada una de ellas ponen un gran núméro de huevos; y como sus larvas chupan los jugos nutricios de las plantas, lo mismo que el insecto perfecto, estas no tardan en consumirse y en perecer de languidez, ó á lo menos caen en un estado tal de mal estar que ya no pueden producir, ni ser buenas para nada.

Esta familia comprende dos géneros muy interesantes; que son los pulgones y las cochinillas.

§. I. Los PULGoNes (aphis) 'son unos insectos muy singulares, y $\sin ^{\circ}$ embargo son tan poco conocidos, que vulgarmente se da este nombre á todo pequeño insecto, que vive sobre las plantas á espensas de su savia. Pero para los naturalistas, los pulgones son unos hemípteros de la familia de los afidianos, cuyos tarsos tienen dos articulacionès y están terminados por dos ganchos, y cuyas antenas son largas y de grosor uniforme en todà su estension.

Se encuentran los pulgones reunidos en tropas numerosas sobre las hojas del tilo, del manzano, \&c. Inmóviles en el mismo sitio, pasan toda su vida ocuTọ̣IO III. 


\section{2}

pados en estraer con su trompa los jugos del vegetal. A sus picaduras son debidas esas escrescen cias tan comunes en las hojas del quejigo', del álamo \&c. Al verlos de este modo fijos y sín movimientos apreciables, se les tomaria mas bien por unos cuerpos inertes, que por animales que gozan de todas sus facultades.

Pero por poco que se hayan visto estos insectos, no se duda mucho tiempo sobre su naturaleza; unos enjambres de hormigas, que se ven corretear sin cesar alrededor de ellos, no tardan en probar que son pulgones. Estos tienén en la estremidad de su abdómen dos tubos que producen un liquido meloso que gusta mucho á las hormigas, de suerte que en todas partes en donde hay afidianos es seguro encontrar hormigas. Aun se preten de que estas últimạs se apropian rebaños de estos hemípteros de los que cuidan, á fin de alimentarse de su miel.

Pero el hecho mas curioso y mas notable de la historia de los pulgones es el modo como se reproducen: Hemos dicho que hacen muchas posturas al año; en tanto que dura el buen tiempo las hembras producen hijuelos vivos que, saliendo del seno de su madre, se esparcen por los árboles en donde encuentran un alimento fácil y una temperatura bastante suave. Pero al fin del otoño, como los frios harian perecer á estos seres delicados, no producen ya sino huevos que ponen al abrigo de los rigores del invierno, y que se cónservan hasta la primavera, época en que se empollan para perpetuar su raza.

Se conoce un gran número de especies de este género que se designan con el nombre de lá planta qué cada una de ellàs frecuenta con preferencia; asi es que se dice el pulgon de la encina (fig. 11.), del haya, del quejigo, del sauco \&ce. 


\section{3}

Un género proximo al precedente es el de los psiLos, (psilla) llamados tambien quermes ó falsos pulgones los que se diferencian de los verdaderos por su agilidad y por sus antenas terminadas en punta. Tal es el psilo del box (chermes buxi, L.), que habita la cima de box, y hace que se hinchen sus hojas.

§. II. Las cochintllas (coccus) (fig. 12.) tienen mucha analogía con las especies del género pulgon por sus costumbres; pero se distinguen de él facilmente, porque tienen una articulacion única en los tarsos y dos cerdas en la estremidad de su abdómen.

Estos insectos tienen las formas poco agradábles, sus hembras principalmente parécen mas bien unas escrescencias en forma de bola, riñon ó batel, que unos seres animados. No ejecutan movimiento alguno y permanecen siempre fijos en el mismo sitio, con la trompa metida en la corteza y chupando los jugos de la planta; su vida nada presenta de notable hasta el momento de su reproduccion. La hembra no pone huevos, ni produce hijuelos vivos. Cuando se han formado los gérmenes en su cuerpo, muere, sư cadáver se seca y les sirve de un abrigo que los defiende de los rigores de la mala estacion, de suerie que en la primavera siguiente el calor del sol los hace nacer, y salen una multitud de pequéñas larvas que no tardan en fijarse como su madre. Sin embargo algunas especies se desembarazan de sus huevos; pero tienen cuidado para preservarlos del frio, de cubrirlos de una capa densa de materia algodonosa y blanda, que mantiene al rededor de ellos el calor necesario para su conservacion $\bar{y}$ desarrollo.

Se conocen. muchas especies de este género, de las que la mas célebre es la cochinilla del nopal, ó higuera de Indias, que se encuentra en la América meridional en el estado salvage y doméstico; vive sobre una espe- 
cie de cacto llamado nopal, y suministra ese magnífico color encarnado que reemplaza á la púrpura de los antiguos, y del cual se forma el carmin, la escarlata y el carmesí. Este insecto constituye una de las principales riquezas de Méjico, y aun de nuestras provincias meridionales, como Valencia, Almería \&c.

\section{QUINTO ÓREN.}

\section{NEÚRóPTEROS.}

Los insectos de que hemos hablado hasta aqui son ápteros, ó tienen cuatro alas, de las cuales las dos anteriores se diferencian mas ó menos de las posteriores por su estructura mas firme, y forman á estas últimas una especie de estuche. En el órden de los neurópteros, las cuatro alas son de la misma consistencia ; lo que impedirá siempre confundirlos con las especies precedentes. Ademas se les distinguirá fácilmente de los órdenes que siguen por el número de estas alas, que es de cuatro, al paso que no es mas que de dos en los dípteros, por su superficie, que no está jamas cubierta de esas escamas que se encuentran en las de los lepidópteros, y. por su estructura, que es reticulada ó formada por una red muy fina, y que es simplemente nerviosa en los himenópteros. Por otra parte, estos últimos tienen las alas superiores siempre mayores que las inferiores, al paso que los neurópteros las tienen generalmente mas cortas, ó á lo mas de la misma magnitud. Es preciso añadir á estos caractéres la conformacion de la boca, que está formada, en los insectos de que hablamos, de dos mandíbulas y de dos maxilas, que nunca tienen la forma de un tubo apropiado para la succion, y no pueden servir sino para masticar materias sólidas. 


\section{5}

Por lo que tóca á las costumbres, nada presentan de constante los neurópteros; unos no sufren mas que una semi-metamorfósis, otros la esperimentan completa. Pero en todos casos el animal conserva su agilidad bajo sus tres estados, y vive principalmente de sustancias animales.

Este órden se puede dividir en dos familias, los subulicornes y los planipennas.

\section{PRIMERA FAMILIA.}

\section{SUBULIGORNES. (Lám. $X X X V I$.)}

Tres caractéres principales distinguen á los neurópteros de esta familia ; una cabeza gruesa y propista de dos ojos salientes en cada lado, unas maxilas y mandíbulas enteramente cubiertas por los lados ó por una eminencia de la frente, y unas antenas puntiagudas y en forma de lesna, lo que les ha hecho dar el nombre de subulicornes (1).

El cuerpo de estos insectos es largo, delgado, endeble, y presenta las mas vecès cuatro alas muy desarrolladas é iguales en estension; rara vez tienen solo dos á consécuencia del aborto de las inferiores. Mas no por eso vuelan con menos agilidad durante su corta existencia; apenas descansan algunos instantes. Estan constantemente ocupados á lo largo de las aguas en perseguir su presa, que consiste en insectos. Pero destruyen muy pocos, pues mueren todos luego que han hecho su postura y atendido á las necesidades de su posteridad; el tiempo que exige este cuidado no pasa de algunas horas en ciertas especies. En recompensa su vida

(x) Subula quiere decir lesna, y cornu antena. 
en el estado de larva es mucho mas larga, y se prolonga durante muchos años: Pasan todo este tiempo en él agua, en donde viven de gusanos y de insectos como cuando han tomado alas. Pero salen de este elemento para sufrir su última metamorfósis.

Esta familia no encierra mas que tres géneros: las libelulas ó doncellitas, los efímeros y los friganeos.

S. I. ¿Qué niño habrá que no haya visto y perseguido á esos lindos insectos de cuerpo esvelıo y ligero, de colores delicados y variados, de alas anchas y trasparentes, que los naturalistas llaman cibécúcas (libellula), y que vulgarmentè les dan el nombre de doncellitas por razon de su gracia y de la elegancia de sus formás? Estos son unoś neurópteros de là familia de que hablamos, y que se distinguen de los de los généros siguientes por sus alas iguales, por sus maxilas duras $y$ córneas, y por un apéndice en forma de gancho ó de hoja que termina su largo abdómen.

Al ver estos insectos tan frágiles y tan delgados no se dudará de que son unos animales voraces y crueles, que en los movimientos á que les vemos entregarse en las márgenes de los arroyuelos, persiguen sin descanso á las moscas, mosquitos y otros pequeños insectos volantes. Pero en el estado de larvas es cuando principalmente las libelulas son carniceras, Su boca presenta entonces dos pièzas movibles y dentadas, que juegan una sobre otra como las ramas de una tenaza, y de las que el animal se sirve con mucha ventaja para coger y despedazar su presa. Para poder alcanzar con mas facilidad á sús víctimas, tienen en la estremidad del ab. dómen una abertura susceptible de abrirse y cerrarse alternativamente, $y$ de la que se sirven para hacer entrar en su cuerpo cierta cantidad de agua, que ellas arroján en seguida con fuerza para acelerar sus movimientos. Es- 

T. III. NEUROPTEROS, HIMIINOPTEROS LEPIDÓPTERUS YDIP'TEROS .

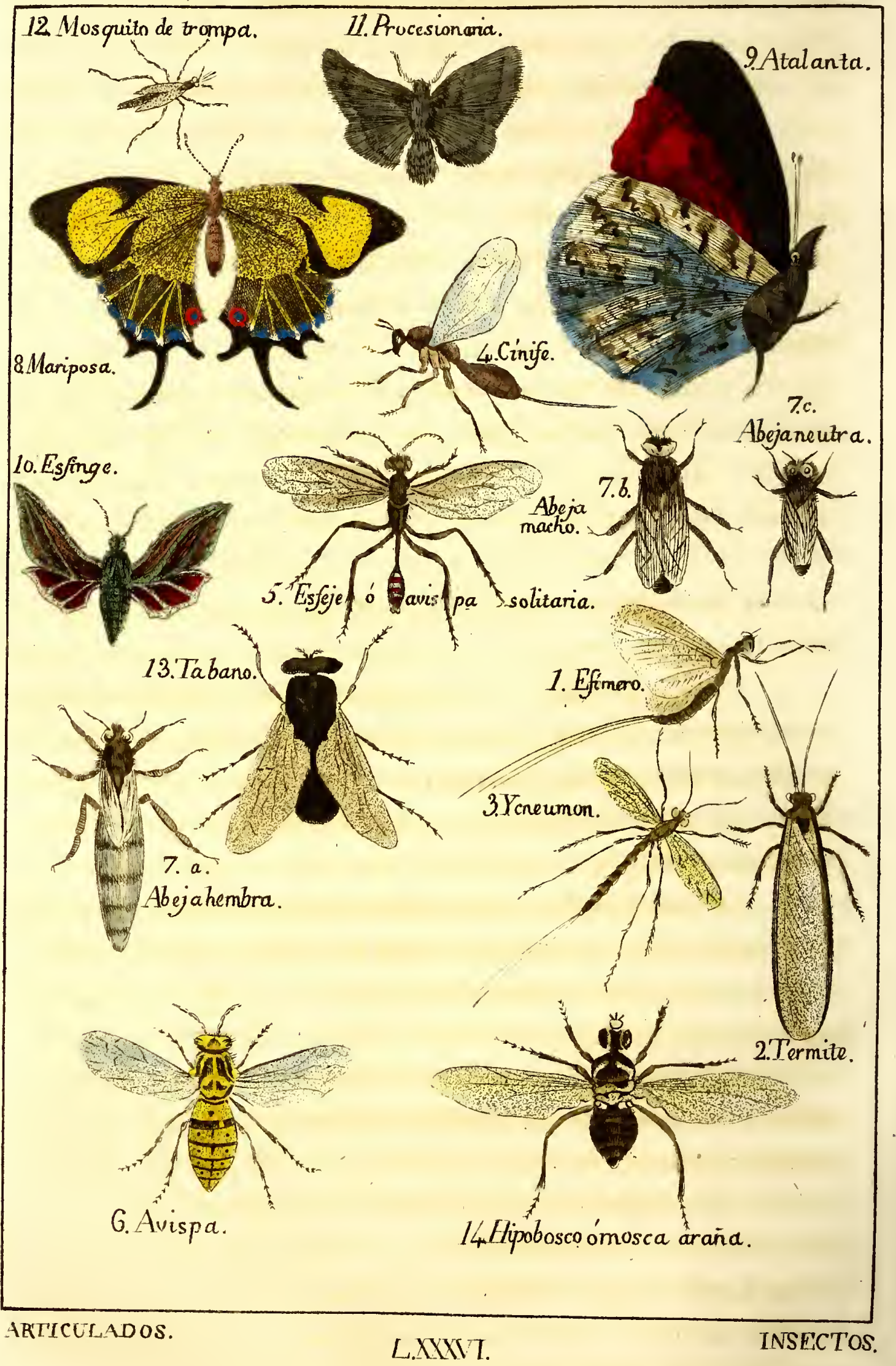


tas larvás viven de este modo por espacio de cerca de once meses; y al duodécimo, y siempre durante el buen tiempo, salen del agua para trepar á lo largo de los tallos de las plantas acuáticas, y desembarazarse de su cuhierta de crisalida. Esta operacion se hace en poco tiempo; una ó dos horas bastan ordinariamente, y nunca necesitan mas de un dia.

Las principales especies de libélulas que se encuentran en España son la gran doncellita, la doncellita de tenazas \&c.

§.II. Los insectos viven generalmente poco tiempo en el estado 'perfecto; pero sin embargo no ha y ninguno que viva tan poco como los Efímeros (ephemera). (fig. 1.), cuya existencia se limita muchas veces á algunas horas, y jamas pasa de un dia, de suerte que merecen realmente su nombre, que quiere decir viviente un dia.

La figura de estos neurópteros tiene muchas relaciones con la de las libélulas, pero se diferencian de ellas por la estructura de su boca, cuyas maxilas son muy blandas y poco distintas, y de un modo mas aparente por la pequeñez de las alas inferiores y por dos ó tres filamentos muy largos que terminan su abdómen. Su vida, luego que han adquirido los órganos del vuelo, puede mirarse como concluida, porque ya no comen, y esta es la razon por que sus órganos masticatorios son tan incompletos, que no pueden servir para pre; hension ni para la trituracion de ninguna especie de alimento.:

La única funcion que tienen que egercer en el estado perfecto es la reproduccion; luego que las hembras han puesto, lo que siempre verifican en el agua, se las ve caer muertas en su superficie y ser presa de los peees. $\mathbf{Y}$ como ordinariamente estan reunidas en tropas 
muy considerables, forman una capa bastante densá, á la que los pescadores dan el nombre de maná. La caida de una especie, notable por la blancura de sus alas, renueva, durante el buen tiempo, el espectáculo de aquellos dias de invierno en que se ven cubiertos los campos de.una vasta capa de niere. Caen algunas veces en tan gran cantidad, que sus cadáveres forman montones bastante considerablés para que se puedan recoger á carretadas, y emplearse para estercolar las tierras.

Pero si los efímeros viven poco tiempo en su estado perfecto, no sucede lo mismo en el de larvas; la vida de estas últimas llega á dos y aun á tres años; durante este intervalo se alimentan de insectos, y aun, segun dicen, de arcilla ó mas bien dẻ las moléculas orgánicas que contiene.

Se cuentan un gran número de especies de esté género; las mas comunes son el efímero comun, el efiméro dé cola larga y el éfímero díptero.

§. III. Muchos naturalistas hacen una familia particular del género FRIGANEO (phriganea) porque carece enteramente de mandíbulas, y porque tienen las antenas muy largas y las alas inferiores plegadas en la direccion de su longitud. Pero como tiene muchas relaciones con los efímeros por la cortedad de su vida en el estado perfecto y por sus costumbres acuáticas bajo el de larvas, le reuniremos á los dos géneros precedentes, como lo han hecho muchos autores célebres.

ta historia de estos insectos no ofrece nada de interesante en el último periodo de su existencia; pero es de las mas curiosas en los primeros tiempos de su vida. Sus larvas, prolongadas y casi cilindricas, no están revestidas mas que de una piel blanda y delicada, y se verian espuestas sin defensa á los ataques de sus enemigos, si no tuviesen el instinto de hacerse una especie 
de escudo protector. Este es un estuche sólido, que se construyen con una sustancia glutinosa y paja, trozos de conchas, granos de arena \&c; poco mas ó menos como lo hacen làs terebelas entre los anelides. En seguida se meten enteramente en él, á escepcion de la cabeza que dejan fuera y van paseándóse en todas direcciones por el fondo del agua, llevando consigo su habitacion, la que jamas abandonan á no ser por fuerza.

De este modo viven libres hasta la época en que deben transformaŕse en ninfas. Llegado este momento, se fijan á alguna raiz acuática, y cierran exactamente la entrada de su tubo por medio de una rejilla bastante sólida para impedir á sus enemigos llégar hasta ellos, pero no tan cerrada que intercepte el paso del flnido que necesitan para respirar.

Luego que ha llegado el tiempo de su última metamorfósis, rompen sus lazos y se elevańlá la superfiçie del agua en donde abandonan su estuche para trepar por los cuerpos vecinos. Sin embargo las especies mas pequeñas conservan su antigua habitacion, y se sirven de ella como de una navecilla para sostenerse en la superficie del agua.

Las principales especies de friganeos son cl frigané: grande (phriganea grandis, L), de alas grises y con ondas y manchas pardas ó negruzcas, el friga neo estriado (Phr. striatus, L.) cuyas alas son pardo-rojizas con estrias longitudinales negras, y el friganeo de hilos largos (Phr. filosa, L.) pequeño, que tira á pardo, y con antenas tres veces mas largas que el cuerpo \&cido 


\section{SEGUNDA FAMIIIA:}

\section{PLANIPENNAS. (Lám. $X X X Y 1$ )}

Todos los neurópteros de la familia precedente tienen sus alas levantadas y unidas una a otra en estado de quietud (fig 1); los plánipentás por el contrario, llevan estos órganos echados sobre su dorso horizontalmente 6 en forma de tejado (fig. 2.). Estos últimoś tienen ademas la boca formada siempre de partes muy distintas, las antenas largas ó claviformes y el abdómen generalmente desprovisto de esos largos filamentos 6 de esos apéndices, que le terminan en casi todos los géneros que preceden.

La mayor parte decllos previenen de lạras carniceras, iviven en familias como las hormigas , y esperimentan metamorfósis completas ; „de suerte que sus niñfas son enteramentel inmóviles como las de los coleópteros. Su vida de insectos perfectos, aunque mas larga que en los subulicornes, es con todo muy limitada, pero emplean menos tiempo en sufrir las transformaciones sucèsivas, que deben conducirles á este estado.

a Esta familia comprende tres géneros principales: las hormigas leones, los hemerobios y los termites.

§. I. Las HORMIGAS LEONES (myrmeleon) son para los insectos pequeños, y principalmente para las hormigas, lo que el leon es para los cuadrúpedos, un objeto de terror y espanto, y á esta circunstancia de: ben su nombre en castellano y en griego. Siendo fáciles de distinguir por su forma delgada y prolongada, por sus antenas en forma de maza y por las cinco articulaciones dé sus tarsos, no teniendo nada de notable en su organizacion ni en sus costumbres, los antiguos las ha- 


\section{1}

bian despreciado ni aun les habian dado nombre.

Pero la historia de sus larvas es demasiado interesante para pasarla en silencio. Tienen el vientre escesivamente grueso en comparacion, de lo restante de su. cuerpo, $y$ las patas tan pequeñas, que no pueden moverse sino con lentitud y hácia atras; y con todo, su. organizacion les obliga á alimentarse de presa viviente, la que tienen que coger ya corriendo, ya por medio de. la stucia. Como el primer medio les es imposible, emplean el segundo; hacen en la arena un agugero en forma de embudo, cuyas paredes son tan lisas que ningun insecto puede pasar por alli sin rodar al fondo del abismo. Esta obra, á pesar de ser muy penosa y embarazoșa para un animal poco ágil, la termina con bastante prontitud, á no ser que encuentre alguna piedrecita demasiado pesada para poderla arrojar á lo lejos; entonces se ve obligado á colocársela sobre el cuerpo y á mantenerla en equilibrio andando hácia atras por los bordes res. baladizos de su embudo. Por poco que pierda su equilibrio, la carga rueda al fondo del embudo, y cual nuevo Sisifo, el insecto se ve obligado á empezar de nuevo muchas veces su trabajo.

En estando preparada la trampa, la larva se establece en el fondo de su embudo, no dejando fuera mas que dos pinzas agudas, prontas á agariar la primera victima á quien su mala estrella conduzca al rírculo fatal. ¡Desgraciada la hormiga que se vea introducida en él! en vano procurará sostenerse por medio de sus patas para no caer entre las garras de su cruel enemiga; este hace llover sobre ella con su cabeza una rociada de granitos de arena que la aturden y la arrastran infaliblemente al fondo. La larva la coge sla chupa en un momento y arroja sus despojos á lo lejos, por temár de que, si quedára cerca de su agujero, no fuese pa- 


\section{2}

ra otras un aviso que las hiciera desconfiar del lazo. Sin embargo estas astucias de las hormigas leones no siempre tienen buen éxito; sucede con frecuencia que no pasa ningun insecto por su agugero ó que los que pasan por él consiguen escaparse; en este caso su organizacion se presta fácilmente al ayuno, $J$, espera con paciencia un tiempo bastante considerable sin tomar nada. Pero la tolerancia de su estómago tiene un termino, pasado el cual se veria comprometida su vida si no se procurase alimentos: entonces se ven obligadas á abandonar su habitacion y á establecerse en un sitio mas favorable á sus designios.

Se conocen muchas especies de hormigas leones, La hormiga leon comun (myrmeleon formicarium, L.) se encuentra muy comunmente en España; tiene una pulgada de largo, y es de color negruzco y manchado de amarillo bajo; sus alas son trasparentes, y los nervios de ellas negros con intersecciones blancas.

§. II. Los HeMerobios (hemerobius) se parecen mucho á las hormigas lecones por sus formas esbeltas y ligeras y por la mayor parte de sus caractéres zoológicos; pero se diferencian de ellas por sus antenas terminadas en filamentos agudos, y por sus palpos que son solamente en número de cuatro, al paso que las precedentes tienen seiș. La delgadez de su cuerpo, la finura de sus alas, que tienen la transparencia de la gasa, la hermosura de sus colores delicados y agradablemente matizados, han merecido á estos insectos el nombre de doncellitas terrestres, denominacion que indica bastante las relaciones de los hemerobios con las libélulas á las que se parecen por sus formas y colores, pero de las que se distinguen por sus costumbres terrestres.

Estos insectos se encuentran con frecuencia en los 
jardines, en donde se les ve revolotear de rama en rama, buscando un sitio apropiado para recibir sus huevos. Eligen principalmente las plantas habitadas por pulgónes, cuyas larvas les gustan mucho. Guando la hembra ha encontrado una hoja á propósito para llenar su objeto, hace salir de la parte posterior de su abdómen, por uná abertura análoga á la que se observa en las arañas, una gota de un liquido viscoso que saca, por decirlo asi, como por hilera, y que, secándose por el contacto del aire, toma bastante solidez para sostener un huevo. La hembra hace tantos filamentos de estos como huevos tiene que poner, es decir, cerca de una docena.

Las larvas que salen de estos gérmenes son muy carniceras, y devoran una gran cantidad de insectos y principalmente pulgones, lo que ha hecho dar a los hemerobios el nombre de leones de pulgones, asi como se llaman los insectós del género precedente, hormigas-leonés ó leones de hormigas.

Entre las especies de este género se puede citar el hemerobio verde (hemerobius perla, L.) cuyo cuerpo y, nervios de las alas son de un hermoso color verde, y el hemerobio verde y negro (hem. chrisops, L.) cuyo cuerpo y parte nerviosa del ala son de color verde azulado con manchas negras; los ojos de estas dos especies son de un precioso color de oro; ambas se encuentran en casi toda Europa.

§. III. Los Termutes (termes) (fig. 2.) ó termes no tienen mas que cuatro articulaciones en los tarsos, al paso que todos los demas géneros de la misma familia tienen generalmente cinco, á escepcion de uno solo que no ofrece mas que tres. Sus alas, poco reticuladas, son muy largas $\mathbf{y}$ echadas horizontalmente sobre el dórso del animal. 


\section{4}

Estos neurópteros son quizá de todos los insectos los que tienen las costumbres mas curiosas, sin esceptuar las abejas y las hormigas. Propios de los paises próximos á la línea, son conocidos allí bajo el nombre - de hormigas blancas, de piojos de bosque \&c., y hacen horribles estragos. Reunidos en tropas inmensas (mas de sesenta mil), se construyen; como las abejas, unas especies de nidos comunes á toda la sociedad. ¡Pero que diferencia entre sus habitaciones $\mathrm{y}$ las colmenas de las abejas! á yeces son verdaderas chozas de diez á doce pies de alto, y de una solidez capaz de resistir á los huracanes mas violentos, y sostener sin doblarse el peso de un buey entero. El interior de estos edificios está dividido en un númera iafinito de compartimientos y galerías dispuestas con tanto órden y simetria, que pueden dar cabida á muchos millares de estos insectos y permitirles á todos una-libre circulacion en todas sus partes.

Los habitantes de estos pequeños estados tienen un rey y una reina, que son insectos perfectos, trabajadores que son larvas; y soldados que algunos naturalis: tas miran como ninfas, pero cuya verdadera naturaleza es desconocida. Cada uno de estos habitantes tiene su tarea que hacer; los trabajadores, que son de la. magnitud de una hormiga grande, deben construir la habitacion y proveer á la subsistencia de la sociedad; los soldados, que son mucho mas fuertès y mejor armados, estan encargádos de defender la habitacion y de alejar de ella á los enemigos. Por lo que toca al rey y á la reina, su único deber es multiplicar la especie. Iua hembra pone en veinticuatro horas hasta ochenta mil huevos, que les trabajadores Ilevan, á medida que salen, á un cuarto ó celula particular.

Nada iguala á la actividad de los termites; trabaja- 
dores y soldados estan constantemente ocupados. Estos velan sin cesar alrededor de la habitacion comun, y no dejan aproximarse á ella á ningun animal sin arrojarse sobre él y morderle hasta derramar su sangre; su furor es estremado; principalmente cuando ven que les destruyen su habitacion; se dejan matar todos antes que dejarla maltratar; se han visto dejarse arrancar á pedazos sin soliar la presa. Por lo que toca á los trábajadores, unos amàsan la tierra destinada para la construccion de los tabiques interiores, otros van á coger la goma de que llenan sus almacenes. Estos cuidan de las larvas jóvenes, aquellos llevan el alimento al rẻi y reina \&ce.

Se conocen muchas especiès de este género : el termite fatal ó belicoso que es la espécie mas comun y la de que acabamos de hablár; y el termite viagéro célebre por las emigraciones que hace de un parage á otro, y por el órden admirable que reina en su marcha. Los obreros se adelantan ordenados en muchas líneas de frente, en columnas cerradas, y son protegidos por los soldados, de los cuales unos van errando por los lados y otros se colocan de centinelas sobre las plantas vecinas para esplorar los alrededores. Al menor peligro que amenaza á la tropa, una señal de los centinelas la-hace apresurar ó retardar el paso, segụn lo exijan las circunstancias. A mas de estas especies, hay otras que se llaman especialmente piojos de madera, en razon de los estragos que hacen en las vigas, las tablas y en toda la madera seca; se introducen en su interior por una abertura casi imperceptible, y le reducen enteramente a polvo, teniendo cuidado de no atacar la superficie por temor de ser sorprendidos. De este modo destruyen á reces una casa entera antes de que se tenga noticia de su presencia. 
Los negros parece que comen con deleite las larvas de todos estos insectos; y algunos viageros que las han gustado, aseguran que tienen un sabor azucarado de los mas agradables; y que forman un manjar de los mas délicados.

\section{QUINTO ÓRDEN.}

\section{HIMENÓPTEROS.}

Los himenópteros forman el órden mas numeroso de la entomologia despues del de los coleópteros; comprende todos los insectos que tienen cuatro alas desnudas y membranosás, con nervios. longitudinales, y de las que las superiores son siempre mayores que las inferiores. Su boca está armada de mandíbulas distintas, pero sus maxilas y su labio inferior son delgados, largos y dispuestos en forma de una especie de trompa ó chupador, que no es acomodado sino para chupar el jugo de los vegetales. Su abdómen èstá las mas veces separado del coselete por un estrechamiento que divide su tronco en dos partes, y se terminá, en las hembras : por un aguijon ó por un taladro destinado á agugerear la corteza de las plantas ó la piel de los animales, en que depositan sus huevos.

Todos los himenópteros sufren metamorfósis completas. Entre sus larvas, unas estan desprovistas de patas $y$ 'son enteramente inmóviles; otras, por el contrario, tienen, á mas de las seis patas ordinarias, de docé á diez y seis patas falsas; pero no por eso son mas ágiles, antes bien no pueden egecutar especie alguna de movimiento. Es preciso pues, que la madre, que muere siempre antes del nacimiento de sus hijuelos, coloque sus huevos en un sitio en donde esten preservados de 


\section{7}

los peligros esternos, y en donde las larvas encuentren un alimento preparado de antemano. Con este objeto construye para su posteridad una habilacion particular, en donde amontona alimentos escogidos, ó bien los deposita en el cuerpo de animales, si sus hijuelos deben ser carniceros. En todos casos las larvas tienen un labio atravesado por un conducto para el paso de la materia sedosa que debe emplearse para la fabricacion del capullo de.la ninfa.

La duración de la vida de los himenópteros, desde su nacimiento hasta su entero desarrollo, está limitada al círculo de un año. Siendo larvas, viven ya de materias animales, ya de sustancias vegetales; cuando son ninfas no toman ninguna especie de alimento; hechos insectos perfectos, viven todos en las flores, sobre las que se les ve revolotear durante todo el buen tiempo.

Segun la figura del apéndice que termina el cuerpo de las hembras, se pueden dividir los himenópteros en dos sub-órdenes; los terebrantes y los aculeiferos, de los cuales unos tienen un taladro y otros un aguijon.

\section{PRIMER SUB-OR DEN.}

\section{TEREBRANTES.}

Estos insectos se diferencian de los siguientes, no solo por el carácter de que hemos hablado, sino principalmente por sus costumbres. Al paso que los aculeíferos viven todos en sociedades mas ó menos numerosas, hacen en comun trabajos mas ó menos considerables, y forman verdaderas repúblicas, de las que cada miembro tiene deberes particulares que llenar, los terébrantes viven siempré aislados, y llaman la atencion principalmente por el instinto adwirable que les hace 'Iono III. 
proveer á las necesidades de su posteridad. Por lo demas es preciso dividir este primer subgénero en dos familias, que se diferencian principalmente por el modo como se alimentan sus larvas. Las unas son herbívoras, que son los serriferos ó porta-sierras, y las otras carniceras y son los pupívoros.

\section{PRIMERA FAMILIA.}

\section{SERRÍFEROS.}

Como solamente las hembras estan provistas de la sierra abdominal, que forma el carácter del sub-órden de los serríferos, y es muy dificil, y á veces imposible, conocer el régimen de un insecto, los naturalistas han procurado por otros medios distinguir la familia de los, serríferos, y han encontrado que de todos los himenópteros, estos insectos eran los únicos cuyo abdómen es sentado, es decir, unido al coselete en toda su anchura, de suerte que parece ser una continuacion de él, y que no goza de ningun movimiento particular. En todos los demas himenópteros estas dos partes estan unidas por un pedículo estrecho ó por un estrechamiento que permite á la última moverse independientemente de la primera, como se puede observar en la abeja, en la hormiga \&cc. (lám. XXXVI, fig. 3, 4, 5 y 6.)

Todos estos ínsectos provienen de larvas llamadas orugas falsas, porque : se parecen mucho á las de las mariposas, de las que sin embargo se diferencian par el número de sus patas, que es lo menos de diez y ocho; y que puede llegar hasta veintidos: al paso que las verdaderas orugas nunca tienen mas de diez y seis. Estas larvas salen de huevos que la hembra coloca en los troncos lde los árboles, despues de haber horadado su corte- 
za por medio de su taladro. Se alimentan de jugos vegetales que les suministran las plantas; sobre las que se encuentran hasta la época en que debe verificarse su trasformacion en ninfa. Entonces se desprenden de la planta y se dejan caer á tierra, en cuyo seno sufren su metamorfósis.

Esta familia es bastante numerosa, pero las especies que encierra tienen tantas relaciones entre si, que casi se podria no formar mas que un solo género, el de los TuNTREDos ó moscas de sierra (tenthredo).

Estos insectos son generalmente pequeños, y no tienen mas que siete ú ocho líneas de largo; su figura se asemeja á la de las avispas, escepto que nunca tienen como estas últimas el abdómen separado del coselete, y que sus alas estan plegadas y parecen como ajadas. Ademas sus costumbres son enteramente diferentes. Los tentredos habitan en los árboles durante el buen tiempo; y cuando ha llegado el momento de la postura, la hembra empieza á recorrer con diligencia todas las ramas del arbol que habita para buscar la que mejor la convenga. Luego que la ha encontrado, se pone á practicar en ella agugeros con su. sierra; en cada agugero deposita un huevo y una gota de un líquido espumoso, cuyo uso es, segun se pretende, impedir que se cierre la abertura.

Algunos dias despues de esta operacion se ve que la corteza se hincha todo alrededor de la herida; al mismo tiempo el huevó se desarrolla y concluye muchas veces por formar una agalla ó escrescencia análoga á una pequeña fruta. Estas agallas, que al principio no sirven sino para proteger el huevo, se convierten, despues de la rotura de este último, en domicilio de la larva, la que sufre en él todas sus metamorfósis, y del que no sale sino para pasar al estado de insecto perfec- 


\section{0}

to. Pero en la mayor parte de los casos no se produce agalla. Entonces la larva se fija sobre alguna hoja, á cuyas espensas se alimenta, y sobre la que se trasforma ordinariamenté en ninfa é insecto.' Sin embargo, algunas veces sufre este último cambio en el seno de la tierra.

La estension de este género le hace dividir èn muchos subgéneros, de los que los principales son: los cimbes, cuyas orugas son notables por la facultad que tienen, cuando se las atormënta, de arrojar un líquido verdoso y odorífero hasta la distancia de un pie; los hilolomos, de los que se halla una especie en el rosal, y los tentredos propiamente dichos, cuyas principales especies son: el tentredo ó mosca de sierra de la escrofularia ( $T$. scrophularia, L.), negro, con las antenas, piernas y tarsos leonados; el tentredo ó mosca de sierra verde ( $\boldsymbol{T}$. viridis, L.), verde, con manchas negras en el torax y una linea del mismo color sobre el lomo; la mosca de sierra amarilla (tent. lutea, L.), cuyo color es amarillo con manchas negras en el coselete; vive sobre el sauce y el álamo-blanco, igualmente que la $M$. de $S$. de grandes inuslos (tent. femorata,.L.), que es mayor que la precedente, $\mathrm{y}$ tiene los muslos de atras muy gruesos, el cuerpo y pies negros, y las antenas amarillas.

\section{SEGUNDA FAMILIA.}

\section{pupívoros. (Lám. $X X X Y I$.)}

Esta familia se diferencia de la precedente porque tiene el abdómen bien distinto del coselete; disposicion que la asemeja á los himenópteros del sub-órden siguiente; pero se distingue de ellos por muchos caractéres: en primer lugar el primer segmento abdominal hace parte 


\section{1}

del cosolete, de suerte que el segundo anillo es el que está unido al primero por una especie de pie, y el torax parece formado de cuatro segmentos; los aculeiferos por el contrario tienen el coselete formado de tres anillos solamente, despues de los cuales viene el pedículo y en seguida el abdómen. En segundo lugar las antenas de los pupívoros estan compuestas de mas ó menos de trece articulaciones en los machos, y de mas ó menos de doće en las hembras, ó bien su abdómen no está formado mas que de tres ó cuatro anillos; al paso que en los aculeíferos las antenas tienen constantemente trece articulaciones en los machos y doce en las hembras, y el abdómen of rece siempre siete anillos en los primeros y seis en las segundas.

Por medio de estos dos caractéres sacados del número de las articulaciones de las antenas y del de los anillos del abdómen, se puede siempre distinguir á los pupívoros de los aculeíferos independientemente del taladro que las hembrás de los primeros tienen en la estremidad de su cuerpo para poner sus huevos, y el que, en los segundos, es reemplazado por un aguijon ó aun por una simple glándula, que segrega un líquido cáustico. ó asqueroso que les sirve de armas ofenșivas.

El nombre de pupívoros, que quiere decir comepequeños, se ha dado á estos insectos, porque en el primer periodo de su existéncia sè alimentan casi esclusivamente de animales pequeños, en los que la hembra deposita sus huevos, y los sirven de abrigo al mismo tiempo que los suministran su subsistericia; porque siendo apodes sus larvas, no pueden ni sustraerse á los peligros que las amenazan, ni procurarse los alimentos necesarios para su conservacion y desarrollo.

Esta numerosa familia encierra un gran número de 


\section{2}

géneros, entre otros los icnéumones, los cínifes y las crisidas.

§. I. Los IGNÉUMONES (ichneunion) (fig. 3.) son fáciles de conocer por su cuerpo generalmente estrecho y casi linear, y principalmente por sus antenas largas (mas de diez y seis articulaciones) y muy movibles; lo que les ha hecho ta mbien llamar moscas vibrantes.

El nombre de icnéumon, que los antiguos aplicaban á la mangosta porque se creia que este cuadrúpedo se introducia en el cuerpo del cocodrilo para devorarle las entrañas, se ha dado por analogía á los insectos de este género, que pasan todo el primer tiempo. de su vida en el cuerpo de las orugas de las mariposas, y roen sus órganos uno tras otro. Bajo este aspecto los icnéumones hacen un gran servicio á la agricultura y jardinería, que sufren tanto de la voracidad de estas larvas.

El instinto de estos ánimalitos es verdaderamente admirable, ya como insectos perfectos, ya como larvas. El de las hembras se manifiesta de un modo muy sensible en la época de la reproduçcion, Luego que ha llegado el momento de la postura, se ocupan en buscar orugas, $y$ saben descubrirlas con una sagacidad increible hasta débajo de la corteza de los árboles que las oculta; y cuando han encontrado una, la pican con su laguijon para depositar en ella un huevo; pero tienen büen cuidado, al tiempo de atravesarlas, de no atacar ningun órgano esencial, de suerte que la oruga continúe viviendo.

9rin Entretanto el huevo depositado se desarrolla y se trasforma en larva. Esta empieza á roer la gordura que la oruga ha acopiado, teniendo cuidádo de no tocar á ningun órgano importante, á fin de no matarla demasiado pronto. Pero luego que ha llegado el tiempo de su 


\section{3}

metamorfósis, ya no toma precaucion alguna, la hace perecer y sale de su asilo; iemblema patente de la ingratitud y maldad mas odiosa! En este momento es cuando hace su_capullo, que consiste en uno ó dos copos blancos ó amarillos, que se encuentran á millares, en verano, sobre las tapias de las huertas y en las ramas de los árboles. Cuando se desprenden estos capullos de los cuerpos á que estan pegados, las crisalidas saltan con agilidad doblándose en arco y soltándose en seguida.

Se conoce un número muy considerable de especies de icnéumones; las principales son: el icnéumon amari: llo, el icnéumon enterrador y el icnéumon asesino.

§. II. Los cínifes (cynips) (fig. 4.) son unos pequeños insectos que tienen la cabeza estrecha y el torax grueso y combado, lo que les hace parecer gibosos. Pero su caracter mas marcado se saca de la forma de sus alas inferiores, que no presentan mas que un solo nervio, y del número de las articulaciones de sus antenas que no pasa de quince, y nunca es menos de catorce en los machos y de trece en las hembras.

Sus costumbres son análogas á las de los tentredos; su postura principalmente se hace absolutamente del mis. mo modo. Agugerean la corteza y las hojas de los árboles para depositar alli sus huevos. La presencia de estos no tarda en determinar la afluencia de los jugos hácia la parte picada, y produce de este modo esas escrescencias, á veces monstruosas, conocidās con el nombre de agallas ó de agallones que se emplean para teñir de negro, y que son tan comunes sobre las hojas de encina y en el tallo de los rosales. En lo interior de estos tumores, y á sus espensas, se desarrolla el huevo depositado, y la larva se alimenta y se trasforma sucesivamente en ninfa y en insecto. Llegada la época de su última metamorfósis, horada su habitacion y sale volando 


\section{4}

para buscar en otra parte un sitio á propósito para recibir sus huevos. Sin embargo algunas especies abandonan la agalla inmediatamente despues de su nácimiento; y se introducen en la tierra, en donde permanecen hasta șu última trasformacion.

Entré las especies mas comunes de este género, llamaremos la atencion hácia el cinife tintorial, que procede de una especie de encina del levante, y cuya agalla se usa mucho para la fabricacion de la tinta de escribir; el cínife del agabanzo, que produce en este arbusta esas escrescencias espumosas tan comunes. Pero la especie mas célebre y útil de todas es el cínife de la higuera silvestre de que los griegos modernos y los habitantes de la Andalucia sacan un gran partido para ayudar al desarrollo y madurez de los higos tardios. Se sabe que la presencia dę sus huevos hace madurar mas rápidamente las frutas. Por consiguiente, luego que la hembra los ha depositado en los higos precoces de la higuera silvestre, se cogen estos últimos, y despues de haberlos ensartado se cuelgan en las higueras cultivadas mas tardias: "No encontrándose bien las larvas en los higos que no reciben ya jugo de la planta los abandonan para establecerse sobre los que están todavía en el árbol y los hacen madurar con mas rapidez de lo que hubieran podido hacerlo. Este procedimiento, muy usado en Oriente se llama caprificacion.

§. III. El nombre de CRISIDA (chrysis) y el de avispa dorada, que es su traduccion, se ha dado á unos irisectos de la familia de los pupívoros, notables por la riqueza y brillo de sus colores que rivalizan con los de los colibrís y pájaros moscas, y que se conocen por su abdómen oval, cóncavo por debajo y compuesto de tres ó cuatro anillos solamente.

Són unos himenópteros vivos y avispados, que se 


\section{3}

ven pasear sin cesar con agilidad por las paredes y los maderos viejos bien espuestos al sol. Se conoce poco lo restante de sus costumbres: únicamente se sabe que se sirven de sus taladros, como los precedentes, para agujerear la corteza de los árboles ó la piel de los insectos, en que acostumbran á depositar sus huevos. Las crisidas ponen los suyos en el nido de ciertas abejas, cuyas larvas parecen destinadas para servirles de habitacion y de alimento. Su taladro no les es útil sino para defenderse cuando tratan de cogerlas ó para picar á sus enemigos. Ademas de este medio de defensa tienen tambien la facultad de arrollarse en forma de bola y de ocultar su abdómen.

Las especies de este género; que se encuentran en nuestros climas son: la crisida azul y roja (chrysis igni$\left.t a, L_{0}\right)$, de cabeza y coselete azules con tornasol dorado y abdómen rojo con tornasol de oro; la crisida verde y azul (chr. cianea, L.), azul con tornasol verde dorado, la crisida listada \&c.

\section{SEGUNDO SUB-ÓRDEN.}

\section{ACULEÍFEROS.}

Los himenópteros de este segundo sub-órden se diferencian de los precedentes por la falta de taladro. Este órgano está reemplazado por un aguijon compuesto de tres piezas que, en el estado ordinärio, está escondido en lo interior del abdómen y no sale sino cuando lo exige la defensá del animal ó la necesidad de depositar sus huevos. Pero es preciso observar que esta arma ó instrumento no se encuentra mas que en las hembras, $y$ aun falta en muchầs especieș en las que se halla reemplazado, á lo menos como medio de defensa, por un lít

ToMo III. 
quido ácido que conservan en cavidades especiales, de donde pueden arrojarló á su voluntad contra sus enemigos.

La existencia del aguijon no puede pues tomarse por un carácter constante é invariable; pero el modo de union del abdómen con el coseleté, por medio de un pedículo siempre bien marcado, y algunas veces muy largo, la pequeñez de las mandíbulas, que son menos déntadas en los machos que en los demas individuos, el número dearticulaciones de las antenas que es constantemente de trece en los maehos, y de doce en las hembras; por fin, la conformacion del abdómen. que está formado de siete anillos en los primeros, y de seis en las segundas, no permitirán jamas confundir á los aculeíferos con los terebrantes.

El género de vida de estos insectos es muy variable segun las familias; pero siempre muy interesante. La mayor parte de ellos viven en sociedades numerosas, y forman especies de repúblicas, en las que cada miembro contribuye por'su parte al bien estar general. Es. tas especies de gobiernós se componen de tres suertes de individuos, los machos y las hembras, que son siempre en corto número, yque estánencargados del cuidado de la propagacion de la especie, y los obreros que, lo mismo quée eatre los termites, dében construir la babitacion y buscar las provisiones necesarias para la sociedad; sobre ellos carga todo el peso del gobierno interior. Ellosson los que alimentan á los machos, hembras y larvas; cuiidande estasúltimas igualmente que de las crisalidas preparăndoles la pasta; sustáncia mélifera que forma el alimento mas conveniente pára ellas, y suministrándolas los medios de transformarse; porque como las larvas están desprovistas de patas, no pueden ptoveen por sítmist:

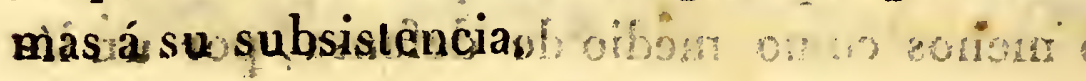


Los aculeiferos se han dividido en cuatro familias: tos formicarios, los cavadores, los diplopteros y los meliferos.

\title{
PRIMERA FAMILIA.
}

\author{
FORMICAILIOS.
}

Los formicarios ó mirmegos comprenden todos los himenópterơs análogos á las hormigas; por consiguiente tienen el abdómen separado del coselete por un pedículo bien marcado, $y$ sus antenas, en vez de estar en línea recta, estan encorvadas y como plegadas. Solo los machos tienen constantemente alas, y aun no las conservandurante toda su vida; las hembras las tienen ordinariamente, pero las pierden muy pronto. Los obreros núnca las tienen.

Esta familia comprende muchos géneros, de los cuales el mas importante es el de las hormigas y el de las mutilas, que se distinguen por la figura de la primera pieza de sus antenas, que es muy larga en las primeras, é iguala al tercio de la longitud total del órgano, al paso que es si empre mas corta en las segundas.

§. I. Se ha háblado mucho de la prevision y actividad de la HORMIGA (formica); pero se ha alabado sin razon la sabiduría de este animal, cuando se ha pretendido que acopiaba durante el buen tiempo para comer en el invierno. La hormiga se entorpece durante toda la estacion fria, y por consiguiente no tiene necesidad de provisiones. Todo lo que se la ve conducir á su habitacion, está destinado para alimentar á las larvas ó para construir sus aposentos. Se han exagerado pues las cualidades de estos insectos, y con tanta menos razon, cuanto que lejos de sernos útiles, causan grandes estragos en nuestros jardines y casas, principalmente 
en nuestras provisiones de boca. Como viven en sociedades numerosas, compuestas de tres especies de individuos, necesitan para construir su habitacion, materiales muy considerables que sacan de todo lo que encuentran á su alcance, y para proveer á su subsistencia, una gran cantidad de sustancias vegetales ó animales que toman de nuestros graneros, campos y huertos. Si hay pues algo que alabar en la historia de las

- hormigas, no es su prevision ni su sobriedad; pero lo que hay de admirable en estos animalitos, es el órden peifecto y la disciplina exacta que reina en su sociedad; es el instinto que induce á las obreras á alimentar á los machos, hembras y larvas, y á privarse algunas veces de su alimento para dárselo á ellos; es el ralor con que defienden, en caso de peligro, las crias confradas á su cuidado, á veces hasta espensas de su vida. Lo que nos admiraria tambien en ellos, si no estuviesemos habituados á verlo en una multitud de otros animales, es la sagacidad con que eligen para colocar su domicilio la base de un tronco de árbol ó un terreno elevado, á fin de estar al abrigo de las inuñdaciones; es el arte con que componen, con unas partículas tan pequeñas de madera, rastrojo, hojas \&c., un edificio sólido, en el que no vemos mas que confusion, pero cuyo conjunto es la imágen de una poblacion con sus calles,"callejuelas, casas \&c.; de modo que las obreras las recorren continuamente sin el menor embarazo, á pesar de la actividad que necesitan, principalmente cuando tienen que alimentar á las larvas. Entonces es cuando se las ve correr en todas direcciones con diligencia, unas cargadas de provisiones que les llevan; otras yendo á buscar genos, frutas, migajas, \&c. Este tiempo de fatiga dura para las hormigas todo el verano, porque siempre hay larvas en su nido. Para couvencerse de ello, bas- 
ta abrir un hormiguero durante esta estacion; alli se ven mezcladas hormigas, restos de vegetales, cortezas, y unas especies de gusanos blancos, que se llaman vulgarmente huevos de hormigas, y que no son otra cosa que las larvas.

El cuidado de las obre rás no se limita solo á alimentar á estas, y á las demas ocupaciones de que acabamos de hacer mencion, pues tienen otras muchas obligaciones respecto de ellas. En efecto, en los dias buenos traspor tan á las larvas fuera de la habitacion, para procurarlas algun calor, las vuelven luego á bajar al aproximarse la noche ó el mal tiempo. Finalmente, cuando consideran las neutras de algunas especies conveniente aumentar su número, se procuran auxiliares de otras diferentes por medio de la fuerza. Con este fin, al declinar el dia, y por muchos de ellos consecutivamente salen de sus nidos lás hormigas llamadas legionarias ó amazonas; sé adelantan en columna cerrada mas ó menos numerosa segun la poblacion, y se dirigen al hormiguero que piensan atacar. Luego que llegan, penetran en él, á pesar de la defensa y oposicion de los propietarios, cogen en sus mandibulas las larvas y las ninfas de las hormigas neutras, propias de estas sociedades y las transportan siguiendo el mismo órden á su hormiguero. Otras hormigas neutras de su misma especie, arrancadas de sus nidos, cuidan de estas larvas y ninfas igualmente que de la posteridad de sus vencedores.

Se conocen un gran núméro de especies de hor migas; las principales que se encuentran en España son: la hormiga roja y negra, (formica rufa, L.) que es de cerca cuatro líneas de larga, negruzca, con una gran parte de la cabeza, torax, y pies rojo-leonádos. Su hormiguero es regularmente de un pie de alto y le cons- 
truyen de tierra, leña, \&ce; ; la hormiga sanguinea ó roja (F. sanguinea), en la que las neutras son seméjantes á las precedentes, pero de color rojo sanguíneo, con el abdómen de un negro ceniciento; la hormiga negra y cenicienta (F. fusca, L.) de color negro ceniciento brillante; con la base de las antenas y los pies rojizos, la hormiga rojiza i\&c que es la especie llamada par Huber amazona.

ל. II. El género MUThL (mutila) comprende muohás menos especies que el de las hormigas; no se encuentra masique trés ó cúatro de estas en los alrededores de Paris; y lo que hay de singular, es que no se sabe casi nada de sus costumbres; todo lo que se ha observado, es que frecuentan los terrenos arenosos en donde corren con mucha velocidad, que viven aisladas $y$ que los machos tienen alas, al paso que las hembras están privadas de ellas. Pero por lo que háce á sus costumbres, metamorfósis, género de vida \&cc, se ignoran completamente.

\section{A SEGUN DA FA M IL IA. \\ CAVADORES. $(X X X V I)$}

- Seria un error el creer, segun el nombre impuegto á esta familia, que todos los himenópteros que comprende tienen la costumbre de cavar la tierra. Esta denominacion wo se les' ha aplicado colectivamentes sino parque la especie más antiguamente conocida hace ordinariamente su postura en un agujerito que praćtica en la arená.;pero dista tanto de que todas tengan la misma costumbre, que por el contrario hay muchas que viveh sobre las plantas revoloteando de flor én flor para chúpar su nectar, cy dépositan sú huevos ya en 
los troncos viejos, ya en las paredes que, sirven para cercari: las huertas.

Estós insectos son muy comunes durante todo el verano, y llaman atencion por su forma delgada y por la longitud del estrechamiento que separa al torax del abdómen (fig. 5.): pero su carácter principal se saca de la conformacion de sus tarsos, que no pueden servir mas que para andar, y que están desprovistos de esas especies de pelos que guarnecen los de las abejas, para hacerlas á propósito para coger el polen de lạs flores. Se diferencian, ademas, de los formicarios porque tienen las antenas rectas ó encorvadas, y los machos y las hembras son igualmente alados.

Por otra parte sus costumbres son enteramente diferentes: jamas viven en sociedad, $y^{*}$ sus larvas no pueden ser alimentadas del mismo modo que las de la familia precedente. Pór consiguiente, la hembra se ve obligada á hacer con respecto á ellà el oficio de las, obreras entre las hormigas; porque siendo apodes; sus hijuelos, no pueden proveer por si mismos á su subsistencia. Con este objeto no pone en un sitio, sino despues de haber primeramente conduciủo á él cierta cantidad de alimentos, que la lapva encuentra a su al cance en el momento de salị det huevo.

Aunque se pudiera en rigor no formar mas que un sologénero de todas las especies de la familia, los nat uralistas han creido deber formar muchos de los que los mas importantes son los esfeges y los crabros.

§. I. LOS ESHEGES ó avispas solitarias (sphex) (fig. 5.) no son menos interesantés que los ichéumones tocantelá la previsiòn y celo que manifiestan por su posteridad. Luego que ha llegado la época de su postura, las hembras cavan con sus patas y maxilas un agugero mas ó menos profando en arena. 
Despues de haberle preparado, se van á cazar por los alrededores. Si encuentran algun insecto débil $y$ sin defensa, se apresuran á atravesarle con su aguijon ó á arrancarle las patas y las alas para impedirle que se escape. Pero si atacan á alguna araña gruesa ó á algun insecto capaz de resistirles, necesitan de todo su valor y agilidad para apoderarse de él. Es un espectaculo de los mas curiosos, aunqué no es raro durante el buen tiempo, el ver á los esfeges hembras combatir con su adversario, procurar traspasarle con su dardo y evitar sus armas ofensivas. Cuando á fuerza de trabajo han llegado á vencerlé, cogen el cadáver de su víctima y le lleván en triunfo á su nido, en donde de depositan al mismo tiempo que un huevo. Repiten la misma operacion para cada uno de ellos, de suerte que este período de su vida se pasa todo en combates. Despues de haber provisto de este modo á las necesidades de su posteridad, han llenado el deseo de la natúraleza; y no tardan en perecer.

Los esfeges son muy numerosos; pero se conocen siempre fácilmente por la longitud de sus patas posteriores, que" son lo menos una vez tan largas como la cabeza y el coselete reunidos, y por la figura de sus antenas que son siempre largas y retorcidas. Las especies mas comunes son, el esfege de los caminos (sphex viatica, L.) negro, con alas uegruzcas y tres rayas rojas en el abdómen (fig. 5.), el esfege de los campos (sphex arvensis, L.) negro, liso y matizado de amarillo; tres listas amarillas en el abdómen, la segunda interrumpida. Estás especies tienen los colores mucho mas oscuros que el bello esfege (sphex speciosa; Lu) que es el mayor de todos, pues llega á tres pulgadas y media de largo, y cuyas alas parecen ser de un raso de color rojo, y que el esfege verde dorado, (sph. lobuta, L.) 
mitad menos que el anterior, pero, de un hermoso verde brillante, con tornasol azul y alas amarillas (fig. 5). Estas dos últimas especies son exóticas.

§. II. Los crabros (crabro) se distinguen de los precedentes por su cabeza gruesa y como cuadrada, por sus antenas cortas, $y$ por sus patas posteriores que apenas son mas largas que la cabeza y el coselete reunidos.

Una de las especies mas notables de este género, es la que se llama vulgarmente ollero ó alfarero, (sphex figulus, L). Es de un negro reluciente, con la caperuza cúbierta de un vello sedoso y plateado. En el momento de su postura, lleva á unos agugeros que encuentra en los troncos viejos podridos, los insectos, y principalmente las arañas á quienes ha privado del uso de sus mienbros ; y despues de haber depositado alli sus huevos, tapa exactamente la abertura con tierra humedecida, para que ningun animal pueda ir á desordenarlos: de aqui le viene su nombre específico de ollero.

\section{TERCERA FAMILIA.}

DIPLÓPTEROS. (Lám: $X X X V 1$.)

Esta familia se compone principalmente del género AVISPA (vespa) (fig. 6.) insecto muy conocido y bastante parecido á las abejas, de las que no obstante se distingue por su cuerpo menos velludo, por sus antenas en forma de maza, y principalmente por sus alas superiores dobladas longitudinalmente; lo que ha hecho dar á la familia el nombre de diplópteros (alas dobles).

Las abispas viven la mayor parte en sociedad, compuesta de mąchos, hembras y obreras ó neutras, y se Tono III. 


\section{2}

construyen una habitacion hecha con mucho mas arte que la de las thormigas, y que rivaliza con la de las abejas. Es una reunion de tubos que pegan unos á otros de diversos modos, pero que siempre los disponen de suerte que puedąn aumentar su número á su voluntad. Al conjunto de estos tubos se da nombre de avispero el que cuelgan dé la rana de unárbol; ;óle colocan en tierra. Está cconstruido con pedacitos de madera ó de corteza machacados y reducidos a una especie de pasta de la naturaleza del papel ó del carton; y que, secándose, toma una consistencia bastante firme para resistir á la intemperie del aire. En lo interior de éste edificio es donde estan colocados los huevos cada uno en una cavidad separada, con la cantidad déalimento ó de pasta necesaria para su desararóllo.

Pero es preciso observar, por lo que toca á estas sociedades , que no empiezan como las de las hormigas; sino que una hembra echa siempre sola los primeros cimientos, construyéndose uno ó dos tubos en los que hace su postura. Las larvas que provienen de esta nó tardan en hacerse obreras, que empiezan á trabajar con ella y á hacer nuevos tubos, destinados á recibir nuevos huevos. La colonia seria muy pronto numerosa ; si los frios del invierno no hicieran perecer á la major parte de los habitantes, no se salva mas que un corto número de machos $\mathrm{y}$ hembras; ; y estos, son los que en la primavera siguiente, fundan una nueva sociedad.

Entre las especies de este género, hallamos en España la avispa comun (sespa vulgaris, $\mathrm{L}_{\text {. }}$ ), el abispon \&c. (wespa crabro, L.), que viven debajo de tierra. La avispa cartonera, (vespa nidulans et vespa tutua) por el contrario, suspende su nido de una rama de árbol y le construye con un arte admirable. 


\section{CUARTA FAMILIA.}

\section{MELÍFERÓS (Lä́m. XXXVI.)}

Los melíferos han sido en todos tiempos célebres con el nombre de abejas, por susociabilidad, por su industria, por a cera, y sobre todo por su miel, sustancia preciosa para nosotros, pero que lo era mucho mas para los antiguos, que no tenian como nosotros azucar, en abundancia.

Estos insectos componen su útil producto con el polen de los estambres, que recogen en las flores por medio de sus tarsos posteriores. Para este efecto, estos órganos tienen una disposicion muy particular, que basta para distinguir á los melíferos de todos los demas bime-j hópteros, $\mathrm{y}$ aun de todos los insectos conocidos, $\mathrm{Su}$ primera pieza está ensanchadá en formá de páleta, ya cuadrada, ya triangular, que les sirve para transportar á su nido lo que han recogido.

Otro carácter propio de estos himenópteros es tener la boca provista de una trompa formada por el labio y por las maxilas, por medio de la cúal el insecto perfecto chupa el jugo de las florés, y la larva la miel que la ha sido preparada por su madre ó por las obreras.

Esta familia es muy numerosa, y comprende cuatro generos bastante diferentes por sus costumbres; estos son las andrenas, los jilocopos, los abejones y las abejas.

§. I. Las aNDRENAs (andrena) han sido colocadas por muchos naturalistas entre las abejas pero se diferencian de ellas por muchos rasgos de organizacion y por sus costumbres. Su trompa es mas corta, sus tarsos mas velludos, sus patas posteriores mucho mas largas que el 
abdómen y su cuerpo está generalmente menos cubierto de pelos.

Estos insectos viven siempre solitarios; y no ofrecen mas que dos especies de individuos, machos y hembras. Estas solas están encargadas del cuidado de construir la habitaçion y de proveer á la conservacion y subsistencia de las larvás. La tierra movida en la margen de los senderos es la que algunas especies prefieren para establecerse; otras hacen una galería horizontal en la tierra 6 arena que se elevan en las orillas de los caminos ó de los fosos. En todos casos empiezan por conducir allí una cantidad de miel proporcionada al número de huevos que han de depositar; y despues que han ącabado de poner, cierran la abertura de todos los agugeros que han hecho cón la tierra que han sacado. Toman esta precaución por causa de las hormigas; pues á estas les gusta escesivamente la pasta destinada á las larvas, y si el agugero que la encierra quedase ábierto, no tardarian en encontrarla en sus correrías, y se llevarian toda la provision de alimento antes que los huevos llegasen á su, término.

España produce muchas especies de este género , entre otras la andrena de las paredes, que es bastante comun en nuestros alrededores.

§. II. Todos los melíferos de que nos resta hablar tienen una trompa larga y doblada hácia abajo cuando estan en inaccion; pero unos tienen los pies pósteriores guarnecidos de cepillos para recogér el polvo de las flores, y una cesta $u^{\prime}$ hoyo en el borde esterno de sus. piernas; tales son los abejones y las abejas. Otros estan privados de este aparato, y son las abejas solitarias, de las que las mas notables son las que se han llamado Jicocopos ó abejas carpinteras. Eiste nombre les proviene de la costumbre que tiénen de fabri- 
car en la madera vieja un conducto vertical bastante largo, el que dividen por unos tabiques horizontales en muchas cavidades, en cada una de las cuales depositan un huevo con una provision de pasta. Otras especies, casi enteramente semejantes á.las precedentes, y que las han llamado abejas albañilas, construyen su nido con tierra muy fina, de la que forman una argamasa $y$ le aplican á las paredes espuestas al sol, en donde no tarda en adquirir una dureza considerable.

§. III. No entendemos aqui por ABEJONES (bombus) los machos de las abejas, que se designan vulgarmente con este nombre, sino un* género particular de insectos análogos á las abejas por su trompa larga y por sus costumbres sociales, pero que se diferencian de ellas porque tienen en la estremidad de sus piernas posteriores una espina de que estas últimas carecen. Por otra parte su cuerpo es mas relludo $\mathrm{y}$ menos delgado, $\mathrm{y}$ las sociedades que forman son-incomparablemente menos numerosas que las de las abejas. Nunca se componen de mas de trescientos individuos, $y$ las mas veces no hay mas que de cincuenta á sesenta, al paso que las abejas forman ordinariamente enjambres de veinte á treinta mil. Por lo demas, estas reuniones tienen los mismos elementos que las de todos los insectos que tienen costumbres análogas, y estan formadas de machos, hembras y obreros. Los primeros, que son los mas pequeños, nunca trabajan; las hembras son las mas gruesas y echan los cimientos de la habitacion, al paso que los obreros, que son de una magnitud média entre los dos precedentes, estan encargados del cuidado de continuar el edificio, de defenderle de los enemigos, de cuidar las larvas, de llevarles, el alimento \&c. 


\section{6}

El nido de los abejones merece cónocerse; es un agugero subterráneo al que se va por un Jargo camino oculto por la yerba, y cuyo techo está tapizado de musgo cardado y espulgado con el mayor cuidados Preparada la habitacion, los obreros recogen una gran cantidad de miel, de la que forman una bola bastante parrecida á una criadilla de tierra, y en la que la hembra deposita sus huevos. Las larvas salen al cabo de cuatro ó cinco dias, se desarrollan rápidamente, y se hallan en estado, para el mes de mayo, de tomar parte en los trabajos de la sociedad.

Se encueutran en nuestro pais el abejon ó abeja de las piedras (apis lapidaria, L.), negro con el trasero rojo; el abejon terrestre (apis subterranea, $\mathbf{L}_{\text {.) }}$, negro con la estremidad posterior del torax amarilla y el ano blanco, y el abejon de los musgos (apis muscorum, $\mathrm{L}_{\text {. }}$ ), amarillento con los pelos del torax leonados \&cc.

§.IV. Por mucho que puedan admirarse los trabajos de las hormigas y de los abejones, asi como el órden y disciplina de sus reunipnes, las ABEJAS (apis). los sobrepujan en mucho por su industria, y sobre todo por su utilidad. Reunidas en una sociedad de muchos millares de individuos, forman una especie de estado; compuesto como todas las sociedades de este género, de tres especies de miembros: una ó muchạs hembras ó reinas, algunos cientos de machos ó zánganos, $y$ un número indeterminado deobreras ó peones; tales son las bases de un enjambre.

Una vez reunidos, estos insectos principian por buscar un sitio conveniente para establecer en él su habitacion; este es ordinariamente un tronco de árbol viejo. hueco, ó un agugero en una peîa ó en una pared. Luego que le han halládo, las obreras salen al campo para buscar una materia grasa llamada propolis, que sirve para 
cubrir todo el interior de la colmena y tapar todas sus avenidas, á escepcion de las que son necesarias para la entrada y salida de los habitantes. Hẹcho esto, empiezan á construir los alvéolos ó cavidades destinadas para servir de aposento á los machos, á las hembras y las larras, ó de almacenes para conteñer la miel. Las de los machos son mayores que las de las larvas, pero mucho mas pequeñas que las de las hembras, en cuya construccion las obreras emplean hasta ciento cincuenta veces mas materiales que para las de las larvas; por esta razon las designan con el nombre de celdillas reales. Todas estas obras las hacen con el polvo de los estambres; que trasforman en cera, mezclandole y amasándole con jugos particulares para hacerle impermeable al agua.

Terminado el edificio, las obreras van á buscar en el cáliz de las flores esá maleria azucarada tan conocida.con el nombre de miel: de ella llena': los alvéolos destinados á recibirla, y los cierran en seguida herméticamente con una cobertera. Durante este tiempo la hembra hace su postura, y deposita en cada celula un huevo que fija en ella por medio de una materia viscosa de que esstá bañado en el momento de su salida. El número de los huevos que pone de este modo puede llegar; , segun dicen, hasta doce mil, jy esto en el espacio de veinte dias.

Cerca de tres dias despues que ha sido puesto el huevo, sale de él una larva, á la que los peones llevan un alimento proporcionado á su debilidad, y cuya cantidad y calidad aumentan y varian á medida que avanza en edad. Cerca de seis dias despues de su nacimiento la larva se convierte en crisalida, se forma un capullo, y rompiendo por fin su prision hácia el noveno dia, va con sus compañeras á tomar parte en los tra- 
bajos de la comunidad. Pero se ha observado que los huevos de los machos y de las hembras emplean mas tiempo en sufrir sús metamorfósis , y son puestos mas tarde.

Sucede con frecuencia que la colmena que habita una sociedad de abejas se hace demasiado pequeña para contenerlas á todas. Entonces una parte de ellas se separan para ir a formar una colonia en otra parte. Despues de háber andado algun tiempo bajo el mando de una hembra, el enjambre se păra sobre alguna rama de árbol mientrás su guia va á esplorar los alrededores para descubrir un sitio conveniente para establecerse.

Se conocen muchas especies de abejas, de las que la mas útil es la abeja.comun (apis mellifica, L.), que se cria en el campo, por la cera y la miel que produce.

\section{QUINTO ÓRDEN.}

\section{LEPIDÓPTEROS.}

Dos caractéres bien marcados distinguen á los lepidópteros de los demas insectos con cuatro alas membranosas, que son unas escamas harinosas que cubren á estas últimas (de donde su nombre de lepidópteros, alas. escamosas), y la forma de su boca, que consiste en una irompa ó lengua arrollada en espiral, y formada de dos piezas que representan cada una una maxila; instrumento con el que estraen la miel de las flores, que es su único alimento en el estado perfecto.

Estos son los insectos mas interesantes de su clase por èl brillo y riqueza de los colores de şus alas, por la elegancia y ligereza de sus formas, y por la singularidad de sus costumbres. Todos sufren metamorfósis completas. Al salír del huevo tienen la figura de un 
gúsano largo, provisto de seis patas con ganchos, que corresponden á las del insecto perfecto, y de cuatro á diez pies membranosos, como hemos visto en algunos otros insectos; se designan especialmente con el nombre de orugas. Todas son ágiles y viven de hojas de vegetales, en las que hacen horribles estragos, ó de pieles, á las que no causan menos perjuicios. Llegadas al último término dé su desarrollo se construyen un capullo de seda, en el que estan como empaquetadas y parecen una momia. No permanecen en este estado mas que algunos dias, y rompiendo el tegido de su cubierta se hallan trasformadas en mariposas, y van á revolotear sobre las flores para robarles su néctar.

Se dividé el órden de los lepidópteros en tres familias, segun la disposicion de sus alas y la figura de sus antenas; y son los diurnos, los crepusculares y los nocturnos.

\section{PRIMERA FAMILIA.}

\section{DIURNos. (Lám XXXVI.)}

Aunque la naturaleza ha concedido la hermosura á la mayor parte de los lepidópteros, en los diurnos es en quienes ha derramado sus tesoros con mas profusion. Por los brillantes colores que les há prodigado, por la agilidad de los movimientos con que les ha dotado, és fácil ver que los ha creado para recreàr la vista del hombre, y presentarlos á su admiracion como una prueba de su poder y de la variedad de sus obras. Por esta razon, al paso que las demás familias de este órden no salen de sús guaridas sino á la caida del dia, ó durante las tinieblas de la noche, los diurnos se manifiestan mientras el sol brilla con toda su fuerza, y no cesan de esponer á nuestra vista sus adornos sino ToMo III. 
cuando la ausencia del dia nó pone en la imposibilidad de apreciar isu niqueza y variedad.: Durante todo este tiempo se les ve revolotear continuamente de flor en flor para chupar el líquido azucarado que encierran, y aun cuando descansan, tienen siempre las alas levantadas, prontas á tomar su vuelo al menor peligro; disposicion que solo se abserva en esta familia ; porque en las dos siguientes las alas inferiores estan provistas de un gancho que fija á las superiores y las obliga á estar echadas horizontal mente sobre el dorso del animal.

Aunque la vida ide estos lepidópteros, á los quese da el nombre de mariposas mas especialmente que á los crepusculares y nocturnos, es generalmente muy corta $y$ limitada al espacio de algunos dias, no por eso estos insectos dejan de ser comunes durante todo el buen tiempo, parque siendo sus especies muy numerosas, y pareciendo en épocas diferentes, se suceden continuamente desde el principio del verano hasta el fin del otoño.

Las orugas de estos insectos tienen siempre diez $y$ seis patas, y sus crisálidas son ordinariamente angulosas y se fijan por la cola á las ramas y á las hojas.

Se ha fundado la division de esta familia, tan dificil de estudiar, en la conformacion de las piernas, que estan armadas de uno ó dos espolones, en la figura de sus patas anteriores y en algunos otros caractéres minuciosos. De este modo se han formado cerca de treinta géneros, entre los cuales no citaremos mas que los mas importantes: Ias mariposas, las ninfas, los argos y las hesperias.

§. I. Las Mariposas (papilio) (fig. 8.) no tienen mas que un par de espolones bien aparentes en las piernas posteriores, $y$ las seis patas casi semejantes y todas apropiadas para andar. Este género 


\section{1}

comprende los lepidópteros mas notables por su magnitud y por la variedád de, su colorido, y se halla principalmente diseminado en las regiones ecuatoriales. El número de estos insectos es tan considerable, que se han tenido que dividir en muchos sub-géneros El primero es el de las mnriposas. Tal es la gran mariposa: de cola ó manipasa dèl hinojo (papilio Machaon, (I,) que se halla canacterizada por tener las alas amarillas con manchas y rayas negras; las inferiores estan prolongadas en formade colai, y llevan cercadel borde posterior unas manchas, azules, de las cuales una es en forma de ojo con algo de rojo en el ángulo. Su larva es verde, con anillos négros moteadós de rojo y vive sóbre la zanahoria óel hinojo, de cuyas hojas se alimenta. Tal es tambien entre las mariposas de cola el podaliro (pap podalirius), ouyas prolongaciones de la cola se asemejan, por ser de un color negruzco y tener encima unas manchas amarillentas, á unas teas ó hachas encendidas: estas dos especies son muy comunes; pero el alejanor es mucho mas rara. $20^{\circ}$ Vienen ẹn seguida las parnasianas, que se han llamado, asi porque se encuentran en las altas cordilleras de montañas: tales son en Europa la apolo comun (pap. apollo, $\mathbf{L}_{\text {. }}$ ), cuyas alas son blancas con atgunas manchas, y la apolo pequeña algo parecida á la precedente. $30^{\circ}$ Por fin encontramos las pierides, que son generalmente mas pequeñas que las anteriores, y muy comunes en España, por ejemplo, da $m a-$ riposa de la col (pap. brassica, , $\mathrm{L}_{0}$ ) de alas blanquizcas; el estremo y dos puntos de encima de las anteriores negros. Su oruga solitaria $y$ gris con tres rayas amarillas vive en la col; la mariposa del rábano (pap. rapai, L.) se parece á la anterior pero es la mitad mas chịca, y proviene de una oruga verde con tres líneas amarillas ó de color de cóbre, que se halla en las coles, rábanos y capu- 
china ; finalmente la aurora (pap. cardamines, L.), la amarilla de limon P. (mamni, L.), la cleopatra (pap. cleopatra, L), \&c.

§. II. El género NINFA (nymphalis) se compone de todos los lepidópteros diurnos, cuyas dos patas anteriores son mucho mas cortas que las otras icuatro y apenas aparentes, ó muy velludas; por lo demas tienen como los precedentes los espolones muy salientes y simples. Este: grupo ha sido tambian subdividido en:

1. . Los satiros "cuyas principales especies son el fauno, la anacoreta, la fedra, el mirtilo, lá galatea ó mariposa de medio luto.

2. Las ninfas propiamente dichas, como la ninfa del álamo, el iris ó grande marte y el pequeño marte. 3. Las vanesas, de las cuales las principales son la antiopa (papilio antiopa, L.) cuyás alas son angulosas, de un color negro purpúreo subido, con una lista amarillenta ó blanquecina en el borde posterior y una fila de manchas azules encima. Su oruga es negruzca, espinosa, con una fila de manchas rojas cuadradas y divididas en dos á lo largo del lomo. Vive en sociedad sobre el álamo blanco ó en las mimbreras, y se alimenta de las hojas de estos árboles; la io ó pavo real de dia (pap. io, L.) de alas angulosas y dentadas, por encima de un leonado rojizo, con una gran mancha en forma de ojo sobre cada una, la de las superiores rojiza en el medio, y rodeada de un círculo amarillento; la de las inferiores negruzca con un círculo gris al rededor; sembrado de manchas azuladas. La parte inferior de las salas tira á negro. Su larva es negra, moteada de blanco con espinas simplemente vellosas : rive en la ortiga ; la bella dama ó mariposa de cardo (pap. cardui, L.) de alas dentadas, por encima rojas, y variegadas de blanco y de negro; por debajo jaspeadas de gris, amarillo y pardo, con 
cinco manchas en forma de ojos azulados en sus bordes. La oruga vive solitaria en los cardos. Las hay parduscas con rayas amarillas, ó bermejas con listas transversas tambien amarillas. El vulcano ó atalanta (pap. àtalanta, L.) (fig. 9.) tiene tambien como la anterior las alas dentadas, y un poco angulosas y negras, superiormente atravesadas por una lista de hermoso rojo con manchas blancas en las anteriores; inferiormente jaspeadas de diversos colores. La oruga es negra, espinosa, con una fila de rayas de amarillo de limon á cadalado; vive sobre la ortiga. El mismo subgenero comprende aun otras especies muy comunes en nuestro pais, tales son la tortuga grande (pap. polychloros, L.), la torluga pequeña (pap. urtica, L.), y el Roberto el diablo (P.C. album). La crisálida de esta represen ta groseramente una cara humana.

4. Las arginias, cuyas principales especies son la mariposa de Tabaco encarnado, la anacarada, la tablero de damas, y la atalia. \&c.

§. III. El nombre de argos (polyomma) ó poliomatas comprende un gran núméro de lepidópteros diurnos de poca magnitud, adornados de colores bastante hermosos, y que sobre un fondo uniforme, presentan manchas imitandoá unas especies de ojos, lo que les ha hecho dar su nombre de argos; se distinguen de las precedentes en que tienen las piernas provistas de una espina apenas prominente. Su oruga es menos larga y se asemeja casi á un cloporte. Muchás especies tienen tambien en la estremidad de sus alas un apéndice.. en forma de cola, como la mariposa del hinojo, y se llaman vulgarmente pequeñas mariposas de cola.

Las especies mas comunes de este género son: el argos azul (pap. argus, L.), mariposita de alas dentadas, de hermoso azul por encima con una raya negra y una 
franja blanca, de gris de perlá con ún punto negro por debajo; su oruga es verde con una raya parda; en el lomo y la cabeza; los pies son negros:

Adewas pertènecen tambien á este género el argas bronceado, el janto, el argos de la encina y el argos de. la planta llamadá virga aurea ó vaso de oro.

§. IV. Las mariposas, las ninfás y los argos tienen todos, como lo acabamos de ver, un par de espolones, en sus patas posteriores, y ha sido preciso, para distinguirlos entre sí recurrir á: la longitud de estos órganos y á la conformacion de los miembros anteriores; que son semejantes á los posteriores en unos, y diferen tes de ellos en otros. Para conocer las hesperias ( hesperia) basta asegurarse de si las patas tienen dos espolones en cada pierna; todos los lepidópteros que presentan esta particularidad pertenecen efectivamente al género de que hablamos. Tal es entre atras especies que cria España, la mariposa de la malva (hesperia malva, Fab.) que es pequeña con las alas pardo-negruzcas y sembrada toda de manchas blancas por encima y de gris verdoso por debajo; tales son igualmente la hesperia; vergeteada, el espejo \&c.

\section{SEGUNDA FAMILIA.}

\section{GREPUSGULARES (Lám: XXXVI.)}

Los lepidópteros diurnos llaman la atencion no solamente por la elegancia de sus formas, sino tambien por el brillo y hermosura de sus colores. Los crépuscu. lares, que solo se dejan ver por la mañana durante el corto espacio de tiempo que separa la aparicion de la aurora de la salida del sol ó por la tarde desde el ocaso de este astro hastala noche, no ofrecen jamasesos. 
matices brillantes que son de la propiedad esclusiva de los animales que reciben los rayos del sol. Sus formas son tambien mas toscas y gruesas, lo que les ha hecho dar algunas veces el nombre de mariposas-abejones; sus alas en vez de estar aplicadas una á otra cuando el animal no se sirve de ellas, estan echadas horizontalmente sobre su dorso porque las inferiores tienen en su borde. esterno una espina que encaja en un gancho de las superiores y las tiene bajadas á la fuerza. Este caracter que distingue à los crepusculares de las mariposas diurnas, pero que les es comun con los de 'la familia siguiente, no basta para hacerlos conocer; es preciso añadir la forma de las antenas, que en ellos estan engrosadas ya en el medio, ya en la estremidad, al paso que son en forma de hilo ó de cerda en los lepidópteros nocturnos.

Los crepusculares tienen tantas relaciones entre si, que se puede, á pesar del número de especies que se conocen, reunirlos todos en un solo género, el de las ESFINGES (sphinx) (fig. 10), nombre que les puso un antiguo naturalista, en razon de la actitud que tienen ordinariamente sus orugas; actitud que les da cierta semejanza con este monstruo fabuloso.

Este gran género se divide en :muchos sub-generos de los que los mas importantes son el de las esfinges y el de las cigenas. Al primero pertenece la esfinge calavera (sphiñx atropos, L.); gran mariposa de color obscuro á la que se ha dado su nombre específico, á causa de una gran mancha que lleva en su pecho, y en la que se ha creido ver una calavera. Tambien corresponde á este la esfinge del titimalo (sph. euphorbia, L.), cuyas alas superiores son por encima de un color pardo rojizo con tres tnanchas y una ancha lista verde; las inferiores son superiormente rojas con una lista negra y una mancha negra; la esfinge de la viña \&c. 
En el sub-género cigena encontramos la cigená de la filipendula, que es de un verde obscuro con seis manchas rojas en las alas superiores, y la cigena turquesa especie notable entre los crepusculares por su hermoso color verde.

\section{TERCERA FAMILIA.}

NOCTURNOS.

Aunque los lepidópteros de la familia precedente no tienen ya los colores vivos de las mariposas diurnas, al menos conservan todavia matices bastante bien distribuidos, formas agradables y movimientos ágiles. En los noclurnos ó mariposas de noche', veremos empañarse todos los colores y tomar un tinte oscuro, acortarse el cuerpo y volverse pesado, entorpecerse los movimientos y cambiarse en un modo de andar rastrero ; por esta razon casi nunca se les ve volar mientras el sol está sobre el horizonte. Sus orugas, que casi siempre tienen menos de diez y seis patas, son generalmente vellosas, y se hilan un capullo antes de transformarse en ninfas; una de las especies de esta familia es la que produce la seda haciendo su capullo.

Es tan considerable el número de los lepidópteros nocturnos, que se han tenido que formar de ellos muchos géneros, de los que los mas importantes son:

$\S$. I. Los Bombices (bomby $x$ ) están caracterizados por su trompa, que solo existe en rudimentos, por sus alas enteras y lisas de las que las inferiores, en el estado de quietud, son mas anchas que las: superiores. Sus orugas se alimentan de hojas y de yemas tiernas, y se hilan, para sufrir sus metamorfósis, un capullo de seda casi pura. Las principales especies 


\section{7}

de este género son el atlas, el pavo real nocturno, el bómbice procesional, ó procesionaria (fig. 11.) y el bómbice del moral ó gusano de seda. Los dos primeros nada tienen de notable mas que su magnitud y las hermosas manchas que presentan en sus alas. El tercero es curioso por la costumbre que tiene de vivir. en sociedades numerosas, y por el órden que guarda en su marcha cuando cambia de domicilio, lo que sucede de tiempo en tiempo. Uno solo abre la marcha, detras de este van dos; despues tres, cuatro, cinco, y asi súcesivamente aumentándose uno en cada fila, de modo que toda la tropa forma un iriángulo, cuyo vértice es la vanguardia y la base la retaguardia. Por lo que respecta al cuarto, es sin duda algana el insecto mas: útil que se conoce en Europa.

Este bombice jamâs hubiera sido observado por el pueblo en el estado perfecto, si su oruga no hubiera llamado la atencion, por la costumbre que tiene de producir ese hilo delgado y ,fino, al que debemos nuestros mas hermosos tejidos. Pero parece que, desde la mas nemota antigüedad (muchos siglos antes de la era cristiaha, 2700 años, segun álgunos autores orientales), los chinos advirtieron el provecho que podian sacar de este precioso insecto, $y$ se oeuparon con tan buen éxito en esta industria, que llegaron en poco tiémpo á hacer tejidos dé aquel. De Ja China, pasó la cria del gusano de seda á los pueblos vecinos, y principalmente á la Persia y a la India, de donde los antiguos estraian toda su seda. En el reinado de Justiniano es cuando se conoció en Europa el animal que la produce. En esta época ; dos moonges griegos trageron huevos de él á Constantinopla y llegaron á hacerlos producir. Se intentó entonces multiplicarlos, y tuvo tan buen éxito, que en algunos años todo el mediodia ToNo III: 
de la Europa orièntal quedó cubierto de moreras para alimentarlos. Durante la guerra de las Cruzadas, fué transportada esta especie á Sicilia, de donde se estendió poco á poco por Italia, España y Francia, en donde forma en el dia un ràmo importante dè comercio.

Como el gusano de seda exige, para criarse, muchos cuidados mińuciosos, y su cria es muy interesante, vamos á entrar en algunos pormenores con este objeto.

Aunque se podria en rigor criar estos insectos en. todas partes en donde crece la morera, cuyas hojás sirven para alimentarlos, sin embargo, todos los paises no son á proposito para ello. Oriundos de los paises orientales del-Asia, necesitan un clima casi semejante; y este clima, se encuentra en Sicilia, en Italia, en España, en Grecia, ế el mediodia de la Francia y otros puntos análogos por la temperatura. Es preciso además buscar la $a_{2}$ situacion mas conveniente para el local destinado á recibir los gusanos de seda; se debe, pues, evitar el colocarlos prôximos á las lagunas y rios, porque los malos olores y la humedad son contrarios á su multiplicacion.

Hallado el lacal, se procura semilla ó huevos, y cuando llega la estacion favorable, es decir la primavera, se disponen por capas ligeras sobre el fondo de unas cajas de madera muy delgada y forradas de papel, y se llevan á un cuârto que se calienta gradualmente hasta la época del nacimiento de las orugas. A medida-que estas salen, se van quitando de las cajas y se colocan sobre unos cañizos cubiertos de hojas de morera. Entoaces tienen un poco mas de una línea de largo.

El tiempo que el bombice pasa en el estado de larva comprende un periodo de cerca de treinta y cinco dias, durante los cuales cambia de piel cuatro veces y 
crece considerablemente, puesto que cuando llega el momento de convertirse en crisálida, tiene cerca de tres pulgadas de longitud. Cada una: de sus mudas es precedida de una especie de agitacion, dưrante la cual el animal consume muchas hojas, pero que cesa algunas horas antes de que cambie de piel; el gusano de seda se halla durante esta operacion en un verdadero estado de enfermedad pasagera, pero que nada tiene de molesto; porque apenas se ha terminado la muda, cuando le vuelve de nuevo su apetito y va en aumento hasta un nuevo cambio de piel. Cuando ha llegado el momento de la metamorfósis, se colocan encima de los cáñizos que sostienen á lós gusanos, unos ramos de brezo ó de encína verde, sobre los que se apresuran á subir las orugas para hilar su capullo. Empiezan por fijarse á un pequeño tronco y se ponea inmediatamente á trabajar; tres dias despues, la operacion se halla concluida y se pueden coger los capullos; porque mas tarde (18 ó 20 dias) la crisálida convertida en insecto perfecto horada su capullo y sale á buscar otro individuo de su especie para propagarla: despues la hembra hace su postura $y$ muere, y antes de ella el macho.

Cogidos los capullos no resta mas que devanarlos; para esto se eimpapan ante todas cosas en agua caliente para despegarlos, y en seguida se toman cuatro ó cinco, cuyos cabos se juntan para no formarde ellas mas que un hilo y deva. narlos todos juntos; cada uno de ellos produce una hebra de cerca de nuevecientos pies de largo, independientemente de un pequeño nụcleo que no se puede desenrredar, y que despues se carda para hacer filadiz.

§. II. - Las Nocru-As (noctua) se distinguen de los hombices por sus patpos inferiores, cuya última pieza es mas fina que las demas, por su trompa larga y cór- 
nea, y por las escamas que cubren su cuerpo.

Aunque estos lepidópteros, pertenecen por la disposicion de sus alas á la familia de los noclúrnos, presentan sin embargo unos colores mas vivos y variados que la mayor parte de las demas géneros de la misma familia $\cdots$ aun de la precedente; jamas 'se dejan ver durante la obscuridad de la noche, y aun vuelan por. el dia sobre las flores cuya miel chupan.

Las orugas de este género son muchas veces carniceras, destruyen una gran cantidad de otras larvas y aun se atacan á veces entre sí las que son mas fuertes matan siempreá las mas débiles, y las devoran cruelmente:

Las principales especies de este género numeroso son: la noctua dorada, (ph. crisitis, L.). cuyas alas son por encima de color de laton pulimentado. con manchas grises; la noctua gamma (ph. gamma, L.) que liene grises las alas de encima, matizadas de pardo y con una gamma griega de color de oro en medio de ellas; y la noctua del gordolobo ( $p h$ : verbasci, L.) de alas estrechas, dentadas, amarillentas $y$ rayadas de pardo.:

§. III. El género FALENA (phalana) comprendia antiguamente todos los lepidópteros nocturnos; despues se ha reducido á las especies cuyo cuerpo es delgado, la trompa corta, las alas anchas y el cuerpo siempre desnudo; sus orugas no tienen ordinariamente mas que diez patas y andan de un modo enteramente particular. Primeramente se fijan por medio de sus patas anteriores, en seguida levantan la parte posterior de su cuerpo para aproximarla á la anterior, y en habiendo fijado las posteriores á su.vez, desprenden las primeras y llevan sa cuerpo hácia delante. La repéticion de esta operacion determina su progresion, y les ha hecho 
dar el nombre de geómetras ó de agrimensoras, pues parece que miden el espacio que recorren. Su actilud estandó quietas es muy estraordinaria; fijadas á las ramas ó ramos de diversos vegetales por las patas posteriores, tienen su cuerpo suspendido en el aire en línẹa recta y perfectamente inmóvil, lo que les.ha valido el nombre de orugas en forma de baston. Si se tocan en este estado, se dejan bambolear; pero en vez de caer á tierra, permanecen suspendidas en el aire, por medio de un hilo que pueden alargar ó acortar á su voluntad; de suerte que, cuando se buscan en el sitio en que han debido caer, sorprende el no encontrar nada. Por este medio escapan de un gran número de peligros, en que hubieran perecido á no ser por esta estratagema.

Las especies de falenas mas comunes en nuestros paises son la falena azufrada ó del sauco, la falena de la lila, la falena del grosellero, \&c.

§.IV. Las polinlas (tinea) son los lepidópteros más pequeños que se conocen y se distinguen facilmente por sus alas plegadas en el estado de quietud. Sus orugas son siempre lisas y sin pelos, y provistas. de diez y seis patas á lo menos. Viven siempre escondidảs en unas habitaciones fijas ó movibles que se practican á espensas de las sustancias que roen. Las mas veces van á buscar los materíales á nuestros armarios, y nos causan de este modo estragos considerables. En los almacenes de pieles es en donde principalmente son mas temibles. Si no se tiene cuidado de airear de. tiempo en tiempo las mercancías, se propagan en ellas en tal cantidad que concluyen por destruirlas enteramente.

Pero no todas las especies son domésticas : Hay algunas que viven en los campos de hojas y de las partes 
tiernas de los vegetales; estas son mucho menos dañosas. Una particularidad muy notable; es que cuando comen las hojas estos insectos jamas atacan á la epidermis ó mémbrana que forma sus dos caras; sino que únicamente roen el parénquima, es decir, la parte comprendida entre las dos hojas epidérmicas.

Se conoce un grán número de especies de polillas, cuyos nombres específicos se sacan del objeto de que particularmente se alimentan, tales son la polilla de la cera, la polilla de las colmenas, la polilla de los tapices, la polilla de los paños, la poililla de las pieles, la polilla de las semillas \&c.

\section{SÉPTIMOÓ R D N.}

\section{D ÍP T E R O S}

Es fácil formarse una idea exacta de los insectos de este órden por la figura de la mosca comun y del mosquito. Todos tienen una boca propia únicamente para chupar los alimentos líquidos, dos alas membranosas y trasparentes, debajo de ellas dos pequeños apéndices movibles en torma de balancines (halteres) que algunas veces se han mirado como los rudimentos de dos alas, pero cuyo uso es enteramente desconocido:

Aunque estos animales no tienen mas que dos alas, mas pequeñas aun que las de la mayor parte de los demas insectos de su grandor; no por eso dejan de gozar de urr vuelo ágil y estenso, que les pèrmite sost tenerse en el aire durante horas enteras, á veces. sin que parezca que se mueven; tan rápido es el movir miento que impirimén á sus aląs! Se han vista algunas especies seguir, duranie múchas léguas, á un caballo 
que andaba alternativamente ạl trote y al galope. Se aprovechan de esta aptitud al movimiento para buscar á su posteridad un asilo, en donde pueda encontrar la seguridad y la subsistencia porque sus larvas, privadas de patas, no pueden proveer por si mismas á sus necesidades. Con el doble objeto de ponerlas à abrigo del peligro y de colocar alimentos á su alcance, elige su madre para hacer su postura las materias animales en putrefacéion, y llega algunas veces. á depositar sus huevos hasta en el cuerpo de algunos ànimales, en los que los hijuelos que provengań dé ellos dében salir y desarrollarse.

A pesar de que siempre la boca de los dipteros es en forma de trompa, sin embargo presenta modificaciones bastante importantes; en efecto, unas veces contiene en sú interior un cierio número de cerdas sólidas, con las cuales el insecto horada la cubierta de los cuerpos organizados cuyos humores sirven para alimentarlos; otras por el contrario hace simplemente el oficio de una rentosa, y no puede thas que aspirar los líquidos colocados en su superficie. Y aun en algunas es pecies, esta parte de su'cuerpo está enteramente en rudimentos, y se halla reducida á un simple orificio apeñas prominente En todos casos, los dípteros no pueden tomar mas que sustancias líquidas á lo menos en el estado perfectó; porque bajo el dề larvas, tienen la boca àrmada de ganchos, que les sirven para despedazar y triturar materias sólidas:

Lo restante de la organizacion de estos insectos nada ofrece de notable; su cabeza presenta unas antenas generalmente cortas, sus tarsos se terminan por unos ganchos muy finos que les sirven para agarrarse a las plumas y pelos de los animales sobre que viven, y preseutan á veces unas especies de pelotas membrano- 
sás que les sirven de ventosas parafijarse sobre los cuerpos mas brúnidos, y sostenerse muchas veces contra las leyes de la gravedad, como lo hacen las moscas.

Si bien por un lado los dípteros pueden causarnos perjuicio chupando nuestra sangre y la de nuestros ganadoś, ó depositando sus huevos en nuestras provisiones de boca cuya descomposicion apresuran de este modo; por otra nos hacen servicios señalados desiruyendo una multitud de cadáveres, cuyas exhalaciones podrian ser peligrosas. Por lo demas, únicamente en el esstado de larvas es cuando nos pueden ser útiles ó dañosos. En el estado perfecto, tienen la vida tán corta', que apenas les queda el tiempo necesario para hacer su postura, y mueren casi inmediatamente despues sin. haber comido.

El órden de los dípteros se divide en cinco familias: los nemóceros, los tanístomos, los notacantos, los ateiciceros y los pupíparos.

\section{PRIMERA FAMILIA.}

\section{NEMÓCEROS. (Lám. XXXVI:)}

Nemóceros es una voz griega que significa añlenas en forma de hilo, y que conviene tanto mejor á los dípteros de la familia de que hablamos, cuanto que són los únicos de su órden que tienen estos órganos de una longitud superior á la de la cabeza y coselete reunidos, y están compúestos á lo menos de seis piezas y las mas veces de catorce á diez y seis. Por otrá parte estas antenas : van disminuyendo insensiblemente de grosor desde su origen hasta su estremidad, ó á lo menos nunca presentan ún engrosiamiento bien marcado en ningună de sus partes, y están á lo mas guar- 


\section{5}

necidas por los lados de cerditas finas, dispuestás como las barbas de una pluma.

En cuanto á la forma de su cuerpo, tienen la cabéza pequeña con dos ojos grandes, el coselete corto $y$ como giboso, el abdómen largo y compuesto las mas veces de nueve anillos, las alas mas bien estrechas que anchas, las patas muy largas y delgadas; en una palabra, unas formas finas y ligeras.

La mayor parte de los nemóceros, principalmente las especies pequeñas, se reunen en tropas numerosas en el aire, y forman volando unas especies de bayles regulares por espacio de algunas horas. Aunque se encuentran estos insectos durante todo el buen tiempo, son principalonente mas comunes hácia el otoño. Parece que la madurez de las frutas es una de las condiciones que favorecen mas su desarrollo y propagacion. Abundan con especialidad en los paises de viñedos, hácia la épo-1 cá de las vendimias.

Entre estos insectos, unos hacen su postura en el: agua, otros en la tierra; pero todos, terrestres y acuáticos, sufren metamorfósis completas; sus larvas son apodes, largas y parecidas á unos gusanos. Por lo que toca á las ninfas, unas veces estan desnudas, otras encerradas en capullos; en todos casos, se mueven y presentan todas, las partes esteriores que distingen al insecto perfecto.

Està familia comprende dos grandes géneros, los mosquitos y las tipulas.

§. I. Todos saben, por su propia esperiencia, lo incomodos y fastidiosos que son los mosQuiros. (culex) (frg. 12), no solamente por el raido monotono con que aturden nuestros oidos, sino tambien por las picaduras profundas que hacen en nuestro cuerpo. Por medio de una trompa saliente y casi tan larga como sus anTono III. 
tenas, y principalmente de cinco pinchos que encierra, horadan la piel de la mayor parte de los animales para chupar su sangre. Ávidos déla del hombre, le persiguen, le impacientan sin cesar y particularmente por la noche. Sus vestidos no bastan para preservarle de sus ataques; su larga trompa atraviésa estos obstáculos para llegar hasta él y causa unas heridas tanto mas. dolorosas cuanto que vierte en la llaga un,líquido venenoso cuya presencia determina la hinchazon y escozor, que acompañan ordinariamente á la picadura de estos insectos. En América, en donde les dan el nombre de maringüinos ó mosquitos son tan importunos que en muchos parages no se puede salir por la noche sin cubrirse con una especie de velo, al que se da, por razon de su uso, el nombre de mosquitera. Parece que solamente las hembras son las que nos atormentan de este modo. Sin embargo, no se dirigen á nosotros para hacer su postura, porque no depositan sus huevos sino en el agua; lo hacen de un modo bastante notable; puies los reunen entre si en forma de un barquichuelo que flota en la superficie del líquido. Las laryas y las ninfas que provienen de ellos no dejan este elemento, en donde nadan con mucha agilidad, sino en la época de su última transformacion.

Entre las especies de este género, las mas conocidas son el mosquito comun (culex pipiens, L.) (fig. 12.). el masquito de trompetilla, llamado tambien cínife, pero que no debe confundirse con los que hemos descrito en los púpivoros, el mosquita de los caballos \&c.

§. II. Las típuras (tipula) se asemejan mucho á los mosquitos por sus formas ligeras, por sus alas estrechas, y por sus patas largas y delgadas ; pero se distinguen, de ellos fácilmente por la conformacion de su boca, cuya trompa es apenas visíble; por otra parte sus colorés 
aunque siempre oscuros, son sin embargo mas variadb que los de los precedentes.

Las típulas no estan menos esparcidas, ni son menos abundantes que los mosquitos; se encuentran por todas partes desde el principio de la primavera hasta el otoño. Pero en donde principalmente son umas cọmunes es en esta última estacion y en los terrenos de plantio; entonces no se puede dar un paso por estos sitios sin hacer marchar á muchas de ellas, y no es raro ver als gunos pequeños enjambres ejecutar en el aire movi $\rightarrow$ mientos regúlares de subida y descerso, sin desviarse de la línéa yertieal y sin pasar jamas de los puntos estremos tanto superior como inferiormente, y esto durante un tiempo muy considerable. Por lo demas se ignora completamente cual puede ser el objeto de esta singular maniobra.

Entre estos insectos, unos depositan sus huevos en ta tierra, particularmente en la que contiene restós de materias orgánicas; las larvas que provienen de ellos se alimentan de las moléculas nutritivas que allí encuen-tran; otros los depositan en el agua, y sus hijuelos viven poco mas ó menos como los de los mosquitoṣ. Algunas especies hacen st postura en agallas, afras en la madera vieja podrida, y sus larvas sacan su subsistencia de los mismos sitios en donde se encuentran. Segun esta varierlad de costumbres, se han dividido las -tipulas en muchos sub-géneros. $10^{\circ}$ Las típulàs-mosquitos son pequeñas y tienen las larvas acuáticas, como la típula culiciforme, la típula anular, la típula variegada. 2. Las típulas comunes son generalmente mayores y tienen las larvas terrestrés, táles son da típula de los prados, la típula gigantesca, la típuta arachoides. Esta última es muy notable por razon de que se da encuen- 
tra con bastante frecuencia en invierno sobre' la nieve ó el hielo.

\section{SEGUNDA FAMILIA.}

\section{tanístomos ( Lám. $X X X Y I$.}

Esta familia se diferencia de la que precede por la cortedad de sus antenas, que son ordinariamente mas cortás que la cabeza del insecto, y no estan compuestas mas que de dos ó tres piezas articuladas á lo mas, y de las siguientes por la última pieźa de esţos órganos que no ofrece ninguna division transversal, escepto en el género tábano que es fácil de conocer por el número de piezas de su chupador; su trompa es generalmente saliente y compuesta de cuatro ó seis de ellas. fo Las larvas de estos insectos se parecen á unos gusanos largos casi redondos y sin patas, y tienen la boca compuesta de ganchos que les sirven para roer las sustancias de que se alimentan.

Eista familia, mas numerosa que la precedente, comprende los géneros asilo, lepta y tábano.

(t) I. Los AsILOS (asilus) son unos insectos cuya figura se asemeja á la de las moscas, peróque son mucho mayores y presentan, por otra parte diferencias bastante sensibles. Tienen el cuerpo largo y velloso, las antenas aproximadas por su base y isubuladas ó en forma de lesna, la trompa prominente hácia.delante, las alạs . cruzadas sobre el dorso, y las patas largas y armadas de ganchos:

Los asilos son entre los dípteros, lo que las aves de rapiña entre las aves. Uniendo la fuerza muscular y el - poder de las armas á un caracter feroz y carnicero, 
son para todos los insectos, y principalmente para las mariposas y las moscas, unos tiranos encarnizados que vuelan sin cesar tras de sus victimas, y que, agarrándolas con los ganchos agudos de sus patas, las tienen confuerza y las chupan con su trompa, hasta que han estraido todas sus partes líquidas. Aun á veces atacan á los coleópteros, cuyya piel es mucho mas sólida, y ofrece tanta mas resistencia-á sus esfuerzos, cuanto que el animal brega con fuerza. Pero el asilo le retiene y sujeta con sus garras, hasta que ha llegado à atravesar la cubièrta córnea; despues le da la muerte, $\mathrm{y}$ se le lleva para dexorarle mas á su libertad.

Se encuentran los asilos en los huertos, en las praderas y en los campos, en donde incomodan mucho, con sus picaduras, al ganado que está paciendo ó trabajando. Sus larvas viven en la tierra, en cuyo seno se abren un camino con des ganchos vigorosos de que está armada su boca."

Se cuentan mas de cien especies de este género : las principales son el asilo avispon que tiene cerca de una pulgada de largo y que es la especie mayor de Europa, y. el asilo gigante, que es de América y escede al precedente en magnitud.

§. II. Los Leptos (leptis) se diferencian de los asilos por su trompa mas corta, nurca saliente, $y$ casi siempre susceptible de retirarse en una cavidad de Ia frente. Sus antenas son casi filiformes, escepto que su última pieza es gruesa y se termina por una cerda simple; sus alas que son mas largas que el abdómen estan muy apartadas una de otra durante la quietud.

En España tenemos dos especies notables de este géneno, que son el lepto becada y el lepto gusano leon. El primero, que es muy común en los bosques de nuestro pais, tiene las formas delgadas $y$ las patas. 
largas, lo que le ha hecho dar sü nómbre especifico. El segundo es mas pequeño $y$ no ofrece nada de nota-s ble en el estado perfecto; pero la larva es por lo menos tan digna de conocerse como la de la hormiga-leon. Del mismo modo que esta última, y muchas veces de sociedad con ella, el gusano-leon (porque asi es como se llama esta larva) se fabrica un agugero fon forma de embudo, y se coloca en el fondo en emboscada sobre la arena. Luego que ha cogido un insecto, le arrastra debajo de tierra, despues de haberle atravesado con su dardo, y le chupa tranquilamente. En seguida se desembaraza de la piel de su victima del mismo modq que la hormiga-leon. Pero lo que hay de singular en la historia de esta larva, es que á pesar de su viveza natural, se queda inmoril cuando se siente cogida. Por más que la meneen, no da ninguna señal de vida pero si por cạsualidad se la deja en libertad, recobra poco á poco su agilidad, y el primer uso que hace de ella, es procurar cavar la tierra para fabricarse uná guarida.

§. III. Los TÄbuNos (iabanüs) (fig. 13) son unos insectos gruesos, muy conocidos por los tormentos que causan á nuestras caballerias de carga y fáciles de distinguir por sus antenas cortas, cuya primera pieza está cortada interiormente en forma de media luna , $y$ por su trompa que contieue dentro seis especies de lancetas, para picar la piel de los animales cuya sangre chupan.

Estos insectos parecen unas moscas grándes, y soun tan temidas de nuestros ạnimales domésticos , a causa de las picaduras que reciben de ellos, que solo á su vista se ponen furiosos y ya no obedecen á la voz de - su dueño. El aşno principalmente les teme de tal modo que arroja todó lo que lleva para revolcarse en el polvo y desembarazarse dectlos. Es muy difícil el hacerlos soltar - porque se agarrana los pelos de los animales con los 


\section{1}

ganchos de sus tarsos y con unas pelotas que garnecen á estos órganos.

En los tiempos de tempestad es cuando principalmente los tábanós estan mas importunos ; entonces sucéde que persiguen al hombre mismo, el que, á pesar del uso de sus manos; le cuesta trabajo el hacerlos huir, pues vuelven á embestir con tanta tenacidad, y escapan con tanta destreza de la mano que quiere sacudirlos, que es casi imposible no ser picado de ellos.

Las principales especies de este género son el tábano de los bueyes (tab. bovinus, L.) que es negruzco con àlas pardas; este es el mas conocido de todos; el tába:no del camello (tab. marocianus, Fab.) que es negro con manchas de amarillo dorado en el abdómen, y atormenta continuamente á este rumiante; y el tábano negro ( $t a b$. niger.) que se encuentra en el mediodia de España. Parece que este es el género á que debe per̀tenêcer tambien la especie tan temida del leon.

\section{TERCERA FAMILIA.}

\section{NOTACANTOS.}

En los notacantos la última pieza de las antenas es constantemente ensortijada, carácter que los distingue de todos los tanístomos, escepto de los tábanos, que tambien la présentan; pero su chupador, compuesto de seis piezas cớrneas, no permite confundirlos con ningūn otro díptero de antenas cortas.

Cuando estos insectos han tomado alas, revolotean continuamente alrededor de las flores, cuya miel chupan, al paso que en el estado de larras viren principalmente en el agua. Por lo demas, sús costumbres son poco conocidas, escepto las del género estrationo (slra- 
tiomys), que es el mas importante de la familia.

Estos insectos, que se llăman comunmente moscas armadas, sacan su nombre, asi como el de el stratiomys (mosca soldado), que tiene la misma significacion, de un cierto número de espinas situadas en la estremidad de su escudo sobre el coselete; este carácter, unido á la figura de sus antenas, que son mas largas que la cabeza, y cuya primera pieza forma un ángulo con la que precede, impide siempre confundirlos con ning un otro género de la misma familîa.

La larva de los estratiomos es de forma prolongada, sin patas, y presenta en su estremidad posterior una especie de ernbudo, formado de un gran número de pelos, en cuyo centro se halla situado el orificio del órgano respiratorio. La posicion de este orificio exige que estas larvas, que son todas acuáticas, esten vueltas de modo que todo su cuerpo se sumerja en el liquido, al paso que la cola y los pelos que la forman sirven para sostenerlas en su superficie, y permiten al aire introducirse por los estignas. Cuando el animal quiere zambullirse replega sus pelos; los réune en un manojo, y cubre con ellós la abertura de las traqueas, en donde conserva aun una corta cantidad de fluido atmosférico para poder permanecer mas tiempo débajo del agua.

Las larvas de los estratiomos se trasforman en ninfas sin formar capullo; la piel que teniah se endurece alrededor de ellas y les hace el mismo oficio. En éste estado flotan á merced de las aguas hasta el momento en que rompen su cubierta para convertirse en insectos. En esta época se elevan á la superficie del líquido, hacen saltar los dos últimos anillos de su cubierta, y salen volando hácia su nuevo elemento.

La especie mas comun de este género en nueștro 
pais es el estratiomo camateon ó mosca armada grande (St. chamaleon, Fab.), que tiene seis ó siete líneas de largo, y es de color negro, con tres manchas de amarillo de limon á cada lado de la parte superior dél abdómen.

\section{CUARTA FAMILIA?}

\section{ATERÍCEROS: (Lám. $X X X V I$.}

La mosea comun, estudiada en su organizacion y en sus costumbres, puede darnos una idea bastante exacta de todos los ateríceros. Se halla en todos estos insectos, asi como en la primera, una boca en fórma de trompa corta y contractil, y que no encierra ordinariamente mas que dos piezas córneas, unas antenas de tres piezas articuladas, de las que la última jamas está dividida trasiersalmente.

En el estado perfecto estos dípteros se alimentan del jugo de las flơres, de materias animales en putrefaccion, de la sangre de los animales \&c., es decir, que sus costumbres son enteramente diferentes segun las especies. Las de sus larras no son menos variables; las hay que viven en los nidos de las abejas, en el agua, en las cloacas, en la basura \&c., pero siempre en sitios en donde encuentian un alimento preparado y generalmente líquido. Para pasar al estado de ninfa, no hilan capullo; su piel le suple, como en los estratiomos, adquiriendo mas consistencia, $y$ basta para protegerles durante el poco tiempo que viven bajo esta forma.

Esta fámilia cómprende tres géneros principales: los sirfos, las estros y las moscas.

¿. I. Los sinfos (sirphus) tiènen una trompa que encierra cuatro cerdas, al páso que en todos los demas géneros no contiene mas que dos. Su cabeza es tambien

Tonó IIr. 
304

mas gruesa, casi enteramente acupada por los ojos y tan ancha como el abdómen; sus antenas son muy cortas, rectas y muy aproximadas por su base. Su forma general se asemeja á la de los abejones y las avispas, á: los que se parecen tambien por el zumbido que prof: ducen volando, y, por la cost umbre que tienen de vivir sobre las flores.

Las larvas de estos insectos, como las de todos los dípteros, son blandas, sin patas, y se mueven por la contraccion de sus anillos. Unas viven en los árboles, y hacen grandes estragos entre los pulgones; los devo-s ran en tanta cantidad, que se ha visto á una sola chu par veinte de ellos en el espacio de un minuto, y es raro encontrarlas sin tener un pulgon en la estremidad de su trompa. Otras se sitúan en los nidos de las abejas Y hacen la guerra á la cria de estas últimas. Algunas en fin, que se han llamado larvas de cola de raton porque su abdómen se termina por una especie de cola que les sirve para respirar, habitan en el agua, y viven de las materias corrompidas que sacan del cieno. Se las ve frecuentemente nadar en las aguas cenagosas, con la cabeza hácia abajo, la cola hácia arriba y fuera del líquido.

El sirfo del grosellero y el sirfo del rosal son las. especies de ęste género mas comunes en Españá.

§. II. Los estros (astrus) forman un género muy fácil de distinguir, porque en el sitio de la boca no tienen mas que tres pequeños tubérculos ó débiles rudimentos de trompa.

Estos insectos tienen el aspecto de una mosca grande, muy velluda, cuyas alas estan apartadas en la quietud, y cuya cabeza es ancha, con unos ojos grandes y unas antenas muy pequeñas.

Rara yez se encuentran los estros en el estado per- 
fecto, porque sú vida es muy corta, y se limita generalmente á hacer la postura. Siempre depositan sus fiuevos en el cuerpo de los grandes cuadrúpedos, agugereándoles la piel can un aguijon que tienen en la estremidad de-su abdómen, La presencia de estos huevos no tarda en producir una hinchazon mas ó menos considerable y en formar pequeñas elevaciones; en el momento en que la larva rompe su cubierta, se alimenta del pus que alli se produce. Algunas veces la hembra se contenta con fijar sus huevos en las inmediaciones de alguna cavidad, tal como las orejas, las narices, la boca, y aun el ano, de modo que la larva se introduce en ella inmediatamente que nace, y se agarra por medio de dos ganchos de que está armada su boca.

Sin embargo algunas especiés colocan sus huevos lejos de estas cavidades y los pegan á los pelos en los sitios en que el animal acostumbra á lamerse con frecuencia Por médio de esta precaucion sucede tarde ó temprano que la lengua encuentra estas larvas, $y$ las Heva á la boca, y en seguida al conducto intestinal. En todos casos, una vez establecidas en las vias digestivas, se alimentan alli de tos diversos jugos producidos por sus paredès, y permanecen hasta que, habiendo llegado á su completo desarrollo, son arrojadas con los esçrementos, en los que vẹrifican su trasformacion en insectos perfectos.

Es de prever que las especies que depositan sus huevos en el esterior no hacen grán daño á los animales sobre que viven; pero las que horadan su piel y en seguida se introducen en las aberturas naturales, causan las mas vecés dolores muy vivos; muchas de ellas se vé á los caballos, bueyes y carneros agitarse, patear ócechárá correr con la cabeza baja en la primera dirección que se presenta hasta que se ha calmaito un poco 
el dolor: Esto es lo que se llama picarles la mosca. Enz tonces es muy peligroso hallarlos al paso.

Las principales especies de estros son: el estro del buey ( costrus bovis), el estro del carnero (ast. ovis, L.) y el estro, del caballo (ost. cequi, L.). El primero tiene unas siete líneas de largo, y es muy velludo; su tôrax amarillo con una lista negra; el abdómen blancó en la base con la estremidad leonada; las alas son uno poco oscuras. El segundo tiene estos últimos órganos trásparentes y el cuerpo mas pequeño. Es poco velludo; la cabeza pardusca ; el torax ceniciento con puntos negros; el abdómen manehado de párdo ó de negro. Finalmente, el tercero es poco velludo, de color párdo leonado; mas claro en el abdómen; dos puntos negros y una lista del mismo color en las alas.

§. III. Un volúmen podria escribirse sobre el género Mosca (musca), pues comprende mas de mil especies, número superior al que encierran muchas clases de la zoologia. Por esta razon la mayor parte de los naturalistas han subdividido este grupo en müchos subgéneros, y aun en muchas familias, de las que cáda una contiene muchas secciones. Y $Y$ sin embargo, se han separado de este género un gran número de especieś que los antiguos referian á él, porque en otro tiempo comprendia casi todos los dípteros conocidos, á escepcion de las típulas, de los mosquitos y de un corto número de otros, al paso que hoy en dia no encierra mas que los ateríceros, cuya trompa pequeña, pero muy aparente, no tiene más que dos cerdas, y puede retirarse enteramente á la cavidad de la boca, y cuyas antenas tienen la última pieza articulada, aplastada y con una cerda lateral.

Las moscas son quizá los insectos mas generalmen: te conocidos se encuentran por todas partes, en las, 
casas, en los campos, en las praderas y en los bosques. Por medio de los ganchos y de las pelotas de que estan guarnecidos sus tarsos, se agarran á todos los cuerpos lisos ó ásperos, a los primèrés háciendo el vacio con sus pelotas, á los segundos asiéndose á las asperezas con sủs ganchós. Asi es coño se la ve correr por lơs cristales y cielos rasos, en una posicion vertical y aun vueltas boća a rriba!

Estos insectos vuelan con rapidez y producen un pequeño zumbido, que es caúsado por el rozamiento de sús alás contra el cóselete. Bajo este punto de vista son incómodos; pero lo que lós hace mucho más molestós es la costumbere que tiènen de situarse sobre nosotros y' cáusarnos con su trompa unas picazones siempre in-

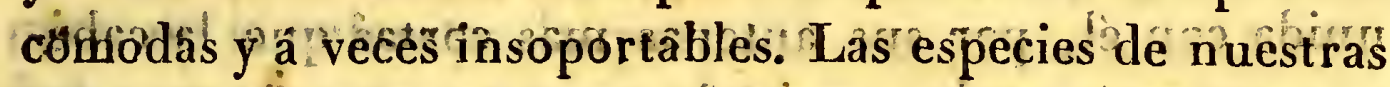
hábitaciones lo ensucian tódo con sus inmundicias, los espejos, lo comestibles, fas frutas, porque se alfmentán casi indistintamente de toda especie de materias ani-

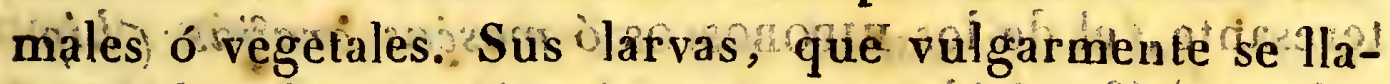
man guscuros , lo infestan todo, la carne fresca ó cor rompida, la miel, el queso \&c,; porr todás partes se introducen. A fortunadamente tieñen nứmerosos enemigos? las aves, las arañas y btros lés thacen una caza activa?

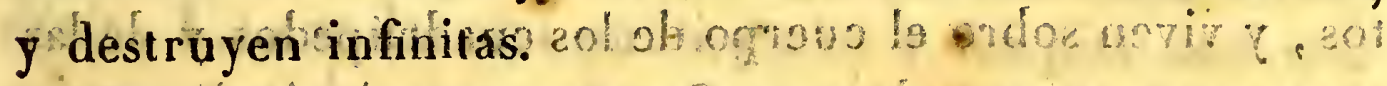

Las especies mas esparcidas son la mosca doméstica, la mosca azul de la carne, cón el abdómen azul brillante y la frente leonada, la mosca verde dorada; la mosca

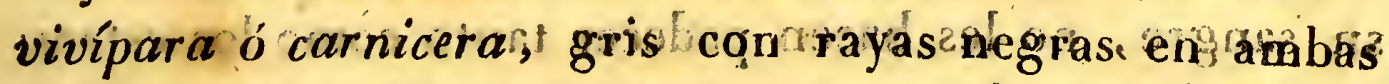

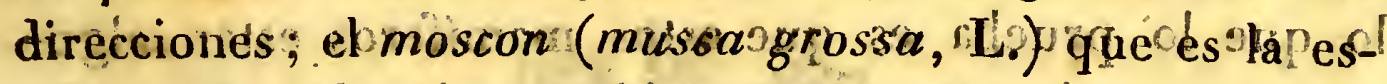
pecie mas gruesa de las comunes ystoda negra con ${ }^{2} \mathbf{a}$ cabezá de color de roro bajo yo la basé den las alas leor

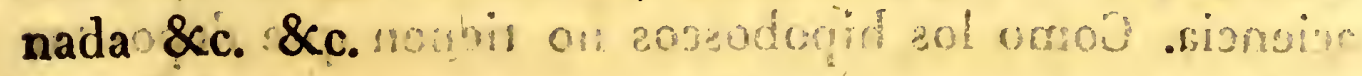




\section{QUINTA FAMILIA.}

\section{PUPÍPAROS (LÁm. XXXK1)}

El nombre de pupiparios está formado del latin pario, yo produzco y pujpus hijuglo ó mas bien ninfa. Todos los insectos comprendidos en estalfamilia conservan en efecto sus huevos en su abdómen hasta que se han trasformado en hinfas de suerte que estas últimas no tienen en el momento de su nacimiento mas que romper su piel para echar á volar. Se distinguen fát cilmente estos dípteros por su cabeza casi enteramente confundida con el torax, ó al menos muy intimamente unida con él, por sus anterias mas cortas que la cabej za y muy separadas, y e fin, por su trompa wuy pequeña compursta de sdos flamentos muy juntos.sqeo - Esta familia no compres de mas que un género in teresante, el de los Hipoboscos ló moscas ârañas) (Chippobosca) (fig. 14) a cuyas especies tienen todas ol cueri po grueso y chato, la piel dura, las alas largas y casi opacas, las patas largas y robustas. Su género de tida es análogo al de los estros es decir, que sơn parasi-t tos, y viven sobre el cuerpo de los cuadrúpedos y de las aves, cuya sangre chupan. Se agarran principalmente á los caballos, sobre los cuales se reunen en tropas numerosas; pero aunque se alimentan esclusivamente de su sangre, ng les hacen padecen tanto como los estros; lo que lo prueba es que estos mamíferós estan algu nas veces casi enteramente cubiertos de ellos sin enfurecerse, y aun álgunás veces sin dar muésiras de im paciencia. Como los hipoboscos no tienen que depositar sus huevos, puesto que los conservan en su abdómen hasta su trasformacion en ninfa, pican menos profun- 


\section{9}

damente, y la succion que egercen es mas bien incómoda que dolorosa, se la puede comparar á la picadurade una pulga.

El hecho mas curioso de la historia de estos insectos es su reproduccion. El hijuelo, que es casi tan grueso como el vientre de la hembra, éstá cubierto de una piel sólida, dentro de la cual está en un grande estado de blandura, de suerte que abriéndola no sale de ella mas que una materia blanda é informe; pero si se hiende la piel despues de haber hecho cocer el animal, se le halla con su forma ordinaria, tal como la debe tener despues de su última trasformacion, Cuanda ha llegado este momento, el insecto hace saltar una parte de la cubierta, la que cede con tanta mas facilidad, cuanto que está como circunscrita por una línea, bajo la cual la piel tiene mucha menosi solidez.

El género hipobosco es mucho menos numeroso que la mayor parte de los que hemos hablado; comprende pocas especies, entre las cuales las mas comunes son: el hipobosco del caballo (hip. equi, L.), pardo, con el coselete manchado de blanco y los dedos con cuatro uñas; el hipobosco de ta golondrina (hip, hirundinis, L.) con las alas puntiagudas y los pies con seis uñitas, y el hipobosco del carnero (hip. ovína, Lio), sin alas, $y$ que se halla entre la lana de los carneros \&c. 


$$
\text { stais ond his }
$$

En los animales de las tres divisiones que preceden hemos hallado un número de relaciones de estructura bástantè grande para que no fuese fácil conocerlas ; sus principales sistemas orgánicos llaman la atencion por lá semejanza de su estructura y de sus usos. En los animales radiariọs esta uniformidad desaparece para dar lugar á una gran diversidad de formas y de funciones. Eloúnico carácter bien marcado que presentan consiste en da sencillez de su organizacion, evidentemente in ferior á la de los vertebrados, moluscos y articula dos cy en la disposicion de sus partes, que forman ordinariamente alrededor de un eje ó centro comun wna especiè de rayos semejantes á los de una rueda y á los petalos de una flor, lo que les ha hecho dar tambien el nombre de zoófitos. Su sistema nervioso, lejos de llegar á un desarrollo comparable al de los demás animales, no tiene centro comun (celebro) para recibir las sensaciones ó para presidir á los movimientos; jamas tienen sentidos especiales para la vista, el oido, el olfato y el gusto; el tacto pasivo es el úničo de que gozan. Sus movimientos no son mas desarrollados que su sensibilidad; fuera de un pequeño número de escepciones, carecen de apéndices locomotores, y no manifiestan su existencia sino por la mutacion de lugar de 
algunas de sús partes. Muchos están fjos durante toda su vida en el sitio donde han nacido, y forman alli muchas reces agregaciones numerosas de individuos ha; bitando la misma morada, y teniendo en algun modo una vida comun.

Su nutricion se hace de una manera en estremo sencilla; su cavidad digestiva no tiene las mas reces sino una abertura que sirve igualmente para la introduccion del alimento y para la espulsion de los escrementos; algúnas otras comunica con el esterior por muchos orificios, que todos tienen la propiedad de absorver las materias nutritivas y dè espelér el residuo de ellas, asi como los restos usados del cuerpo. En las especies mas sencillas no se ençuentra ya vestigio alguno de conducto alimenticio; su nutricion se efectúa del mismo modo que la de los vegetales, por la absorcion inmediata de los jugos que el agua les lleva continuamente.

Se concibe que los órganos de la respiracion y de la circulacion no deben existir, ó al menos ser muy imperfectos en esia clase de animales; lampoco se encuentra en ellos sino raramente corazon ni pulmones ; solo cuando tienen una cavidad digestiva se ven salir de ella algunos vasos que llevan los jugos nútricios á las diversas partes del cuerpo. Eu una palabra, su organizacion es tan poco complicada, que un gran número de ellos pueden multiplicarse por da division mecánica de su cuerpo en muchas paries. En otros se ven brotar sobrei isu piel unas éspecies de yemás semejantes á las de los vegetales, las cuales, cuando estan suficientementè desárrollądas, íse désprenden del cuerpo al que estaban adheridas, y se convierten en seres vivientes yanimados cóno él. Es preciso sin embargo advertir qué la ma-

ToNo III. 


\section{2}

yor parte se reproduce igualinente por huevos.

Estos hechos y otros análogos hacen muy interesante el conocimiento de esta parte de la zoologia; desgraciadamente está todavía muy atrasada por falta de suficientes observaciones. La poca utilidad material que sacamos del estudio de estos animales le ha hecho descuidar por mucho tiempo, y solo de algunos años á esta parte ha progresado hácia la perfeccion, á consecuencia de las nuevas especies que los naturalistas y viageros han descubierto en nuestras costas ó en las de mares lejanos.

Se dividen los zoófitos en cinco clases, segun la mayor ó menor complicacion de su organizacion; estas son los equinodermos, los entozoários, los acalefos, los pólipos y los microzoários ó infusorios.

1. Los equinodermos se conocen por su forma radiada, por su piel sólida y generalmente cubierta de espinas, por su conducto intestinal, casi siempre provisto de dos aberturas, y por la existencia de órganos de la respiracion y circulacion (lám. XXXVII, fig. 1 , 2. $\mathrm{y}$.)

2. : I Los entozónios tienen el cuerpo largo como los gúsanos; sin radios bien señálados, escepto en la boca, y un conducto digestivo de dos orificios, como los precedentes; pero carecen de órganos distintos para la circulacion y respiracion. (fig. 4 y 5 .)

3.: Los acalefos no tienen, como los entozoários, órganos circulatorios y respiratorios ; pero su forma radiada y su cavidad digestiva de un solo orificio, unidas á la poca solidez de su piel, bastan suficientemente pará distinguirlos de los a nimales de las dós clases precedentes. (fig. 6 y 7.)

-6.4. Los pólipos son unos pequeños zoófitos notables 


\section{3.}

por la blandura de todos sus órganos, y por los brazos ó tentáculos que rodean su boca. (Lám. XXXVIII, fig. 3 y 5.)

5. En fin, los infusorios son todos aquellos seres microscópicos que viven en cantidades innumerables en las aguas mansas, y de los cuales la mayor parte no presentan órgano alguno bien distinto para el desempeño de sus diferentes funciones. 


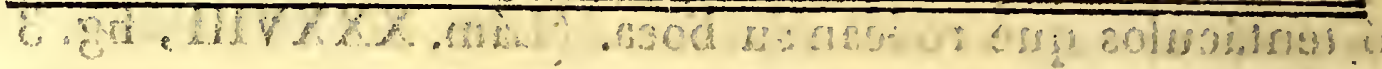

\section{PRIMERA CLASE.}

(1) Entinologta

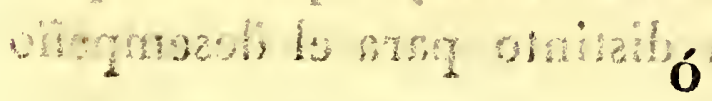

HISTORIA NATURAL DE LOS EQUINODERMOS.

Esta clase comprende los animales mas complicados de la última division. Tienen órganos imperfectos para la circulacion y la respiracion, y una piel bastante bien organizada, porque está sostenida por una especie de esqueleto esterior análogo á él de los articulados, y al cual se atan comunmente unas puntas ó espinas movibles que reemplazan en algun modo los miembros de la mayor parte de los animales superiores. Las piezas sólidas que componen su esqueleto estan unidas entre sí de tal manera, que les permite moverse unas sobre otras, de donde resulta que el animal goza de una verdadera locomocion, y puede trasladarse en totalidad de un lugár á otro. Pero para que sus movimientos sean fáciles es preciso que sean secundados por los del agua, que, sosteniendo su cuerpo, hacen mas fácil su traslacion de un punto á otro. Por esto los equinodermos jamas dejan el elemento líquido, en donde no solamente se encuentran con mas comodidad, sino que todavía les suministra, en los animales que cria en su seno, el género de alimentos mas conveniente á su organizacion, y los materiales necesarios á su respiracion branquial.

La reproduccion de estos animales es siempre oví- 
pára, y no podria verificarse por division; sin embargo se observa que las diferentes partes de sus cuerpos que. hạn perdido accidentalmente, no tardan en volver á parecer, aunque un poco menos desarrolladas de lo que antes lo estaban.

Esta clase se divide en dos órdenes, los estelíferos ó equinodermos pediculados, ylos helmintoides, ó equinodermos sin pies.

1. El órden de los estelíferos comprende todos los equinodermos provistos de pies, y cuya forma es muy radiada.

2. Los helmintoides carecen de apéndices locomotores, y sú cuerpo se asemeja mas al de un gusano que al de un animal radiario.

\section{PRIMER ÓRDEN.}

\section{ESTELÍFEROS.}

A los zoófitos de este órden es á quienes conviene especialmente el nombre de equinodermos, que quiere - decir piel erizada de pinchos. Su cubierta cutánea está en efecto llena de un gran númęro déagugeritó, có; tocados en series regulares en toda su superficie, y dan'do paso á unós tentáculos membranosos y cilíndricos; muy favorablemente dispuestos para la locomocion. Ar-: mados en su estremidad de unas ventosas semejantes á la que tienen en la boca las ssangiuijuelás, estos órganos sirven para fijar el animal á los cuerpos submarinos, y para mudar de sitio con una prontitud variable, pero ien! general mediana. Se podrian pues cơm+ parar estos tentáculos á los de los céfalopodos entre los mol uscos ; pero ademas de que estós ińllimos estos àpéndicęs són del todo carnosos, mientras que los de los 
esteliferos élan compuestos de pièżas sólidas, su modo de obrar es en teramente diverso; no son en efecto mus-: culos: los que ponen en juego los pies de las radiarios! de que hablamos', coma se observa en los brazos ide dos: cefalopodos y en los miembros de los animales vertebrados: y articulados; estos lórganos estan a travesados por un conducto interior que hiay en toda su estension, y que comunica con una cavidad llena de agua colocada en su base; y este líquido es él que, dirigiéndose de una parte á otra, determina el alargamiento y acortamiento alternativos de estos apéndices, y por consiguiente la progresion del animal.

Este órden, que es el mas numeroso de la clase; comprende tres pequeñas familias: la de los estelérides: la de los equínides y la de los holotúrides.

\section{PRIMERA FAMILIA.}

\section{ESTELÉRIDES (Lám. $X X X V I I$.}

Bajo el nombre de estelérides; se designan todos los equinodermos, cuyo cuerpo es aplastado y generalmente dividido en radios que son las mas veces en número de cinco; en el punto central, en donde se reunen estos radios, es donde se halla colocada la boca que es inferior y que sirve al mismo tiempo de ano. La armazon de su cuerpo se compone de pequeñas piezas óseas, que por la diversidad de su disposicion contribuyen á formar los agugeros de los tentáculos y facilitan sus movimientos, que son mucho mas estensos que los de todos los demas animales de la misma division:

Todos estos radiarios son carniceros y viven de moJuscos, de anelides $y$ de otros zoófitos que trituran con facilidad, por medio de las piezas durás de qué èstá 


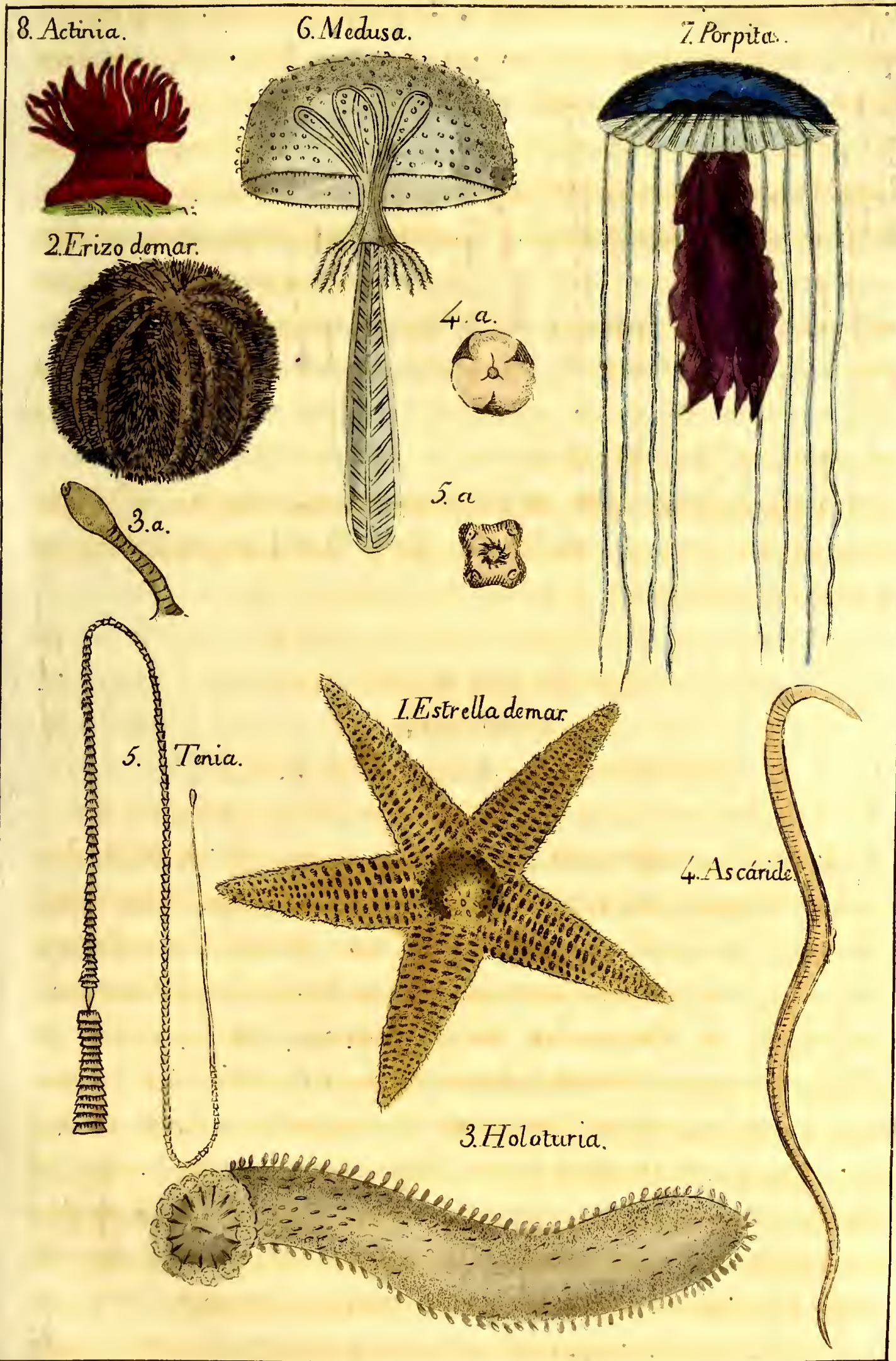

RADLARIOS. 

armada su boca. A su vez ellos son devorados por los peces, cangrejos \&c. que los mutilan; arrancandoles uno ó muchos de sus radios; pero su fuerza de reproduccion les tal, que se han vistolalgunos que no conservaban mas que una sola de estas partes, reparar todas las demas en muy póco tiempo. Sin embargo es preciso observar que la parte reproducida nuncal ad quiere la maguitud de la primitiva; esto es lo que hace que se encuentren tan frecuentemente estelérides irregulares.

- Los estelérides están esparcidos en todos los mares: sob tan abundantes en ciertas cóstas que se sirven de ellos para éstercolar las tierras, úuico usó en que se les ha empleado hasta ahora: Se divide esta familia en dos géneros: las ASTERTAS (asterias) (fig. 1.) ó estrellas de mar, que lienen cinco radios séncillos, y las Eurialas (euryalus) ó cabezas de medusa, cuyos radios van dividiéndose y subdividiéndose deśde su base, lo que les da la apariencia de un manojo de serpientes. En el primera se distingue da A. comun (ast. rubens, L.) que es rojiza $y$ cuyas ramas son gruesas y redondas $y$ su punta poco aguda; la A. glácial (ast. glacialis, L.) que tiene muchas veces mas de un pie de diámetro. Las espinas que revisten la parte superior estan rodeadas de uua multitud de tubitos que forman al rededor de las bases de las espinas como una especie de almohadillas. La A. anaranjada (ast. aurantiaca, L.) es la mayor de las de nuestro pais y los bordes de sus ramás estan cubiertas de unas piezas que imitan á un empedrado, sobre las cuales se articulan unas espińs movibles. Toda la superficie supèrior está cubierta de otrás espinas terminadas en cabezuelas truncadas y ásperas. 


\section{SEGUNDA FAMILIA.}

EQUÍNIDES. (Lám. XXXVII.)

Aunque haya diferencias esteriores bien marcadas entre los equínides y los estelérides s la organizacion de estás dos especies de zoófitos presenta numerosas relaciones.; todas las partes esenciales son las mismas, esceptuando sin embargo que la cavidad digestiva de los equínides tiene dos orificios, mientras que la de las estrellas dé mar no tiene mas que uno. Por otra pariedos primeros no tienen esta disposicion radiada y ramosa tan notable en estos últimos; su cuerpo; de figura globosa ó redondeada, está revestido de una especie de concha ó de cubierta calcárea, compuesta de piezas que se unen exactamente, y que estan atravesadas de muchas filas regulares de agugeritos por donde pasan unos pies membránosos. La superfieie de esta cubieria está ademas armado de cspinas implantadas sobre pequeños lubér culos movibles, lo que ha hecho dar á estos animales el nombre vulgar de cri do que los equinides se hallan provistos de dos especies de órganos locomotores : dos pies, que són blandos y contractiles, y las espinas que son duras é inflexibles; pero á pesar de este doble aparato, los movimientos de estos equinodermos no son mas ágiless antes al contrario son muy lentos y mas limitadós que los de los estelérides?

Todos los equínides son carniceros, como los precedentes, y se alimentán de pequènos mảriscos quê agarran con sus pies, y que rompen con un aparato déntario vigoroso. Este se compone de una boca armada, de cinco dientes enclavados en una armazon muy com- 


\section{9}

plicada guarnecida de muchos músculos, á la que se da el nombre de linterna.

Se divide esta familia en muchos géneros; de los que los principales son : $10^{\circ}$ Los EQuinos ó ursinos (echinus) (fig. 2.), que tienen la boca en medio de su cara inferior y el ano en la parte opuesta; tal es el equino comun (echinus esculentus, L.) que es de la figura $y$ grosor de una manzana, y que se come en los puertos de mar; el turbante (ech.cidaris, L.) cuya concha es un esferoide aplastado hácia los polos, y tiene cinco paseos en zig-zac; en cada intervalo hay dos filas de gruesos pezoncillos que tienen cincuenta largas y gruesas espinas estriadas, con una multitud de ellas pequeñísimas en su base; y el equino de color de violeta (ech. atratus, L.) por encima plano y con diez paseos las espinas de toda la parte convexa parecen unas cabezas de clavos y estan muy apiñadas ; las de la base son un poco mas largas y aplastadas. 2. Los CLIPE.$^{\circ}$ Stros ó escudiformés (clypeaster), cuyo nombre, que significa broquel, espresa bastante bien su figura, que es deprimida convexa superiormente y concava por debajo; su ano no está situado en medio del cuerpo.

\section{TERCERA FAMILIA.}

\section{HOLOTÚRIDES. (XXXVII.)}

Esta familia no se compone mas que de un solo género las holoturia (holoturia) (fig. 3.), que comprende unos animales de cuerpo oblongo, casi vermiforme y evidentemente destinados á establecer un paso de los esteliferos á los helmintoides. En su estremidad anterior está la boca, que se halla rodeada de tentáculos, mientras que el ano ocupa la estremidad opuesta; tambien en esta 
última abertura es donde estan colocadas las branquias, que no tienen solamente por objeto vivificar la sangre, come se observa en los peces y en la mayor parte de los moluscos, sino tambien favorecer la locomocion; porque ciertos músculos, sometidos á la voluntad del animal, le permiten llenar ó vaciar á su voluntad la cavidad que contiene estos órganos é imprimir al cuerpo movipientos bastante estensos.

La piel de las holoturias es menos dura que la de los equinodermos precedentes; tiene tambien bastante flexibilidad para que el animal pueda cambiar de forma cuando se le toca, y contraerse de modo que ocupe un pequeño espacio ; algunas veces, cuando está agitado por el temor de algun peligro, sus contracciones son tan fuertes y repentinas, que desgarra y vomita sus intestinos.

Nuestros mar es crian muchas especies de este género; tales son la holoturia real, la holoturia escamosa, la holoturia temblona \&c. La primera (hol.regalis, L.) tiene mas de un pie de largo, y de tres á cuatro pulgadas de diámetro; toda ella es almenada; la segunda (hol. squammata) es generalmente mas pequeña, aunque adquiere mayor volúmen en los mares cálidos. La tercera en fin, (hol. tremu$l a, \mathrm{Gm}$.) que se encuentra en nuestros mares, y principalmente en el Mediterráneo, es de un color negruzco y tiene mas de un pie de largo; su dorso está lleno de puas cónicas y blandas; su boca está guarnecida de veinte tentáculos ramosos. 


\section{1 \\ SEGUNDO ORDEN.}

\section{HELMINTOIDES.}

Este ớrden es incomparablemente menos numeroso que el de los estelíferos; no comprende sino un corto número de especies, cuyo cuerpo largo, cubierto de una piel coriacea, y desprovisto de pies, recuerda el de los anélides, entre los cuales las colocan algunos naturalistas; pero de los que los alejan su organizacion interior y sobre todo su sistema nervioso.

Sus costumbres son muy análogas á las de los gusanos marinos, pues pasan su vida en el agua ó en la arena que cubre las orillas del Océano, adonde los pescadores van á buscarlos cuando baja la marea para emplearlos como cebo. Algunas especies sirven tambien. de alimento en los puertos de mar.

No citaremos de este órden mas que un solo género, el de los siponclos (siponculus), cuya historia bastará para dar una idea de la de todos los demas animales del mismo órden.

Estos son unos radiarios cuyo cuerpo es largo $\mathbf{y}$ cilíndrico como el de las lombrices., con las que algunos natūralistas los han confundido, y cuya piel gruesa está arrugada transversalmente y en el sentido de su longitud. Tienen una boca en forma de trompa, que puede entrar ó salir á voluntad del animal por medio de los músculos interiores de que está guarnecida; su intestino es bastante largo para atravesar toda la estension del cuerpo y venir á abrirse al lado de la boca. Se ignora de qué especie de alimento hacen uso; no se ha encontrado hasta ahora en su cavidad digestiva mas que granos de arena y restos de mariscos. Esta última circunstan: 
cia haria presumir que viven de moluscos; no obstante que la figura de su boca haria sospechar mejor que se alimentan de las materias órganicas contenidas en el cieno. Se encuentran los siponclos escondidos en la arena, como los arenícolas $\mathrm{y}$ otros muchos anélides, y los sacan de aquí tambien para que sirvan de cebo en la pesca. La especie mas notable es el siponclo comestible (lumbricus edulis, Gm.) del mar de las Indias, que algunos pueblos van á buscar en la arena para comerle. Hay tambien en el mismo mar otra especie que no tiene menos de dos pies de largo. 


\section{SEG U N DA GLASE.}

Entojoologia.

ó

\section{HISTORIA NATURAL DE LOS ENTOZOÁRIOS.}

\section{I}

a clase de los entozoćrios mas vulgarmente conocidos con el nombre de lombrices intestinales, es una de las mas dignas de estudiarse, primero porque los animales que comprende no viven sino en el interior de otros'animales á espensas de su substancia, y segundo porque el modo como se reproducen es uno de los hechos mas dificiles de esplicar de la fisiologia. Se sabe bien que son ovíparos, $\mathrm{y}$ que sus huevos se desarrollan como los de los animales que presentan este modo de generacion; pero ¿cómo se introducen en el cuerpo ? De afuera no provienen, pues que hasta ahora no se han visto vivos en otra parte mas que en su interior; es preciso pues que se formen alli espontáneamente, ó que se transmitan de pa. dre á hijo por via de generacion. Pero en el dia ya no se cree en las generaciones espontáneas, lo que destruye la primera hipótesis. En cuảnto a la segunda, ¿ cómo conciliarla con la observación diaria de animales que crian muchos de ellos, mientras que sus padres no los tenian? Siu embargo no es imposible hacer concordar este hecho con la hipótesis de que hablamos, suponiendo que todos los animales contienen gérmenes de lombrices intestinales, pero. que estos gérmenés 
no pueden desarrollarse hasta tanto que se encuentren en circunstancias favorables. Se sabe cuanto favorecen las constituciones débiles y delicadas la multiplicacion de estos serés parasitos.

Qualquiera que sea el modo de reproducirse, los entozoários preséntan en su figura esterior relaciones con los anélides; pero ademas de que su cuerpo no está compuesto, como el de estos últimos, de una serie de anillos articulados, tienen su organizacion mucho menos complicada; no se les encuentra ni tráqueas ni branquias, ni órganos circulatorios ólocomotores; a penas se descubre en ellos algunos vestigios de nervios. Solo su conducto intestinal está bien desarrallado ; casi todos tienen una boca y un ano bien marcados.

No se debe creer, segun el nombre vulgar de lombrices intestinales que se da á estos animales que el conducto alimenticio es el único órgano en donde se desarrollan, pues se encuentran tambien en el hígado, pulmon, bazo y cerebro; y aun nacen hasta en las cavidades que no tienen comunicacion alguna natural con lo esterior.

Los inconvenientes que resultan de la presencia de estos animales en el interior del cuerpo dependen en primer lugar de su número, y despues de la importancia del órgano que habitan. La cavidad digestiva puede contener algunas veces cantidades, notables, sin que de esto rèsulten graves accidentes; uno solo basta para comprometer la vida, si se encuentra en un órgano muy esencial. Una de las causas que disminuyen el peligro de la presencia de los entozoários en el conducto intestinal es la posibilidad de espelerlos; : los purgantes producen casi siempre este resultado.

Esta clase se divide en dos órdenes: los vavitarios y los parenquimatosos. 
1. Los cavitarios tienen un conducto intestinal flotante en una cavidad interior, y provisto de dos orificios, uno para la introduccion de los alimentos, y otro para la espulsion de su residuo:

2. Los parenquimatosos no tienen cavidad distinta, y sus intestinos, cuando existen, parecen mas bien unos vasos ramificados que un tubo digestivo.

\section{PRIMER ÓRDEN.}

CAVITARIÓS.

Este grupo se compone de los entozoários mejor organizados; $y$ en los que se encuentral constantemente un conducto intestinal de dos aberturas, flotando en una cavidad interna, lo que les ha hecho dar el nombre de cavitarios. Su cuerpo, que es largo y generalmente redondeado, les da tanta mas semejanza con los anélides cuanto que su piel está marcada, como la de estos últimos; de estrias transversales que imitan á los anillos ó segmentos de esta clase de articulados.

Nada diremos de las costumbres de estos seres singulares; se ve bien que, encerrados en 10 interior de otros animales, es muy difícil observarlos. Únicamente haremos notar que los cavitarios, aunque en general son mas comunes en el conducto intestinal que en ninguna otra parte, no dejan de presentarse en otras muchas cavidades, $y$ hasta en el tejido celulár que envuelve las vísceras del pecho, del abdómen, \&c.

Este órden se divide en dos familias: los filaréos y los ascaridéos. 


\title{
PRIMERA FAMILIA.
}

\author{
FILARÉOS:
}

Los filaréos toman su nombre de su forma delgada y larga que se ha comparado á un hilo; se desarrollan en tan' gran cantidad en el cuerpo de toda especie de animales, que llegan á formar pelotones bastante considerables, encerrados en una cubierta comun; rara vez se encuentran aislados. $Y$ por una singularidad notable, no se les halla solamente en las cavidades que comunican con lo esterior, como el conducto intestinal, el pulmon \&c.; sino que tambien son muy comunes en los órganos mas ocultos, y hasta en lo interior de los músculos.

Lás filárias y los tricocéfalos son los únicos gẻneros de esta familia.

§. I. El género Filakia (filaria) comprende todas las espeeies cuyo cuerpo es filiforme y casi de igual grosor en toda su estension: tal es la filária comun ó dragoncillo mas célebre bajo el nombre de lómbriz de Medina ó de Guinea. Esta abunda mucho en los paises cálidos, en donde' se insinua bajo la piel del hombre, principalmente en las piernas y bajo la planta de los pies. Como al principio causa poco dolor, pasa allí bastante trempo sin ser notada, y no se conoce su presencia hasta que ha crecido considerablemente. Entonces el animal es del grosor de un cañon de pluma, y tiene $Z$ veces mas de diez pies de largo; causa dolores atroces, convulsiones nerviosas horrendas y aun algunas veces la muerte. El único medio de hacer cesar estos terribles accidentes es estraerla prontamente con la precaucion de no dejar nada de ella, porque la 
menor parte basta para reproducir el resto y renovar el mal.

§. II. Los Třicocéfalós (tricocephalus) se distinguen de las filarias por su cuerpo grueso y redondéado por atras y muy delgado por delante, lo que les ha hecho dar su denominacion científica, que significa cabeza en forina de cabello, y el nombre vulgár de lombriz de cola de hilo. Adviértase; que en esta última denominación, se confunde la parte anterior del cuerpo con la posterior; porque la párte delgada, como lo hemos dicho al caracterizar el géneró, no es la cola, sino la cabeza.

La especie mas conocida de este género es el tricocéfalo del hombre, que tiene de una á dos pulgadas de largo, y que es muy común en el intestino grueso.

\section{SEGUNDA FAMILIA.}

\section{ASCARIDÉOS. (Lám XXXVII:)}

Estos entozoários que son los mas comunes son fáciles de conocer por su cuerpo largo, cilíndrico y adelgazado en sus dos estremidades; lo que los distingue de los filáréos que le tienen del mismo grosor en toda su estension, ó mas delgado en su parte anterior.

De todas las lombrices intestinales, los ascaridéos son los mas generalmente conocidos porque son los que causan los mas de los accidentes verminosos, sobre todo en los nin̂̀os. Algunas veces se multiplican con tanta rapidez que no es raro éncontrar en la cavidad digestiva de individuos muertos de esta enfermedad, algunos pelotones del grosor del puño, enteramente formados por el entrelazamiento de su cuerpo. En la cavidad digestiva es donde se encuentran principalmente estos cavitarios; no

Tono IIr. 
obstante se hallan taimbien en otras muchás visceras, y hasta en lo interior de los vasos sanguíneos.

- Citarenos de esta familia lós géneros ascáride y. estrongilo.

§. I. Las Ascártoes (ascaris) (fig. 4.) tienen la boca guarnecida de tres papilas carnosas (fig. 4 a), entre las cuales sale de tiempo en tiempo una trompa muy corta.y

La especie mas conocida de este género es la ascáride dombricoides, que se encuentra muy frecuentemente en el conducto intestinal del hombre y de un gran número de'mamiferos; tiene muchas vecés dos pies de largo y aun mas, y causa accidentes bastảnte graves. La ascáride vermicular es mucho mas pequeña, soló tiene de cinco á seis líneas, y se dirige con preferencia á la estremidad del conducto intestinal, en donde causa ordinariamente vivas comezones.

§. II. Los estrongilos (slrongilus) se parecen de tal modo á lás ascáridés que la mayor parte de los naturalistas los confunden; la única diferencia que los separa, es que los estrongilos tienen el ano envuelto en una esperie de bolsá ó saco que falta en las ascárides. Rara vez se les encuentra en el ińterior del hombre. - 2 La especie mas célebre es el estrongilo del caballo, que tiene cerca de diez pulgadas de largo, y que se desarrolla en todas las vísceras de este solípedo, y hasta en sus arterias. Una segunda especie, el estrangilo gigante, es el mayor de todos los entozoarios, tiene hasta tres pies de largo y aun mas, é iguala en grosor al dedo pequeño; es ordinariamente de un hermóso rojo y créce principalmente en los riñones de algunos carnívoros digitigrados y devora su sustancia causándoles dolores atroces. 


\section{SEG UNDO ÓRDEN.}

\section{PARENQUMATOSOS.}

Estos animales tienen la organizacion mucho mas sencilla que los del órden precedente; carecen de cavidad intestinal ; su cuerpo no of rece mas que un tegido homogéneo, en el cual no se distingue ningun otro órgano sino algunós chupadores colocados en la superficie esterior, y que se continuan en lo interior: baja ka fórma de pequeños conductos ramificados que reemplazan al conducto digestivo; por consiguiente carecen de verdadera boca asi como tambien de ano, de modo que la nutricion se reduce en ellos á la absorcion inmediata de las materias alimenticias, que encuentran preparadas en el cuerpo de los demas animales. Ésté órden ha sido dividido en cuatro familias, de las cuáles las dos mas importanteś, son los trematodes y los tenioídes.

\section{PRIMERA FAMILIA.}

\section{TRE M A TODES.}

Bajo el nombre de trematodes se distingue una pequeûa familia de entozoarios cuya figura es muy araxia ble, pero que se conoce siempre fácilmente sen que tienen, ya en medio de su cuerpo, ya en sus estremidades , unos órganos húecos en forma de ventosas; de que se sirvén para adherirse á las diferentes vísceras en que se desarrollan.

Pocos de estos animales habitan el.cuerpo del hombre; muchás despecies se tevicuentranken el de nuestros 
ganados, y principalmente en là oveja; pero el mayor número parece que se nutre á espensas de los habitantes de las aguas, como los peces, los moluscos y crustáceos. Haciendo este género de vida á los trematodes todavía mas difíciles de observar que los demas entozoarios, se ve que su historia natural debe estar bien póco adelantada con respecto á sús hábitos; aśi todos nuestros conocimientos 'sobre este objeto se limitan á algunas observaciones acerca de las costumbres de las especies que viven en el interior del cuerpo de nuestros animales domésticos.

El género mas importante de esta familia es el de las dístomas (distoma) especie de lombrices blandas, cuyo cuerpo generalmente aplastado, presenta dos ventosas ó chupadóres colocados el uno bajo del vientre y el otro hácia su parte anterior; á esta doble abertura débên su nombre científico de dístomas que quiere decir dos bocas.

Las dístomas son todas unos pequeños animales, de las que las mayores no llegan á una pulgada de largo, y que no tienen ordinariamente sino algunas lineas de una éstremidăd del cuerpó á lă otra. Como son de una consistencia muy blanda es dificil determinar rigurosamente su figura; las hay largas, ovales, aplastadas, cilindricas, sin que la diversidad de estas formas pueda esplicarse por la diferencia de las espécies; porques se les ve; como á las sanguijuelas, alargarse y acortarse, ya en totalidad, ya en parte, segun la sensácion que resperimentan. De los dos orificios que pre: sentan estos animales, el de adelante constituye la boca y está destinado ấ absorver él álimento; el dèl vientre no parece servir sino para fijar el animal á las vísceras en que isésdesarrolla.

20" Se conócén mas de doscientas espeçies deldístomas? 
de las cuales la mas célebre es la díst ma del hígado, que se encuentra en la mayor parte de los rumiantes, en el puerco, el caballo y aun en el hombre. Su cuerpo es aplastado, oval, grueso hácia delante, delgado por atrás. Pulula algunas veces de tal modo en lo interior de los carneros que pacen en las praderas húmedas, que no es raro ver á estos mamíferos volverse hidrópicos y perecer á consecuencia de su escesiva multiplicacion.

\section{SEGUNDA FAMILIA.}

TENIOÍdES. (Läm. $X X X V I I$.

Los tenioídes han sido llamados asi de su principal género, el de los tenias, que tambien han sacado su nombre del latin tonia, cinta.

Tienen el cuerpo generalmente largo y aplastado y provisto en su éstremidad de dos á cuatro poros ó chupadores que les sirven de boca. Se encuentra tambien ordinariamente hácia la misma estremidad una ó muchas espinas en forma de ganchos, por medio de los cuales el animal se adhiere á los órganos internos.

Los principales géneros de esta familia son los tenias, las hidátidas y las lígulas.

§. I. Los Tenias (toenia) (fig. 5.) tienen el cuerpo estremamente largo y: compuesto de un gran número de articulaciones débilmente unidas, fáciles de separar y que pueden cada una en particular, reproducir el animal todo entero. Sủ cabeza presenta en su parte media cuatro puntos negras (fig. 5. a.), que podrian desde luego tomarse por unos ojos, pero que en realidad no son sino chupadores, con cuyo auxilio estos gusanos parasitós chupan el quilo contenido en el conducto intesti- 
nal. Apropiándose de este modo los alimentos destinados al animal, determinan en él un hambre insaciable, y le estenuan rapidamente.

Es tanto mas dificil espelerlos del cuerpo donde viven, cuanto que se adhieren á todos los órganos por medio de sus ganchos. Es preciso para obtener este efecto, emplear los purgantes mas violentos; y aun sucede muchas veces que no se arroja sino una parte, $y$ lo que queda reproduce el tenia en un corto espacio de tiempo.

El hombre cria dos éspecies de este género: el tenia ancho (F. lata), cuyas articulaciones son mas anchas que largas y quellega comunmenté á veinte pies de longitud, y el ténia ó lombriz solitaria, llamada asi segun la opinion errónea de que no se desárrolla jảmás sino una sola en el cuerpo del mismo individuo. Esta última se distingue de la precedente en que tiene sus árticulaciones mas largas que anchas.

§. II. Las HIdátidas (cysticercus) tienen la cabeza configurada poco mas ó menos como los tenias, pero sus articulaciones son poco marcadas y su cuerpo se termina posteriormente por una especie de vegiga.

Estos entozoarios son mucho menos notables por sí mismos que por la balsa que se fabrican á espênsas del individuo en el que se desarrollan. Se hace algunas veces tan grande que puede contener hasta treintalcuartillos de agua; basta para esto que se encuentre colodas da en sitio favorable á su dilatacion, como debajo de 1 a piel ó en el abdómen.

- Se conoce un gran número de especiés de este género; las mas notables son Ya hidátida celulosa, que determina en el puerco la enfermedad conocida con el nombre de lepra, y la hidátida oerebral, que nace en et cerebro dé las okejas yo que les causa ula especie de 
parálisis que se llama vértigo porque les hace volver involuntariamente de lado, como si tuviesen vértigos. El hombre cria tambien muchas especies de ellas, que se desarrollan en el higado, pulmon, cerebro \&c.

§. III. Las Lígulas (ligula) forman un tercer género análogo á los ienias, de los que se diferencian principalmente por la falta de chupadores esternos, los que, á lo que parece, están reemplazados por los poros de que está provista su piel. Estos son por consiguiente los entozoarios cuya organizacion es mas sencilla; porque no solo no se encuentra en ellos cavidad intestinal, sino que ni tienen boca para tomar sus alimentos; su nutricion se verifica por la absorcion de los materiales ya elaborados que encuentran en lo interior de los animales en que se desarrollan.

El cuerpo de las lígulas se asemeja como el del tepia, á una larga cinta marcada en toda su estension de estrias transversales y longitudinales. Parecen ser para las aves y sobre todo para los peces lo que las especies de los dos géneros precedentes son para los mamíferos; pues las lígulas viven principalmente en los peces de agua dulce, cuyos intestinos envuelven y constriñen hasta el punto de hacerlos perecer; este funesto accidente acontece frecuentemente á la brema. La especie de lígula que vive en este ciprino llega hasta cinco pies de largo, y pasa en ciertās comarcas de Italia por un manjar agradable. 


\title{
TER G R A GAS E.
}

\section{$\mathcal{A} \mathfrak{e} \mathfrak{a} \mathfrak{l} \mathfrak{f} \mathfrak{d} \log \mathfrak{i} \mathfrak{a}$}

\author{
6 \\ HISTORIA NATURAL DE LOS ACALEFOS.
}

E

sta tercera clase comprende todos los zoófitos de figura radiada, cuyo cuerpo blandujo, gelatinoso y trasparente no presenta mas órganos que algunos conductos, que parecen ser ramificaciones de intestinos, poco mas $\delta$ menos como los entozoarios parenquimatosos. La poca consistencia de estos seres singulares les permite mudar de forma á su voluntad hasta el punto de ocupar diez veces menos espacio, cuando se contraen, que cuando estan en espansion. Se conoce bien que esta contractilidad no puede ser sino favorable á los movimientos; asi los acale fos se mueven con facilidad en las aguas que habitan constantemente; y como son todos fosfóricos y esparcen una viva luz durante la noche, sus movimientos se parecen á las ondulaciones de la llama, de modo que se creeria que el mar, que ellos cubren en una vasta estension, está entregado á un grande incendio, que se propaga lentamente por el impulso de un viento ligero y continuo.

Los marinos y los viageros designan á todos los animales de esta clase con el nombre de ortigas de mar, 


\section{5}

denominacion impropia sin duda, pero que espresa bien la sensacion dolorosa que producen sobre la piel del que los maneja, sensacion que se ha comparado á la que nọs háce éspérimentar la planta de este nombre cuando la tocamos. Los antiguos, que les conocian igualmente esta propièdad, lés dieron el nómbre de acalefos que significa tambien ortiga.

Esta clase de radiarios se divide en dos órdenes, ó mejor dos familias, la de los acalefos simples y la de los acále fos hidrostáticos.

\section{PRIMERA FAMILIA.}

\section{ACALEFOS SIMPLES.}

Se ha dado el nombre de simples á estos acalefos -porque no tienen para moverse estas vegigàs aéreas que hacen de los de la familia siguiente una especie de barquillas vivientes, figura que, unida á sus costumbres, les ha hecho dar por los viageros $y$ marinos el nombre de fragatas ó de galeras; flotan y nadan en el agua del mar por las solas contracciones y dilataciones -de su cuerpo, sin que tengan' órgano alguno particudar para la lacomocion.

Estos zoófitos se conocen por su cuerpo circular y isiempire aplástado por su cara inferior, en cuyo centro -se halla colocado el orificio del conducto digestivo, que sirve all mismo tiempo de boca y ano. Este orificio está giarnecido ordinariamente de pequeños tentácúlos, de - que se sirve el animal con mucha destrezả para atraer. - agarrar su presả ; y aunque no tiene órgano alguno propio párá tritúrar su alimento, se observa que le digiere con una rapidez estraordinaria. Es probable que

TOMO III. 
el líquido acre y ardiente que destila, y que le ha hecho dar el nombre de ortiga, es un disolvente enérgico que facilita la digestion de los alimentos:

15 Esta familia comprende dos géneros principales; las medusas y las porpitas.

§. I. Las NEDusas (medusa) (fig. 6.) tienen el cuer po orbicular, mas ó menos convexo superiormente, aplastado y aun ligéramente cóncavo en sú superficie inferior, en dande se ve, ademas de la boca que está colocada en el centro, un grán número de apéndices carnosos, que en algunas especies" parecen destinados á suplir á la boca, mientras que en otrás tienen por obgeto agarrar los animalitos de que se alimentan, como son los insectos, moluscos, gusanos \&c. En sumạ, su figura se parece tanto á un hongo, que es fácil equizócárse ; por èsta razón se da á estos animales él nombre de sombrilla. Su cuerpo, como el de todos los acalefos, es fosforescente durante la! noche ; sin embargo, esta propiedad no le es enteramente inherente, $y$ parece lestar subordinada á la voluntad dél zoófito; porque los. naturalistas y los viageros han observado frecuentemente en los mismos individuos el páso del estado fosforescente al estado apaco, yice versa. Pero únicamente durante su vida pueden cambiar asi; despues de su muerte son siempre fosforescentes.

Como las medusas son enterameñte gelatinosas y iel menor choque puede destrozarlas, huyen cuanto pueiden de las ovillas y escollos, y permanecen en alta mar sostenidas en la superficie del agua por las contraeciones y dilataciones alternativas de su cuerpo dejándose thevar del impulso del viento á no ser que este las empuge hácia la costa, en cuyo caso tratan de iresistie á isu açcion pero no lo logran siempre tya marea las arroja 


\section{7.}

-muchas veces sobre la orilla en cantidades bastante cónsiderables para haber ensayado el sacar alguir provecho de ellas, estrayendo el amoniaco que contienen en aban: dancia.

Ademas de estos accidentes, que destruyen un gran número, estos acalefos tienen que temer dos enemigos no menos respetables, que son las actinias y las baJlenas ; estas últimas sobre todo tragan millares de individuos de una pẻqueña especie de medusa que frecuenta los mares del norte.

Entre las numerosas especies de este género citare. mos como la mas abundante la medusa orejuda.

$\therefore$ §.II. Las porpitas (porpita) (fig. 7.) tienen la figura orbicular y radiada de las medusas; pero su cuerpo es mas aplastado por encima y encierra interiormente un cartilago sólido que le da un poço mas de consistencia: tambien su' superficie superior está marcada de líneas concéntricăs que se cruzan con otras que se dirigen del centro á la circunferencia, casi cómo se observa en ciertas conchas bivalvas. Su cara inferior presenta, además de la boća, un grản número dé pequeños tentáculos que sirven para la locomocion, y próbablemente tambien para la prehension.

Se ve segun esto que las porpitas se parecen mucho á las medusas; sin embargo hay en su modo de existir una diferencia que no permite confundirlas, aun mirándolas de lejos en la superficie de las aguas. Las medusas cuando flotan, estan casi enteramente ocultas debajo del agua, mientras que las porpitas se mantienen siempre fuera de este líquido, y nadan en su superficie al, modo de las aves acuáticas, sirviéndose de sus tentáculos como estas últimas de sus patas.

No se conoce bien sino una sola espeeie de este 
-género, que hábita el Mediterránéo y el mar de lạ́s:Inc dias, da cual es notable por su hermoso color ázuloric

\section{SEGUN D A F A M I LIA.}

\section{ACALEFOS HIDRŐSTÁTICOS.}

Aunque las medusas y las porpitas son verdaderamente hidrostáticas, púes que nadan siempre en la sưperficie de los mares, no se da el nombre de acale fos hidrostáticos sino á las especies que, estando provistas de una ó de muchas vejigas aéreas, , se sirven de ellás para sostenerse sobre las aguas. A este aparato locomotor se une ordinariamente un cierto número de tentáculos, de los cuales tos mas cortos hacen oficio de chupadores, y los mas largos, obrando como una especie de remos," secundan los esfuerzos de la vejiga aérea.

Esta familia, mucho menos estensa que ta prece dente, no encierra sino un género notable, que son las Fisalias (physalia); seres singulares que se ven en gran número en la parte meridional del Océáno Ațán.tico. Su cuerpo, de figura aovado-oblonga, parece un pequeño batel; una cresta que se eleva sobre su dorso les sirve de vela para recibir la impulsion del viento, mientras que los tentáculos que parten de la cara inferior de su cuerpo les hacen oficio de remos y de timon, de suerte que, luego que han hinchado su vejiga haciendo entrar aire en ella, flòtan sobre las aguas como unas pequeñas barquillas, lo que les ha hecho dar los nombres de fragata, galera, navio \&c. Estos animales se mantienen de este modo en la superficie del mar cuando el tiempo está sereno; pero luego que cesála calma 


\section{9}

se apresuran á vaciar su vejiga, y se dejan ir á fondo para volver a aparecer con el buen tiempo.

Las fisalias tienen, como las medusas, un jugo acre y quemante, que produce vivas comezones cuando se las toca, y esparcen por la noche una luz fosfórica.

- Se encuentran algunas especies de ellas en casi todos los mares.

is

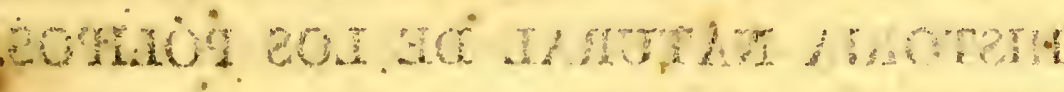

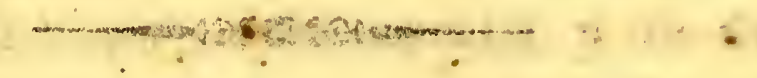

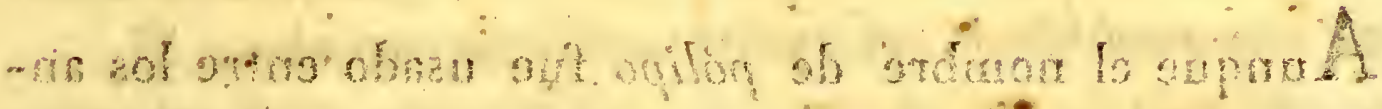

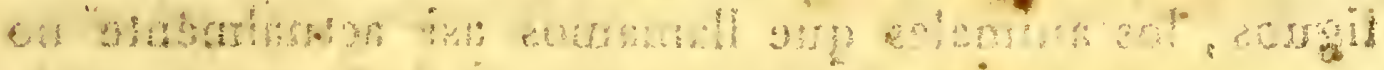

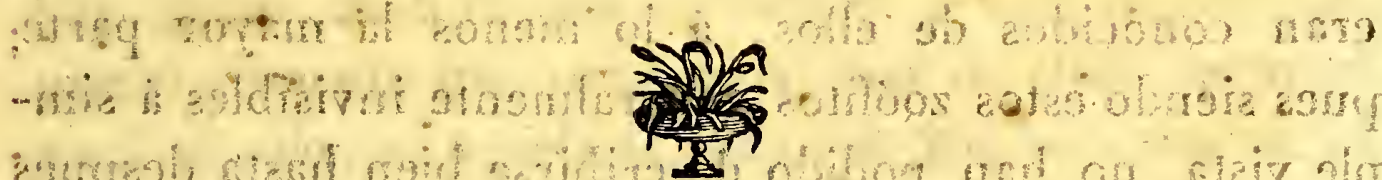

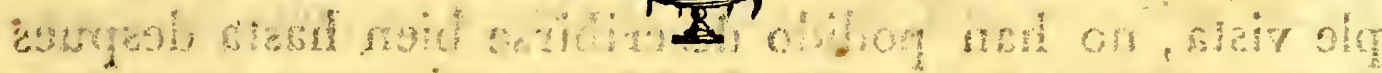

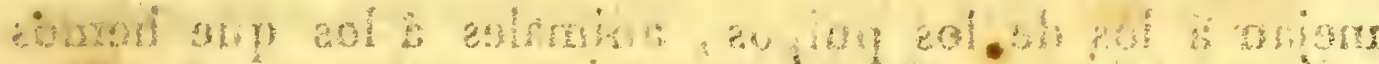

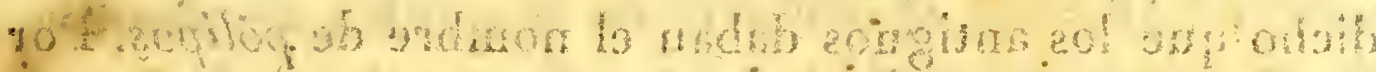

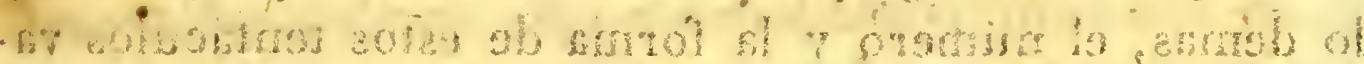

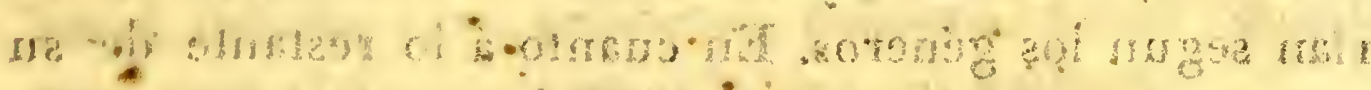

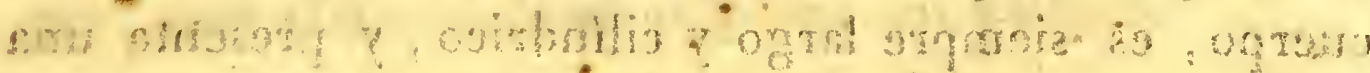

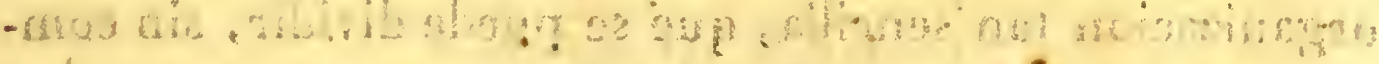

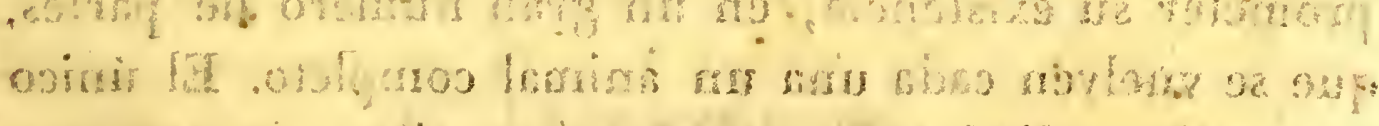

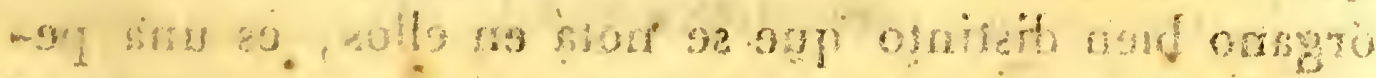

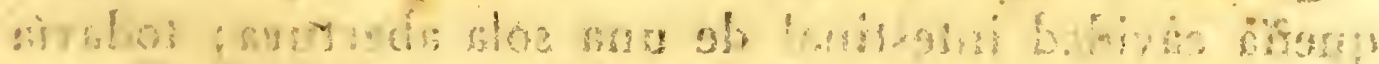

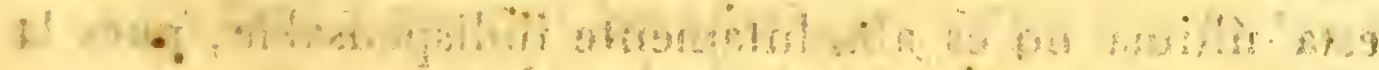

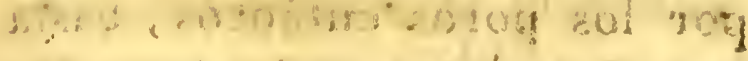

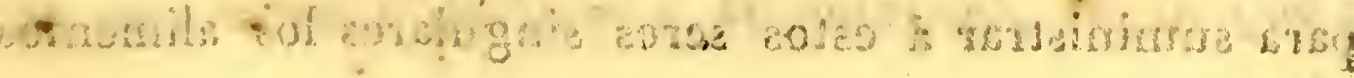




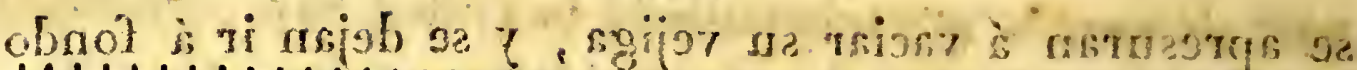
CUA ITA CHAS E.

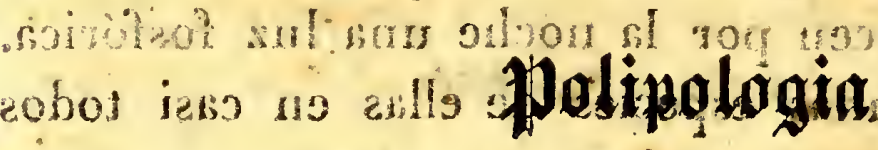

ó

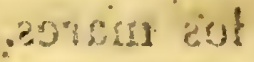

\section{HISTORIA NATURAL DE LOS PÓLIPOS.}

Aunque el nombre de pólipo fue usado entre los antiguos, los animales que llamamos asi actualmente no eran conocidos de ellos, á lo menos la mayor parte; pues siendo estos zoófitos generalmente invisibles á simple vista, no han podido describirse bien hasta despues del dęscubrimiento del microscopio.

Los naturalistas han llamado asi á esta clase de zoófitos, porque los tentáculos que rodean su boca se asemejan á los de los pulpos, animales á los que hemos dicho que los antiguos daban el nombre de pólipos. Por lo demas, el número y la forma de estos tentáculos varían segun los géneros. En cuanto á lo restante de su cuerpo, és siempre largo y cilíndrico, y presenta una organizacion tan sencilla, que se puede dividir, sin comprometer su existencia, en un gran número de partes, que se vuelven cada una un animal completo. El único órgano bien distinto que se nota en ellos, es una pequeña cavidad intestinal de una sola abertura; todavía esta última no es absolutamente indispensable, pues la absorcion que se efectúa por los poros cutáneos, basta para suministrar á estos seres singulares los alimentos 


\section{1}

necesarios $\mathrm{Su}$ reprodurccion puede sero opipa ra gemmipara, ,ó escisípara En el primer cáso hay en los pálipos, como en todos los demas lapimales un órgano especial en el que se forman lós huevos ; en el ségundo brotan en la superficie del cuerpo unas especies desemas análogas á las que se desarrollan sobre los vegetar les, y que dan origen á un nuevo individuo que se desprende prọto ó tarde de su madne para sivir independiente. Ip cuanto á la generacion escisípara, es la mas sencilla de todas; consiste en la seccion ó division natural ó ar bificial de una parte del cuerpo que éstando separada del resto, se desarrolla y se núvelve un animal entero.

El modo con que los zoáfitos se repròducen por yes masiles hace: susceptibles de formár seres compuestos que gocen de una vida particular y comung dé modo que el alimento que toma cada uno de ellos aprovecha ya á él solo, ya á toda la sociedad lEn los casos en que estan asi reunidos, se construyen una habitacion comun ; bien cárnea, bien lapidea ,pero siempre sólida á la que se da el nombre de polipero. Pero no todos presentan esta particularidad, y segun esta diferencia en el modo de existir se ha dividido la clase de los zoóftos en dos órdenes idos gimnopólipos ique estan en general aislados y no producen polipero y y los simpólipos, que viven en compnidad en up polipero,

\section{PRIMER ${ }_{9 S}$ QRDEN}

\section{GINNOPQ́rIPQS.}

Es fácil distinguir los animales de este primer órden por la consistencia blanda de su cuerpa, que les permite contraerse á dilatarse á sy voluntad, segun que se 
dreen en peligro b́ séguridad. Són rụay nónables por su fuerza de reproduccion; sé pueden cortar, sin nin gữ inconvenientè y los tentáculos que rodeam su boça, pues bastan algunos diás para que sestós organos se vụelvan a formar absolutamente semejantes á lo que eran arntes. En estos zoófitos es donde iprincipalmente se encuentran mas egemplos de generavion escișpara; cada parte separada no tarda en volverse un animal perfecto do que sin embargo no impide que se reproduzcan igualmente por hovesos.

- hat Ningano de estos animales se construye un polipero para habitacion, lo que les ha hecho llamar tambien pólipos desnudos; viven generalmente libres, y casi nunea contren adherencia con los denas cuerpos. andste órden se divide en dos familias : los actinia-

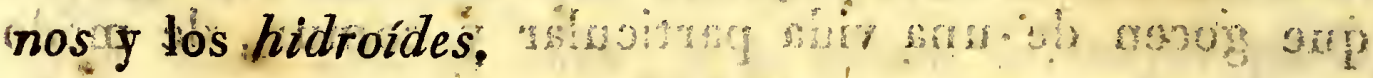

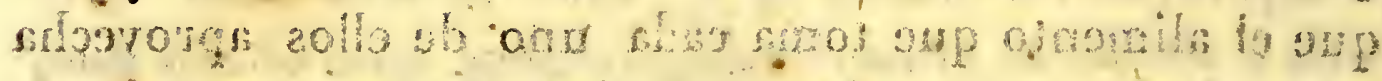

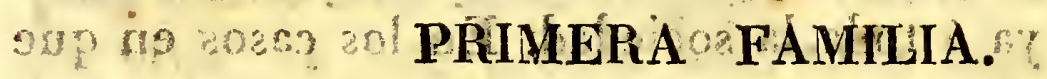

\section{ACTINIANos (Lám. XXXYH.)}

Los actiniaños ô pólipös carnósós no se diferencian solamente de los siguientes por un a consistencia más firmé, sino que tiêten los tentáculos de la boca mas numerosos, mayor mantud, y el cuerpo casi cilíndrico, terminado por abajo por un pie que puede fijarse en el fondo del agua ó desprenderse de él, segun la voluntad del animal. En este últing easo ya se deja. llevar á merced de las aguas, ó ya se dirige por medio de sus tentáculos. Por lo que acaba de decirse se ve que estos últimos sirven igualmente á la locomocion y a la préhensión de los aliméntoś

- Elut género más ińteresanté de esta familia è el de las Actinias (actinia) (fig. 8.), seres raros que un 


\section{3}

exámen superficial ha hecho algunas veces clasificar entre los vegetales. Si se les ve en la superficie del mar, abiertos en forma de roseta adornada de los mas vivos colores, sus tentáculos tienen tanta semejanza con los pétalos de una flor, que no se les señala vulgarmente sino con el nombre de anémonas de mar. Cuando en un tiempo tranquilo y sereno se reunen en gran númcro en algun punto poco distante de la orilla, la superficie del agua que cubren se parece á un cuadro de flores. Pero por poco que cambie el estado de la atmósfera, estas pretendidas anémonas se contraen, y uo forman mas que un cuerpo redondeado semejante á un puño de baston que se precipita repentinamente al fondo del agua, y permanece allí hasta que la calina se restablece. Por esto las actinias se miran por los marineros como unos escelentes barómetros que predicen el tienfo con una certeza casi absoluta.

Se encuentran muchos de estos zoófitos á lo largo de las costas durante la buena estacion; donde hacen una guerra encarnizada á los gusanos, á las merlusas, á los pequeños crustáceos \&c., que cogen muy diestramente con sus tentáculos. Pero en el invierno se dirigen á alta mar, ya porque allíencuentren un alimento mas abundante, yá porque disfruien de una temperatura mas suave.

Las actinias se multiplican con rápidez, tanto por la seccion mecánica como por la generacion vivípara. En este último caso dan á luz sus hijuelos por la boca.

Las principales especies de este género son la actinia coriáceá, la actinia purpurea, la actinia blanca \&c. 


\section{SEGUNDA FAMILIA.}

\section{HIDROIDES. (Laim. XXXVIII.)}

Los hidroides ó pólipos gelatinosos tienen el cuerpo enteramente homogéneo, en vez de tener una piel dura y sólida como las actinias; : su organizacion por otra parte es todavia mas sencilla que la de estas últimas. No solo se puede cortarlos de todos modos, quitarles los tentáculos \&c. sin comprometer. su existencia, sino que aun se puede, sin que cese de verificarse la nutricion, volverlos de dentro á fuera, de modo que el estómago forme la cubierta esterior, mientras que la piel haga oficio de cavidad intestinal.

Esta familia comprende tres géneros principales: las hidras, las cristatelas y las vorticelas.

§. I. Las hidras (hydra) (fig. 1.), mas conocidas bajo la denominacion vulgar de pólipos de brazos, han recibido este último nombre á causa de los largos tentáculos que rodean su boca, tentáculos cuya longitud. es casi igual á la de todo el cuerpo. Son unos animales casi microscópicos, en los que la organizacion está reducida á su último grado de simplicidad. No se encuentra en ellos órgano alguno particular para la autricion, la generacion; la sensibilidad ó la movilidad; su cuerpo tiene la figura de un cucurucho gelatinoso cuyos bordes estan guarnecidos de tentáculos, y cuya cavidad hace oficio de estómago; y es tal su homogeneidad, que dividiéndole en muchos pedazos, cada uno de ellos eucierra todas las condiciones de existencia, y se vuelve un pólipo entero.

Y sin embargo, á pesar de esta estremada sencillez, estos animales nadan, se arrastran por la tierra, andan, 


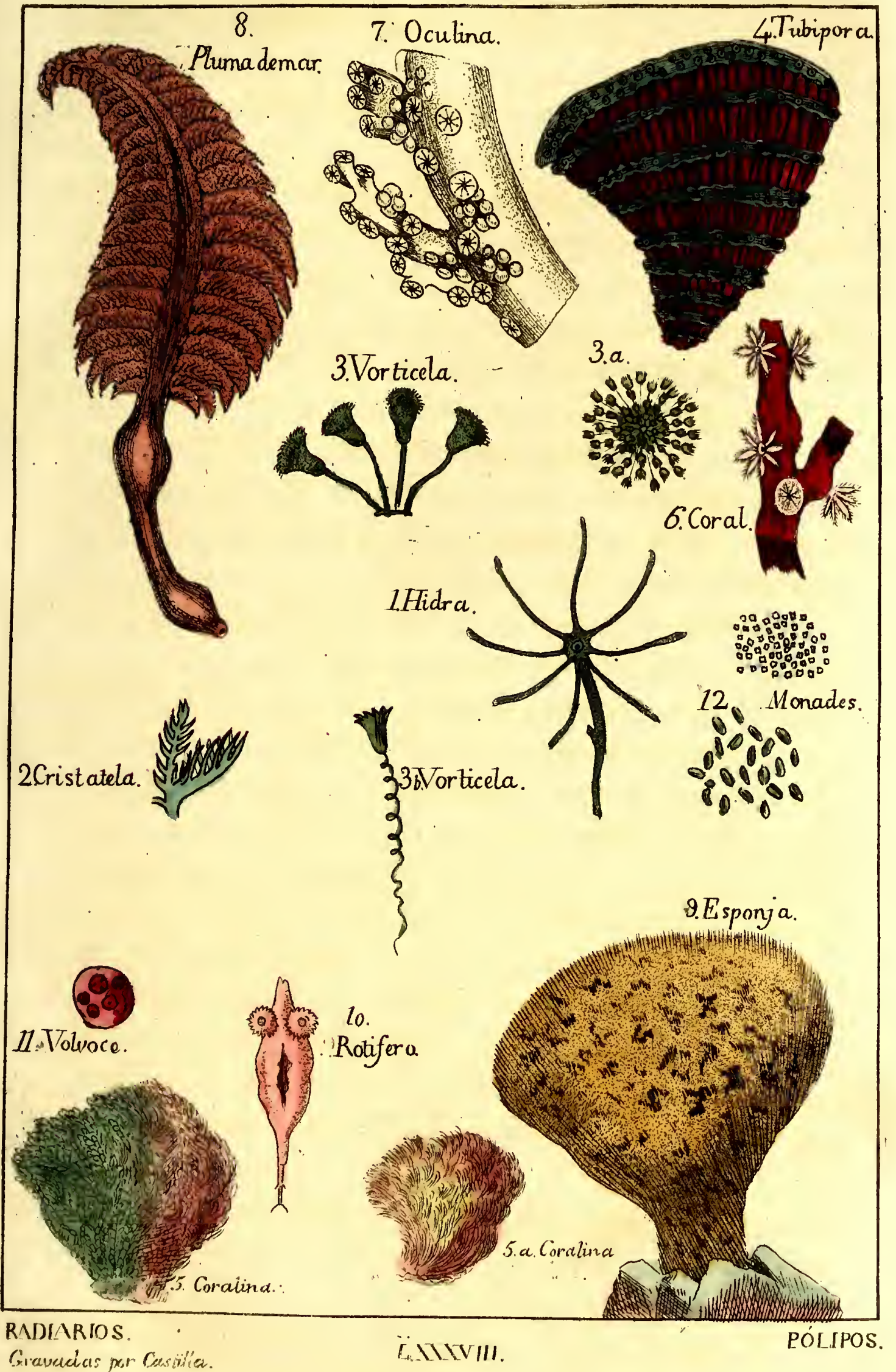



cogen sú presa, y son sensibles al menor contacto, y aun á la accion de la luz.

Basta para asegurarse de la sutileza de sú tacto el comunicar algunos mosimientos al agua en que moran; inmediatamente se les ve contraerse para sustraerse al peligro á que se creen espuestos. La luz produce, á lo que parece; sobre toda la superficie de. su cuerpo, el mismo efecto que sobre nuestros ojos, porque si se les priva de ella, poniendo un cuerpo opaco entre esta y el pólipo, este deja su lugar para ponerse en un sitio donde pueda recibir su influencia.

La fuerza de reproduccion en estos animales llega al mas alto grado. Cada tentáculo que se les quita se repara prontamente; $y$ aun se puede renovar la seccion cuantas veces se quiera sin que su energía reproductriz se debilite de un modo sensible. Se puede igualmente cortarles cualquiera otra parte de su cuerpo sin hacerles perecer; bien pronto cada porcion se vuelve un animal completo ; de suerte que pueden multiplicarse estos seres á voluntad por una simple seccion. Pero su generacion natural se hace por unas yemas ó hijuelos que salen de diferentes punios del cuerpo, sobre el cual forman como unas ramas.

Las hidras son en estremo comunes en la mayor parte de las aguas dulces; se encuentra principalmente una gran cantidad de ellas en los estanques; balsas y otras aguas encharcadas bajo las lentejas aguáticas que crecen allí en abundancia, y viven de los animalitos que atraen á su boca por medio de los tentáculos de que está rodeada.

Las especies mas comunes en España son la hidra verde (hid. viridis) cuyos brazos son mas cortos que el cuerpo, y la hidra pardusca ó polipo de brazios largos (hid. fusca) mas rara que la anterior y de color pardo. Sus 
brazos son mas de diez veces mas largos que el cuerpo; y este tiene como una pulgada.

§. II. Las CRISTATELAS (fig. 2.) (cristatella) llevan en la boca una especie de plumero formado de una doble fila de tentáculos que están colocados en un vástago comun, paralelos unos á otros ó formando pincel. Su movimiento le sirve al animal para llevar á la boca los cuerpecillos de qué se alimenta. Las cristatelas habitan las aguas estancadas y tienen un volúmén tan pequeño que un monton de ellas se asemeja á una mancha de moho. La principal especie es la cristatela moho (crist. mucedo) cuyo cuerpo comun tiene muchas bocas ó plumeros, y no en forma de un árbol dividido en ramas, sino en una sola masa redonda é irregular. Los plumeros parecen unos pein es con doble fila de dientes

§. III. La mayor parte de las hidras son visibles á simple vista; las vonticel As (vorticellas) (fig. 3.) son todas microscópicas y tan menudas, que apenas pueden verse montones que contengan muchos centenares de ellas. Pero cuando se examinan estos pequeños pólipós con el auxilio de una lente de aumento se les halla una figura muy análoga á la de los precedentes; esta es un tronco dividido ordinariamente en muchas ramas, de las cuales cada una terminá por un engrosamiento en forma de cucurucho ó de campana, de suerte que su cuerpo se parece á una planta adornada de flores, lo que les ha hecho dar et nombre de pólipos de penachos.ó de ramillete (fig. 3. y 3. a.) En el centro del engrosamiento terminal se encuentra la boca rodeada de muchas filas de tentáculos, dispuestos circularmente y dotados de una gran movilidad. El animal agita sin cesar estos órganos, para imprimir al agua un movimiento de rotacion, que lleva á su boca las moléculas organicas que tiene en disolucion. 
Las vorticelas son muy comunes en la mayor parte de las aguas dulces; se encuentran sobre los tallos de las plantas acuáticas, en donde se multiplican con rapidez prodigiosa y de un modo curioso. Una sola se divide primero en dos; algunos instantes despues cada fragmento se divide á su vez, y asi sucesivamente. Pero se propagan tambien por germenes y por yemas, como la mayor parte de los pólipos. Las especies de este género son la vorticela convalaria (vort. convalliaria) cuyas flores son en forma de campanilla sobre un pedúnculo arrollado en espiral (fig. 3. b.); la vorticela trompeta (vort. stentorea) que no tiene pedúnculo, pero que sc adelgaza formando cola; y la vorticela mora (vor. crotegaria) sin pedúnculos y reunida en masas que se parecen á unas moras. Su aspecto es como el de unos corpúsculos redondos.

\section{SEGUNDO ÓRDEN.}

\section{sIMPóLIPos.}

Se llaman simpólipos todos los radiarios cuya organizacion se asemeja á la de las hidras y otros animales análogos, pero que viven reunidos en mayor ó menor número en una habitacion ó polipero comun; estos son por consiguiente los pólipos de polipero.

Esta habitacion varia en su figura y en su naturaleza, ya blanda y flexible como el cuerno, ya dura y petrosa como la concha de los moluscos, está dispuesta de modo que todos los individuos que encierra, comunicando entre si sin tener necesidad de dejar su sitio, pueden tomar su parte del alimento que coje cada uno de ellos ó apropiárselo enteramente para sí.

No hay duda de que los pólipos libres del órden prece- 
dente inspiran un vivo interes por la sencillez de su estructura, unida á las costumbres tan variadas y tan curiosas como las que nos han presentado; sin embargo, los pólipos compuestos escitarán aun mas vivamente nuestra curiosidad. Q Qué admiracion no causa la vista de estos seres apenas bosquejados, reuniendo sus esfuerzos para cons. truirse una habitacion comun, en donde pasan toda su vida en la mas perfecta union! ¿ Hay nada mas admirable que esta armonía entre tantos animales diferentes, que digieren juntos los que cada uno de ellos absorbe en particular? $\mathbf{Y}$ como crecerá el interes que inspiran, cuando se sepa que estos seres tan pequeños por sí , forman, reuniendo sus fuerzas, políperos de muchas leguas de superficie cuadrada y de mas de diez metros de espesor? Aun hay mas, alguuos naturalistas pretenden que ciertas islas y escollos del mar del Sur han sido producidos por la acumulacion sucesiva de las habilaciones de estos zoófitos. Pero aunque esta opinion sea exagera$\mathrm{da}$, siempre es cierto que las habitaciones de los simpólipos dan origen á montones considerables de materia calcárea, y que au n formaban mas antiguamente, pues que se encuentran en el seno de la tierra capas en teras; que han sido evidentemente producidas por estos animales reunidos.

Pero no es solo por su estension por lo que los poliperos deben llamar nuestra atencion; su variedad, por decirlo asi, infinita, no debe admirarnos menos. Pueden ser blandos, córneos ó lapídeos, y en estos tres estados sus formas son igualmente variadas. Unos constituyen masas informes y groseras en las que no se encuentra simetría alguna ; otros estan divididos en ramas ó estendidos en forma de hojas largas y anchas, como los tallos de las plantas marinas y se asemejan tan bien á la forma de un vegetal, que se les ha mirado por mucho tiem- 
po como pertenecientes á esta parte del reino orgánico. Algunos forman unas membranas tan delgadas y tan delicadas, que parecen un fino encage, adornado de los mas brillantes colores.

Tales son las maravillas que produce un animalito casi microscópico por medio de una materia mas ó menos sólida que exhala, del mismo modo que el molusco segrega su concha.

Dividiremos este órden en dos familias, segun que el animal vive en una cavidad del polípero ó en la superficie de este último; estos son los tubiporéos y los corticiferos.

\section{PRIMERA FAMILIA.}

\section{TUBIPOI ÉOS. (Lám. XXXVIII.)}

Todos los pólipos de esta familia habitan las cavidades de su polipero, que ya son largas y estrechas como los tubos de órgano, ya irregulares y sin figura determinada. La naturaleza del polipero varia considerablemente segun los géneros, de los que los principales son las tubiporas y las coralinas.

§. I. Las tubIPoras (tubipora) (fig. 4) tienen un polipero de substancia lapidea ${ }_{1 .}$ compuesta de muchos tubos soldados entre sí por una argamasa de la misma naturaleza del polipero, y destinados á alojar cada uno un animal. Esta disposicion de los tubos ha hecho dar. á estas habitaciones el nombre vulgar de órganos.

La especie mas notable de este género es el órgano de mar (lubipora musica, L.) que es de un hermoso rojo, al paso que los pólipos son verdes; abunda en el mar de las Indias.

§. II. Las coratinas (corallina) tienen el polipero flexible y formado de muchos tallos articulados $y$ sos- 
350

tenidos por una especie de raices, de suerte que considerado en su tóalidad, parece una verdadera planta ; por esto se ha mirado por mucho tiempo como tal.

La naturaleza de este polipero es mas córnea que. calcárea ; algunas veces su superficie está enteramente cubierta de una materia sólida y gredosa, en la que se distinguen, por medio del microscopio, unas pequeñas células invisibles á simple vista. En cuanto al animal que le produce, nos es enteramente desconocido.

Se hallan las coralinas bajo todas las latitudes; pero son mas abundantes y de colores mas vivos en los mares ecuatoriales que en los de los paises templados. Estas son en general de un color rojizo ó purpúreo, que se oscurece por su esposicion al aire; pero las de los mares vecinos á la línea son naturalmente adornadas de colores mas vivos y aun de figura mas elegante que las nuestras. Todas estan adheridas á las rocas submarinas, de las que no se desprenden sino por el choque de algun cuerpo duro; porque son capaces de resistir á la violencia de las aguas revueltas por la tempestad. La especie mas célebre de este género es la coralina oficinal (corallina ofi-: cinalis, L.) (fig. 5.) cuyas porciones son en forma déóvalo invertido, las ramas pequeñas dispuestas como las hojas pinnadas y sosteniendo otras ramas ordenadas del mismo modo. Su color es gris, rojo ó verdoso. En el comercio se la encuentra blanqueada ya por la esposicion al sol ó al aire $y$ mezclada con otras especies entre las cuales es mas notable una que se asemeja á una planta de musgo (fig. 5. a.), y en la que no son muy aparentes las articulaciones. Todas ellas se administran indistintamente como vermífugo. 


\section{SEGUNDA FAMILIA.}

\section{CORTICífEROS. (Lám. $X X X V I I I$.}

En los corticíferos el polipero petroso ó córneo es constantemente sólido y revestido en su superficie de una capa gruesa de sustancia carnosa ó gelatinosa, en cuyas cavidades estan alojados los animales que le producen. Por formar esta capa blanda al rededor del tronco de los simpólipos una especie de corteza análoga á la que cubre los vegetales, se ha dado á los animales que presentan esta particularidad el nombre de corticíferos ó lleva-corteza.

Esta familia, mucho mas numerosa que la precedente, comprende al mismo tiempo especies mucho mas abundantemente esparcidas. En ella se encuentran estos monstruasos poliperos que se estienden muchas leguas cuadradas en el fondo del mar, y que forman, en el interior del globo, masas bastante considerables para que los geólogos hayan creido deber establecer un terreno madrepórico, casi esclusivamente compuesto de poliperos corliciferos. Aunque son comunes en todos los mares, son sin embargo incomparablemente mas abundantes en los mares meridionales que en los del norte. Parece que la influencia del sol y de la luz es indispensable para su desarrollo; porque ademas de lo que acabamos de decir sobre las latitudes bajo las que se encuentran estos animales, se sabe positivamente que, aun en los mares ecuatoriales no se encuentran á profundidades inaccesibles al calor y á la luz. Los fondos que distan mucho de la superficie del agua no ofrecen, por decirlo asi, ningun vestigio de ellos, á lo menos en el estado de vida.

Tomo III. 


\section{2}

Los principales géneros de esta familia son : los antipatos y las gorgonias, que se han llamado tambien ceratofitos, por tener el eje interior el aspecto de la madera ó del cuerno, y estar fijo; los isis, los corales, las madréporas y las miléporas que han recibido el nombre de litófitos por ser el eje interior de una sustancia lapídea y fijo; las pennatulas ó pólipos nadadores, los borbechos y las esponjas sin eje petroso ó córneo.

§. I. Los antipatos (antipathes) llamados tambien rulgarmente coral negro, tienen la sustancia del eje ramosa y de aspecto leñoso y cubierto de una sustancia tan blanda, que se destruye despues de la muerte. Asi es que parecen en los gabinetes unas ramas de leña seca.

Las principales especies de antipatos son el A. espiral (art. spiralis) cuyo tallo es enteramente sencillo y del grueso de un cañon de pluma; se arrolla irregularmente en espiral y tiene espinas pequeñísimas, y el $A$. en forma de abanico (ant. flabellum) que tiene el tallo mas corto y delgado. A ambos lados de este nacen ramos, que suben en el mismo plano, y se subdividen del mismo modo, representando una especie de abanico. $\mathrm{Mu}$ chas veces las últimas ramificaciones estan pegadas unas con otras. Esta especie es del mar de las Indias, pero la anterior se cria en diferentes mares.

§. II. Todo lo contrario que los antipatos tienen las gongonias (gorgonia) la sustancia leñosa ó córnea de su cje cubierta de una corteza, que está de tal modo incrustada de granos de arena, que se deseca sobre el eje, y conserva sus colores muchas veces muy vivos y muy hermosos; los pólipos tienen ocho brazos dentados y un estómago en una palabra, la misma estructura que los del coral. Las especies de gorgonias son muy númerosas, pero la mas principal es ta gorgonia en forma de abanico (gorgonia flabelum), en la cual cada ramita se une á la mas inmediata, y todás 


\section{3}

se quedan en el mismo plano, de modo que el conjunto forma un enrejado ó red á veces de algunos pies de. ancho y de largo, con la corteza amarilla.

§. III. Los ISIS (isis) tienen el eje ramoso sin impresiones ni células en su superficie, pero sí alternativamente compuesto de partes córneas como en las gorgoniàs, y lapídeas como en el coral. La corteza animal que le cubre, está sembrada de granos de arena como en lás gorgonias.

El coral negro y blanco (isis hippuris) que es la especie mas conocida, tiene las articulaciones calcáreas de color blanco limpio, y las córneas de pardo muy obscuro; lo que hace un hermoso contraste en esta especie que se cria en todos los mares.

§. IV. En los corales (coralium) (fig. 6.), todavía mas que en las coralinas, todo parece concurrir á favorecer el error de los naturalistas sobre la naturaleza de estos seres. Considerados en fragmentos mas ó menos gruesos, tienen por su dureza y por su aspecto bruñido la apariencia de un cuerpo inorgánico. Examinados enteros, parecen vegetales provistos de un tronco y de muchos ramos cubiertos de flores.

Todavia, un exámen atento podrá hacer conocer siempre la naturaleza del zoófito; no será dificil ver un polipero en el tronco y en las ramas, y pequeños pólipos en estas rosetas abiertas que los adornan con tanta gracia. Estos radios divergentes, que se tendrian por los pétalos de una flor, son otros tantos tentáculos, en cuyo centro se halla colocada la boca del animal.

Se encuentran los corales, cuyo número es bastante considerable, en los mares del mediodia, sobre cuyo fondo forman unas especies de cuadros de flores tan agradables por la diversidad de sus troncos como por el brillo de sus colores. 
La principal especie de este género es el coral del comercio, uno de los mas hermosos poliperos que se conocen; se asemeja hasta el punto de equivocarse á un pequeño arbusto, y sobre todo á una rama de albérchigo ó de almendro en flor. Fijado á las rocas submarinas por un largo pie que forma cuerpo con ellas, arrostra el furor de las tempestades y adquiere envejeciendo una dureza comparable á la del mármol ,y una altura de cerca de un pie. La profundidad de las aguas en que puede vivir è en estremo variable, pues se encuentran pies, desde treinta hasta doscientos metros de la superficie del agua; pero se observa que el que se saca de una gran profundidad es mas pálido y menor que el que crece cerca de la superficie del mar.

El hermoso color rojo de este polipero le hace buscar para hacer de él pequeños objetos de adorio, con especialidad collares y pendientes; estos adornos son muy de moda, principalmente en Turquía. Se hace la pesca del coral eu la mayor parte de las costas del Mediterráneo; para cogerlo, se sirven de pedazos de maderá atados en forma de cruz ó de estrella, en cuyo centro está rolocada una piedra gruesa. Por medio de una cuerda larga, se baja este aparato al fondo del agua eu donde se le lleva en todas direcciones; y en los movimientos que se le comunican arranca de cuando en cuando algunos pies de coral que se enredan en las estremidades de este aparato, y que se sacan sucesivamente.

La principal pesca de coral se hace en las costas de Berberia; tambien se pesca en las de Francia é Italia.

§. V. Las MAdRÉPORAS (madrepora) (fig. 7.) se parecen mucho á los precedentes por la naturaleza petrosa de su polipero; pero ademas de que la figura de este último presenta muchas mas variedades que en los 
córales, él animal que le construye es del todo diferrente, porque se parece á una actinia por su organizacion. Por lo demas, las madréporas están durante el estado de vida cubiertas como los corales de una corteza gelatinosa y organizada, toda sembrada de rosetas formadas por los tentáculos del animal.

Se cuentan un gran número de especies de este género, que se han dividido en muchos subgéneros, de los que los principales, son las oculinas, las madréporas propiamente dichas $\mathrm{y}$ las astreas. $10^{\circ}$ Las oculinas tienen un tronco $y$ ramas cortas, tal es el coral blanco (oculina axilaris). (fig. 7.) 2. Las madréporas son unas masas petrosas, cuya superficie está todá erizada de estrellitas de bordes salientes; á veces forman bancos muy considerables. $32^{\circ}$ Las astreas son unos poliperos de superficie plana ó globulusa, sem. brada de pólipos, cuyos brazos están dispuestos en una sola hilera. Se encuentran bajo la tierra capas muy considerables de ellas.

§. VI. Las MILÉPoras (millepora) son unós litófitos, cuyos receptáculos ó cavidades no son mas que unos simples poros ó águgeritos apenas perceptibles. Tambien hay muchas especies y variedades de miléporas, pero entre ellas se distinguen unas que son ramosas como la milépora sólida ó de diversas formas (millepora polimorpha) blanca, dura, con las ramas cortas; nume. rosas y de todas figuras. A simple vista no se perciben sus poros $y$ parece maciza; en algunos mares abunda tanto que la usan como cal. Otras son membranosas, y representan hojas irregularmente plegadas; tal es la milepora hojosa (mill. foliácea) hojosa, plegada y con poros por ambos lados; cubre las piedras, conchas \&c. Se halla en el mar de las Indias. Alguuas otras, en fin, son como redes; esto es, delgadas, planas, y con un 


\section{6}

grandísimo número de agugerítos que atraviesan de parte a parte; por egemplo, el mánguito de Neptuno.6 gasa de mar, (mill. cellulosa) que está sobre un pedúncuilo y se ensancha cómo un cáliz; sus paredes están plegadas $y$ taladradas de agugeritos tan espesos que parece un encage ó una red. Es comun en todos los mares.

§. VII. Mientras que los precedentes están todos fijos en el mismo sitio, las penNatulas (pennalula) (fig. 8.), aunque viven como ellos en un polipero comun, conservan' su libertad $y$ no contraen adherencia alguna con los. cuerpos sub-marinos; ellas nadan en el seno de las aguas por las contracciones de su cuerpo y por la accion combinada de todos los pólipos que habitan juntos.:

La figura de estos animales es muy notable. Su polipero es un tronco mas ó menos largo, guarnecido por dos ladós opuestos de unas especies de alas ó barbas, semejantes á las que se ven en las plumas de las aves. Entre estas barbas es donde están colocados los pólipos, que pueden á su volúntad ocultarse enteramente en su interior ó manifestarse en la superficie. Solo la parte inferior del polipero queda desnuda, to que le da una semejanza mayor con una pluma ordinaria, de donde le proviene el nombre de pluma de mar.

El animal que habita las pennatulas se parece mucho á los pólipos; tiene constantemente ocho tentáculos alrededor de la boca, y esparce durante la noche una viva luz fosfórica.

Se encuentran estos simpólipos en todos los mares; los mas comunes en los que bañan la España son la pennatula gris (penn. grisea) mas grande, de barbas anchas, mas espinosas y tallo liso, y la pennatula roja (penn. rubra), cuyo tallo es muy áspero por detras, entre las barbas. 
§. VILI. Los AEcionros ó berbechos (alcyanium) tienen el iaterior blando, quębradizo cuando está seco, com. puesto de fibras, finas, tiesas y divergentes que rodean á infinitos conductos, en medio de una sustancia gelatinosa. La cubierta es una corteza blanda, sin particulas calcáreasi, que al șecarse se hace coriácea y que está atravesada de celdillas de las que salen las cabezas de los pólipos que son como los de las pennatulas, de ocho brazos dentados $\mathrm{g}$ cuyos intestinos se prolungan en la masa de los ovarios.

Este género encierra algunas especies, de las que las mas comunes en nuestros mares son la maneta de mar ó alcionio çomun (alc. digitalum), que se divide en gruesas ramas, y el alcionio de ramas largas (alc. exos) que las tiene mas delgadas y de un hermoso color rojo. Ademas de estas hay otras notables por su forma globulosa, por egempla, la naranja ó criadilla de mar (alc. lincurium, L.) de figura irregularmente globulosa, vacia por dentro y pegada á las rocas por un punto solo: su superficie es blanca, y atravesada de muchos poritos; y el higo ó pelota de mar (alc. ficus, L.) que se parece á un higo ó á una pera: está pegado por un pedúnculo, y por la parte de arriba atravesado de una ó dos grandes celdillas. Tambien hay otras varias que se estienden formando como una corteza en la superficie de varios cuerpos como el alcionio con pezoncillos (alc, mamilosum), cuya superficie es carnosa, y que en su interior contiene una especie de arena fina; cubre las rocas y presenta pezoncillos espesos muy arrimados unos á otros, y atravesado cada uno de ellos de una celdilla cilíndrica,

§. IX. La naturaleza de las EsPonjas (spongya) (fig. 9.) está muy poco decidida, razon por la que los naturalistas han estado largo tiempo sin resolverse sobre el lugar que debian señalarles. Entre los antiguos, unos las miraban como animales, todayía bas. 
tanté bien organizados, pues que las creian capaces de mudar de sitio á su voluntad, mientras que otros las colocaban entré los vegetales. La mayor partè de los naturalistas modernos hán adoptado el modo de pensaride los primeros fundados en su opinion por los movimientos bien sensibles que el animal egecuta siempre que se le toca, y principalmente por su modo de reproduccion que se ha visto verificarse por huevos. "Seá como sea, estos seres ambiguos viven generalmente, en las aguas salädas, aunque tambien se han observado en las aguas dulces Son mucho mas abundan: tes en los mares ecuatoriales que en los que se acercan mas à los polos. Allí es donde adquieren su mayor desarrollo; algunas veces llegan á veinte pulgadas de altura. Se fijan en las rocas por medio de un pie ensanchado $\mathrm{y}$ alli se âdhieren con suficiente fuerza, para que el movimiento de las aguas no pueda desprénderlos. Pero las profundidades á que crecen varian considerablemerite: al paso que unos viven en las mayores, otros se mantienen sobre las rocas que las olas cubren y abandonan alternativamente. Abundan principalmente en los mares vecinos al ecuador.

Los animales de las esponjas son los mas sencillos que se conocen; en un principio están aislados, pero á medida que crecen, se acercan unos á otros, y concluyen por formar por su reunion una masa gelatinosa y uniforme, que cubre toda la superficie del polipero penetrando en los tubos que le forman, y cuya pared interior tapiza. Parece que se nutren aspirando las moléculas orgánicas contenidas en el agua, y espeliendo en seguida el resíduo de su digestion.

La principal especie de este género numeroso es la esponja comun, de la que la economía doméstica bace un uso tan frecuente. Se pesca en el Mediterrá- 


\section{9}

neô, y principalmente en las islas del Archipiélago griego, en donde es objeto de un comercio considerable. Se la busca zambulléndose, y cuando se ha sacado. del mar, se lava con muchas aguas para limpiarla la arena y la materia gelatinosa que la ensucian; en seguida se sumerge en una disolucion de cloro para emblanquecerla y quitarla el olor desagradable que exhala. 


\section{QUINTA CLASE.}

\section{Altrerozoologia}

ó

\section{HISTORIA NATURAL DE LOS MICROZOARIOS.}

Bajo el nombre de microzoarios, microscópicos, infusorios ó animalillos, se señala un gran número de animalitos esencialmente acuáticos que no se pueden percibir á simple vista, y en los que no se encuentra órgano alguno especial para la sensibilidad, movilidad, reproduccion y nutricion.

Por consiguiente son unos seres de una estructura casi homogénea, en los cuales la nutricion se limita á la absorcion que hacen sus poros esteriores de las moléculas orgánicas que el agua contiene en disolucion, y cuya generacion se verifica, ya por yemas, ya por una seccion mecánica.

Las propiedades mas notables de que gozan los $m i$ crozoarios. son en primer lugar un tacto de una delicadeza estremada y una contractilidad no menos desarrollada ; tambien aunque estos animales no nos presentan nervios ni músculos distintos de la masa del cuerpo, sienten y se mueven con una viveza que no se encontraria en seres mas elevados én la escala animal. Se les ve, por medio de un microscopio, agitarse en todaś direcciones en una gota de agua, para huir de un peligro ó para 


\section{1}

atacar una presa. Tienen la superficie esterna bastante sensible para conocer si se hallan en un sitio donde el líquido se evapora, y en donde se hallan en peligro de quedar pronto en seco ; en este caso se apresuran á pasar á unas aguas mas profundas para prolongar su existencia; porque ninguno de estos animales puede vivir fuera de este elemento. Luego que salen de él, se secan y pierden toda especie de movimiento, y aunque sé haya asegurado lo contrario, no vuelven á la vida despues de haber sido privados de ella.

Se divide esta clase numerosa, pero dificil de estudiar, en dos órdenes principales: los rotíferos y los gimnodéos.

1. Los rotiferos se conocen en que tienen constantemente algunos apéndices carnosos, ya alrededor de su. boca, ya en la estremidad posterior del cuerpo.

2. Los gimnodéos son mucho mas sencillos, y no presentan sino un cuerpo globuloso ú oval sin ninguna especie de apéndice anterior ó posterior.

\section{PRIMER ÓRDEN.}

\section{ROTÍFEROS.}

Bajo el nombre de rotíferos se conoce en gran número de microzoarios, cuya boca bien visible está rodeada, como la de las hidras, de un cierto número de apéndices en forma de rueda y muy movibles, y que ademas presentan en la parte posterior de su cuerpo una especie de cola destinada á favorecer los movimientos.

Su cuerpo es generalmente de figura oval y de consistencia gelatinosa ; se distingue en él fácilmente una boca, un estómago; un intestino, y muchas veces un 
ano cerca de la boca: Tambien ciertos observadores han creido notar en su cabeza unos puntos salientes que han tomado por los ojos. Por consiguiente son mucho mejor organizados que la mayor parte de los pólipos. Estos animales se aliméntan de pequeños microscópicos que atraen á su boca por el movimiento rotatorio de sus apéndices, y persiguen su presa con una agilidad y encarnizamiento increibles en estos animalillos.

Este órden se divide en dos familias, segun la naturaleza de la cubierta cutánea, á saber: los rolíferos propiamente dichos y los crustodéos, de los cuiales los primeros tienen el cuerpo completamente desnudo, mientras que los segundos le tienen cubierto de una especie de armadura crustácea.

\section{PRIMERA FAMILIA.}

ROTÍFEROS PROPIANENTE DICHOS.

Los rotíferos (fig. 10.) se colocan al principio de la clase de los microscópicos porque son superiores á todos los demas por el número y por el desarrollo de sus órganos. No forman simplemente masas homogéneas, pues se les encuentra una especie de cabeza con una boca rodeada de apéndices muy movibles, de los que se sirven para. hacer arremolinar el agua, de suerte que estos animales se aproximan bajo este punto de vista á los radiarios, y principalmente á ciertos pólipos.

Estos órganos, que son de la misma naturaleza que: lo restante de su cuerpo, parece sírven no solo para atraer el alimento á la cavidad digestiva, que existe evidentemente en todos los rotíferos, sino tambien para formar unas branquias imperfectas. Tambien se les encuentra un aparato circulatorio, y aun un corazon , en 


\section{3}

el que puede observarse la contraccion y dilatacion sucesivas. Por esta razon los rotíferos estan evidentemente mejor organizados que un gran número de animales de las clases precedentes, en los que no se ve vestigio alguno de aparato respiratorio ó circulatorio. Asi es que no se propagan por seccion como los pólipos; tienen ovarios, de los cuales salen los gérmenes que deben perpetuarlos. Por consiguiente se deberia colocarlos antes de muchas clases de animales radiarios; pero como no se puede observarlos fácilmente, porque es preciso para servirse del microscopio mucho hábito y práctica, se les incorpora ordinariamente en una misma clase con las especies del órden siguiente.

Se divide esta familia en muchos géneros; entre los cuales no citaremos sino los furcularios y los tubicularios, de los cuales los primeros tienen el cuerpo desnudo, y los segundos estan encerrados en un tubo análogo á el de las terebelas.

\section{SEGUNDA FAMILIA.}

\section{CRUSTODÉOS.}

Esta familia encierra los animales mas interesantes de su clase, en razon de que establecen el paso de los microscópicos á los branquiopodos de la clase de los crustáceos ; su cuerpo está en efecto protegido por una especie de cubierta semejante á la de las langostas de mar y cangrejos comunes, escepto que no ofrece jamas articulaciones trasversáles. Por lo demas los crustodéos son un poco mayores que las especies de las familias siguientes; se les encuentra siempre un órgano intestinal, una boca, y aun un corazon. La naturaleza de su cubierta se opone á que se nutran por absorcion; todos viven de 
presa, y los demas animales microscópicos son los que les sirven de alimento.

Esta familia es poco numerosa; nos contentaremos con citar de ella un solo género, el de los braquionos, del que se cuenta un gran número de especies.

\section{SEGUNDO ÓRDEN.}

GIMNODÉos.

Estos microzoarios son en general muy sencillos; se necesita mucho trabajo para reçonocer en ellos algun órgano interno, y nunca presentan en su superficie apéndice alguno análogo á los que hemos notado en las especies del orden de los rotíferos. Su cuerpo ofrece el aspecto de una jalea trasparente; y aunque está desprovisto de órganos locomotores, se mueve en el seno de las aguas con una agilidad sorprendente, sin que á pesar de esto la vista pueda distinguir, aun ayudada de un escelente microscopio, por qué mecanismo se efectúan estos movimientos.

$Y$ sin embargo estos seres tan mal organizados tienen una voluntad, se mueven en una direccion mas bien que en otra, evitan los obstáculos que les impiden dirigirse á su objeto, y procuran ponerse al abrigo del calor y de la luz, cuya influencia determina la evaporacion del líquido en que viven.

El órden de los gimnodéos se divide muy propiamente en dos familias, segun la figura de su cuerpo; la primera, la de los vibrionides, encierra las especies que tienen una figura larga como un gusano, y la segunda, la de los monadarios, se compone de los que son esféricos ó redondeados. 


\section{PRIMERA FAMILIA.}

\section{VIBRIONIDES.}

Esta familia poco numerosa comprende todos los gimnodéos, cuyo cuerpo lárgo ú oblongo se parece á el de una anguila, ó mejor á el de una pequeña lombriz. Aunque su organizacion sea un poco menos perfecta que la de los microscópicos precedentes, los vibrionides no dejan de presentarnos todavía algunos bosquejos de órganos para la nutricion y la reproduccion; la mayor parte de ellos nos ofrecen tambien una cola, y se mueven con agilidad por las ondulaciones de su cuerpo, que doblan en arco y estienden alternativamente, como lo hacen las anguilas, las culebras y los demas animales apodes cuando andan. Pero nunca tienen esos apéndices carnosos, de que se sirven los rotíferos para agitar el agua y moverse en su seno.

Entre los géneros de que se compone esta familia, solo citaremos los vibriones.

Los VIBRIONes (vibrio) son conocidos desde mucho tiempo bajo el nombre de anguilas microscópicas, porque en efecto tienen la figura larga de estos peces. Su magnitud, bastante considerable para poderlos ver á simple vista, y la rapidez con que se propagan en el vinagre y en el engrudo, han inducido á un gran número de observadores á ocuparse de ellos. Su cuerpo es anguiforme, grueso anteriormente y terminado en punta por su estremidad opuesta; todos tienen una boca distinta y un conducto intestinal, que se estiende por toda la longitud de su cuerpo; se reproducen por huevos, y aun por hijuelos vivos; en una palabra, parecen 


\section{6}

mucho mejor organizados que la mayor parte de los demas animales de la misma familia. Sus movimientos son vivos $\mathrm{y}$ rápidos, ya que persigan una presa, ya que procuren escapar de un sitio en donde el agua poco abundante les anuncia un fin próximo.

Estos vibriones estan muy esparcidos en la naturaleza, y se encuentran igualmente en las aguas puras y en los líquidos en fermentacion. La masa para hacer pan, el engrudo \&c. los producen en cantidades muy considerables. Entre las especies mas notables de este genero, citaremos el vibrion ó anguila del vinagre, el vibrion del engrudo \&c.

\section{SEGUNDA FAMILIA.}

s.

\section{MONADARIOS.}

Toman su nombre del griego monas, átomo, porque en efecto su cuerpo está reducido á un simple punto esférico ó globuloso, en el cual no se halla ni boca ni cola. Se nutren por una especie de imbibicion análogá á la que hace penetrar el agua en el interior de una esponja. En cuanto á sus movimientos, se efectúan por la contraccion de su piel, sin que ningun órgano muscular contribuya á ellos.

Esta familia comprende tres géneros principales: los vólvoces, los protéos y los monades.

§. I. Los vóLvoces ó esféricos (volvex) (fig.11.) forman un género muy notable por su figura esférica, por la falta de cola y por su estructura compuesta. Su cuerpo consiste en una especie de saco ó bolsa que encierra uno ó muchos glóbulos que estan continuamente en movimiento. Es muy curioso ver á este animalito, en el que se 
mueven en todas direcciones unas pequeñas masas redondas que parece obran con discernimiento, y se dirigen á un lado y á otro, mientras que el animal entero goza de su movimiento propio. Si se abre el saco que contiene los glóbulos, se les ve inmediatamente escaparse por la abertura que se les presenta, nadar aisladamente y concluir por formar una aglomeracion semejante á aquella de que habian salido.

Estos animales abundan en general en la mayor parte de las aguas corrompidas, y se forman continuamente en las infusiones de las flores, en donde se les ve rodar en todas direcciones con una gran rapidez, lo que les ha hecho dar el nombre de vólvoces, de volvere, girar. La especie mas comun de este género es el vólvoce esférula (fig. 11.), que se halla en otoño en las lagunas, estanques \&c.

§. II. No se puede asignar á los. Proteos una forma determinada, pues esta cambia á cada instante. Tan pronto es redondeada y recogida, como dividida $y$ subdividida en tiras del modo mas estraordinario.

§. III. Los Monades (monas) (fig. 12.) deben mirarse mas bien como el elemento de todos los cuerpos organizados que como animales verdaderos: son por decirlo asi unos átomos imperceptibles y homogéneos, en los cuales el mejor microscopio no puede hacer descubrir vestigio alguno de órgano particular. A pesar de esta scncillez de organizacion, los monades gozan de una movilidad prodigiosa. Cuando se examina una gota de agua, se perciben en ella una multitud innumerable de estos animalillos ó átomos globulosos, que ruedan continuamente unos sobre otros. Pero para que este movimiento se verifique es preciso que el animal esté sumergido en el agua; pues luego que queda en seco, cesa de obrar, y muere.

TOMo III. 


\section{8}

La principal especie de este género es el monade elemental, llamada asi por alusion á lo que acabamos de decir, que es el principio de toda organizacion. Una segunda especie es el monade polvo, que se encuentra, asi como la especie precedente, en todas las aguas, aun las mas puras.

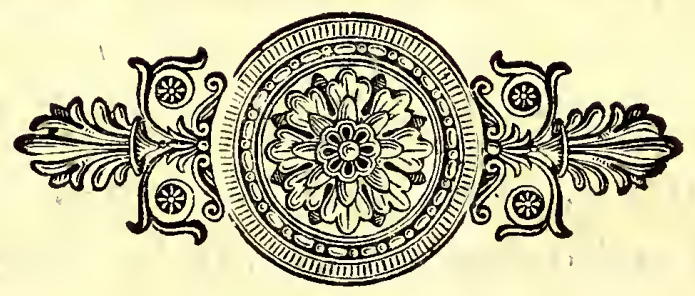




\section{SISTEMAS ZOOLÓGICOS.}

A medida que se van estendiendo los límites de la Historia Natural, por el descubrimiento de nuevas islas y continentes, por la perfeccion de los instrumentos de Física y las investigaciones de los sabios en los paises ya conocidos, los sistemas, segun los que se clasifican la inmensidad de seres que constituyen y pueblan la tierra, deben modificarse, variarse y aun sostituirse por otros mas perfectos. Asi á los grupos de Aristóteles y Plinio se han sucedido los de los otros muchos autores, y haśta el famoso siśtema de Cárlos Linn (I), ha sido generalmente reemplazado por el de Cuvier, que hemos espuesto con algunas ligeras alteraciones, como el mas exacto y al nivel de las actuales luces. Tal vez antes de mu-

(I) En latin Linnæus donde se ha formado el de Linneo. Este célébre autor fué profesor de Historia Natúral en la universidad de Upsal (Suecia). 
cho tiempo ceda su lugar al de Blainville ú otro, porque ademas de que todo cambia en la escena móvil del mundo, estamos todavía léjos de que los conocimientos humanos hayan llegado á su apogeo.

Pero limitándonos á hacer el paralelo entre estos últimos sistemas, se observará cuan defectuoso, aparece el de Linnéo en muchas partes, sea que se tome por punto de partida la duodécima edicion de su sistema naturæe de I 766 , ó la décima tercia corregida por Gmelin, é impresa en I 788 , que es de la que nos hemos servido.

Efectivamente, atendiendo Linnéo mas á las formas esteriores que á la estructura interna, ha debido separar seres en la realidad muy análogos y reunir otros muy diversos. Algunas veces tambien hasta la semejanza de las formas no se ha tenido en consideracion, porque dos ó mas de ellos tenian entre si relaciones por algunos caractéres aislados. En el órden de los próceres tenemos una prueba evidente de lo que aqui afirmamos. Los géneros Homo, Simia, y Lemur, aunque gozan de los atributos generales de los mamíferos, difieren bastante del Vespertilio, y solo se parecen algo por su sistema dentario. Pero si bien en los pri- 


\section{SUB-ÓRDENES Y GENERO}

es Vespertilio.

min
des
1 p
$s:$
me
n Iyrmeleon, Phryganea, Hemerobi bles me

ens, Ichneumon, Sphex, Scolia, Thy $y_{2}$, Mutilla os ;

am ................................. Géneros:

disr.

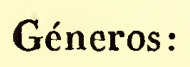

la 3 .......................... Ionoculus,

- le los animaIes........... Géneros: inguatula. occ syophyllus,

to maria, Pedicellaria, Ascidia, Sal /Holuturia, lelapia, Clio, Lobaria, Lernea, Scilhyssophora, Asterias, Echinus.

talium, Serpula, Teredo, Sabella.

do Nautilus, Conus, Cyprea, Bulla, lix, Nerita, Tellina, Cardium, Mactra, Donalus, Pinna. as, Pholas.

aralillepora, Madrepora.

exi Alcyonum, Spongia, Flustra, Tubu exia.

inos......................... Géneros.

ue esternos..................... $\longrightarrow$ io, Enchelis, 



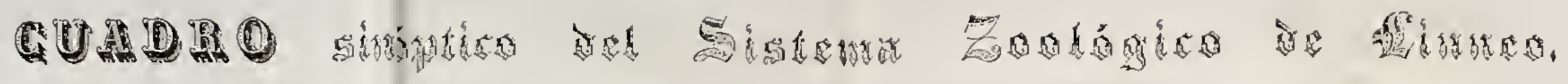

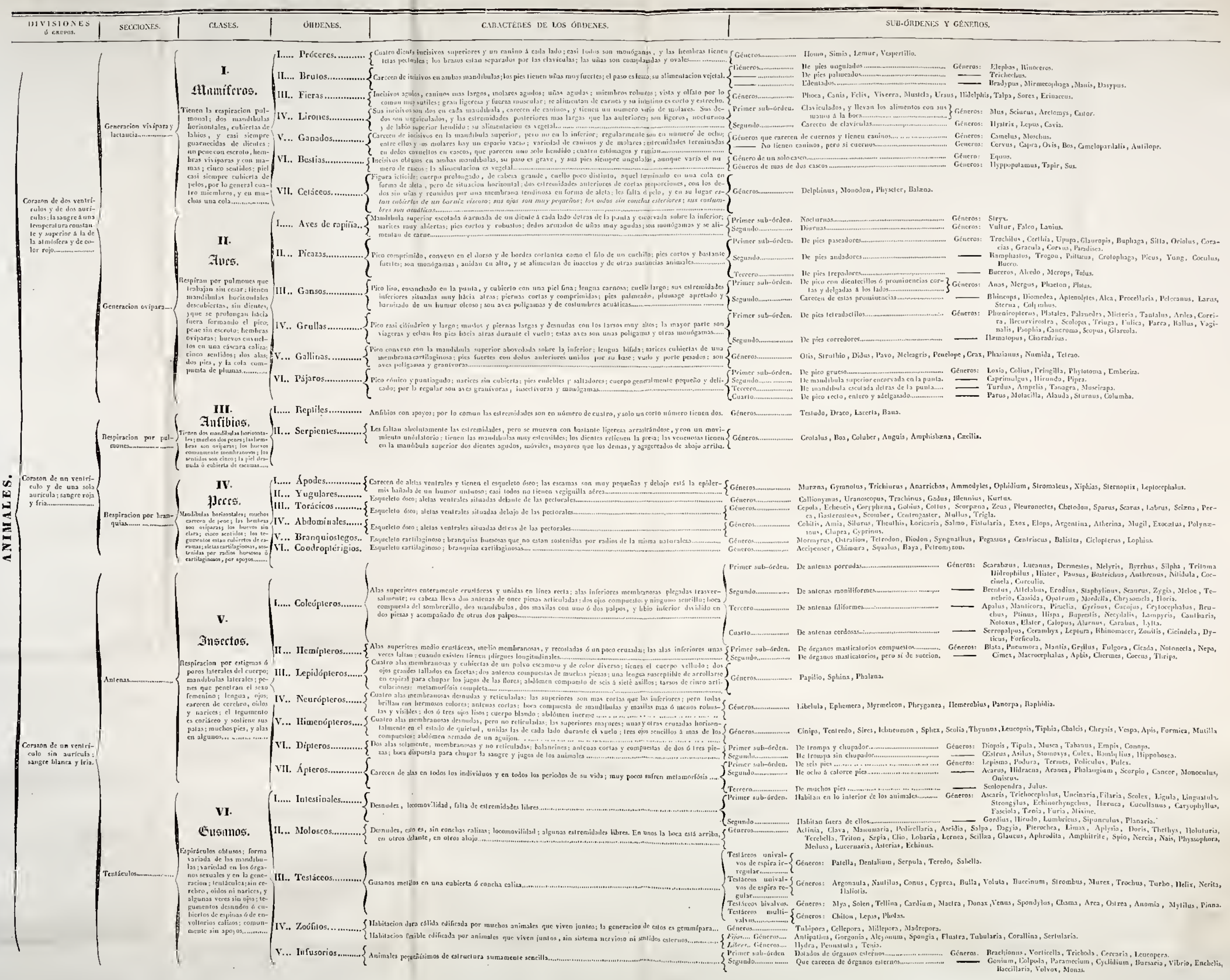


rabitacion fi

Animales peq 
meros grupos hay aglomeraciones impropias, y algunos seres mal colocados, en el de animales de corazon de un ventrículo sin aurícula y de sangre blanca y fria abundan mucho mas, y han sido tan manifiestas que los naturalistas posteriores se han visto precisados á separar animales tan heterogéneos. Los géneros Serpula, Térebella, Dentalium, Sabella , Amphitrite, Aphrodita , Lumbricus, $\mathrm{Ne}_{-}$ reis, Hirudo \&c., tienen sangre roja, y el primero, tercero y cuarto se hallan incluidos en los testáceos univalvos, al paso que los otros se encuentran en los moluscos con las actinias cuya organizacion es tan sencilla, con la Aplisia y el género Limax, que son unos animales de estructura mas complicada, dotados de órganos de los sentidos, de un tubo digestivo compuesto de diversas cavidades y órganos accesorios. Solo su blandura es lo único que puede hacerles comprender en una misma clase.

Mas no por esto en nada se empaña el brillo del ingenio del esclarecido naturalista sueco; pues él clasificó los seres segun los conocimientos que en un tiempo pudieron adquirirse, y no es culpa suya que los que se han conocido posteriormente no se hayan descubierto mucho antes. 
Fácil nos fuera de este modo proseguir la comparacion clase por clase, órden por órden, género por género, pero seria demasiado largo; mas como sea muy importante no dejar de hacerlo, seguiremos de otro método mas breve y ventajoso; por el cual se podra comprender cómodamente la relacion de tódos los grupos de ambos sistemas, al mismo tiempo que se dan los caracteres distintivos de todas las divisiones sirviendo asi de resúmen al sistema de Cuvier (I).

(1) Hallada esta relacion es facil clasificar cualquier gabinete por ambos sistemas y entender los libros que versan sobre objetos de Zoologia. 
CLASIFICA CION de los animales segun el sistema Cuvier modificado por Salácroux y correspondencia de sus divisiones con las de Linnéo.
Divisiones.
Caracteres.
Corresponden en Linnéo.

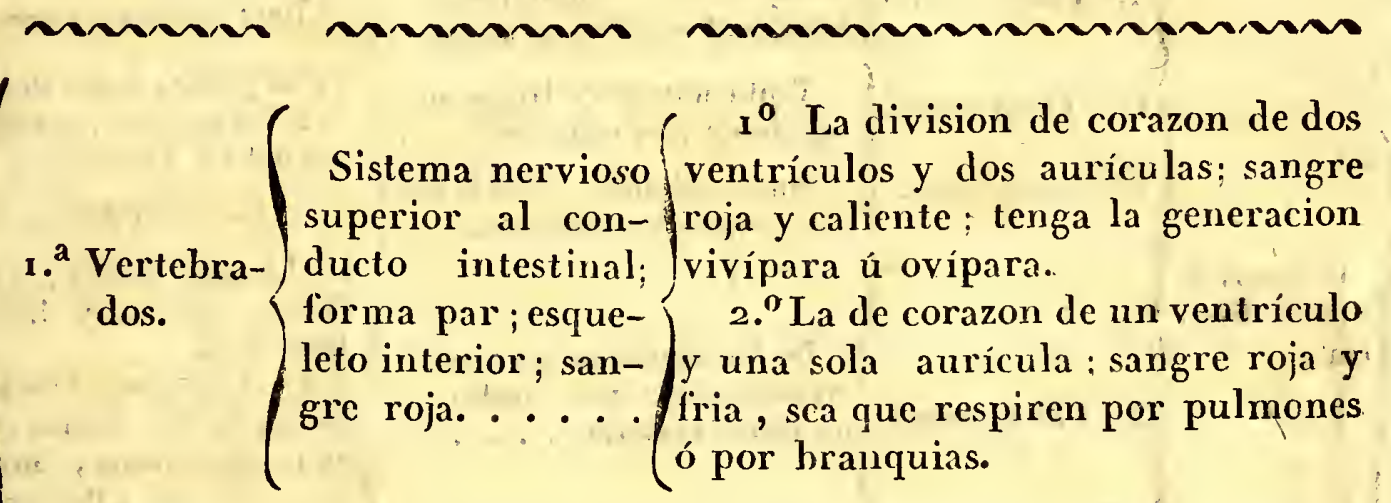

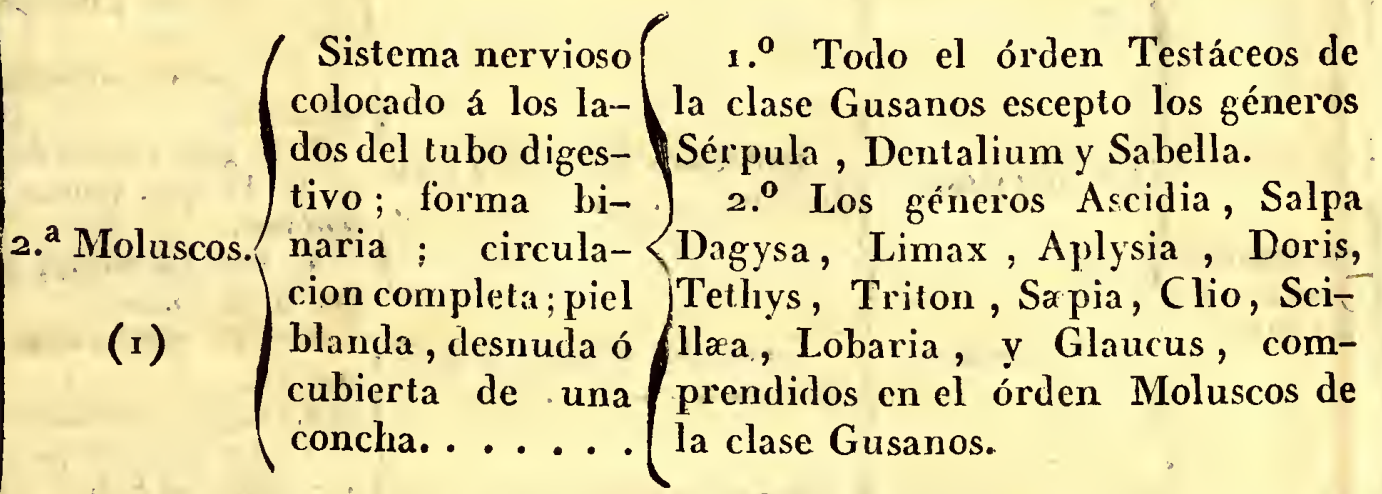
\{

3. ${ }^{2}$ Articnla-

Sistema nervioso debajo del conduc1. Toda la clase insectos. 2: Los géneros Hirudo, Gordius y Lumbricus, del órden de los Intestinales. 3. Los géneros Aphrodita, Amdos. $\mid \begin{gathered}\text { ma binaria ; par- } \\ \text { tes duras al } \\ \text { terior... } . . . . . .\end{gathered}$ phitrite, Nereis, Nais, Terebella, Spio del órden Moluscos. 4. ${ }^{\circ}$ Los géneros Sérpula, Dentatalium y Sabella del sub-órden de los Testáceos univalvos de la clase Gusanos.

Sistema nervioso r. $^{\circ}$ Los géneros Planaria y Sidispuestocircular- punculus del órden Intestinales y mente al rededor todos lo gen. del mismo órden que $40^{2}$ Radia- $\left\{\begin{array}{l}\text { de la cavidad di- } \\ \text { gestiva; forma ra- }\end{array}\right.$ habitan el interior de los animales. 2. Los géneros Actinia ; Pedicerios. diada; órganos circulatorios y respiratorios ningunos pha , Holuturia , Lernea, Physophora, Medusa , Lucernaria, Asterias y Echinus del órden Moluscos. 6 poco distintos... 3. Los órdenes Zoófitos é Infusorios de la clase Gusanos.

(1) Nota. Las tres últimas divisiones formaban en Cuvier la de los invertebrados que luego subdividia en las mencionadas. 

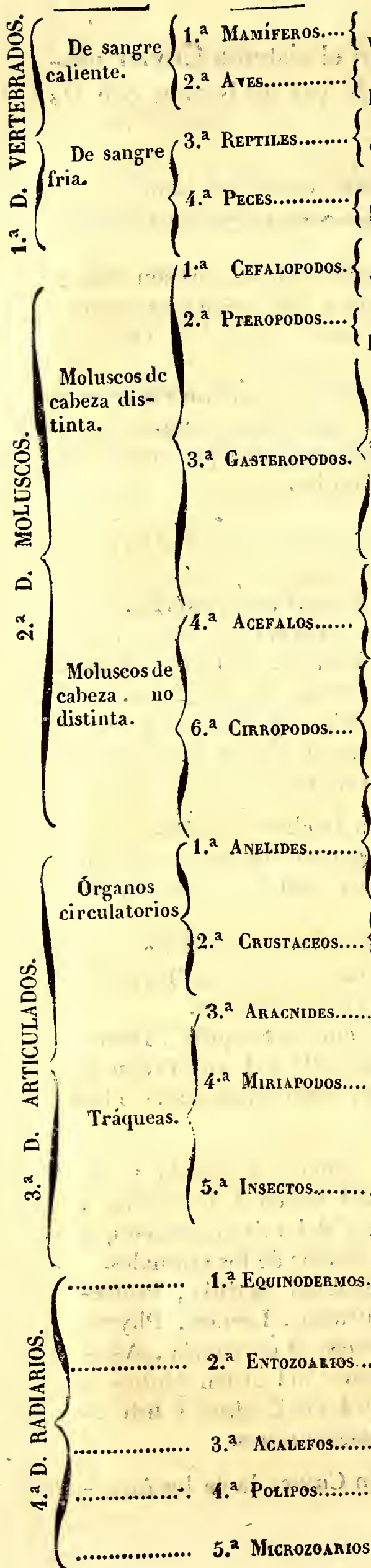
<

3. ${ }^{\mathrm{a}}$ Aracnides.
Tienen mamas y pelos, y son viviparos.............. $\{$ Carecen de mamas, y son ovi- \{ paras, plumas, alas y pico. $\{$.

Respiracion pulmonal é incompleta ; cuerpo desnudo ó es-\{ camoso; son oviparos. ..... Respiracion branquial; miembros conformados en aletas. \{ Tentáculos muy largos sir- \{ viendo de pies ó brazos. ... Sin tentáculos y nadando
por medio de membranas. .

De tentáculos muy cortos y arrastrándose por medio de $20^{\circ}$ Los gén. Trochus, Turbo, un disco carnoso. ...... Helix, Nerita, Conus, Cypræa, Voun disco cara.... luta, Buccinum, Murex, Strombus, Haliotis, Patella, Chiton de los Testaceos.

1. ${ }^{\circ}$ Todo el subórden de los Test. bivalvos.

$2 .{ }^{\circ} \mathrm{El}$ gén. Teredo de los unisalvos.

Tentáculos̄ningunos ó poco distintos. 3. E. Eén. Pholas de los multivalvos,

4. ${ }^{\circ}$ Los gẻn. Salpa ; A scidia y Dagia del 0 . Moluscos.

1. ${ }^{\circ}$ El gén. Lepas de los Test. Tentáculos córneos y arti- $\left\{\begin{array}{c}1 . \\ \text { multiv. }\end{array}\right.$

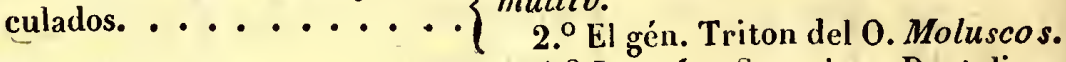

1. Los gén. Serpula, Dentalium (Órganos circulatorios, san- $\left\{\begin{array}{l}\text { y Sabella del Subor. Testaceos uni- } \\ \text { valvos. }\end{array}\right.$

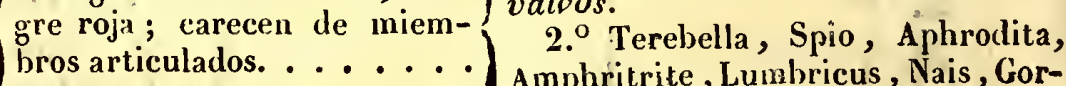
\begin{tabular}{cl|l} 
bros articulados. ...... Amphritrite, Lumbricus, Nais, Gor- \\
dius y Hirudo del O. Molu scos.
\end{tabular} $\left\{\begin{array}{l}\text { Órganos'circulatorios; sangre Los gén. Cancer, Monoculus, y } \\ \text { blanca; branquias; miembros }\{\text { Onís :us del } 0 . \text { Apteros de la Clase }\end{array}\right.$ articulados. ........ insectos.

Sin alas, ni antenas; cabe- Los gén. Aranea, Scorpio, Phaza confundida con el pecho; $\{$ langium, Hidracna, Acarus del 0. miembros articulados. .... Ápleros de la clase lnsectos. 4.a Miriapodos.... $\left\{\begin{array}{c}\text { Cuerpo compuesto de una sc- } \\ \text { rie de anillos semejantes, sos- } \\ \text { Los gén. Scolopendra y Julus del }\end{array}\right.$

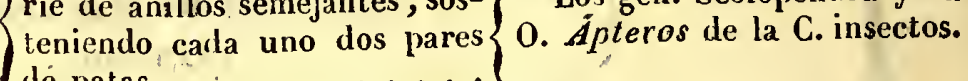

de patas. ..........

Cuerpo dividido en tres par- Todos los órdenes de la C. insec$5 .^{\text {a }}$ Insecros a....... tes distintas: cabeza, torax y tos, escepto los géneros incluidos en abdomen; miembros articula- $\{$ las dos clases precedentes de Cuvier.

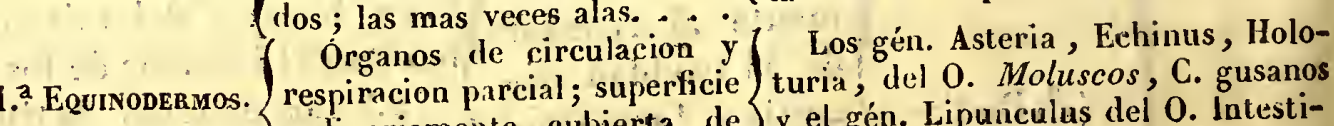
ordinariamente cubierta de y el gén. Lipunculus del 0 . Intesti(espinas. . . . . nales. 2. ${ }^{a}$ Evrozosatos... $\left\{\begin{array}{c}\text { Figura prolangada sin ór- } \\ \text { ganos de circulacion y respi- } \\ \text { intestinales, el gén. Planaria del } 20^{\circ}\end{array}\right.$

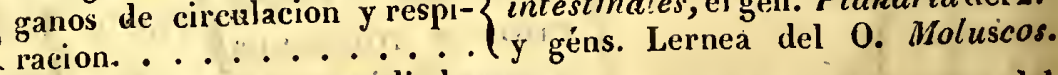
Forma circular y radiada Los gén. Medusa y Physophora del

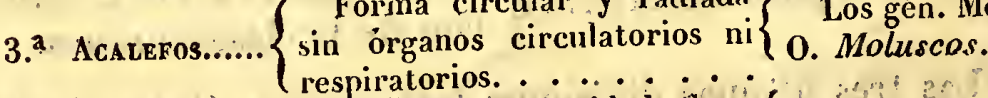

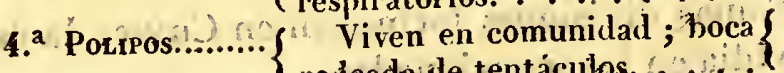
routenda de tentáculos.

Todo el órden. Zoófitos.

$5 .{ }^{2}$ Microzonros. $\left\{\begin{array}{c}\text { Animales pequeńos, mi- }\{\text { Todo el órden. Infusorios. } \\ \text { croscopicos }\end{array}\right.$ 


\section{ÓRDENES; FAMILIAS, TRIBUS y GÉNEROS.}

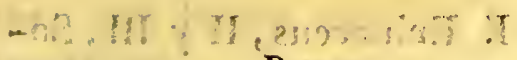

$-u \cdot 2 \cdot \mathrm{e}$ to Division.

Caricteres:

ORDENÉS.

- Corkesponden eN Thanea:i)

)

$\iint_{0}^{d}$

Dienteg $\left\{\begin{array}{l}\text { solamente......... } \\ \text { En Lo pies y }\end{array}\right.$

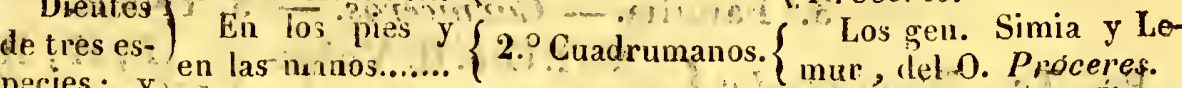

Unguicu-
lados. De raenos, De caninos sola-

pulgáres f En los pies so- ( Todo el $0:$ de Fieras separados. lamente........... $30^{\circ}$ Carniceros.... y el gen. Vespertilio del

(a) ${ }^{2}$ (chus del O. Erulos.

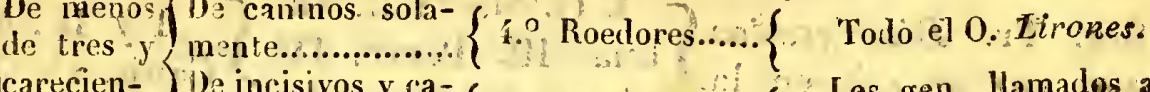

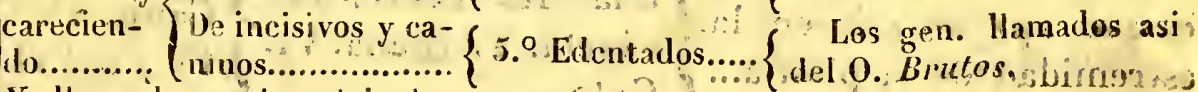
Y llevando en la pelvis do Yhesos para sostener la bolsa
abdominal. $\left\{\begin{array}{l}\text { o Marsupiales.. } \\ \text { O. Fieras. Didelphỉs del }\end{array}\right.$

2x.2.

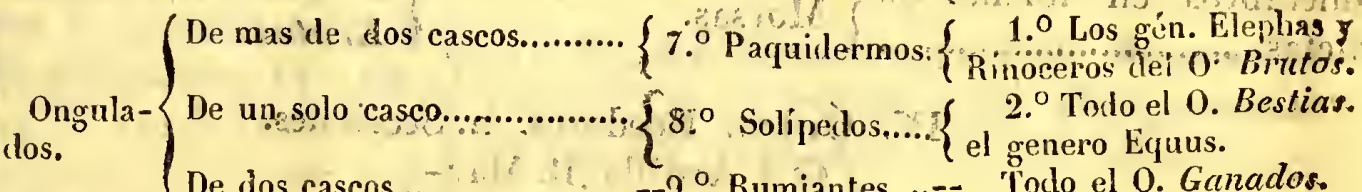

De dos miembros solo, anteriores;

los postèriores formando unaj cola ic-

tioide pero horizontal y todos dispues-

tos en a'etas.

1. Óden. Bimanos. Una sola familia. (1).

Género único. Hombre equivale al gen. Homo del o. Próceres de Jin.

Todo el 0. Cetciceos.

IL Ordent $\int 10^{\mathrm{a}}$ Mones de forma parecida a la del hombre uńas aplastadas en todos los dectog. 2. a Makis hocico puntiagulo ; ñas agudas en

1. ${ }^{2}$ Familia.-2. Monos.-2. Tribus.

6ri, Tr. Catarrinos ó monos de C Géneros. I. Orang. 11. Gibon. III. Mico. aberturas de la nariz abajo....... IV. Cinocélalo. V. Semnopíteco. VI. Ma- C FI gen. Simia; Seg. Tr. Platirrinos ó de aber-\{ caco. turas de la nariz al lado. Géneros. 1. Sapaju. Il. Sagüina III. ceres. de 4 .
Vistiti. 2. ${ }^{\text {F }}$ Fmilia Makis.

Géneros. I. Indris. II. Makia. III. Loris. IV. Galago. V. Tarsero EI gen. Lemur $\left\{\begin{array}{l}\text { del O. Proce- } \\ \text { res de L. }\end{array}\right.$

C 1. ${ }^{\text {a }}$ ueiropteros que tienen un repliege de la piel estendido ni. Orden Carniceros 3. fam. entre sus cuatro niembros.

2 ? Iiscectivoros cuatro miembros libres y aptos para andä. 3. ${ }^{\mathrm{a}}$ Carnivoros cuatro miembros líbres; molares con tubér culos obtusos y cortantes.

1. ${ }^{\mathrm{a}}$ Familia - Queiropteros $=2 \mathrm{Tr}$.

Pr. Tr. Galeopitecos ó dé

repliegue lateral que no for- $\{$ Género único. Galeopiteco.
ma ala, y sí un para caidás.' Seg. Tr. Murcielago ó de ra- Géncros. I. Téropo. II. Filostomo. III. Ri- $<$ tilio del O. Prá

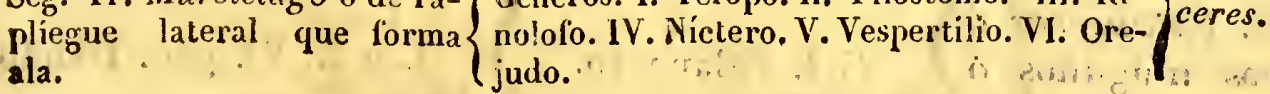

(1) Nota. No se especifican las correspondencia de las familias por cvitar repeticiones puestas aqnellas se deducen de los géneros que estas abrozant: 


\section{2. ${ }^{2}$ Familia Insectivoros.}

Géneros. I. Erizo II. Mușaraña ............................. \{ III. Migal. IV. Topo 3. Familia. - Carniceros. - 3. Tribus.

I. Erinaceus, II y III, Sorex, IV. Taspa del O. Próceres de Lineo.

Pr. Tr. Plantigrados $\left(\right.$ G. I. Oso. II. Vulpe- $\int$ I, II, III, y IV. el gén. o que apoyan toda la plan- \{ ta del pie para andar.......

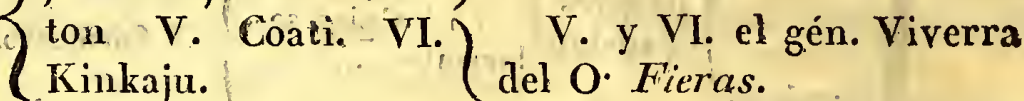

Seg. Tr. Digitiorcidos $\left\{\begin{array}{c}\text { I. G. Marta. II. Nu- } \\ \text { tria III. Perro.- IV. }\end{array}\right.$ I y II, Mustela.'III. y V. que se apoyan solo en la tria III. Perro. IV. $\{$ Canis. IV. Viverra. VI. Feestremidad de la planta... (Gato Ter. Tr. Anffbios, ó de $\quad$ G. 'I. Phoca II.
miembros en forma de lis, del O. Fieras. alétas Morsas.

I. Phoca del O. Fieras. II. $\left\{\begin{array}{l}\text { el 'gen." Trichechus / del } 0 . \\ \text { Brulos. }\end{array}\right.$

IV. Órden. Roedores. "2. Sècciones.

G.I. Ardilla. II. Mar-(

mota. III. Liron. IV. I. 'Sciurus. II. "Arctomis.

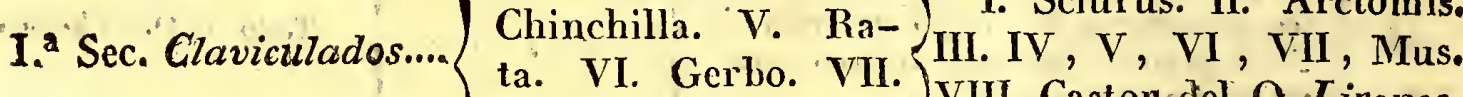
ta. VI. Gerbo. VII. VIII. Castor del O. Lirones.
Rata-topo. VII. Castor.

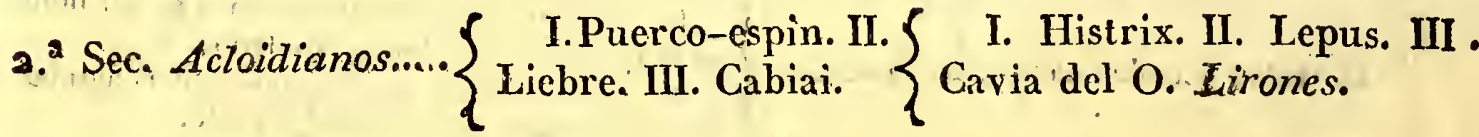
V. Órden. Edentados. - 2. Familias.

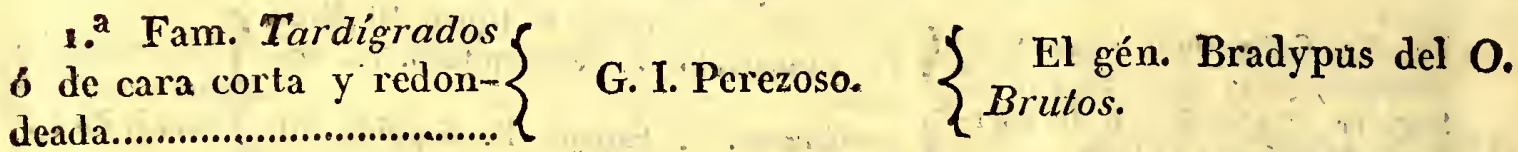
2. ${ }^{\mathrm{T}}$ Fam. Edentados 5 G.I. Tato.II. Pan- I. Dasypus. II. Manis. III. propiamente dichos ó de $\left\{\begin{array}{l}\text { galin. III. Hormigue- } \\ \text { ho. }\end{array}\right.$

VI. Órden. Marsupiales, - 5. Familias.

$1{ }^{2}$ Familia, pedimanos miembros terminados por

2. ${ }^{2}$ Fam. Tilacineos óde caninos igualmente largos; \{ y sin pulgar oponente en los miembros posteriores..

3. Fam. Falangeros ó de incisivos nìngunos ó muy pequeños; miembros terminados en manos.t.me

\section{G. I. Zarigueya. $\{$ I. Didelphis del O. Fieras}

G. I. Tilacinos. II. Sin correspondencia en Dasiuro. IIII. Pera- Linneo, pero algunas espemel.

G I. Falangero. II. Petaurista. cies har sido clasificadas èn el gén. Didelphis del O. Fieras.

I. y II. El. gén. Didelphis del O. Fieras. 
Fam. $4^{\mathrm{a}}$ Macrotarsos 6 de estrem. post. 2 ól3 aves mas largas que las.) gurú. anteriores.

Fam. 5. Monotremos. 6 de mandíbulas en forma de pico y sin dientes y cola como las aves.

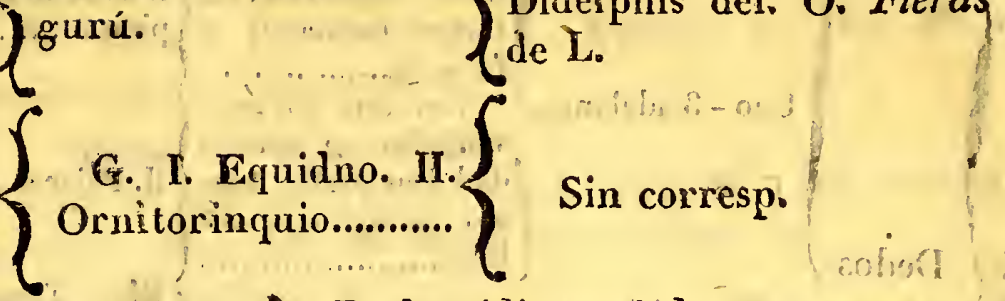
VII. Orden.Paquidermos. 2. fam. $\left\{\begin{array}{c}x a^{2} \text { Proboscidianos } b^{\prime} \text { de trompa. } \\ 2 .^{2} \text { Paquidermos propiamente dichos, } \\ \sin \text { trompa y menos dedos. }\end{array}\right.$ Fam. $x^{\text {a }}$ Proboscidianos.

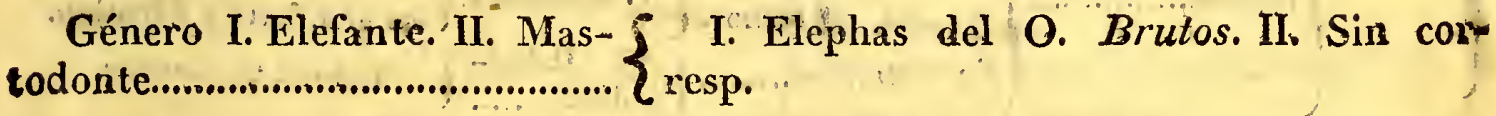

\section{Fam 2. Paquidermos.}

Géncros I. Rinoceronte. II. Tapir. III. Paleoterio. IV. Hi- $\int$ I. El gén. Rïnoceros. del O. Brulos. II. popótamo. V. Cerdo. VI. Ana- Tapir. IIf. sin corresp. IV. Hipopotamus. ploterio V: Sus del O. Bestias. VI. 'sin corresp.

VIII. Orden. Solipedos. un so- $\{$ Equus del O. Bestias.
o gén. Caballo................................

IX. Orden. Rumiantes. 2. fam. $\begin{cases}10^{a} & \text { Sin cuernos. } \\ 2 .^{a} & \text { Con cucrnos. }\end{cases}$

\section{Fam $\pm 0^{2}$ Rumiantes sin cuernos}

Géneros I. Camello. II. Lla- $\{$ I. y II. Camelus. III. Moschus del O. Gaw ma. III. Cervitillo......................... $\{$ nados.

Rumiantes $2 .^{2}$ con cuernos. 3 Tribts.

Pri. Tr. R. de $\{$ Gén. único. Ciervo...... $\{$ Cervus del O. Ganados. Seg. Tr. R.
de cuernos per- $\{$ Gén. I. Girafa.......................
sitentes............... sitentes. de cuernos ca- $\{$ Gén. I. Antilope. II. Ca- $\{$ I. Antilope. II. Capra. IIr. ducos.................. \{ $\{$ bra. III. Oveja. IV. Buey: Ovis: IV. Bos del O Ganados.

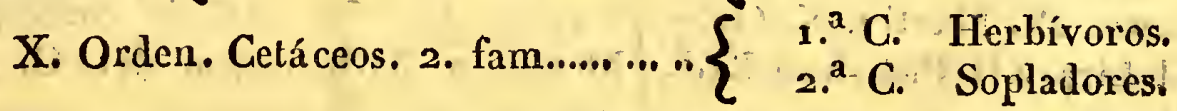

Fam. 1. ${ }^{a}$ Cetáceos herbicoros."

Género único. Manati........... \{ $\begin{aligned} & \text { Comprendido en el gén. Trichechus del } \\ & \text { Orutos. }\end{aligned}$

\section{Fam. 2a Cetáceos sopladores. 2. Tribus}

Pr. Tr. Delfinoides ó de cabeza pequeña y forma de delfin.

$$
\begin{aligned}
& \text { I. Delfin. II. Marsopla. III. } \\
& \text { Narval.......................................... } \\
& \text { I. Cachalote. II. Ballena,........... }
\end{aligned}
$$

Seg. Tr. Macrocé-

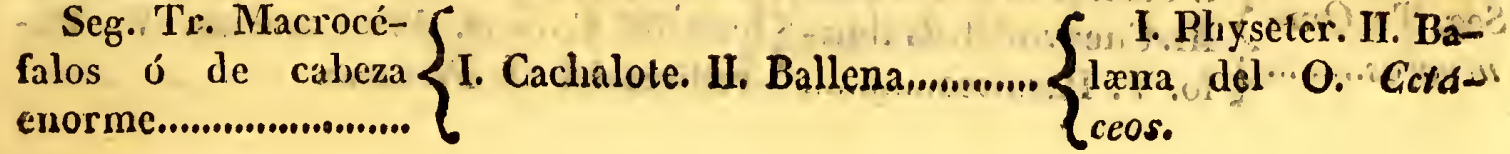
III. Monodon del 0 . Cetácios 


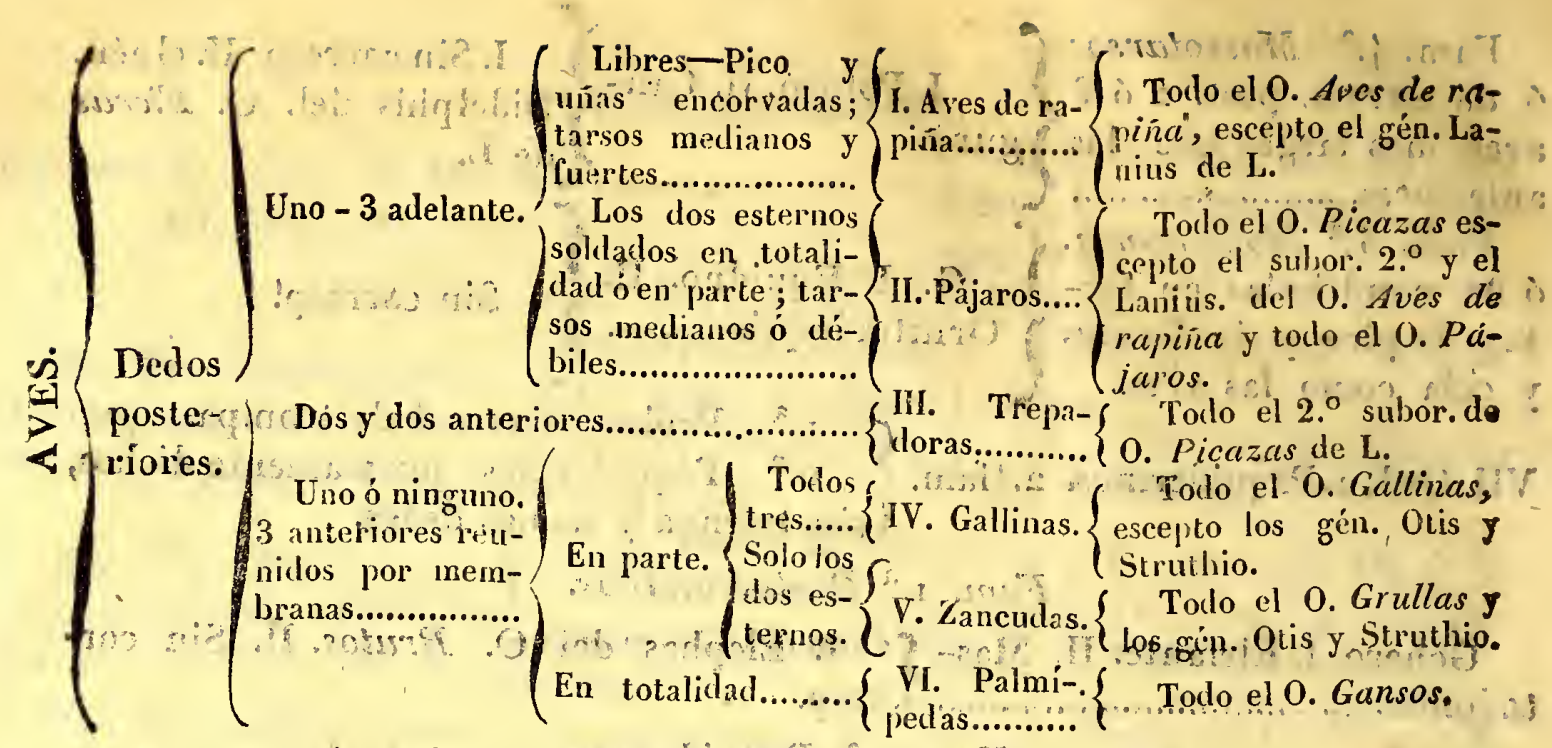

1. Orden. Aves de rapiña. 2. familias. ${ }^{\mathrm{a}}{ }^{\mathrm{D}}$ Diurnas. $2{ }^{\mathrm{a}}$ Nocturnas.

Fam, $10^{\mathbf{a}}$ Diurnas.

Géneros I. Buitre II. Aguila. III. \{I. Vultur. II. III. IV. y V. Falco del O. Azor. IV Halcon: Vi Mensagero........ \{ A Aes de rapiña de $\mathrm{L}$.

Fam. 2. ${ }^{\text {a }}$ Nocturnas.

Género único. Buho

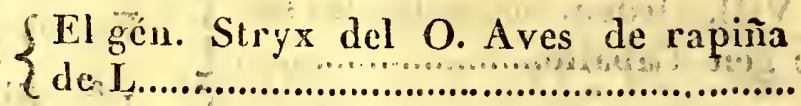

1. Dentirostres ó de cscotädura en el pico ; dédómedio y esterno separados.

2. ${ }^{a}$ Fisirostres ó de picocorto: sin escotadura, encorvado ymuy hendido: a las mas largảs que la cola.

II. Órden. Pájaros. 5. fam.

3. ${ }^{\mathrm{a}}$ Conirostres ó de pico fuerte., cónico ý sin escotadura ce la panta.

4. Tenuirostres ô de pico delgado casi siempre largo y sin escotadura.

5. Sindáctilos ó de dedo medio y esterno casi siempre reunidos.

\section{¿ Fam. 1" Dentirostres.}

Géneros. I. Pegareborda. II. Pa- (I. Lanius. del O. Aves de rapiña. pamoscas. III. Cotinga. IV. Tangara. II. Gracuela del O. Picazas de L. II. MuV Mirlo. VI.Hóniguero. VII. Cinclo scicapa. MII Cotinga. IV Tanagra V. Ta VIII. Maiņato. IX. Martị. X Oro- Turdus. VI. VII. VIII. sin corresp. XII." péndola. XI Gira. XII. Piço-fino. XIII. Motácilla XIII. Pipra. dél O. PájaManaquí.................................................. ros.

\section{Fam. 2. Fisirostres.}

Géneros I. Golondrina. II. Ve- II. YI. Hiruudo. III. Caprinulgus del O. ncejo. III. Chotacabras........................ \{ P Pujäros de L.

\section{Fann $3{ }^{a}$ Conirostres. 2. Tritus.}

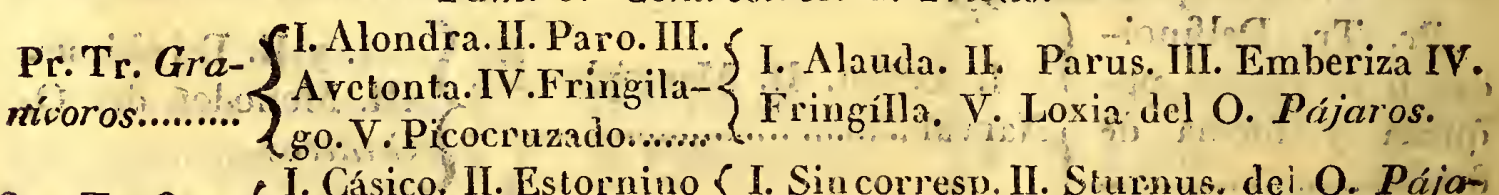
Seg. Tr. Om-3 I. Cásico. II. Estornino $\left\{\begin{array}{l}\text { I. Sin corresp. II. Sturnus de O. O. Pájó- } \\ \text { ros III. Corvus." IV: Coracias. V.: Pa- }\end{array}\right.$

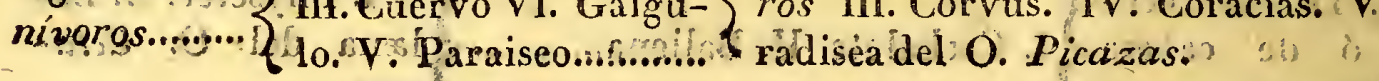
.2237 ! 
Fam. $4^{\text {a }}$ Tenurostres.

Géneros. I. Sitela. II. Tŕepador. III. Y I. Sitta. III. Certhia. III. sin corresp. IV. Süimanga. IV. Colibrí. V. Abubi- $\left\{\begin{array}{l}\text { Trochilus. V. Upapa. del O. Pica- } \\ \text { zas de }\end{array}\right.$ lla

\section{Fam. 5. Sindactilos.". in}

Géneros: I. Abejaruco. II. Alcion. \{ I. Merops. II. Alcedo. III. sin corresp. III Momot, IV. Calao IV. Buceros del O. Picazas.

III. Orden. Trepadoras una sola familia.

Géneros. I. Jacarna II. Pico. III. (I. Sin Correspondencia. II. Picus. Tuercecucllo. IV. Cuclillo. V. Barbudo. Vr. Curucú VII. Anis. VIII. Ju can. IX. Papagayo. X. Turaco.......... VIII. Ramphastos. IX. Psiltacus del O. Picazas.

1. ${ }^{a}$ Gallinaceas propiamente dichas

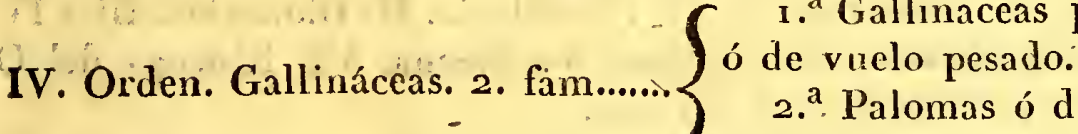

$\left\{\begin{array}{l}2 .{ }^{\mathrm{a}} \text { Palomas ó de dedos libres en su } \\ \text { base y vuelo sostenido. }\end{array}\right.$

Fam. 1. ${ }^{a}$ Gallináceas.

Géneros. I. Alector. II. Pavoreal. III. $\int$ I. Crax. II. Pavo. III. Meleagris IV. Pavo. IV. Pintada. V. Faisan. VI. $\{$ Numida. V. Phasiauns VI. y VIII. TeTetras. VII. Ganga. VIII. Perdiz.......... tras "del O. Gallinas VII. sin corresGerendencia.

Género único. Paloma....................._- Columba del O. Pájaros de L.

Fam. 2." Paiomas.

1. Brevipennas ó de pennas cortas y de barbas separadas.

2. Presirostres ó de pico medianamente largo y

Orden. V. Zancudas. fuerte.

3. Cultrirostres ó de pico grueso, largo y cortante

5. fam. en sus bordes.

$4 .^{2}$ Longirostres ó de pico largo; delgado y algunas veces flexible.

5. Macrodáctilas ó de dedos muy largos terminadas en uñas largas.

Fam. 1. ${ }^{a}$ Brevipennas.

Géneros. I. Avestruz II. Casoar. $\left\{\begin{array}{l}\text { El gén. Struthio del O. Gallinas: } \\ \text { de L. }\end{array}\right.$ Fam. 2. ${ }^{a}$ Piesirostres.

Géneros. I. Avutard. II. Pluvial. III. $\{$ I. Otis del O. gallinas. II. ChaAve-fria. IV. Ostrero. $\left\{\begin{array}{l}\text { radrius. III. Tringa. IV. Hæmatopus } \\ \text { del O.Grullas. }\end{array}\right.$

Fum. 3. ${ }^{a}$ Cultrirostres.

Géneros. I. Agamis. II. Grulla. III. \{ I. Psophia, II. III. y IV. Platalea del Garza. IV. Ciguieña. V. Espátula.......... \{ O. Grullas de L.

Fum. 4. Lonoirostres.

Géneros. I. Ibis. II. Chorlito. III. (I. II. III. y IV. Scolopax.'V. sin corBecada IV. Barga. V. Zancudo. VI. Avoceta. VII. Caballero. VIII. Tringa. $\{$ Th

IX Revuelve piedras. X. Falaroresp. VI. Recurvirostra VII. Géneros. Tringa y Scolopax. VIII. IX. yX. Tringa del O. Grullas de L. 
V. Orden. Palmipedas. $\left\{\begin{array}{c}1 .^{2} \text { Braquipteras. Alas muy cortas, y andan difi- } \\ \text { cilmente por tierra. } \\ 2 .^{a} \text { Longipennas. Alas muy largas ; vuelo muy } \\ \text { sostenido. }\end{array}\right.$ 4 fam.

3. ${ }^{2}$ Totipalmes Palmeadura completa que abraza el pulgar.

4. ${ }^{a}$ Lamelirostres. Pico aplastado en parte ó en totalidad, ancho y. profundamente dentado.

Familia 1. Braquipteras.

Géneros. I. Colimbo II. Somor- $\{$ I. II. y III. Colymbus IV. Alca. V.

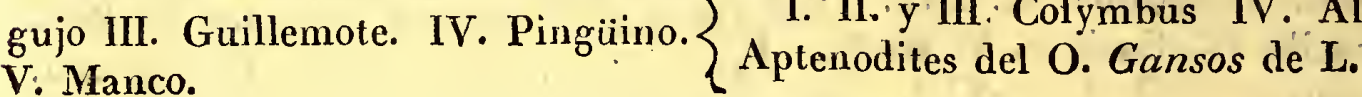

\section{Fam. 2." Lonoripennas.}

Géneros. I. Petrelo II Albatrose. $\int$ I. Procellaria. II. Diomedea. III y IV. III. Gaviota. IV. Estercorario V. $\{$ Larus. V. Sterna. VI. Rincops del O. Golondrina de mar. VI. Picotijeras. Gansos.

Fam. 3. ${ }^{\text {a Totipalmes. }}$

Géneros. I. Pelicano II. Cormo- $\int$ I. II. III. y IV. Pelecanus. V. Plotus. ran. III. Fragata. IV. Ave loca.- V. $\left\{\begin{array}{l}\text { I. Pl Paeton del O. Gansos. } \\ \text { Auhinga. V. Faetonte.......................... }\end{array}\right.$

Aulinga. V. Faetonte Fam. $40^{\mathrm{a}}$ Lamelirostres.

Géncros- I. Pato. II. Mergo.......... = I. Anas. II. Mergus del O. Gansos.

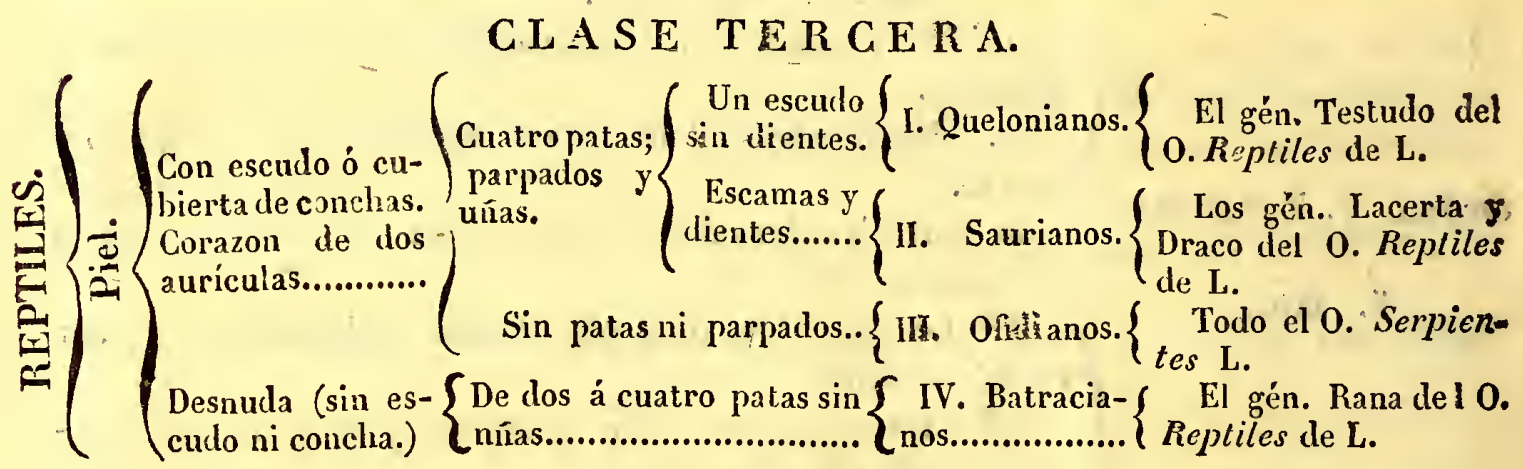

I. Orden. Quelonianos.

Gén I Tortuga 3 . Galápago. III.Queloneo.=El gén.Testudo del O. Reptiles de L. 1. Palcosaros. Familia destruida; miembros terminados en aleta.

2. ${ }^{\text {a }}$ Cocodrilianos. Cola aplastada lateralmente, pics palmeados; 5 dedos en los de adelante, 4 en los de atras.

3. a Lacertianos. Pies pentadáctilos; lengua delgaII, Orden. Saurianos. da estensible y bifida.

$40^{2}$ Iguanianos. Como los precedentes ; lengua grue7. Fam. sa, inestensible y escotada en su estremidad.

$5:^{2}$ Geccotianos. Formas horribles; miembros cortos; dedos de casi igual longitud; cabeza aplanada.

6. Camelonianos. Cuerpo comprimido; lomo agudo : cabeza piramidal.

7.: Estincoidianos. Cuerpo cubierto de escamas iguales; miembros cortísimos ; lengua inestensible: 
beza 6 acefalos 6 .................................. Acefalianos.

Anelidianos.

se. De piel provista de chupadores ó.. Cirrodermarios. (23. $\left.{ }^{\mathrm{a}}\right)$

se. De piel fina y sin chupadores ó... Aracnodermarios. $\left(24^{\circ}\right)$ se. De tentáculos gruesos, huecos y numerosos ó.............................. Zoantarios.

se. De tentáculos filiformes ó............. Polipiarios.

se. De tentáculos pinuados ó ramosos como las hojas compuestas de los vegetales ó.

Zoofitarios.

o animal las coralinas, los nematofitos ó confervas uliporas que, segun él y otros muchos naturalis- 



\section{GUADAO SAMODTICO}

DEL:

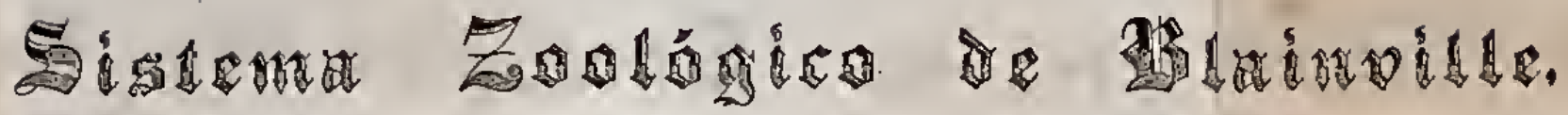

\section{INIMALES.}

Seres muy organizados y azoolizados, constanlemenle prorislos de uli lubo di- geslivo mas ó menos complelo, de fibras conlractiles y escilables, casi sicmpre visibles ; por consiguienle digieren $y$ sienlen mas ó menos sus relaciones con los cuerpos esleriores, lo que demuesiran por los movianiculos repentinos que les semos cjecular con un fin delerwinado.

\section{ZiGOMORFOS}

Ó DE FÓRMA DETERMINADA, PAR Y SINÉTRICA, ́ MAS BIEN BI. NARIA, es decir, dispuesta en dos planos paralclos.

Su esqueleto estís formado de piezas mavilles, cubiertas por los múscalos y la piel, y lievien músculos que se insertan en ellas y producen las movinientos. Su cuerpo tiene un tronco dividido en dos $\delta$ tres cavidades csplscricas: ceri todos poseen niembros; una fils de huesos linecos forma una especie de coluınia (espinazo) que ocupa la linea media del cuerpo y conticne la médula espiuti. En la eslremidal superior 6 anlerior de esta columa está contenido el encéfalo, y se lalla la cara que presenta lis boca y las órganes de los sentililos. La boca está compucsta de dos mandilialas borizontales guarnecidas de licntes 6 ceubierlas de materia córnea; el conduc10 intestinal está provisto de Blśdulas eccretorins que soll ordinariamente las glásululas salivales, el higado y el páucress. Toulos tiencu la circulacion doble, sangre roja, un coracon doble, arterias, vessas, vasos liufáticos y quiliferos. Los sexos cothin separados.

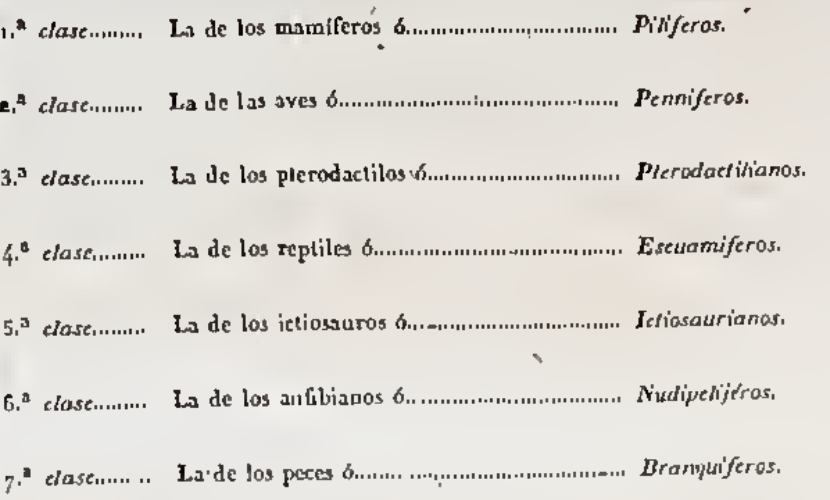

\section{ENTOMIOZOARIOS}

6 ARtictrados esteriorMENTE.

Tienen una esprecic de esqueleto compueslo de piezss articuladas, ordinariamente córnezs y dependienter de la piel que sirven de purito de apoyo á los músculos. Pl conducto intestinal completo, y los ganglios que liscento digestivo, orde zótula espiual están debajo del aparato digestivo, ornada, y carecen de circulaciou propiamente diclsa.

nada, y carecen de circulaciou propiamente

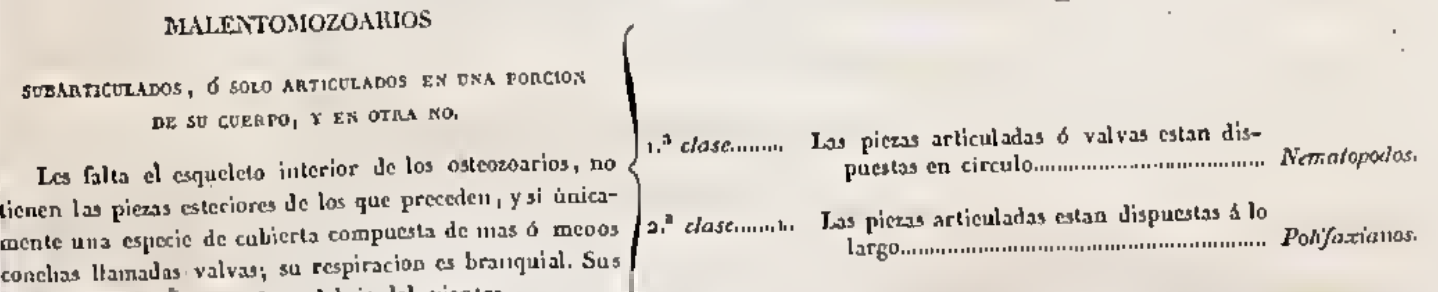

De $11^{2}$ clase. Los de seis pies, insectos b́.......... Herrupados.

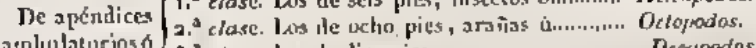

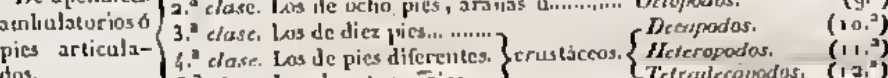

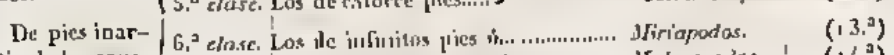

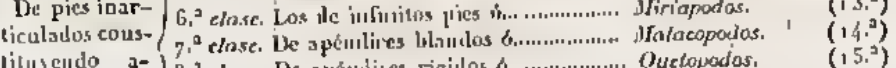

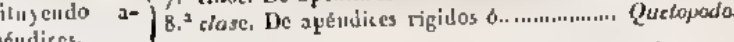
Sin apéndires $\left\{g^{3}\right.$ elase. Apodos.

fanglios formaú una calcisa debojo del vicatre.

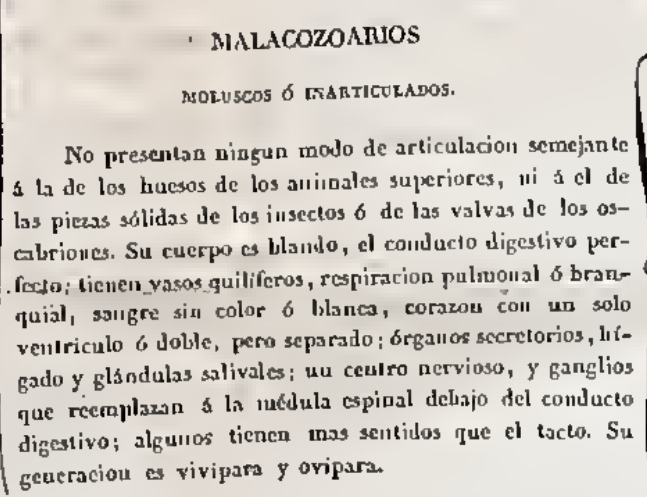

\section{ACTINIMIORFOS.}

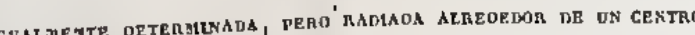

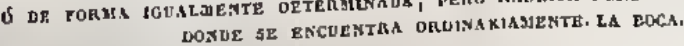

Estos animales, que se coufunden con frecuencia bajo el nombre impropio de Estos animales, que sol digestiva con una $\delta$ dos aberturas; carcecu de sistema nervioso, 6 solo consiste en ganglios colocados al inivel de cada roblio. Estos ganflios no tiencu centro comun, y distrilíayen sus ramifimaciones inclistintaucute en

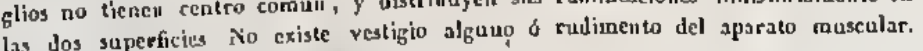
La generacion es escisipara 6 gemmípara.

\section{A MORFOS}

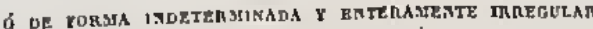

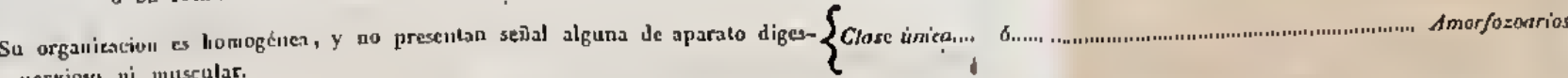

Verdadera- $\left\{2,{ }^{3}\right.$ clase. De piel provista de chupadores 6.. Cirrodermarios.

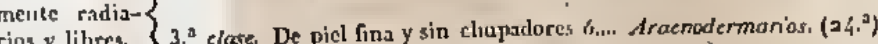
Verlalera- $44^{a}$ elose. De teillsculus gruesos, huecos y

unente radia- numeronos ón........................ Zoantarias,

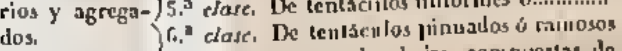
come liss liojas conpuestas de Zoofitarios

(*) NOTA. Blainsille crec que no deben comprenderse en el reino animal las coralinas, los nemalofilos ó confervas y los sicodiorios que son vegetales, ni tampoco las nuliporas que, segun el y olros nuctios naluralistas, wo son animales ni regelates, 

Fam. ${ }^{2}$ Paleosauros.

sauro.

\section{$\{$ Sin corresp.}

Fum. 2. ${ }^{\text {a }}$ Cocodrilianos.

Género único. Cocodrilo..................... = El gén. Lacerta del O. Reptiles.

Fam. 3 a Lacertianos.

Géneros I. Monitor. II. Ameiva. III. $\{$ El gén. Lacerta.

Fam. 4. ' Iguanianos, $20^{\text {à }}$ Fam.

Pr. Tr. Aga- $\int$ Géneros. I. Estelion. II. $\int$ I. II. y III. Lacerta. IV. Dra-

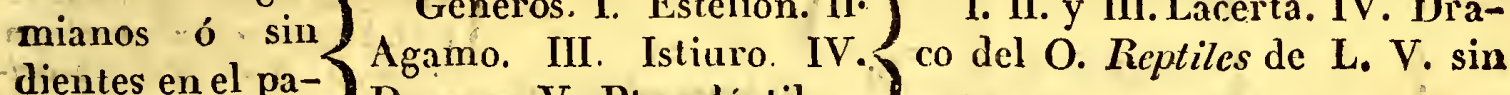
dientes en el pa- Dragon. $V$ Pterodáctilo... corresp.

nianos Tr Igua- con Géneros I Iguana. II. \{

dientesen el pal. Basilisco. III. Anolis.......... \{ tiles.

Fum. 5. ${ }^{a}$ Geccotianos.

Género único Gecco...................... = El gén. Lacerta.

Fam. $6 .{ }^{2}$ Camelonianos de $S$.

Género único. Camaleon.................. = El g n. Lacerta.

-Fam. $7 \cdot^{\text {a Estincoidianos. }}$

Géneros. I. Estinco. II. Sepedon $\left\{\begin{array}{c}\text { I Lacerta II. En parle al gén la- } \\ \text { certa y en parte el gén. Anguis. III. }\end{array}\right.$ III. Bípedo. IV. Bimano... ................. Anguis del O. Serpientes. IV. Sin correspondencia.

C r. Orvetos: rudimentos de miembros debajo de la

III. Orden. Ofidianos. piel; escamas uniformes en todo el cucrpo.

3. fam.

2. ${ }^{a}$ Serpientes. Sin" vestigio de miembros; escamas

de formas diferentes.

3. ${ }^{a}$ Serpientes desnudas ó 'sin escamas.

Fám. ¿a Orvelos.

Género. úníco. Orveto.................... =El gén. Anguis.

Fam. 2. ${ }^{\mathrm{a}}$ Serpientes. 3. Tribus.

Pr. Tr. Do- $\{$ Géneros I. Anfisbena II. \{ Amphisbæna. del O. Ssrpienble andadoras. $\{$ Tíllope... ............................... tes II. sin correspon.

Seg. Ti. Serp. $\{$ Géneros. I. Boa. II. $\mathrm{Cu}-\mathfrak{S}$ I. Boa. II. Coluber. del O. sin veneno....... \{ lebra. III. de S. .................

Ter.'Tr. Sep. $\{$ Géneros. 1. Crótalo. II. $\{$ I. Crotalưs. II. Coluber. del venenosa........... $\{$ Víbora................................... $\{0$. Serpientes.

Fam. '3.' 'Serpientes'desnudas.

Género único. Cecilia........................ $=\mathrm{El}$ gén.: Cecilia del O. Scrp. de I.

IV. Batracianos. 3. fam. $\left\{\begin{array}{c}1 .^{a} \text { Anouros: respiracion pulmonal; carecen de } \\ \text { cola. } \\ 2 .^{a} \text { Urodelos : respiracion pulmonal, pero tie- } \\ \text { nen cola. } \\ 3 .^{a} \text { Neumo branqios : tienen cola pero respiran } \\ \text { por pulmones y branquias' al mismo tiempo. }\end{array}\right.$ 
Fam. Anouros.

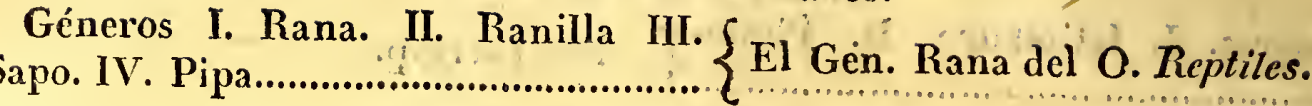

Fam. 20. Urodclos.

Géneró único. Salamandra........................ El gen. Lacerta del O: Reptit.

Fam. $3 .^{a}$ Neumobranquios.

Géuero I. Protéo. II. Sirena................... = I. sin coíresp. I. ${ }^{a}$ sin corresp. exacta.

\section{CLASE. CUARTA.}

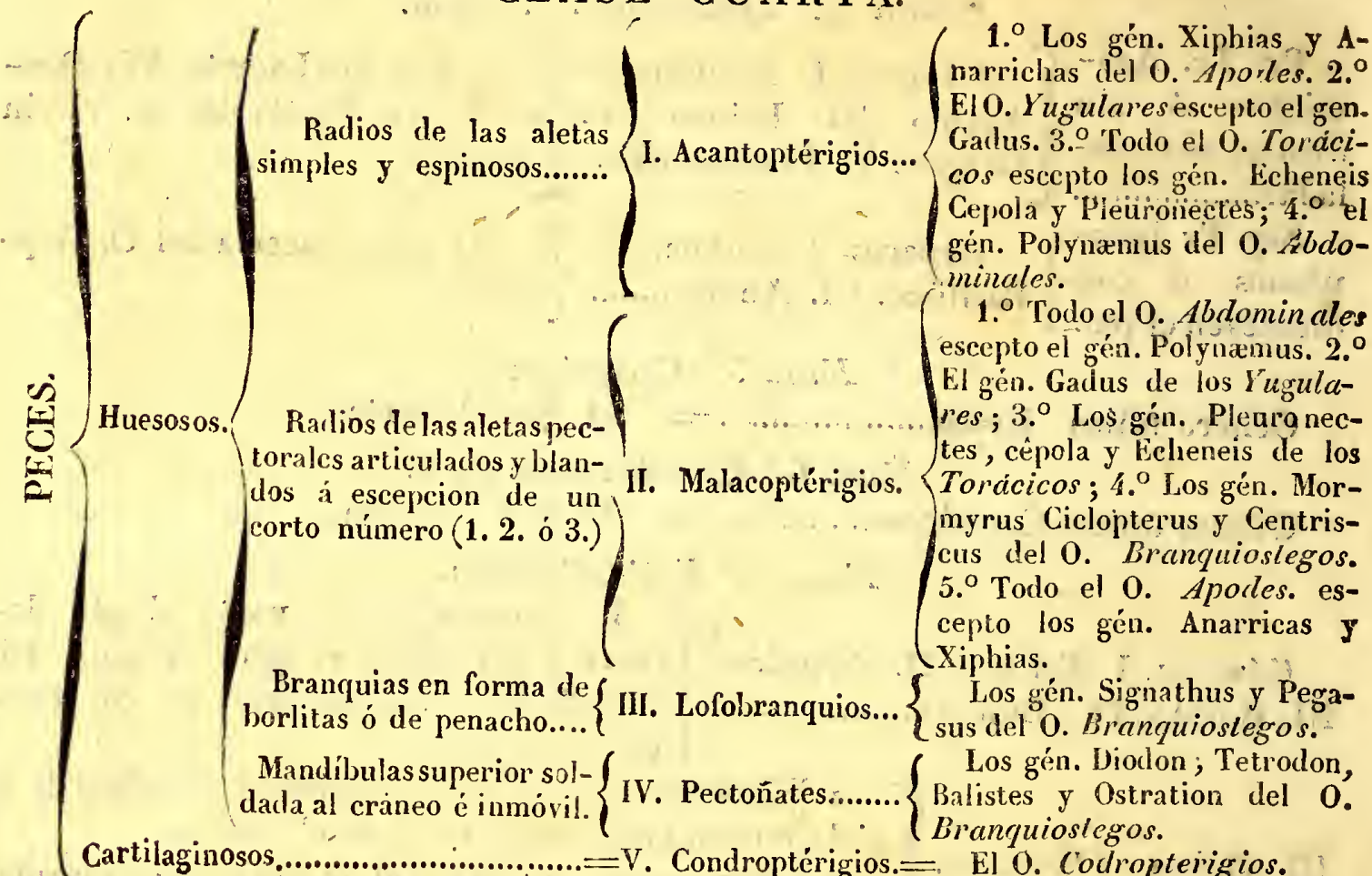
1. Los gén. Xiphias y Anarrichas del O. Aporles. $2 .^{\circ}$

ElO. Yurulares escepto el gren.

Cepola y "Pléuroinectes; ; $4: 0$ : el

gén. Polynænus del 0 . Azbdo-

1. Todo el 0. Abdomin ales escepto el gén. Polynamus. 2. El gén. Gadus de los Yugulares ; $3 .^{\circ}$ Loș gén. Plearg necTorácicos; $40^{\circ}$ Los gén. Mormyrus Ciclopterus y Centriscus del 0. Branquioslegos. 5. ${ }^{\circ}$ Todo el 0. Aporles. escepto los gén. Anarricas $y$

Branquias en forma de borlitas ó de penacho....

dada al craneo é inmóvil. $\left\{\right.$ IV. Pectońates........ $\left\{\begin{array}{l}\text { Balistes y Ostration del } 0 . \\ \text { Branquioslegos. }\end{array}\right.$ Cartilaginosos

( 1. ${ }^{a}$ F. ${ }^{a}$ Percoides cucrpo oblongo: escamas duras y ásperas; paladar con dientes; operculo dentado.

2. ${ }^{a}$ Trigloides: suborbitarios articulados con el preoperculo.

$3 .^{a}$ Escienoides: operculo y preoperculo dentados 6 espinosos: carecen de dientes palatinós y de armadura cn la cabeza

$4 .^{a}$ Esparoides; sin dentellones ni espinas en el operculo.

I. Orden. Acantopte-

5. ${ }^{2}$ Escuamipennas: Aletas escamosas.

rigios. I o. fam.

6. ${ }^{a}$ Escomberoides: cuerpo liso, escamas pequeñas y delgadas, cola vigorosa.

$77^{\circ}$ Estrepsibranquios. Branquias retorcidas que forman.ca vidades láberínticas.

8. ${ }^{2}$ Labroides. Labios carnosos y susceptibles de alargarse en forma de tubo.

$9{ }^{2}$ Lofios. Sus aletas pectorales sostenidas por una especie de brazos; cabeza erizada de espinas; hócico guarnecido de barbillas.

ro. ${ }^{a}$ Gobioides. Piel glutinosa dorsal sostenida por espinas largas y flexibles. 
Pri. Fam. Percoides

3 Tribus.Pr. Tr. Percoides ó parecidos á la perca.

G. I. Perca. II. Serrato. $\left\{\begin{array}{c}\text { I. y II. Perca del O. } \\ \text { Torácicos. }\end{array}\right.$

Seg. Tr. Traquinoides $\{$ G. I Pejearaña. II. Ura- $\{$ I. Trachinus. II. Urao par.al Pejearaña......... $\{$ noscopio.................................. $\{$ noscopus del O.Yugulares.

Ter. Tr: Salmonetes f G. I. Salmonete. II. Po- $\{$ I. Mullus del O. Toráanálogos al Salmonete. $\{$ linemo. $\left\{\begin{array}{l}\text { cicos. II. Polymæmusdel O. } \\ \text { Abdominales. }\end{array}\right.$

Seg. Fam.Trigloides. G. I. Trigla. I.

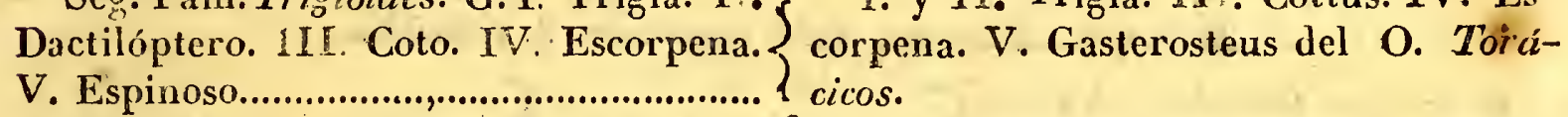

Ter Fam. Escienoides. G. único Corvina

El gén. Sciæna. del O. Torácicos.

Cuar. Fam. Esparoides. G. I Espa- $\{$ El gén Sparus. del O. Torácicos. ro. II. Boga III. Méndola....................
Quin. Fam. Escomberoides. G. I. Quetodonte. II. Arquero.

$\{$ I. Chetodon. II. Sin corresp.

Ses. Fam. Escomberoides. G. I. Es-S T. III. y IV. Scomber del O. Torácicombro. II. Pez espada. III. Centrono- $\{$ cos. II. Xiphias. del O. Apodes. V. Coto. IV. Carango. V. Corifena. VI. Ceo... riphæna y VI. Zeus del O. Torácicos.

Sєp. Fam. Estreépsibranquios. G. Ana- \{ bas. II. Ofic falo.

Oct. Fam. Labroides. G. únịco. Labro. II Escaro.......................................... \{rácicos.

Nov. Fam. Lofios. G. único. Pejesapo...= Lophius. del O. Branquiośtegos.

Dec. Fam. Gabioides. G. I. Baboso. II. $\int$ I. Blennius. del O. Yugulares. II. AAnarrico. III. Gobio.

Sin correspond. narichas del O. Apodes. III Gobius del lO. Torácicos.

I. Subór. M. Abdominales ventrales situadas en la parte posterior del cuerpo á grande distancia de las pec-

II. Órden. Malacoptéritorales.

gios. Tres subórdenes........

2. Subór. M. Subbraquianos: Radios siempre blandos y flexibles; ventrales colocadas en frente ó delanic de las pectorales.

3. ${ }^{\circ}$ Subór. M. Apodes: Falta de ventrales.

Subór. 1. Malacop. Abdominales. 5. Familias.

Pr. Fam. Ciprinos boca pequeña y á la estremidad del G. I Carpa. Ir. $\int$ T. Cyprinus.'II y III. hocico; falta de dientes maxila- Loche. III Anablepo. Cóbitis del O. Torácicos. res pero no de palatinos.

Seg. Fam. Esocéos : hocico deprimido ; boca hendida y dientes maxilaresfuertes yganchosos.

Ter. Fam. Siluroides : cuerpo privado de escamas y cubicrto en algunos puntos de chapas osceas. G. I. Sollo. II. E- $\left\{\begin{array}{c}\text { I. Exox. IT. Exocatus } \\ \text { del O. Abdominalcs. III }\end{array}\right.$ Mormyrus del O. Branquiiostegos.

G. I. Siluro. II $\int$ I y III. Silurus del $O$.

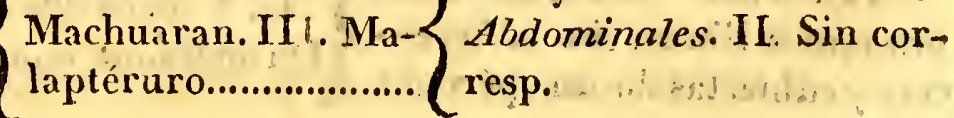
$48=2 .^{\circ}$ 
Cuar. Fam. Salmonéos ó de escamas dispuestas regularmente ; la aleta primera do:sal sostenida por radios; la segunda adiposa.

Quin. Fam. Clupeas: falla de la aleta adiposa en el lomo; en lo demas parecidas á los salmonéos

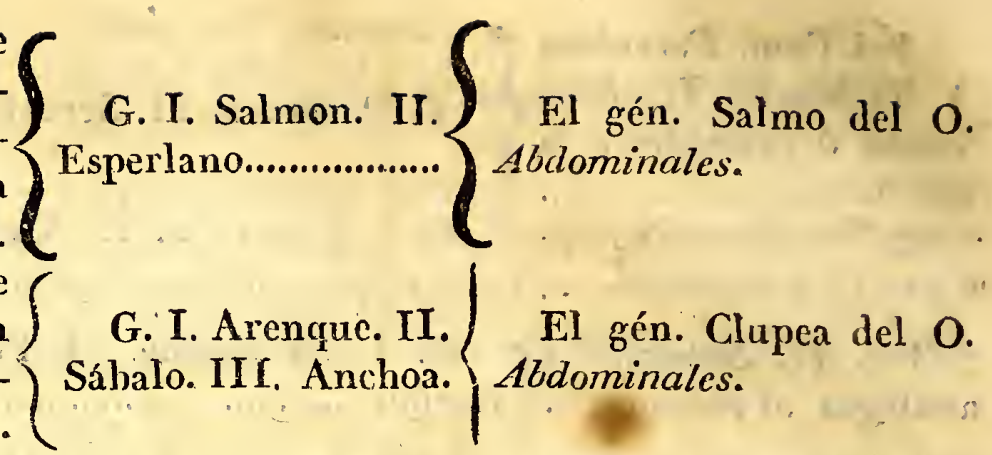

Subár. 2. Malacop. Subbraquianos. 3. familias.

\section{*} Sest. Fam. Gadoides: formas
perfectamente simétricas; ven-
trales separadas é insertas en la
parte anterior del cuerpo de-
lante de las pectórales.................
Sep. Fam. Plcuronectes. ojos
colocados en un mismo lado de
la cabeza : boca oblicua, aletas
impares inclinadas á un lado
ú á otro..........................................

Oct. Fam. Dioscobolos 6 de ventrales reunidas formando un disco.

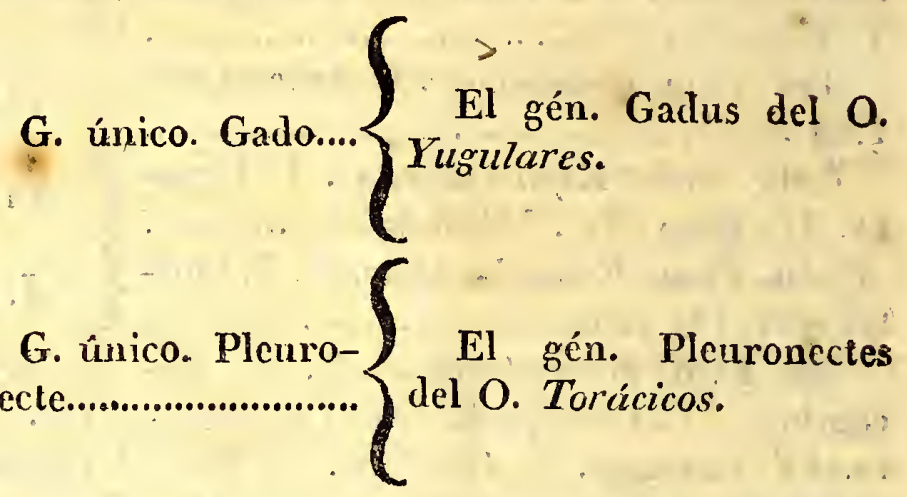
$\left\{\begin{array}{c}\text { I. Sin correspond. II. } \\ \text { Cyclopterus del O..Bran- }\end{array}\right.$ quiostegos. III. Echeneis del O. Torćcicos.

Subór. 3. Malacop. Ápodes.-Una sola familia.

Nov. Fam. Anguiliformes: cuerpo largo y cilíndrico; pectorales pequeñisimas; carencia de ventrales. G. I. Anguila. II. I I Maræna. II. GimnoGimnota. III. Arn- tus III. Ammodytes del modite...................... O. Apodes.

III. Orden. Lolobranquios una sola familia.

Género. Singnato. II. Pegaso......, g... $\left\{\begin{array}{c}\text { I Syngnatus. II. Pegasus del O. Bran- } \\ \text { quiostegos. }\end{array}\right.$ IV. Orden. Pectoñates. 2. familias. Pr. Fam. Gimnodontes: man-
díbulas guarnecidas de un re- (G.I. Orbe. II.Rueborde de una sustancia ebuinea

Seg. Fam. Esclerodermos ó de tegumento esterior cubierto de chapas duras óseas y articuladas al rededor del cuerpo: dientes solo en los boides dentarios.

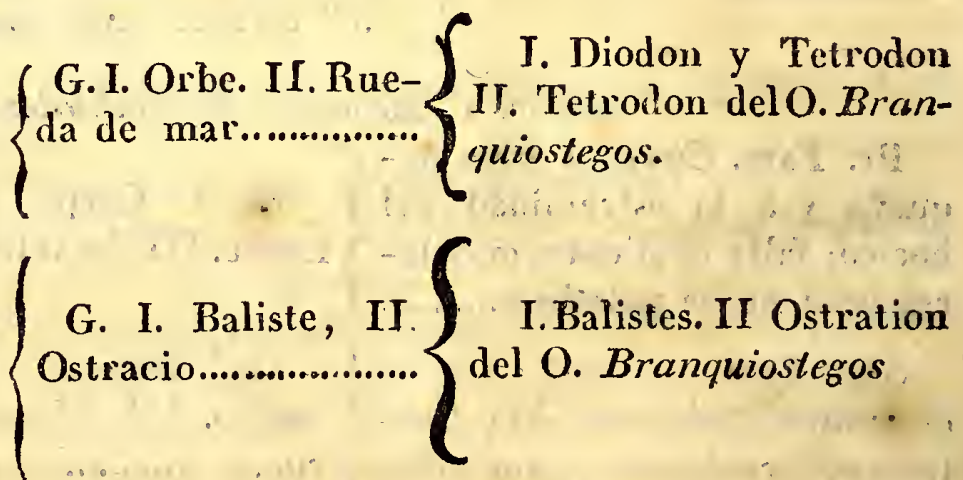
V. Orden. Condroptérigios. 3. familias.

Pri. Fam. Esturionianos: branquias libres, sin adherencia, y cubiertas de un opérculo. 
Seg. Fam. Selacianos. Branquias adherentes ála piel, y que se abren afuera por varios agujeros que la perfora $\mathbf{n}$; forma Raya. aplastada conica ; pectorales chicas.

Terc. Fam. Giclostomos. Branquias adherentes; forma "cilin$\left.\begin{array}{l}\text { drica ó anguiliforme ; pectora- } \\ \text { les nulas......................................... }\end{array}\right\}$ Arnmoceto.

G. I. Escualo. II.

alus. II Raia del O. Condroptérigios.

\section{MOLUSCOS.}

\section{Clase primera. Cefalopodos. $=2$. familias .}

Pr. Fam. Scpiarios. Un rudimento de concha interior ó una concha entera de una sola celda

Seg. Fam. Nautilaceos. Una concha arrollada en espiral dividida interiormente en $\mathrm{mu}-$ chas cavidades.

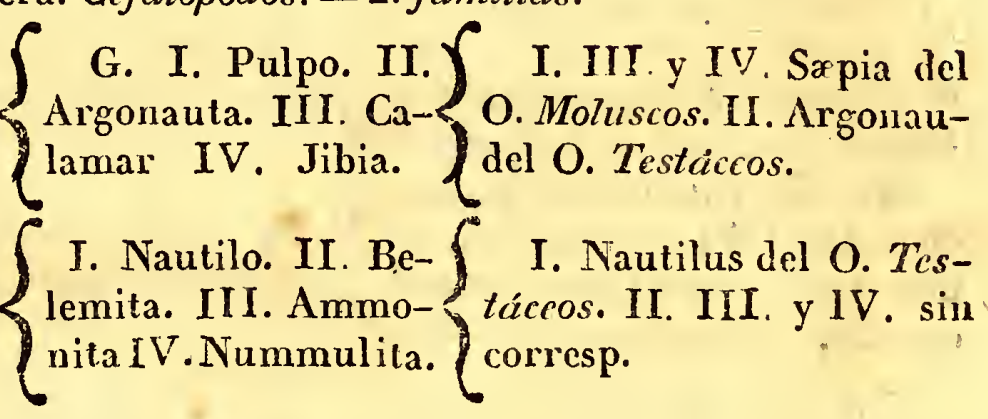

\section{Clase Segunda. Pteropodos.}

Géneros. I. Clio. II. Cimbulio. III. Neumodermo IV. \{

I. Clio del O. Moluscos. Limasino. V. Hiala. VI. Cleodoro. VII. Pirgo. II. II IV. V. VI. VII. sin corresp.

\section{Clase tercera. Gasteropodos.} 3. Ordenes. $\left\{\begin{array}{l}1.0 \text { PuImonados. Respiran por pulmones. (1) } \\ 2.0 \text { Dermobranquios. Kespiran por branquias cubiertas de un pliegue del manto; }\end{array}\right.$
$3 .^{\circ}$ Pectinibranquios. Pie carnoso que ocup'a solo la parte anterior del vientre; concha generalmente cónica y arrollada en espiral.
I. Órden. Pulmonados. - 2. familias.

Pr. Fam. Limacineos óseme- $\int$ G. I. Limaza II $\int$ I. Limax del O. Molus-

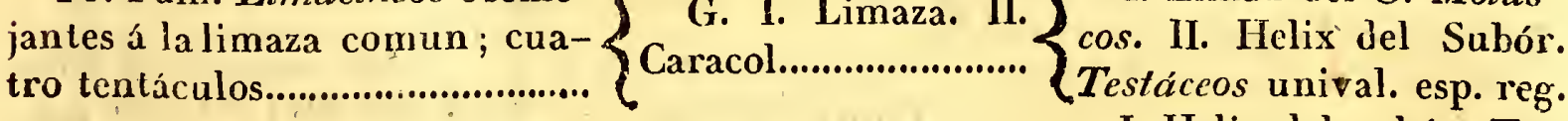

Seg. Fam. Limneanos ó pare- $\{$ G. I. Planorbe. II. $\{$ I. Helix del subór. Tes-

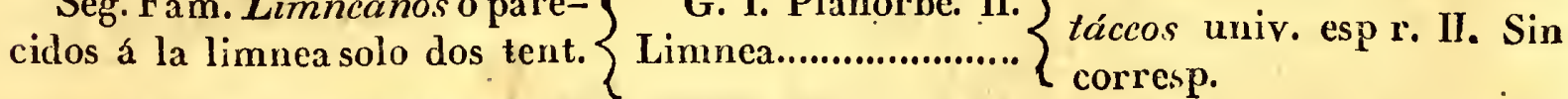

II. Orden. Dermobranquios. 3. familias.

Pr. Fam. Nudibranquios ó sin $\int$ G. I. Doris. II. Tri- $\int$ G. I. Doris. II. Sin corconcha; branquias en el dorso $\left\{\begin{array}{l}\text { tonia. III. Tetis. IV. } \\ \text { desnudas............................................. }\end{array}\right.$ Escilea. V. Glauco... $\left\{\begin{array}{l}\text { resp. III. Tethis. IV. Scil- } \\ \text { læa. Glaucus del O. Mo- }\end{array}\right.$ Escilea. V. Glauco... (luscos.

Seg. Fam.Tectibranquios ó de $\{$ I. Aplysia. II. Bu- $\{$ I. Aplysia del O. Molusbranquiascubiertas porel manto $\left\{\right.$ la................................... $\left\{\begin{array}{l}\text { cos. Il. Bulla del Subór. } \\ \text { Testáceos univ. esp. reg. }\end{array}\right.$

(1) No se especifican las correspondencias linneanas de estos órdenes porque abrazan muy pocos géneros. 
Ter. Fam. Escutibranquios ó de concha en forma de escudo y $\sin$ espira.
I Haliótide II. $\mathrm{Pa}_{-}$ tela. III Oscabrion.

úniv. esp. reg. II. Patella del subor. Test. úniv. esp. irreg. III. Chiton del sub.

Test. univalvos.

1. ${ }^{\text {a }}$ Trocoides : La cavidad branquial comunica coin la esterior por un agujero.

III. Orden Pectinibranquios 2. Fam. $\left\{2 .^{\mathrm{a}}\right.$ Buccinoides ${ }^{2} \mathrm{La}$ cavidad branq. comunica con el est. por un conducto prolongado ó sifon.

Pr. Fam. Trocoides. G. I. Troco. I. Trochus. II. Turbo. III. Nerita. del II. Trompo. III. Ampularia. IV. Ne rita. \{ subor. Test. bivalv. III. sin corresp.

Seg. Fam. Buccinoides.' $\mathrm{Pr}$. Tr. Buccinoide arrollados: conchas ovales de aber. estrecha en lana. III. Huevo........ toda su longitud; casi sin espira.

Seg Tr. Buccinoides escotados: abertura constantemente max ancha; en su base, una es cotadura para el paso del sifon.

Ter. Tr. Buccinoides canaliculados; un conducto de longitud y.direccion variable; , espira promienente.

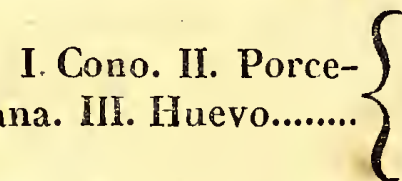

I. Conus. II. Cyprea del Subor. Testáceos univ. esp. reg. III. sin coresp.

I. Buccinum. II sin I. Casco. II. Cerita. corresp. III. Murex. VI. III. Murice. IV. Hu- sin corresp. V. Strombus. so. V. Estrombo. $\begin{aligned} & \text { del subor Testáceos univ. } \\ & \text { esp. reg. }\end{aligned}$

\section{Clase cuarta. Acéfalos.}

2. Ordenes. $\left\{10^{\circ}\right.$ Monomiarios: Un solo músculo que se dírige de una valva á otra.

2. Ordenes. $\left\{2 .^{\circ}\right.$ Dimiarios: Dos músculos que pasan por las estremidados del cuerpo.

I. Orden. Monomiarios. $=3$. familias.

Pr. Fam. Ostráceos: con-C clia de dos valvas desiguales; una inferior mas grande com-\{ bada y otra superior pequeña y chata.

G. I. Ostra. II. Peine. III. Anomia.
I. Ostrea y Spondylus. II. Ostrea. III. Anomia del Subór. Test. bivalv.

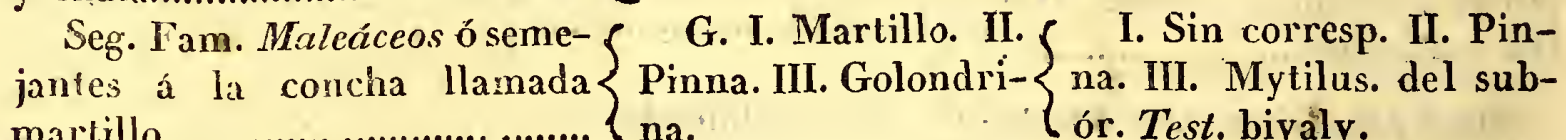
martillo..................................

Ter. Fam. Tridacnos. Dien- \{ tes en la charncla; ligamento visible esteriormente; magni- $\left\{\begin{array}{l}\text { dácno. } \\ \text { tud colosal................................... }\end{array}\right.$ Gén. único. Tri- \{ Sin corresp. II. Orden. Dimiarios. $=5$. familias.

Pr. Fam. Camáceeos: La forma de la charnela parecida á la de los tridacnos; pero las valvas son desiguales.................. (

Seg. Fam. Arcíceos: Conchas de valvas iguales, guarnecidas de numerosos dièntes; figura oblonga. tunculo. G.único. Cama. $\left\{\begin{array}{c}\text { El gén. Chama del sub- } \\ \text { Test. bivalv. }\end{array}\right.$

G. I. Arca. II. Pe- $\{$ El gén. Arca del suborr Test. bivalv: 
Ter. Fam. Mitiláceos. Conchas de valvas iguales; negruzcas y córneas, de estructura foliácea.

Cuart.fam.
Cardiá-
ceos. 2.
Tribus....... $\left\{\begin{array}{c}\text { Pr. Tr. C. de dos } \\ \text { especies de dientes charnela..... } \\ \text { Seg. Tr. C. que } \\ \text { no tienen mas que } \\ \text { dientes cardinales }\end{array}\right.$

Quint. Fam. Encerrados Manto arrollado sobre sí mismo en forma de tubo saliente fucra de la concha, escepto una len. III. Foladas. IV.

G. I. Almeja. II. \{ Anodonte. III. Unio. del subór. Test. bivalv.

G. I. Bucarda. II.

I. Cardium. II. Dónax. Dónace. III. Ciclada.
IV. Canastilla. V.Lu-
cina. VI. Tellina. III. IV. y V. $\sin$ corresp. VI. Tellina del sub. Test. bivalv. $\int$ G. I. Venus. II.

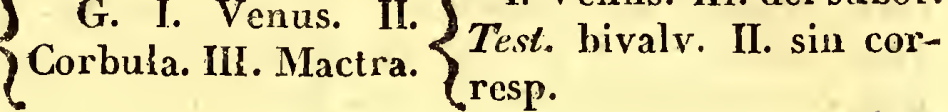

I. Mya. II. Solen. del G. I. Mia. II. Sóabertura para el paso del pie; Broma. V. Regadera. concha siempre abierta y de valvas iguales.

III. Orden. Braquiopodos. Una sola familia.

Géneros. I. Terebrátula. II. Lingula. III. Or- $\{$ Sin correspond.

IV. Orden. Tuuicarios 2. familias.

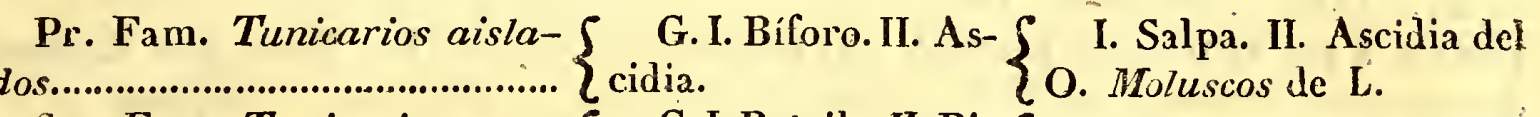

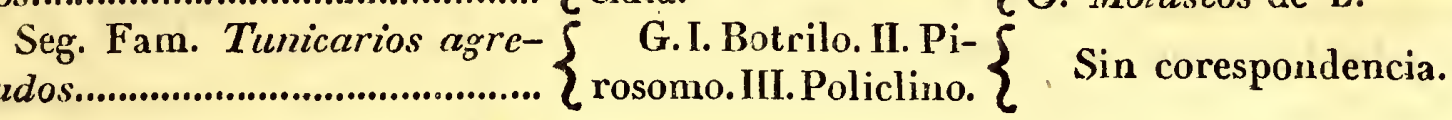
gados.

Clase quinta. Cirropodos.

Géneros. I. Anatifa. II. Balanita. $\left\{\begin{array}{c}\text { El gén. Lepas del Subór Test. } \\ \text { multivalv. }\end{array}\right.$

\section{ARTICULADOS.}

\section{Clase primera. 3. órdenes.}

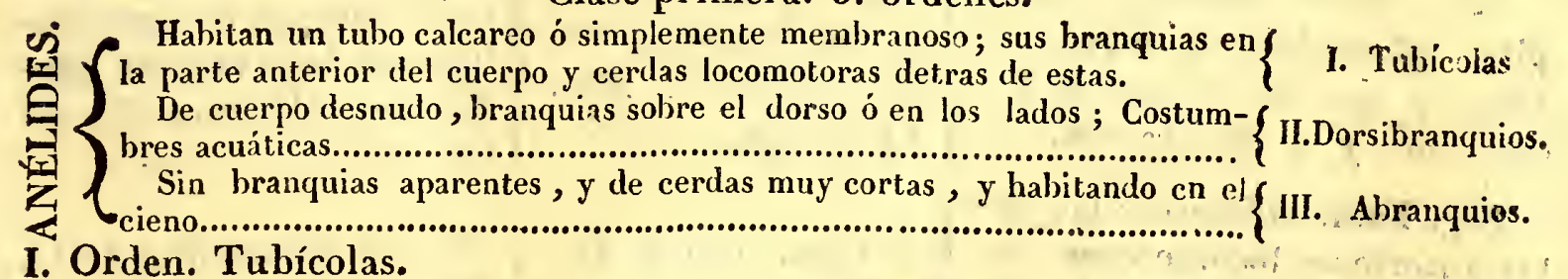

I. Sérpula del subor. Test. univ. esp.

G. I. Serpula. II. Terebela. III. An- irreg. II. Terebella: III. Anphitrite del O. fitrite. IV. Arenícola. V. Dentalio......... Moluscos de L. IV. Lu mbricus del O. Intestinales. V. Dentalium Test. univalv. de esp. reg.

II. Orden. Dorsibranquios.

G. I. Afrodita. II. Nereida.................. $\left\{\begin{array}{c}\text { I. Aphrodita. II. Nereis. del O. Mo- } \\ \text { luscos. }\end{array}\right.$ III. Orden. Abranquios.

G. I. Lombriz. II. Sanguijuela. III . I I. Lumbricus II. Hirudo del O. IntesNayada. Ztinales. III. Nais. del O. Moluscos. 


\section{Clase segunda.}

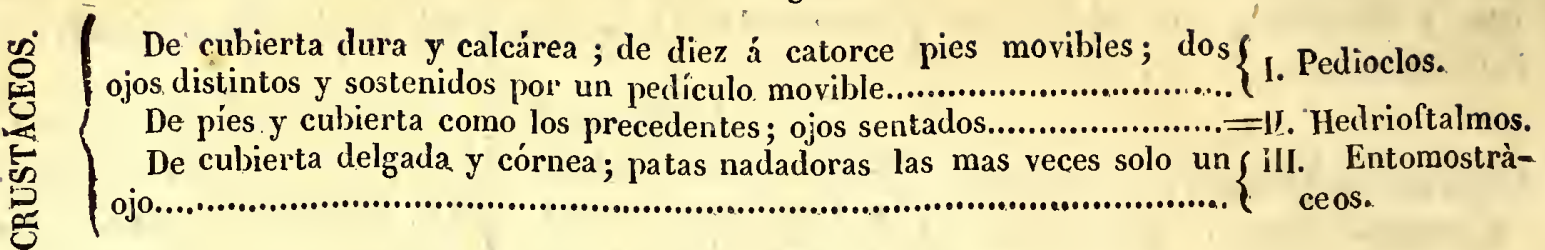

Pr. Fam. Braquiuros; cola G. I. Portuno. II. corta, desprovista de aletas; es- Cangrejo. III. Pincudo aplastado y ancho; ca- nótcro. IV. Gecarcibeza confundida con él............... no. V. Dromia. arga.

Seg. Fam. Macrouros; cola 1. Remípedo. II. $\mathrm{Pa}-$ guro HII.Cangrejo comun. IV. Langosta de mar. V. Langos-

El gen. Cáncer del 0 .

Ter. Fam. Estomatopodos: cabeza scparada del torax; 14 Gen. único Espies y los dos primeros muy quila.

aproximados á la boca. tino.

II. Orden Hedrioftalmos. 2. familias.

Pr. Fam. Anfipocios, parecidos á los crústáceos prece- $\{$ I. Gamaro.II. Co- $\{$ I. y II. el gen. Cancer. dentes pero carecen de coselete;
sus patas terminan en punta... rofio III. Talitro. $\quad$ III sin correspond.

Seg. Fam. levererts. Sin palpos en las mandibulas; branquias debajo de la cola; cucrpo aplastado y compuesto de ani- porte.

III. Orden. Entomostráccos. 2. familias.

Pr. Fam. Branquiopodos: pies aplas!ados en forma de aletas y que sirven para la locomocion y la respiracion.

I. Cíclope II Po- Sin corresp. la mayor lifemo. III. Cipro. IV. parte escepto los gen. PoBranquipo. V. Apo. lifemo y Apos porque corVI. Dafnia. . .. $\quad$ O.Apteros.

Seg. Fam. Jifosuros : las patas anteriores locomotoras; las posieriores semejantes á las de los branquiopodos........................

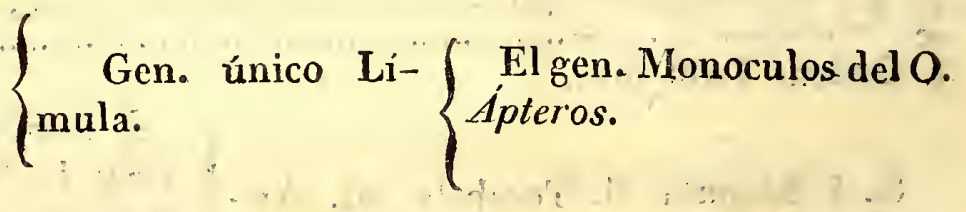

\section{Clase Tercera.}

I. Orden. Pulmonados $=$ a. familias. 
Pr. Fam. Araneidas: cuerpo grueso, velludo, compuesto de un pequeño cosclete, abdomen enorme separado por una depresion; patas largas y pelosas.

Seg. Fam. Pedipalpos: Torax y abdomen confundidos y formados de anillos articulados: mandibula s terminadas en pinza ; su tegumento casi crustáceo

II. Orden. Traqueenos. 2. familias.

Pr. Fam. Fulangianos: cuerpo globoso y cubierto de una epidermis comun; patas lar- dor. guisimas.

Seg. Farn. Acarides animales parasitos y Micros- $\{$ El gén Acarus de O. Apcópico.

I. Tarántula. II. Escorpion.
I. Migala. II. Araña. III. Argironeta. IV. Licosa.
El gén. Aranea del 0. Apteros de $\mathbf{L}$.

I. Aranea II. Scorpio. del O. Apteros.

\section{Clase cuarta Miriapodos. $=2$. familias.}

Pr. Fam. Quiloñatos : sostienen dos pares de patas en \{

Seg. Fam. Quilopodos: sos- $\{$ G.I. Escudífero. II. \{ tienen solo un par.................... Escolopendra. $\{\mathrm{O}$, Apteros.

Clase Quinta. Insectos. 7. ordenes.

I. Orden. Apteros 6 sin alas 3 familias.

Pr. Fam. Tisanouros: cola $\{$ G. I. Forbicina. $\{$ I. Lepisma. II. Podura. con filamentos ó cerdas........... \{II. Podura. $\quad$ del O. Apteros de L.

Seg. Fam. Parasitos: Viven $\{$ G. I. Piojo. II. Ri- $\{$ El gén Pediculus del sobre el cuerpo de los anima-
les cuya sangre chupan........ cino. $\left\{\begin{array}{l}\text { O. Apteros de L. } \\ \text { L }\end{array}\right.$

Ter. Fam. Sifonápteros ó $\left\{\right.$ Gén. único Pulga. $\left\{\begin{array}{c}\text { El gén. Pulex del } 0 . \\ \text { Apteros. }\end{array}\right.$ chupadores.

1. De cinco articulaciones en los tarsos. C. Pentámeros.

II. Orden Coleópteros, que tienen élic- ${ }_{\text {rómeros }}^{2.0}$ De numero diverso. C. Hetetras y alas estas plegadas: al traves y boca masticatoria.

3. ${ }^{\circ}$ De cuatro articulaciones. C. Tetrámeros.

$4^{\circ}$ De tres articulaciones. C. Trímeros. 


\section{Subórden Colcópteros Pentâmeros. 3 Familias.}

Pr. Fam. Carniceros: Seis palpos; dos en el labio inferior y dos en cada mandibula ; cadera igual á las patas.

$10^{a} \mathrm{Tr}$. Cicindelalos: G. I. Cicindela. I. Manticora y Cican2. ${ }^{a}$ Tr. Carábicos. dela del $\mathrm{O}$. Coleópteros. y G. I Braquino. II. II. II. Sin corresp. III. ciFeronia. III. Elafro. cindela.IV. Carabus del $O$. IV. Carabo. 3. ${ }^{\mathrm{r}}$ Tr. Hidrocán- I. Dyticus. II. Gyrinus taros. G. Ditisco. II. del O. Coleópteros.

Gyrimo.

Seg. Fam. Braquélitros. Cuerpo prolongado ; cua tro palpos y elictras demasiado corlas; no contiene mas de un género que es el Estafilino y corresponde al Staphilinus del O. Coleópteros de $\mathbf{L}$.

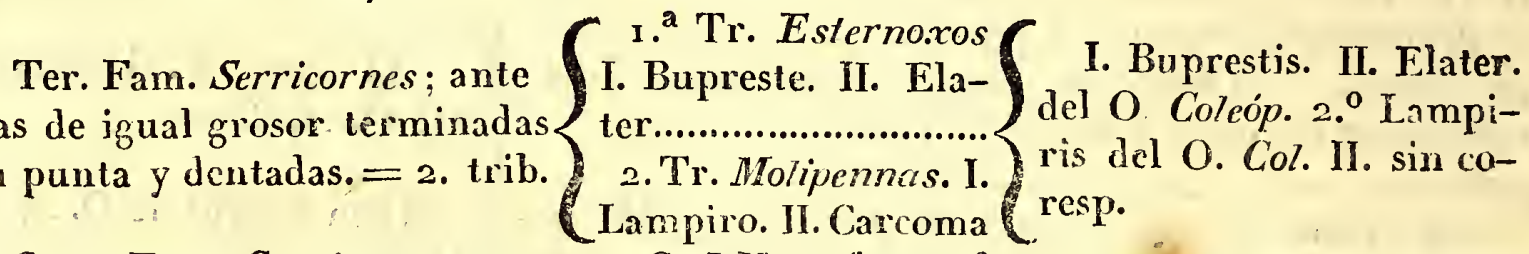

Cuar. Fam. Clavicornes; an- G I.Necróloro. $2^{\circ}$ tenas en forma de maza..............

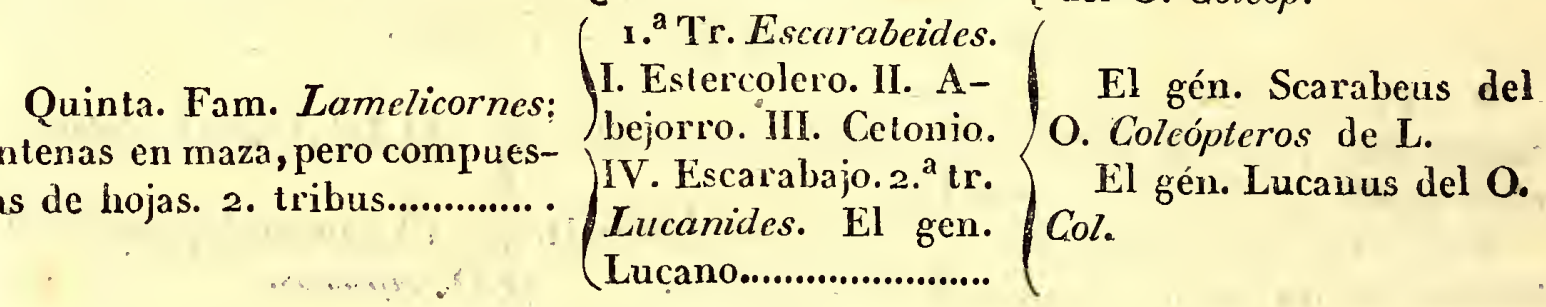

- Subórden Segundo. Coleópteros Heterómeros 2. familias.

Pr. Fam. Melasomos: color $\{$ I. y I. Dañino. II. $\{$ I. y II. Tenebrio del O. sombrio y uniforme................... Tenebrion................... $\{$ Coleóp.

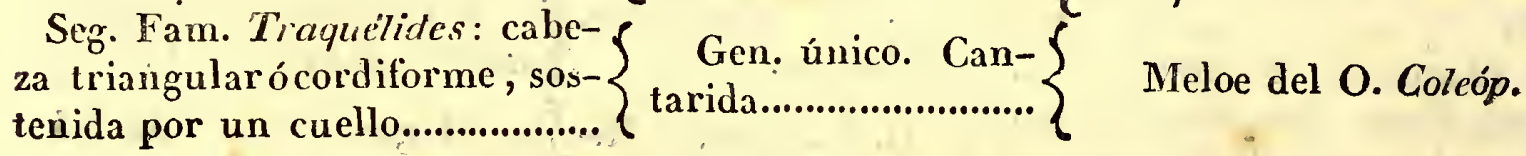

\section{Subórden Tercero. Coleópteros Tetrámeros. $=3$. Familias.} Pr. Fam. Rinc óforos. pro-
longacion en la cabeza en forma
de cuerno......................................... $\left\{\begin{array}{c}\text { G. I. Brento. II. }\left\{\begin{array}{r}\text { I. Brentus. II. Bruchus. } \\ \text { Brucho.III. Gorgojo... }\end{array} \text { III. Curculio del O. Colcóp. }\right.\end{array}\right.$ Seg. Fam. Longicornes; 'ante- $\{$ G. Priono. II. Ca- $\{$ I. y II. El gén. Ceram-

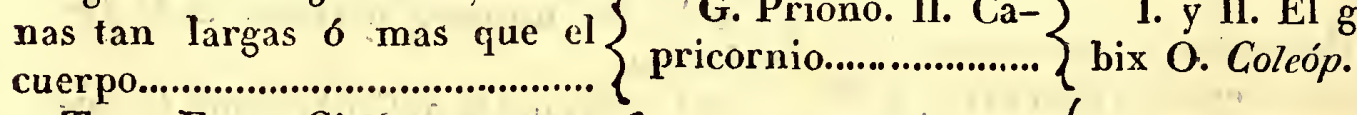
redondeado y sin distincion en-
tre el coselete y el abdórnen..... $\left\{\begin{array}{c}\text { G. I. Cásida II. } \\ \text { Crisomela..................... }\end{array}\left\{\begin{array}{c}\text { I. Cassida. II. Chryso- } \\ \text { mela. del O. Coleópteros. }\end{array}\right.\right.$

\section{Subórden Cuarto: Coleópteros Trímeros.}

Gén. único Coccinela.............. $=\mathrm{El}$ mismo gén. Coccinela del O. Coleop.

III. Orden Ortópteros; elictras, pero las alas plegadas álo largo, boca masticatoria. 3. Familias.

Pr. Fam. Corredores pies $\{$ G. I. Tigereta II. $\{$ I. Forficula. del O. Co-

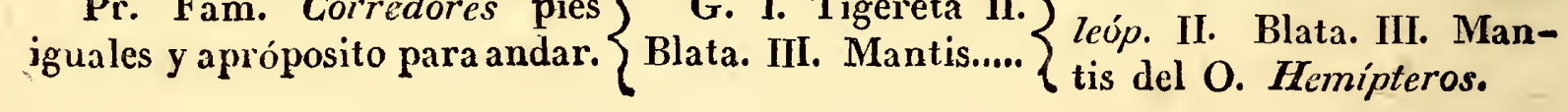


Seg. Fam. Saltadores, patas posteriores mas largas y fuertes que las anteriorcs

G. I. Grillo. Lan- \{ gosta. III. Acridio..... \{ Hemípteros.

IV. Orden Hemípteros. Cuatro alas ó ninguna; boea dispuesta para chúparsin mandíbulas ni maxilas: Dos súb-órdenes.

Primer sub-órden. Heterópteros: el pico nace de la frente; alas mitad crustáceas, mitad membranosas. 2. fam.

Pr. Fam. Geocorisos ó chin- $\{$ I. Chinche. II. Re- $\{$ I. y II. Cimex. del O. ches terrestres............................ \{ duvio.......................... \{ Hemipteros.

Seg. Fam. Hidrocorisos ó chin- $\{$ I. Naucoris. II. Ne- $\{$ El gén. Nepa. del O. ches de agua.... $\{$ pa.

Hemíleros.

Subórden Segundo. Homópteros estuches de consistencia uniforme $=3$ fam.

Pr. Fam. Cicádarios tres artic. en los tarsos; antenas pequeñas terminadas en punta: elictras mas consistentes que Cicadela. WI.Fuigora. las alas.

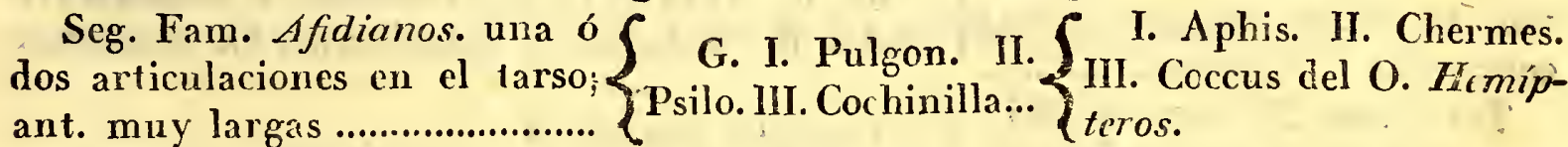
V. Orden. Neurópteros' cuatro alas membrancsas, reticuladas y sin escamas. 2. fam.

Pr. Fam. Subulicornes; an-\{ G. I. Libélula. II. $\{$ I. Libellula. II. Ephxtenas en forma de lesna, alas
levantadas....................................... $\left\{\begin{array}{l}\text { Efimero. III. Friga- } \\ \text { neo. }\end{array}\right.$

Seg. Fam. Planipennas, Alas G G.I:Hormigaleon. I. Myrmeleon. II. He-

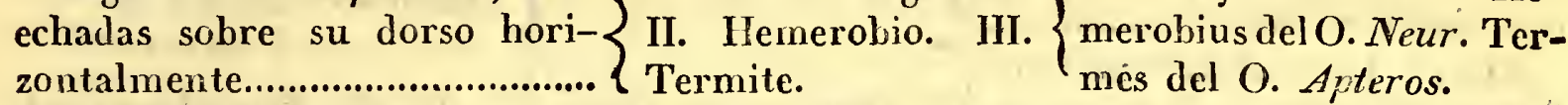

VI. Orden. Himenópteros: cuatro alas membranosas, sin eseamas, no reticuladas, pero sí nerviosas; nervios longitudinales. 2. subórdenes.

Primer subórden. Himenop. Terebrantes ó armados de un aguijon. = 2. fam.

Pr. Fam. Serrifecos..............= G. Tentredo.= Tentredo del O.Himenópteros.

Seg. Fam. Pupívoros. Pr.Seg- $\{$ G. I. Icnéumon II. $S$ I. Ichneumon. II. Ci-

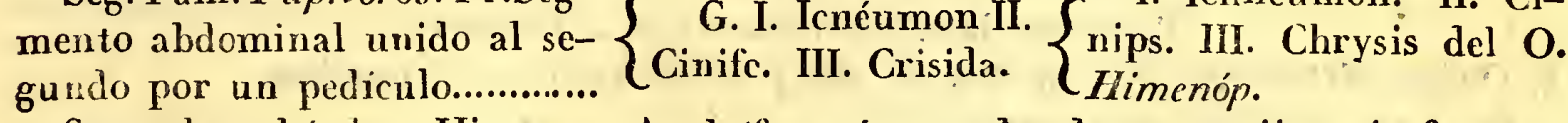

Segundo subórden. Himenop. Aculeíferos ó armados de un aguijon. 4. fam.

Pr. Fam. Formicarios. Coselete separado del abdómen por un pedículo; antenas encor-
vadas............................................. .

Seg. Fam. Cacadores. Con $\left\{\begin{array}{l}\text { G. I. Hormiga. II. }\left\{\begin{array}{l}\text { I. Formica. II. Muti- } \\ \text { Mutila. }\end{array} \text { lla del O. Himenópteros. }\right.\end{array}\right.$

G. I. Esfege. II. $\{$ El gén. Sphex del $O$.

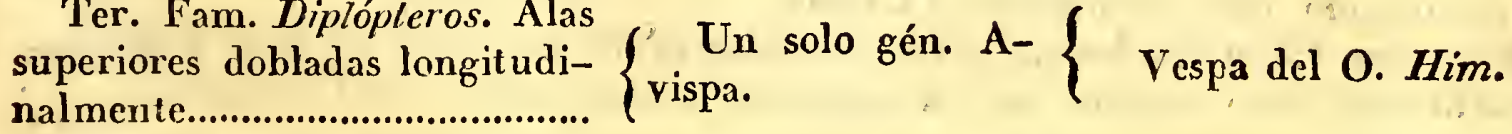
el pedículo que separa el abdómen del coselete muy largo.

Ter. Fam. Diplópleros. Alas

Crabro.
Un solo gén. A-
vispa.

Cuar. Fam. Melíferos. Primera piezi de los tarsos posteriores ensanchada en forma de paleta.
G. I. And rena. II. \{ Jilocopo. III. Abejon. $\left\{\begin{array}{r}\text { El gé } \\ \text { IV. Abeja. }\end{array}\right.$ 
VII. Orden. Lepid opteros cuatro alas membranosas, cubiertas de escamas harinosas. $=3$. familias.

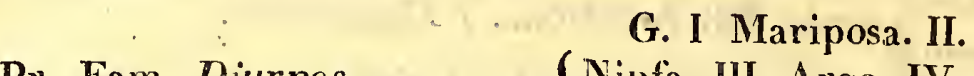

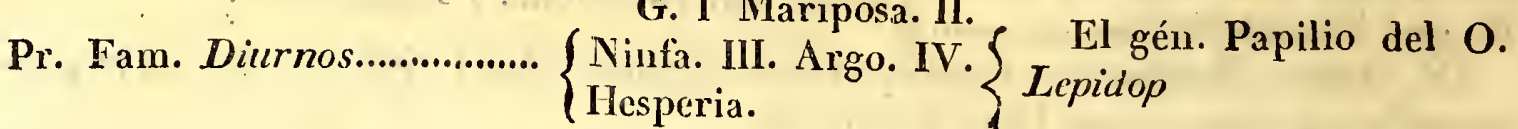

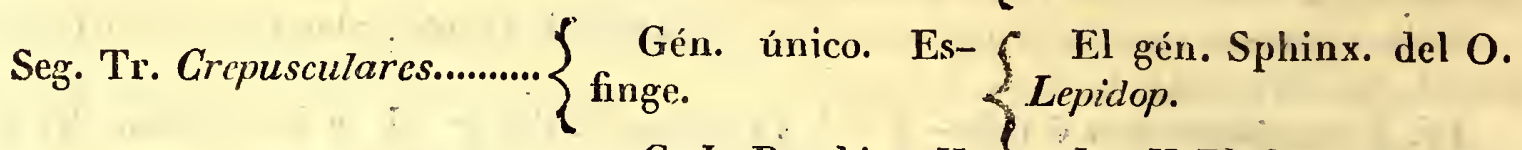

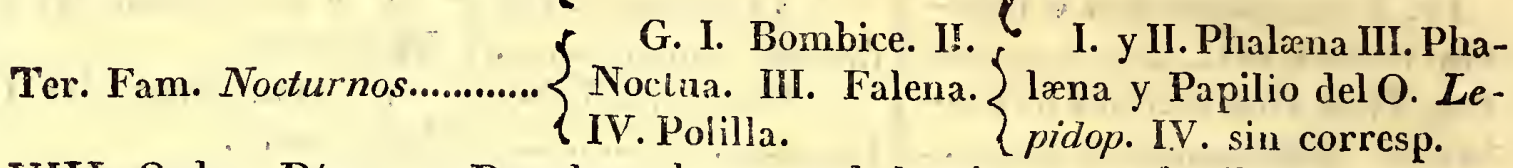

VIII. Orden. Dípteros: Dos alas solamente: balancines. $=5$. familias.

Pr. Fam. Nemóceros; antenas

filitormes mas largas que la

caleza y coselete, de mas de Tipula.

6 articul. (de 12 á 16 genere.

G. I. Mosquito. II. $\int$ I. Culex II. Típula del

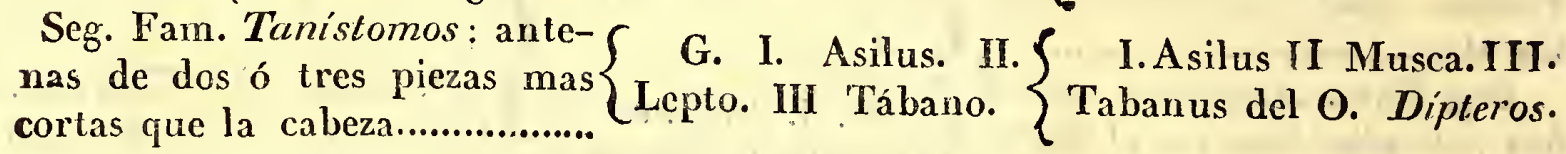

Ter. Fam. Notacantos ulti-

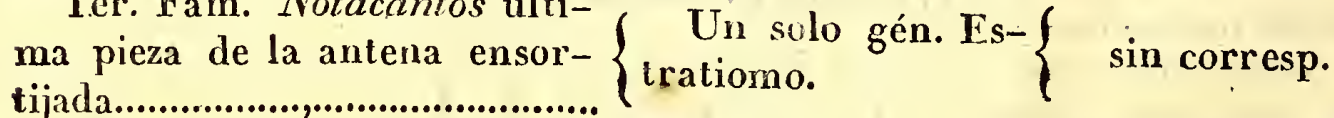

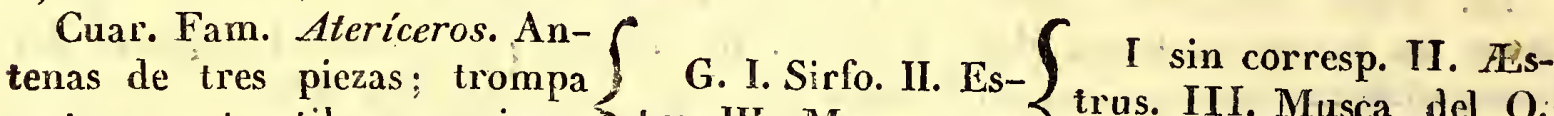
corta y contractil que encierra dos piezas córneas.......................

Quint. Fam. Pupivoros: cabeza confundida con el torax; Gen. único. Hipo-? antenas mas cortas que aque-) bosco. lla y separadas. tro. HI. Mosca. O. Dipteros del L. $\left\{\begin{array}{l}\text { trus. III. Musca del O: } \\ \text { Dipteros. }\end{array}\right.$

Gen. único. Hipo- El gén. Hippobosca del O. Dípteros.

\section{RADIARIOS.}

Primera clase. Equinodermos. 2 Ordenes.

I. Orden. Estelíferos ó provistos de pies y forma radíada. 3 familias.

Pr. Farn. Estelerídes; cuerpo aplastado gencralmente dividido er radios; boca-anoen el centro
dirigida hacia abajo.......................

G. I. Asteria. II. $\{$ I. Asteria del O. MoluEuriala. $\{$ scos. II. sin corresp.

Seg. Fam. Equínides. Cavidad digestiva de dos orificios ; cuerpo globoso..

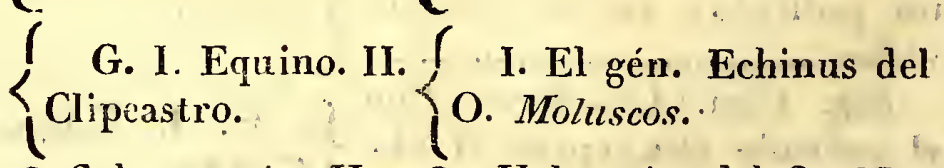

Ter. Fam. Holotúrides; cuer- $\{$ Solo un gén. Ho- $\{$ Holoturia del O. Mopo prolongado casi vermiforme. Lloturia.

Ziuscos.

II. Orden. Helmintoides cuerpo largo cubier to de una piel coriácea y desprovista de pies. Solo contiene un gén. siponclo. = Sipunculus del O. intestinales.

Clase Segunda. Entozoários. $=2$. ordenes

I. Orden. Cavitarios : conducto intestinal notando una cavidad interna.=2. familias.

Pr. Fam. Filáreos; formadel-\{ G. I. Filaria. I.Tri-\{ I."Filiaria. II. Tricoce-

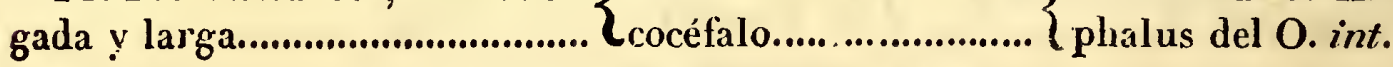


Seg. Fam. Ascaridéos cuerpo largo, cilíndrico adelgazado en sus dos estremidades.
G. I. Ascaride. II. $\{$ I. Ascaris. II. Strongylus. iel O. Int.

II. Orden. Parenquimatosos. Carecen de intestino flotante, pues son de un tegido homogéneo. 2. familias.

Pr. Fam. Trematodes: Tienen en su centro y estremidades unos órganos huecos á manera de ventosas. = Un solo gen. Distoma.= El gen. Fasciola del O. Intestinales de $\mathrm{L}$. Seg. Fa m. Tenioides. Cuerpo
largo y aplastado, de 2 á
chupadores en su estremidad... $\left\{\begin{array}{r}\text { I. Tenia. II. Hidá- }\left\{\begin{array}{r}\text { I. Tenia. III. Ligula del } \\ \text { tida. III. Ligula......... }\end{array} \text { O. intes/. II. sin corresp... }\right.\end{array}\right.$

CIase tercera. Acaléfos. = 2. familias.

Pr. Fam. Acalefos simples: $\{$ G. I. Medusa. II. $\{$. El gén. Medusa del $O$. verse::

Seg. Fam. Acalefos Hidrostáticos: con vegigas aereas......... Porpita....................... $\{$ int.

\section{$\{$ Gén. único. Fisalia. $\{$ Sin corresp.}

\section{Clase cuarta. Pólipos. $=2$. ordenes.}

I. Orden. Ginôpólipos. Pólipos generales aislados y`sin póliperos. 2. familias.

Pr. Fam. Actinianos: Tentáculos numerosos en la boca; cuerpo grande, terminado por un pie que puede fijarse ; nu solo gén. = Actinia. del O. Moluscos.......

Seg. Fam. Hidroides. Sustan- $\{$ G. 1. Hidra. II. Cris- $\{$ I. Midra.cel O.Zoófitos. cia homogénea............................ \{ tatela. III. Vorticèla \{II. y III. siń corrésp

II. Orden. Simpólipos; Pólipos reunidos en polipero. 2. familias

Pr. Farn. Tubiporéos: viven $\{$ G. I. Tubípora. II. $\{$ I. Tubípora II. Coraen las cavidades del polipero. $\{$ Coralina.................... Ullina del O. Zoófíos.

G. I. Antipato. II. $\int$ I. Antipathes. II. GorGorgonia. III. Isis. IV. gonia. III. Isis. IV. Ma-

Seg. Fam. Cortíferos. Viven Coral. V. Madrépora. $\{$ drepora. V. Millépora. en la superficie.

VI. Milépora. VII. $\{$ VII. Pennatula. VIII. AlPennatula. VIII. Al cionium. IX: Esponja del sionio IX. Esponja..... O. Zoófítos.

Clase Quinta. Microzoarios.-- 2. Ordenes.

I. Orden. Rotiferos. Boca rodeada de apéndices muy movibles en forma de rueda. 2. familias.

Pr. Fam. Rotifero propia- $\left\{\begin{array}{c}\text { I. Furculario. II. }\{\text { Sin corresp. } \\ \text { Tubicolario. }\end{array}\right.$

Seg. Fam. Crustodéos. Cuerpo protegido por una cubierta semejante á la de los crustáceos. Un solo gén. Braquiono.=Brachyonus del O. Infusorios.

II. Oiden. Gimnodéos. Sin apéndice alguno; aspecto gelatinilorme. 2. familias.

$\operatorname{Pr}$ Fain.. Vibrionides. Figura larga. = gen. ún. Vibrion $=$ Vibrio del O. Infusorios.

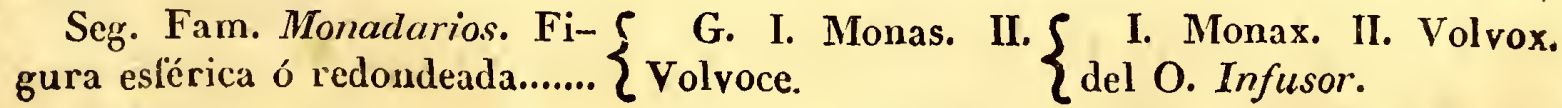




\section{2}

No es menos filosófico el sistema de Blainville que el de Linnéo; por lo tanto le creemos digno de conocerse, aunque esté muy distante de ser generalmente adoptado, como lo han sido los que hemos espuesto. Pero al hablar de el no creemos necesario entrar en minuciosas comparaciones que no permiten los límites de esta obra, y que pueden hacerse fácilmente en vista de la correspondiente tabla. Solo haremos observar que si las grandes divisiones de Linnéo giran sobre la estructura y disposicion de los órganos circulatorios, las de Cuvier en el sistema nervioso y el esqueleto, en Blainville es principalmente sobre el primero de escos últimos.

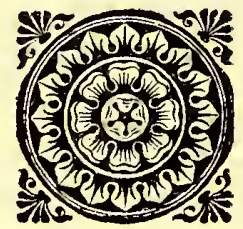




\section{TABLA ALFABÉTICA}

DE

$P_{\alpha}$ materia contenida en los tres primeros tomos.

Abadejo, II, 339.

Abadejo comun, ib.

Abadejo largo, II, 342 .

Abeja, III, 276.

- albañila , III , 275 .

- carpintera. (V. Jilocopo.)

- comun, III, 278.

- solitaria, III, 274 .

Abejaruco, II , 72.

- comun, ib.

Abejon, III, 275 .

- de las piedras, III, 276 .

- de los musgos, III , 275 terrestre, $i b$.

Abejorro, IIİ , 196.

- batanero, III, I 97.

- comun, $i b$.

- de estío, $i h$.

Aboma, II, 222.

Abranquios., III, 105.

Abubillas, II , 70 .

Acalefologia, 1II, 334 .

Acalefos, $i b$.

- hidrostáticos, III , 338.

- simples, III , 335.

Acantoptérigios, II , 257 .

Acárides, 111 , 15 .

Tомо III.
A

Acedia, II , 343.

Acéfalos, III , 57 .

Acéfalos desnudos. (V. Tunicarios.)

Acridio, III , 226.

- de alas azules, III, 227 .

- de alas rojas, $i b$.

Actinia, III , 342 .

- blanca, III , 343.

- coriacea, $i b$.

- purpúrea, ib.

Actinianos, III , 342.

Acuchi , I, 169 .

Aculeíferos, III , 263 bis.

Afidianos, III, 240.

Afrodita, III, I 04 .

- erizada, $i b$.

Agamianos, II, I9I.

Agamis, II , I 13.

Agamo, II, 192.

- ocelado de la nueva Holanda, II , 193.

Agatinas, III, 29.

Agregados, III , 86.

Agrimensoras. (V. Falenas)

Agua , II , 243.

Agudo, II , 16 o.

Agugero de cerradura, (V. Fisu49 
- rela de las tierras magallánicas.) Águila, II , 18.

- comun, II, ig.

- coronada, II, 2 o.

- de cabeza blanca, ib.

- de cola blanca. (V. Pigargo)

-- de cola corta, II, 20.

- destruclora. (V. Harpía grande)

- grande de mar. (V. Águila quebranta huesos.)

- grande ó real, II, I 9.

- imperial, $i b$.

- manchada ó pequeña, ib.

- pequeña de garganta desnuda; II , 20 .

- pequeña de las Indias, ib.

-quebranta-huesos, $i b$.

Águilas pescadoras. (V. Halietos) Aguja ammodites, II , 355.

- del Brasil. (V. Aguja espada.

- de los Sicilianos, II, 290.

- del Mediterráneo, II, 32 I.

- espada, it.

- paladar, $i b$.

Agujas de mar. (V. Singnatos propiamente dichos)

Aguti , I, 168.

- comun, ib.

- con cresta, I, 169 .

Aguza-nieves. (V. Lavanderas)

Ahumada. (V. Anfisbena fuliginosa.

Ai , I , 73 .

Aia, II, I 3 I.

Alacran. (V. Escorpion)

Alactaga, I, 155.

Alacha, II , 337 .

Albatroses, II , 144 .

Albur, II , 3 I 6.

Alcaravan, $11,117 \ldots$
- comun, ib.

Alcata, II , 98.

Alce , I, 246.

Alcion, 11,73 .

Alcionio, 111, 357 .

- comun, ib.

- con pezoncillos, ib.

- de ramas largas, $i b$.

Alcotan, II , 24.

Aléctor, II, 9 .

Alejanor, III, 28 I.

Alfaneque. (V. Buso comun)

Aligator. (V. Caiman)

Almeja , III , 73 .

- comun ó comestible, III, 74 .

- de estanque. (V. A nodonte)

- de los pintores. (V. Unio de los pintores)

- del Rhin. (V. Unio del Rhin)

- litofaga; III, 74 .

Almenado, I, 79 .

Almendra de mar, III, 38.

Almizclada. (V. Ampolla.)

Almizclero. (V. Cervitillo.)

- comun. (V. Cervitillo comun.)

Almohaza. (V, Portuno.)

- comun, 1II, I 17 .

- pequeña, $i b$.

Alondra, II , 5 I.

- con cresta. (V. Alondra monuda.)

- de los árboles, II , 42.

- de los bosques, II, 52 .

- de los campos ó campestre, ib.

- de los prados, II , 42 .

- de mar, II, 126.

- moñuda, II, 52 .

- trivial. (V. Pipi.)

Alosa. (V. Sábalo.)

Alpaca, I , 239. 
Aluato, I, 6 I.

- bermejo, ib.

Amarilla de limon, HII, 282.

Ameiva, II, 188.

- azul, $i b$.

- comun, ib.

Ammoceto, II , 389.

Ammodites, II , 355.

Ammonitas, III , I 9.

Ampolla, III , 38 .

Ampularia, III , 45 .

Anabas, II , 297.

Anablepo, II , 3 I 8 .

Anacondo, II, 222.

Anacoreta, III, 282.

Anaploterio, I ,-222.

Anarrico, II , $3 \circ 8$.

Anatifa, III, 90 .

- de pie de cabra, III, 9 I.

- lisa, il..

Anchoa, II , 337 .

- comun, il.

Anda-rios. (V. Culi-blanco.)

Andiraguazu. (V. Vampiro.)

Andrena, III , 273 .

— de las paredes, III, 27 4.

Anelides, III, 97.

- errantes. (V. Dorsibranquias.)

Anémona de mar. (V. Actinia.)

Anfibios, I, 127.

Anfinomo, III, Ior.

Anfipodos, 1II, I 29.

Anfisbena, II, 217.

- blanca, II , 2 I 8.

- fuliginosa, $i b$.

Anfitrite, III, ror.

- de las ostras, III, 102.

--de panal, il.

Angel comun, II, 38 r.

- de mar, $i b$.
Anguila, II, 35 o.

- comun, ib.

- de hocico aplastado, II , 352.

- de hocico large, $i t$.

-- del vinagre. (V. Vibrion.)

- eléctrica. (V. Gimnota eléctrica.)

- microscópica. (V. Vibrion.)

- pimperneau, II , 352 .

- vernieaux, $i b$.

Anguiliformes, II , 349 .

Anhinga, II, I 55.

- comun, II , 156 .

Ánis, II , 84.

- de las sábanas, II, 85.

- de los pantános, ilu.

A nodonte, III, 74 .

- cisne, III, 75 .

- de los estanques, il.

Anolis, II, 200.

- de banda, II , 20.1.

- dè cresta, $i b$.

- de garganta roja, ib. de papada, $i b$.

Anomia. (V. Placuna.)

Anon. (V. Eglefin.)

Anouros, II, 234.

Antilope, I, 249 .

- comun, I, 252 .

- de cuernos ahorquillados, I, 254.

- de cuernos con arista en espiral, ib.

- de cuernos con doble corvadura, I, 253.

- de cuernos con triple corvadura , I , 252 .

- de cuernos largos, il.

- de cuernos lisos, I, 253.

- de cuernos rectos, I, $25 \mathrm{I}$. 
-de las Indias, I, 252 .

- de Nubia, $i b$.

- furcifera ó cubril, I, 255.

- ordinario, I, 252 .

- pintado, I, 254.

- saltador, I, 25 I.

Antiopa, III, 282 .

Antipato, IlI, 352 .

- en forma de abanico, $i b$.

- espiral, $i b$.

Anto, II, 42.

Apara, I, 176 .

Aperea, I, 165 .

Aplysia, III , 36.

- depilatoria, III, 37 .

- moteada, III, 38.

- ribeteada, $i b$.

Apolo comun, III, 28 I.

- pequeña, $i b$.

Apos, III , 135 .

Ápteros, III, 166 .

Ara, II, 87 .

- jacinto, II, 88.

- tricolor, ib.

Aracaris, II, 86.

Aracnides, III , I 38 .

- hiladores. (V. Araneidas.)

- sedentarios, III , 143.

Aracnologia, III , 138.

Arador. (V. Sarcopta.)

- comnn, III, 153.

Araneidas, III, 14 I.

- vagabundos, III , I 46.

A raña , III, 143.

- alljañila, $i b$.

- atroz, III, I 44 .

- cangrejo. (V. Migala.)

- de agua. (V. Argironeta.)

- de las aves, III , I 43.

- de mar. (V. Pejearaña.)
- doméstica, III, 144.

- loba. (V. Licosa.)

- perfida, III, 144.

Arca, III, 7 I.

- de Noé, ib.

- torcida, $i b$.

Arcaceos, ib.

Ardilla , I , I 37 .

- comun, I, I3g.

- de los Pirineos, $i b$.

- enmascarada, $i b$.

- grande de las Indias, $i b$.

- gris de la Carolina, ib.

- ladrante. (V. Suslik de la Luisiana.)

Arenicola, III, I 02.

-- de los pescadores, $i b$.

Arenque, II , 333.

- descargado, II , 334.

- frescal, $i b$.

- lozano, $i b$.

- lleno, $i b$.

Argali, I, 258.

Arginia, III, 283.

Argironeta, III, 144.

- comun, III, 145 .

Argonauta, III, 14.

--ártico, III, 2 I.

Argos (Ave), II , 96.

Argos (Molusro), III , 49 .

Argos (Insecto), III, 283.

- azul, ib.

- bronceado, III, 284.

- de la encina, $i b$.

- de la virga áurea, ib.

Armadillo. (Cuadrúpedo)(V.Tato.)

Armadillos, III , 132.

Armiño, I, I o3.

Arni, I, 963 .

Arquero, II, 285. 
-- sagitario, II , 286.

Artero, II, 302.

Artesa. (V. Mactra.)

Articulados, IHI , 93 .

Asapan. (V. Polatuca de América.)

Ascáride, III , 328.

-- lumbricoides, $i b$.

--vermicular, ib.

Ascaridéos, III , 32.7 .

Ascidia , III, 86.

Ascite, II, 326.

Asilo, III, 298.

-- avispon, III , 299.

- gigante, $i b$.

Asno, I, 228.

-- salvage. (V. Onagro.)

Asperones, II , 26 I.

Aspid, II, 23 .

_de Egipto ó de Cleopatra. (V. Haja.)

Astacianos, III, 124.

Astas de Ammon. (V. Ammonitas.)

Asteria, III, 3 I 7 .

- anaranjada, $i b$.

- comun, $i b$.

- glacial , ib.

Astrea, III , 355.

Atahorma, II, 20.

Atalanta , 1II, 283.

- Atalia, ib.

Atel, I, 6I.

Ateríceros, III, 3 o3.

Atlas, III, 287.

Atun, II, 288.

- de vientre rayado. (V. Bonito de los trópicos)

- vulgar, II, 28 g.

Aurocs, I, 262.

Aurora, III , 282.

Autillo, II , 26 . .
Ave del paraiso anaranjada, II, 64. del paraiso dorada, II , 63 .

- del paraiso roja, $i b$.

Ave de S. Martin, II, 22.

Ave fria, II, I I 0 .

- fria comun ó moñuda, II, II 1 .

- fria pluvial, $i b$.

- fria suiza. (V.. Ave fria pluvial)

Ave loca. (Ave-tontas), II, 54.

Ave loca, II , I 54.

- loca bubi, II , I 55.

- loca de Basano, ib.

Avellanero. (V. Moscardino.)

Ave real. (V. Grulla coronada.)

Ave real del paraiso. (V. Manucodiata.)

Aves del paraiso. (V. Paraiseos)

- de rapiña, II , I3.

- de tempestad, II, I 44 .

Avestruz, II, Io 4 .

- de América. (V. Nandú.)

Ave tonta, II , 53 .

- tonta comun, II. 54 .

- tonta de Laponia, $i b$.

- tonta de las nieves, $i b$.

- tonta de los cañaverales, ib.

- tonta de los setos, ib.

Ave toro. (V. Alcaravan comun.)

Ave zonza. (V. Buso comun.)

Avicula (V.Golondrina.)

Avispa , IlI, 27 I.

- cartonera; III, 272.

- comun, ib.

- dorada. (V'. Crisida.)

- solitaria, (V. Esfege.)

Avispon, III. 272.

Avoceta, II, 124.

- comun; ib.

Avutarda, II, I 08.

- comun, II, rog. 
- pequeña ; $i b$.

Axis, (V. Ciervo manchado de la India.

Axolote, II , 248.
Azor, II ; 20.

- comun, II, 2 r.

- reidor, ib.

Azucareros, II , 68.
Babirusa, I, 220.

Baboso, II , 3 o 7 .

- comun, II , 308.

Babuino, I , 58 .

Bacalao. (V. Abadejo.)

- ling. (V. Abadejo largo.)

- pequeño. ( $V$. Narvaja.)

Balanita, III, 3 I.

- tulipan, III. $9^{2}$.

Baliste, III, 366.

— de banda, II. 368.

- porta-pinceles, $i b$.

Baltimor, II, 59 .

Ballena, I, 282.

- franca ó comun, I, 284.

Ballenópteros, I , 285.

Ballesta. (V. Balistes.)

Bandolera', II , 285.

-de pico. (V. Quetodonte de picn.)

Barbada. (V. Loche.)

-de rio, II, 317.

- franca, ib.

Barbastelá, 1, 82.

Barbican, II , 83 .

- de vientre de color de rosa, it.

Barbo; II , 3 工 5.

- comun, II, 3 I 6.

- marino. (V. Mulo.)

Barbudo, II, 32.

- elegante, II, 83.

Barga, II , 122.

- de cola negra, II, 123.

- labrador ó bermejo, ib.
Barquillo, III , 38 .

Barrena, III, 189 .

Barrica, III, 5 I.

Bartavella. (V. Perdiz griega.)

Basilisco, II , 199.

Batracianos. II, 232.

Becada, II , I 2 I.

- comun, II. I 22.

Becarda. (Ave), 1I, 32.

Becarda. (Pez), II, 33o.

Becasina, II, 122.

Becerromarino. (V. Foca comun.)

Belennita, III, I 9 .

Beluga, I , 2.74.

Bella dama, III, 282 .

Bellota de mar comun, III, $9^{2}$.

- marina. (V. Balanita.)

Bentaveo, II, 33.

Bernacho, II , 160.

Bernicla, ib.

Bestia del diente grande. (V. Vaca marina.)

Besugo, II , 28 I.

Bíbaro. (V. Castor del Canadá.)

Bíforos, III, 85 .

Bimanos. (Cuadrúpedos), I, 4 I.

Bimano. (Reptil), 11, 2 1 0.

-lumbricoides, $i$.

Bipedo, II, 209.

- del Brasil, $i b$.

-del Cabo, il.

- de la Nueva Holanda, ib.

Bisonte, I, 262. 
Blanquilla. (V. Anfisbena blanca.)

Blanquilla (Pez), II, 336.

Blapto. (V. Dañino.)

- comun, III. 203.

Blata, III, 220.

- de América. (V. Cakerlás,)

- oriental ó de las cocinas, III, 22 I.

Blennio. (V. Baboso.)

- de cabeza roja , II , 3 o8.

Blongios, II, I 7 .

Boa, II , 22 I.

- adivina ó apretadora, II , 222.

- elegante, $i b$.

Boaquira, II , 227.

Bobác. (V. Marmóta de Polonia)

Boga, II , 28 I.

- comun, II , 282 .

Bogo. (V. Mandril)

Bómbice, III, 286.

- del moral, III. 287.

- procesional, $i b$.

Bonito de los tropicos, II , 289 .

Boqueron (V. Anchoa comun).

Borbechos. (V. Alcionios.)

Botrilo, III , 87.

- amontonado, $i b$.

Bradipos. (V: Perezosos)

Branquiopodos, III, 133.

Branquipos, III, I 34 .

Braquélitros, III , 184.

Braquino, III , I 78 .

- bombardero, III, 179

- petardero, $i b$.

- pistola, $i b$.

Braquiopodos, III, 83.

Braquípteras, II , 136.

Braquiuros, III , I 5 .

Brecas, II, 3 I 6.

Bremas, ib.

Brento, III , 20.8.
- ancoriforme de Cayena, il.

Breves, II, 38.

Brevipennas, II, 103.

Bromas, III ; 82.

Brucho, 1II, 207.

- de las semillas, III, 208.

-- del cacao, ib.

- de los guisantes, $i b$.

Bruja , II , 26.

Búaro, II , 24.

Búbalo, I , 253.

Bucárda, IlI , 77 .

Buccinoides, III , 46.

- arrollados, III , 47 .

- canaliculados , 111 , 52 .

- escotados, III, 50 .

Buccinos, III , 5 I.

Bucéfalo, (V. Dipsade indiana.)

Buey, I, 260.

- almizclado, I , 263.

- comun, I, 26 I.

- de Escocia , I, 262.

- de Indias, $i b$.

Búfalo, I, 262.

- de cola de caballo (V. Yack.)

- del Cabo, I, 263.

Buhito. (V. Escopes.)

Buho., II , 26.

- bracquiato, II , 27 .

- comun, $i b$.

Buitre, II , i 6 .

— barbado, II , I 7 .

- ceniciento, ib.

- de la California, ib.

- de los corderos. (V. Buitre barbado.

- grande de los Andes. (V. Condor.)

- leonado, II , 17.

Bulas, 1II, 38. 
Bulfrog, II, 240.

Bulimo, III , 28.

- escotado, III, 29.

Bupreste, III , 186.

- esternicornio, III, , 87 .

- pequeño ó enano, $i b$.

- verde, $i b$.

Busardo, II , 22.
- bermejo, $i b$.

- ceniciento, $i b$.

- de los pantanos, ib.

Buso , II, 22.

- calzado, $i b$.

- comun, ib.

Buvrelo, II , 56.

- de Europa, $i b$.

C

Caama. (V. Ciervo del Cabo.)

Caballa. (V. Sarda.)

- bastarda. (V. Saurel.)

Caballero. (Ave), II, I 25.

- de los bosques, $i b$.

-- de los pies rojos, $i b$.

- de los pies verdes, $i b$.

-negro, $i b$.

- rayado, $i b$.

Caballero. (Pez), II, 285.

-- variegado ó pequeño, $i b$.

Caballo, I, 223 y 225.

-- marino (Cuadrúpedo.) (V. Hipopótamo.)

-- marino. (Pez.) (V. Hipocampo.)

Cabasú, I, 176.

Cabeza de Medusa. (Molusco ), III, 4 I.

Cabeza de Medusa. (Zoófito.) (V. Euriala.)

Cabiais, I, I64.

Cabra, I, 255.

-- comun, I, 258 .

- de Angora, ib.

- de Cachemira, ib.

- silvestre. (V. Egagro.)

-- sin cuernos de España, I, 258.

Cabrajo (V. Cangrejo de mar.)

Cabron de Judá, I, 258.
-- montés, i $i$.

- montés del Cáucaso, $i b$.

Cacatoe, II, 88.

- azufrado, $i b$.

- con cresta, $i b$.

-- morado, ib.

Cacerola. (V. Límula.)

Cachalote, I, 28 o.

- - comun , I, 282 .

Cachicamo. (V. Tato negro.)

Caiman, II , 184.

-- con anteojos, ib.

- de hocico de sollo, ib.

Cakerlás, III, 22 I.

Calamar, III, 15.

- grande, III, 16.

-- pequeño, $i b$.

- vulgar, ib.

Calamito. (V. Sapo de los juncos.)

Calamon, II , 133.

Calandria, II, 5 .

- pequeña, ill.

Cálao, II, 75 .

-- de casco aplastado, ' II , 76 .

- rinoceronte, $i b$.

- trompeta, $i b$.

- unicornio, ib.

Calasomo, III, 18 I.

Calitricho, I, 57 . 
Callithrix. (V. Sagüino.)

Cama, III, 7 o.

Camáceos, ib.

Camaleon', II, 203.

- de tres cuernos, II, 205.

- enano, ib.

- vulgar, ib.

Camaleonianos, II , 203.

Camaron. (V. Palemon esquila.)

Cambiante de Egipto, II, 193.

Camelo-pardo. (V. Girafa.)

Camello, I, 234 .

- comun, I, 237 .

- marino, II , 369.

- pardal. (V, Girafa.)

Camichi, II, I 3 o.

- comun, III, I 3 r.

Campañol volante, I, 8 r.

Campañol. (V. Raton campesino.)

-- de los pradós, I, I 5 I.

Canario, II, : 56.

Cańastilla, III, 77 .

Cancelaria, III, 5 r.

Cangrejero, II, I I 7 .

- comun, ib.

Cangrejo comun de las costas, III, I 18.

- de agua dulce, III, 124.

- de mar, $i b$.

-- escudado, III , I 8.

- pulga. (V. Gamaro.)

- rabioso. (V. Cangrejo comun de las costas.

Cangrejos arqueados, III, ir 7.

-comunes, III, 124.

-c cuadriláteros, III, I 19.

-- de las Molucas. (V. Límulas.)

-- nadadores. (V. Portumos.)

-- orbiculares, III, I I 8.

-- propiamente dichos, III, I 7 . Tomo III.
- tortugas. (V. Dromias.)

Cangurú, I, 195 .

- elegante, I, 197.

- filandro, $i b$.

- gigante, $I,>96$.

- rata, (V. Potorú.).

Canná, I, 254 .

Cantárida, III, 205.

-comun, $i l$.

- livida, $i b$.

-- negruzca, $i b$.

Cañuto de mar. (V. Sérpula.)

Capistrato. (V. Ardilla enmascarada.)

Caprícornios, III , 21 r.

Caprisco , II, 368.

Carábicos, III, 177 .

Cárabo, III, I 80.

-- jardinero ó dorado, III, $18 \mathrm{r}$.

Caracal, I , 125.

Caracara comun, II, 20.

Caracol, III, 27.

- comun. (V. Carácol grande de las viñas.)

- de boca aplastada. (V. Troco.)

-- grande de las viñas, III, 28.

-- pequeño de los árboles, ib.

Carango, II, 293.

-- bastardo, II, 294.

-- comun, ib.

Carbonera. (V. Paro de cabeza negra.)

- peque r̃a, II , 53.

Carcoma. (V. Barrena.)

Cardenal, II, 37.

Cardiáceos, III, 75 .

Cardina, II , 345 .

Cardo ó

Cardon, III, 126.

-c comun, $i b$.

50 
Carei, II, I 75.

Carnero de Berbería, I , 259.

-- de cinco cuartos. (V. Carnerode Berbería.)

- de cola gruesa. (V. Carnero de Berbería.),

Carneros del Cabo. (V. Albatroses.)

Carniceros (Mamíferos), I, 7.0.

Carniceros (insectos), III, 17.5 .

Carnívoros, I, 88.

Carpa, II , 3 I 4 .

- comun, II, 3 I 5 .

-- de espejo, $i b$.

- dorada. (V. Dorada de la China.)

Caruge, II , 59 .

- bastardo, ib.

Casca-nueces, II , 6 r.

Casco. (Ave.) (V. Cásico.)

Casco. (Molusco), III , 53.

- con malla, $i b$.

-- dentado, $\mathrm{i} l$.

- rayado, $i b$.

- rojo, ib.

-- triangular, $i b$.

Cásico, II, 58.

-- de rabadilla roja, II, $5 \mathrm{~g}$.

- negro, ib.

Cásida, III, $2 \times 3$.

- moteada, III, 2 I 4 .

-nebulosa, ib.

-- verde, $i b$.

Casoar, II, ro6.

- con casco. (V. Emeu.)

-- de la nueva Holanda, II, 106.

Casoario, (V. Casoar.)

Castañas de mar. (V.Equínides.)

Castor, I, I 56.

- del Canadá, I, 15.

Cata. (V. Alcata.)
Catarrinos, $\mathrm{I}, 52$.

Catartos, II, 17.

Cauana, II, 175 .

Cavadores, 1II, 268.

Cavitarios, III, 325.

Cayopolin, I, 187 .

Cazon, II, 38 o.

Cebellina, I, ro4.

Cebra, I, 230.

Cecela, II, 20.9.

Cecilia, II, $23 \mathrm{r}$.

— anillada, II, 232.

- glutinosa, $i b$.

- lumbricnides, $i t$.

-_tentaculada, ib.

Cefalopodos, III, 10 .

Cefalopologia, $i b$.

Ceixupira, II, $29^{2}$.

Celan, II, 336.

Centronotos, II, 29 I.

Centropromos, II, $26 \mathrm{r}$.

Centrotos, III, 239.

Ceo, II , 296.

-- comun, $i b$.

Cerambices. (V. Capricornios.)

Cerasto. (V. Víbora cornuda:)

Ceratofitos, III, 352.

Cerceta, II, 16 o.

Cerdo, I, 2 I 6.

-- de Guinea, I, 220.

-- de orejas grandes, $i b$.

- de Polonia, ib.

-- de Rusia, ib.

-- de Siam, ib.

- turco, $i b$.

Cerdos de tierra. (V. Oricteropes.)

Cerita, III, 54.

-- gigante, $i b$.

Cernícalo comun, II, 24.

- pardo, ib. 
Cervicornio, II, 274.

Cervitillo, 1, 240 .

- comun, 1, 241.

- pigmeo, ib.

Cetáceos, I, 264.

- herbívoros, 1, 266.

- sopladores, I, 268.

Cetonio, III, 197 .

- dorado, 111, 198 .

- magnifico, $i b$.

- pequeño, $i b$.

Cibeto. (V.Gato de algalia.)

Cicadarios, III, 236 .

Cicadelas, 11I, 238 .

Cicindela, 111, $177^{\circ}$

- campestre, $i b$.

- de los bosques, $i b$.

Cicindeletos, III, 176 .

Ciclada, III, 77 .

Cíclicos, 111, 212.

Cíclopes, $111, \times 34$.

Ciclópteros, 11 , 347 .

Ciclostomos , II , 386.

Ciervo, I, 243.

- comun, I, 247.

- del Cabo, I , 253.

- del Canadá, I, 247.

-- de Virginia, $i b$.

-- manchado de la India. (V. Axis.)

- rojo grande. (V. Gazu-pocú.)

--volante, HI, 200.

Ciervos de astas aplastadas, I, 246.

- propiamente dichos, $i b$.

Cigarra, III , 236.

-del quejigo, III, 238.

- hematodes, $i b$.

-plebeya ó comun, ib.

Cigena, III , 286.

- de la filipéndula, ib.

- turquesa, il.
Cigüeña, 11 , 117.

-- blanca, II, II8.

- negra, $i b$.

Ciguetai, I, 230 .

Cimbes, III, 260 .

Cimbulios, III, 21 .

Cinclos, II, 38.

Cínife , $111,263$.

-- del agabanzo, 111,264 .

- de la higuera silvestre, $i b$.

-- tintorial, $i b$.

Cinocéfalos, I, 57 .

Ciprinos, II , 3 r3.

Cipros, III, 134 .

Cirquinzon, 1,176 .

Cirropodos , III, 89 .

Cirropologia , $i b$.

Cisne, 11, 159 .

-de pico negro, $i b$.

- de pico rojo, $i b$.

- negro, $i b$.

Civetas, I, I I 2.

Clausilias, $111,29$.

Clavicornes, III, rgr.

Cleodoros, III , 22.

Cleopatra, III , 282.

Clio, III , 20.

- boreal, III, 2 r.

Clipeastros, III , 3 I 9.

Cloportes, III , 33 .

- verdaderos, HI , 132.

Clupeas, II, 332.

Coaita , I, 6 r.

Coala ceniciento, I , 197 .

Coatis, I, 9.8.

Cobayas, 1 , 165.

Cobra Capello. (V. Naya.)

Coccinela, III , 2 I 6.

- de dos puntos, ib.

- de dos pústulas, ib. 
- de siete puntos, ib.

Cocodrilianos, II, 180.

Cocodrilo, II, I 83.

- vulgar, ib.

Cochero, II , 285.

Cochevis, (V. Alondra moñuda.)

Chochinilla, III , 243 .

- del nopal ó higuera de Indias, $i b$.

Cochinillo de Indias, I, 66.

Codorniz , II , 99.

-- comun, ib.

- de América. (V. Colin.)

Coendú , I , I6r.

Cofre. (V. Ostracio.)

-- atigrado, II , 369.

- concantenado, II, 370.

- de cuatro cuernos, ib.

- liso, $i b$.

- paralelipipedo, ib.

Cogujada. (V. Alondrá de los campos.)

-- verdadera. (V. Alondra moñuda.)

Cola de látigo de Egipto, II , 192.

-- roja , II , 42.

Coleópteros, III, 173.

- heterópteros, III, 200.

- pentámeros, III, 175 .

- tetrámeros, III, 206.

-- trímeros, III , 2 I 5.

Colibrí, II , 69.

- topacio, II, 70 .

Colimbo, II , 136.

-cornudo, II , I 3.7 .

- de carrillos grises, $i b$.

-- moñudo, $i b$.

- pequeño, ib.

Colin, II, 99. --vulgar, $i b$.

Colombelas, III, 5 I.

Colombino, II, , I o I.

Collaliba, II , 42 .

-- comun, ib.

Comadreja, I, I o.2.

- rayada de Madagascar, I, 103.

Combatientes, II, I 26.

Concha de Santiago. (V. Peine mayor.)

Conchas de los pintores. (V. Unios.)

-- de peregrino. (V. Peines.)

- de Venus, (V. Porcelanas.)

Conchologia , III , 57 .

Condiluro, I , 88.

Condoma. (V. Cudu.)

Condor , II ; 7 .

Condroptérigios, II , 370 .

Conejo comun, I, 163.

- de Aroe. (V. Cangurú filandro.)

- magallánico, I, 163.

Conepato, I, I 02.

Congrio, II, 352.

Coni-rostres, II, 49.

Cono, III, 48.

-- atigrado, $i b$.

- escrito. (V. Mil puntos.)

- grande almirante, III , 48.

- paño de oro, ib.

Conquiliologiá, III, 3.

Coracia. (V. Cuervo-grajo comun.)

Coral (Molusco), III, 64 .

Coral (Zoofito), III , 353.

-- blanco, III , 355 .

-d del comercio, III, 354 .

-- negro. (V. Antipatos.)

- negro y blanco, III, 353.

Coralina, III , 349.

- oficinal, III, 35 o. 
Coras. (V. Mandril.)

Corazones. (V. Cardiáceos.)

Corbulas , III , 77.

Corcolí, II , 126 .

Cordilo, II , 92.

Cordon azul, II , 35.

Corifena, II, 294.

--del Mediterraneo, II, 295.

Corina, I, 252 .

Coris, III, 49 .

Cormoran, II , 152 .

-- comun, II , I 53.

- pequeño ó zonzo, $i b$.

Corneja, II , 6 I.

-cabizcana, ib.

- de pico blanco, ib.

- pequeña de los campanarios, $i b$.

Corofios, III , I 3 o.

Corredera. (V. Blapto comun.)

Corredores, III, 2 I 8.

Cortadores de agua. (V. Pico-tijeras.)

Corticíferos, III, 35 I.

Corvinas, II, 278.

Corzo , I , 247.

Cotingas, II , 34 .

- propiamente dichos, II , 35.

Coto, $11,273$.

-- comun, II, 274.

- de cuernos de ciervo. (V. Cervicornio.)

-d de largas espinas, II , 274.

-- de Rusia, ib.

Cotorra, II , 88.

-- comun, ib.

- de collar, $i b$.

Crabros, III, 27 I,

Crepusculares, III, 284.

Criadilla de mar. (V. Naranja de mar.)

Cricetos. (V. Hansteres.)

Criquetes. (V. Acridios.)

Crisida, III , 264.

-- azul ỳ roja, III, 2,63 bis.

- listada, il.

-- verde y azul, $i b$.

Crisocloro del Cabo, , I , 88.

Crisomela, III, 2 I 4.

- del álamo, III , 2 I 5.

- de las cereales, $i b$.

- sangninolenta, $i b$.

Crísope , I, 62.

Cristatela , III , 246.

- moho, ib.

Crótalo, II , 226.

- de la Guayana. (V. Duriso.)

- de los Estados unidos. (V. Boaquira.)

Crustáceos, III, I I 0.

Crustodéos, III , 363.

Cruz de los caballeros, III , 231 .

Cuadradillo, I, 85.

Cuadrante, I!I , 45.

Cuadratulo. (V. Acedia.)

Cuadrumanos, I, 48 .

Cuadrúpedos. (V. Mamíferos.)

Cuaga , I , 23 o.

Cuatro ojos. (V. Zarigüeya mediana.).

Cucaracha. (V. Blapto comun.)

-- verdadera. (V. Blata oriental.)

Cuclillo, II , 8I.

-- comun, ib.

Cucuyo, III, 188.

Cudú, I, 254.

Cuervo, II , 59 .

- de mar, II, 279.

- vulgar, II, 6 I. 
Cuervo-grajo, Il, 7 o.

-comun, ib.

Cuguar, I, $x 25$.

Cui, I, I6r.

Culebra, II , 222.

- bordelesa, II, -224.

- comun ó de collar, ib.

- de cuatro rayas, $i b$.

- de Esculapio, io.

- lisa, ib.

- verde y amarilla, $i b$.

- viperina, ib.

Culi-blanco, II, 2.4 .

- de rio. (V. Caballera rayado.)
Cultri-rostres, II, 112.

Cuquillo. (V. Cuclillo.)

Curruca, II, 42.

- comun, ib.

- de invierno, $i b$.

- parlera, ib.

- pequeña, $i$.

Curucú, II, 83.

- verde, II, 84 .

Curururi, II , 244 .

Cusco, 1, 193.

- de grupa dorada, $i b$.

- manchado, ib.

- ursino, $i b$.

\section{CII}

Chacal, I, xo.

Chámsés. (V. Cocodrilo vulgar.)

Charlador, H, 35.

- de Europa, ib.

Chica. (V. Pulga penelrante.)

Chicarra, 1, 255.

Chimpansé, 1, 54 .

Chinche (Mofeta), I, 102 .

Chinche (Insecto), III, 231 .

- de la col, $i b$.

- de las camas, ib.

- de las cruciferas, it?

Chinches de agua. (V. Hidrocorisos.) Chupadores. (V. Ciclostomos.)
- moscas. (V. Reduvios.)

- navecillas. (V. Naucoris.)

- terrestres. (V. Geocorisos.)

Chinchilla, I, 144.

Chocha perdiz. (V. Becada comun.)

Chorlito, 11, 121.

- comun, $i b$.

- pequeño, ib.

Chotacabras, 11,47 .

- comun, $11,48$.

Chova. (V. Corneja pequeña de los campanarios.)

- de mar. (V. Oscabriones.)

\section{D}

Dactilóptero, H, $27 \%$.

- comun, 11,273 .

Dafnia, III, 135 .

- pulga, $i b_{\text {. }}$

Danta. (V. Tapir.)

Jañinos, III, 202.
Dasiuro, I, 189 .

- de cola larga, I, 190.

- erizado, $i \phi_{6}$.

Dátil, III, 81 .

Delfin, I, 271 .

- comun , I, 272 . 
- grande, $i b$.

Delfiná ptero, I, 274.

- de hocico blanco, 275.

Delfinoides, I, 27 I.

Delfínulas, III , 45 .

Dendrocolapto, II , 67 . comun, $i b$.

Denti-rostres, II , 28.

Depona, II, 222.

Derbio, II , $29^{3}$.

Dermeste, III ; 192.

- de la peleteria, III, 193.

- del tocino, $i b$.

-raton, $i b$.

Dermobranquios, III, 3 r.

Desinan (Rumiante). (V. Cervitillo comun.)

Desman (Carnicero). (V. Migale.)

- de los Pirineos, I, 86.

- de Rusia, ib.

Desollador, II, 32.

Dezmeño. (V. Rata de los muladares.)

Diablos. (V. Centrotos.)

- de Java. (V. Pangolines.)

- de mar. (V. Pejesapos.)

Diána, I, 57 .

Didelfos. (V. Zarigüeyas.)

Digitígrados, I, 98.

Dimiarios, III , 69 .

Diodon, II , 363.

- armado, II, 364 .

- atinga, $i b$.

- erizado, $i b$.

Diodonte.-(V. Diodon.)

Dioscobolos , 1I, 346.

Diplópteros, III , $28 \mathrm{r}$.

Dipsade, II, 223.

- indiana, II, 22 .

Dípteros, III, $29^{2}$.
Dístoma, III, 33 o.

- del hígado, III, 33 เ.

Ditisco ; 11. , 182.

- anchisimo, III , 183.

--de Ræsel, ib.

- marginal ó ribcieado, $i b$.

Diurnas, (Aves), 11 , I 4 .

Diứrnos, (tepidópteros), III, 279.

Doble-andadoras, II, 217 .

Dónace, III , 77 ,

Doncellita. (V. Libélula.)

-de tenazas, III , 247.

- grande, ib.

Doncellitas terrestres. (V. Hemerobios.)

Dorada comun, II, 28 i.

-- de la China, II, 3 I 5.

Doris, III, 33.

- argós, ib.

-- de ancho borde, $i b$.

-- estrellado, III , 34 .

- nudoso, $i b$.

- tomentoso, ib.

-- velloso, $i b$.

Dorsibranquios, IIII, , 03 .

Dragon, 11 , 194.

-- de mar. (V. Pegaso dragon.)

-- de mar comun. (V. Pejearaîia comun.)

-- pardusco, 195.

- rayado, $i b$.

-- verde , $i b$.

Dragonas, II, I 87.

Dragoncillo. (V. Filaria comun.)

Dril , I , 58.

Drinas, II , 227.

Dromia , III , I 20.

-calavera, III, i 2 I.

-- comú, III , I 20.

Dromedario, I, 237 . 
Duco , I, 58.

Dudongo, I, 268 .

Duque grande, II , 27.
- mediano. (V. Buho comun.)

- pequeño: (V. Escopes.)

Duriso, II, 227.
Edentados, I, 169 .

- propiamente dichos , I, I 73.

Efímero, III, 247.

-comun, III , 248 .

- de cola larga, $i b$.

- díptero, ib.

Egagro, I, 257.

Eglefin, II, 340 .

Eider, II, I 6́o.

Elafro, III , I 79 .

-- riberiego, III , I 80 o.

Elan. (V. Ciervo del Canadá.)

- del Cabo. (V. Cánna.)

Elater, III, I 87 .

- bronceado, III , I 88.

- castaño, $i$.

- de collar rojo, ib.

Elefante, I, 206.

-- de Africa, I, 208.

--de las Indias, il.

-- de mar, (V. Foca trompuda.)

Elodones, III, I I 4 .

Emargínulas, III , $4 \mathrm{r}$.

Embudos, III , 45 .

Emeu, II , I o6.

Emides. (V. Galápagos.)

Emisauros, II, I 72.

Encarnadillo. (V. T'eropo.)

-- de otoño, III , I 53.

- pequeño. (V. Teropo pequeño.)

Encerrados, III, 77 .

Encubertado, I , 176 .

Enterrador. (V. Necróforo.)

-- de Hungría, III, 192.
Entomologia, III, I 5 g.

Entomostráceos, III , I 32.

Entozoários, III, $\mathbf{3}_{2} 3$.

Entozoologia, $i b$.

Eperlano, II, 33o.

Epimaco, II , 7 o.

- de adornos rizados, $i b$.

--de dos filamentos, II , 7 I.

- magnífico, $i b$.

-real, $i b$.

Equidno, I, r 99 .

-- espinoso, I, 200.

-- sedoso, ib.

Equínides, III , 3. 8.

Equino, III, 3 I 9.

-- comun, ib.

- de color de violeta, $i b$.

Equinoderínos, III , 3 I 4 .

Equinologia, $i b$.

Erizo, I, 83 .

- de Europa , I, 84.

-- de orejas grandes, $i b$.

Erizos de mar. (V. Equinides.)

Ermitaño Bernardo, III, I 24.

Escalatas, III , 45 .

Escalope, I , 88.

Escarabajo, III, 198 .

_-de cuerno a horquillado, III. I 99.

-- de patas largas, $i b$.

- de resorte. (V. Elater.)

-- hercúleo, III , I 98 .

- pelotero. (V. Estercolero.)

- tortuga. (V. Cásida.)

Escarabeides, III, 194. 
Escaro, II, 3 o3.

- de Creta, $i b$.

-- papagayo, II , 3o4.

-- rojo de oro, $i b$.

Escienoides, II, 277.

Escilea, III, 34.

- comun, $i b$.

Escineo. (V. Estineo.)

Esclerodermos , II, 365.

Escolopendra , III, 158.

- comun, $i b$.

- de América ó mordedora, ib.

- de ocho patas, $i b$.

- de mar. (V. Nereida.)

- Escomberoides, II , 286.

Escombros, II , 287.

Escopes, II , 27.

Escorpena , II , 275 .

- grande, $i b$.

- horrible, II, 276.

- pequeña, II , 275 .

- voladora, $i b$.

Escorpion, III , . 48.

- comun , III, 149 .

- de África, ib.

- de agua (V.: Nepas.)

- de mar, II , 274.

Escualos, II, 377.

Escudíferos , III, I 58.

Escudiformes. (V.,Clipeastros.)

Escutibranquios, III , 38.

Escherman , I , 15 I.

Esfege, III, 269 .

-- bello , III ; 170.

- de los caminos, ib.

-- de los campos, ib.

-- verde dorado, ib.

Esfenisco del Cabo II, $14 \mathrm{x}$.

Esféricos. (V. Volvoces.)

Esfinge, III , 285.

Tomo III.
- calavera, $i b$.

-- de la viña , ib.

- del titimalo, $i b$.

Esmarrido, II , 283.

- alcion ó martin pescador, $i b$.

Esmeralda, II , 63.

Esmerejon, II, 24.

Esmeril , II , 22.

Esocéos, II; 3 I 9.

Espada , III , 80.

Esparavan. (V. Esmerejon.)

Esparo; II, 28 o.

- artero, II, 302.

Esparoides, II , 280.

Espátula , II , 1 18.

- comun ó blanca, $i b$.

- de color de rosa, II, Irg.

Espectro, III , 222.

- gigante, $i b$.

Espejo, III , 284.

Espermofilos, I , 142.

Espinoso, II , 276 .

- comun, ib.

- pequeño, ib.

Espírula , III , 18.

Espolonero, II , 93.

-- comun, $i b$.

Espóndilo, III, 63.

- gederopo, $i b$.

Esponja , III, 357.

-- comun, III. 358 .

Espuelas , III , 45 .

Esquammipennas, II , 283.

Esquilas, III, 1.27 .

Estafilino, III, I 84.

- odorífero, III, 8.5 .

- peludo, ,ils.

Estelérides, III, 3 I 6.

Estelíferos , III , 3 × 5.

Estelion, II , 192. 5 x 
-comun, ib.

Estercolero, III , 95.

-- momo, III, I 96.

- tifeo ó falangisto, $i b$.

Estercorario, II, 14.7 .

- catarata , II, I 48.

- parasito ó de cola larga, $i b$.

- pomárino, $i b$.

Esternoxos, III, 86.

Estinco, II , 206.

-- de las farmacias, II , 207

-- de tres rayas, II, 208.

Estincoidianos, II, 206.

Estomatopodos, 11I, I 27 .

Estorninos, II , 59.

Estratiomo, III , 301.

-- camaleon, III, 3 o3.

Estrella de mar. (V, Asteria.)

Estrellados, II, I92.
Estrepsibranquios, II , 296.

Estringe gorrion. (V. Lechucite.)

Estro, III , 304.

- del buey, III, 306.

- del caballo, $i b$.

- del carnero, ib.

Estrombos, III , 56.

Estrongilo, III, 328.

-- del caballo, $i b$.

- gigante, $i b$.

Esturion, II , 372.

- comun, II, 3,73 .

- grande, II , 3.74 .

- pequeño , ib.

Esturionianos, II, 372.

Eurialas, III , $3 \times 7$.

Exoceto, II, 321 .

- saltador, II , 322 .

- volante, $i b$.
Factonte, II, 156 .

- comun, II , I 57 .

- de cola roja, $i b$.

Fahaca de los árabes, II , 363.

Faisan, II , 95 .

- comun, II, 96 .

- de agua (V. Rodaballo comun.)

— de Juno. ( $\mathrm{V}$. Argos, ave:)

- dorado, II, 96.

- plateado, $i b$.

Falangero, I, r 90 .

- enano, I, I92.

- volante. (V. Petaúrista.)

- zorra, I, 92 ?

Falangianos, III, I 50. .

Falaropo, II, i 2.7 .

- ceniciento, II, II 28.

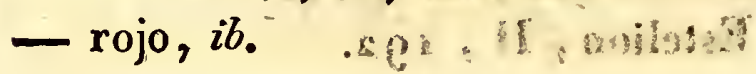

Falena, III, . 290.

— azufrada ódel sauco, HII, 291.

— de la lila, $i b$. An :

- del grosellero, $i b$.

Faringianos laberintiformes. (V. Estrepsibranquios.)

Fascolomos, I, I97. . Fatagin, $\mathbf{I}, \mathbf{x} 78$.

Fauno, III, 282 .

Fedra, ib.

Feronia, III, I 79 .

- de ojos blancos ; $i b$ metálica, ib.

Filaréos, III, 3.6.6. Filária, ib.

- comuñ $i$ ib:

Filocrocoras, (V. Cormoranes.)

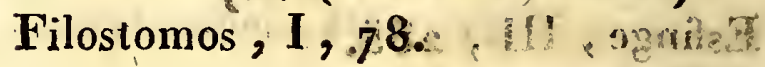
. 18 ons 
F isálias, III , 338.

F isi-rostres, II, 44 .

Fisurelas, III, $4 \mathrm{I}$.

- de las tierras magallánicas, $i b$.

Flamenco, II , i 33.

Flasco-psaro. (V. Fahaca de los árabes.)

Fleso, II , 344 .

Fletan, ib.

Foca, I, I 29.

- comun, I, $\mathrm{x} 3 \mathrm{o}$.

- con crines, I , I 3 I.

- de vientre blanco, I, 130.

- trompuda, $i b$.

- ursina, I, I 3 I.

Folada, III, 8 o.

- vulgar. (V.Dátil.)

Forbicina, III , I67.

- del azucar ó plateada. (V. Lencera.

-jaspeada, III , I 68 .

Formicarios ; III, 265.

Fosana.(V. Gineta de Madagascar.)

Fragala. (Ave), II, 153.
- comun, II, i 54 .

Fragatas. (Zoófito.) (V. Acalefos.) Fraile. (Foca.) (V. Foca de vientre blanco.

Fraile.(Mono), I , 64.

Frailecillo, II, 140.

- comun, $i b$.

Francolin, II, 99.

- de Italia , $i b$.

Friganeo, III, 248.

— de hilos largos, III , 2490

- estriado, $i b$.

- grande, $i b$.

Fringilagos, II , 54 .

Fulga, II, I6o.

Fulgora, III, 239 .

- europea, III , 240 .

- porta-candela, $i b$.

- porta-linterna, ib.

Fulica, II , I 33 .

- comun, $i b$.

Fulmar, II, 144 .

Furcularios, III, 363.
Gacela, I, 252 .

- comuń, $i b$.

Gadoides, II , 338.

Gados, $i b$.

Gálago, I, 6 .

- enano, I, 70 .

- grande, $i b$.

Galápago, II , 170.

- cenagoso, II, I 72.

- comun ú orbicular r, ib.

Galatća, III,, 282.

Galeopíteco, I , 73 .

- bermejo, I, 74 .
Galeóte, II , r $9^{3}$.

Graleras. (V. Acalefos.)

Galgo, I , I og.

Gálgulo, 1I, 6 .

- comun, II , 62.

Gallina doméstica, 96 .

Gallináceas, II , 89.

Gallincta ciega. (V. Becasina.)

- ciega comun, II ; 122.

- ciega sorda, ib.

- de mar. (V. Ceo.)

Gallo; II, 96.

- de mar. (V. Ceo.) 
- de roca, II, 43 .

- de roca comun, $i b$.

- de roca del Perú, ib.

- de roca verde, $i b$.

-doméstico, 11,96 .

- silvestre. (V. Tetras.)

- silvestre de cola ahorquillada, II , 98 .

- silvestre de jaral. (V. Gallo silvestre grande.)

- silvestre grande, II , 98 .

Gamaros, III, I 29.

Gamba. (V. Zarigüeya grande del Paraguay.)

Gambeta. (V. Caballero de los pies rojos.)

Gamo, I, 246.

Gamuza , I , 253.

- del cabo. (V. Antilope de cuernos largos.)

Ganga , II , 98.

- de los arenales, $i b$.

Ganso, II, i59.

- comun, $11,160$.

- de frente blanca, $i b$.

- de nieve, $i b$.

Garceta grande, II, I1 7 .

- pequeña, $i b$.

Gardon, II , 3 I 6.

Garduña , I, 103.

Garganta azul, II , 42 .

- negra, $i b$.

Garrapata, III , 153.

Garza, II , 15.

- real purpúrea , II, 117 .

- real vulgar, $i b$.

Garzota, ib.

- de Europa, ib.

Gasa de mar. (V. Manquito de Neptuno.)
Gasteropodos, III, 22.

Gasterosteo. (V.Espinoso.)

-- de escudo ventral dividido, 1I, 2.76.

Gato, I, 17 .

-- calzado. (V. Lince.)

-c cerval, I, 125.

- comun, I, 123 .

- de algalia , I, 1 I 3.

- de Angora, I, 124.

- de Constantinopla. (V. Gineta comun.)

- de España, I , 124.

-de los Cartujos, il.

- de mar. (V. Lija pequeña.)

- volante. (V. Galeopíteco.)

Gavial, II , 183.

- comun, $i b$.

-) pequeño, $i b$.

Gavilan, II , 2 I.

- cantor, II, 22.

Gaviota, II, 145.

-blanca, II, 47 .

- de capucha negra, ih.

- de pies amarillos, $i b$.

- de pies azules, $i b$.

- de pies rojos, $i b$.

- tridactila, $i b$.

Gazu-pocú. (V. Ciervo rojo grande.)

Gecarcino, III, 1 r 9 .

- de los campos, III, 120.

Gecko, II , 202.

- de las casas, ib.

- de las paredes, $i b$.

- filuro ó de cola en forma de hoja, II , 2 o3.

Geckotianos, II, 201.

Geocorisos, III , 230 .

Geómetras. (V. Falenas.)

Geopítecos (V. Sangüinos. 
Geotrupo, III, 196.

-de primavera, $i b$.

- estercolero, $i b$.

Gerbillo, I, 155.

- de las Indias, $i b$.

Gerbo, I, 154 .

Gerboa, I, 155.

Gerifaltes, II, 23.

Germon, II, 289 .

Gial , I, 263.

Giobar, I, 285.

Gibon, I, 54 .

- agil, I, 55.

- grande. (V. Onko.)

- pequeño. (V. Gibon agil.)

Gilguero, II , 55.

Gimnodéos, III, 364.

Gimnodontes, II , 36 r.

Gimnopólipos, III, 34 r.

Gimnota, II , 353.

- eléctrica, III, 354 .

Gineta , I, I13.

- comun, I, 114 .

- de Java, ib.

- de las Indias, $i b$.

- de Madagascar, $i b$.

Girafa, I, 248.

Gladiador. (V. Orca.)

Glano. (V. Saluth.)

Glaucos. III, 34 .

Glomero, III , 157 .

Gloton, I, 96.

- del Norte, I, 97.

Gobio, II, 3og.

- azul, II , 3 го.

- blanco, $i b$.

- de rio, II , 3 r 6 .

- negro, II, 3ro.

- rojo, II , ib.

Gobioides, II , $3 \circ 6$.
Goelandio. V. Gaviota.)

- burgomaestre', II , 147 .

- de manto azul, $i b$.

- de manto negro, $i b$.

Goelandios propiamente dichos, $i b$. Goliats, III , 198.

Golondrina. (Ave), II, 45.

Golondrina. (Molusco), III, 67.

- de chimenea, II , 46.

- de mar. (Ave), II, 148.

- de mar. (Pez), II , 272 .

- de mar de pico negro, II, 149.

- de mar de pico rojo, $i b$.

- de mar negra, $i b$.

- de mar pequeña, ib.

- de roca, II, 46.

- de ventana, $i b$.

- riberiega, $i b$.

Gondoleras, III, 5 I.

Gorfú, II , 14 x.

Gorgojo, III , 208.

- anubarrado, III, 209.

- brillante, $i b$.

- comun, ib.

- imperial, $i b$.

- tenebroso, $i b$.

Gorgonia , III, 352.

- en forma de abanico, ib.

Gorrion, II, 55.

- de los campos, ib.

- de noguera. (V. Gorrion de los campos.

- doméstico, $i b$.

Grota de agua, III, 38.

Grajo, II, 6r.

- comun, ib.

Grajuela. (V. Martin.)

Gran bestia. (V. Alce.)

Granivoros, II, 50.

Grebo. (V. Colimbo.) 
Gremillas, II , 263.

Grifeas, III , 63.

Grifitas. (V. Grifeas.)

Grifos, II , I 7 .

Grillo; III, 223.

- de los campos, III, 224.

- doméstico, III, 25 .

Grillo-talpa, II , 223.

- comun, III, 224.

Gryllus lineola, III, 227.

- umbraculatus, III', 25.

Grimio, I, 252 ,

Gris pequeño. (V. Ardilla comun.)

Grison, I, 97.

Grison. (Marsúpial), I, 187 .

Grulla , II , I I 4 .

- comun, II, 1 I 5 .

- coronada, $i b$.

Gruñidor, II , 27 I.

Guacamayo. (V. Ara.)

- azul, II, 88.

- rojo, ib.

Guadaña." (V. Zorra de mar.)

Guan, II, 92 .

— con cresta, $i b$.
- katraca, ib.

- marrail ; $i b$.

Guanaco, I, 238.

Guariba, I , 6 I.

Guarino, $i b$.

Guazuti , I , 247.

Guepardo, I , 126 .

Guerlinguete, $\mathbf{I}, \mathbf{3} 3 \mathbf{9}$.

- enano de Cayena, I, I 40.

- grande de América, $i b$.

Guevei , I, 252.

Gillemote, II , 139 .

- de capucha, $i b$.

- de espejo, blanco, $i b$.

- enano, ib.

Guitguit, II , 68.

Gunelo, II , 3o 8 .

Gusanillo. (V. Filaria comun.)

Gusano de la harina. (V. Tenebrion de tahona.

—del oido (V. Tijeretas.)

- de luz. (V. Lampiro.)

- de seda. (V. Bombiçe del moral.)

- de tierra. (V. Lombriz.).

\section{II}

Haja II , 229.

Halcon, II , 22.

- comun, II , 23.

- perdiguero. (V. Esmeril.)

Halicto, II, I $9 \cdot$

Haliótides, III, 39 .

Hamster , I , I 46.

- comun, I, I 48 .

Harfango, II, 26 .

Harpas, III, 5 I.

Harpía, II, 20.

- grande, $i b$.
Hediondo. (V. Veso.)

- del cabo. (V. Zorrillo.)

Hidrioftalmos, HII, , 28.

Helicologia , III , 20.

Helmint ides, III, 32 I.

Hélmintologia, III, 97 .

Hemeróbio, III, 252.

— verde, III, 253.

- verde y negro, $i b$.

Hemípteros, III, 228.

Herina. (V. Gerbillo de las indias.)

Herpetologia, II, I62. . . . 
Herraduras: (V. Rinolofos.)

Hesperia, III, $28 \%$.

- vergeteada, $i b$.

Heterópteros, III, 229 .

Hiala, III , 2 I.

- córnea ó cristalina, ib.

Hidátida, III, 332.

- celulosa, $i b$.

- cerebral, $i b$.

Hidra, III, 344:

- pardusca, III , 345 .

- verde, $i b$.

Hidrocántarós, III', 8 I.

Hidrocorisos, III , 233 .

Hidroides, III , 344 .

Hiena , I , I 15.

- manchada, I, II.

- morena, ib.

- rayada, $i b$.

Hierro de lanza. (Cuadrúpedo, I, 79 .

Hierro de lanza. (Pez.) (V. Trigonocéfalo.)

Higo de mar, III , 35.7. 11 ? widit,

Hilotomos, III, 260 .

Himenópteros, III , 256 .

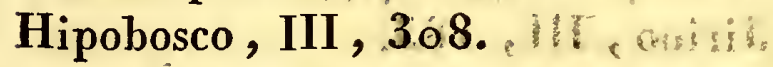

- de la golondrina, $11 \mathrm{H}$, fog 6 -

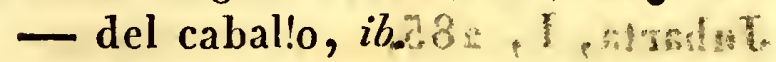

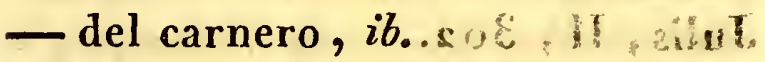

Hipocampo, II , 358.: "1sman, nom

Hipopótamo, I, 2 I 5. . is . 10:

Hoco, II, 9 r.

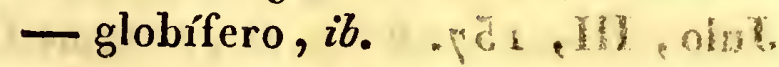

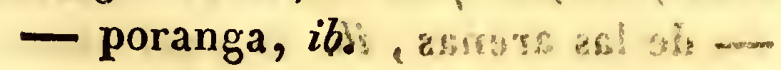

- rojo, $i b$.

Hoja de lirio, III, 226.

- seca, III, 222.

Holoturia, III, 3 x 9 .

- escamosa, III, 320 .

- real, ib.

- temblona . $i b$.

Holotúrides, III , 3 ×9.

Hombre, I, 4 I.

Homópteros, III, 235.

Hormiga , III, 265.

- leon, III, 250 .

- leon comun, $\Pi 1,252$.

- negra y cenicienta, III, 268 .

- roja y negra, III, 267 .

- rojiza ó amazona, III, 268.

- sanguínea ó roja, ib.

Hormigas blancas. (V. Termites.)

Hormiguero. (Ave), II , 38.

Hormigùero. (Manifero), I , I 78.

- espinoso. (V. Pangalin.)

- propiamente dicho , I, 8 . 8 .

Hormilla de boton, III, 45.363

Hornero, II , 68.

Hortelano, II , 54 .

Houtin de Ios belgas. (V Lavareto falso.)

Hubara, II , rog.

-Hucho, II , 33 o.

Huevos, III, 49.

Huletas, III, 646.m.

Huron, I, I 02.

Husos, III , 55 .

Hutú. (V. Momot de cabeza azul.)

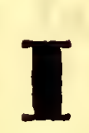

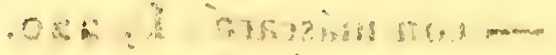

Ibis, II , I 20.

- negro. (V. Ibis verde.)
- rojo, II , r 20.

- sagrado, $i b$. 
- verde, II, I 2 I.

Icneumon. (Mamffero.) (V. Mangosta de Egipto.)

Icnéumon. (Insecto), III , 262.

— amarillo, III , 263.

- asesino, $i b$.

- enterrador , $i b$.

Ictiologia , II , 250.

Ictiosauro, II , I 79 .

- comun, II, 180 .

Iguana , II , 197.

- comun, II, 199 .

- cornuda, $i b$.

- de cola armada, $i b$.

- de color de pizarra, $i b$.

- de cuello desnudo, $i b$.

Iguanianos, II, 19 o.
- propiamente dichos, II, 197. Impocko. (V. Canna.) Indicadores, II, 82 . Indri, I, 67 . - de cola corta, $i b$. Inflados. (V. Orbes.) Infusorios. (V. Microzoarios.)

Inquisidor, III I 81 . Insectivoros, I, 82. Insectos, III , $15 \mathrm{~g}$.

Io , III , 282 .

Iris, $i b$.

Isatis. (V. Zorra azul.)

Isis , III , 353 .

Isopodos, III, 13 I.

Istiuros, II , 194.

Iulides. (V. Quiloñatos.)
Jabirú, II 118.

Jacamar , II , 78.

- comun, ib.

- grande, $i b$.

Jacana, II , 129.

- bronceado, II , 130 .

- comun, $i b$.

- de cola larga, $i b$.

Jacki, II , 240.

Jaco, II , 88 .

Jacú , (V. Guan.)

Jaguar, I, 124.

Jamoncillo. (V. Pinna.)

Janto, III, 284 .

Javalí, I, 2 I 9.

- con máscara, I, 220.

- de Etiopia, ib.
- de Europa, ib.

Javalina, $i b$.

Javato, ib.

Jibia , III , 16.

- comun, III, 17 .

Jilocopos, III, 274.

Jirino, III, , 83 .

- nadador, ib.

Jabarta, I , 285.

Julis, II , 302.

- comun, $\mathrm{i} b$.

- rojo, ib.

- turco, ib.

Julo, III, 157 .

- de las arenas, $i b$.

- terrestre, $i b$. 


\section{7}

\section{$\mathbf{K}$}

Karruvet. (V. Oficéfalo punteado.) Kinkajú , I, 98.

Kebel, I, 253.

Kukurlacho. (V. Orang-utang.)

\section{$\mathbf{L}$}

Labro, II, 3or.

-- tordo. (V. Vieja verde.)

Labroides, II , 3 oo.

Lacertianos, II, I 84 .

Ladilla, III, 7 I.

Lagartija, II, r 9 o.

Lagarto, II , i 88 .

- gris de las arenas, II, 189 .

- verde ocelado, II, 190.

Lágomis, I, 163.

-- enano, I, 164 .

-- gris, $i b$.

-- pica, $i b$.

Lagópedo, II; 98.

-comun, $i b$.

--de los sauces, $i b$.

Lamantin: (V. Manatí)

Lamelicornes, .11I, 193.

Lameli-rostres, II , 157 .

Lamentador, II, 35 .

- grande, $i b$.

- pequeño; $i b$.

Lammergeyer. (V. Buitre barbádo.)

Lámpara. (V.Patela.)

Lampiro, III, 188.

Lamprea , II, 388.

二 de rio, $i b$.

- grande, $i b$.

Lampregüela, II , 389.

Langosia , III , 225.

- de alas rojas. (V. Acridio de alas rojas.)

Tomo III.
- de mar, III, 125.

- de paso, III, 226.

- grande ó verde, $i b$.

Langostino, III, 126.

Lapa. (V. Patela.)

Lari de Sumatra, I, 140.

Lates, II, 26 r.

Laud, II, $x 75$.

Lavandera, II, 42.

Lavareto, II, 33 r.

- falso, $i b$.

- propiamente dicho, $i b$.

Lechucita, II, 26.

Lechuza comun, $i b$.

- de los peñascos. (V. Miloca.)

- solitaria. (V. Zumaya).

Leminge, $I$, I $5 \mathrm{r}$.

- de Noruega, I, 152 .

Lemurienos, I, 66 .

Lencera, III , 68 .

Lenguado (Pez.) , II, 345 .

Lenguado.

Leon, I, 120.

— de pulgones. (V. Hemerobio.)

- marino. (V. Foca con crines.)

Leopardo, I, I 23 .

Lepidópteros, !1:, 2.78 .

Lepto, III , 299.

- becada, $i b$.

- de otoñio. (V Encarnadillo de otonิo.)

- gusano leon, IH, 299 , 52 
Leroto, I, 144.

Libélulas, HI , 2 \&6.

Librea. (V. Caracol pequeño de los árboles.)

Licornes, III, 52.

Licosas, III, 145 .

Liebre, I, 16 I.

- comun, I, 163.

- de mar (Pez). (V. Mariposa de mar.)

- de mar (Molusco). (V. Aplisia.)

- pampas, I, 69.

-- variable, I, í63.

Ligula, III, 333.

--de la broma, $i b$.

Lija, II , 377 .

-comun, II , 378.

- pequeña, $i b$.

Lima, III, 64.

Limacíneos, III, 26 .

Limanda. (V. Platija propiamente dicha.)

Limasinos, III, 23.

Limaza , III , 27.

- de mar. (V. Aplisia.)

- gris, III, 27.

- gris pequeña, $i b$.

- roja, ib.

Limnéa, III , 3 x.

- de las lagunas, $i b$.

- enana, $i b$.

- mediana, $i b$.

- viagera, $i b$.

Limneános, III , 29.

Limpia troncos. (V. Sitila.)

Íímulas , III , 136.

Lince, I, 125.

- del Canadá, ib.

Lingulas, III, 84.

Liparis, 11 ; $34 \%$.
Liquia, II , 292.

- comun, ib.

- sinuosa, II, 293.

Lira (Ave), II , 40.

Lira (Pez), II, 272.

Liron, I, 143.

- espinoso, $i b$.

- propiamente dicho, I, 144.

Litófitos, III, 352.

Lobo, I, Iog.

- cerval, $I_{2} 125$.

- de mar, 11, 3og.

- de Méjico, I, ro.

- dorado. (V. Chacal.)

- negro, I, I 10.

- rojo, ib.

Loco. (V. Ave loca.)

Loche, II , 3 I 6.

- de charca. (V. Misgurn.)

- fosil. (V. Misgurn.)

Lofios, II , 3o4.

Lofobranquios, II, 356.

Lofóforos , II , 93.

Lombriz, III, 107.

- de cola de hilo. (V. Tricocéfalo.)

- de la harina. (V. Tenebrion de tahona.)

- de mar. (V: Arenícola de los pescadores.)

- de Medina ó de Guinea. (V. Filária comun.)

—intestinal, III, 323.

- solitaria. (V. Tenia comun.)

Longicornes, $1.11,210$.

Longipennas, II, $14 x$.

Longi-rostres, II, I 19.

Loris , I, 69.

- gracil, $i b$.

- perezoso, $i b$.

Loros , II , 88. 
Lota, II , 34 I.

- comun ó de rio, II , 342 .

Lubina, II , 36o.

Lucánides, III, 199.

Lucanos, $i b$.

Lucerna (Pez), II , 27 2,

Lucerna (Insecto) (V. Luciérnaga.)

Lúciérnaga , III, 189.
- comun, ib.

- de Italia , $i b$.

Lucina, III , 77 .

Luén. (V. Argos, ave.)

Lumpo, II , 347.

Luna de mar. (V. Rueda de mar.) del Mediterráneo, II , 364 .

\section{LL}

Llamas, I, 238.

M

Macaco, I, 58.

- comun, ib.

Macrocéfalos, I, 276 .

Macrodactilas, II, 128.

Macrotarsos, I, I94.

Macrouros, III, I 2 I.

Mactras , III, 77 .

Macho cabrio doméstico, I , 258.

Machuaranes, II, 325.

Madre de perlas, III, 67 .

Madréporas, III , 354.

Magnífico, II, 63.

Magote, I, 58.

Magro, II, 278.

Mainato, II , 39 .

- de Java, ib.

- de las Indias, $i b$.

Maki , I , 66 y 68 .

rojo, I, 68.

Mal agüero. (V. Blapto comun.)

Malacologia , III , 3.

Malacoptérigios, II ; 3 I o.

- abdominales, II , 3 I 2.

-ápodes, II , 349 .

— subbraquianos, II, 338.
Malacostrologia, III, 110.

Malaptéruro, II , 326.

- eléctrico, II, 327 .

Malarmado, II , 272.

Maleaceos, III , 65.

Malruke, II, 275.

Malvís, II , 38.

Mamantes. (V. Mamíferos.)

Mamíferos, I, 28.

Mammuth, I, 209 .

Manaqui, II, 42.

- blanco, II, 44.

- de cabeza dorada, $i b$.

- de cabeza roja, ib.

- de garganta blanca, $i b$.

- militar, II , 43.

Manatí, I, 268.

Manco, II, I 40.

- grande, II, 141 .

Mandril, I, 58 .

Mañeta de mar. (V. Alcionio comun.)

Mangabey, I, 57 .

Mango de cuchillo. (V. Sólen.)

- de cuchillo comun, III, 80. 
Mangon. (V. Folada.)

Mangosta, I, I I 4 .

- de Egipto, ib.

- de las Indias, $i b$.

Manguito de Neptuno, III, 356.

Mánticoros, 1II, I 77 .

Mantis, III, 22 I.

- comun ó rezadora, III, 222.

Mantos. (V. Esquilas.)

Manucodiata , 1I, 63.

Mapa geográfico, III, 49.

Mapache. (V. Vulpeja lavadora.)

Mapurito, I , I 02.

Marabú, II , x 8.

Marena, III , 33 I.

Margaritifera. (V. Madre de perlas.)

Marginela, III, 5 r.

Marikina , I , 66.

Maringüino. (V. Mosquito.)

Mariposa, III , $28 \mathrm{o}$.

- anacarada, III, 283.

- de cardo. (V. Bella dama.)

- de la col, III, 28 I.

- de la malva, III, 284.

- del hinojo. (V. Mariposa grande de cola.)

- del rábano, ib.

- de mar, II, $3 \circ 8$.

- de medio luto. (V. Galatéa.)

- de Tabaco encarnado, III, 283.

- grande de cola, III, 28 r.

- pequeña de cola , III , 283 .

Mariposas-abejones. (V. Crepusculares.)

Mariposas de noche. (V. Nocturnos.)

Mariquita, (V. Coccinela.)

Marmosa. (V.Zarigüeya ratonina.)

Marinota, I, 40.
- de Alemania. (V. Hamster comün.)

- de los Alpes, I, I 43.

- de Polonia, ib.

Marsopa. (V. Marsopla.)

Marsopla , I, 273.

- coinun, I, 274 .

Marsupiales, I, i 82.

Marta, I, yoo.

- comun, I, ro3.

Marte grande. (V. Iris.)

-pequeño, III , 282.

Martillo (Pez.), II, 38 o.

- vulgar, ib.

Martillo (Molusco), III , 65.

Marlin, II , 39 .

- propiamente dicho, ib.

- pescador. (V. Alcion.)

- pescador, II, 74 .

Mastin, I, I o9.

Mastodonte, I, 209 .

- de dientes estrechos, $i b$.

- grande, $i b$.

Mataco. (V. A para.)

Medusa, III , 336.

- orejuda, III , 337 .

Megacéfalo, III, 225.

Megalonix , I , I 7 I.

Megalosauro, II, I 87 .

Megaterio, I, r.7 I.

Melasomos, II, 20 r.

Meleta. (V. Sardineta.)

Melíferos, III, 273 .

Memina. (V. Cervitillo pigmeo.)

Menas. (V: Cangrejo comun de las costas.)

Méndola, II , 283.

- comun, $i b$.

Mensagero, II , 24.

Mergo, $1 \mathrm{I}, \mathrm{x} 6 \mathrm{O}$. 
- grande ó vulgar, II, I6r.

- moñudo, $i b$.

- pequeño, $i b$.

Merino, I, 259.

Merion, I, I 55.

- del Canadá, ib.

Merlan. (V. Pescadilla.)

-- amarillo. (V. Truchucla.)

Merlango. (V. Pescadilla.)

Merluza, II , 34r.

Merú , II , 262.

Mía , III , 78 .

-- de las arenas ; III ; 79 .

-- truncada, $i b$.

Mico (V'́stiti), I, 66.

Micos , I , 55.

Microps (V. Mular.)

Microscopios. (V. Microzoários.)

Microzoários, III, 36 o.

Microzoologia, $i b$.

Migalas, III , 142.

Migales, I, 85 .

Mikiri, I, 6 I.

Mil puntos, III , 48 .

Milandro, II , 38 o.

Milano; II , 22.

-n negro, ib.

- real, ib.

Milépora, III , 355.

- hojosa, $i b$.

- sólida ó de diversas formas, $i b$.

Miliar, II, 227.

Miloca, II , 27.

Miluinam, II , 16 o.

Miluino, $i b$.

Mink, I , r o3:

Miriapodos', III , 154.

Miriapologia, $i b$.

Mirlo, II , 37 .

\section{Europa.)}

- azul, II, 38.

-- calvo, II , 39 .

- comun, II , 38.

-- de agua. (V. Cinclo.)

-- de color de rosa, II, 3 g.

-de oro. (V. Oropéndola de Europa.)

-- de pechuga blanca, II , 38.

- de roca, $i b$.

- religioso. (V. Mainato.)

Mirmegos. (V. Formicarios.)

Mirtilo, III, 282.

Misgurn, II , 3 I 7 .

Mitiláceos, III, 72.

Mitras, III , 5 r.

Mitú. (V. Hocos.)

Mococo, I, 68.

Mochuelo del Ural, II, 26.

- gavilan. (V. Surnia.)

- lapon, II, 26.

- vulgarmente dicho. (V. Buho bracquiato.)

Mofela, I , I O I.

- comun, I, Iо2.

Molinero, II, 3 I 6.

Molipennas, III, 188.

Moluscos, 11I, I.

Momot, II, 74 .

- de cabeza azul, III, 75 .

Mona, I, 57 .

Monadarios, III , 366.

Monade, III, 367 .

- elemental, $i b$.

- polvo, ib.

Monax, I, I 43 .

Moneda. (V. Coris.)

Mongú, I , 68.

Monitor , II , 185.

- amarillo. (V. Oropéndola de
- del Nilo, II , 186. 
- terrestre, II, I 87 .

Monja. (V. Paro palustre.)

Mono, I , 5 I.

- leon. (V. Marikina.)

- rojo del Senegal. (V. Patas.)

- verde. (V. Calit richo.)

Monóculos. (V. Entomostráceos.)

Monomiários, III, 59 .

Monos arañas. (V. Ateles.)

- aulladores. (V. Aluatos.)

- de América. (V. Platirrinos.)

- de cola. (V. Micos.)

- de cola de Zorra. (V. Sakis.)

- de hocico de Zorra. (V. Makis.)

- de noche. (V. Sakis.)

- del antiguo continente. (V. Catarrinos )

- llorones. (V.Sajúes.)

- perezosos. (V. Loris.)

-- sagrados. (V. Semnopítecos.)

- terrestres. (V. Saguiinos.)

Monotremos, I, 198.

Montan̂és grande, II, 54.

Morillon, II , I6o.

Mormiros, II , 322.

Morsas, I , 13 I.

Morvan , I , 259

Mosca, III, $3 \circ 6$.

-- araña. (V. Hipobosco.)

- armada. (V. Estratiomo.)

- armada grande. (V. Estraliomo camaleon.)

-- azul de la carne, III, 307.

-- de luz. (V. Cucuyo.)

--de sierra. (V. Tentredo.)

- de sierra amarilla, III , 260.

-- de sierra dé grandes muslos, $i b$.
-- de sierra de la escrofularia, ib.

- de sierra verde, $i b$.

-- doméstica, III , 307 .

- verde dorada, $i b$.

- vibrante. (V. Icneumon.)

-- vivipara ó carnicera, III, 307.

Moscardino, I, 144.

Moscareta , II , 33.

- de Madagascar. (V. Vadiola.)

-- del Paraiso, II , 33.

Moscon, III , 3 o 7 .

Mososauro, II , 187 .

Mosquito, III, 295.

-comun, III, 296.

-- de los caballos, ib.

-- de trompetilla, $i b$.

Mostacho, II , 53.

Motacilla lúgubre, IIİ ; 42.

Motolita. (V. Lavandera.)

Muesca ; III , $4 \mathrm{t}$.

Muflon, I , 259.

Mular , I , 282 .

Mulo. (Mamífero), I, 229.

Mulo. (Pez), II , 267 .

Murciélago, I, 74 .

-- comun. (V. Vespertillo.)

-- marino, II , 305.

Murclas. (V. Cotos.)

Murena , II, 353.

Murices, III', 54 .

Musaraña , I, 84.

-_ almizclada de las Indias, I, 85.

-- de agua, $i b$.

-- pequen̂a ó comun, ib.

Mustela. (V. Méndola.)

Mutilas, III , 268.

Muttah. (V. Oficéfalo rayado.) 
Nacagua. (V. Azor reidor.)

Nagor, I, 252.

Nandú, II , 105.

Naranja de mar , III, 357 .

Nariz-blanca, I , 57 .

Narval ${ }^{-}, 1,275$.

Narvaja, II , 340.

Nasas, III , 5 r.

Nátices, III , 46.

Naucoris, III, 234 .

-- chinche, $i b$.

Naucrates. (V. Rémora piloto.)

Nautiláceos, III , 17 .

Nautilo, III , I 8.

-- de llamas. (V. Taza de Venus.)

-- papiráceo. (V. Argonauta.)

Navios. (V. Acalefos.)

-- de guerra. (V. Albatroses.)

Naya, II, 229.

- propiamente dicha, $i b$.

Necróforos, III, 192.

Nemóceros, III, 294.

Nepa, III, 234 .

- cenicienta, III, 235 .

- linearis, $i b$.

Nereidas, $111,105$.

Neritas, III , 46.

Neritinas, $i b$.

Neumobranquios, II , 247.

Neumodermos, III, 21 .

Neurópteros, III , 244.
Nevatilla. (V. Lavandera.)

- amarilla, II , 42 .

-- de primavera, $i b$.

Níctero, I, 8 o.

- de java, I, 8 I.

--de la Tebaida, ib.

Nigua. (V. Pulga-penetrante.)

Nilgó. V. (Antilope pintado.)

Ninfa, III, 282.

--del álamo, ib.

Niú, I, 254.

Noctua, III, 28 .

-- del gordolobo, III, 290.

- dorada, ib.

- gamma, $i b$.

Nóctulo, I, 8 I.

Nocturnas, II , 25.

Nocturnos, III, 286.

Nodis, II, 149.

-- negro (V. Pájaro loco.)

Nomparelles. (V. Clausilias.)

Nónol, II , 93.

Notacantos, III, 3or.

Notopodes (V. Dromias.)

Nudibranquios, .11I, 32.

Nummulitas, III, 19.

Nutria, I, ro4.

- comun, I, 105.

-- de mar, ib.

- pequeña de la Guayana. (V. Oyapodk.)

Nu (V. Niú.) 
o

Oblade, II, 282.

Oculinas, III , 355.

Odre de mar. (V. Ascidia.)

Oficéfalo, II , 298.

-- punteado, II , 299.

-- rayado, $i b$.

Ofidianos, II , 2 工 o.

Ogoton. (V. Lagomis gris.)

Ojo de buey, III, $4 \mathrm{x}$.

- de rubí, $i b$.

Olivas, III , 5 r.

Ollero ó alfarero, III, 27 I.

Omnivoros, II , 57 .

Onaga, I, 23 o.

Onagro, I, 228.

Ondatras , I , 53.

Onko, I, 55.

Onquidios, III, 3 o.

Oposum. (V. Zarigüeya.)

Orangs, I, 53 .

Orang-utang, I 54 .

Oranverde, II, 83.

Orbes, II, 362 .

-- espinośos, II , 364 .

Orbículas, III , 84.

Orca, I, 27.4 .

- blanca. (V. Beluga.)

_-de cabeza redonda, I , 274.

Oreja de asno, III , 40 .

- de mar. (V. Haliótide.)

-- de mar comun ó tuberculosa, III, 40 .

Orejudo, I, 8 I.

- comun, I, 82 .

Orfias, II , 32 I.

Organo de mar, III , 349.

Orictéropes , I, 180.
Oricú, II , I 7:

Oriol. (V. Oropéndola.)

Ornitologia , II , I.

Ornitorinquio, $I, 200$.

- paradoxal, $i b$.

Oropéndola, II , 40.

-- de Europa, $i b$.

Ortega, II , 98 .

-comun, ib.

-- negra de América. ib.

Ortigas de mar (V. Acalefos.)

Ortópteros, III, 2 I 7.

Orugas en forma de baston. (V. Falenas.)

Orveto, II, 2 I. 4 .

- comun, II, 2 I5.

Oscabrion, III, $4 \mathrm{I}$.

-- escamoso, III, 42 .

-- ribeteado, ib.

Osifraga. (Y. Águila quebrantahuesos.)

Oso, I, 9 I.

-- blanco de mar Glacial, I, 93.

-- del Tibet, ib.

- juglar de las Indias, ib.

- marino. (V.- Foca ursina.)

-- negro, I, 93 .

- pardo, ib.

- terrible de la América Septentrional, $i b$.

Ostra, III, 6r. 241 : ext

-c comun , III , 62.

- espinosa. (V. Espóndilo.)

- hoja, III, 63.

- parasita, ib.

-- pequeña del Mediterráneo, $i b$.

Ostráceos , III , 6 I. 


\section{5}

Ostrácios , II , 368.

Ostrero, II , I I I.

-d del Brasil, II , I 12.

-negro, ib.

Otarios, I, I3o.
Oveja , I, 255.

-c comun, I, 259 .

Oxirinquio, II , 322.

Oyapock, I, 187.
Pacas, I, 166.

Pagro, II, 28 r.

Paguro, III, I 22.

- de cola ancha, III, $\times 24$.

Pajarita de las nieves. (V. Lavandera.)

Pájaro loco, II, 149.

- mosca, II, 7 o.

- mosca gigante, $i b$.

- mosca magnífico, ib.

- mosca pequeño, $i b$.

- niño. (V. manco.)

- trompeta. (V. Agami.)

Pájaros, II 27.

Pajel, II , 28 I.

Palatina, I, 57 .

Palemon, III, 126.

- esquila, ib.

Paleosauros, II, I 78 .

Paleoterios, 1, 214.

Paleto (V. Gramo.)

Palmípedas, II , 34 .

Paloma, II, roo.

- de la Groenlandia. (V. Guillemote enano.)

- gura ó coronada, II, rox.

- lumachela, $i b$.

- magnífica, $i b$.

- torcaz ó de roca, $i b$.

- zorita , bravía ó campesina, ib.

- zorita pequeña (V. Colombino.)

Paludinas, III , 46.

Tomo III
Paneiris, II , 298.

Pangolin, I, I 76 .

- propiamente dicho I , 178 .

Pantera ; I, 123.

-- grande. (V. Jaguar.)

Papafigo. (V. Reyezuelo.)

-- propiamente dicho, II, 42 .

Papagayo, II, 86.

- amazona, II, 88.

- ceniciento. (V. Jaco.)

-c comun, II, 88.

-- de agua (V. Dafnia, pulga.)

- de mar (Ave.) V. Frailecillo.)

- de mar (Pez.) (V. Escaro.)

Papa-moscas, II, 32.

-- de Lorena ó de collar, II, 34.

-- pardo ó comun $i b$.

Papa-mosquitos. (V. Moscaretas.)

Papavientos. (V. Chotacabras.)

Papion, I, 18.

Paquidermos, I, 203.

-- propiamente dichos, I, 2 I

Paraíseos, II , 62.

Parasitos, III, 169 .

Pardillo, II , 55.

-- pequeño. (V. Sizerin.)

- propiamente dicho, II , 56.

Parenquimatosos, III, 329.

Parmacelas, III, 27.

Parnasianas, III, 28 r.

Paro, II , 52.

-- de cabeza azul , II , 53.

53 
- de cabeza negra, $i b$.

-- de cola larga, $i b$.

- mon̂udo, $i b$.

- palustre, $i b$.

Pasan. (V. Antilope de cuernos largos.)

Paseng. (V. Egagro.)

Pastinaca, II , 385.

- comun, II, 386. .

Patas, I, 57 .

Patela, III , 4o.

- comun, III, 4r.

- griega, $i b$.

Patira, I, 222.

Pato, II , 58.

— almizcleño, II, 160 .

- arlequin, $i b$.

- comun, $i b$.

- de la Carolina, ib.

- de la China, ib.

- silvador, $i b$.

— suavisimo.(V. Eider.)

Pauxi, II, 91.

- con piedra, II, 92 .

Paviota. (V. Gaviota.)

Pavo, II, $9^{3}$.

- comun, II, 94 .

- ocelado, $i b$.

- real, II, 92.

—real de dia. (V. Io.)

— real de mar. (V. Vieja rayada.)

- real doméstico, II, 93.

- real espicífero", $i b$.

- real nocturno, III, 287.

Pavón. (V. Pavo real.)

Pavones de doble espolon. (V. Espoloneros.)

- de impei. (V. Lofóforos.)

Pecari, I, 22 I.

- de collar. (V. Patira.)
- de labios blancos. (V. Tayazú.)

Peces, II, 25 o.

- blancos. (V. Brecas.)

- de méjillas armadas. (V. Trigloides.)

- del Paraiso. (V. Polinemos.)

- volantes. (V. Dactilópteros.)

Pectinibranquios, III, 42 .

Pectoñates, II, 359.

Pedimanos, I, 184 .

Pedioclos, III, II4.

Pedipalpos, III, 147.

Pega-reborda, II, 3 o.

- bermeja, II , 32.

- comun, $i b$.

- meridional, ib.

- parda. (V.Pega reborda conun.)

-- pequeña ó de Italia, II, 32.

Pegaso, II, 358.

--dragon, II , 35g.

- nadador, $i b$.

- volante, $i b$.

Peine, III, 64.

-- mayor, ib.

Pejeangel. (V. Angel de mar.)

Pejearaña , H, 263.

- comun, II, 264 .

-- grande, $i b$.

-- pequeño, $i b$.

Pejesapo, II , 3 o.5.

- comun, $i b$.

Pekan, I, r 04 .

Pelícano, II, 5 I.

- comun, II, 152 .

Pelidnos, II , 26.

Pelota de mar. (V. Higo de mar.)

Pelotero lunar, III, 196 .

- sagrado, ib.

Penátula, III, 356.

- gris, $i b$. 
-- roja, ib.

Pentatoma de patas negras, $\mathrm{HI}, 23$ r.

Peñascos, III , 55.

Peónzas. (V. Trocos.)

Peramel, I, r 9 o.

- de hocico puntiagudo.

Perca, II, 26 o.

-- comun, ib. .

- gigante. (V. Merú.)

Percas de mar. (V. Serratos.)

- del Nilo. (V. Lates.)

- gobionerasa (V.Gremillas.)

Pernóptero de Egipto, II, 17 .

Pércoides, II , 25 .

Perdiz. (Ave), HI, 99.

Perdiz. (Molusco), IiI, 5r.

- blanca de los Pirineos. (V. Lagópedo comun.)

- de América. (V. Colin.)

- de la Guayana. (V. Tocro.)

- de mar. (V. Lenguado.)

- de nieve. (V. Lagópedo.)

-- griega, II, 99.

-gris, $i b$.

- roja, $i b$.

Peregrima grande. (V. P.eine mayor.)

Peregrino, , II, 3.86 o.

Perezoso, I, I 7 . I.

Perico ligero. (V. Unó.)

Periquito. (V. Sitáculo.)

Perro, I, x 05 .

- de aguas, I, rog.

-- de. ganado, ib.

-- de las praderas. (V. Suslikg de la Luisiana.)

-- de mar. (V: Lija comun.)

- de presá, I, rog.

-- doméstico, I, 107 .

- volante. (V.Graleopíteco.)
Peruasca, $\mathbf{I}, \mathbf{1} 03$.

Pescadilla, II, 34r.

- comun, $i b$.

- negra, $i b$.

Petaurista, I, I 93.

- de cola larga, I, I9.4.

- de pies velludos.; i $i$.

- enano, I, r93.

-- grande, $i b$.

- orlado, $i b$.

Petrelo, II, 1.42.

-- blanco ceniciento. (V.. Fulmar.)

- gigante, II, I/4.

-- pintado, $i b$.

Petrelos golondrinas. (V. Talasidromos.)

Petronia, II, 56.

Petúnculo, II, 7: i.

- comun, III, 72 .

- jaspeado, $i b$.

Pez armádo.(N. Diodon armado.)

- ballesta. (V. Caprisco.)

— de S.Pedro. (V. Ceo comun.)

- espada, II, , 289 .

- espadacomun, II, 290.

- Iuna. (V. Rueda de mar.)

- manga. (V. Polinemo de filamentos lárgos.)

- sierra, II, 38 i.

- sierra comun, ib.

- volador del Trópico. (V. Exoceto volante.)

Pezpita, II , $: 4.2$ :

- de Suecia. (V. Garganta azul.)

Picafigo: (V. Reyezuelo.)

Pica-maderos. (V. Curucú.)

Picaza, II, 6r.

- comun, $i b$.

- de mar. (V. Mergo pequeño.)

- de mar. (Ostréro), III, I1 2 . 
Pico, II, 78.

- ceniciento, II , 80 .

- de plata, II, 37 .

- grande, $i b$.

- mediano, $i b$.

- negro, ib.

- pequeño, $i b$.

- tridáctilo, $i b$.

- verde, $i b$.

Pico-abierto, II, I 8.

Pico-cruzado, II, 56.

-comun, II, 57 .

-- papagayo, ib.

Pico-fino, II , 40. alondras. (V. Antos.)

Pico-grueso, II , 56.

- comun, $i b$.

Pico-tijeras, II, I 49.

- ceniciento, II , I 50.

- comun, $i b$.

Pie de asno. (V. Espóndilo gederopo.)

Piedra. (V. Pauxi con piedra.)

Piedras numismales. (V. Nummulitas.)

Pierides, III, 28r.

Pigargo, II, 20.

-zonzo. (V. Subbuso.)

Pilas de agua bendita (V. Tridacnos.)

Pilori, I, 150.

Piloto, II, 29 .

-_ del Brasil, II, 292.

Pimélodes. (V. Machuaranes.)

Pinceles marinos. (V. Tubícolas.)

Pinche, I , 65.

Pingüino, III, 140.

-comun, $i b$.

- grande, $i b$.

Pinnas, III, 66.
Pinnóteros , III, 118.

Pintada , II , 95 .

- comun, ib.

- con cresta, $i b$.

- mitrada, $i b$.

Pinzon, II, 55.

-comun, ib.

- de montaña, $i b$.

-de nieve, $i b$.

-- reál. (V. Pico-grueso comun.)

Piojo, III , I 7 o.

- de la cabeza, III, 171.

--de la ropa, $i b$.

Piojos de bosque. (V. Termites.)

-- de madera, III, 255.

Pipa, II, 244 ,

--comun, ib.

Pipí, II , 42.

Pipistrela, I, 81.

Pirabebe, II, 273.

Pirgo, III, 22.

Pirosomo, III , 87.

Pirulos, III , 56.

Pitirojo, II , 42 .

Pitones, II, 223.

Placunas, III, 63.

Plagiostomos. (V. Selacianos.)

Planipennas, III , 250.

Planorbe, III, 3 o.

- blanco, ib.

- córneo, ib.

--de muchas vueltas, $i b$.

Plantígrados, I, 90 .

Platax, II , 285.

Platija, II, 343.

- ancha, II , 344.

- franca. (V. Acedia.)

- propiamente dicha, 1I, 344. $\ldots$

Platirrinos, I, 59.

Plesiosauro, II , 180. 
Pleuronectes, II , 342 .

Pleurotomos, III , 56.

Pluma de mar. (V. Pennatula.)

Pluvial, II , I 09 .

-- de collar, II, I 10.

-- de garganta negra, $i b$.

- dorada, $i b$.

-- morinelo, $i b$.

Podaliro, III, 28 I.

Podura, III, 168.

- acuática, III, 169 .

- negra, $i b$.

Polatuca, I, 140.

- de Américá, ib.

- de Europa, $i b$.

- de las Indias, $i b$.

Poléas, III , 45.

Polécat, I, ro2.

Policípedas. (V. Anatifas.)

Policlino, III , 88.

- diazona, $i b$.

Polifemos, III , 134.

Polighoto. (V. Tordo burlon.)

Polilla, III , 29 I.

- de la cera, III, 292.

- de las colmenas, $i b$.

- de las pieles, $i b$.

- de las semillas, $i b$.

- de los paños, ib.

- de los tapices, $i b$.

- de mar. (V. Broma.)

- de mar naval, III, 82.

Polinemo, II , 266.

- de filamentos largos, ib.

Poliómatas. (V.Argos. (Insecto.)

Pólipo de brazos. (V. Hidra.)

- de brazos largos. (V. Hidra pardusca.)

Polipologia, III , 340.

Pólipos, ib.
- carnosos. (V. Actinianos.)

- de penachos. (V. Vorticelas.)

- de polipero. (V. Simpólipos.)

- de ramillete. (V, Vorticelas.)

- desnudos. (V. Gimnopólipos.)

- gelatinosos. (V. Hidroides.)

Polla de agua, II, 132.

- de agua comun, II, 133.

- de las lagunas, II, 98 .

- de los avellanos. (V. Ortega comun.)

- sultana. (V. Calamon.)

- sultana comun, II , I33.

Pompador, II , 35.

Pongo. (V.: Orang-utang.)

Porcelanas, III, 49 .

Porpitas, III, 337 .

Porta-cresta. (V. Istiuro.)

- vulgar, II, I 94.

Porta-escudillas, II, 347 .

Porta-plumages. (V. Valvadas.)

Portuno, III, I 6 .

- de Tranquebar, III, I 7 .

Potorú, I, 195.

Prendera, III, 45.

Presi-rostres, II, 107.

Presagia-muertos. (V. Blapto comun.)

Pricka. (V. Lamprea de rio.)

Prióno, III, 2 ro.

- cervicornio, III, 2 I1.

- curtidor ó zurrador, $i b$. mohoso, $i b$.

Proboscidianos, I, 204.

Procelários. (V: Petrelos.)

Procesionaria. (V. Bombice procesional.)

Protéo (Reptil), II 248.

Proteo (Microzoário), III, 367 .

- anguiliforme, $\mathrm{H}, 248$. 
Psilo, III , 243.

-del box, $i b$.

Pteroceles, III, 66.

Pterodáctilo, II , 196.

- antiguo, $i b$.

- gigante, $i b$.

Pteropodos, III, 20.

Puerco. (V. Cerdo.)

Puerco-espin, I, I 5 g.

-comun, I, I 6 o.

- de las Indias, I, I6r.

Puerco-espines de mar. (V. Orbes espinosos.)

Pufino, II , I 44 .

- comun ó ceniciento, ib.

- de Escocia., ib.

- oscuro, ib.

Pulga , III , 172.

- comun, III, I 73 .

- de agua dulce. (V. Dafnia.)
- de mar. (V. Gamaro:)

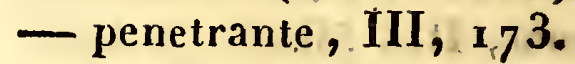

Pulgon, III, 24 I.

- de la encina, III, 2 \%2.

- del haya, $i b$.

- del quejigo, $i b$.

- del sauco, $i b$.

- falso, III, 243.

Pulmonados, III $/, 24$.

Pulmonares, III ; 1 4.o.

Pulpo, III, I 3.

- almizclado, III, I 4 .

- arrugado, ib.

- comun, III, I 3.

Puma. (V. Cuguar.)

Punto de Hungría. (V. Enterrador de Hungría,)

Pupíparos, III, 3 o8.

Pupivoros, III, 260.

Púrpuras, III, 5x.

\section{Q}

Quebranta-huesos. (V. Petrelo gigante.)

Queirópteros, I, 72 .

Queloneos, II, I 72 .

Quelonianos, II, I67.

Quermes. ( V. Psilos.)

Quetodonte, II , .284.

— de pico, II, 285.
- orbicular. (V. Platax.)

Quiloñatos, III, 156 .

Quilopodos, III, 57 .

Quimera, 1I, 374 .

- antártica, 11,375 .

-ártica, ib.

Quimpecé. (V: Chimpansé.)

Quincho. (V. Pingüino.)
Raasch. (V. Maláptéruro electriCo:)

Rabihorcado. (V. Fragata, Ave.)

Rabo de jüco. (V. Facitonte.)

Radiarios, III (93ro.

Ralo. (V.Rascon.) mrroting -
- porzana, II; 32. 1

Rana, II, 237 .

- bermeja, II, 240 ,

- bramante. (V. Bulfrog.)

- de tapirar, II, 24a sologinge punteada, II, 240. 
- verde, II , 239 .

Ranelas, III, 55 .

Ranfocelos, II , 36 .

Ranilla, II, 240.

- bicolor, II , 241 .

- comun, ib.

- pata de ganso, ib.

Rascon, II, I 3 I.

-de agua, III, I 32 .

- de tierra ó de retama, $i b$.

- manchado pequeño. (V. Ra lo porzana.)

Rata, I, 145.

- almizclada de las Antillas. (V. Pílori.)

- almizclada de Rusia. (V. Desman de Rusia.)

- almizclada del Canadá. (V.Ondatra.)

- cavadora. (V. Escherman.)

- comun, I, I 5 o.

- de agua, I, I 5 r.

- de dos pies. (V. Gerbo.)

- de Faraon. (V. Mangosta de Egipto.)

- de las cosechas, I, 150.

- de los muladares, $i b$.

- de trigo. (V. Hamster.)

- gigante de las Indias , I, 150.

- propiamente dicha, I, 148.

Ratas-topos, I, I 55.

Raton, I, I 50.

- campesino, ib.

- campesino comun, I, 15 .

- campesino volante. (V. Campanol volante.)

- marino. (V. Afrodita erizada.)

- silvestre. (V. Turon.)

Raya, II, 382.

- blanca ó cenicienta, II , 385.
- clavada, ib.

- pescadora. (V. Pejesapa.)

- tembladora. (V. Torpedo comun.)

- zarza, II , 385 .

Raza caucasiana ó blanca, I, 47.

-- etiópica ó negra, I, 48.

-- mongólica, mogola ó amarilla, I, 47.

Redecilla, II, 2 I 9 .

Reduvio, III, 232.

-- enmascarado, III, 233.

Regadera, III, 82 .

- de Java, III, 83.

- de manguitas, ib.

Reina de las carpas. (V. Carpa de espejo.)

Religiosas. (V. Mantis.)

Remípedo, III, I22.

- tortuga, ib.

- de las Antillas, ib.

Remiz, II , 53.

Rémora, II, 347 .

- piloto, II, 348.

- vulgar, $i b$.

Rengífero, I, 246.

Reno. (V. Rengífero.)

Reptiles, II, I 62 .

Revuelve piedras, II, 126.

Rey de las codornices. (V. Rascon

de tierra ó de retama.)

-- de los arenques. (V. Quimera ártica.)

- de los buitres, II , I 7 .

- de los cervitillos. ( $\mathrm{V}$. Guevei.)

- de los papa-moscas, II, 33.

Reyezuelo, II , 42 .

- comun, ib.

-- de tres rayas, ib.

Rezadoras. (V. Mantis.) 
Ricachos. (V. Buprestes.)

Ricino, III, I 7 I.

- de la gallina, III , I 72.

- de la paviota, $i b$.

-d del verderon, $i b$.

Ricínulas, III, 52 .

Rincóforos, III, 206.

Rinoceronte, I, 2 I I.

- de Africa, I, 2 × 3.

-- de Asia. (V. Rinoceronte de las Indias.)

-- de Java, I, 2 I 3.

- de las Indias, ib.

-- de Sumadra, ib.

Rinolofos, I, 79 .

Roberto el diablo, III , 283.

Rodaballo, II , 344 .

-- barbudo, II , 345 .

-- comun, $i b$.

-- punteado, $i b$.

Roedores, I, , 33.

— acleidianos, I, I 59 .

- claviculados, I, 137 .

Roe-verrugas, III, 226 .

Rolo, I, 62.
- de Madagascar, ib.

Rolowai. (V. Palatina.)

Rombo. (V. Rodaballo.)

Rorqual , I , 285.

- del Mediterráneo, $i b$.

Roselet. (V. Armiño.)

Resomak. (V. Gloton del Norte.

Rostelarios, II, 56.

Rotíferos, III, 36r.

- propiamente dichos, III , 362.

Rubicon, II , 83.

Ruedas de mar, II , 364 .

Ruiseñor, II , 42.

- ảe pared. (V. Grarganta negra.)

- de rio, II , 42.

- pequeño de rio, $i b$.

Rumiantes, I, 230 .

- con cuernos, I, $24 \mathrm{I}$.

- de cuernos caducos, I, 243.

- de cuernos huecos, I, 249.

- de cuernos persistentes y cubiertos por la piel , I, 248 .

- sin cuernos, I, 234 .

Rupicabra. (V. Gamuza.)
Sábalo, III, 336.

- comun, II, 337 .

Saboga , ib.

Sabueso, I, 109.

Sagüino, I, 62 .

- con mascara, I, 64.

- enlutado, $i b$.

Saí, 1, 62.

Saiga, I , 252.

Sajú , I, 6 r.

- comun , I, 62 .

- cornudo, ib.
- de los pies dorados. (V. Crisope.)

Saki, I, 64.

- de vientre rojo, $i b$.

Salamandra, III , 245.

- acuática. (V. Triton.)

- comun, II, 246.

- grande de la América Septentrional. (V. Triton gigantesco.)

-negra, II, 246.

-- terrestre, $i b$.

- variada, $i b$.

Salangana, II , 46. 
Salicotes. (V. Langostinos.)

Salmon , II , 328 .

-- comun, II , 329 .

-- hembra. (V. Becarda.)

Salmoncillo, II , 33o.

Salmonéos , I , 327.

Salmonete, II ; 266.

-- comun. (V. Trigla comun.)

--gruñidor. (V. Trigla propiamente dicha.)

- propiamente dicho, II, 267 .

- verdadero, $i$.

Salpa. (Pez.), II , 282.

Salpa. (Molusco.) (V. Bíforo.)

Saltadores, I, 222.

Saltamontès. (V. Saltadores.)

Saltones. (V. Saltadores.)

Saluth, II , 324 .

Salvaguardia , II , I 87 .

- grande, $i b$.

Samlet. (V. Salmoncillo.)

Sanderling, II , I 26 .

Sandratos, II , 263.

Sanguijuela, III, 108.

-- del caballo ó borriquera, III, I 09 .

-- medicinal, III, ro8.

Sapajú , I , 6o.

- a marillo. (V. Seimiri.)

- aurora. (V. Seimiri.)

--de Cayena. (V. Seimiri.)

- anaranjado. (V. Seimiri.)

Sapo, II, 24 I.

-- comun, II, 243 .

- de los juncos, ib.

- de mar, II, 3 o5.

- partero, II , 243.

Sarcopta, III , 53.

Sarcoranfos, II , I 7 .

Sarda, H, 288 .

Tомо нI.
- comun, it.

Sardina, II , 335.

Sardineta , II, 336.

Sargo, II, $28 \mathrm{r}$.

Sátiros, III, 282.

Saurel, II, 294 :

- comun, ib.

Saurianos, II , $x 76$.

Savana, II , 33 :

Schilvé ó Squilbé del Nilo. (V. Siluro del Nilo.)

Secretario. ( $\mathrm{V}$. Ménsagero.)

Segador, III , 150 .

-- comun, III , I 5 r.

Seimiri, I, 63.

Selacianos, 11,375 .

Semivulpa. (V. Zarigüeya.)

Semnopítecos, I, 58.

Senador. (V: Gạvioła blanca.)

Señorita de Numidia, II, I 15.

Sepedon, II , 208.

Sephen, II , 386.

Sepiarios, III, I 2.

Sepulturero. (V. Necróforo.)

Serotino, I, 3r:

Serpentario. (V. Mensagero.)

Serpiente de anteojos. (V. Naya propianente dicha.)

- de vidrio. (V. Orveto comun.)

-del Cabo, II , 23 r.

Serpientes, II , 2 I 6 :

- de casciabél. (V.Crótalos.)

- desnudas ó sin escamas, $\mathrm{HI}_{2} 3 \mathrm{I}$.

- $\sin$ veneno, III, $2 \mathrm{i} 9$.

-- venenosas, II , 225.

Sérpula, III, I oo.

-comun, III, IoI.

- vermicular, $i b$.

Serrato, II , 26 r.

- barbero, II, 262. , III pon 
- comun, ib.

-- escrito", $i b$.

- leopardo, $i b$.

Serricornes, III, 185.

Serriferos, III , 258.

Seticaudos. (V. Tișanouros.)

Siamang, I , 55 .

Sicofanta, III, I 8 .

Sierra. (V. Pez sierra.)

Sifileto. (V. Ave del paraiso dorada.)

Sifonápteros, III, I 7.2.

Silagos, II , 263.

Siluro, II, 324 .

-- del Nilo, II, 325.

-- eléctrico. (V. Malaptéruro eléctrico.)

Siluroides, II, 3.23 .

Simio marino. (V: Quimera.)

Simpólipos, III, 347 .

Sindáctilos, II , 7 I.

Singnato, II , 357 .

Siponclo, III , 32 I.

--comestible, III, 322.

Sirena. (Pez), II , 249.

--alagartada, $i b$.

- intermedia, $i b$.

- rayada, $i b$.

Sirena. (Mamífero.) (V. Cetáceos. herbivoros.)

Sirfo, III, 3 o3.

- del grosellero, III, 304 .

- - del rosal, $i b$.

Sitáculo, II, 88.

-- de collar, ïb.

- gorrion, $i b$.
-- inseparable, $i b$.

Sitela, II , 65 .

- comun, II, 66.

Sezerin, II , 56.

Soberbio, II , 64 .

Sólen, III , 79 .

- rayado, III, 8o,

Solípédos, I, 223.

Sollo, $\mathrm{II}, 320$.

-- comun, ib.

- de tierra, II, 208.

-- manchado, II, 32 I.

- reticulado, ib.

Sollos de mar. (V. Centropromos.)

Sollos-percas. (V. Sandratos.)

Sombra caballero, II , 33 o.

-- propiamente dicha, II, 33 I.

Sombrilla. (V. Medusa.)

Somorgujo, I, 137.

-- grande, II , I 38.

- mediano, II ; $\mathbf{3} \mathbf{3}$.

- pequeño, $i b$.

Soplador. (V. Delfin grande.)

Subbuso, II , 22.

Suchet, II, I6.

Suclios, II, I 83.

Suimanga, H, 68.

- de mancha roja, II, $6 g$.

- de vientre purpúreo, $i b$.

Sulgan, I, 164.

Suplicantes. (V: Esquilas.)

Surnias, II , 26.

Suslik, I, I 42.

- de la Iuisiana, I, 143.

- de trece, rayas, I, 142.

\section{$\mathbf{T}$}

Tábanos, III, 3oo.

- de los bueyes, III, 3 or. 
- del camello, ib. negro, $i b$.

Tablern de damas. (Ave.) (V. Petrelo pintado.)

'Tablero de damas. (Insecto.), IH, 283.

Tablero de damas. (Molusco.), III, 49.

'Tadorna, II, 16 o.

Taguan. (V. Polatuca de las Indias.)

Taibi. (V. Zarigüeya ratonina.) -

Taira, I, 97.

Talapino, I , 57 .

Talapiote, I, 67 .

Talasidromos, II, 144 .

Talitros, III, I3o.

Tamandúa , I, I 8 o.

- grande. (V. Tamanuar.)

Tamanuar, I, I \&o.

Tamarinos , I, 65.

Tamatía, II , 83.

- comuni, ih.

- de collar, ib.

Tambor, II, 279.

'Tamia, I, 140.

- palmista, $i b$.

- suizo, ib.

- verberisco, ib.

Tangara, II , 35 .

- obispo, II, 36 .

- tricolor, ib.

Tanístomos, III, 298.

Tapeti del Brasil, I, I 63.

Tapir, I, 2 13.

- de América, I, 214.

- de las Indias, $i b$.

Tarániula, III, 147.

- de Italia, III, I 46.

Tardígrados, I, $7 \mathbf{I}$.

Tarréntola. (V. Gecko de las paredes.)
Tarsero, $\mathbf{I}, 6 \mathrm{~g}$.

- comun, I, 7 o.

- de manos morenas, $i b$.

Tato; I, 14 .

- gigante, I, I 76 .

- negro, ib.

Tatuejo. (V. Tato.)

Tayazú, I, 222.

Taza de Venus, III, i 8.

Tectibranquios, III, 35 .

Tejon, I, 94 .

- de Europa, I ,.96.

- de la bahía de Hudson, $i b$.

'Tela de cehollá. (V. Placuna.)

Telescopios, III, 45 .

Tellina, III , 77 .

Tenca, II , 3 I 6.

Tenebrion, III, 203.

- de tahona, ib.

Tenia, III, 33r.

- comun, III , 332 .

- lata, ib.

Tenioides, III, 33 I.

Tentrados, III, 259 .

Tenuirostres, 11,64 .

Terebela. (V. Anfinomo.)

- conchilega ó recoge - conchas, III , 10 I.

Terebrantes, III , 257 .

Terebrátulas, 111 , 84 .

'Termes. (V. Termite.)

Termite, III, 253.

- fatal ó belicoso, III, 255.

- viagero, ib.

Téropo, I, 77.

- comeslible, I , 78 .

-c comun, ih.

- pequeño, ib.

Teropodos. (V. Pteropodos.)

Testacelas, III, 27.

'Testáceos', III, I. 
Tetígonas. (V. Cicadelas')

Tetis, III, 34.

Tetráceró, , I, 255.

Tetraodontes. (V. Tetrodones.)

Tetras, II, 96 .

-- propiamente dichos, II, 97.

Tetrodones, II, 363 .

Tiburon, II, 378 .

-- comun, ib.

Ticodromos, II , 67 .

Tíflope, II, 2 × 9 .

- lumbrical, ib.

Tigre", I, I'22.

- cazador de los indios. (V.Guepardo.)

- de América. (V. Jaguar.).

Tijeretas, III, 2 I9.

- grande, III, 220.

- pequeño, ib. .

Tilacineos, I, I 88.

Tilacinos, I, .189 .

Típula, III, 296.

-anular, III ; 297.

— aracnoides, $i b$.

- culiciforme, $i b$.

- de los prados, $i b$.

- gigantesca, $i b$.

- variegada, $i b$.

Típulas comunes, $i b$.

- mosquitos, $i b$.

'Tirano, II , 33.

- de vientre amarillo, $i b$.

Tisanouros, III, 167.

Titi. (V. Vístiti comun.)

'Tocro, II, 99 .

Topo, I, 36.

- ciego, I, 88.

- comun, $i b$.

- de hocico estrellado. (V. Condiluro.)

— del Canadá, (V. Escalope)

- marino. (V. Afrodita erizada.)

Tordo, II, 38 ,

- burlon, $i b$.

- vérdadero, $i b$.

- vulgar, $i b$.

Tớilómarino, II, 369 .

Tornillos, III, 5 I.

Torniquete. (V.Jirino.)

Torpedo. (V. Trimielga.)

- comin, II, 384 .

Torta. (V. Cangrejo escudado.)

Tortuga, II , I69.

- coriacea. (V. Laúd.)

- franca, II, 1.74..

- geométrica, II , i 70 .

- grande. (Insecto.), III , 283.

- griegá, II , 170.

- pequeña. (Insecto), III , 283.

- serpentina, II ; 172.

- verde. (V. Tortuga franca.)

Tortugas blandas. (V. Triónix.)

- de agua dulce. (V. Galápagos.)

- de cola larga. (V. Emisauros.)

-- de mar. (V. Quelonéos.)

Totipalmes, II, 150 .

Traqueenos, III, I 49 .

Traquélides, III, 204 .

Traquelipodos. (V. Pectinibranquios.)

Traquinoides, II , 263.

Trematodes, .III, 3 i 9 .

Trepador, II, 66 .

- chamuscado, II, 67 .

- familiar, $i b$.

Trepadoras, II , 76 .

Trepadores de pared. (V. Ticodromos.)

- verdaderos. II, 67 .

Tricocófalo, $111,3,32.7$.

-- del hombre, $i$. 
Tridacno, III, 68.

- gigantesco, III, 69.

Trigla, II , 270 .

-- comun, II, $27 \mathbf{r}$.

- pajel, $i b$.

Trigloides, II , 268 .

Trigonocéfalo, II, 228 .

- amarillo, II, 229.

- de romboides, $i b$. moreno, ib.

Trimielga, II , 383 .

Tringa, II, 126.

- comun, ib.

- negruzco, $i b$.

Trionix, II , 72.

- de América, $i b$.

- del Nilo, $i b$.

Triorque comun, II , 22.

Tripa de mar. (V.Sérpula comun.)

Trisa. (V. Sábalo.)

Triton. (Reptil), II, 246.

- de cola chata, II, 247 .

- gigantesco, ib.

Tritones. (Mamiferos.) (V. Cetáceos herbívoros.)

Tritones. (Moluscos.), III , 55.

Tritonias, III, 34 .

Trocoides, III , 44 .

Trocos, ib:

Troglodita, II , 42 .

Trompeta, II, 358 .

Trompos, III, 45 .

- de tornillo. (V. Delfínulas.)
Tropial , II , 59 .

- de cabeza dorada', ib.

-n variegado, ib.

Trucha. (V.Salmon.)

- asalmonada, II , 33 o.

-comun', ib.

-de los Alpes, ib.

-- del lago de Génova, ib.

- roja, ib.

Truchuela, II, 341.

Tuan, I , I 37 .

Tubicolarios, III , 363 .

Tubícolas, III, 99.

Tubíporas, III, 349 .

'Tubiporéos, ib.

'Tucanes, II , 35.

'Tuerce-cuello, II, 8 o.

-- comun, ib.

Tunicarios, III, 84 .

Tupinambis. ( V. Salvaguardiagrande.)

Turaco, II, 88.

- gigante, II, 3g.

- lori, ib.

- morado, ib.

- musófago, ib.

- paulino, ib.

Turbante, III, 3 × 9 .

Turbinelas, III , 56 .

Turon, I, I 5 o.

- grande. (V. Rata de los muladares.)

Turritelas, III , 45 .

Uaran del Nilo. (V. Monitor del Ular sawa, II, 223. Nilo.)

- terrestre. (V. Monitor terrestre.)

Uéla, II , 35.

Umbrina, II , 27.9.

Unguiculados, I, 34 .

Ungulados, I, 34 y 200.

Unio, 1II, 7 午. 
- de los pintores, III, 75 .

- del Rhin, ib.

Unó, I, I 73 .

Uranoscopio, II, 264.

- áspero, ib.

Urodelos , II, 245.

Urogallo. (V. Gallo silvestre gran- de.)

- pequeño. (V. Gallo silvestre de cola ahorquillada.).

Urraca. (V. Picaza.)

Ursinos. (V. Equinos.)

Urson, I , 6 I.

Urubú, 1I, 17.)
Vaca de Berbería, I, 253.

- de S. Anton. (V. Coscinela.)

- gruñidora. (V. Yack.)

- marina. (V. Morsa.)

Vadigo, II , $29^{2}$.

Vadiola, II , 33.

Vaginales, III, 27.

Vaina, III, 8o.

Vair. ( $\checkmark$. Ardilla comun.)

Valrus, I, i 33 .

Valvadas, III , 46 .

Vampiro, I, 79 .

Vanesas, III , 282.

Vanga, II, 32 .

- comun, ib.

- destructor, $i b$.

Vansiro, I, I 14.

Vapiti. (V. Ciervo del Canadá.)

Vari, I, 63.

Vario, II, 3 I 6.

Velero, II, 290.

Venado. (V. Ciervo comun.)

Vencejo, II , 46.

- de montaña ó comun, II, 47 .

- de pared, ib.

Venus, III, 77 .

Verdeaula. (V. Hortelarro.)

Verderol, II , 56 .

Verderon, ib.

Veso, I, I о2.

- conun, ib.
- de África, I, ro3.

- de Polonia. (V. Peruasca.)

- de rio. (V. Vison.y Mink.)

-- de Siberia, I , I 03.

Vespertillos ó vespertilios, $\mathbf{I}, \mathbf{1} 8 \mathbf{I}$.

Víbora, II , 227.

- comun, II , 23 o.

- cornuda, II, $23 \mathrm{I}$.

- de cola corta, ib.

- de hierro, de lanza. (V. Trigonocéfalo amarillo.)

- de hocico cornudo, II, 23 r.

- de la Carolina. (V. Trig nocéfalo moreno.)

- de penacho, III, 23 f .

- negra, ib.

- pequeña, il.

Vibrion, III , 365.

- del engrudo, III , 366.

- del vinagre, $i b$.

Vibriónides, III, 365 .

Vicuña, I, 239.

Vidrio. (V. Placuna.)

Vieja, II, 368.

- de color de rosa, II, 3о 2 .

- de mar. (V. Labro.)

- manchada, II, 3or.

-rayada, II , 3 o 2.

-verde, $i l$.

Vison, I, , o3.

Vistiti, I, 64 . 
-comun, I, 65.

--de pinceleś, $i b$.

Vivo de cabeza radiada. (V. Pejearaña pequeño.)

- grande de manchas negras. (V. Pejearaña grande.)

Volutas, III, 50.

Volvarias, $i b$.

Volverena, I, 97.

Vólvoce, III , 366.

Wouwou, I, 55.

\section{$\mathbf{X}$}

Xifosuros ó Jifosuros, III, , 35 .

$\mathbf{Y}$

Yack, I, 263.

Yapoco. (V. Oyapock.)

\section{W}

-- convalaria, III, 347 .

- mora, ib.

- trompeta, $i b$.

Vulcano. (V. Atalanta.)

Vulpeja , I , 93 .

-cangrejera, I , 94.

- labrador, ib.

Vüvú. (V. Wouwou.)

\section{.}


Se suplica á los lectores tengan á bien corregir las siguientes erratas contenidas en este tomo.

\begin{tabular}{|c|c|c|c|}
\hline Páginas. & Líneas. & Dice. & Debe leerse. \\
\hline 8........ & I $1 . . .$. & folades. ........................... & foladas: \\
\hline Ibm.... & $25 \ldots . .$. & cefalópodos................... & cefalopodos. \\
\hline & & pterópodos................... & pteropodos. \\
\hline & & gasteró podos.................. & gasteropodos. \\
\hline $43 \ldots .$. & $3 \ldots \ldots$ & 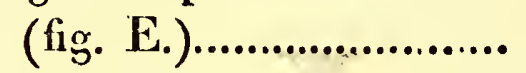 & (fig. I 3. E.) \\
\hline Ibm.... & 4....... & (fig. D.)........................... & (fig. I $4 . D_{0}$ ) \\
\hline $47 \ldots \ldots$ & I $9 \ldots . . .$. & acanalados...................... & canaliculados. \\
\hline $77 \ldots \ldots$ & $8 \ldots . .$. & paralelos.......................... & paralelas. \\
\hline Ibm.... & $9 \cdots \ldots$ & enrejados....................... & enrejadas. \\
\hline $86 \ldots .$. & $21 \ldots . .$. & estas..................................... & estos. \\
\hline $104 \ldots \ldots$ & I $8 \ldots \ldots$. & élitros............................. & elictras. \\
\hline $167 \ldots \ldots$ & 3о....... & los poduros.................... & las poduras. \\
\hline $206 \ldots .$. & I $4 \ldots \ldots$ & 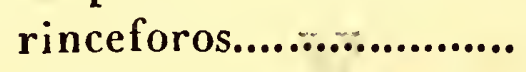 & rincóforos. \\
\hline $23 x \ldots .$. & $31 \ldots . .$. & Al primero...................... & $\Lambda$ l segundo. \\
\hline $232 \ldots$. & I....... & del segundo.................. & del primero. \\
\hline $237 \ldots \ldots$ & $28 \ldots \ldots$ & conformacion............... & formacion. \\
\hline $256 \ldots \ldots$ & $6 \ldots$ & Quinto órden.............. & Sexto órden. \\
\hline $278 \ldots . .$. & $16 \ldots . .$. & Quinto órden............... & Septimo órden. \\
\hline & $14 \ldots \ldots$ & Septimo órden............. & Octavo órden. \\
\hline $385 \ldots . .$. & $27 \ldots \ldots$ & Anelides......................... & Anélides. \\
\hline $386 \ldots .$. & $26 \ldots \ldots$ & Aracnides....................... & Arácnides. \\
\hline Ibm...... & × $5 \ldots \ldots$ & Arenicola......................... & Arenícola. \\
\hline
\end{tabular}







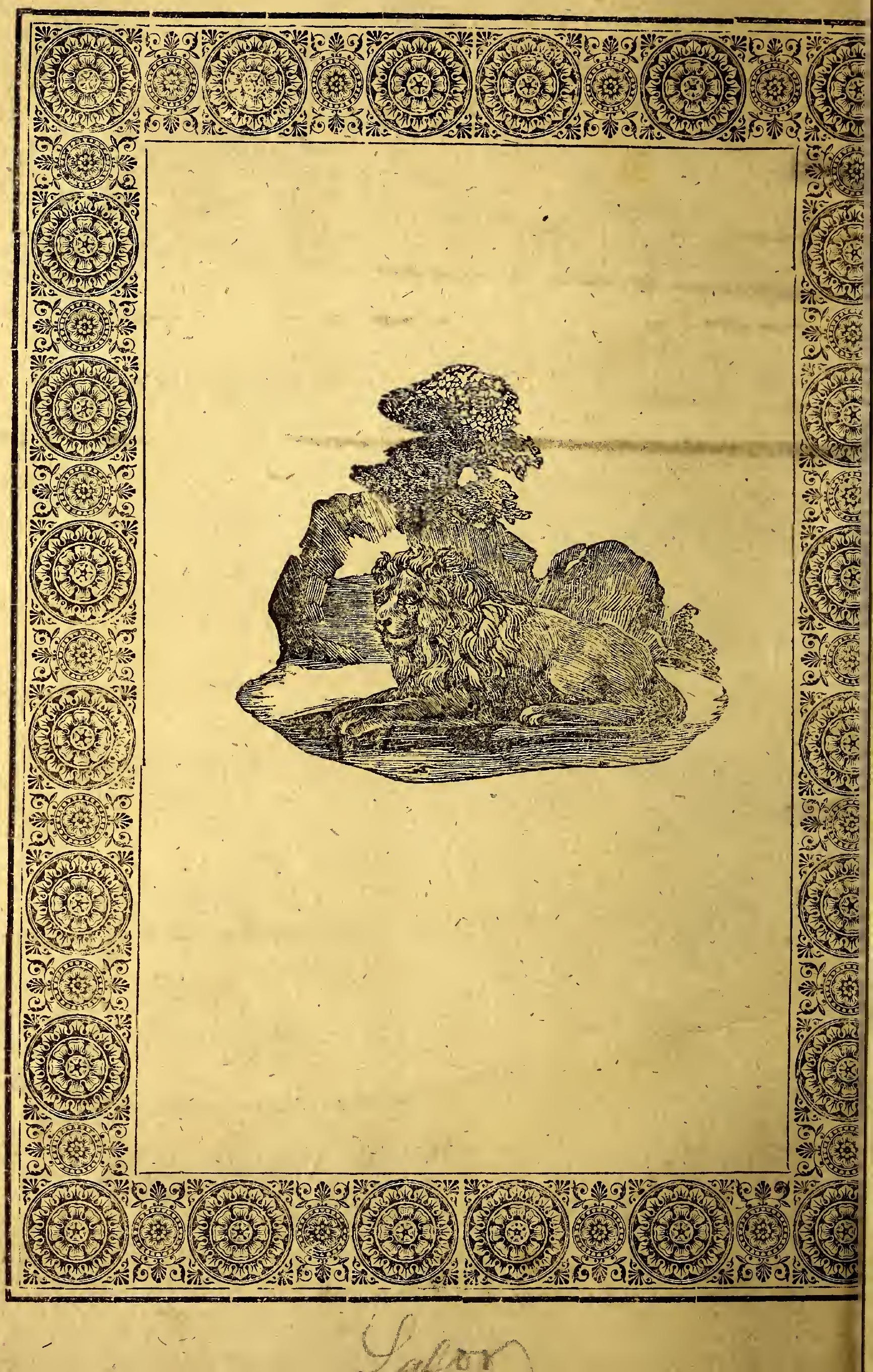









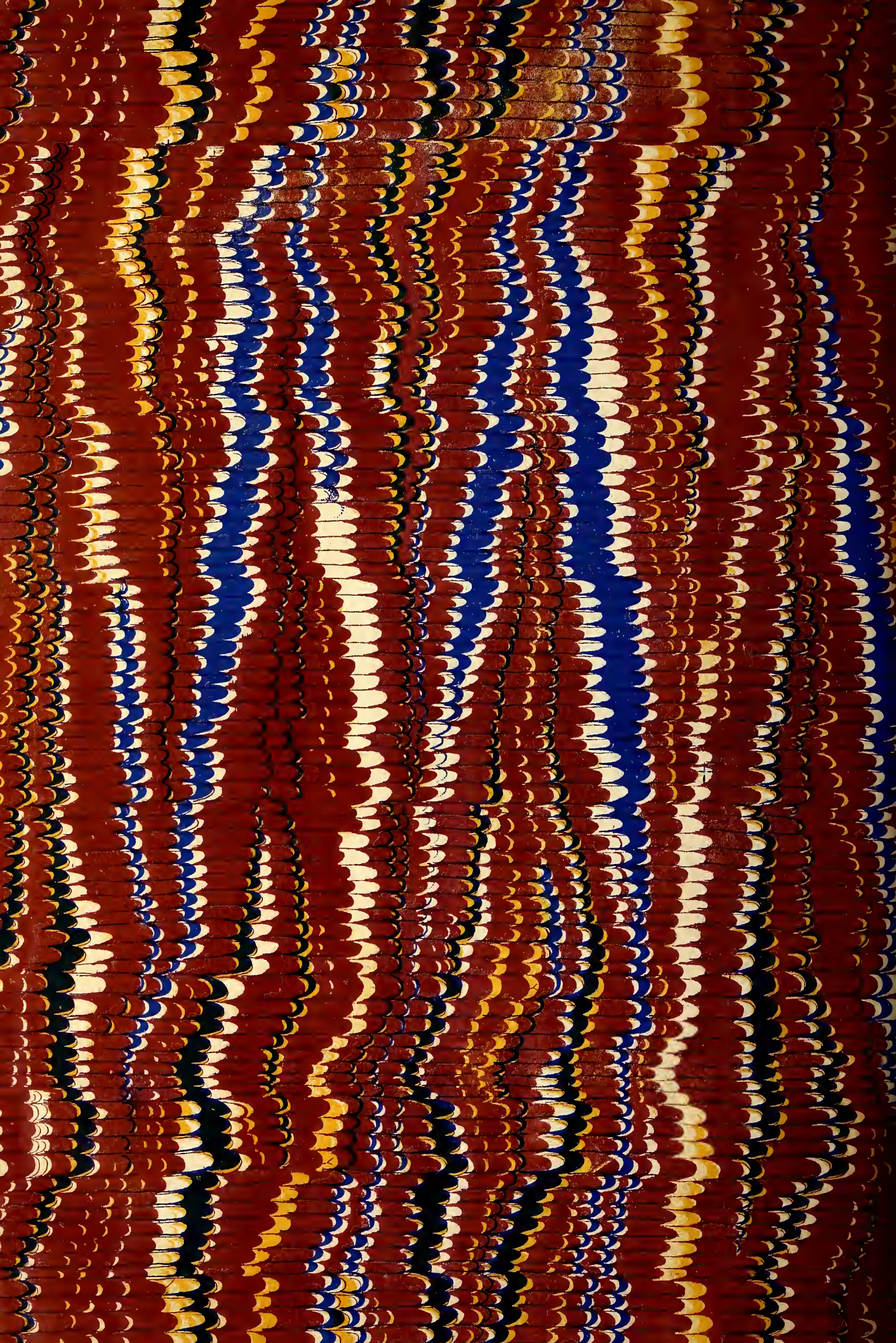




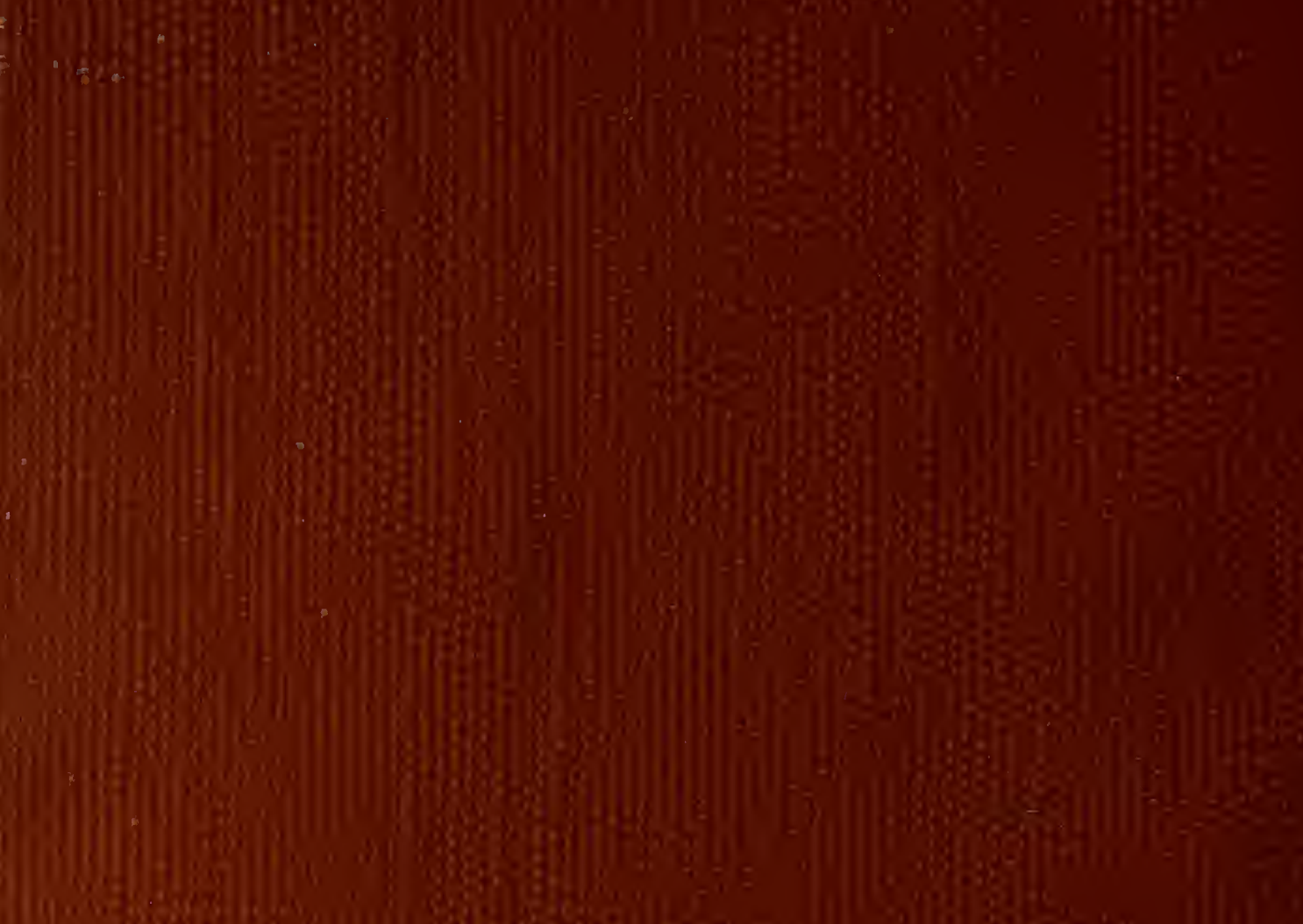

yongy

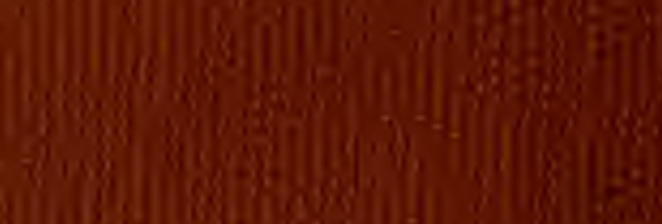

ilis.

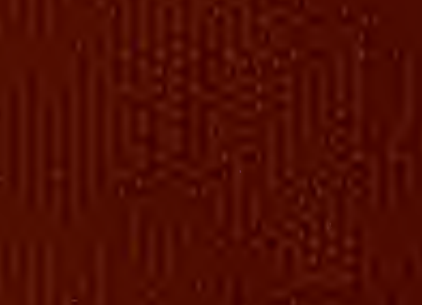

I)

XII)

ISW

$\frac{9}{3}+\frac{1}{3} \mid$

(2)

(1)

|fil. 